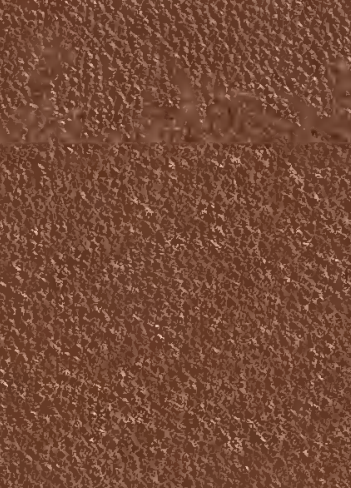

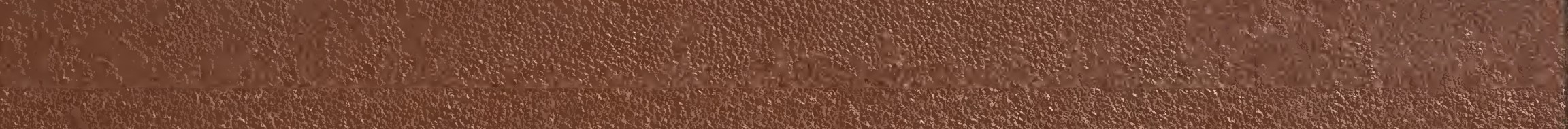

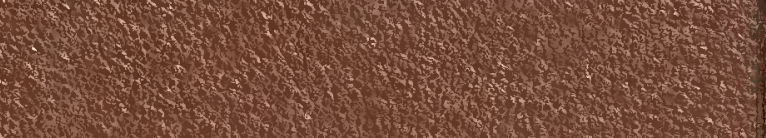

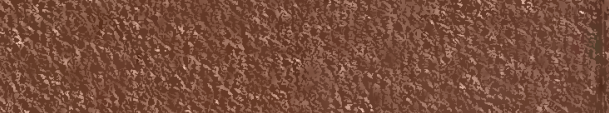

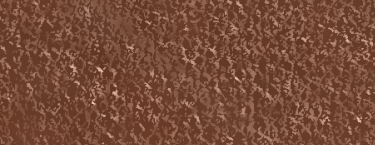

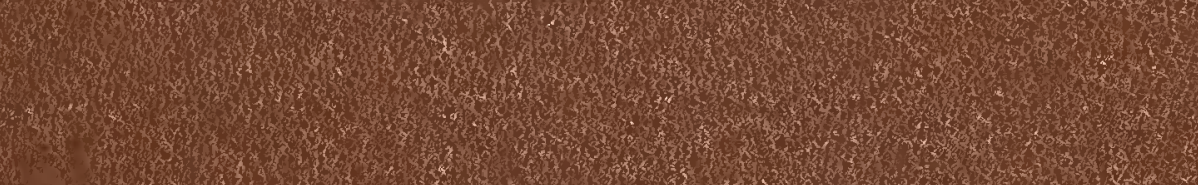

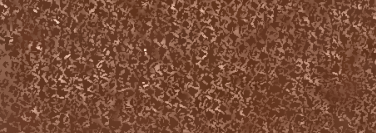




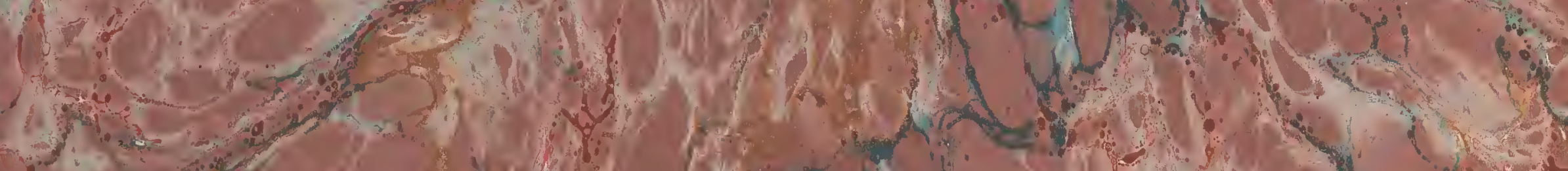

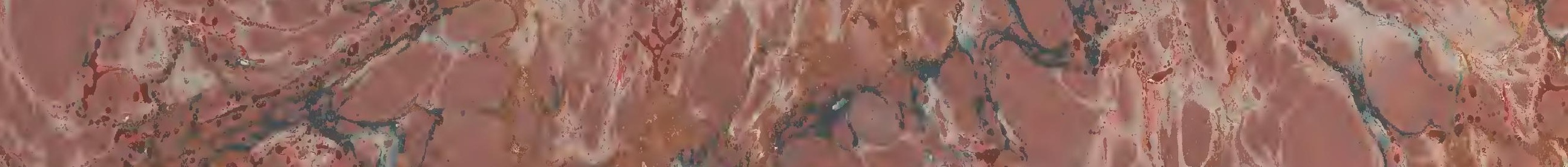
(4)

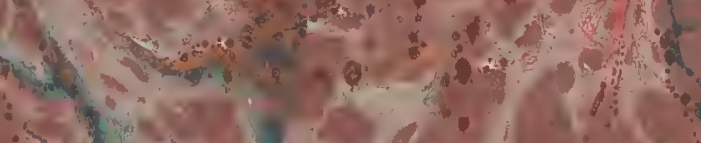

$3+2 y+204$ i. ark

t. and

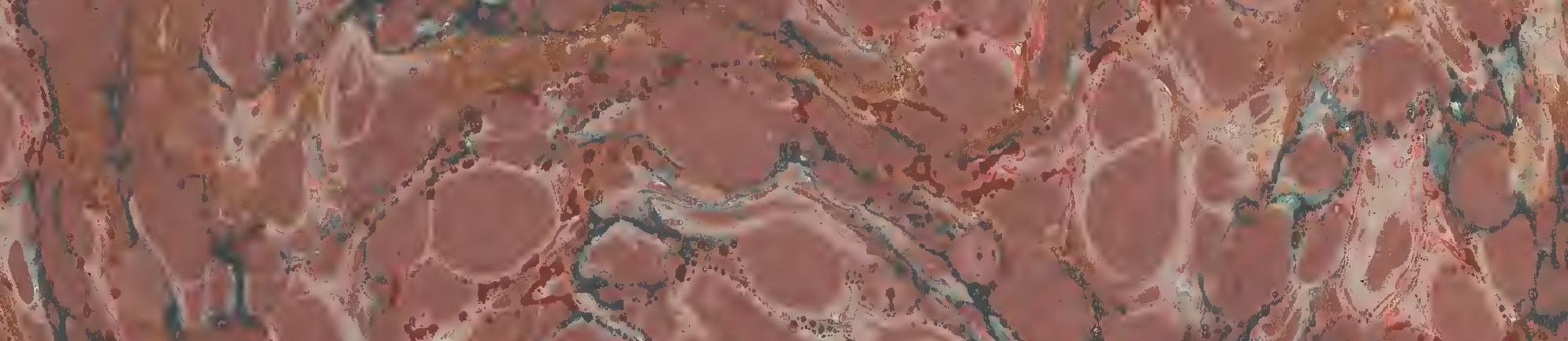

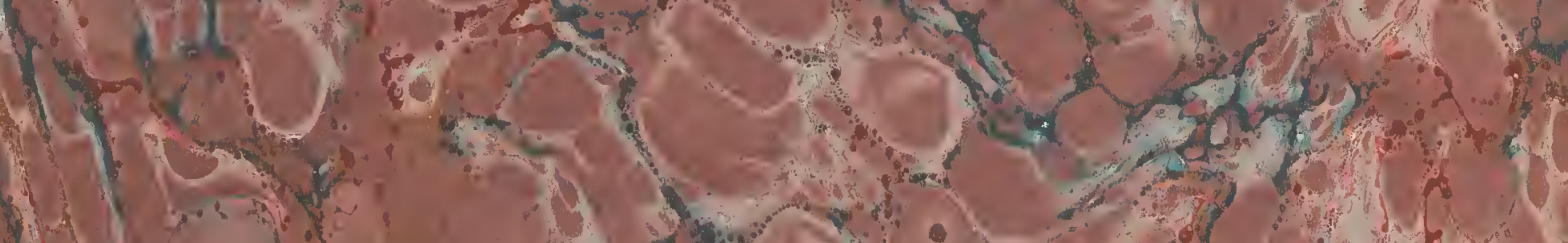

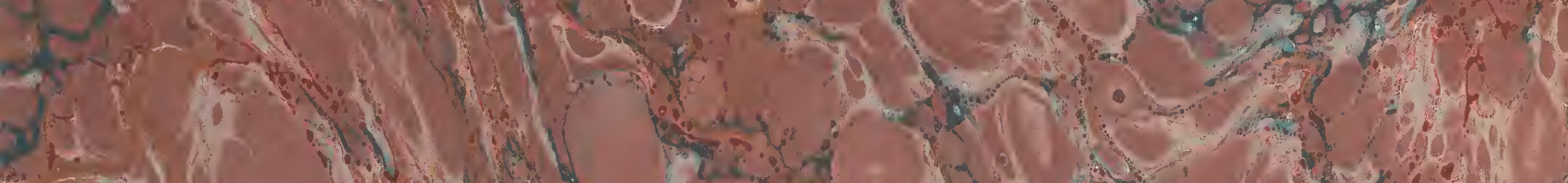

- $m=1$ I.t. to

2.

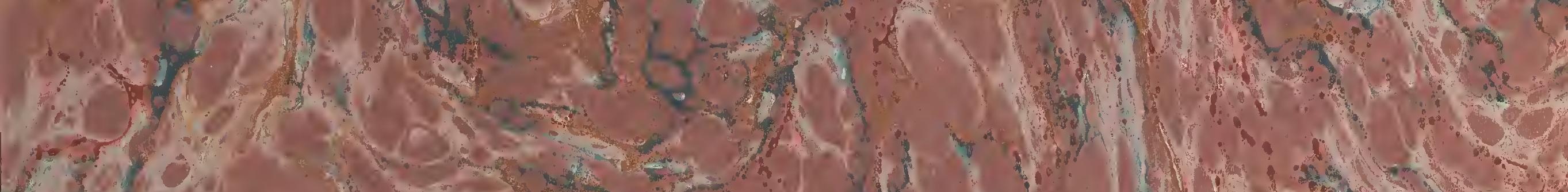
deces r. (2) Cos $0 .-2 x-524$ xe

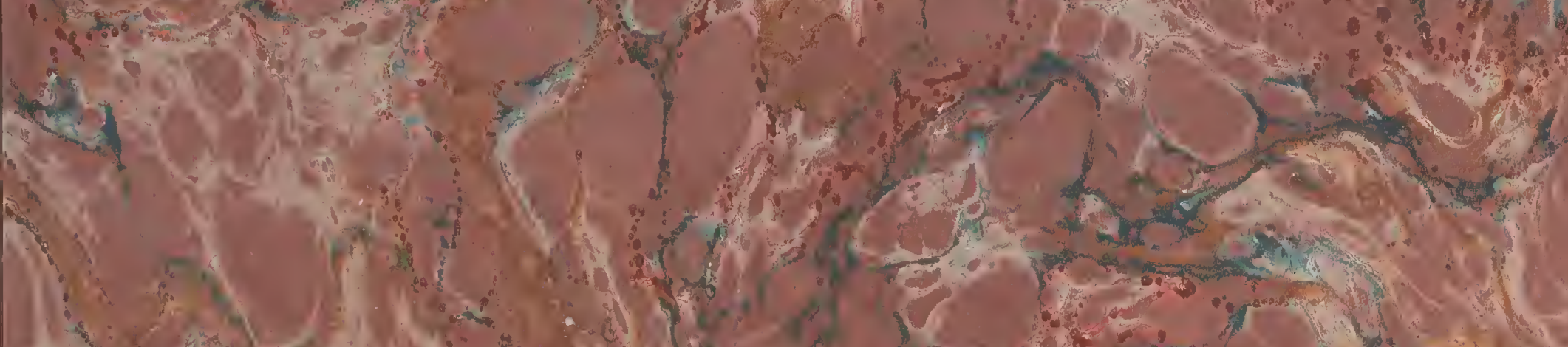
es $x$ ? 24 mint 460.

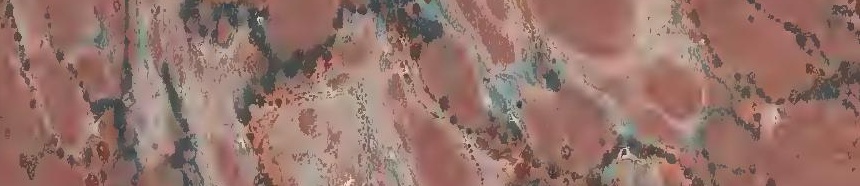
$+x$

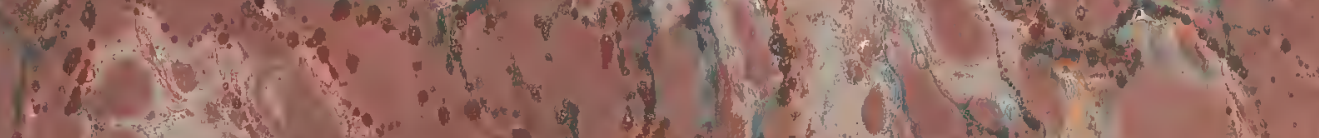

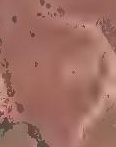
tow 







\section{HISTORIA NATVRALIS}
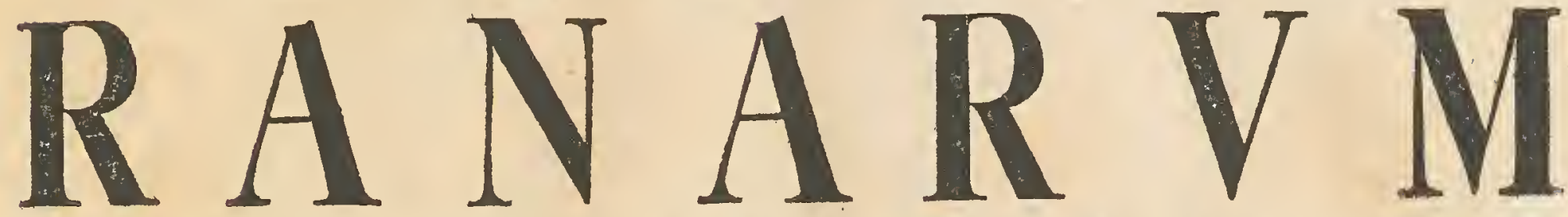

NOSTRATIVM

IN QVA

OMNES EARVM PROPRIETATES,

PRAESERTIM

QVAE AD GENERATIONEM IPSARVM PERTINENT, FVSIVS ENARRANTVR.

CVM PRAEFATIONE

ILLVSTRIS VIRI

A L B E R T I v. H A L L E R

SOCIETATIS REGIAE SCIENTIARVM GOETTINGENSIS PRAESIDIS.

IDIDIT

ACCVRATISQVE ICONIBYS ORNAVIT,

AVGVSTVS IOHANNES ROESEL von ROSENHOF.

NORIMBERGAE, Typis IOHANNIS IOSEPHI FLEISCHMANNI.

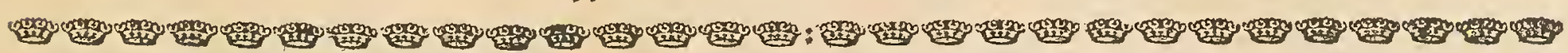
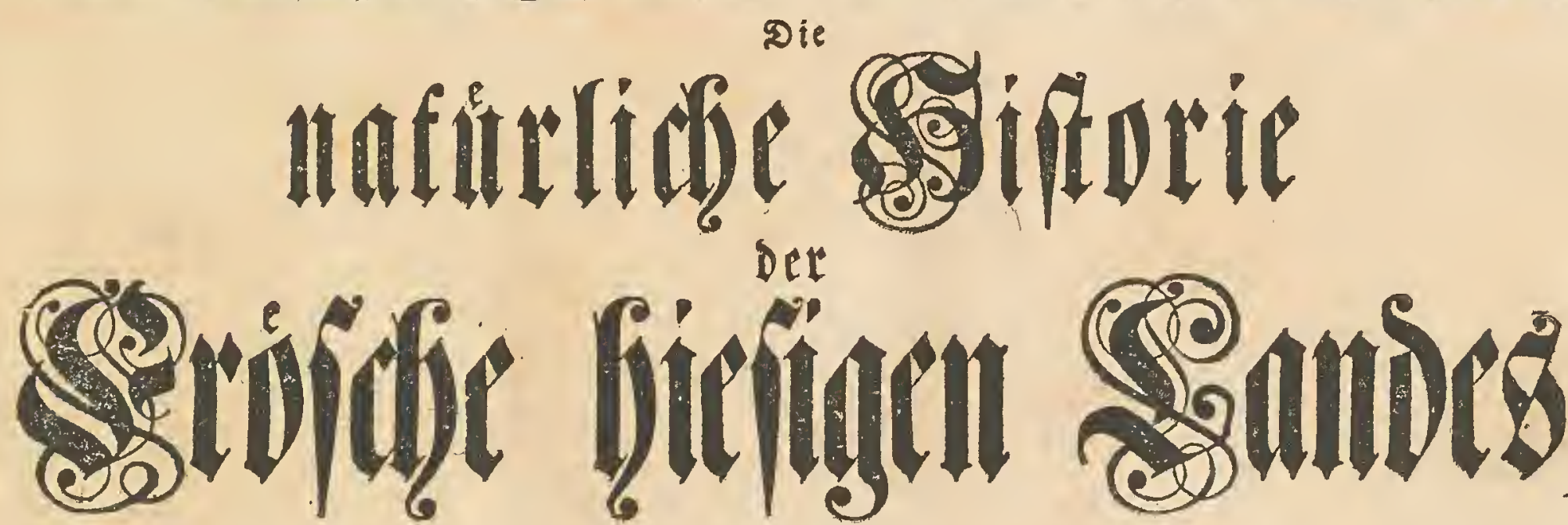

torittitent

alle

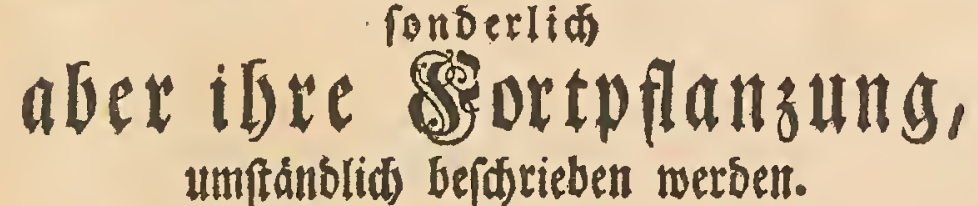

Hit einer Dorrede

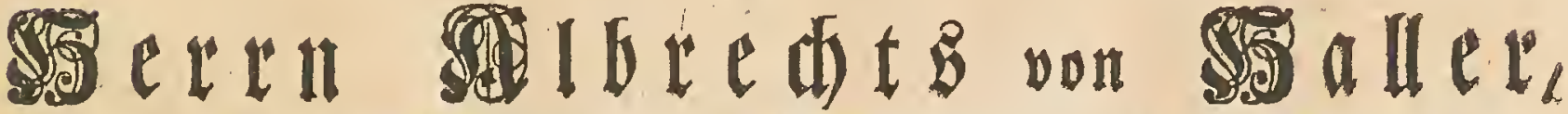

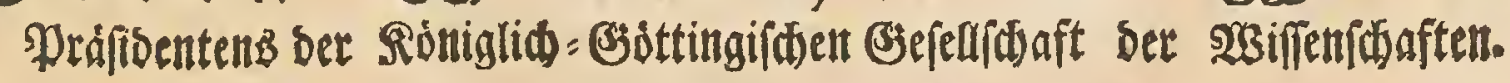

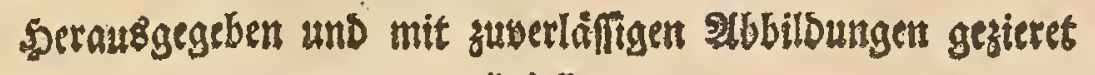

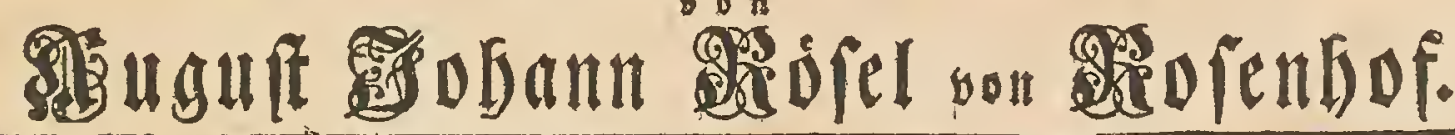





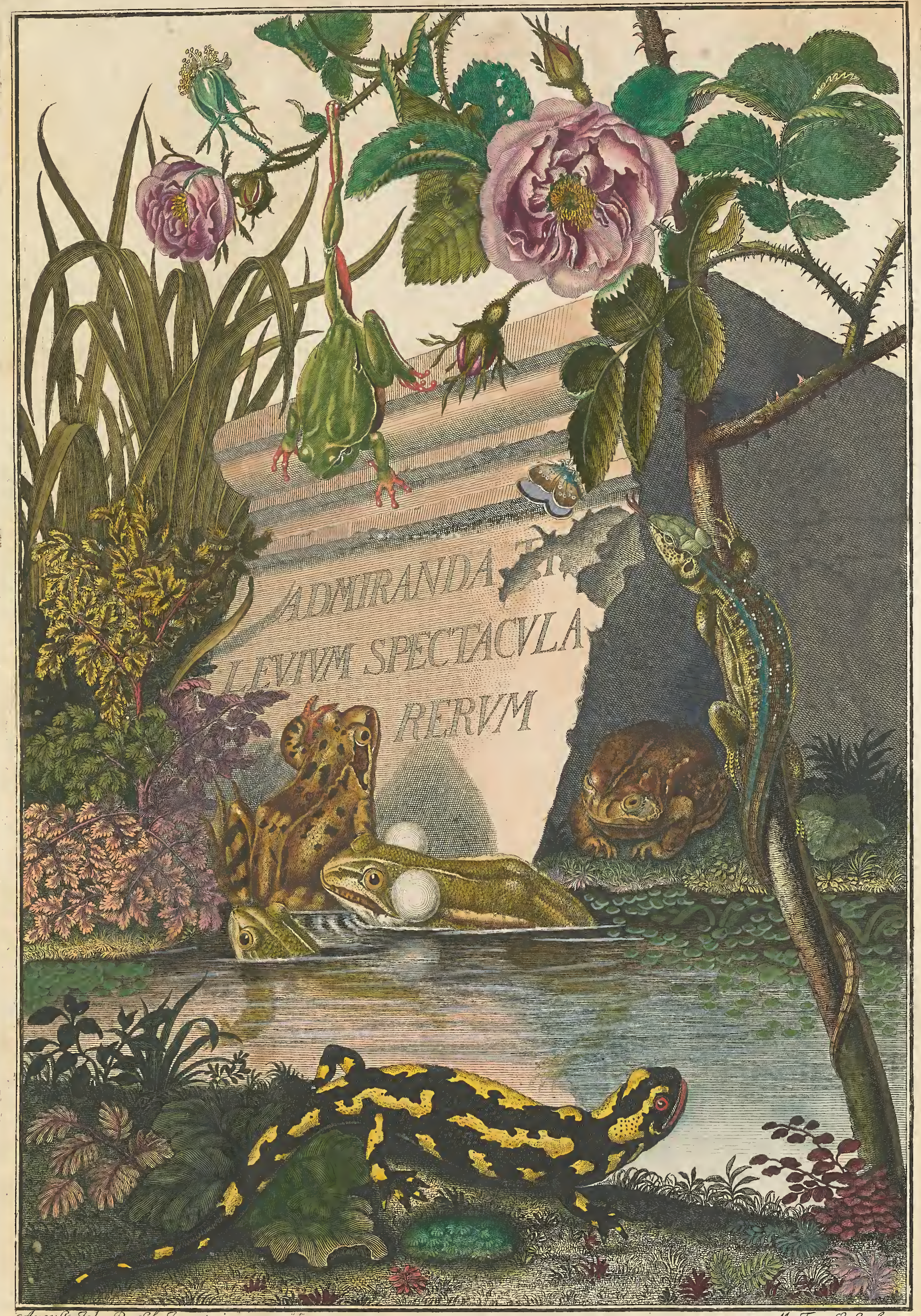





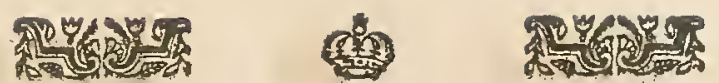 \\ ILLVSTRIS VIRI \\ ALBERTI v. HALLER, \\ $\mathfrak{S} \in \mathbb{1} \mathfrak{n}$ Sulteredt wor allet,}

SOCIETATIS REGIAE GOETTINGENSIS PRAESIDIS,

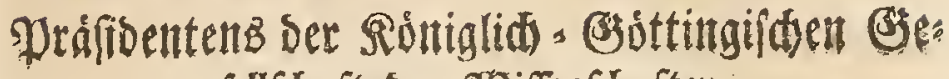
fellfhaft Der WBifenfdoaftem

P R A E F T I O.

E tfi in vniuerfum fuperbiam inter virtutes minime numeramus; eft tamen humilitas, quae inter maxima vitia cenferi meretur, et qua de patria noftra humiliter lentimus.

Ridiculus vtcunque faftus eft, quo elatae pleraeque gentes, fe iuper reliquos mortales ponunt; et ad fatyram pertinet externarum gentium contemtus, qui Sinernibus, fed non folis, familiaris eft. Nam etiam in moratiori noftra Europa ii populi, quos opulentia fua et numerofus miles, ab alis imperiis tutos, vicinis vero formidabiles facit, in vniuerfum gentes alias, aut minori potentia militari armatas, aut vnice minus aliquanto lepidas, artibusue leuioribus minus indulgentes, inter barbaras referunt, et fuperciliofe defpiciunt. Grauis fatis is faftus mihi contigit, quo tempore per pulchriorem Europae partem iter feci. Mlerique equidem florentiffimi imperii incolae, et reliqua regna, et ipfos etiam corum regnerum ciues, minime diffimulato contemtu excipiebant. Nihil praeter fuum imperium pulchrum, nihil magnum, nihil forte, nihil denique perfecum aut nafci, aut fieri, quotidie geftu, voce fcriptoque declarabant. Simpliciter denique et absque erroris metu, viri non de vulgo, non de indocta nobilitate, fed deprincipum ingeniorum felectu, paffim pronunciabant, extra fuam gentem absque vitio fcribi non pofle; ordinem, methodum, limpiditatem dictionis, fuas effe virtutes, non aliis conceffas gentibus. Laborem, compilationem, aliquando etiam, quam vocant, profunditatem, vicinis fuis, tanquam junioribus fra. tribus, ipfi primogeniti naturace filii, pro fua aequitate dimittebant; fibi vero eam judicii vim fumebant, quae nihil nimii, nihil par. ui, nihil negligentior is in fcripta fua admittat. Neque nunc, poft triginta annos, ejus gentis de aliis populis judicia mitiora facta funt.
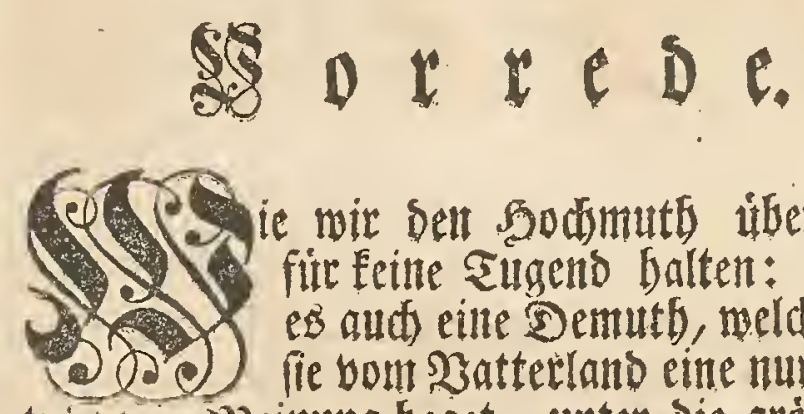

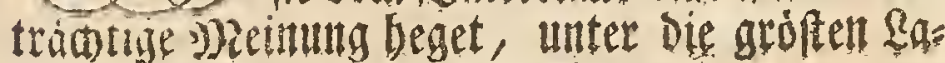
fter gered)tet ju werben bersientet.

Der Stols mowon Die meifen Bodfer ip febr anfigeblajen fino, bas fie fiti úber alle andes

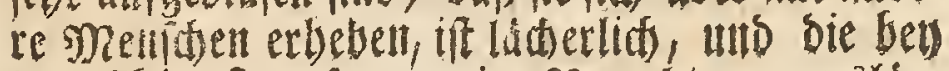
ben Chinefecn fo gemeine Serabtung aubláns Difuer pidfer fpottents merth. Dod biefe Sdimadbeit finbet fid ben ben Chinefern nidie alleine: Denn auth in unferem mely gefitteten (E) ropa, pfegen biejentgen 3 bifker, melose wegen ibres Rerchtbums uno wegen iber gabletiden

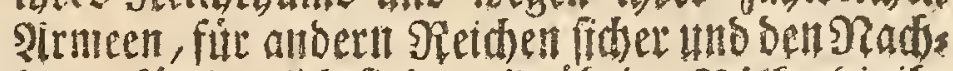
baren firchterlid fimb, alle itbrige Boffer bie ifs:

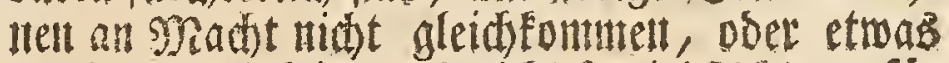

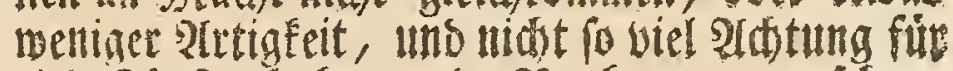
eitle Runfte baben, als Sarbarent antzueben, uno bowntuthig zu verladen. Diefer Stor mar mir faft unertráglido, alB id bell foboneren Ibeil von suropa burdircipte. Dis meiten

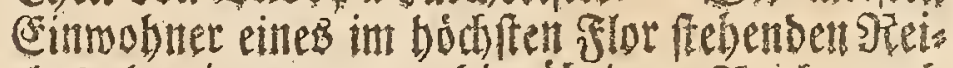
des, begengten gegen bie ubrigen seidie uns

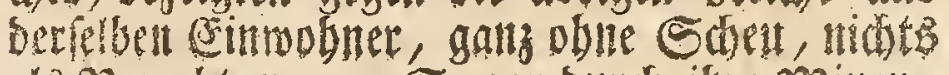
als szeradinng. So gar burth ibre Mitten,

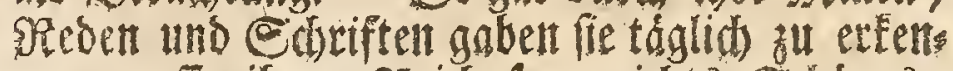

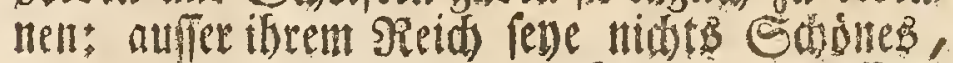
nictis (Sroffes, nichts saprece anjutreffen;

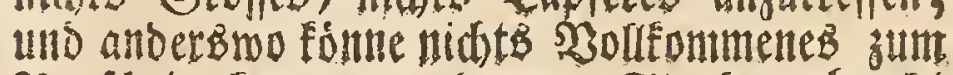
3oridein fommen, oder ful (Stanto gebrads

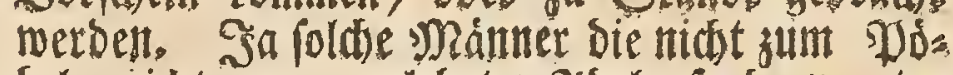
bel, nidt) jum ungelebrten 21 del; conbertt unter bie peltenften unt groften Geifter gebourten, bes baupteten bit uns mieser; ben ibnest mur fónne maut untabelbaft fotreiben; Die Soromung, bie

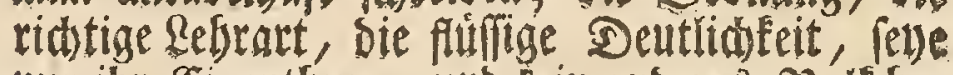
nut ibr Cigentfum, und tein anberes 20 le bas

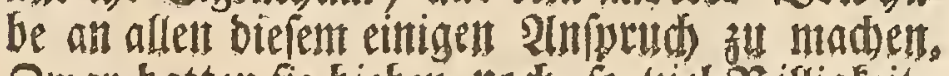
3mar batten fie bieben nod fo siel Bitlligeeit,

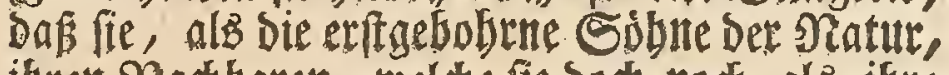

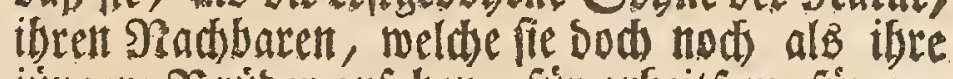

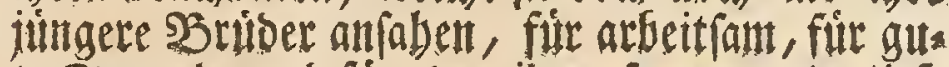
te Eammler dnt fír, yon ibnen ís gettannte, tief: finnige Reute gelten lieffer, fith felbften aber eigs neten fie eine foldse fábigfeit im lutbeilent zu, bermuge meldber fie it ibrett Sdriftent alles

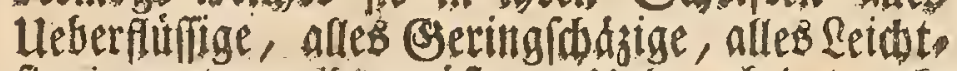
finnige zuvermeiben milten. Lutb auth jezt nod) nach bereits berfortenen brenfig Jabren, yfiege ${ }_{2} 2$ bies 


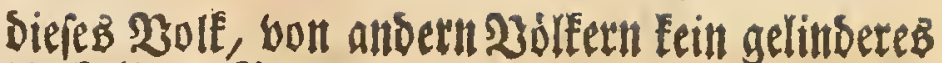
Urtheil zu fállèl.

Sed etiam his non valde certe benignis cenfuris, amarior mihi accidebat eorum hominum mifericordia et animi liberalis aequitas, qua noftra ingenia, noftras virtutes, pro bonitate fua tolerabant, vttamen fentires, non meritis fuis alienarum gentium ciues, fed indulgentiae politiflimi populi, mollius id judicium debere.

Non jufta fatis haec mihi celebratae gentis faftidia videbantur. Verum aequus intelligebam tamen, hanc de fuis rebus opinionem ipfi genti vtilifimam, et maximorum commodorum cauffam effe.

Et humiliores quidem illae, fed lucrofae artes, quarum operibus Imperii diuitiae ftant et robur, et fublimiores aliae, quae ingenia expoliunt; perinde fere in praemiorum ratione funt. Ita comparati funt hominum animi, vt fpe regantur metuque. A vitiis metu fere abfterrentur aut poenae, aut infamiae; ad virtutes et induftriam, fpe et commodo proprio accenduntur; aufer ea, pigro certe in aequore, ad modum nauigii, immotus ftagnabit hominum animus, et vetufta ingeniofi viri exftat fententia, meticulofum fore quemque mortalium fi quid auderet. Eam ergo gentem reliquas fuperaturam arbitor, quae induftriae, fortitudini, ingenio, maxima proemia proponit. Militaris virtutis apud Romanos gloriam, fed fummam, fed popularem fed folam pariebat, co tempore quo pura luxu ciuitas diuitiis facile carebat, neque alio ftimulo mentes Quiritunn agitabantur, quam honorum ad quos virtus ducebat. Ita effectum eft, vt res romana vniuerfis gentibus fuperior euaderet. Accenfis ad eam gloriam animis neque militaris Graecorzlm difciplina, neque barbara Gallorum fortitudo, neque Afiaticorum immenfus numerus, neque Poenorumi diuitiae pares fuerunt.

Quae ambitionis ad virtutes ciuiles excitandas vis eft, eadem lucri ad accendendam induftriam eft potentia. Mortales fponte pigri ad laborem, ad aemulationem, ad elaborationem indefeffam perfecti operis vnice fere ea fpe incitantur: quodcunque fuae quieti juuenilibus annis detraxerint, id omne rei acceffurum familiari, qua ipfa omnia vitae commoda, et beatum denique fenium fibi emant. Aufer hanc exfpectationem, continuo videbis aratra deferi, et telas imperfectas fufpendi, et nauium curfus inhiberi, et de ea gente induftriam, folertiam, peitinaciam laboris operumque perfectionem fuge$r e, a$ qua lucri fpem abegeris.

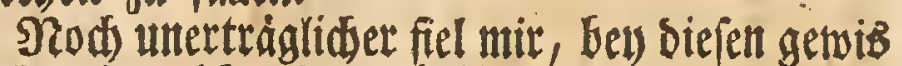

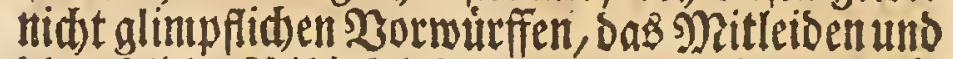

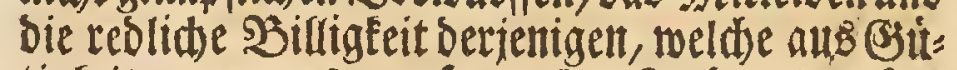
tigfeit gegen unb , tufferent 2erftand unt unfere gutte (Gaben, zwar nod) etwas gelten lieffen; fíd)

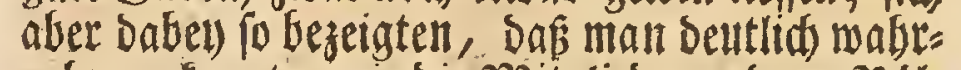

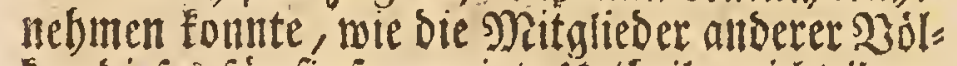
fer, biefes für fie fo geneigte urtheil, nid)t ibrent sBerbienften; fonbern einig und alleine, Der gelints

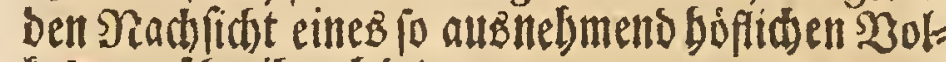
fes zujuldireiben bätten.

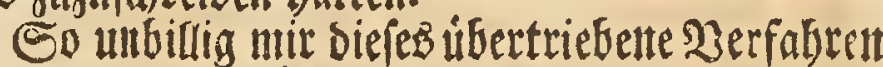

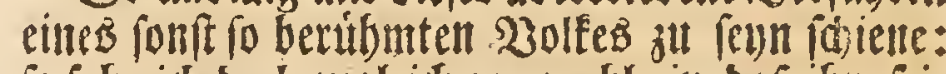

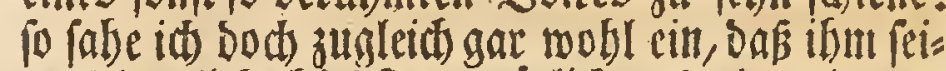

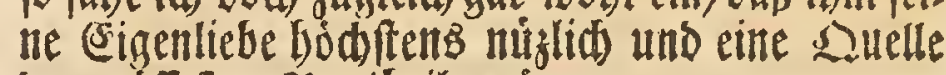
ber groffeiten sortbeile ware.

Sie niebrigenn aber cintráglidsen Rünfte, twel

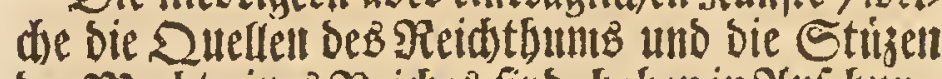

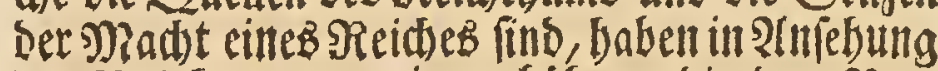
ber $\mathfrak{B}$ elobnumg, zu jenet boberell Die Den 2 Jers

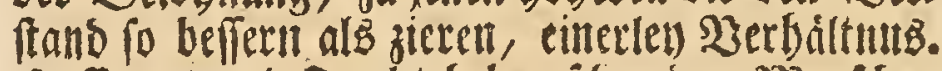
Soffinung uno Furdbt beberricten Der Mentiden (Semuther. Dir Furdt fut Strafe oder (Et)muf bált fie von ben \&aftert a $\mathfrak{b}$; Soffinung uns esigen=

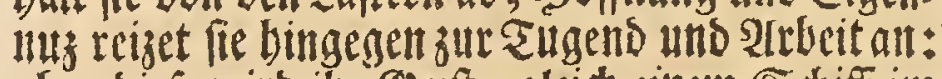
ohtte biefe wirb ibr (Sent, gleid ritem Edjiff im

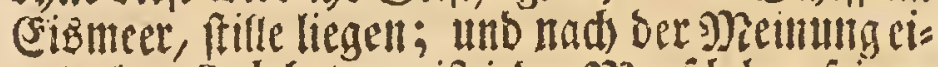
neB alten (selebrten, ift jeber Mieniab bey feinent Unternebmungen furdtfam. Sbeti baber aber

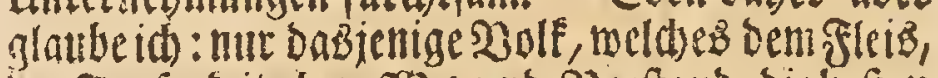
Der Tapferteit, bem $13 i a$ uns Serftano, bie biften Belobitungett befinmmet, weroe fici) fit andern

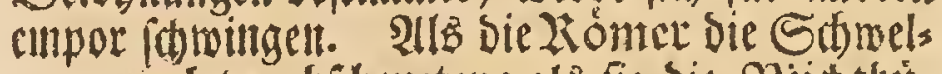
gerel) nod verabidteuten; als fie bie Rieidotlyi=

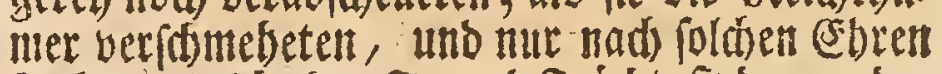
freebten, welde Der Tugens Fruthte fint ; mar ber

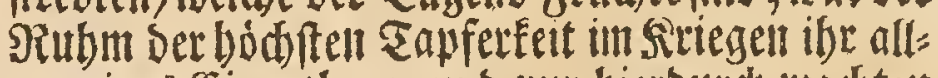
genceites (Eigentbun, und nure bierourdy unad)tent iie fid) alle Nyolfer unterwirfig. Skbrem cinigut

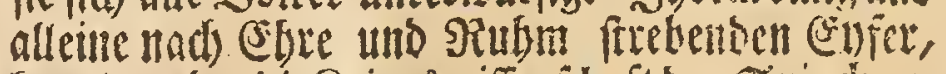

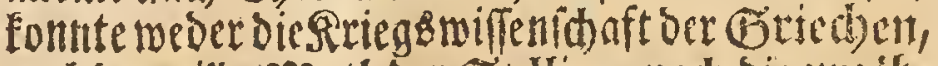
nod) ser wilde Mittb ber (Gallice, nod) Die unzáb)

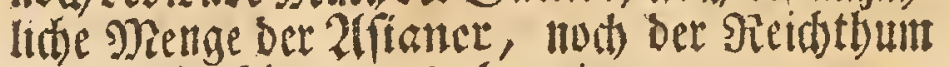
ber Corinthier etmas abgeminuell.

So febr bie Rubmbegierde ju sell butrgerliden Tugenbent anretiet: fo mádhtig if ber Trieb ber (Seminnutht in Estregung ber Probeitamtcit. Piur blos bie 5offnung: wer Der Patbe in ber Sugento

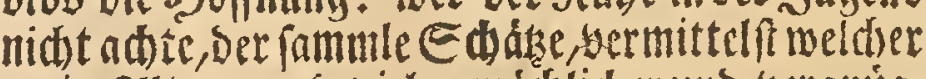
ex, in Pllter, unt fo viel gemád)lider unto vergnitg= ter leben fónme, mad)t, oné bie von Siatur trágen Menfiden Der श(ebeit ofliegen; andern nad)\}uelse fert fít befreben, unb nit utermúbetem fletiset: wab 230 lleommenes ju Stans ju bringent fid) be: mitben. Jatten fie biefe nid), fo fiuntoe ber D) fin ftille; bierraerfftátte wurben rubert; bie Sdbiffe

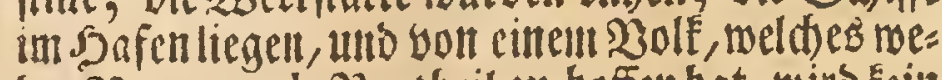
ber gillaen nod 2jortbril ju boffen bat, wirb Eein

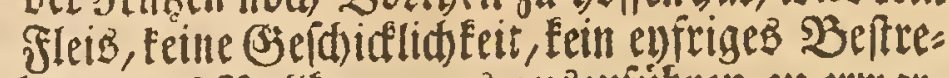

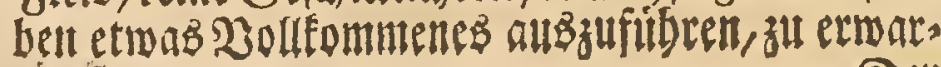
Facile ten (x)!n. 


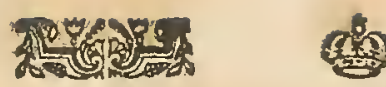

Facile ea praeuides, Leetor amice, quáecunque his principiis fim fuperitructurus. Eam nempe gentem plurimum et induftria valituram et bellicavirtute, et ingenio demum, quae fe ipfam amauerit, quae fưos ciues laudauerit, quae merces proprio in gremio natas, peregrinis praetulerit, quae fuorum fcriptorum ingenia majoris fecerit, quae denique, vt vno omnia comprehendam verbo,opinionem de fuis rebus fuisque ciuibus, conceperit maximam.

Contrarios oppofitivitii effectus fore absque demonftratione intelligitur. Si quae gens fuorum artificum opera fpreuerit, fi fuos poetas deriferit prior, fialiena opificia, et nata extra fuos limites ingenia laudauerit; ei inquam gen$\mathrm{ti}_{1}$ ajo, neque ingenia fore, neque induftriam, neque mercaturam, neque opes adeo, neque vires, neque aut ingenii laudem aut folertiae.

Non obfcurum eft quam gentem haec tan. gant conuicia. Eft in Europa immenfa natio, induftriae fummae, laboris fupra alias patiens, diues inuentis, ingeniorum gloria nulli inferior, voluptati mediocrius dedita, inter fortes fortifima; et ea tamen gens le ipfam defpicit, fe odit, aliena omnia emit, laudat, imitatur: neque culte fe veftri putat, nequelaude exceptam dapibus, neque potam luculente, neque commodis aedibus inftruatam, nifi $\mathrm{ab}$ aliis, et hoftilibus fane populis, veftes, vina, coquos, fartores, pannificia, architectos caro redemerit. Eadem gens alieni ingenii dotes effert vnice, poetas, qui alia lingua cecinerunt, pictores, extra finum fuum nutritos, fcriptores, fi dis placet; rerum propriarum, etiam vitiofiffimos, etiam infideles, etiamfibi iniquos, folos legit, emit, admiratur.

Manifefta funt, quae haec, magnatibus potiffimum familiaria, de ciuibus fuis judicia fequantur. Languent artes, fubliftit intra vulgatiffima et quotidiana, induftria artificum, ingenia ipfa ad ea quae vitam hactenusalunt, ad inftituendam iuuentutem, ad compilandum, ad libros vertendos deprimuntur: ita alis quafi praecilis, ad omnia magna natae gentis vires humi repunt, et aliarum nationum ingenia, induftria artesque excitantur et increfcunt. Ideo ab ea gente academiae, quales majoribus aufpiciis alere oportet, $a b$ funt, et artes, quaecunque publicis praemiis indigent majoreque fumtu, in elementis languent; ideo innumerabiles et fummae induftriae ciues in fculptura, in pictura in re ftatuaria, vix quidquam pariunt aut grande aut nouum; neque ad epica carmina, et tragoedias, aliaque majora ingenii humani tentamina hactenus adfpiratum eft. Ad ea omnia fatis eft, in ea femper gente, quam amo dum

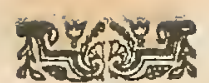

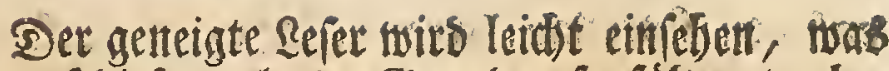

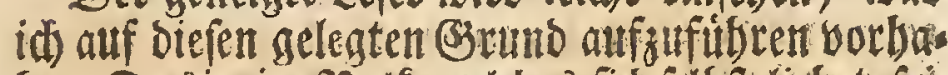

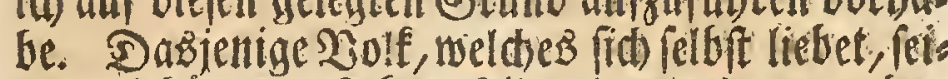
the Mitburger enbebet; feine eigente $23 a$ aten ben fremboen yor giebet, feine Scribenten bod)adftet, unb bas id nit menigem allez age, von fíd) unto beme Seiniaen bie befte Meinumg beget, wirb alle

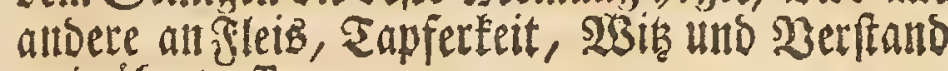
weit itbertreffent.

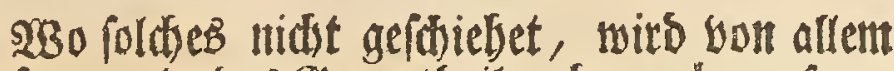
biefen gerade Das (Siegentbeil twabrzuneloment feun.

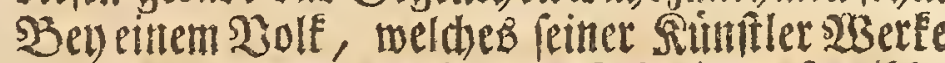
veradtet; feiner Poeten zu enft pottet; frenibbe

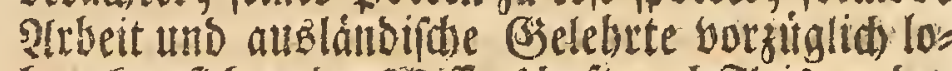

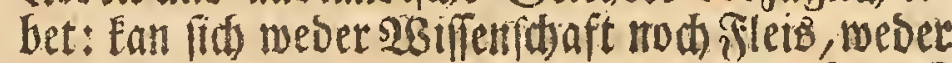

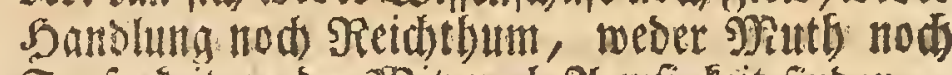
Sapferfeit, weser $2 B$ is nod 2 emfigeeit finden.

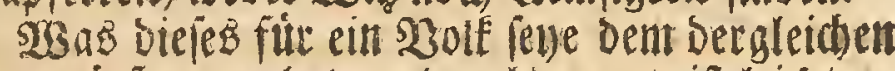
23otwurfe gemadbet nerben fonten, ift leibt ju

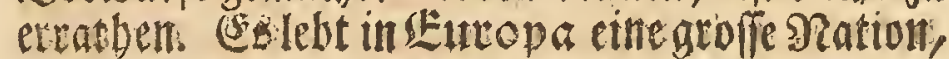

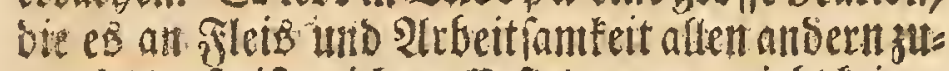

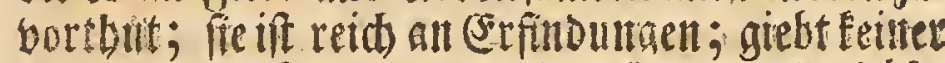

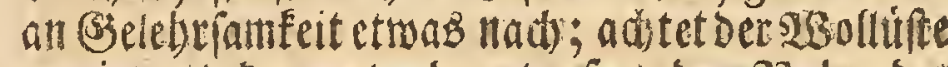
werig, uno lan unter ben tapfern ben siubm bet

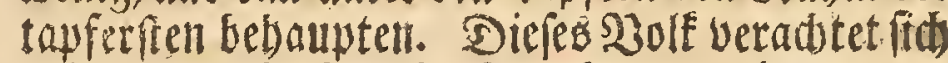
filbif, es baflet fid); Eanft, lobt uno abmet mur bHos mas frembe beiffet naif. (EB glautet fith weber wobl zu fleiben, nod etwas nied lides affen, nod etwas forflides trinteert, no b bequent wobnell

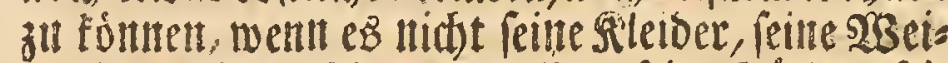

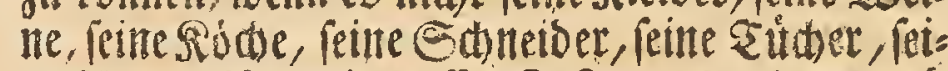
ne 23 numeiffer, mit groffen Roften aแz anbern, und moblaac boit Teinben bemobiten Ranbern foms

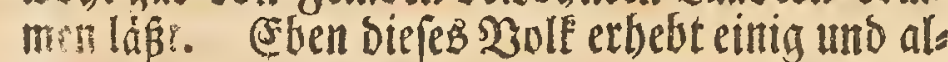

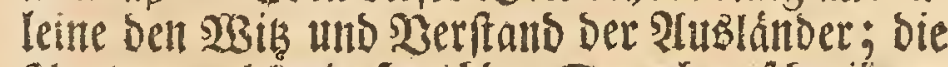
Woeten, weldie in frenbben Epradsen fidereiben; Die auslánbiidjen Mabler; Die feine eigette. (J)e fididte anf bas feblerbaftefte, ungetreuefte anto gebaffigfte bortragende elende Scribenten, merbent nut afleine bon ibut gelefert, gefauft uno benutubert.

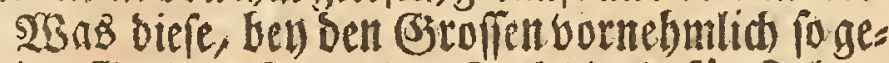
meitre BSeringadtunt oer Lanbsleute für Solgent

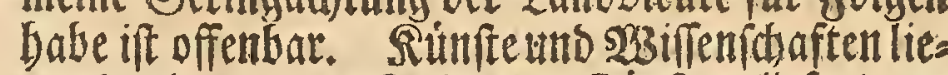
gen Danieber; Der fleis Der Rúnftier liefert nue

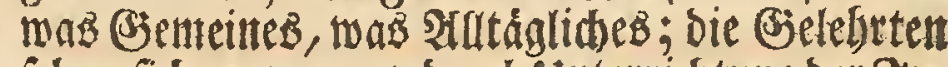

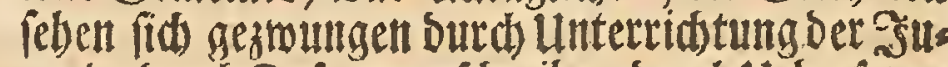

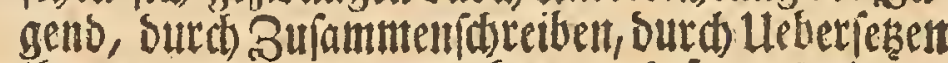
ibren unterbalt zu erwerben, uns fo ntuB ein zu allen grofient Linternebmungen túdhtiges 2Bole, ben ermantenben St)mingen, in Staub friedsen; wentn int Esegentbeil bie (S)elebrianteit, Der Fleiỏ

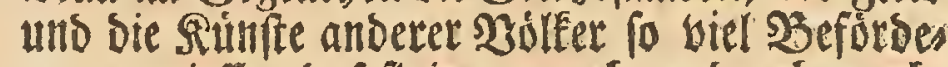
rung genieffen, ba pie immer nebre uno mebr wad) fen uns zunebmen. Daber finbet man atto bey biefem 2olf feine burd boberen Sdun zu unters

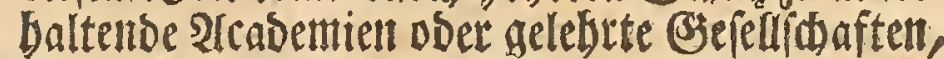
unt bie siunter welde iffentliche SBelobmungen verbienten, fonter groffe soften aber nidst wobs

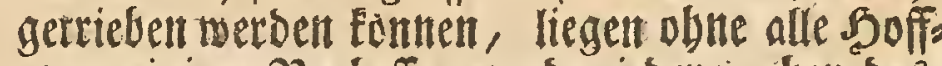
nung einiget Berbefferung Danteber; ebent Des. megen wiro auf son einer fo unsablbarent DRenge Der arbeitfamfen sourget, im suwferfecten, in $x)$ 


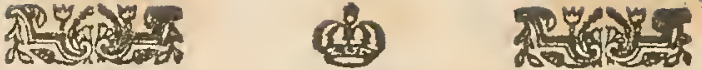

caftigo, folertiae, ingenii, laboris; deeft autem in Principibus, in Magnatibus, in ditioribus ciuium is patrae amor, qui norit fua laudare dona, fua fibi et domeftica gloria placere.

Verum ejusmodi quidemReges et Principes noftris defideriis de coelo euocare non licet: id folum fupereft, vt docti certe viri, et fcriptorum judices cenforesque, fuorum ciuium famam fibi finant effe commendatam, fuoque fuffragio porro velint adjuuare. Ita quidem femper fui animatus, vt ingenium, virtutem, induftriam in quacunque gente amarem, laudaremque; in noftra tamen, inque meis ciuibus, majori cum affectu extollerem, et tanquam cognata mihi, parternque mei, iis, quae mihifola fuperfunt, officis furtentarem.

Ergo, quafi mea fubeffet aliqua induftria, exfultaui olim, et BERNOVLLIORVM ingeniis et EvLERorvm calculis, et Gesneriana dictione eruditioneque, et mufa KLopsTockI, et fermonibus JervsAlEMI, et laboriofis PotTri crucibulis, et Mexeli fcalpello, et PreIsLeri ícalpro, et EHRETII penicillo.

Eo verior vero ingeniorum in Germania laus eft, quo magis proprio vnice ardore, exiguis plerumque praemiis propofitis nullisue, ad excellendum incitantur.

Vides amice Lector quam vicina fcopo haec mea fit oratio. Egregii Viri, et fuam merendo nobilitatem adepti, opus, mea praefatione comitor, AvgVsti JoHANNis Roesel DE Rosenhof. Dudum ille propria veri cupidine vnice animatus, inter debilitati corporis varios languores, a nullo aut Principe adjutus, aut Maecenate, ad hiftoriam naturalem ornandam acceffit. Difficilem ejus partem, infectorum nempe tribum, fibi fumfit, non minus de ea meriturus, quam in Italia VALISNERivs, in Gallia Renatvs Antonivs Ferchavlt DE Reavmvr, in HeluetiaAbranamvs Trembley et Carolvs Bonnet, in Suetia Carolvs de GEER. Nam aliorum inter exteros fcriptorum induftriam facile fupergreffus eft, neque a fummi olim his in rebus Auctoris JoHannIs SWAMMERDAM folertia longe diftant, quae nofter ad polyporum hiftoriam addidit, hactenus celebribus his, quos laudaui viris, latius meritus, quod mores naturae et obferuauerit, et felicifimo penicillo exprefferit, quo
Der Mablecen, in der 2 billbbauterfunt, faum et:

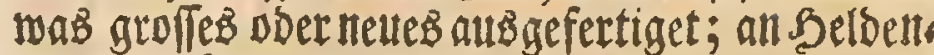
gebidite aber, an Trauteripiele unto an andere grofs

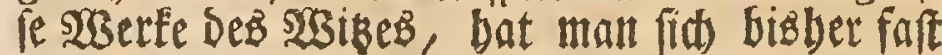
nidst gewaget. Und bod feblt es biefem 2zolf, weldes id ungeadtet meines Tabels denno(t) lies be unb adi)te, zu allem biefen, meber alr fábiaffeit

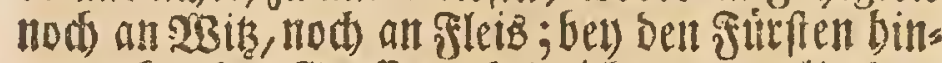

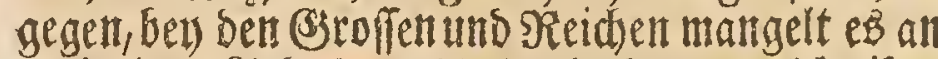
Derjenigen Riebe des $23 a t t e r(a n d e B$, weld)e ibre eigette (S)

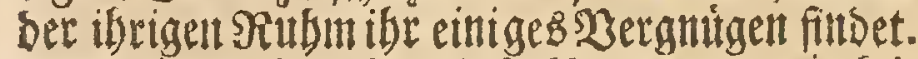

Dod buth anfere SY3infide twerden wir feite

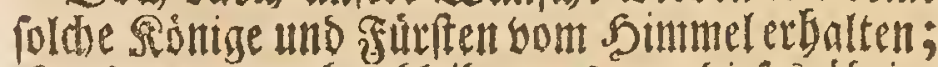

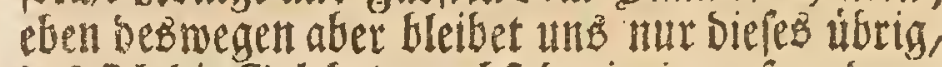
bos fid bie (S)elebrten nebit bententgen, fo anderer 23serfe zu beurtbeilent int Stand finto, Den SRuthm ibrer Randozleuteanbefoblen felyn laffen, mo felbi. ge mit ibrent 3 enfall unterftusen. $230 B$ midf

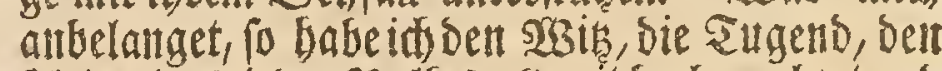

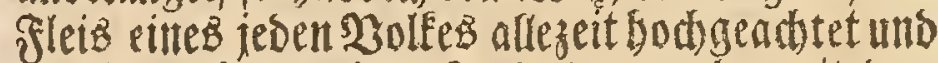
gepriefen, ben) meinen Lanosicuten aber mit Den grósten $3 e t g$ túgen gelobet uno nad) meinem $23 e r=$ mogen, als etwas fo mich gall nabe angebet, als eiren Theil meinte sigenthuntes, mit alter Dienfgefiffenbeit' zu beforbern geftudet.

(Syent baber babe ids bent Seift Der Sernoulli, bie Sectumaent ber Euler, bie Beteofanteit ando groffe swiffenthaft eines Gesners, bie Mille ei.

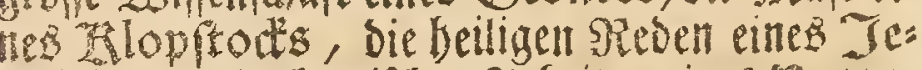
ritfolents, bie (hemifden Plrbeiten eitte Dotts,

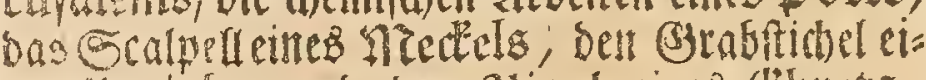

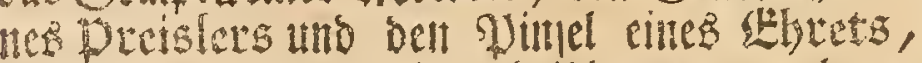
froloctent und als ob it) Sbeil baran zu nelymen Gótte, benumbert und gepriefent.

Sie Belebrten tuts Sinfuter Der Deutfdan aber verbienet un fo viel mebr abs; je mebroles

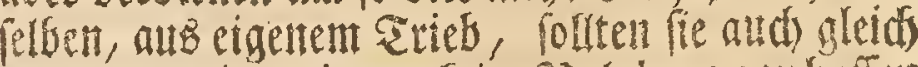

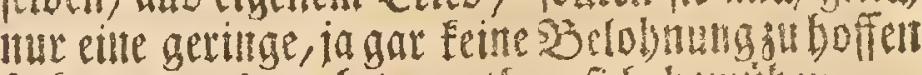

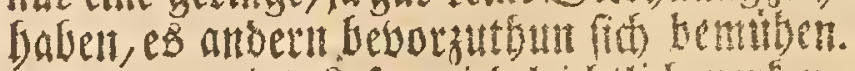

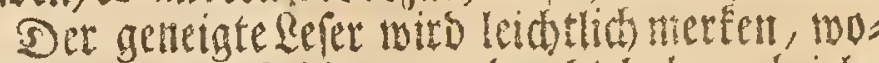
bin $D a B$, maB $i d$ bier borgebracht babe, afiziele.

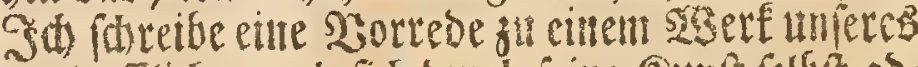
bortzeffichen uno fia burds feine fiunt felbit abs

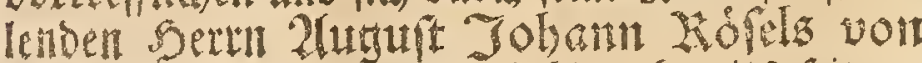
ziofentyof. es bat fid felsiger bereitz fort ge=

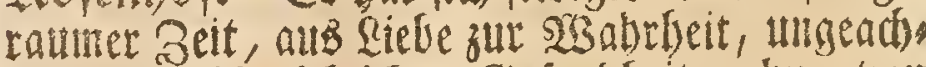
tet reiner fatwádbritbent (Ssejutsbeit, obne bon

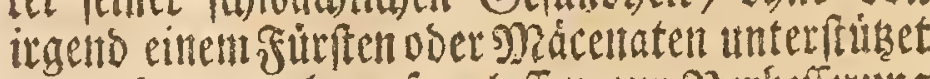
all weroen, angelegenferyn laffen, zut szerbefferming ber Saturbiftorie bas Eeinige berzuttrager. Sein Fleis bat fin eitten fatmeren Sheil berielbelt, Die fantilie Der: Snfecten, gewáblet, under miro fid) um ferbige eben fo verbient maden, als $\mathcal{V}_{\text {as }}$

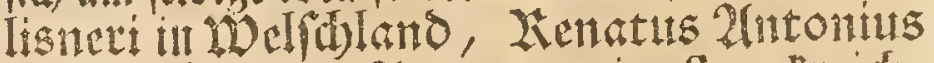
ferchault von zealmute in franteridh, 2lbrabamerembley und Carl\$onntet in ber

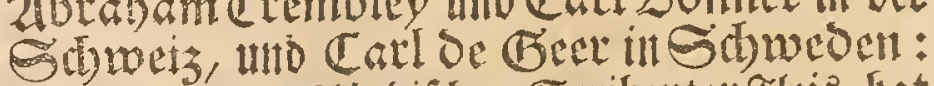

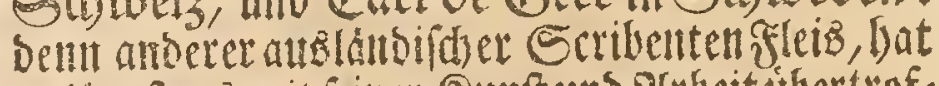

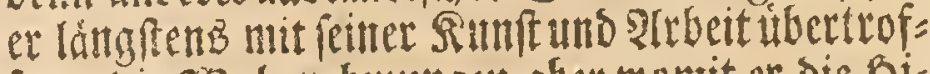

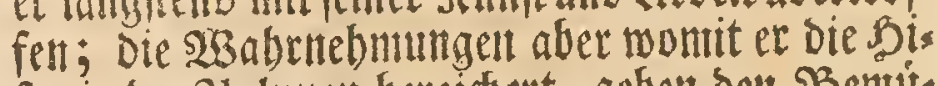
ftorie ber Polupent bereidert, geben ben 2 enut. butrgen, Des in bergleiden Dingen ebedem yot: treffli: 


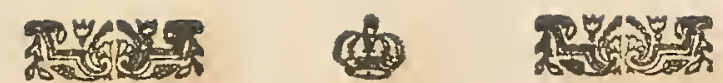

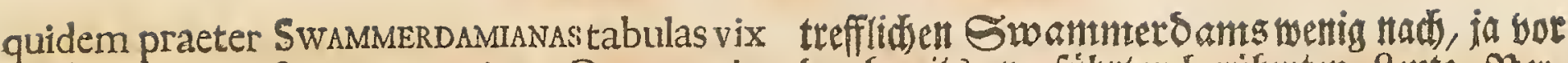

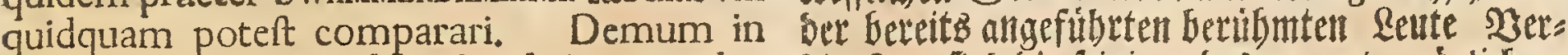

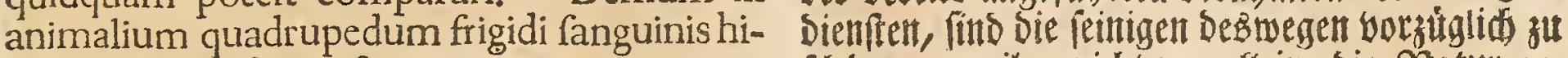
ftoria, ita verfatus eft, vt ante eum nemo, fitáken; weil er nitbt nut alleilte bie Satutu ges Ejus operis priorem partem editam lauda- jtau beobadtetet, fondert aud butd feinen Winfel mus, alteram, qua lacertarum familia conti- fo mobl nadigeabuttet bat, Dab, attier Dent safelnt

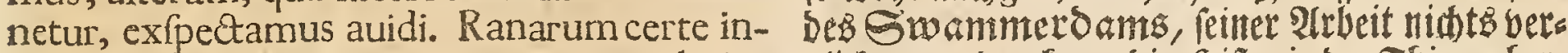
digenarum fpecies omnes, a prima euolutio- glichen werben Ean; bie Siftorie ber Sbiere aber, ne ad vltimum adulti animalis officium, nem- welthe cint faltes SBlut belebet, ift bor ibm bout pe ad generationem fobolis, ita eft profecu- niemantoen in ein foldebs Ridit gefetet worbent. tus vt mores, cibum, anatomen animalis fe- Diejer erfte Sbeil serfelber verbientet alles \&ob;

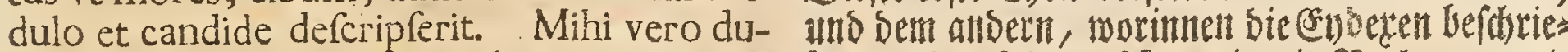
dum ii foli libri videntur aut legi mereri, aut ben werben follen, rebent wir mit Szerlangen ents

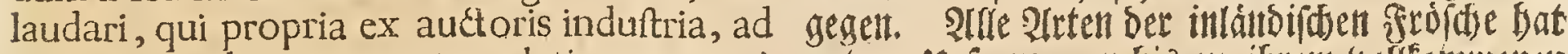
naturae exploratae contemplationem nati funt,

Tria fere contraria vitia huic laudi opponuntur, quorum alterum Germanis folent exprobrare exteri; alterum ingeniolis hominibus et hoc feculo etiam magis proprium eft; tertium fere omnes gentes tangit aequaliter.

Nempe in gente laboriofa fed modice diuite, cum Principes fumtus experimentorum ceffarent fuppeditare, neque aliis praemiis priuatorum hominum ftudium rependerent, neque anatomicis laboribus theatra faus numerofa aut inftructa paterent, neque nofodochiorum ad defcribendos morbos effet abundantia, neque horti regiis opibus adrem herbariam ornandam colerentur, neque inftrumentum experientiae phyficae eruditis hominibus publice exhiberetar: factum eft vtique, vt multi fcriptores, ex aliorum commentariis, rerum naturalium hiftoriam colligerent, fibique ordinem fere folum compilatae fuppellectilis proprium feruarent, ld vitium, vti diffmulari nequit, ita contrariis certe exemplis abunde compenfatum eft, ipfumque proprium fere Germaniae cbemiae ftudinim demonftrauit, naturam perinde a noftris amari, quoties res familiaris ipfi excolendae fufficeret. Porro co etiam faeculo, quo PavLlins aliique compilatores, animalium et plantarum defcriptiones adeo humiliter ex alienis opibus congerebant, exftiterunttamen Gverickir, HeveliI, Hermanni, Wepferi, RaviI aliique, etiam numero fuo patriam vindicaturi, fua in arte principes viri. Deinde, quam primum bonis artibus fubfidia publice reddita funt, nulla certe gens fupra Germanos in natura cognofcenda eminuit; fiue ftellarum itinera accurate contemplari jubeas, fiue experimentis naturam fatigari, fiue artificiofe corpora hominum et animalium diffecari,fiue er boun uriprumg an bis zu ifrem bolfommenett

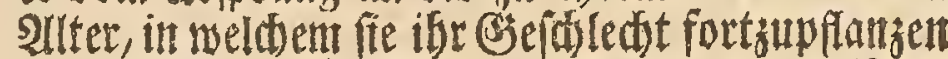
tridstig fitto, fo bejorieben, saf er uns gon ibren Eigenfobften, bon ibrer Speife, und bon ibremt

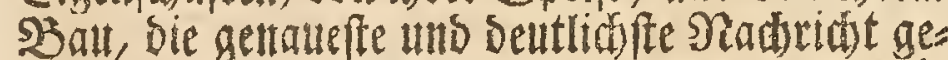
gebent. SWd aber babe allegeit metr biejenigen SBit= d)er fir lejens: tnd lobenswarbig gebalten, mets (b) beB 3 erfaffer

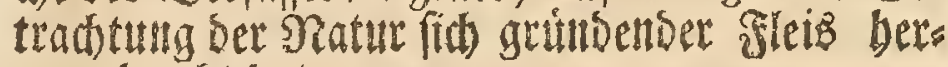
vornebvadst bat.

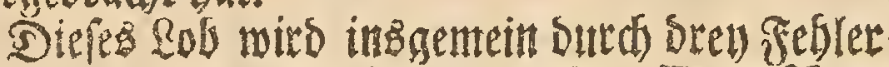
bertunelt. Der eite pleget den Deutfibent bon bett Muslänern vorgeworffen zu werben; Det ansere if ben (Selebrten ponberlid zutuferen 3 eis tell eigen, Into ber britte finvet fith faft bey allent Moifert.

Ba $e^{8}$ ber Den Deutiden, einen stwat arbeits fanten aver mittelmápin reidbent 2301 , lang]am

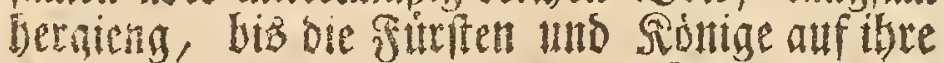
Soften

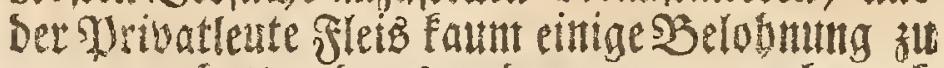

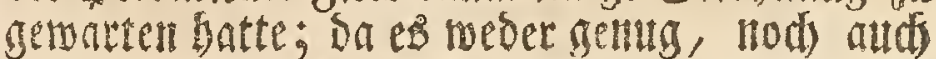

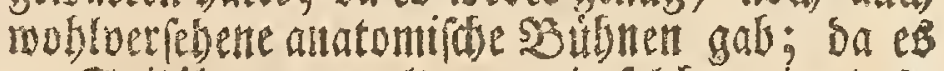
ant Sprtalent inangelte, unt in foldyent eitte bolfs

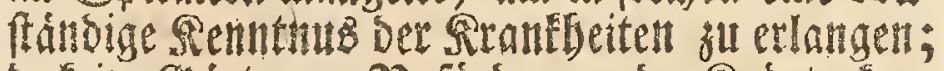

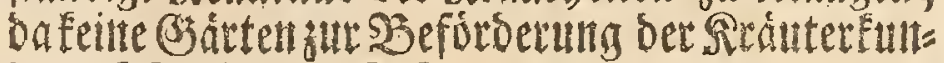
be auf Soltigliche Soften angeleget wutsen; ba

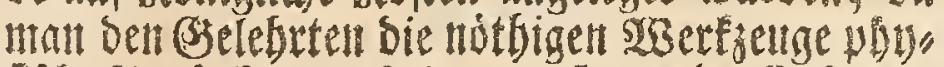
fifde Berfuche anzufellen, auf gemeine Sioften zu veridaffen unterlies: io baben frevlid viele Scri:

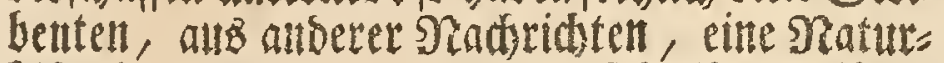

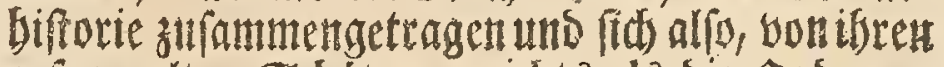

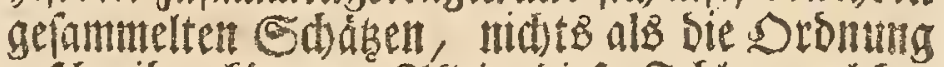

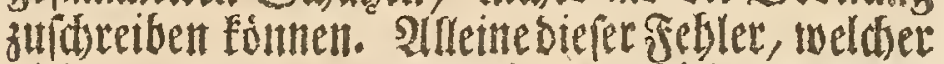
nidst du latgnen, ift binch gegenfeitige Exempel therfinbig erfeket worben, und Sie ben beuts fogen fait allen eigene Chemie, Eat genuglatt

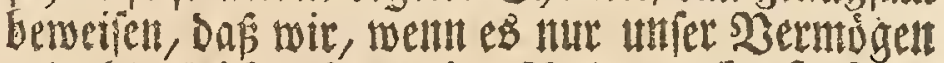

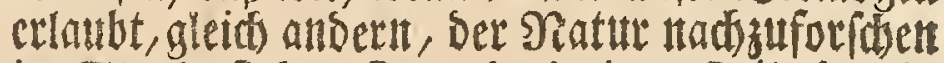
int Stanbe find. Sa zu berjentigent Zeit, sa eint paullini nebf andern, bie Siftorie ber Thiere unt Dfanzen, auf baB niebertrád tiglte aus auts Dern anamtutenforieb, gab es bod auth einten Guertace, einen Sevel, einen Sermant, einent Wepfer, einen kiat, und nod ntbrete, beren jeser in feiner Sunfte ein meifter beiffest connte,

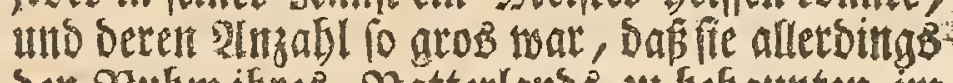
bet SRuldmifres 3atterlantos zu befauptent int Stans maren. Solals aber nadigebenos die )$\left(x_{2}\right.$ 


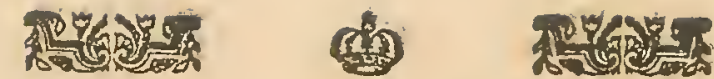

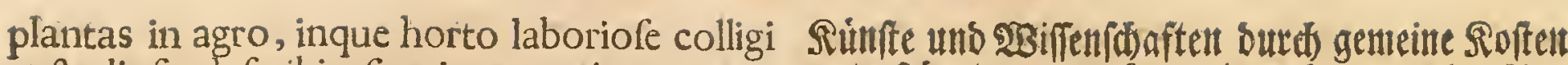
et ftudiofe defcribi, fiue igne variam materiam torqueri, fiue medicinam nouis medicaminibus augeri velis.

Alterum gentium ingeniofarum vitium eft, folis rationibus, \& ampliffima fuarum cogitationum periphrafi, et vagis et infra plenam veritatem fubfiftentibus rerum ideis, \& femifirmis hypothefibus libros explere, quibus pura dictio, aut periodorum ingeniofus nitor pretium addat. Perinde mihi hoc librorum genus inutile videtur, quo non res ipfae, fed auctorum fuorum de rebus opiniones continentur. Ingenii fcilicet quam in compilatoribus hic plus eft, vtilitatis forte minus. 11 li enim omnium conuiciis exagitati collećtores vtiliffimas faepe rerum memorias confervant, quas laboriofe inuenires, fi absque ipfis foret, et commodos eorum indices nobis praeftant, quae de quaque re apud innumerabiles fcriptores dicta fuerunt. Deinde a compilatoribus non perinde ad erroneas opiniones deducimur, vt quidem ab illis ingeniofis naturae non vifae imitatoribus, qui in rem naturalem poeticam libertatem traducunt.

Non minus denique, et atróciuspene vitium eft, quando obferuatae equidem naturae hiftoria promittitur, et tamen praeceps authoris imperitia alienos a veris euentus, neque rem ipfam expreffurum fermonem audax proponit. Non pauci fuerunt eiusmodi miraculorum venatores, aut infidi operum diuinorum contemplatores, qui figuras et defcriptiones temerarii ediderunt, quas veras credas, nifi cum natura comparaueris.

Aliena ab his malis funt, quaecunqne nobilis Auctor edidit. Sua fola, et naturae fidelem picturam offert, artificio vero aut diffectricis manus, aut nitidi penicilli, aut intenti armatique oculi, nemini fe tecundum praeftitit, neque quidquam fuperent dubii, quin hic labor inter clafficos naturalis hiftoriae libros honoratum locum fit tuiturus.

Biernae d. 26. Ianuarii 1758.

unterfutiset wurden, bat es in ertenntnus der פia

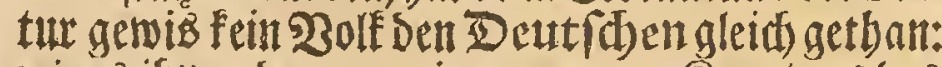
wie es ifytten benn an einergenauen Senntmus bes

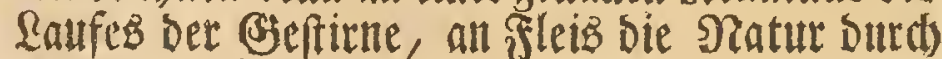
S3eriude múbe zu madjen; bie Siórper ber Mien=

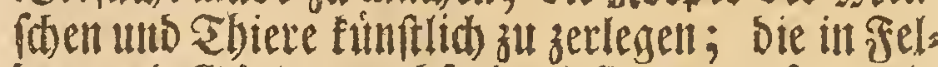
bern uns Gárten wadjende s) fanjen zu fammeln und genau zu befdereiben; manderten Rórper

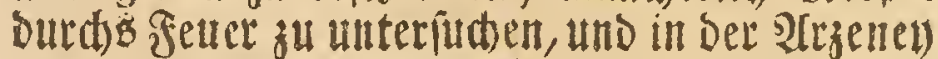
neue Sillfemittel zuentoeden, ganz uno gar nid)t fellet.

Der anbere beu mikigen 3 ólfern fid findenbe Febler befrebet barinnen, Das fie ibere Sdriften nu⿰ blos nit eigenen Meinurnen, mit weitláufig

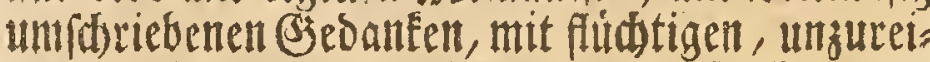
dienden falfiten Begrifen und auf fatwathen (3) únoen ftebenden Sypotbejen anfitlen, welchen eitte reine Sdreibart, ober vie yon 28 Bis g! eiffende Werioben, erft einen sBerth geben múffen. Diefe Irt bon Buthern, worimnen man nitbt bie Sadjent

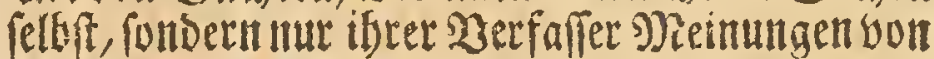
ben Sadben findet, ideinen mie gleid) wenig gilts Benl 3 baber. Mian trifft zar in lelbigen mebr S23is, als ut ben aus andern zulamntengetragenen Stiriften an, feineswegb aber fdaffen fie uns

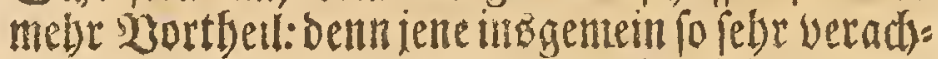
tete Sammler, erinnern uns bod vielmals ber núblidfiten Singe, melde wir, obute ibee SBenbutlfe, effeters mit ber groffen Mritbe faum autefintoig maden murben; auth gebell fie uns bequente Ser. $^{2}$

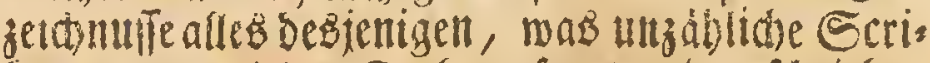
benten, bon jeder Sadje gefíget unto gejutriebent baben; úberdem aber fo verfitgeen fie un febr zu irrigengieinungen, als mobl bisjenige, wels

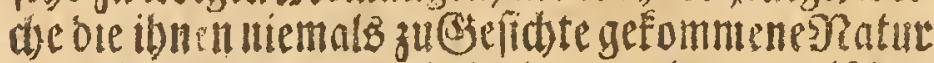

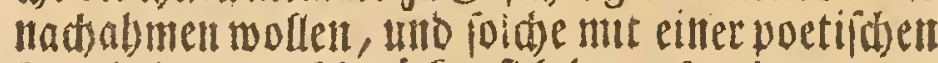

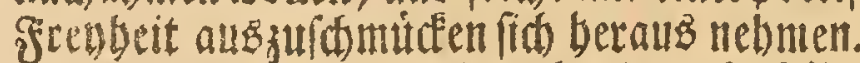

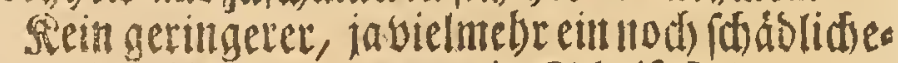
rer Jebler if es, ment uns ein Sdriftifeller, zmar eine (S) fofidste ber bon ibm genau beobadteten Ratur veripridet, aber ftatt ber wabren, faliote 2 gebenbeiten, mit foldsen 230 orten, weldje gan? was anbers auzeigen alş fie fagen follen, auf bas berwes genfevortrăgt. Drrgleiben nur vem 233 utbertias

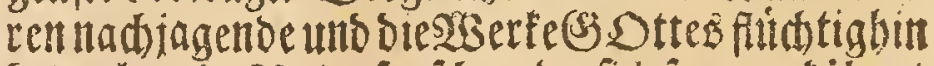
betrad)tenbe Seaturforider, bie fid jogar crfüibnet

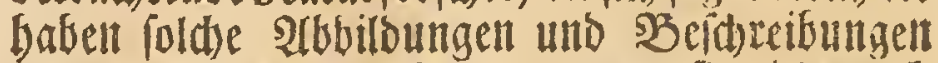
beraus zu geben, weldie man, wern fie nicts nad)

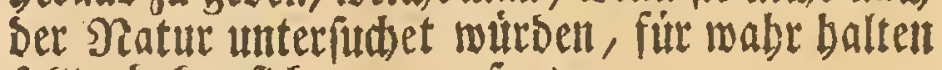
follte, baben fif genug gefutoen.

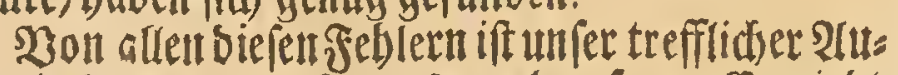
tor in bem was er berausgegeben fren. (Er giebt

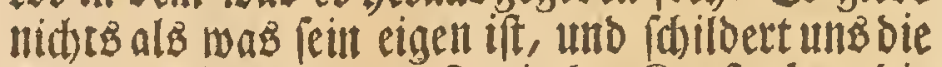
Sintur auf Das getreuefte; in Der Runft aber die

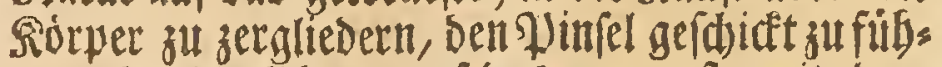
telt, ober bie siórper auf bas genauefte mit bein 23ergrófierumgagglaz ju betradtett, meichet er uies manben: Daber denn aud gans und gar nidbt zu

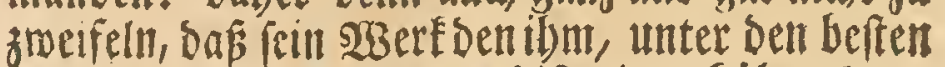

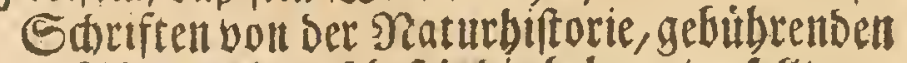

Plaks, nid̆tauf befánbig bebauptenfollte. 


\section{HISTORIA NATVRALIS RANARVM NOSTRATIVM. DDel:}

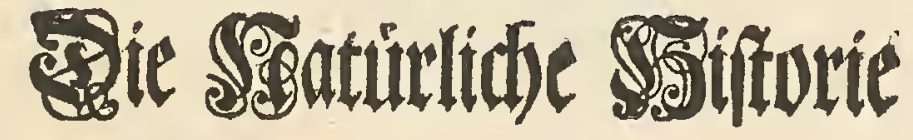

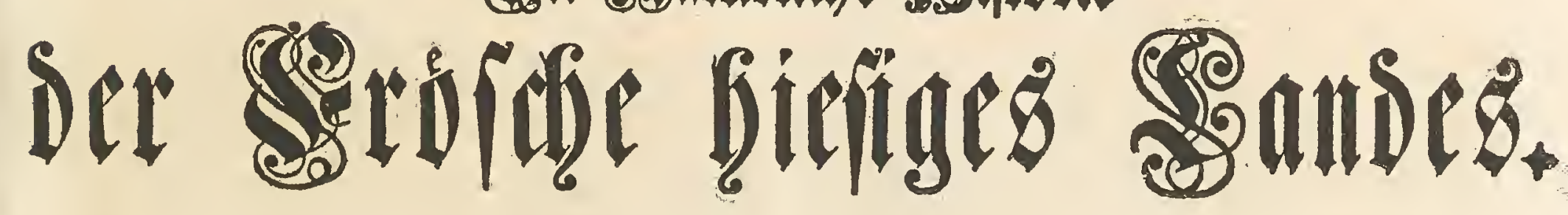




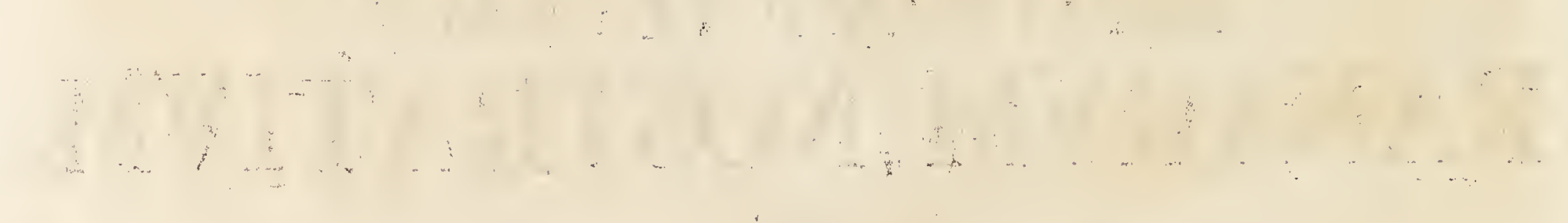

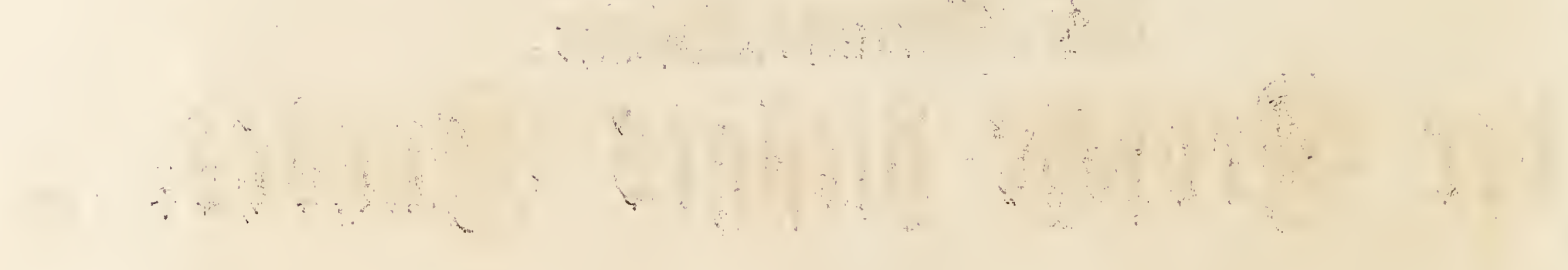




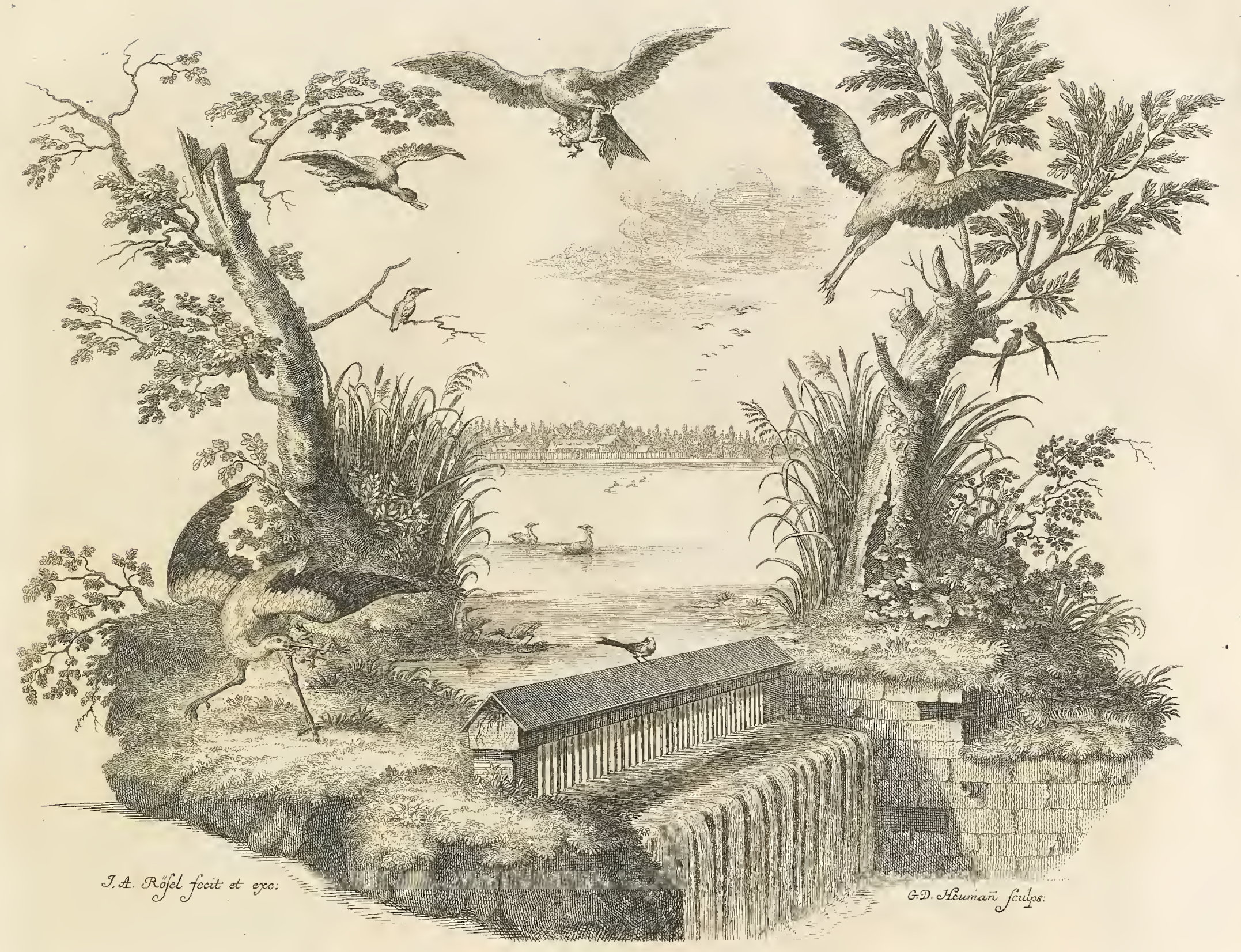

\section{PRAEFATIO.}

$\mathbf{P}$

oftquam varia animalia, atque inter illa ea praefertim, quae antiquitus iam ex putredine oriri credebantur, accuratius contemplatus fum penitiusque examinaui: in fcrutatorum rerum naturalium eam non potui non tranfire fententiam, qua ftatuunt, omnia non folum animalia, fed ipfam etiam inter res creatas nobiliffimam, hominem, fuam ex ouo ducere originem. Quod ad hunc attinet, recentiores quidem inuenere Phyfici, effe bina illa corpora globo$\mathrm{fa}$, quae in foeminarum abdomine prope vterum haerent, quaeque veteres earum appellarunt tefticulos, variorum oulorum receptacula, vel ipfa potius ouaria, a quibus, poft praeuiam impraegnationem, ouulum vtplurimum vnum, interdum duo, nonnunquam tria, rarius autem plura foluantur; per tubas vterinas ipfum in vterum deferantur, ibidemque tamdiu morentur, donec foetus in ipfis latitans, omni ex parte perfectus, ruptis membranis quae ouulum formabant, viuus nafcatur. Eadem etiam ratione res fe.habet cum quadrupedibus nonnullisque aliis animalibus: reliqua e contrario omnia nunquam foetum fuum

\section{Sortede.}

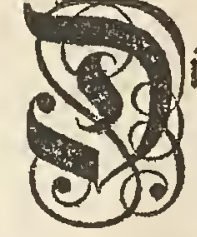

ie gettaiuere SBetradtumg unt utrterfila

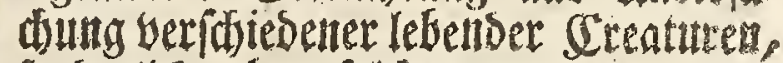
fortberliat) aber folder bont benten mast bon langen Beiten ber geglauthet lat,

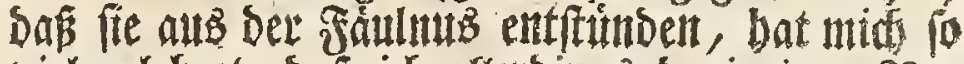

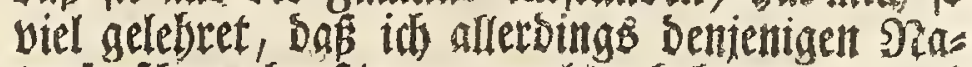

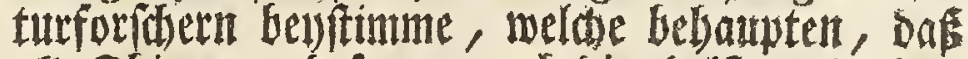
alle Shiere, und fo gar auth bie edelffe unter bent

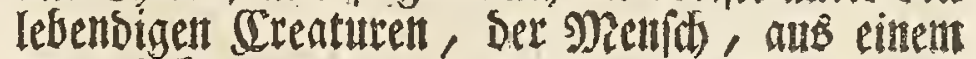

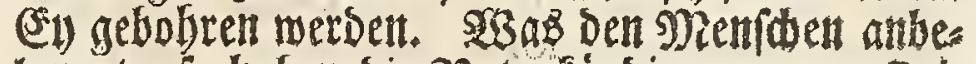
langet, to baben bie ?atureitndiger netterer 3 ei

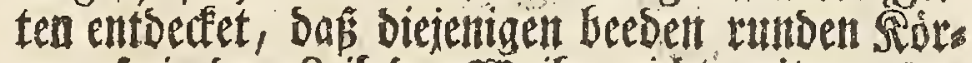
per, fo in bent \&eib ser sseitber nidut meit bunt bee

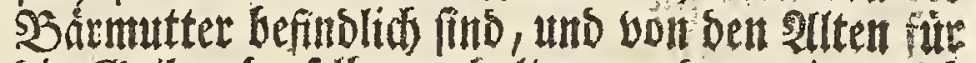
bie Gseilen Derfellben gebalten worben, eigentisid

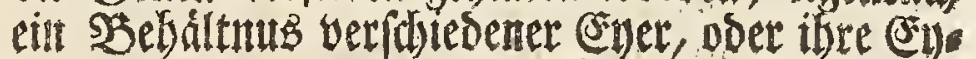

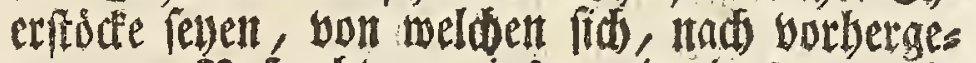
gangetter SBefurhttuts, ittsgentein eines, mantio. malent zwel), uthb bis̄meilen autób breje, féfr feltent aber mebrere (E) aer ablópent, buted bie Matter trompeten in Die S3árntuttter Eomment, uns in bets Felbent fo lange bleibett, bis bie dariment entegaltes Ite Frutst ibre gebórige 230 deommentheit erreis d)et, worauf fie bent nad) Berreifintg Derientigent

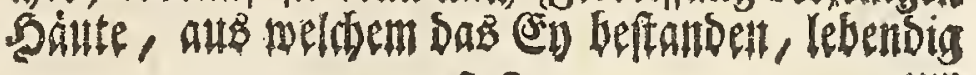
A 2 
fuum edunt viuum; fed femper oua tantum pariunt. Vt enim iam minus de auibus dicam, quae, quod notiflimum eft, dura ponunt oua illaque incubant; crocodili certe, teftudines, lacertae terreftres, omniaque ferpentum genera \&c. oua gignunt, auium ouis quoad formam externam valde fimilia; fed mollia, quaeque parentes minus incubant; excipenda hic vero foret vipera, ferpentibus annumeranda animalibus, fi viuos fuos ederet foetus. Aliam ouorum mollium, fed multo minorum, conftituunt fpeciem, oua quae fluuiatiles edunt pifces: eorum enim genitura, quam, poftquam edita eft, fperma quoque ap.. pellant, meris conftat ouis. Aliud lperma, vel aliam ouorum congeriem, ranae pariunt aquaticaeque lacertae. Sunt conchis cochleisque, vel animalibus teftaceis vniuerfis, fua pariter oua; neque reliqua infecta, ad quae et teitacea pertinent, iisdem carere, certo quoque certius eft: de pluribus faltem noftratium infectorum demonftratum, in mea, id me dedife puto, Injectorum Hiftoria.

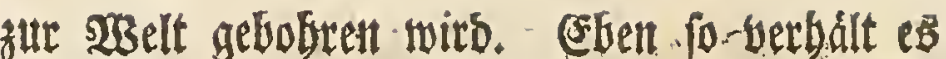
(iid) aud) mit ben bierfîfigen unb cinigen anbern Slieren; Die tibrigen alle bingegen bringent ibre Sumgen nid)t lebenbig zur $23 e l t$, fonbert legen

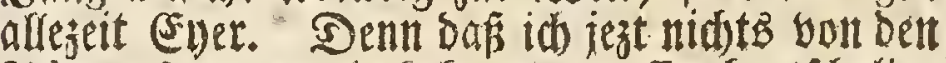

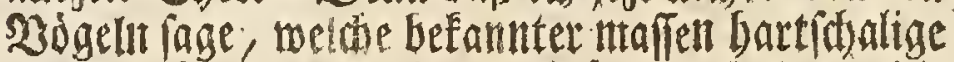
Ever baben und joldbe augbriten, fo legen die Crocodile, bie Edgilberotent, Die Rantendercen, unto alle Sdilakgenartent $2 c$. Einer., welde ber Fornt nad) mit Den Dogeleyern jientid tibereilts fonmett, aber meid) fint uns son ibnell felbit nidt

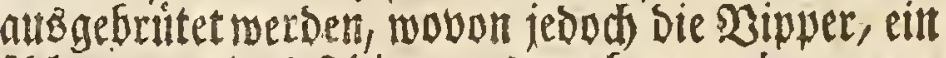

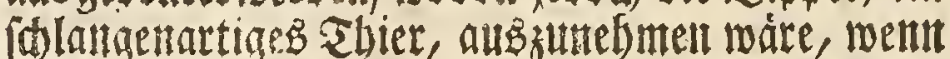
fie ibre Sungent lebendig zut 2 Belt bringen follte.

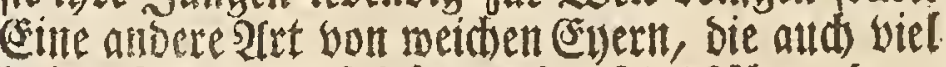

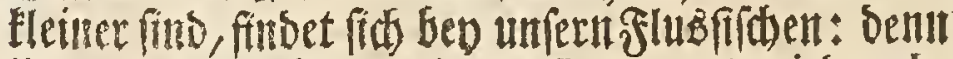
it) SRogen beftebet ant lauter (E)ern, uno mirs aud, wenn fie jelbigen bon fid geben, itgr \&aid gettennet.

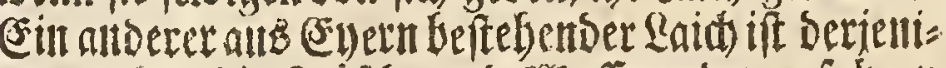

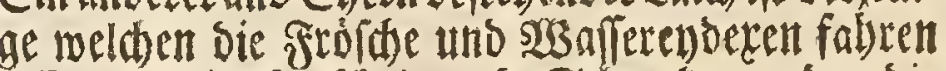

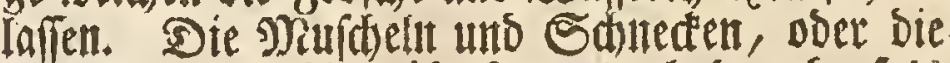
bartidialigen Sfiese ifterbauts Ener, unb baś fid) folde aud bev ben úbrigenGnfecten finden, benn bie bartīinaligen Thiere ges

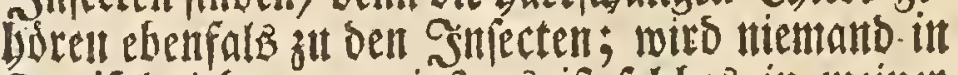
3weifel zielent: wentigftents ift foldes in meiner

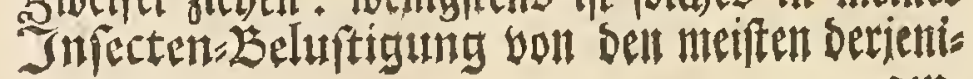




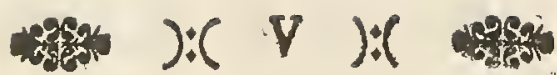

Nullus tamen ex omnibus hifce ouis pro. creatur foetus, nifi ipfo maris foemellaeque viuificentur coitu. Ex ouo gallinae, quam gallus non iniit, nullus excluditur pullus, fpermaque a rana foemella effufum, nifi ipfi a mafculo motus fuerit impreffus, in putredinem abit; idem vero de reliquorum etiam valet animalium ouis. Arborum quidem pediculos, fine coitu generari, perhibent, addunt tamen illi ipf, qui hoc fe obferuaffe affirmant, copulari eosdem coitu quoque. Feruntur vero animalia naturali inftinctu in coitum; fed quum plura eorum, atque inter haec illa praefertim, quorum foetus absque omni parentum adolefcunt cura, innumera gignant oua, hincque vberiore fuo prouentu noxia euadere poffint : certo tantum illa coeunt tempore, fic, vt nonnulla femel in anno, quaedam bis, alia ter quaterue copulentur; atque hic mirum mihi femper vifum eft, quod inter ea, praefertim vero inter infecta, quaedam integro ad fui perfectionem indigeant anno, fimulac autem omni ex parte perfecta fuerint, coeant morianturque. Hemerobius certe poft fui perfectionem, intra viginti quatuor horarum (patium, \& generis propagationi operam nauat, et vitam finit. Quemadmodum vero homo, varias ob proprietates, omnia animalia excellentia fuperat: fic hoc ipfi prae illis etiam datum eft, vt vbi pubuerit, nullum illi ad generis propagationem praefinitum fit tempus. Licet autem fuper reliqua animalia maxime emineat; vix tamen eundem eminentiae tuiturus effet gradum, nifi, vt reliquarum rerum creatarum, fic animalium quoque fcrutaretur proprietates. Factum hinc etiam eft, vt omni tempore, fed diuerfo fudio, in animalium inquifitum fuerit naturam: quae enim certum adferre videbantur vfum, in eorum examine ea defudarunt cura, vt magna reliquorum pars vlla vix digna iudicaretur confideratione, quin prorfus negligeretur; licet curatior eorum inueftigatio fua non caritura fuiffet vtilitate: Leuiffimus et. fam vermis haud vana omnipotentis praebet indicia Creatoris; rana vero, quam multi animal minus perfectum effe putant, omnibus illis inftructa eft partibus, quas in animalibus, vt quibusdam videntur, maxime perfectis deprehendimus. Anatomicus certe in ranae oculo tot, quot in aliorum animalium oculis, inueniet mira; nec etiam cranium iplius, parum licet excauatum, cerebro caret, quod tamen in rana adeffe nonnullos rerum naturalium fcrutatores negare video; nerui vero ex eodem prodeuntes, fenfibus eandem non deftieui probant. Habet infuper ranae fanguis a corde motum, quo per omnes corpo-

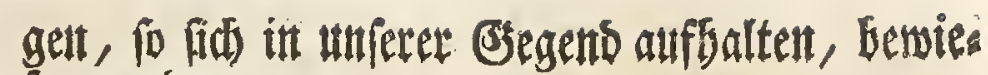
fert worben.

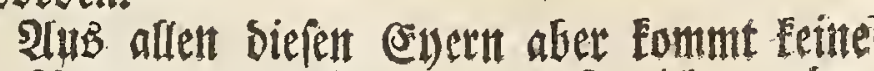

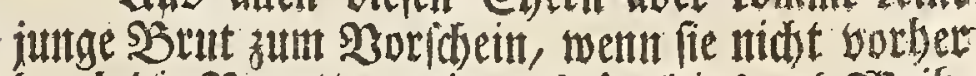

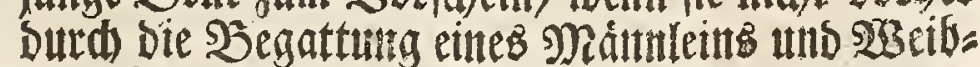

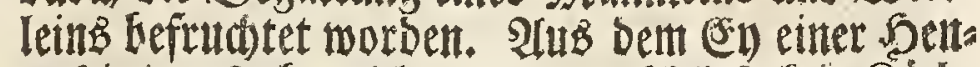

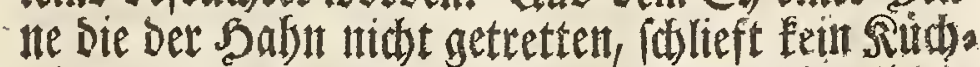

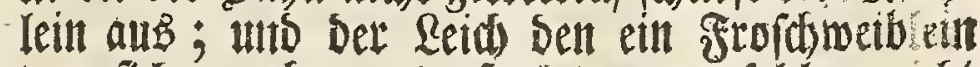

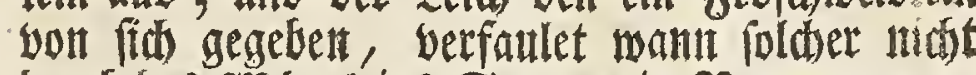
Dutra DeB SRannteitts Saament in SBemegung ges brabt morden: fo aber berbált es fith altut sait

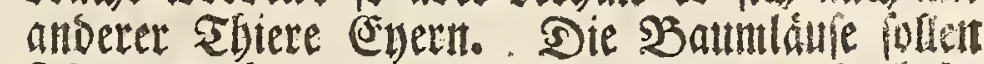
(iid) zmar obite Begattung fortpflamzon; Doot ias gen uns eben biejenigen io foldes beofadtet las

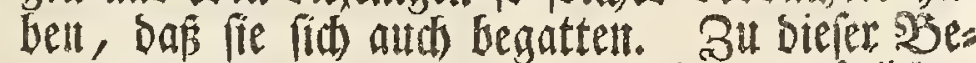
gattung werben bie Ebiere burth cinen naturtiờsen ßeits angetrieben, weil aber biele berferbert, unb

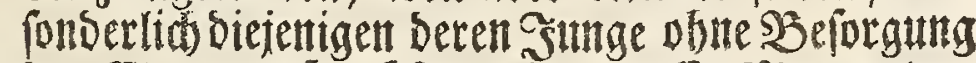
ber EItern aufwadjen, eine groffe Mentge yon

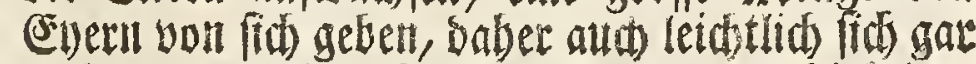

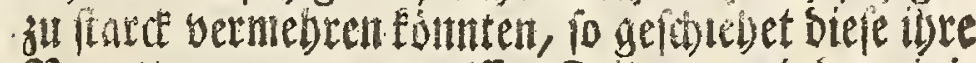
Segattung nut zut geviffen Beicen, uth bey eints gen einmal, bell einigen joetgital, steymal, bis vierntal im Sabr, wober ntir fortortio ber ben

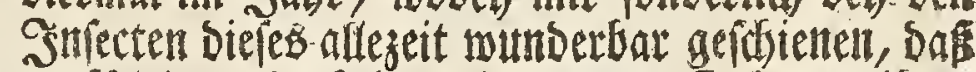

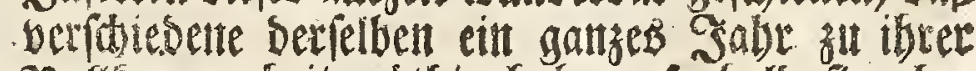
3orfiomutenbeit notthig haben; io balb fie abet forthe erlanget, fid fogleid paaren uns fobentufer" ben; mie seim Das ulferas nad) erbaltener 230 Fommenteit interbalb vier unt zwanzig Stunoent

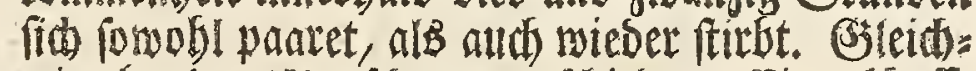

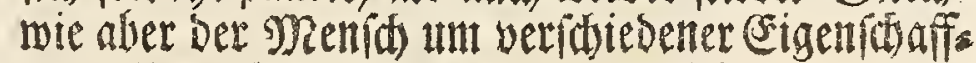
tent millen, ben $230 r z$ bor allen Tbierent beroie: Itet, fo bat er auth biejes yor Denrélbigen zum

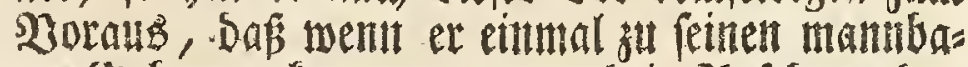
ren Çabrest gefommen, er aud in Infetyung DeB

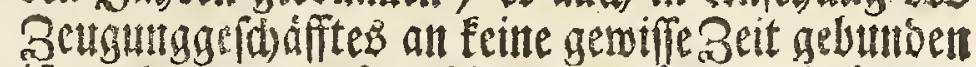
iit. Eo gros aber feitte 20otjetge and inmer find fo febr fiebt er fich Dod ald berbundent, unt felbige in ibrer 230 offenmenbeit zu erbalten, fich, wie um anbere Creatures, fo alth un bie Eigens

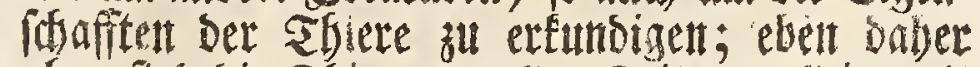
aber fitto sie Tbiere zu allen zeitent, aldeine nit ingletober Sorgfalt, unteriubet morsent: Dent

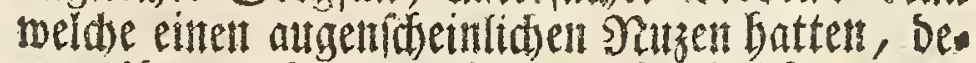

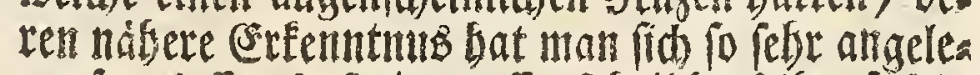

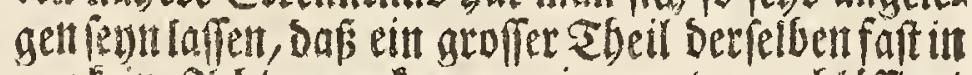

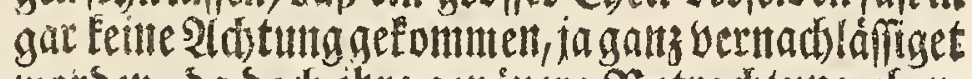

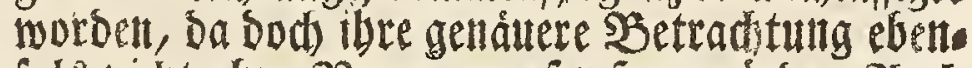

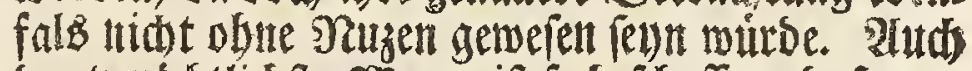

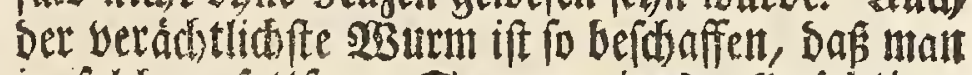
in boldent fattfame Sputren eines aflmád)tigen Sdipters findet, unt eit Trofdis, melder you bies lent firt eitte untoollesmmene Creatur gebalten mirs, ift mit allen benjentigen Shenlen verjeben, bie wie ben) bent bermeintlid) bolleommenfent Sbieren alts treffett. So mirs ein P(tatomicuB ant bent 2 (1tg

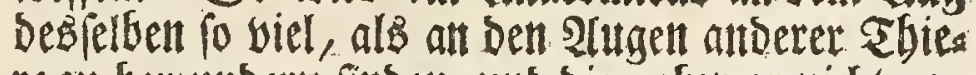

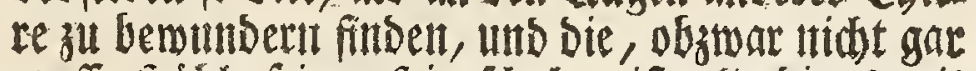

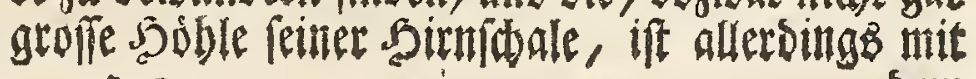




\section{Fig}

ris ipfius fertur partes, aliorumque humorum adiuuantur fecretiones. Sunt ranis fui quoque pulmones, licet non eundem, ac aliis in animalibus, in ipfis praeftare videantur vfum. Adfunt porro in iisdem ventriculus atque inteftina; hepar vero, veficulam fellis, lienem renesque non deeffe, inquirentibus facile patebit. In mafculis eorundem femini fecernendo aptí reperiuntur teftes nec non veficulae idem illud afferuantes; in foemellis contra, praeter ouarium vterus quoque confpicitur \&zc. et quae reliquae aliorum etiam animalium funt partes.

Haec olim vix quidem crediderunt, quum et ii, qui fibi folis fapere videbantur. ranas limo gigni cenferent; alii vero phyficorum nomine fuperbientes, nafci ranas reliquorum etiam animalium more, inuenirent quidem, veterum tamen fententiae, quam et Ovidius his expreffit verbis:

Semina limus babet virides generantiaranas (*)

fimul fauerent, atque adeo, ranas et hoc et illo modo oriri, ftatuerent, nec non alios in varios, hinc ortos, errores deducerent, donec tandem celeberrimus SWAMMERDAMIVS, rem alia longe ratione fe habere, doceret.

Parum vero abfuit quin et ego, antequam peritiffimi huius Phyfici fcripta perluftrandi nactus fum occafionem, in eam quoque deductus fuiffem opinionem, ranas nọn nifi minus perfecta effe animalia; portquam vero ipfius, quam de ranis confcripfit, perlegi hiftoriam, ejusque ad ductum in ipfam ranarum inquifiui fructuram, alia omnia vidi didicique, ita, vt credam, nullo fere negotio me confutaturum, varias illas, quae de ranis circumferuntur, falfas fictitiasque fabulas. Sic facile me monftraturum confido, vt nullis animalibus aliis, fic et ranis nunquam pluere; vbi vero oitendero, qua ratione ranarum peragacur generatio, quaeque ad eandem requirantur, vix dubito quin illi, quibus alii perfuafere, poffe ranas arte etiam produci, facile perficiant, quam ficulneis traditio haec nitatur fundamentis, atque adeo his nullam adhibeant fidem, qui narrant, fuiffe paffim repertos homi-

Metamorph. L. XV, v. 375.

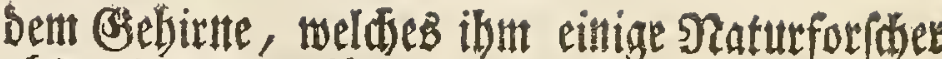
abriprechen, antgefifflet; Die aus jelbigen entfiprits gendegervelt aber, lafert ifn nidot fúbllo s nemtent.

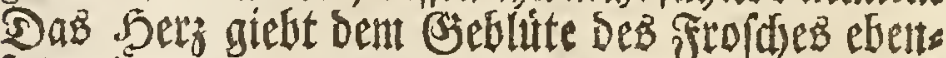
falb eine sbemegung, sermoge welder foldes Durth) afle Sbeile feimes Rónerpers getrieben wiro, und all ben notbigen 1 bionderuttgen anderer Sáfite bas Seintige bentrăaet. Die Runge feblet ben

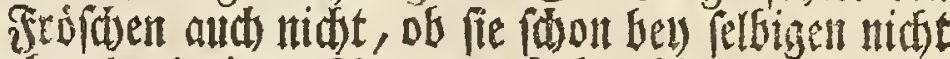

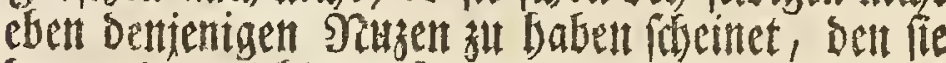

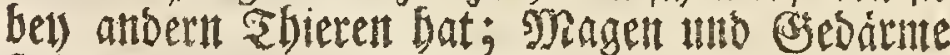
fino in jelbigen gleidufals zugegen, ttro bie Reber,

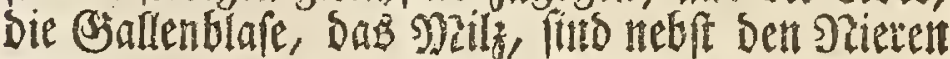

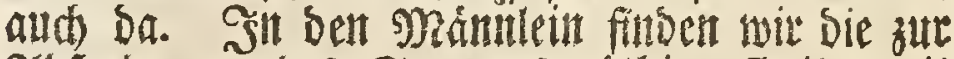

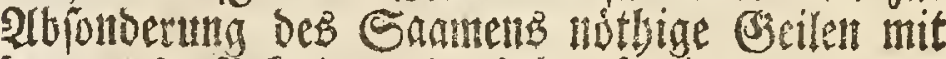

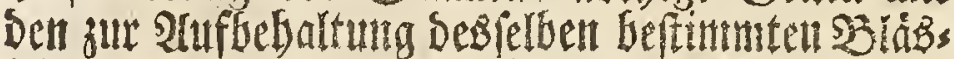
leilt; bel) Dent 23 eiblein aber zeiget fíd) nebit bent

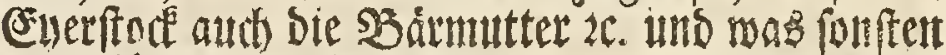
nod) fitr Fheile feunt molgen, bie wir an antbern sbieten fintort.

Ylles biefes bat malt fonftett wobl nidst ges glaubet, ittbem aud io gar biejentigent bie fid bunces en lieffen, fie wáren fluger alB andere, bafur biel:

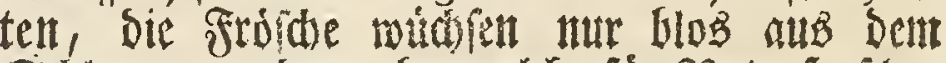

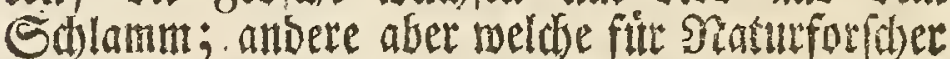

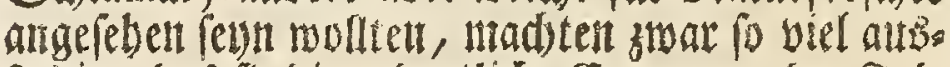

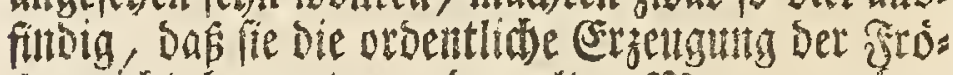
the nidyt laugheten; ber alsent Piensutat aber,

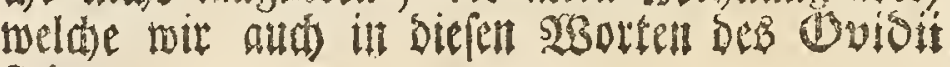
finton:

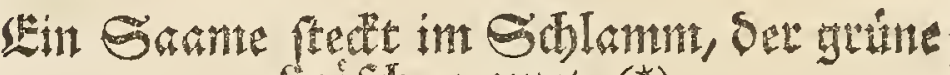
flofibe zeutet, $\left({ }^{*}\right)$

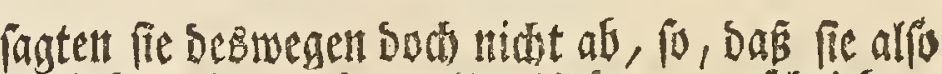
benfellsen einten gesoppelten uripentig jufouriefen, Int baber zt mandeent Şerthum (J)elegentheit ges gejen baben, bis uns entich ber berifgnte Stoammers ant eitt anderes gezeiget.

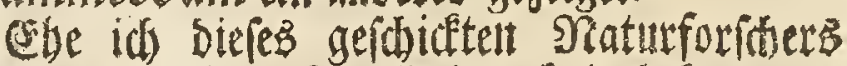

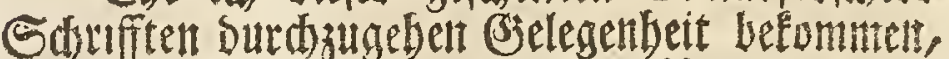
batte it mid) eben antil bald verfithreu lafess oie

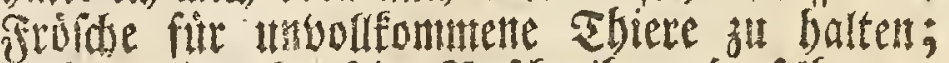

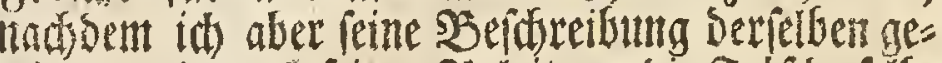

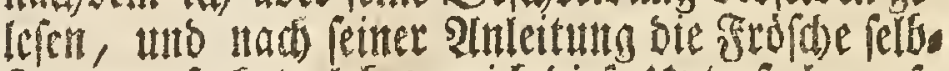

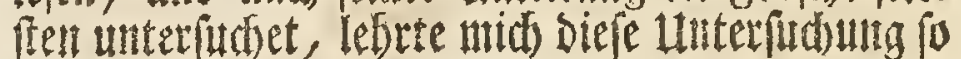

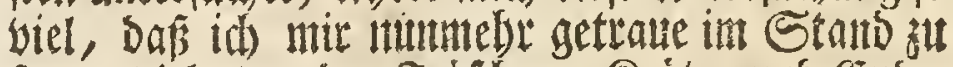

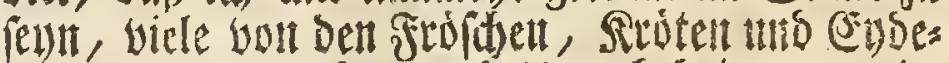

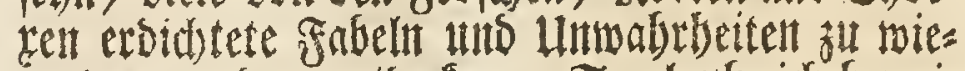
Dertegent utho ju entbectent. So glantbe id bemeis

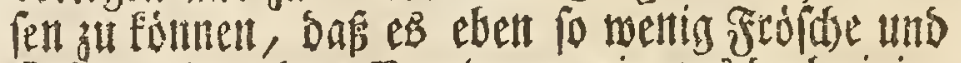
Ritetent als anbere (Creaturen, wie thos dod) cinize bereben wollen, regne; und wentm ids gejeiget ba fell twerbe, was bels ergettgung ber frófite bors gefle utb zu foldser erforbert werbe, fo will ids bofs fent, es werben biejentige, fo fid bon andern bere

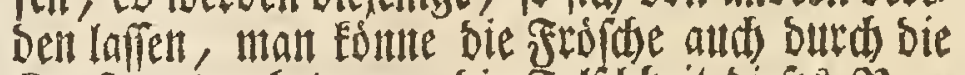

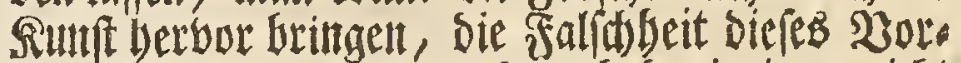
gewens bald cimfeben, uns aud Dettientigen nidst glat:

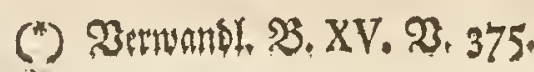




\section{(x)}

homines; quorum in ventre multae habitarint ranae bufonesque, vel ex fpermate ipforum forte cum aqua deglutito nati, vel et magicis artibus ibidem producti.

In his tamen detegendís multa mihi nauranda fuit opera, multus impendendus labor. Defcripfit SWAMMERDAMIVS, quo duce, quemadmodum iam innui, rem aggreffus fum, vnam tantum ranarum fpeciem; ego vero omnes illas, quas noftrae alunt terrae, mihi fumfi examinandas. Poftquam igitur fingula, quae SW AMMERDAMIVS, de ranarum tradidit generatione, quin plura etiam in rana reperi noftrate, cui ranae fufcae terreftris indidi nomen; idem quoque cum rana viridi aquatica tentaui. Plus tamen res haec habebat difficultatis, quam quidem praeuideram, intereaque dum in ea eram occupatus, cafu quodam ranae arboreae, nec non fpeciei cuiusdam bufonis didici proprietates. Haec dum agebam, non folum omnia illa quae obferuaueram chartae mandaui; fed varias timul, ad ranarum hiftoriam pertinentes, feci delineationes atque picturas; de quibus tamen edendis, tunc temporis, ne quidem cogitabam. Factum vero eft poftmodum, vt plurimi ex illis rerum naturalium cultoribus, indigenis aeque ac alienigenis, qui, quod multo mihi honori duco, me faepius inuifunt, quibusque et obferuationes et picturas a me factas oftendi, me ad earundem maximopere hortarentur editionem. Primam hinc anno 1750. edidi tabulam, addita fponfione, me fingulis tribus menfibus fimilem, cum defcriptione ad illam pertinente, in publicum miffurum, atque abfoluta prima ranarum fpecie, frontifpicium affabre pictum cum praefatione effe daturum. Sed varia, atque inter ea grauiffimus, quo,elapfo 1752 anno, correptus fui morbus, quoque adhucdum hoc Martio menfe anni 1753, quo haec fcribo, afficior, quo minus, quae vltimo promifi loco, praeftarem. obftiterunt. Quod vero ad priorem attinet (ponfionem, plus. quidem quam pollicitus fum, effeci; quum binorum annorum fpacio dsodecim tabulas, totidemque typis exferipta folia in publicum emifi. Minus tamen his ipfis harum rerum contenti erant amatores, promiffum potius continuo pofcentes efflagitantesque frontipicium, vt defiderio ipforum fatisfacerem praefationemque adderem, me impulerunt. Quodfi vero fint qui mirentur, me praeter receptam confuetudinem, praefationem edere, quae alias non nifi opere abfoluto confcribi folet; facile eosdem id mihi condonaturos fpero, vbi intellexerint, poffe omnia ea, quae forte ad finem perducto opere in ipfa addenda effent praefatione, fingulis, partitis vicibus edendis, inferi foliis; illa vero quas fummatim de eodem fint profe-

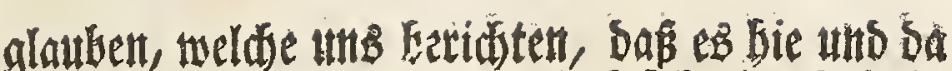

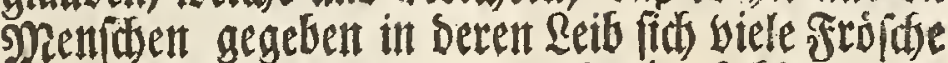
unt Rrotent aufgebalten, weld)e in felligent aus

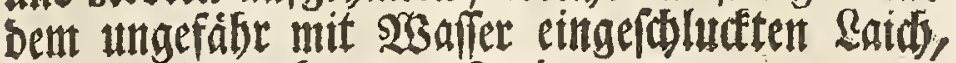
ober surd Bautberen entftantedt.

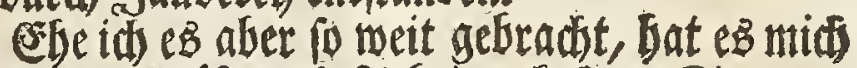
nidt wentig Mitbe und शrbeit geEpofet. Swams mersam, ben id, wie bereits gemelset, zu ntets

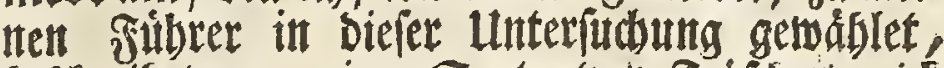

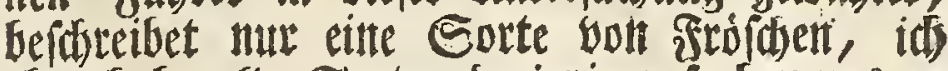

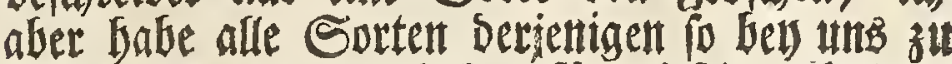
finbent fits zut unterfitodent fir notbig gebalten. Padfoem idt tum alfo in berientigen 2lrt, melife id) bent braltutt Birasfroíd thentme, alles mas Swammers ant in Pmiebung ber Ertengumg bet greoiche gefaget, unt aud) nods eint ntebrers ges

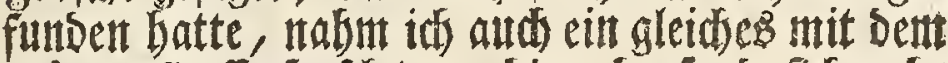

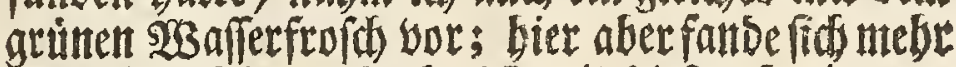

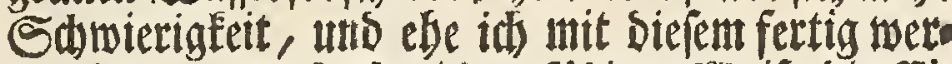

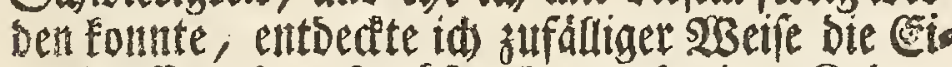

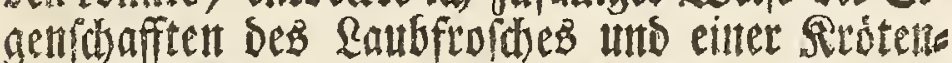

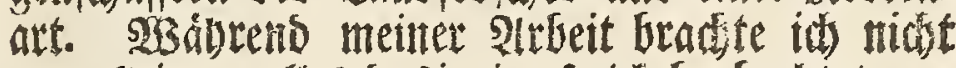

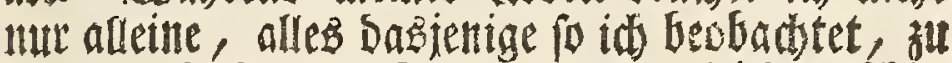
Dapier; fonbert yarfertigte auto sugleiti berínites

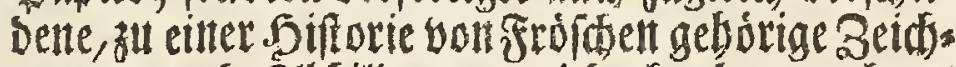

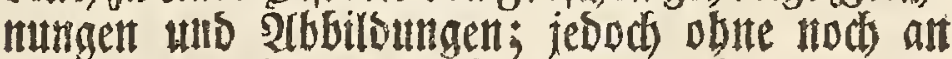

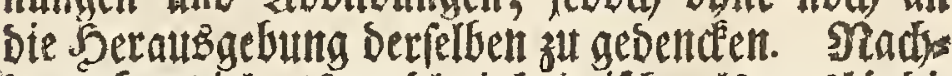

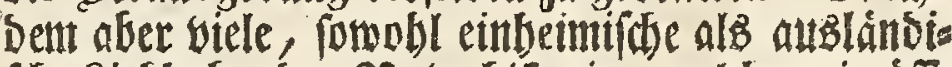
fitse Riebbaber ber ミaturbittorie, welde ntir dffo ters bie ebre ibres 3uiprtttes gónten, unto bes

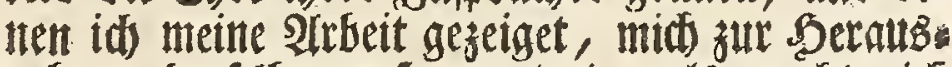
gebutng Derílben auffeemuntert : als madste idj

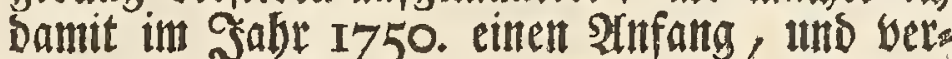

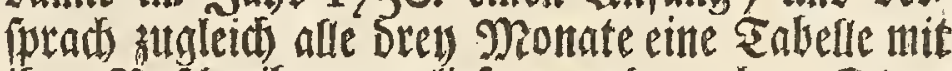

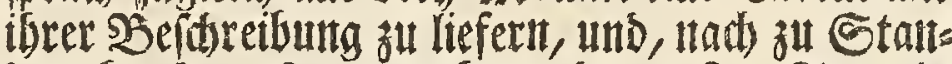
De gebraditer Serauzgebitng Der erftent 2art, eint

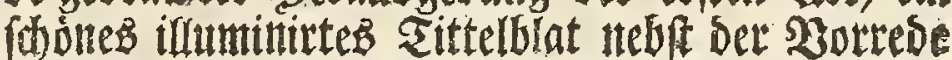

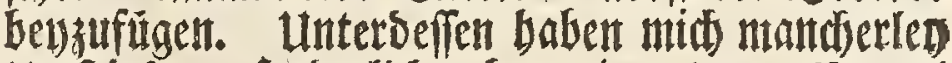
Untefránbe, fonderlid aber eine bont mentat Sctober bes verfoffettent 1752 . Sable bis babe int Meers 1753 . anbaltenbe fedwere Rrantelbeit, ant

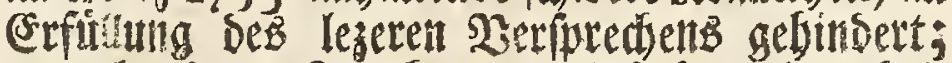
twaB aber DaB erfte antelanget, fo babe mebr geffals

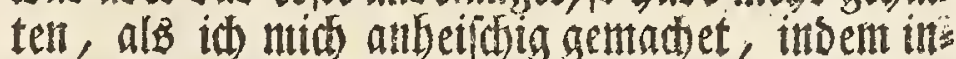
nerbalh swever Sabre zmolf Taferlen mit ibee

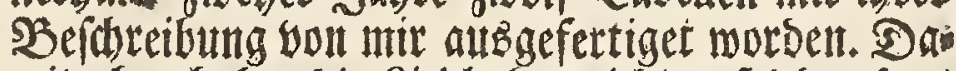
mit aber baben bie Riebbaber nicht zuffieden (ey)t

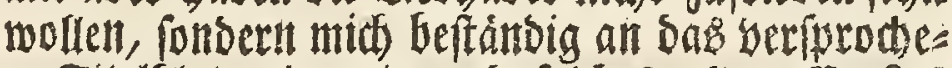
ne sitelblat erimnet, lutio foldes aflen Eentes yon mir verlanget; wešmegent ib mich bent atch

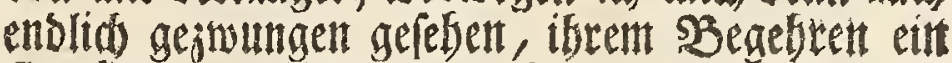

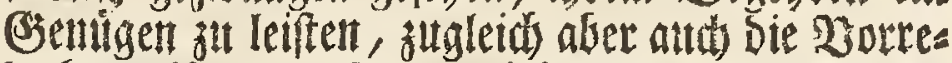
be beysuffigen. Sollte diefes eimen doer ben alt: Dern befremben, weil fonft, gemóbnlider $2 B e i f e$,

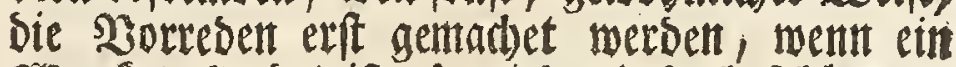

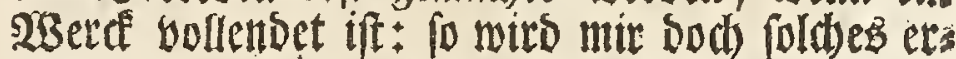
laubet feylt, weil fids alfes basienige was id) et, wann zu fagen baben mógte, wann mein S'Serce zut

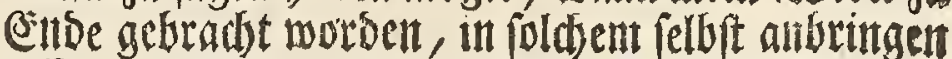

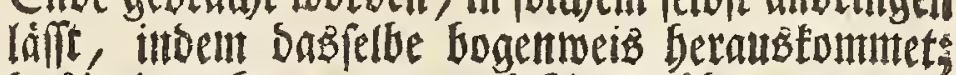

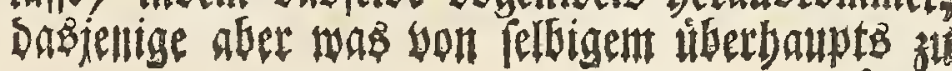

fagets 


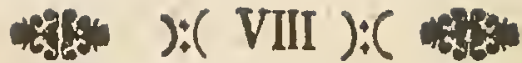

renda, a me iam effe dicta. Supereft tamen $v$ indicem, id quodiam ex ipfo patebit frontifpicio, me non folum de ranis, fed de lacertis quoque in hoc acturum effe opere. Notae mihi iam funt quinque ranarum noftratium fpecies: rana nempe fufca terreftris, rana arborea, rana viridis aquatica, nec non bini bufones, aquaticus terreftrisque: dari tamen his in locis tertiam quandam bufonum fpeciem, eft quod credam, inque ea inueftiganda adhuc dum occupor. Ranarum hiftoriam, illa lacertarum excipiet. Quamuis vero parumhactenus in earundem profecerim examine, eo tamen rem perduxi, vt in lacertarum aquaticarum foemellis viderim, effe partes ipfarum, generationi dicatas, fimiles fere illis ipfis partibus, quibus ranarum inftructae funt foemellae, neque etiam dubito, quin horum animalium hiftoria, meorum laborum fautoribus grata fit futura, quum aliorum in fcriptis, de iisdem pauca tantum legantur exarata. Ante tamen quam huic praefationi finem imponam, exorandi mihi funt operis huius fautores, vt ignofcant, fi forte in eodem confcribendo iuftum non femper obferuauerim ordinem. Quum fumtus in operis editionem impendendi, fingula tantum vt exhibeam folia, me cogant; non poteft non dicendorum interdum turbari ordo: quumque, hoc dum ago, identidem in eorundem, quorum hiftoriam confcribo, occupatus fim animalium examine ; multa faepius a me animaduertuntur, ad ea, quae editis iam in folis dicta funt, pertinentia; quodfi vero eam ipfam ob cauffam fautoribus meis vifum fuerit, opus hoc mifcellas potius de ranis obferuationes, quam concinnam earundem continere hiftoriam, non equidem refragabor, quippe qui in eo tantum elaborandum mihi effe cenfeam, vt illis oftendam, id vnice me meditari, qua ratione eorundem ablectationem augere, et ipfis fimul oftendere porfim, eorum me femper fore

Dabam Norimbergae die 24. Febr: Anno 1753. ftudiofinimum A. I. Roefel.

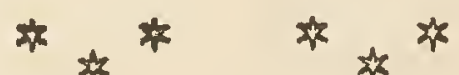

In ROESELII Hiftoriam Naturralem Ranarum noftratium.

Admiranda edis leaium ppeifacula rerum, ROESELI docta, vix imitande, manu. In tenui labor, at tenuis non gloria, raris Namque tuis itudiis ipfa MIN ERVA fauet. jagent ift, bereitz ieso bout mir antge seiget morbent.

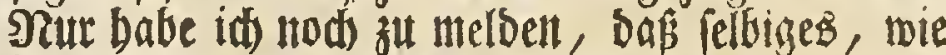
beteitB aub bent Titelblat zu eriebent, midot allein

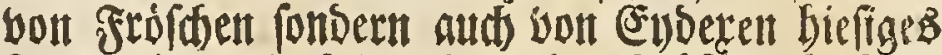

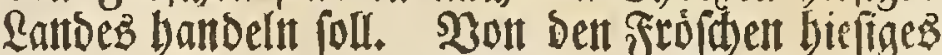
Ranbes find mir fútnferlel) P(rtent befannt: als námlid ber braute erofrofis, ber \&anbfroja, ber

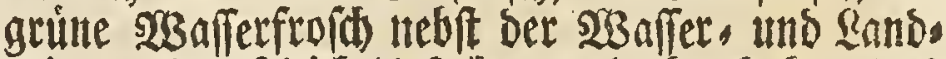

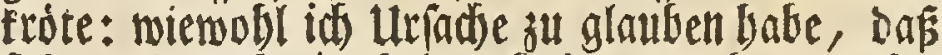
fíd aud nod eine Dritte Sirottenart bey tuns bes

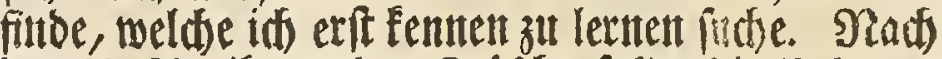

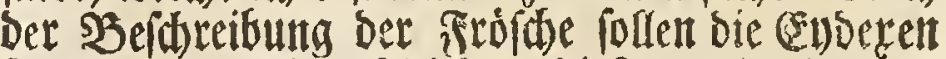
folgen, unb miewobl ifit an biejen nod) vieles zu unterifutben babe: fo bint ids bod) mit pelbigen bes

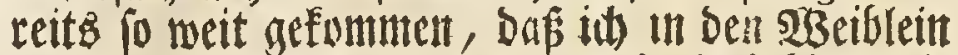
Der $\mathfrak{z a}$ affereuserent gefunden, wie in felbigen bie

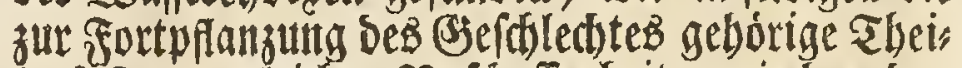
le faft yon gleider Beidaffentheit, wie bey bett

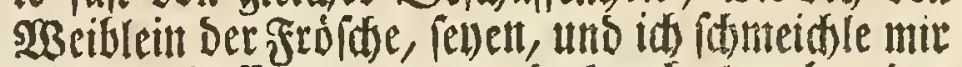
mit ber Soffnumg, es werde Den bodyzutyrenoent

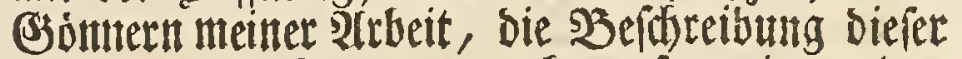
E'reaturen um fo viel angettegmer feun, je mentigec mant von ibitent bey andernt Scribenten finbet.

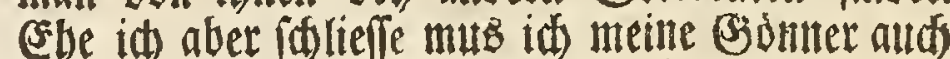
nod) bitten, mir es nid)t úbel zut nebnten, wenn fie

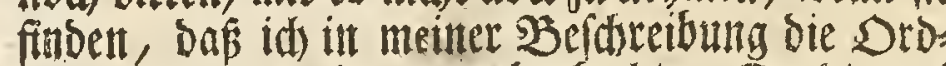
tunng uidt allezeit gentaut beofad)te. Da bie aluf Den $23 e r l a g$ zu vermeltbende soften, trich no:

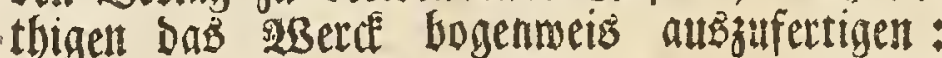

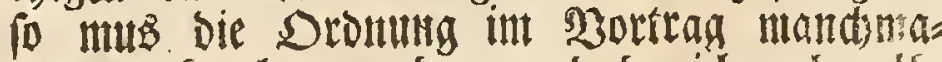
lett unterbrodhent werben; unb ba id ald wábs

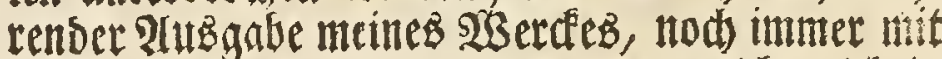
Unteriudung Der ereaturen, bon melden ids it felbigem lanbele, bejdafftiget bin: fo mirs offters

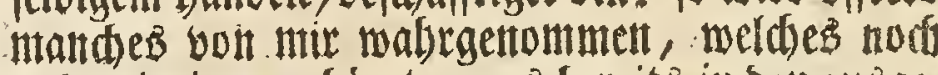
tu bentienigen gebouret, was bereits in ben ausges gebenten Bogen enthalten ift; mollen fie aber ebet

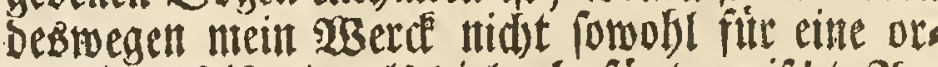

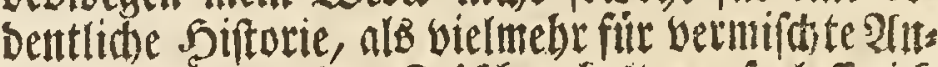

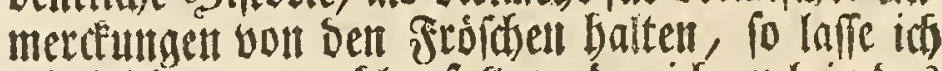
neir ioldes gar wobl gefallen, ber ids auth in bas

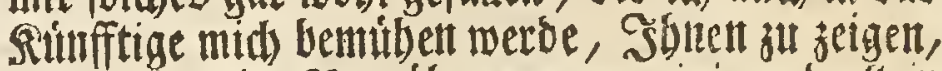
Dap afle meine Bemitlungen nur einig unt allein Dabin afbielent, mids ibnen allezeit gefáallig za ma wett, uns fitets zu beiffen

\section{急}

$$
\begin{gathered}
\text { Rúrnberg Den 24. Sornums } \\
1753 .
\end{gathered}
$$

ergebenfer

2. I. Kơfel.

$$
\text { * * * * * }
$$

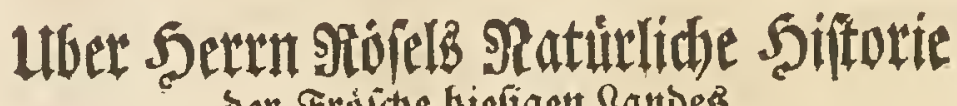
ber Frojito biefigen Randez.

$65 P_{\text {ein }}$ Rófel, Deine 5 and seigt von geringen Dingen, Mit ungemeiner Rutrt, viel 23 underbares an.

Sff gleich Dein 3orwurf fibledt; mus er bod) (Ebre bringen: Selbit Pallas rủbmet, was bier dein feltnet flei gethan.

D. G. L. Hutb.

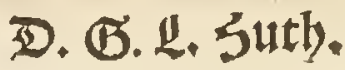




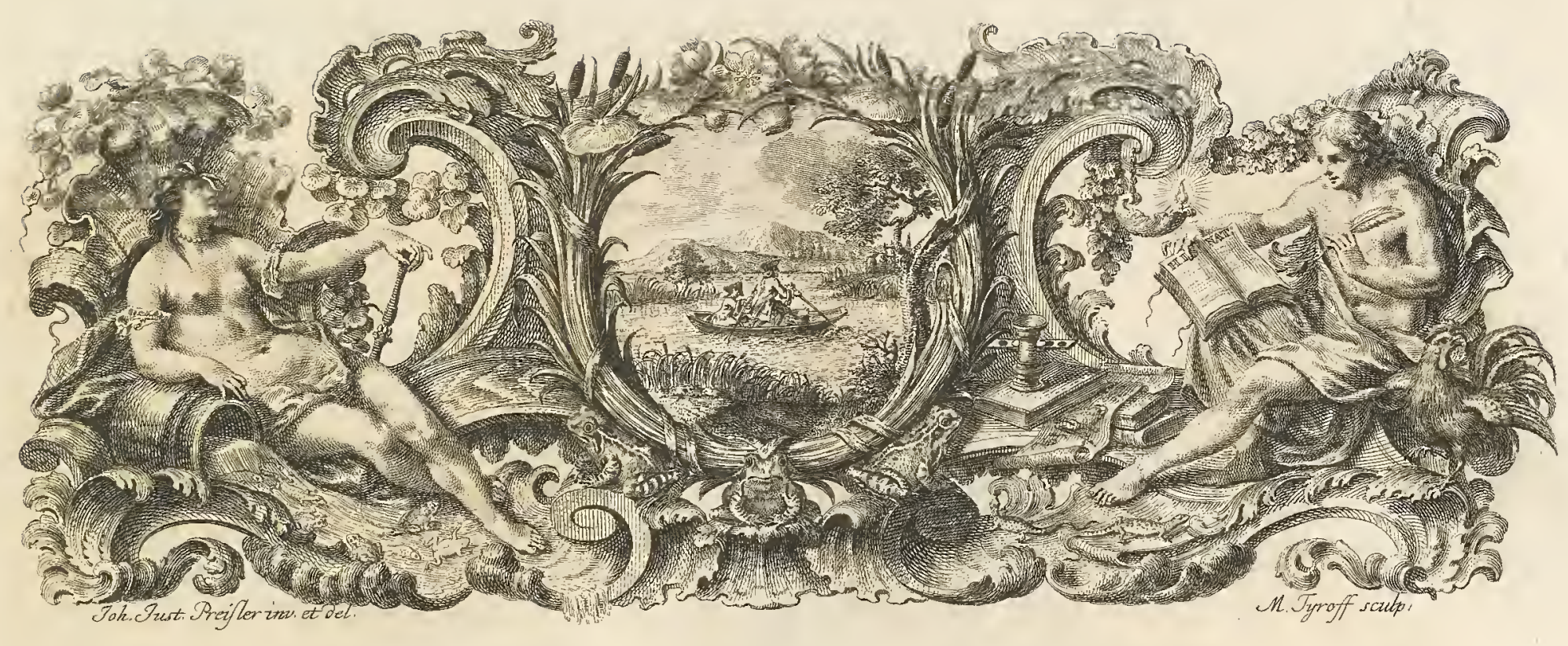

\section{HISTORIA NATVRALIS RANAR VM NOSTRATIVM. SECTIO I.} RANA FVSCA TERRESTRIS. Sober

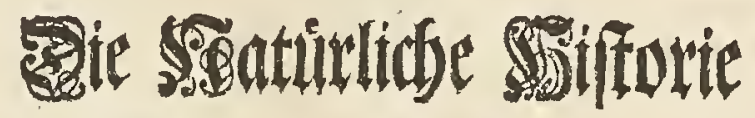

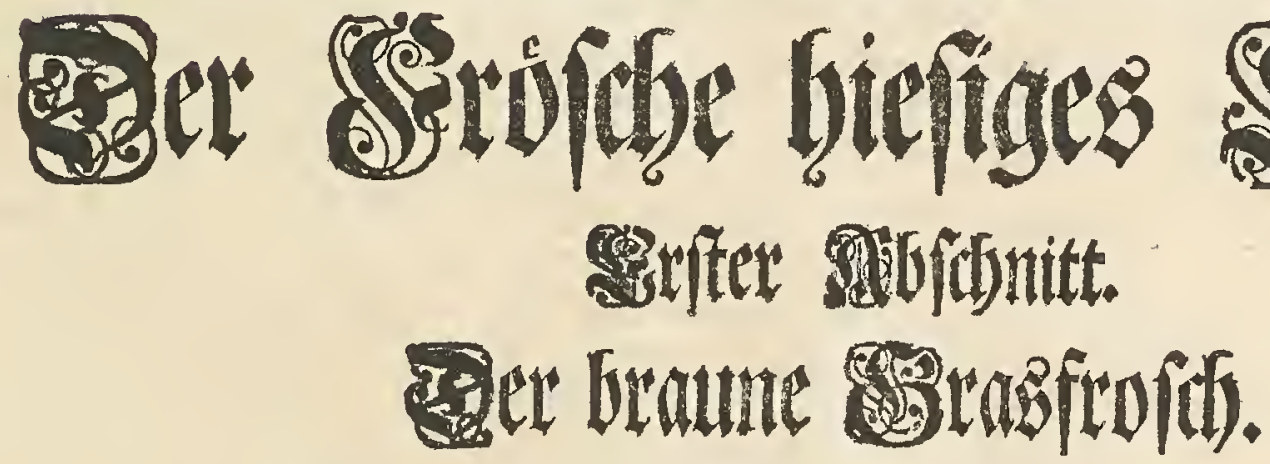

\section{CAPVT I.}

COITVS ET GENERATIO RANAE FVSCAE TERRESTRIS.

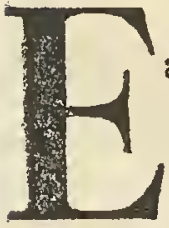

adem illa animi propenfio, qua impellente infectorum fcrutatus fum ingenium, ranas quoque curatius vt examinarem me incitauit. Variae de generatione earundem innotuere fententiae. Credidere veteres, oriri ranas tam fponte fua, limo paluftri, quam ex congreffu ranae maris cum foemina. Recentiores generationem aequiuocam, vel ortum ex putredine, reiicientes, curiofius rem inueftigarunt, atque hinc triplex potifimum in medium producta eft fententia. Ait incomparabilis ille, infectorum aeque, ac aliorum animalium fcrutator, SWAMMERDAMMIVS (a), comple\&i mafoulum foemellae pectus, duobus fuis bracchiis, perfundere. que femine fuo per anum emiffo, oul per femellae podicem excufa. Aliam prorfus fouet fententiam celeberrimus Lipíienfium Profefior FRIDERICVS MENZIVS (b), qui priorem illam, quin nouerit, nullum eft dubium : legit namque obferuationem ab acutifimo de HEIDE publica$\operatorname{tam}(c)$, in qua illa ipfa fententia fimiliter his verbis propo-

(a) Vid. eiusdem Biblia Naturae. Tom. II. p. 808.

(b) Vid. eiusdem Differtatio cui titulus eft: Generatio napa. $\triangle O$ zos in Rana confpicua $\oint_{0} \mathrm{xxy}$.
Ekftes Capitel.

Die Parututs unt Ersengung bes bratto

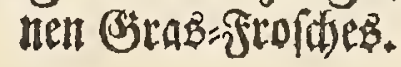

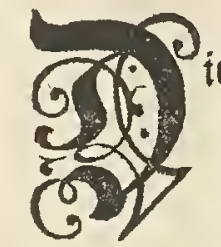

it Reigung soldie midi) angetrieben bie Na tur und eigenfonaffen ber Jinfecten su erfors foren bat mith auth bemogen, Die Fröthe gea natuer zut unterfuchen. $23 a s$ Die Ẽrzengung Derfelben anbelanget, fo firtben wir Davon in terchiedene Netmutgen. Dite 2lten baben geglaubet

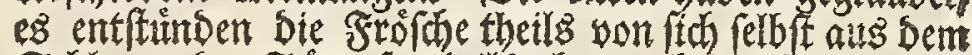
Schlantm Der Simpfe, theils aber aud Dutch Die soaas

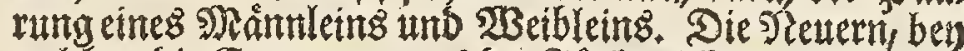
welchen Die Ersengung aus Der F̌ălmus fetten (SIauber mebr findet, baben die Sache genauter unterfitchet, und Da find (onoerlid Drenerlen sReinungen bekant geworden. Grownimerdamm (a) Der in unterfuchung Der Infecten uns anderer Thtere feites gleidhen nicht hat, faget, oas

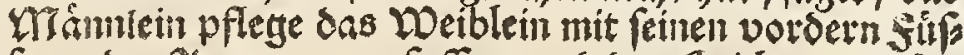
fen, ober 2 trmen su unfaften, tund sen daid, wann fo: ()en Sas WDeiblein ans den Sintewn von fich niebt, mit reinem Gianen aus ben 2lffter su befprengen und zu शै befructio

(c) V. ANT. DE HEIDE M. D. Experimenta cirea Sanguinis miffranem \&c. accedunt eiusdem Ob/eruationes medicae \& Amitel. 1686. Obferuat. XCIX. p. 196. 
nitur: mafculus anticis pedibus, qui eum in finem afperis pollicibus inftructi funt, foemellam arde amplexans, ouorum partum non tantum promouet, sed et ea irrigat; quia deltitutus pene videtur. Licet autem huic fententiae partium infuper faueat ftructura, quam idem ille de HEIDE fimul ex foemella defcribit, tantum tamen abeft, vt MENZIVS illi affentiatur, vt potius paradoxam prorfus proponat, perfuafumque habeat, imprimere marem, foeminam in coitu complęentem, fingularem illam carunculam, qua pollex ipfius inftrudus eft, ranae foemellae pectoris cuti, jicque transmitti femen, atque boc, jpongiofa exceptum carne thoracis, diftillare in afcendentem ex vtero canalem, deriuarique dein per vias oculis nondum patentes in ouarium, hacque ratione foecundari ouula in illo contenta. Tertia de ranarum generatione opinio, quam illuftr. RAIVS (d), clariff. ENTIO adfcribit, ranas fcilicet ore coire ititemque parere, celeberrimum quoque CHARLETO. NVM nacta eft defenforem (e). Vtrum illuftriffimus REAVMVRIVS hac in re methodum naturae magis convenientem detexerit, quemadmodum ipfe celeberrimo LINNAEO retulit $(f)$, docebit eiusdem methodi cum publico communicatio ; nunc vero quae ego hac in re obferuauerim narrabo.

Prodeat igitur rana fufca terreftris: cum hac namque primas meas non folum inftitui obferuationes, fed eft inftper illa ipfa, ex ranis noftratibus, prima quam cum foemella coire cernimus. Simulac enim fub hiemis finem in locis vadofis, ad ripas pifcinarum paludumque, quae alio tempore lenticula paluftri fcatent, glacies liquefcit, ranas has inuicem iunctas deprehendimus. Accidit hoc vtplurimum Martio, interdum etiam Aprili menfe, prout nimirum frigidior anni tempeftas citius tardiusue remittit; in filuis contra vbi vis radiorum folarium lentius percipitur, ranaeque in lacubus ibidem latitantes, ferius eliciuntur, tardius etiam coeunt, id quod ceteris quoque ranarum noftrarum fpeciebus folenne eft.

Coeunt ranae femel tantum in anno; diutius tamen generationis hoc negotium durat, interdumque in quartum vsque diem protrahitur. Vix hine atque ne vix quidem illud obferuari poteft temporis momentum, quo ipfa

(d) Vid. eiusd. Synopfis biffor. guadrupedum.

(e) V. GVALT. CHARLETONI Exercitationes de differentiis et nominibus animalium. Animal, quadrupeda p. 27. Mantif. anatom. p. 93. befubten. Eine gang andere Neinung hat Der beruifm te leipsigifche Sprof. St. DTens (b), Deme Die erftere nicht unbetannt feun tonnen, weil er Des gelehrten be Seide (c) Obrersation gelefen, Der eben Diefelbe in folgenben 530 r. ten yorbringt: Das minnlein weldtes oas Deibleit

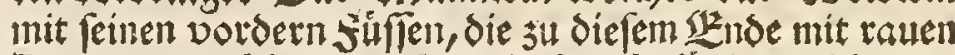
Daumen verfelsen, veft umfafet, befordert nidt nut alleit die Geburt dor Geyer, fondern befprentget fie aucb), weil ibm $\delta a s$ Jeugungsglies ju mantgeln fiteinet. Db mun aleich tiberDent Diefer Neintung Die Structur

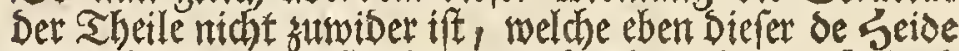

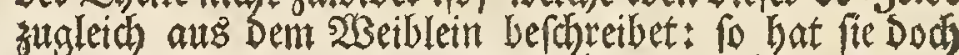

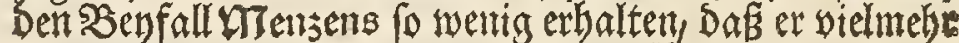
eine ganz paraboxe vorbringt, uno Dafür bält, wann das DTannlein Oas WDeiblein bey oet partung umfafie, fo

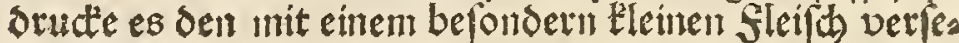
benen Daumen an bet 2 ruff des Doeibleins an, uns da tehe ser Gaame aus felbigem outch das faw wammitge Fleifi de: 23tut in den Canal det aus des Deiblén

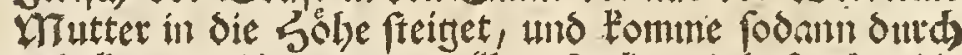
unbetannte IDege 34 Sem <zper-fod, und befrubte die in felbigtem enthaltene Szyer. Die Dritte Mreinung won

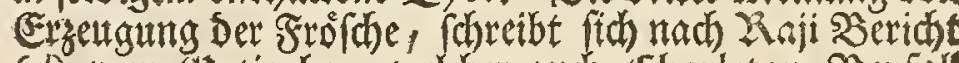
(d) wom yentio her welcher auth Charleton Benfall

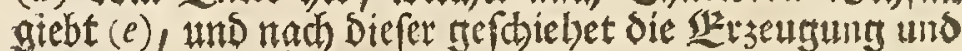
Geburt ser frofine ourb den D7und. Ob aber Sere von Reammut in Interfutung Diefer Sache eime bee Satur gemåffere 2lrt gefunden babe, wie Serr Limnons faget $(f)$, werben wir erfahren, wann er feine Erfindung be Eannt madeen wird; was aber son ntir in biefer Sas de beobaditet worden will id mumelir erzeblen.

Ser braute Brasfrofh foll Den Infang madhen; weil id) aud) mit felbigem meine Ilnferfithung an crften angeftelle uns er unter allen bieftaen Fród arten berer, fte iff Des man gepaaref fündet. Dann fo bald mit Dem Ende Des YBinters, in Den Ieichen und Sumpfen, an reichten uffern, wo fonften wiele seerlinfen su finder,

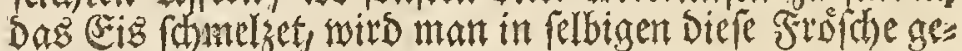
paaret antereffen. Diefes aber prleget insgemein im

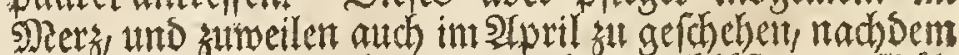

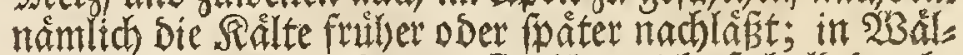
bern aber wo bie Sonnenftraflen nicht fo bald Duths Dringen, und alfo Die in ben Dafelbfit befindidien Teis

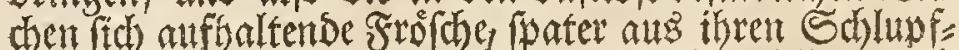
winfeln herfiutgeloctet werden, paaren fich Diefelbige aud foater, weldes Die librigen Frofdarten liberbauptzebens fals zu thun pflegen.

(Es paaren fich aber bie Sroofde im Sabr nut cinmal; fingegen bleiben fie lange uns mandimalen wohl biet Sing gevantet; eben Deswegen iff Dieientge Beit um to

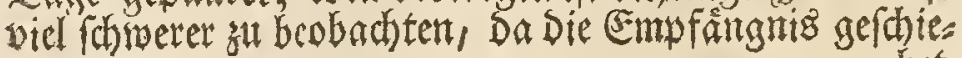

(f) Vid. Ampbibia Gylenborgiana p. $135^{\circ}$. in C. LINNAEI Amoenitatibus academicis. 

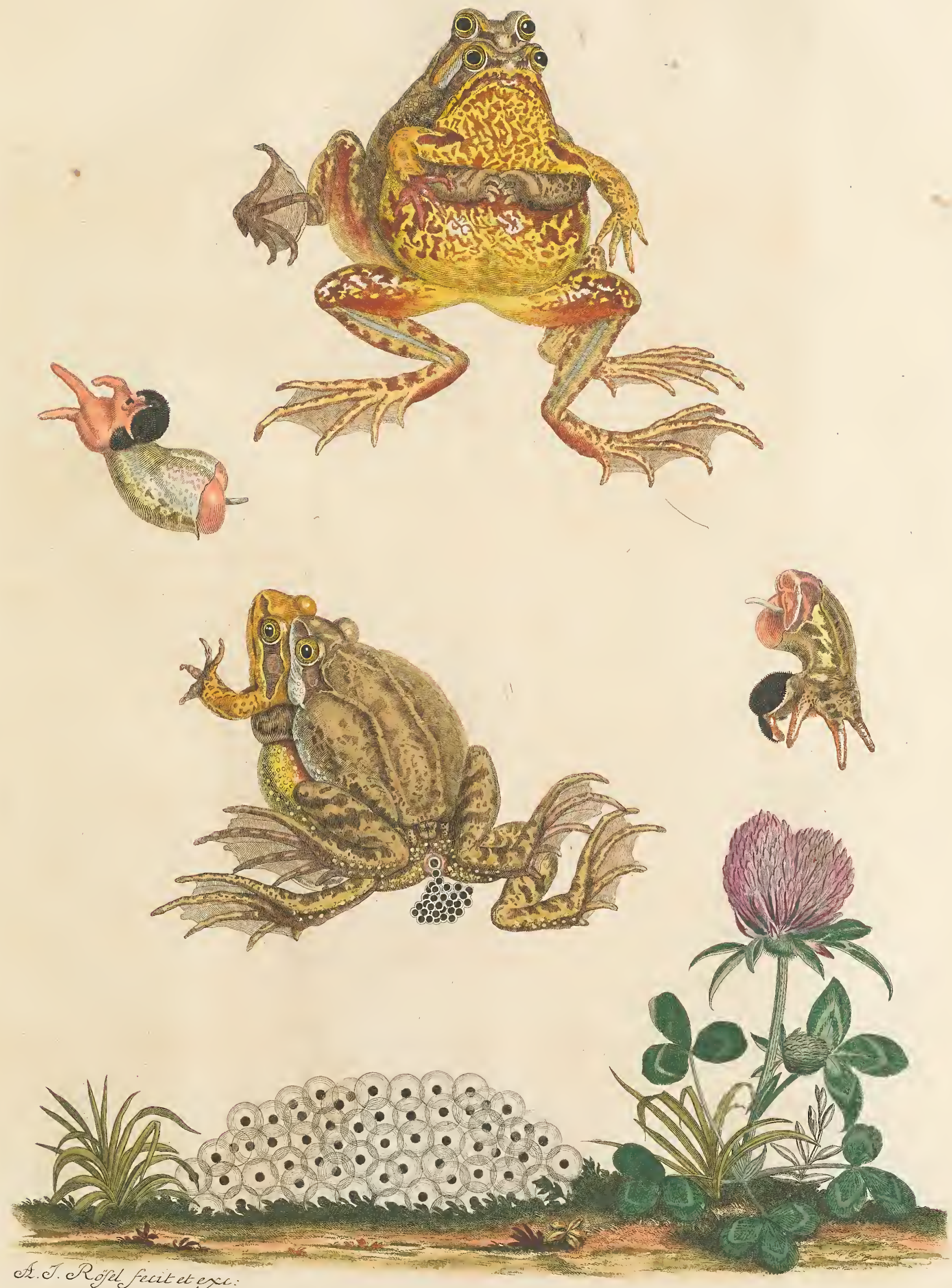

Tab.I.
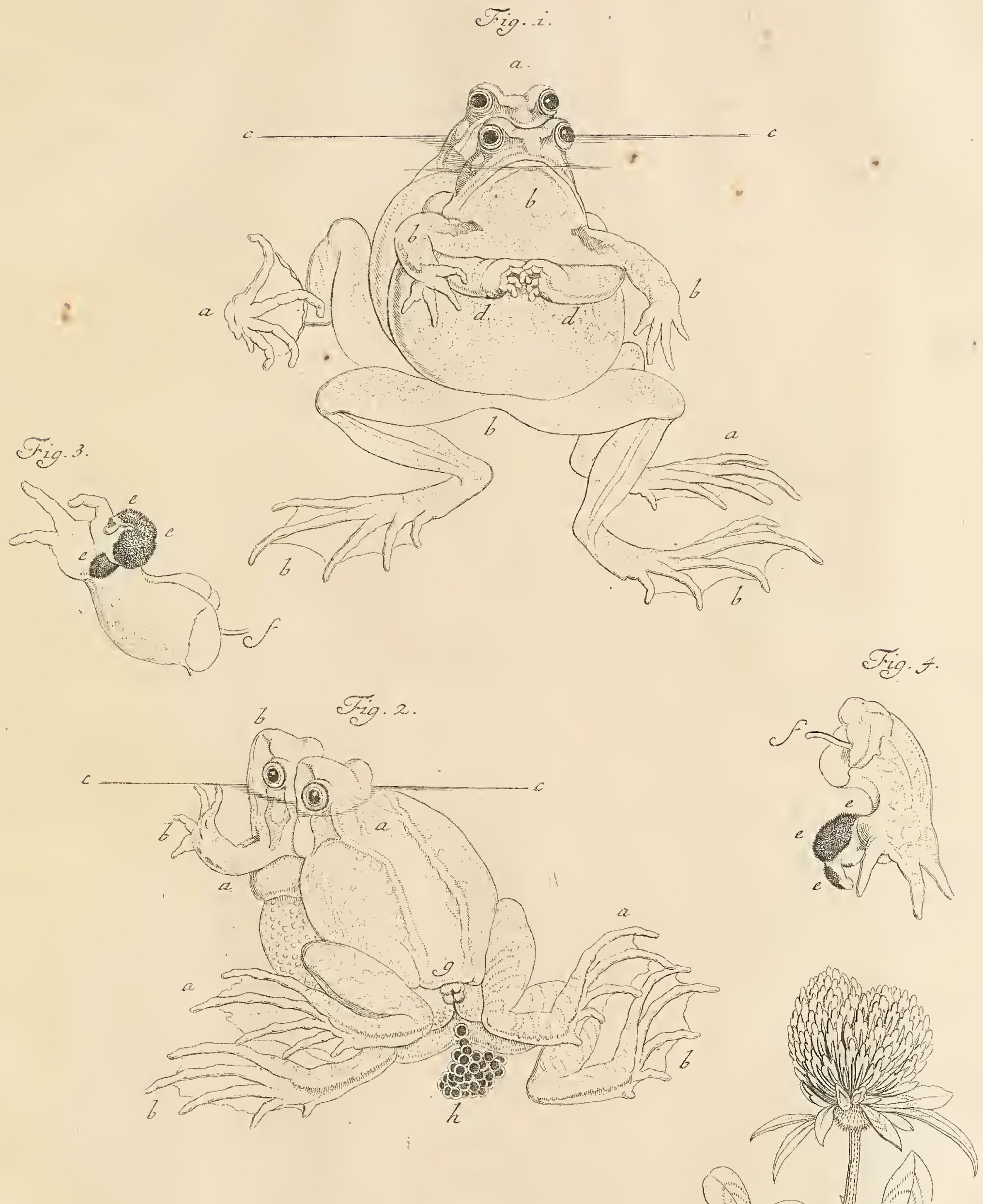

Fig.5 



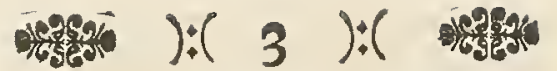

ouorum fit foecundatio, illi maximopere notandum, qui creaturae cuiusdam $a b$ origine defcripturus eft hiftoriam. Tres confumfi annos, antequam viderim, qua ratione oua foemellae ranae noftrae terreftris foecundentur: breuiffimum hic notandum eft temporis fpatium, illud vix aequans, quo gallus gallinaceus gallinam inire folet; hoc itaque ne elabi paterer, iteratis vicibus decem duodecimue harum ranarum collegi paria inuicem iuncta; quodlibet par in vitrum immifi cylindraceum, pellucidum, fat amplum et ad partem vsque dimidiam aqua repletum; hoc vero facto, tantum in contemplatione eorundem vitrorum adhibui curae, vt femel binas noctes infomnes transegerim. Vitra ipfa in orbem pofita illuftrabantur lucerna in centro orbis collocata; atque hac ratione vidi tandem coitus non folum finem, fed etiam foemellam oua fua parientem; ex quibus, quum foecundata erant, tandem etiam, temporis fucceffu, teneras, quemadimodum in fequentibus oftendam, obtinui ranulas. Iam vero primam noftram infpiciemus tabulam figurasque in illa contentas defcribemus, quas ipfas binis repraefentare malui tabulis, quo fingulae diftinctius exhiberentur. Siftit itaque prior ranas earumque partes viuis coloribus pictas; pofterior vero delineationem figurarum coloratarum, cuiuslibet tabulae, litteris fignatam refert.

Ouod igitur ad primam hanc attinet tabulam, monftrat illa ranam fufcam terreftrem eamque coeuntem, id quod, quemadmodum iam dictum eft, verno femper fit tempore. Exhibet figura prima ranas iunctas ab antica, altera vero a poftica parte, mare foemellae dorio nunquam non infidente. Ranam marem indicant in vtraque figura litterae $a \quad a \quad a$ foemellam vero $b b b b$. Differunt inter fe quoad colorem abdominis: in mafculo namque confperfum illud eft maculis ex cinereo albefcentibus, in foemina vero ex flavo rufefcentibus; dorfum contra vix variat, generationis praefertim tempore: lutulentus etenim ipfis tunc eft color, qualis Bufonum effe folet, qui tamen poltea in lucidiorem magisque variegatum abit: folent namque ranae fingulis fere hebdomadibus cutem mutare exuuiasque, mucum tenuem referentes, ponere. Praeter cutem monftrant et pedes differentiam aliquam: habet namque mafculus non folum pedes anticos, brachia quafi referentes, aeque ac pofticos, natatui commodos, longe craffiores quam quidem foemina; fed coitus tempore pollex quoque illius fingulari prorfus obfitus eft carne nigra multisque papillis afpera, quam mox propius fumus confideraturi Ambae ceterum eodem illo tempore ventre gaudent turgidiore; in foemina quippe ouulis fcatet, in mafculo vero haeret tunc temporis, cutem inter carnemque, liquor quidam, mucum potius pellucidum quam limpidam referens aquam, qui tamen finito coitu rurfus euanefcit. Huic etiam adfcribendum eft muco, quod vbi mafculus cum foemina propagandae fpeciei cauffa iungitur, illius venter fuper foemellae dorfum expandatur et ad latera propendeat.

Iplo in coitu non femper exporrigit fefe pars corporis poftrema maris profundius quam ipfum foemellae corpus, quemadniodum SWAMMERDAMMIVS feribit, fed fit hoc eo tantum in cafui, vbi mafculus foemella maior eft conftringitur autem haec tum ab illo complexu tam forti, vt abdomen illius, ouis iam admodum diftentum, faepius rumpatur, ipfacque non, nifi fumma ví, ab inuicem feparari queant: Quin, quum id femel tentarem, femur mafculo

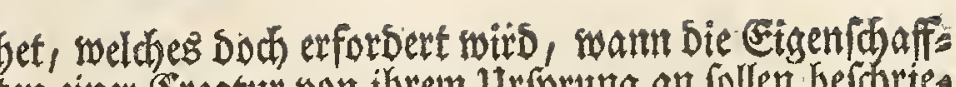

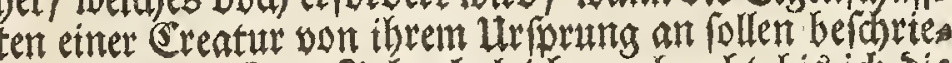
ben werber. Drey Jahre bab id jugebradyt, bis id Die

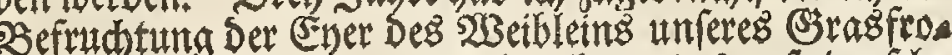
fhes nahraenommen: Dann hier fommt es auf eine fehe

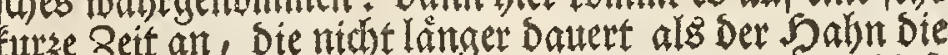
Senne zut tretten pfleget. Damit ich num aber Diefe

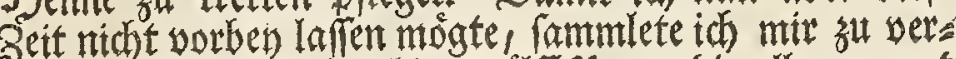

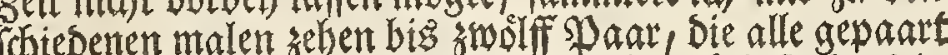
aufemander faffen; jedes soar brachte ich befonders in

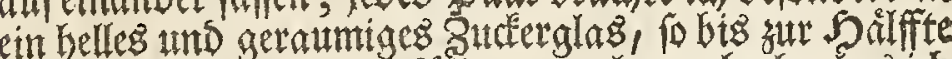
mit bellem 53 affer angefillet war; hernadh aber ltes th

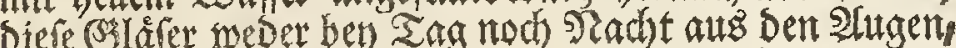
mie idh Dam einmal zwey ganzer Neachte bey felbigen wa

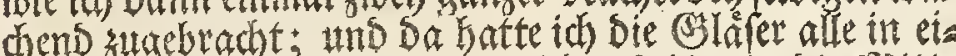
nem Seres, Das Qicht aber swifhen felbige in bie syette gefeset, woben ich enolich wahrgenommen, wie ithe SPans gung au Ende geangen, unt wie Das stseiblein feinen Saich son fith gegeben aus welchem id), weil er yon bem Nectullein befind tet worben, nach und nach bie jungen Frofche erralten, wie aus bem Folgenden erbellen wird. sest aberwollen wir unfere Tabellen betrachter, unb das ienige was auf felbigen yorgeftellet ift, auf Daz genauefte befthreiben. Damit ith mut aber alles redht Deutlid gets

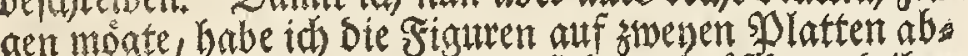
gebildet, ant Der einen setgen fid die zrofoche und ihte Sheile nach Dem Seben gemahlet; uns auf ser andern if

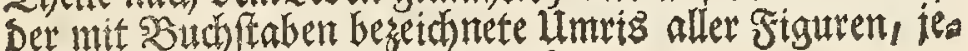
Der gentablen Sabelle, befindlich.

syir fehen Demmach auf Der erften Tabelle Den bralle nen (3) rasfrofh in feiner Waaung, welche nie bereits ges melset worden, allezeif int Fruhling yor fid gebet. Dite erfite Finut zeiget Die gepaarten Frofche von bornen, uns

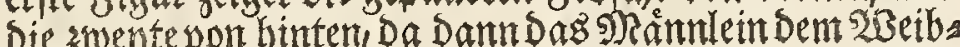
lein allest auf bem SRuten fizet; jentes wirs in beeder Getauren Durd a a a a, Diefes aber surd) b b b b angeget

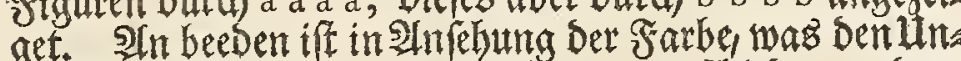

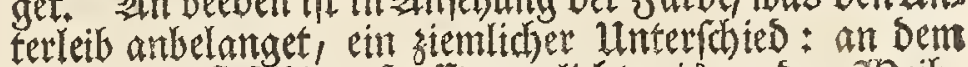
Monnlein ift felbiger fanftit graulichtwets, andem $2 B e i b=$

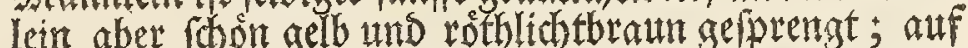
Dem SRuten bingenen zeiaet fich Eein belonberer linters

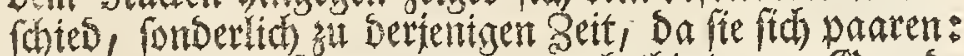
Dam sa boben fie insuemein eine Eothigtarate 3 sumb: farbe, faft mie eine Siote, welche fidh aber nach zebendos verliebrt, tho in eine frifhere uns mebr gefledtere verain:

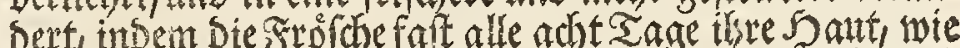
eimen zarten Schletm, ableaen. Ifufer Der Salte if aud anden Fúfeneinunteridted st benterden: Dannandent

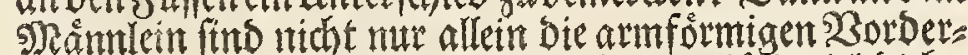

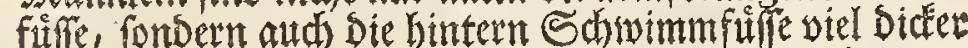

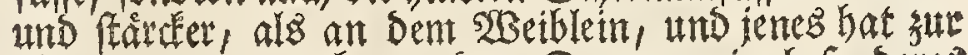
Saarungszeit auth an bem Daumen ein befonderes

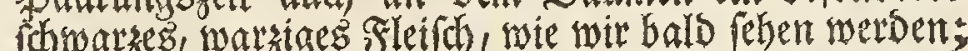
an beeben aber if zat eben diefer Beit, Der Reib ziemlid Die: Dann ben Dem weiblein if er mit said) angefullet

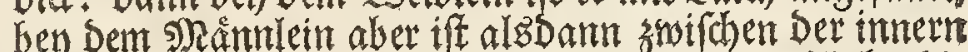
Saut und Dem Fleirh eine Fend)tigkett befindlid), Die

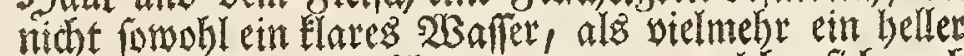
uns Surdfid)tiaer (Sd)leim zu nenten, weld)er fidh nad ber Saarung wieber verliebret. Diefer Shleim macher

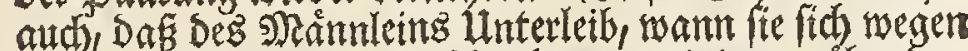
Fortoflansunt ihres (S)efoledites vereinigen, über ben Seib Des 2 Bethleins fich ausbreitet und an Den Seiten herab hanget.

Bey Diefer Saaruma raget aber nicht alleseit Des Nånnleins Sinterleib uiber Den Sinterteib Des $23 e i b=$ leins hinatts, wie Swanneroamm faget, fondern nut in

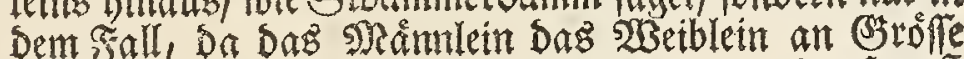

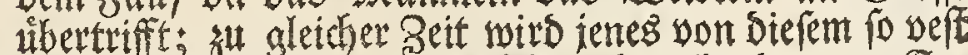
untarmet uns gehaltem Dá offters der ohnedem yon Eys

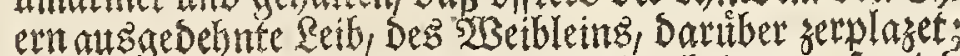
uns will mall fie also ant yon einander bringem, fo wito श्) 2 


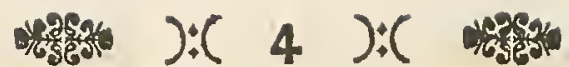

euulf, neque tamen ideo foemella ab eius liberabatur amplexu. Alia vice vfus fum eundem in finem duabus forcipibus minoribus, arreptisque earum ope brachiis mafculi, feiunxi quidem ranas, quum vero easdem in vas vitreum rurfus iniicerem, ruebat mafculus illico in novos amplexus, foemellamque fortius quam antea conftringebat. Licet vero eum in finem mafculus brachiis polleat validioribus, vix tamen retenturus ille effet foemellam euafuram, nifi pollices ipfius fingulari illa, fuperius iam memorata, exafperarentur cute, quam ipfam foemellae pectori tam fortiter apprimit, id quod litterae d d Fig. $x$. indicant, vt etiam cutis illius interdum dilaceretur. Quodfi vero foemella mafculo minor fit, amplectitur hic illam digitis pectinatim iunctis, fimul vero pollices pectori eiusdem ea ratione admouet, qua nos manus noftras eundem in modum iunctas, easque inuerfas, pectori effemus admoturi. Cutis illa, vel caruncula potius, nigri eft coloris, eoque tantum in ranis cernitur tempore, quo generationi operam naulant; non igitur conftans mafculi praebet indicium, quemadmodum quidem SWAMMERDAMMII fert opinio : finito enim coitu euanefcit rurfus, pollicesque, qui aeque ac brachia antea intumuerant, gracilefcunt. Haec quo melius intelligantur, tabulam noftram vt intueamur neceffe eft. Monftrant figurae 3 et 4 anteriorem brachiorum partem eorumque manibus aemulos pedes, magnitudine auctos. Siftit figura tertia palmam integram, quarta vero pedis dorfum. Indicant litterae e e e in vtraque cutem illam nigram afperamque qua pollex obducitur. Tegit eadem integrain fere craffiorem pollicis partem nec non particulam aliquam palmae, (Fig. 3) apicisque ipfus pollicis (Fig. 4). Monftrat porto iisdem in figuris littera $f$ neruum eorundem pedurn qui reliquos craffitudine fuperat. Poffe vero, ope iam defcriptae carunculae, ranam foemellam fuam firmius retinere, inde etiam didici, quum eandem in mafculo coeunte abftuli: licet namque foemellam denuo amplecteretur, facili tamen opera ab illa pro lubitu feparari poterat. Obiici quidem poffet, impediuiffe dolorem, ex ablata illa cute nigra fubortum, quominus mafculus foemellam firmiori conftringere potuerit complexu; fed enimuero dictum iam eft fuperius, euulfiffe me ranae cuidam ipfum femur, nec tamen dimififfe eandem foemellam arctius comprehenfam: ftimulantur praeterea ranae, generationis tempore, tanto libidinis oeftro, vt, SWAMMERDAMMII verbis vtor, proprii corporis quafi curam abiiciant. Hinc etiam fit vt fub. inde mafculus mafculum amplectatur, vel etiam cum foemella mortua, qvin cum bufone coeat, licet cum hoc, quemadmodum quidem nonnulli autumant, ranae nunquam copulentur. Quin vbi eo ipfo tempore plures mafculi par quoddam ranarum generationis cauffa iunctum offendunt, omnes eidem videbis adhaerefcentes, atque tunc facile etiam,mea quidem opinione, contingere poteft, vt abdomine iunctae deprehendantur, vnde fortaffis celeberrimus RIVINVS in eam deductus eft opinionem, vt crediderit, coire ranas duplici ratione, effeque illam, qua abdomine iunguntur, veram: loquitur namque hac de re fequentem in modum: (g) nimirum et ranas obferuanimus cum maribus fuis congredientes eo etiam tempore, quo ouula non omnino nigra, fed variegata comparuerunt, tumque non modo foemellarum tergo, quod folennius eft, sed abdomini incumbunt mares. Qui primus congreefus dubio procul ad impraegnanda ouula idem valet, quod in gallinis e. g. galli coitus, b. e. vt plura fimul oua foecundentur. Fatetur his ipfis verbis clariff. RIVINVS folennius effe, incumbere marem foemellae tergo; quin non poteft non haec ipfa vera effe ratio qua ranae coire folent: quodfi enim obuerfis iungerentur abdominibus, non folum ob turgidiorem foemellae ventrem iufto longius ab invicem diftarent; fed impediret etiam ea ipfa coniunctio, quo minus ranae connexae commode per aquas mouerentur. Debent vero omnino moueri, quia hoc praefertim tempore refpiratione indigent, vtque hanc liberam feruent, iteratis vicibus ante-

riorem

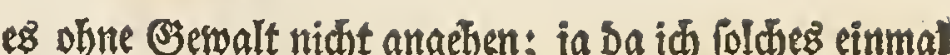
berfuchte, ries id Dem Mannlein fo gar Den hintern Sthendel aus onne Dás eS DaDurch berwogen worben wåre Das 2 Beiblein log zu lafen. Ein anbermal bedients te idh mich swener 3ânglein, mit weld)en ich Die worbern Friffe Des Dianteins fafite, uns als ich endich beebe bon einnoner gebradht, nachgehends aber wieder zuramt men in ein BSlas warf, fo umarmete Das Månnlem Das SBeiblein fogleidh wieber, und noch viel vefter als zunor.

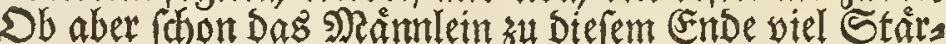

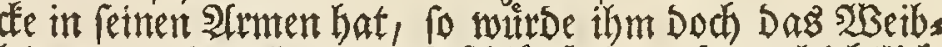

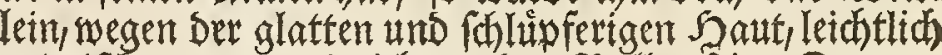
entwifhen, want es nicht an bem bie oben gemeldte befondere, ralle, wargigte Saut batte,

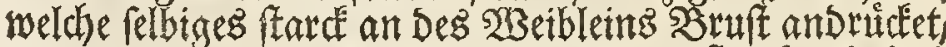
wie d d zeiget Fig. I, unt foldhez bamit wefte hålt, [o, Dafs mandimalen aud Die Saut Diefer 28 ruft bayon aufgerifs ren wird; uno if Das 2 Beiblein eftwan fleitter als Das

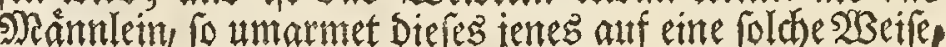

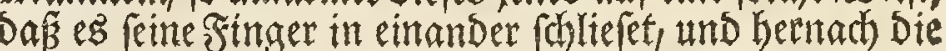
Daumen an Die S3ruft Deg 2 Beibleins anfezet, wie wir et. wan unfere zafammgefaltene 5 ånde, wann wir fte ums wenden follten, an Den Reib antegen wirben. Diefe

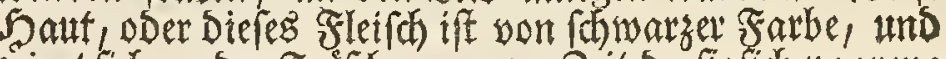
zeiget fich an Den Frófhen mur zur Beit Da fte fich paaren;

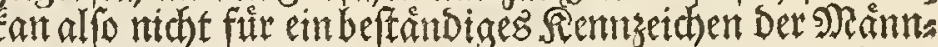
lein angegeben werben, wie Gwammeroamm meinet: Dann nad geithehener Sparung verliebrt es fich wieber. uns bie Saunen bie vorber, eben fowohl als Die 2lrme gans Did tmb aufgefhwollen waren, werben nachgehends wieber gefthmetoiger. Damit wit aber Diefes beffer ver. fteben: fo wollen wir unfere Sabelle in etwas anfehen. Die 3 und 4 Figur weifen Den vordern Theil Der Jüfe, mit Den Daran befindlithen spfoten, wergroffert, da wir Damn Fig. 3 Die ganze 1 fote won innen, Fig. 4 aber yon

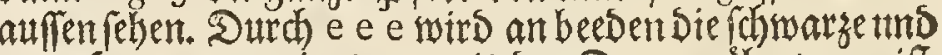
raue Saut angegetget, monit Der Daume tiberzogen iff. Der SSallen an felbigem ift faft gans Damit bedectet, und nach Diefem ift aud nod ein Sheil Der innern Fläche Fig. 3 und an Der Sptze Des Dauments Fig. 4, Damit bereget. Ferner mits and noch an eben diefen beeben Figuren Ditrch f Derienige Nerve angezeiget, to in Diefen beedent

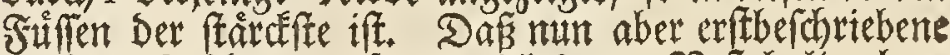

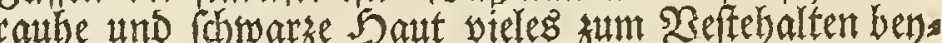
trage, bin ich Daburd tiberzeuget worden, als id an eis nem im Maaren begriffenen sorannlein siefelbige ablörete:

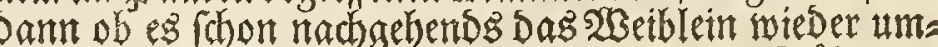
fafete, fo Eonnte es Dod allezeit obne biele \$rutle von (elbigen wieder lozgemachet werden. s)an wende mir nid) ein, Der Sd)merze Der Diefem Meannlein Durch 2tbs lónting ber forwarsen Sant werurfachet worden, habe relbiges an Der veften Limarmung gehindert : Dann id habe bereits oben gemeldet, Das ia einem Frofoh Den eits nert Shendel ausaerifen habe, ohme Dafis er Dadurd bes wogen worben Das $23 e i b l e$ in loszulafien; tiber biefes fo

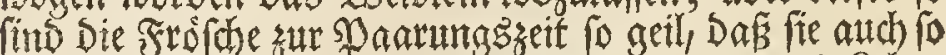
gar, mit Swammeroamm zu reben, ihr eigenes Reben

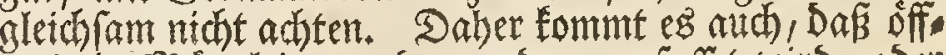
ters ein xánulein yon bem andern umfaffet nird, ober bafi fie fich audh ntit etmem todten 2 Beiblein ta fo gar mit einer Arote paaren, ob fie fich gleith orbentlicher SBeife mit Diefen nicht begatten, wie Doch einige Dafur balten wollen: ia wann aud fu biefer Beit etwan mehrere Noinnlein ein bereits vereinigtes spar antreffen, fo bains gen fiefict alle an Diefem an; ber Diefenumftimben ples get es Dann offters su geftehen, Dafs man fie auch mit gegen einanber aefehrten Interleib gepaatet finbet, wels des mobl Dem berulymen Rivino SGelegenteit mag ges geben habem Daf er sweryerlen Saarung geglaubet, und conderlich Die !ezere vor die redte get)alten, indem er fas get: it babe aud sie fród mit iben mianlein 34 


\section{$48(5):(5):(4)$}

riorem capitis partem ad $c$ c vsque exferunt, in quas tamen, fimulac aduerfi quid perfentifcunt, fefe rurfus abfcondunt, pedibusque fuis pofterioribus remorum inftar vtuntur, foemina praefertim crebriore motu eosdem agitante. Effe autem hanc veram ranarum coeundi rationem, vbi mafculus foemellae dorfo infidet, hinc porro certior factus fum, quod, ipfis ita iunctis, foeminam oua parere vidi, quo facto ambae ftatim feparabantur, quemadmodum quidem fupra iam indicaui, nunc vero fufius fum narraturus.

Contuitus eram ranas meas attentius per plures iam dies, nulla notabili obferuata mutatione, quum tandem easdem inquietiores effe animaduerterem. Grunniebat tum mafculus interdum fuis inftar, foemella interim furfum deorfumque fefe mouente. Lynceis itaque oculis easdem contemplans, vidi tandem eiaculare mafculum quendam ex poftica corporis fui parte liquorem, qui eam ob cauffam femen illius effe mihi videbatur, quod aquam, cui ranae innatabant, turbidam reddidit; non autem ita multo polt deferuit foemellam cum ipfo antea iunctam. Hoc facto per duodecim integras horas exfpectaui, vifurus vtrum foemella oua fua fit editura nec ne, quum autem elapfis illis etiamnum ceffarct, binas hasce ranas, mafculum aeque ac foeminam, cultro fubiecianatomico. Inueni tunc in foemella vterum ex parte ouis repletum, reliqua vero oua haerebant partim in ouario, partim vero in vteri tubis; mafculus monftrabat veficulas feminales, genitali liquore hoc vt plurimum tempore in aliis turgidiores, piorfus cxinanitas. Oua in vtero reperta in aquam inieci limpidam, nullos tamen ex illis obtinui vermiculos; infoecundum itaque harum ranarum fuiffe coitum hinc apparuit. Alia rurfus vice binas vidi ranas ani aperturam momentaneo tantum motu coniungere, quumque ftatim poftea foemella oua parere inciperet, non derelinquebatur a mafculo, donec omnia illa effent excuffa, quae ipfe iteratis vicibus femine fuo perfudit foecundauitque ita, vt ex iisdem poftmodum tenellas etiam obtinuerim ranulas. Siftit figura fecunda binas hasce ranas, atque in hac indicat $g$ anum mafculi, $b$ vero oua ex foeminae ano prodeuntia, quae tum temporis minora vidcntur, poftmodum vero aqua fefe in albumen eorum penetrante maiora euadunt, id quod fisura quinta dcfignatur. Eadem ratione aliarum quoque perficiebatur ranarum coitus; in binis aliis tamen eadem rurfus obfcruaui quae fupra iam indicata funt; derelinquebat fcilicet mafculus foemellam, femine omni profufo, elapfis vero fedecim horis excutiebantur a foemella oul, fed motu tam lento, vt viginti quatuor horarum fpatio dimidia vix earundem pars effet propulfa materque ipfo in partu moreretur. Intumue rant initio quidem oua haecce, aeque ac fi foecundata effent, mox vero dein corrupta peribant, ne vllo quidem ex iisdem prodeunte vermiculo, atque hinc perfuafum mihi eft, infoecundum effe coitum ranarum, fi prius finia- jenigen zeit fid paren felen, oa bie 1 Eyer nod nidy

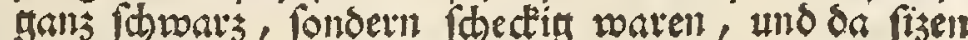

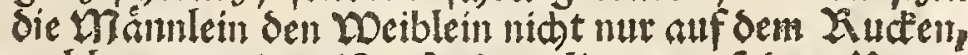
welches gemeiner ift, fondern liegen auf oem Inter leib derfelben. Diefe erfte Paarung bat aber obne

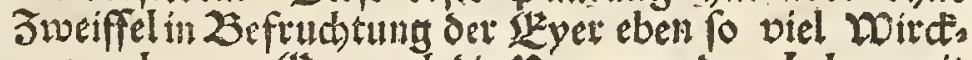

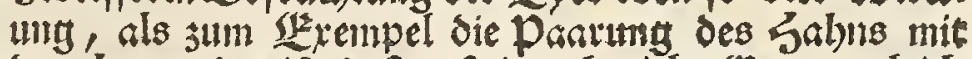
der Seme, das ift, daf anf eimnal viele gyer zugleid befilldet werden. In Diefen 230 nten geftehet Livis ins felbft, es fene genteiner Das ntan ben ber saarung Das SRànlein Dem 53 etblein auf Dem Pructen fisen fe:

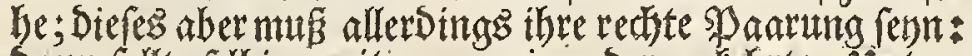
Dann follte felbige mit gegen einander gefegrten linter:

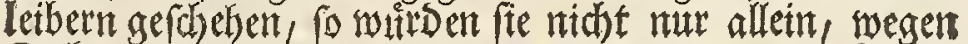
Dide Des 2 Seiblems zu weit yon eintander abferehen

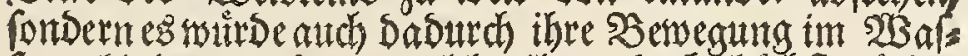

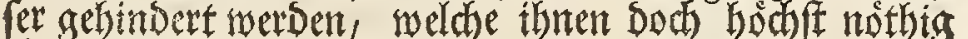
ift, weil fte, zu Diefer beit fonderlich, श्(thent holen muf: fent unto Deswegent fich offters, fo wett, als Durch $c c$ ants aesetget wird, aus Dem SBaffer begeben, in welches fie

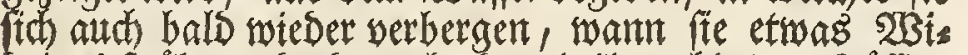

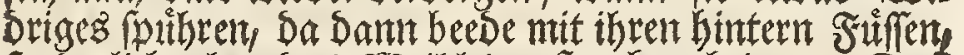
forberlid aber Das 5 Beiblein, ftarck arbeiten. Da

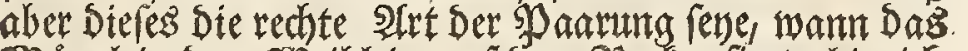

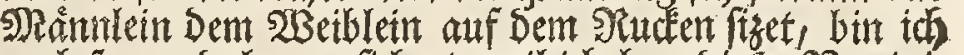
atth ferner baher serfichert, weil th. ben Dteler Bereint: gung Das şeiblem laichen geferten, worauf beede eins ander serlafien baben, wie th bereits oben gemeldet; munntebr aber umftánd lidber erzeblen witl.

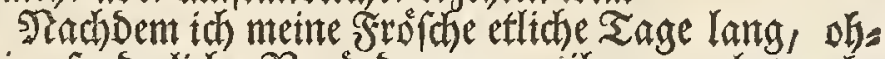

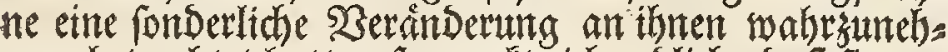
mert, betraditet hatte: fo netedte the endlich, Das fie unt

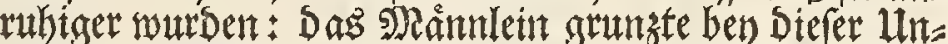

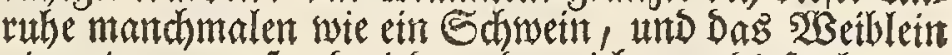
gieng immer auf und nieber; Da mith nun Diefes benog

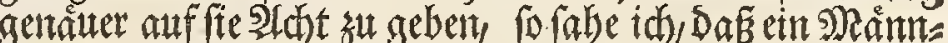

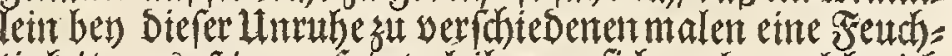
tigkett aus feinent Sinterleib won fidh gab, weldhe id Desmegen fuir Den Saanten bielte, weil fa Das SWafer

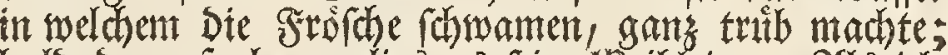

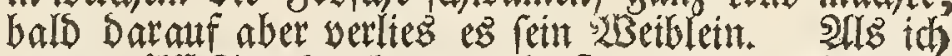
mun swolff Stunden lang untonft aewartet, ob Diefes

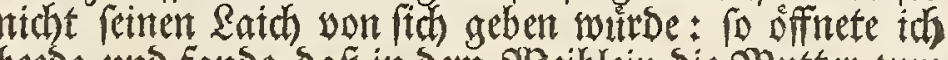
beede, und fande, Das in Dent 3 Beibletin Die Dutter zum Theil mit Enern antgefitllt war, zum Theil aber ftecter Felbige noch in Dent Everfoct unt in Den Evergangen; in Dent Mnanlein fingegen, waren Die Saamenblä:lein

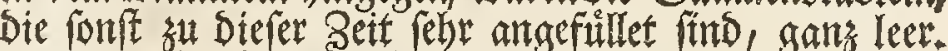
Dite (Ever fo ich in Der SRutter gefunden, legte ids it rets

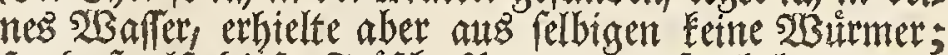

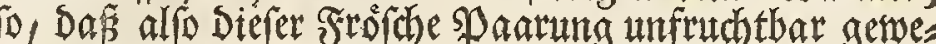
fert. 2tn etnem andern spaar benterdite idh), Daf beede mit Der Deffinuth thres: Sinterleibes auf einen 2 ligents blick zufammen Eamen, aleich Darauf fieng Das $53 \mathrm{setb}$. lein an zulaichent, Das gannlein aber verlies relbiges beswegen ntabt, bits es allen Ratch yon fith gegeben batte, unt befeudtete oldhen unterdeflen etlichemal mit feinem Saamen; wie th Dann auch aus Dierem Ratd nadhgehends junge Fropiche erbielte. Dite sweyte

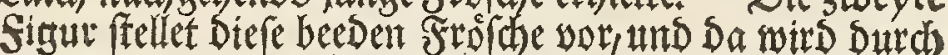
Der SAffer Deg S Månnletns, Durch b aber Der aus Dem

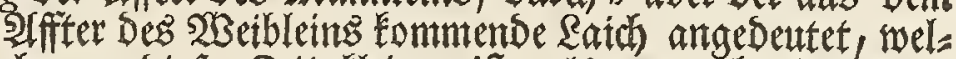
d)er za Diefer Beit flemer ift, als er nadjgehenos im SBaffer wird, indem er aufautllet, wie bie funffte Sigur

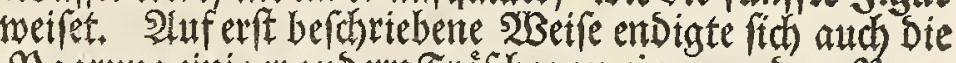
Paarung eintger andern Frofed e; an eitem andern SDate bingegen gieng es eben fo wie tob bereits oben gemeldet,

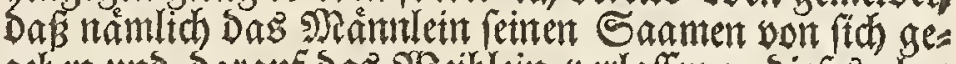
geben und Darauf Das 2 Beiblein verlafen; Dieleg abee

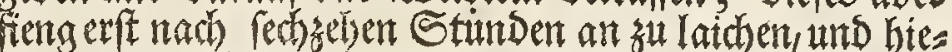
ben gieng es fo langram za, Das felbiges innerbalb yter

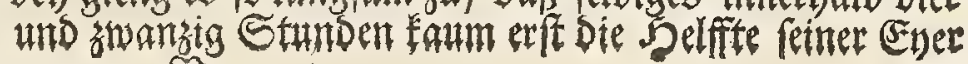


) 6

tur quam fingula oua in vterum fint delata. Rana quaedam, quae foemellam foecundauerat, quam vero ab illa ipfo fub partu auulfi, coiit portmodum alia cum foemella coitum nondum paffa, quam ipfi fociam dederam, eandemque, aeque ac priorem, foecundam reddidit.

Licet autem ex dictis appareat, coitum ranarum a me diverfo tempore obferuatum, non eodem peractum efle fucceffu, id quod carceri in quo afferuabantur adfcribendum effe cenfeo; fatis tamen fuperque obferuationibus meis probari reor, fieri foecundationem ranarum ano potius, quam alia quacunque corporis parte: vtrum vero ipfum femen in foemellae vterum iniiciatur nec ne, affirmare vix aufim, quamuis momentaneam quandam podicis coniunctionem me vidiffe certum fit: quod vero reliquum eft, optime ranarum generationem SWAMMERD AMMIVM defcripfiffe crederem, nifi LINNAEI obftaret fententia $(b)$ : nullam filicet in rerum natura, in vllo viuente corpore, fieri foecundationem vel oui impraeonationem, extra corpus matris. Sed quidquid fit, certum tamen eft, coire ram nas poftica corporis fui parte, id quod et internarum generationi inferuientium partium ftructura magis adhuc perfpicuum reddetur, prius tamen, quam illam ipfam oftendam, ranas ex ouo prodeuntes, variasque quas, antequam veram ranae adipifcuntur formam, fubeunt mutationes, fum defcripturus.

Quemadmodum ranae nunc citius, nunc tardius, coeunt, fic folent quoque oua fua, hoc vel illo anno, citius tardiusue parere, id quod meae, plus fimplici vice, me docuerunt, obferuationes: anno namque 1748 , die duodecimo, decimo tertio et decimo quarto Aprilis easdem oua fua gignere vidi; anno autem 1749 , vere maturius ingruente, factum iam eft idem illud vigefimo yndeuigefimoque Martii die, atque tum obtinui non folum oua illarum ranarum, quas domi meae obferuabam, fed inueni eadem quoque illis in locis vbi libere natabant. Quae vltimo hoc anno nactus fum, infpexi fingulis diebus attentius, atque hinc, quas nunc proponam, natae funt obferuationes. Eft fcilicet vulgo fic dictum fperma ranarum nil nifi congeries ouulorum, magnitudine aeque ac colore fibi fimilium, atque initio quidem ea forma confpectui fefe fiftentium, qua tabulae primae foura fecunda, et tabulae fecundae figura fexta repraefentantur. Conftat quodlibet horum ouorum globulo nigro, materia quadam perfpicua, tenaci atque glutinofa cincto, ita, vt haec albumen, ille vero vitellum, vt in auium ouis, referat, qui vitellus hifce in outulis vtplurimum altero in latere fubcinerea notatus eft macula, nunc magis nunc minus confpicua. Eiaculat nonnunquam vna tantum foemella fexies, quin, SWAMMERDAMMIO referente, vndecies centena ouula, interdumque vnius tantum horae fpatio partus fingulorum abfoluitur. Numerum eorum haud quisquam fine multo inibit labore: glutinofa namque illa materia, vel, fi mauis, albumen quo cinguntur, vifcum tenacitate refert, atque hinc ita inuicem cohaerent, vt vix fine laefione feparari queant. Simulac excreta funt, in fundum aquae fubfidunt, cohaefione eorundem haud foluta; non autem ita multo poft increfcit illorum albumen fenfim fenfinque, vitello priftinam formam retinente, atque hinc obtinet quodlibet eorum, fpatio quatuor horarum, formam fizurae
)$:($

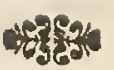

yon fid gegeberi alsoann aber farb foldes. Der Raich (ch)tene swat anfangs gleid) eimem befruditeten auf

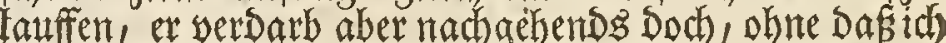
ein eintges Stuirmlein Daraus erbalten; Diefes aber

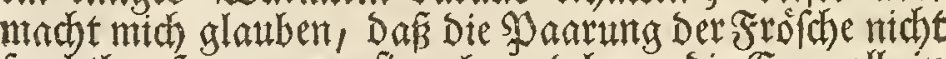
frudtbar fene, waum fie, ehe und bevor Die Ever alle in Die פintter getretten, fid endiget. Ein anderer Ftofde, Der fein SBeiblem befutthtet hatte, und Den ith als fels biaes laichte, mit Sseswalt los ries, waarte fich nachges bends nit einem andern noch nicht gepanaten 2 Betbleim, welches ich ibm zugerellte, und befudidete folches eben: falls, wie Das erftere.

Db min gleith, atts Dem was ich tegt erzehlet, ftt ers

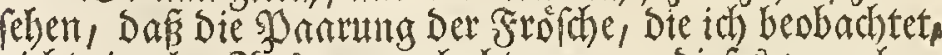

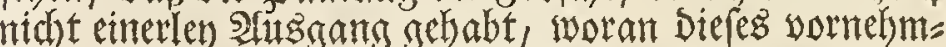

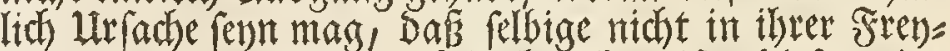
heit gerwefen: fo glanbe ich Doch ca berweifen, biefe meine seobachtungen genugfam, Das die Sefrudtung Der Jrofche Duth den bintern Seib gefhehe: Dak aber Der

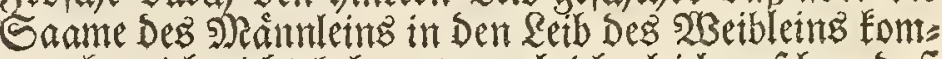

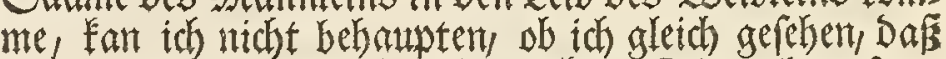
beede ibren sinterleib auf eine furze Beit nabe zufan= men gebradbt; und ftunde mir Die Neeintng bes be= rubmten Limbit $(b)$, es gefdebe die Gibwengerung, oder die 2 efrudtunt des lEves, all lemem lebendis gen Liórper suffer bem Leib der Mrutter, ntcht in 26ea: To wollte ich glauben, Gwammerdamm batte

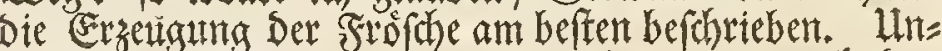
terbeffen bleibt es Dod gewis, Daf felbige Durch den

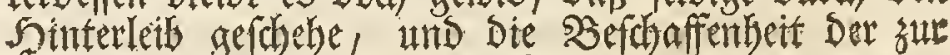
Fortwflanzung Des (siefchlechtes gehortgen inneren

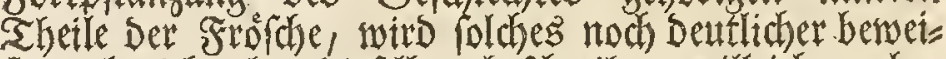
fen; ebe ich aber bickelben befdretbe, will ith worker

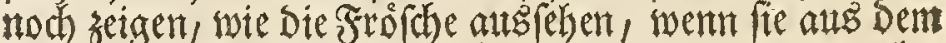
(E) Eommen, uns was noch ferner mit ihnen worgelie, bis fie the sollfommene Sertalt erhalten.

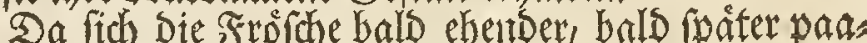
ren: fo laichen fie aud in Diefem Tahr ehender, nut in einem andern fóter, wie id foldhes bey meiner lintes: wuchung mefrrmalen beobadtet: Dann im Sinhr 1748

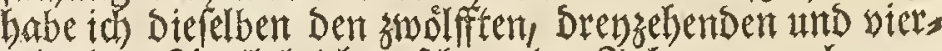
zehenten 2 pril laidsen feren, im Jaht 1749 aber ges

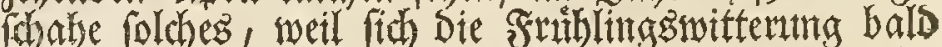
einftellte, bereits Den zwanzighen und ein und zwanzig= 隹en Mery, Da ich nicht nur allein Den Saich yon Dontes

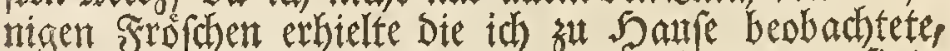
condern felbigen aud in foldhen Drten fande, wo fie it ibrer Jrenkett maren. Sm lezern Sabr babe ich Den Eaid mit vieler Sorgfalt, won sag zu Tag, betradtef, und Folgendes Daran wahrgentommen. Es befteket berfelbe uberhaupts eigentlid aus Evern Die alle ein

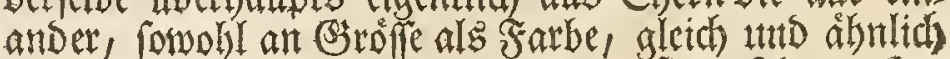
find, alth anfangs fo ansfeben, wie fie auf Der erfter Cabelle in Der sweyten Sigtn, und auf Dex sweyten in Der fecblten oorgeftellet werben. Jebes Derfelben ifteit

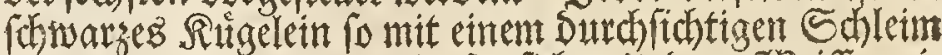
amgeben; Daber Dant Diefer fich mit Dem 2 Beiflen ei nes 20 gelenes, tenes aber mit Dem Dotter wergletdren laift, weldher almber gemeintiglidh an einer Seite cinen bellgrauen Flecten bat, Det an eintigen Einern Dattlid

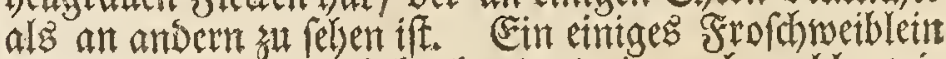
gicbt suneilent ben rech bundert, ia aud) wobl, wie Gwammerdamm faget, bet) eilf butndert folcher Ever yon fich, weldhe alle mandhmalen innerbalb cinte Stumbe gebolyen werben. Ste find aber fo leidtet nicht zuzeblen: Dant Der Sdyleim, doer Das 2Betfere fo fe unt giebt, und weld es fo fleberid als ein 20 gelleim ift, mas wet, Dnf fie yefte an einamber hangen, uno midht leidgt

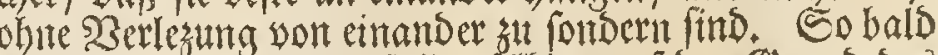
fie geboriren worden, fallen felbige auf Den Grund Des

(b) Vid. ARTEDI Icbthyologiae Pars II, p. 32 , 
Tab.II

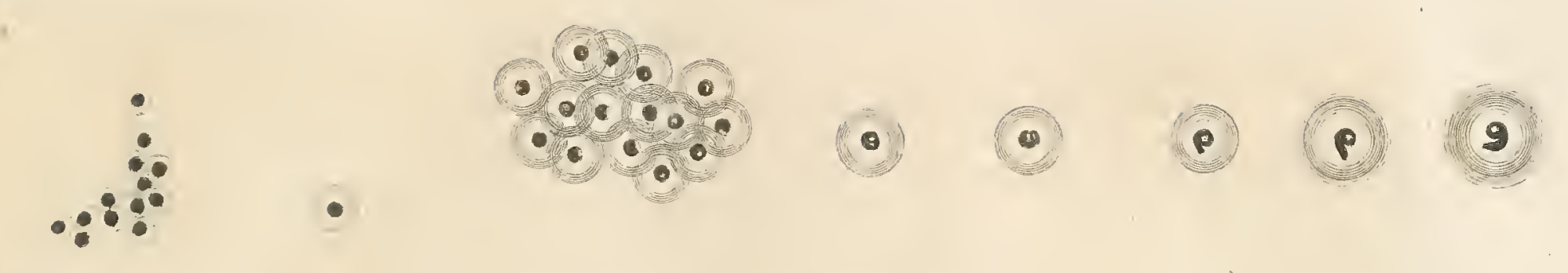

$2 \infty$
$x \rightarrow-\infty$
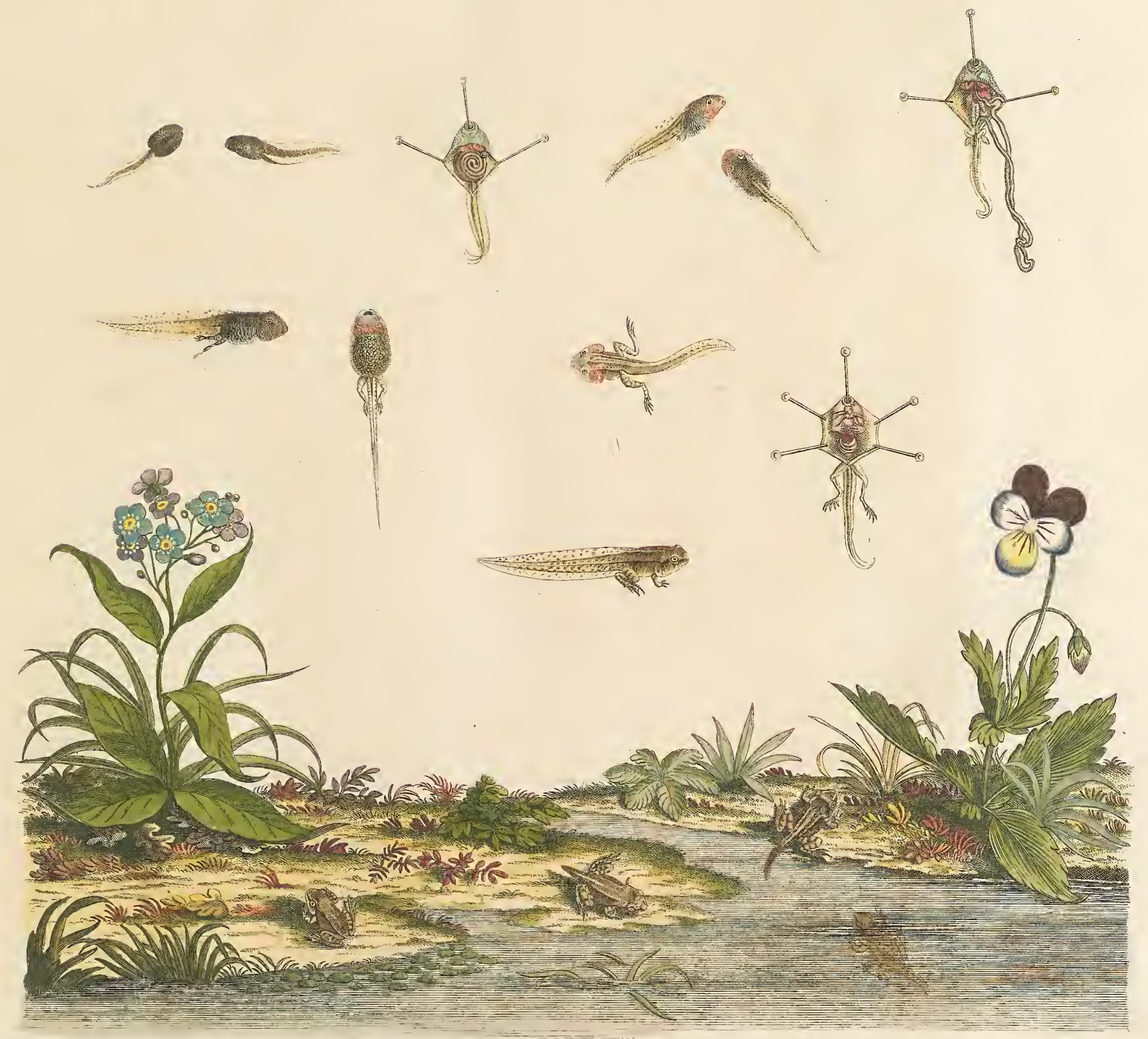

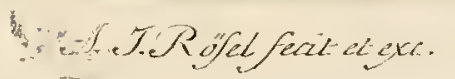



Tab.II.

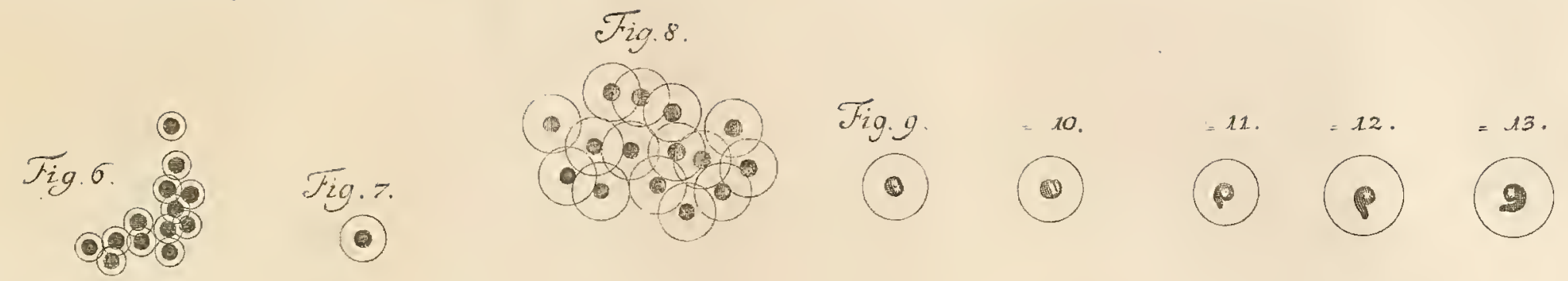

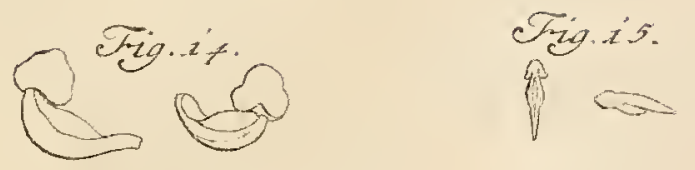

Fig.zir. Fig.is.

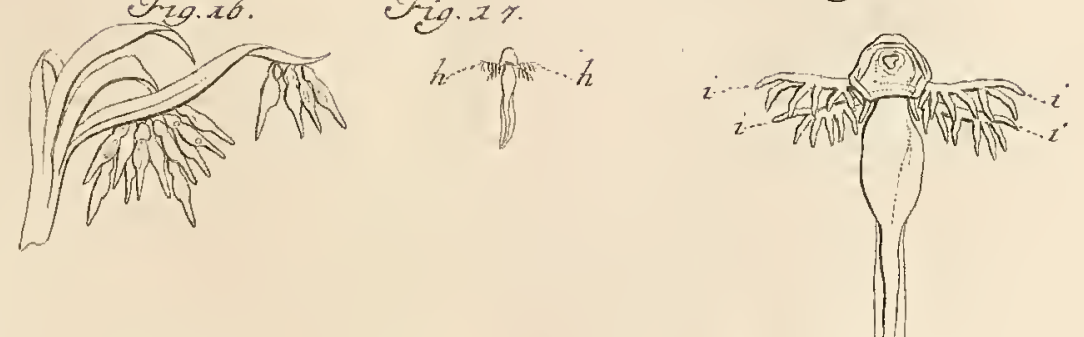

Figig. Frig.20. Frigin

क्त.
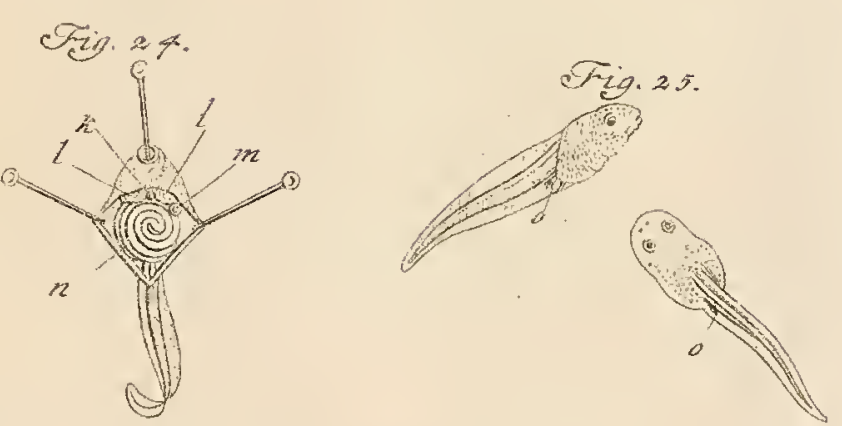

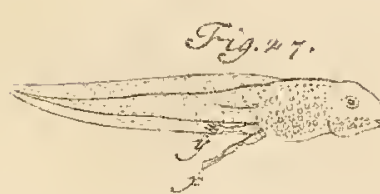
5 . 28
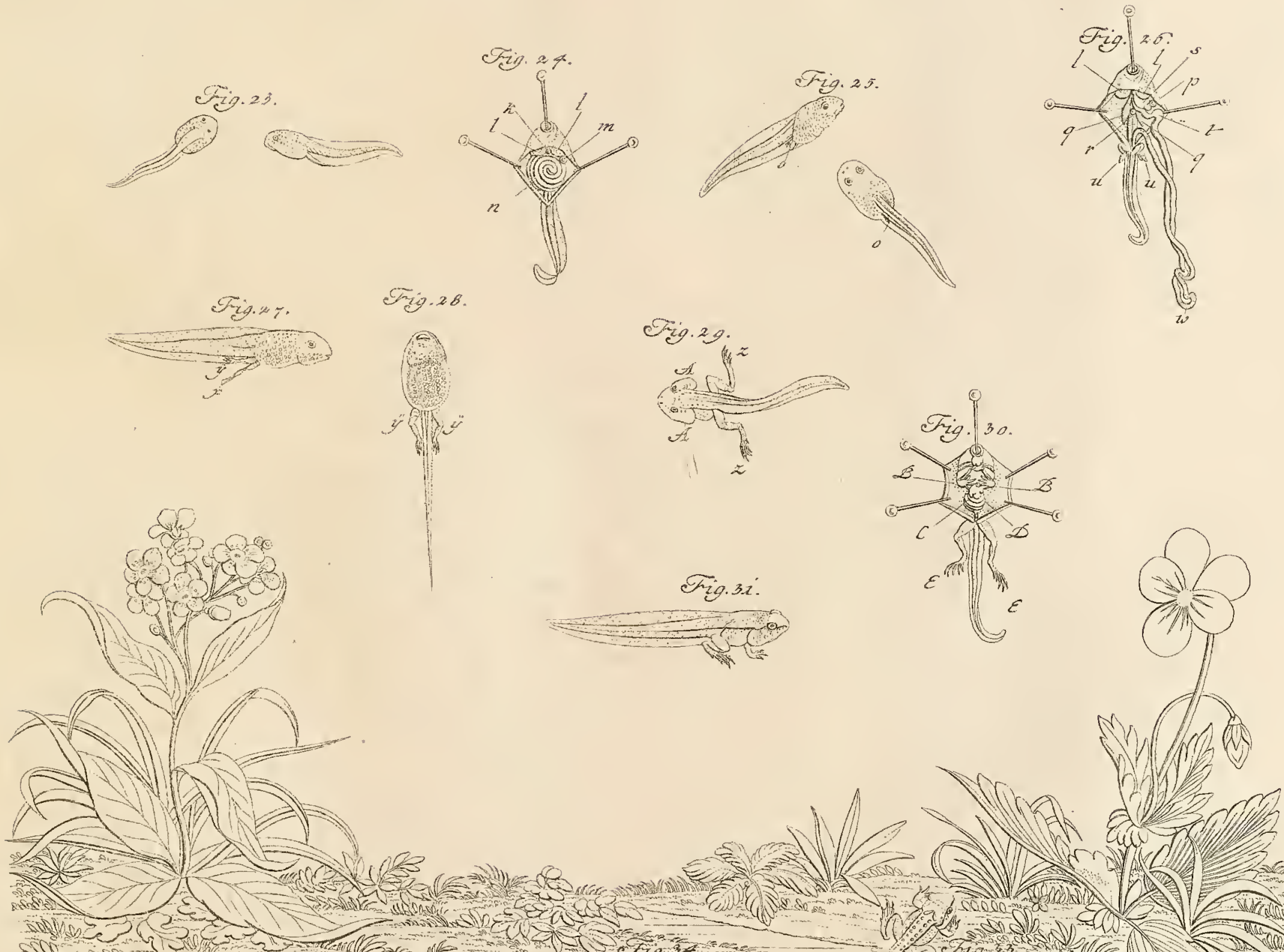

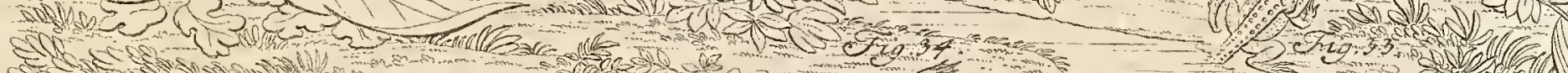

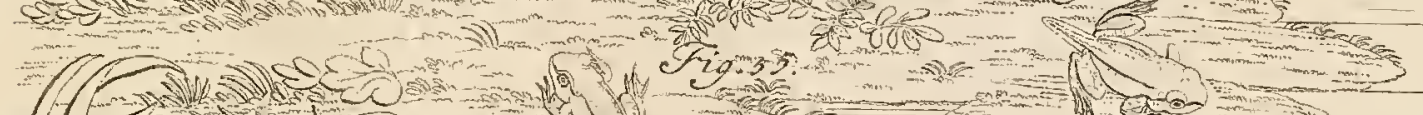

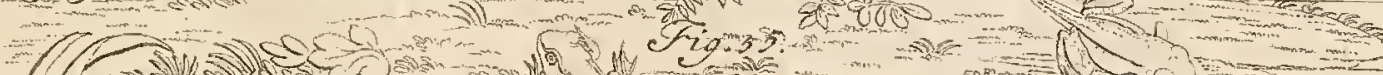

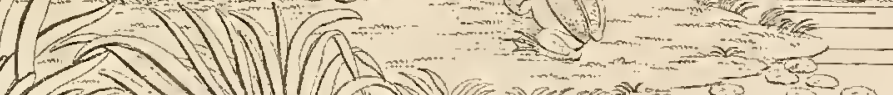





\section{\&}

feptimae; elapfis autem octo horis in multo maiorem expanduntur molem, quam octaua figura indicat; fed aucta fic mole leuiora etiam redduntur, ita, vt omnia fimul, quippe etiamnum cohaerentia, ab aqua eleuentur ipfique innatent; quod fi vero frigidior forte ingruat nox, diutius etiam in fundo morantur.

Quum anno 1749 ranae, quas domi feruabam, die vigefimo vndeuigefimoque Martii, oua fua parerent, ex paludibus quoque ftagnisque, quantum fufficiebat, eorundem ouorum apportandum curaui, quo obferuationes meae eo redderentur exactiores. Docebat me tunc quotidiana eorundem infpectio, augeri adhuc notabiliter ouorum albu-

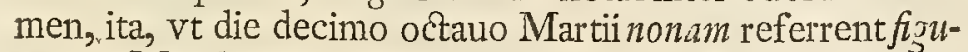
ram. Mutabatur interea temporis vitellus quoque in tantum, vt non folum magis cinereum contraheret colorem, aliquantumque maior euaderet; fed etian formam rotundiorem paululum perderet. Die fexto Aprilis maior rurfus comparebat moles albuminis aeque ac vitelli, atque hic reniformis nune potius, quam rotundus, cicatriculam dabat confpiciendam, fisura decina expreflam, indicantemque, coepiffe nunc vermiculi in ouo contenti euolutionem; hoc tamen non obftante, vix etiamnum poterat dignofci.

Die décimo quinto Aprilis maiorem vitellus fubierat mutationem, diftinctius etiam tum cerncbatur caudae extremitas, quemadmodum figuram ondecimam infpicientibus apparebit, limpidior infuper albuminis circumferentia reddebatur, ac fi illud effet diffluxurum. Die duodecimo Aprilis fimilis erat vermiculus fizurae duodecimae, albumine magis rurfus mutato; multo autem maior notanda erat mutatio die vigefimo octauo eiusdem menfis: tunc enimı vermiculus quoad molem auctus, aequabat figuram decimam et tertiam. Iam vero percipi etiam aliquis in vermiculis poterat motus: licet namque aliquamdiu vita carere viderentur, extremam tamen caudam anteriora verfus interdum mouebant; apparebat tum quoque nutriri cosdem liquore illo vifcido quo ambiebantur. Die trigefimo Aprilis, primoque Maii, vbi rotundam albumina ouorum perdiderant formam, cadebant vermiculi partim in vafis fundum, conglomerati partim ex glutine pendebant, quo ante circumdati fuerant, motu etiam eosdem cieri, diftinctius iam cernebam. Qui in fundum ceciderant, morabantur ibidem per diem fere, poftquam autem corpus fuum, incuruum antea, nonnihil explicuerant, enatabant interdum pernici motu, liquorem illum verfus quem dereliquerant, eidem tanquam lacticinio fuo, quo nutriebantur, crebrius adhaerefcentes.

Structuram horum vermiculorum, quos et gyrinos dicunt, curatius confideraturus, microfcopio nonnullos eorundem fubieci, quos etiam figura decima et quarta, magniitudine auctos delineaui. Difformes tum apparebant, et quemadmodum, nudo oculo confpecti, nigri coloris effe videbantur, microfcopio tamen vifi, colorem prae fe ferebant ex nigro fufcum. Incifura quafi a corpore feiunctum eft caput, angulofum magis quam rotundum, et fere triquetrum. Corpus in medio craffifimum, planum potius quam conuexum, extenuatur poftica verfus, inque breuem
TBafferz, wofelbit fie auth nodh an einander bantgen blew

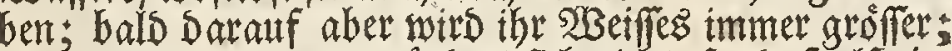

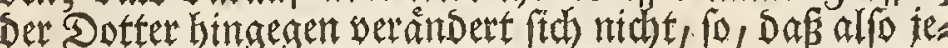
Des innerbalb vier Stunden Das 2nfeben der fiebenden Finur befommet, nad $\mathfrak{B e r f u s}$ yon adht Stumben aber werden Diefe Ener noch groffer, wie aus Der adten fi. tur erbellet; nach Dielem werben fie leidster und son Dem $23 a f e r$ alle zuranmen, weil fie noch immer an ein attber Kangen, in Die So óhe gehoben, Da fie Dann aut Dee

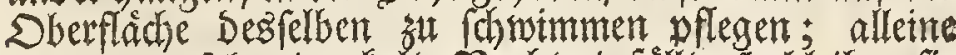
wann untgefehr eime Ealte siadt eimfält, fo bleiben fie auch bohl Iânger auf Dem G3runs liegen.

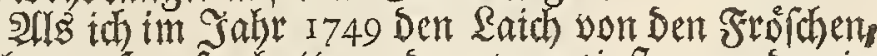
(o id) za Saure batte, Den zwanstaften uns ein

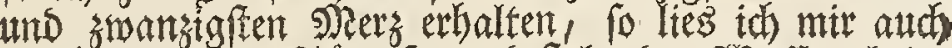
welchen ans Den Stmpfen und fehenden 2 Bafern brits gen Damit meine 2 Babrteh mungent um fo vielmebr \&ses wishet baben mơgen. Die alltágliche Setradhtung Derfelben lebrte midh, Daß Das 2 Beiffe icoes Eves nod immer nerefich groffer watrbe, und Daher fahen fie Den acht und swantigften s)erts to aus, wie fie Die neunte Sigur Darftellet. Der forwarze Dotter veranderte fich unterdefien auth in fo ferne, Da er melir graulich surtos und nicht alletm etwas groffer anzufehen war, fondern atth feine runde Figur einigermaffen berlohr. Den feds. ften STpril war fowohl Das "\$seffe, als Der Dotter, wiez ber un ein merceliches groffer, uno Deefer fabe bamals mehr nerenformis als wind aus, zeigte auth eime fleine Siabe, wie aus Der sebenden Sigur zu erfehen, welches

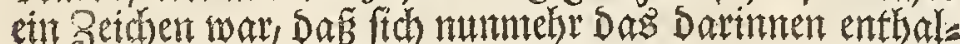
tene şưrmlein allgemach ausgubehnen anfieng; Doch

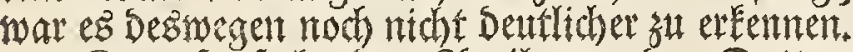

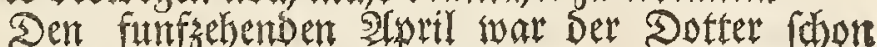
mehr verandert, uns Da zetgte fid Die nunmebr log ge=

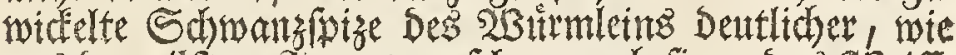
aus Der eilften firtut ztt erfeben, aud Fieng Das 2 Betfie

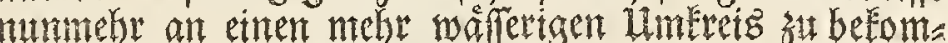

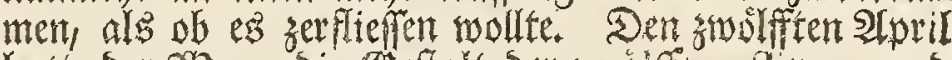
hate Der 2 Bum Die Beitalt Der 3 wolffert Situr, und bas 2isetife war wieder mehr werindert; nodh. ftarder aber zeigte fid Diefe scerainderunts Den acht uns zivats sigften eben Dieres Nomates, Da Das 23 Bumlein tm bies

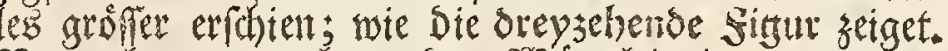
Nummebr wat and an Den 5 Birmlein in etwaz eine Servegung su merden: Dann ob fie gleich eine Bettlang

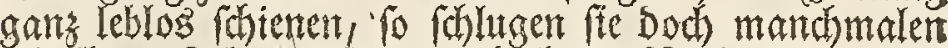

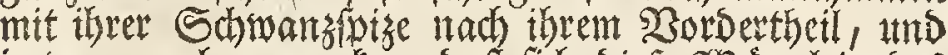
test mar aud sut merteen, Das fich Diefe SBurmlein Des Schleines, yon welchem fie untreben waten, zut ifrer Natyrutng bestenten. Den Drenfigften Itpril und er fen Nay, Da Das SBeithe aller Ever feine runde Form ver= lohren hatte, fielen Die WBimlein theils auf Den SoDen

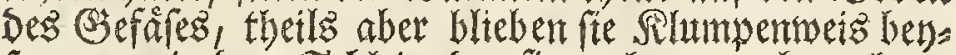
fanmen, in Dent Sdhleim ber fie vorther ungeben, ban: aem, hatten auth eine merditichere semeang. Die auf Dem Soden lagen, blieben fafte einen Tag lang auf felbi: gem liegen; nadbem fie fidh aber etwas attgertitedet batter, bann vorher waren fie noch getrimmt, fhwamen fie wieder, mit fonteller 3 erwegung, zumetlen in bie $50^{\circ}=$

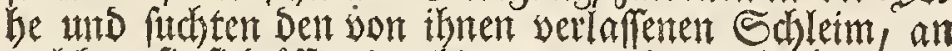
welchem fie fich offters anlitengen, unb atts foldsen, als

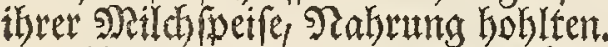

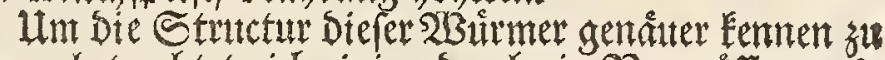
lernem, betrachtete ich-eintge Durd ein 2 ergurofertmgs. glas, uno in ber viersebenden figur babe th felbige o,

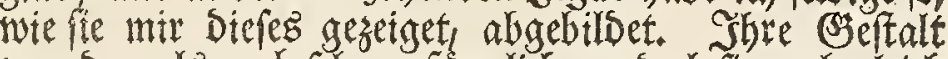
war Damals nech fehr unformlita, und ob fie auth gleidh Dem blofen 2litg forwars yorkamen, fo fotienen fie Doch in

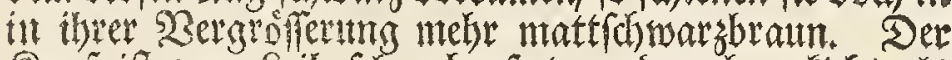

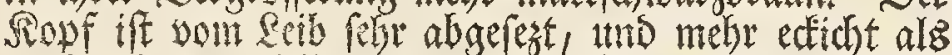

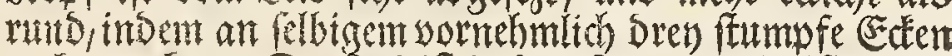
subemerten. Der seib ift in Der soitte am Didefen und $\mathfrak{S}_{2}$ 


\section{)}

et obtufam terminatur caudam, nonnihil adhuc incuruam. Elapfis duobus diebus referebant vermiculi formam figurarum numero is notatarum, quae binos eorum repræfentant, alterum quidem a fuperficie inferiore, alterum a latere. Prorfus nunc erant extenfi, ita, vt corpus eorum cum cauda rectam efficèret lineam, pif́ciculo ceterum fimiles; carebat tamen cauda illorum, etiamnum nigra et obtufa, adhuc pinnis, crebrius autem fortiusque eandem tum moueri notabam, quin natabant iam per aquam furfum deorfum, fociamque agentes vitam tenaci illo nutriebantur humore, quo plantae fcatent aquaticae, quas in aquam inieci, quum noffem appetere illos has ipfas plantas vbi libere in aquis vitam degunt, id quod decima et fexta figu$r a$ indicatur. Elapfis vix aliquot diebus alia prorfus gyrinorum erat forma: die namque quinto Maii obferuabam in plurimis eorundem fingulares prorfus appendices fimbriatas, a SWAMMERDAMMIO ita dictas, vtroque in latere pone caput collocatas, quae et pinnas et pedes referebant, figura decima et feptima ad $b$ b expreffas; ob motum tamen ipfarum pinnae mihi potius quam pedes videbantur, praefertim quum canda quoque, productior nunc graciliorque, colore etiam nigro magis quam fufco praedita, fuperius aeque ac inferius pinna effet inftructa, et quafi fimbriata. Quo autem appendices illas pone caput exftantes clarius cernerem, contemplabar ciusmodi gyrinum microfcopii ope, quem etiam magnitudine auctum fuvura duodewigefima delineatum exhibeo. Siftit eadem inferiorem corporis fuperficiem, in qua non tantum vermiculi os deorfum vergens, fed etiam appendices $i$ i $i$ i ad latera fitae, confpectui fefe offerunt. Conftabant illae vtrinque binis partibus, quarum quaelibet cornu ceruinum feptem ramorum referebat, continuoque a pifciculo agitabatur motu. Incertus etiamnum quemnam partes hæ gyrino praeftarent vfum, animaduertebam octauo nonoque Maii die, minores easdem, gyrinos vero multo maiores effe redditos, quemadmodum fiourae num. Ig et 20 fignatae oftendunt. Numero 19 tres fefe offerunt gyrini a parte fuperna, $n u$ mero autem 20, a latere, appendices laterales easque fimbriatas, nec non pinnam, caudae circumfufam, diftincte exhibentes. Quoad colorem horum gyrinorum, monftrabant illi tum fundum fufcum punctulis lucidioribus confperfum, pinna contra caudae perf́icua atque fubfufca punctulis diftincta erat nigris. Iam vero gyrinis, non amplius fufficiebat lentus ille plantarum aquaticarum humor, maiores quippe redditi, jpfas potius arrodebant plantas, lenticulas praefertim aquaticas, quibus, etiam plurimos eorum enutriui donec perfectam ranarum induerint formam. Iis tamen quos fic eram educaturus perquam noxia erat aqua fontana recens haufta ; fpatio enim viginti quatuor horarum omnes fere ab ea enecabantur, aqua vero diutius iam haufta, nec non pluuia, nullum ipfis ferebat incommodum. Quid ceterum de appendicibus illis fimbriatis ftatuendum effet, cogitatione comprehendere non poteram. Dictum iam eft, mox minores easdem fuiffe redditas ; fed euanuerunt tandem ex omni prorfus parte: non igitur nifi per paucos tantum dies in gyrinis hifce cernuntur. Perfuafum habet fubtilifimus SWAMMERDAMMIVS, qui fimiliter ranam ab ouo defcripfit, obferuationes autem fuas cum alia ranarum fpecie inftituife videtur, intrare appendices hafce ipfius gyrini thoracem et abire ibidem in corpora branchiis pifcium fimilia, quae tamen, in gyrinis meis, ego quidem reperire non potui, neque etiam verifimile mihi fit, indigere gyrinos eiusmodi branchiis, quum iam, quemadmodum ex fequentibus patebit, pulmonibus inftructi fint. utberbaupts mebr platt als erbaben, binten aber wird es gefdmeisiger unto entiget fid int einem Eurzen, ftum:

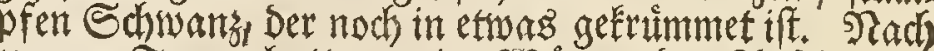

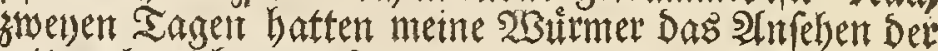
mit Is bezeidheten figuren, wo swir siven Derfelben fes hen, Savon bet cine fich yon Der untert fliche, Der andere aber von Der Seite zeiget. Nummebr waten fie gan

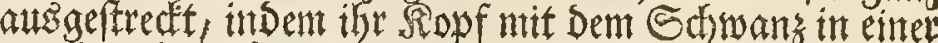
geraben Sintie frumb, und Daber frellen fie eintger mafs ren eit Fifhlein yor; Doch hatte ihe Sthwans, Der Da: mals gans Dundtel tmo finmpf war, noch Eeme Flofie,

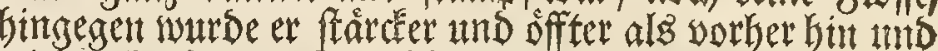

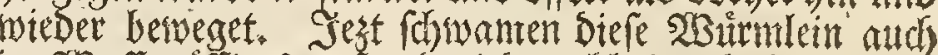
im SBaffer offters aut uns nieder, blieben Dabes inmer gefellig bein einander, und nổrten fich yon bem Sdjlem

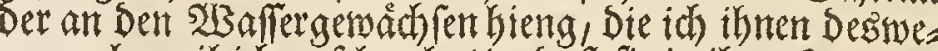

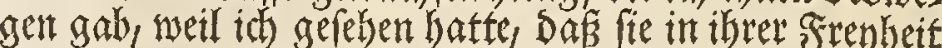
bauffentweis an foldhen hiengen, whe int ber jechsehenden Jigut gezeiget wirb. Raum waren etliche Iage wer: follen, als fich meine Srofchwitmer wieder in einter gan andern (Seftalt zeigten: Dann id fande Den finffen S)ay, Dafís Die meiften Derfelben unter Dem Ropf an ie=

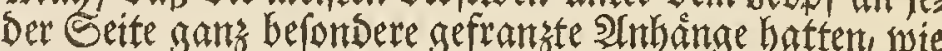
fite Gronmmetosmun mennet, welche fich fowd hl mit einen saar Flosfedern, als mit spoten sergleichen liéen, uns

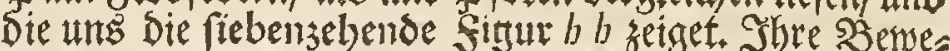
gung madte nich glattben, Daf ich fie sielmeth fir Flofen

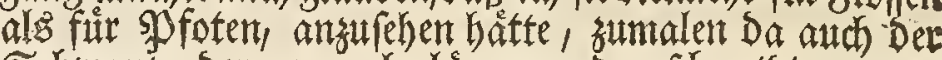
Sd)wang, Ser munmehr langer und gefd meisiger aus" Ghe, und eine mebr fiswarze alb braune sarbe batte, fo wobloben als unfen, eine folofie fuibrte, und gleid) fan

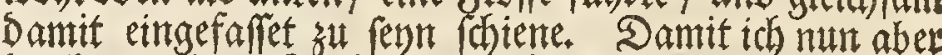
Die binter Dent Ropf befindliche 2 (nthainge befler mónte Eenmen lermen, fo betradtete ich ein foldhes 2 surntlein

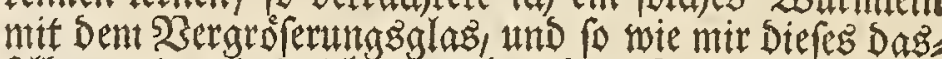
felbe gezeiget, habe id es aud it Der adtsebenden fitur

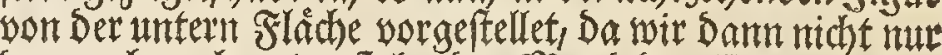
Den nod nach unten fitehenden Mund Des Ylourms fons Dern auch bey $i$ i $i$ i bie beesen an ben Seifen herfitrges wadh fente 2Inhånge wahrnehmen. Sie beftumben aus zmenen Theilen, Davon feser einer mit fieben Enden be: Testen Stange eines Sirficherwenhes glied, und wurben

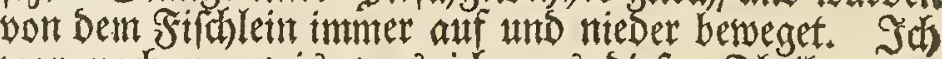
war nod) ungentis was id aus Diefen Theiren ma:

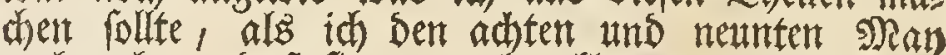

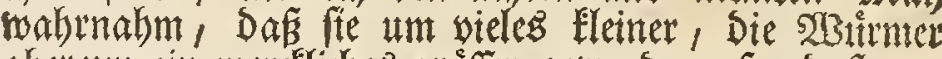
aber um ein mercliches grófier gemorden, fo, Dafi nut

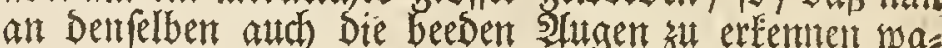
ren, wie wir an Denen mit is und 20 bezeidhnteten

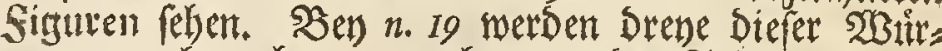
mer won ober, ber $n .20$ aber won Der Seiter geseiget,

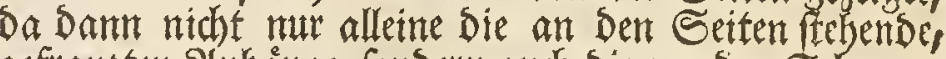
gefransten 2(nt)ånge, fondern auch Die um Den Sabwans gekende Flofie, Deutlith wahrsuntehmen. Der Farbe nad batten Diefe Surmlein Damals einen brauten Brnms Det mit febr zarten bellen \$utnctlein befprenget war, bie Dutrdifthtige uns hellbraune Flofie an Sdwwans hinges

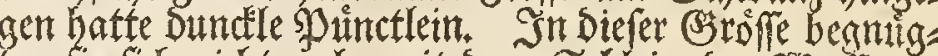

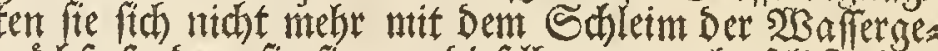
wäbre, fondern fie fiengen diefelben munmely felbft, fon berlich aber die 23 afferlinfen, merdflich zu benagen an : aud habetch mit Diefen gar biele fo lange erzogen, bis fie

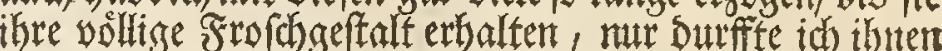
fein frifches Soruntmenwaffer geben: Dann Davon fturben fie innertallb sier und swantsig Stunden faft alle; Das:

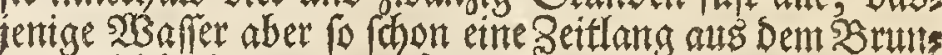

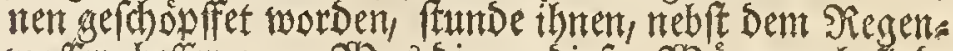

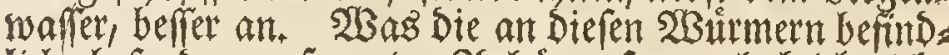
lid)e befondern gefranstert 2 (nhäange (enen, $\mathfrak{h a b}$ id) nid) ausfindig machen fontmen. 2 Bin haben vernommen, Da fie bals flemer geworden, und endich find fie gar serlob: ven gegangen, fo, Das felbige nut etliche Tage an Diefen 


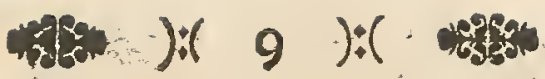

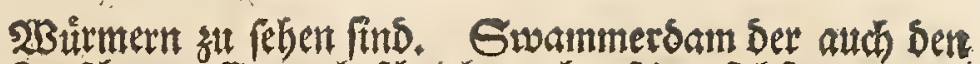
Frofh yom Ey an befdrieben aber feine Sbfervationen mit eimer ansern frood)art gemadbet zu haben fdeinet.

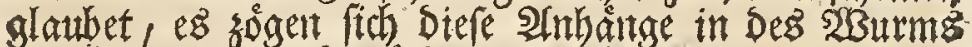
şruft binein, und wuirsen zu foldhen Sorpern Die man bed Den Fifdien Die Ohren nentet; ich habe aber in mets

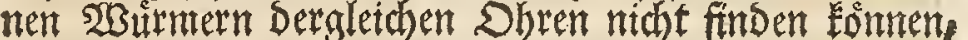

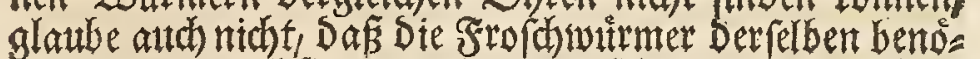
thiget fenn, weil fie, wie sotr unten feken werden, beretis there Sungen baben.

Die decimo fexto et decimo feptimo Mait, gaudebant plures horum gyrinorum ea magnitudine qua figura vigefima prima depicti exhibentur, iam vero fubierant caput corpusque illorum eiusmodi mutationem, vt ambo in vnam quafi eamque ouiformem coalita viderentur maffam, atque hanc etiam formam diutius feruarunt. . Nunc infuper magis fufcus ipfis erat color, punctulaqueilla, lucida aeque ac nigra, diftinctius apparebant; perfpicua autem caudae pinna ex fufco flauefcebat. Certior porro reddebar eo ipfo tempore, ponere gyrinos, fub iterata illa partium reliquarum mutatione, fuam pariter cutem; mutant tamen illam alia quidem ratione quam infecta: haec namque exuuias ponunt fpeciem infecti habentes, syrinorum vero cutis mucum tunc refert, vel vifcidum quendam humorem, quemadmodum fupra iam, quum de ranis adultis loquutus fum, indicaui.

Excreuerant gyrini die vigefimo quarto et quinto in magnitudinem figurarum $n .24$ fignatarum, quarum altera fiuperiorem, altera vero lateralem gyrini partem exhibet; licet autem tum temporis ftructura ipforum parum mutata videretur, vinidiore tamen nitefcebant colore. Quum die trigefima primo Maii magnitudinem figurae vigejmae tertiae haberent, referebant etiamnum, quoad corporis formam ouum, nullo caput inter corpusque dilcrimine apparente; in cauda contra clare nunc confpiciebantur mufculi, lineae cuidam mediae quafi vtrinque adnati, apicemque verfus oblique excurrentes. Lata eaque admodum pellucida caudae pinna furcis diftincta erat maculis, venter quoque, vel inferior corporis fuperficies, lucidior nunc, notata erat pofteriora verfus, aeque ac fuperficies fuperior, punctulis candidioribus.

Augefcente corporis mole, augebatur etịam gyrinorum pawor, quodi enim propius quidquam accedere percipicbant, illico in fundum vafis fefe praecipitabant. Quum vero ex prioribus meis obferuationibus didiciffem, procrefeere in gyrinis huius magnitudinis crura quidem, fed pofteriora tantum, vnum hinc ex maioribus dic quarto Iunii diffecui, aciculisque ad modum figurae vigefimae quartae afferculo affixi, quo fingula in aperto abdomine contenta eo clarius oculis fefe fifterent, crura praefertim etiamnum latitantia inueftigaturus; fed enimuero nulla eadem detegere potui oculorum acie, partes contra internas fat iam diftincte difcernebam: confpiciebam enim cor, in figura per $k$ indicatum, / / binae funt partes coloris carnei infia caput fitae, SWAMMERDAMMIO branchiae dictae, quarum vfum tum minus concipere poteram; $m$ veficula eft fellea fphaerulae fubviridis formam habens; $n$ autem defignat inteftina ex cinereo fufca, inque gyrum conuóluta: plura tunc quidem in partibus hisce tenerrimis, et ad leuiffimum tactum diffuentibus, non erant dignofcenda:

Decimo tandem Iunii apparebant in gyrinis meis, pone corpus ouiforme, prope caudam, bina breuia admodum tenerrimaque crura, -quae in gyrinis, num. 25 notatis, per 00 indicantur. Confpiciebantur tunc temporis, praeter. oculos micarites, nares quoque, ipfum vero corpus a capi(4)on viele Die(Sroffe Der cin und swowsigften Sigur, unt Da ivar ifr Reib uno Ropf in fo weit serensert ba bee De Shetle mur eiten faft owalrumben Sorper ausmadten: biefe (3eftalt aber bebielten fie auth nadher nod) lange. Die Gramb farbe war nummebr an Retb und Sdwans noch brâner, Die hellen und Dundfent Witnctlein zetgten

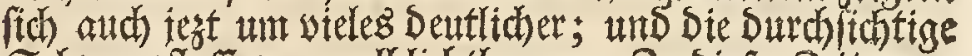
Sdwanzflofe war gelblidtbraun. Bu Diefer Betr wut:

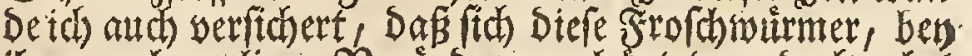

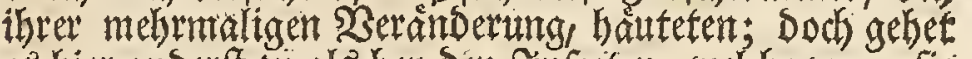
e' bier anderft zu als bey Den Snfecten, welche wam fie ithe Saut berandern einen $\mathfrak{B a l g}$ ablegen, Der Dem Sn: fect faft gletd) fiebet; bey unfern switrmern aber gebet Die alte Saut wie ein Shletm weg, wie ith bereitz ober gemeldet, Da ich bon Den erwadh fenen Frofochengefprodsent.

Die Brofle Der mit $n$. 22. bezetdineten figuten, Das won bie eine Den YBurm son oben, Die andere aber son Der Seite vorftellet, hatten meine 2 Buirmer Den vier und zwatrigften uno finf und swantsigften Nay erbalten umb ob fidh wobl Damals ibre Stritctur in intats veraits bert zeigte, fo war Dod ithre Farbe Deutlicher zu erfen. nen. SUlls fie belt ein und Drenfigften Man Die (Sroffe ber deey uns 3 wansigften figut erlanget, fithrten fie nod) eitten oyalrunden Rorper, ant weldiem Der §opf yom Eeib niditunteridieden war; am Shwang aber gaben fich munntehr Die ant eimer scittellinte, fu beeden Seiten,

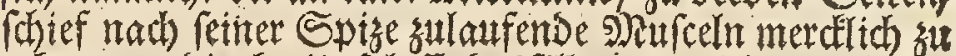

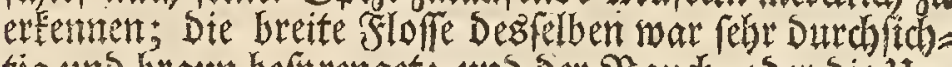
tig und braum befprenget; und Der $\mathfrak{B}$ auch, ober Die 1 th terfache Des aóners fiel mun etwas heller aus, hatte aud gegen binten su, wie Die Dberfliobe, wiele now bels lere silitetlein.

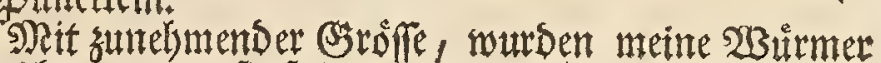
auth) fchetuer (wie fie fich Dann nummebr fogleich auf Den Soben begaben, wann ihnen etwas Jrembez nahe eant. Da mir alth aus metnent vorigen Dbfersationen beEame

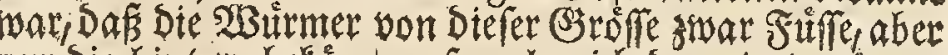
nur Die Gintem befáment, fo nabm ids Den vierten sumit etmen Der groften und fditte foldhen am Setb auf, beff:=

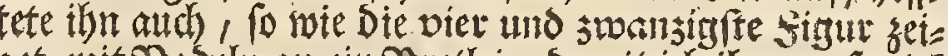
get, mit Nabeln ant eit Bretlein, Damit id ith um foviel beffer betrachten foinnte, weil id begiertg war su febert, wo etwann bie zar Beit nod) verborgene fitife feden moss ten; alleine tid fonnte weber won Den bintern nod vorts Dern etwas gewabr werden; Dod fielen Die inneren sheis

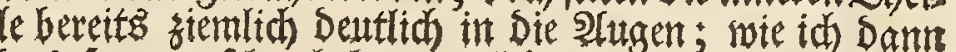
Das Sers zu fehen befam, weldes in Der fitgur Durd $k$ angeseutet wirs, $1 /$ find swen fleifofarbige unter Dem Ropf liegende Ihetle, weldhe Gwammerdam Die Dh: ren nennet, aus Denen id aber Damals nod) gar nichts zu madhen wuffe, $m$ if etne Eleine grunlid)te Sugel und nidhtz anders als bie (Sallenblafe, $n$ aber Die graulicts

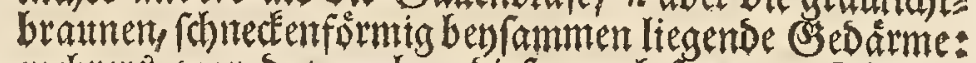
mebrers war Dazumal an Diefen nod fo zarten Sheilen weldye bey Der geringlten 2 eruthrung fogleid zerflofen nidht zut erfernen.

Den zebenden Junit erblidite ith enditd an einigen meiner $\mathfrak{B}$ sirmer, binten am enformigen Reib, uns nahe bey Dem Sd lein, unb fis.25 zeiget zwey folcher sourmer, an weldfen Diele beede Fublein Durch o o angesentet perden. Sou

(E) 


\section{of}

te, leui incifura diftinguebatur. Hac obferuata mutatione, denuo gyrini, ratione fuperius dicta, inftitui diffectionem; peregi illam die decimo et feptimo Iunii, gyrinum autem diffectum exhibet figura vigefima Sexta. Ad $/ l$ binae illae iterum fiftuntur partes, carneo tinctae colore, quas nunc crura nondum formata effe autumabam, et in quarum medio cor collocatum eft; $b$ fellis eft veficula; $q q$ pulmones funt longiufculi, plurimisque quafi veficulis conftantes; quum vero hisce inftructus fit gyrinus, vix quidem intelligo, cur SW AMMERDAMMIVS, qui illos imiliter in gyrino reperit atque delineauit, in eam delapfus fit opinionem, vt crediderit, partes illas $l /$ fignatas, branchias effe, pifcium branchiis fimiles, in quibus illae pulmonum officio funguntur: quodfi enim regeras, indigere gyrinos, non nifi in aquis degentes, branchiis hisce, cur tamen adultis in ranis aboleantur, quemadmodum SWAMMERDAMMIVS fimiliter affirmat, quum hae quoque durante hyeme in aquis latitent, vix capio. Repraefentatur porro in figura noftra lien $r$; hepar ex rubro fufcum $\int$ indicat; $t$ ventriculum; $u u$ crura bina pofteriora eaque minora; $w$ autem inteftina in gyrum antea difpofita, nunc euoluta.

Die vigefimo primo Iunii notabiliter iam maiores euaferant pedes pofteriores, quemadmodum ex figura vigefima Septima, quae eiusmodi gyrinum a latere refert, ad $y$ apparet; faepius etiam, vbi in hanc excreuit magnitudinem, inter pedes eiusdem propendere aliquid cernimus, per $x$ indicatum, quod tamen neutiquam pro corporis quodam membro habendum, quum nihil aliud fit , quam excrementa ex ani apertura prodeuntia. Appetebant adhuc tum gyrini hi lenticulas paluftres, quodfi tamen recens, duriufculumque alius cuiusdam plantae ipfis praebebam folium, diftincte percipiebatur ftrepitus quem illud arrodentes edebant: licet namque in illis parua tum oris fuerit apertura, maxilla tamen illorum fuperior multis iam obfita erat exilibus acutisque dentibus. In latere vtroque capitis, a reliquo corpore nunc aliquatenuts feiuncti, notabatur tunc macula fubrubicunda, a binis illis partibus in figuris vigefima quarta \& vigefima fexta, litteris Il notatis, perque cutem translucentem confpiciendis, atque, ceu quidem mihi videbatur; magis magisque intumefcentibus, oriunda. Eaedem illae partes diftinctius multo per cutem translucebant in figura vigefima oitaua, quam die vigefimo tertio Iunii delineaui, quaeque inferiorem eiusmodi gyrini fuperficiem repraefentat; monftrat infuper eadem illa fundum magis variegatum, nec non pedes yy magnitudine denuo auctos.

Quum tandem gyrini mei die vigefimo quinto et vigefimo fexto Iunii, cibum dereliquentes, ab eo fe abftinere inciperent, binaque crura pofteriora $z Z$ Fig. 29 iam perfecta viderentur, caput illorum prope maxillas, ad $A A$, fubrubicundum tumefactumque apparuit, ventre nonnihil contracto extenuatoque. In mentem mihi hinc veniebat, jam jam comparituros pedes anteriores, atque hinc eosdem curiofius nunc obferuabam. Seligebam itaque vnum ex illis, qui reliquos aetate fuperare videbatur, eundemque, quo clarius omnia cernerem, feparatim in vas inımifi vitreum: vidi tunc, non ita multo poft, mirabundus, protendere eundem interdum, pone Caput, fub maxilla tumefacta, pedem finiftrum anticum, retraherequeillum, ea raratione, vt ne veftigium quidem fupereffet. Autumabam ego quidem, pedem hunc initio minorem futurum, fed fal-

wurbe man auch an felbigen, mebft Den beeden hellen 2tus

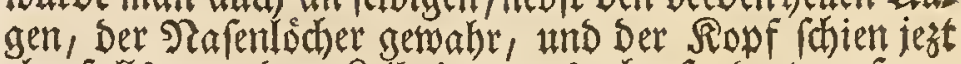
ebenfalls yon Dem Seib in etwas abge(ondert zut renn; Diefe Berainderung aber bewog mich abermal einen fols

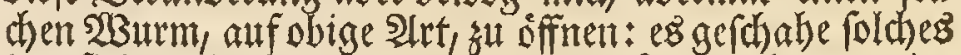
Dent fiebenzehenden Sitnit und in Der fech and 3 wownjigs ften Sigur habe ich Denfelben vorgeftellet. In felbiger werden Durch $1 /$ wiederum bie bereits oben bemerdte stwer fleirh fárbige Theile angeśeiget, Die ich muntehe

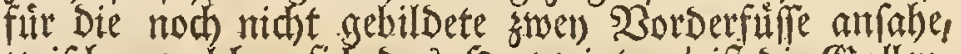
zwirthen welchen fid Das Serzzeigte, $b$ ift Die (Szallens blare, a $a$ fins bie länglichten uns gleid) fam anz lanter

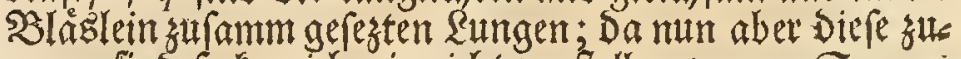
gegen find, fo fan id mir nidht yorftellen, wantm Groams merdam, Der fie eben auth in einem folchen 23 urm ges

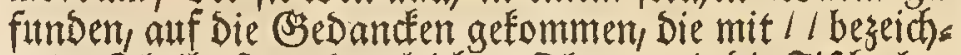
neten Iheile, fenen Dergleichen Dhren, wie die Fifhe has ben, ben welchen foldhe Das afme Der Rumgen vertretten: Dann wollte man gleich fagen, Die Frofdinutirmer baitten Diefer Ohren nothig, weil fie fich nut eintig und allein int $\mathfrak{X}$ affer anfbalten, io wumbert nich, warum relbige in Den

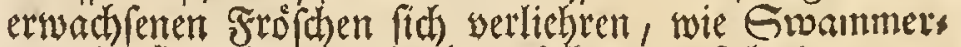
bam felbit meldet, Da Doch Diefelben ebenfals den gan. zen 23 inter hinburch unter Dem 2 Baffer bleiben. F̌ser.

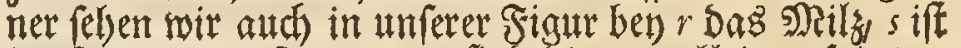

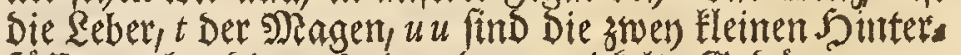
fuffe, $r$ aber Die aus einander gewidélte (3) ed árme.

Den ein und zwansigften Junii waren Die hintern Fitfe um ein merchliches groffer, wie wir bers $y$ an Der fie. ben und zwanzigften Gigut rehen, welche einen Diefer Bitrmer von Der Seite poritellet; ben Diefer Griofle wird man and offters gewaht, Daß etwas zwifden Dies fen Sutfien herabbange, wie allhier Dutrh $x$ angebentet

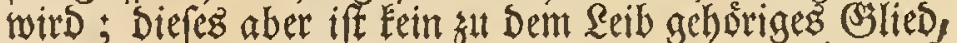
fordern es ift foldhes, Der aus Dem bier befinolichen 2 ff. ter herfintemmende Innath. Damals lieffen fich Diefe

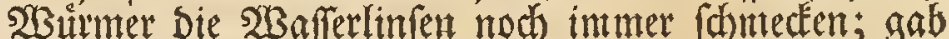
ich ifnen aber etwan ein frifdes und etwas bárteres Slat; einer andern SPlanze, fo Eonnte man fie Deutlich an felbigem nagen horen: Dame obaleich Die runde Deffs nung ibres Spundes noch fiemlich llein, fo war Dod ibr oberer Riefer bereits mit vielen zarten und fiharffen Bâknen befeset. 2fn jeber Seite Des Ropfeż, Der yom Eeib in etras abgefondert erfectien, bemertfe man aud Damals einen rothlichen Sledeen, welcher won nichts anderz alsz Den beeden, in Der vier und swanzigften und fects and zwansigften Sigtur mit $/ /$ beseichneten, Durdh Die Saut fhimmerenden Sheilen herfam, fo immer melse und mehr sat geftrwellen ichienen. Eben Diefe Theile waren in Der add und swansigften figur, in weldher id einen Diefer 23 iirmer, Den brey und zwantzigften Jutii von Ser untern Fláche abgebildet, nod Deutflid)er Durd

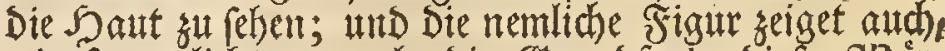

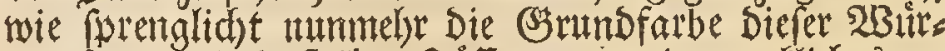

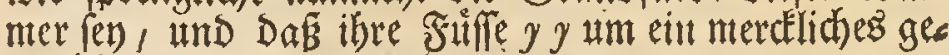
wadren.

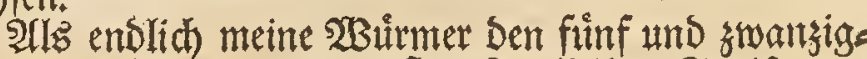
ften und fechs und zwansigften Junti ihre Epeife vets liefen, und su faften anfiengen, aud ibre beeden bintern Fuffe $z z$ vollemmen zu fern fejienen, wie ant Der neum und swansinfren Sigur zu fehen, fo fuien ibr Sopf an Dem Rienbacten, bey $A A$ rothlicht und aufgelauffen zut fenn; Der Reib hingegen fiel in etwas ein, unt wurbe ge= (d) meidiger. Diefe Deránderung bradhte midh auf bie G3edanten, ez whirden fich mumebr aud bald bie vors Dern Suife zeigen, und Daher gab id fleiffig auf fie शlas. tung. Einen, Der and alteftent zal fernn fahiente, thate idy, un thn beffer beobachten zu tonnen, in ein glápernes Bje: (d)irt befonders, und nabm hernach an relbigem, nicht ohne Serwumberung, bald wahr, Dafer Dann und wann, Gintell an Ropf, unter Dem gefd) wollenen Riefer, Den

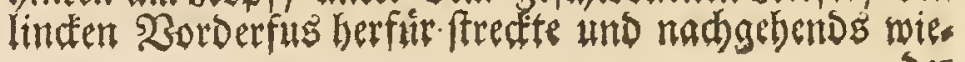


Tab III
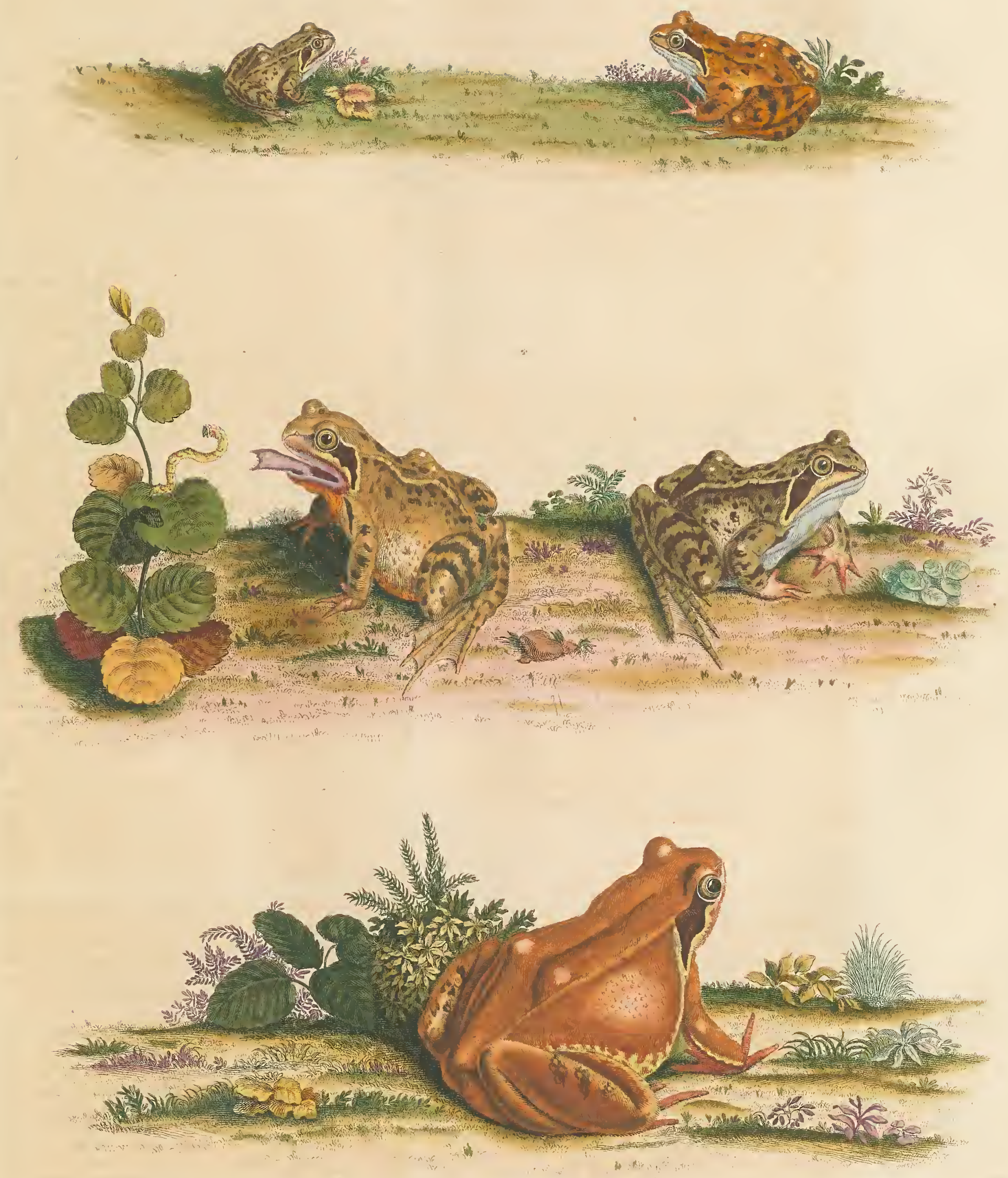

A.J.Röelfecitet exc. 

Tab.III
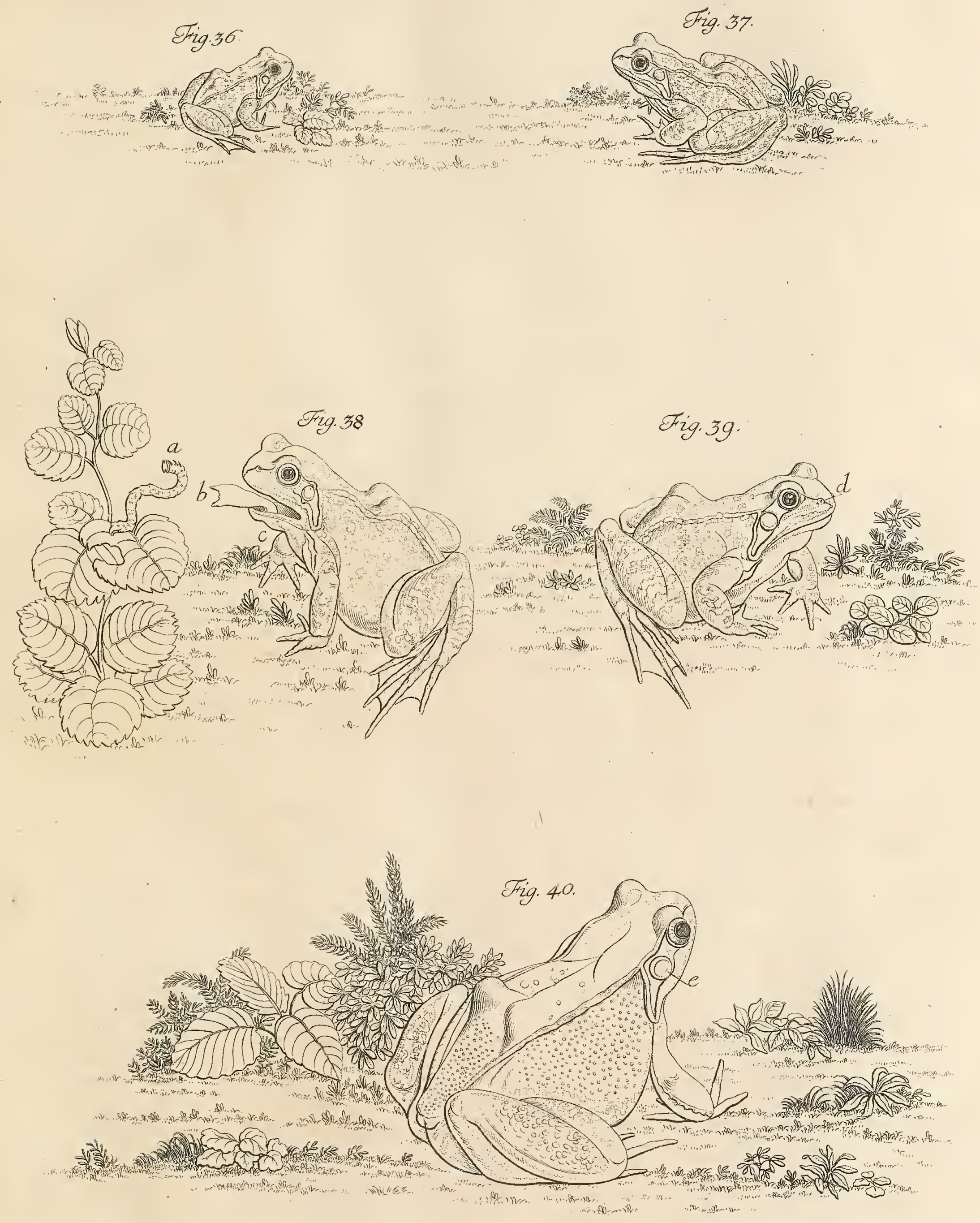



\section{tog $):($ II $):($ (}

lebar: aptam namque habebat magnitudinem; dein vero idem in aliis quoque obferuaui, miratusque fum, oftendere eosdem femper, $a b$ initio, pedem praefertim finiftruin.

Nunc etiam operae pretium me facturum credebam, fi eiusmodi gyrinum diffecarem ; elegi hinc vnum ex illis, qui quidem hactenus nullum pedem anticum monftrauerat, iamiam vero monftraturus erat; quo autem tenellae eiusdem partes duriores redderentur, mucusque ipfi adhaerens nihi minus impedimento effet, in fjiritu vini eundem fuffocaui. Siftit illum foura trigefima, cute vltra os vsque difciffa, apertum. Obferuari iam in eo clariffime poterant bini pedes antici $B B$ nótati, iamque prorfus formati, eundem occupantes locum, in quo antea binas illa partes carneas $/ /$ fig. 24 et 26 vidimus. Inter pedes hosce, fupra hepar $C$, ventriculum tegens, confpiciendum fefe praebebat lien, pulmones autem contraxerat fpiritus vin in tantum, vt vix reperiri poterant. $D$ indicat inteftina, antea longiora quidem, nunc vero ob cibi abftinentiam mutata breuioraque. $E E$ pedes funt portici faltatorii, iamque perfecti.

Procrefcebant tandem in plurimis meorum gyrinorum, die vigefimo fexto et vigefimo feptimo Iunii, pedes antici, quos fioura trigefima prima cernimus, iisdemque perfectis, feruabant nonnulli caudam, cun pinna annexa, per diem adhuc dimidium, absque omni mutatione, fingularis prorfus formæ animalia referentes, quum neque ranae, neque lacertae fimiles effent. Iam vero crebrius enatabant ranunculi hi ad aquae fuperficiem, auram hauriendi gratia; illi autem qui libere vitam agunt, plerumque tum ad 'ripas verfari folent." Cibo eosdem hoc tempore vefci non videbam, caudam contra illorum fenfim minorem red'di facile notabam: defluebat namque non folum pinna eius perfpicua, fub intuentium, vt ita dicam, oculis, fed decrefcebat cauda ipfa, notabiliter admodum, in longitudine aeque ac crafitudine; decidere autem illam fruftulatim, vel integram, quemadmodum nonnulli autumare videntur, ego quidem minus obferuare potui; multo autem minori veritate illa PLINII nititur fententia, figurari pedes, cauda findente $\int e$ in pofteriores (*). Quid autem quaefo fit de hac, fic fatis ampla, ranunculorum parte? Deliquefcere illam nulla ratione deprehendere potui: nonne hinc verifimile fit, nutriri illa ranunculum donec perfectam ranae induerit formam? Illo certe tempore quo eius pedes procrefcunt, ipfeque quoad partes externas magnam fubit mutationem, partes quoque internae valde mutantur, id quod inteftina fatis fuperque oftendunt, quae fisura vigeJama fexta, longa admodum, trigefima vero, multo breuiora fiftit; dum autem hanc ranunculus patitur mutationem, nullum ille aftumere poteft cibum. Sed quocunque res haec fefe habeat modo, . id tamen certum eft, vbi quattor fuis ranunculi hi inftructi funt pedibus, decrefcere eorum caudam; illi.vero quos ego alui, quique die vigefimo fexto \& vigefimo feptimo Iunii caudam adhuc trahebant integram, inonftrabant, partim die vigefimo feptimo, partim vero vigefimo octauo, dimidiam tandem eiusdem partem, qucmadmodum ex figuris trigefima fecunda et tri; yefima tervia apparet; elapfis dein aliquot horis plus rurfus decreuerat, ceu figura trigefima quarta oftenditur; quin integro elapfo die, ita prorfus euanuerat, vt ranunculi, figurae trigejimae quintae nunc fimiles, quoad ftructuram omni-
Der zurutck zog, fo, Dafi gar Eeine Spur mehr Davon zu bemercten. Diefer FHo war aber nidh mehr fo Eleit, wie th alaubte, Daśer anfangs fenth wurbe, fondert er batte bereits feine geborrige (⿶rófe; und nachgehends bemercte ith) aud eit (Sleithes an andern foldhen 23 itrs mern, fonderlich aber, Dá́ fie allezeit Den linden Fus zu erft zum Borfacin bradsten.

Nutn glaubte ich auth, muirbe es Der Naibe werth

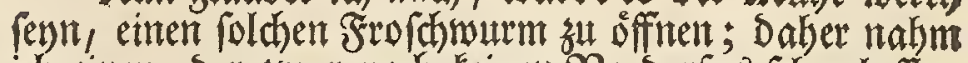
ich einen, Der zwar noch Eeinen Borderfus Gehen lafien,

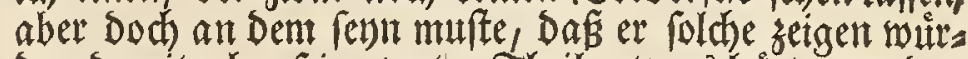
De; Damit aber feime zarten Shetle etwas banter werben mogtert und Der an ihm hangende Sahletm mer nicht himberlich fiele, fo tobeteid Denfelben im 2 Beingeift. In Der oreyfigiten figur feben wir ihn, mit bis utber Den Rumb hin aufge hilizter Saut, gesfinet. Es fielen an Felbigen Die zwen vordern Fitfe, of her mit $B$ B bezeid net find, nach ibrer volligen Sseftalt, gant Dettlich in bie 2lugen, und lagen an eben ber Stelle, wo yorker bie 3wen fleifhtgen Theile / / Der vier und zwanzitgiten, und leds and zwanisigiten Sigut vont uns bemerdet morden. Bwichen Denfelben zeigte fith tiber Der Reber $C$, Die biet Den Neagen bebecfet, Dag Nils; Die Rungen aber hatte Der Weititgeift fo zHammen gezogen, Dafí Die: felben Eaum meft zat finden waren. D find bie yorber

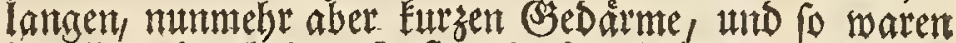
Diefelben Durch Das Faften Diefer $\$$ worbelt. $E E$ find Die bintert/ und jegt volleommente Spltigfutier.

Endich befamen Die meiften meiner 2 Birmer, Der

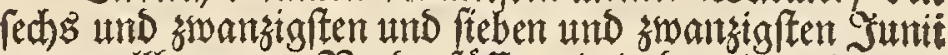

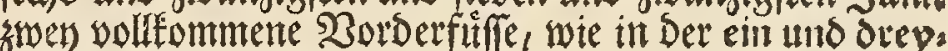
ligften Figur zat fehen; und nachdem fie Diefe erbalten, to bebteltent eintige Derfetben itren Schwant famt Der baran bangenden Floffe, nodi einen balben Iag lang untorêndert, und batten Desmegen ein ganz befonderes Sinfehen; weil fte weder eitrem Sro/d, nod) einter (Evde: te volleommen ấnnlich fahen. Ben Diefen umftantoen Eanten Diefe Eleme Fróthe offiterg alz fonten an Die Ober=

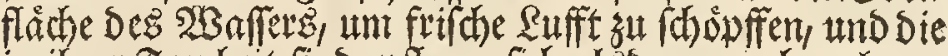
in three Frenheit find, pflegen fich also ann auth methens

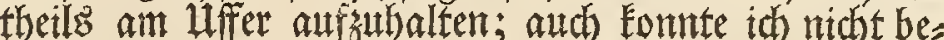

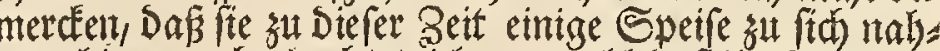

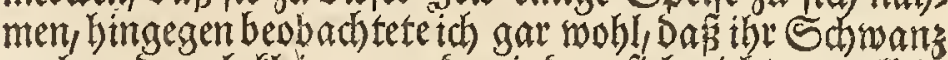
nach utno nach Gleiner numbe indem fich nicht mut alfein Die Durbhfichtige flofe desfelben faft zufehends verloht,

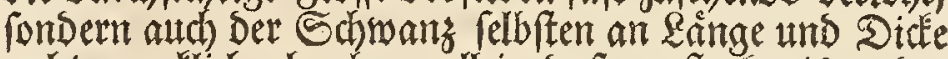

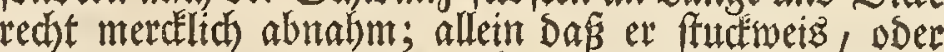
gar auf einmal abgefallen wáre, wie cintge zut glauben

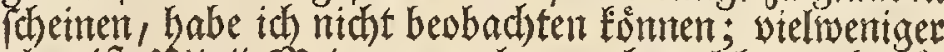
aber if Plinit setmung wahr, nach welcher er Dafut bălt, bie bintern fuffe ber stofice ent fínden aus bem (iic) fpaltenden Sitwans (*). SYo Eommt Dann aber

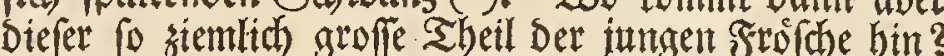

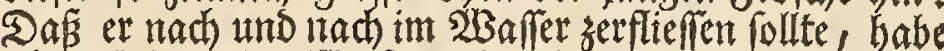

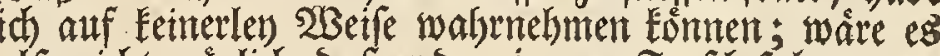
allo nicht móglich, Daf er Dem jungen Frofh folange sue Rabrung Diene, bis er feinte vollfommente Sseftalt erthals

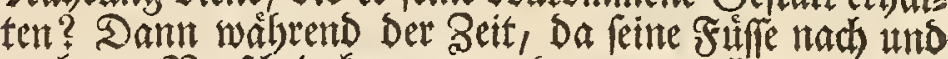
nad) sum $20 r$ fhein fommen, und er von aufent eine siem liche Seråndertuts leibet, gebet auth an leinen innern

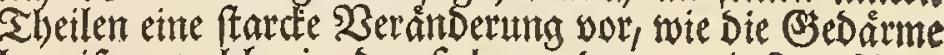
beweifen, welche in Der fechs und swansigften fitnue zitenlich lang, in Der dreyfigften aber um vieles Eirter erfacinen, indem fitch aber biefélbent fo verándern, Ean

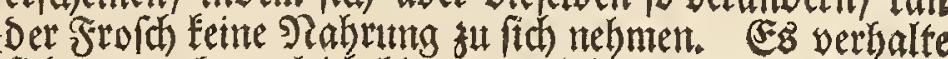
fith nun aber gleich biemit wie inm wolle , fo if es Dod gewis, Daf fich Diefer Sdawang Der Froidse, wann

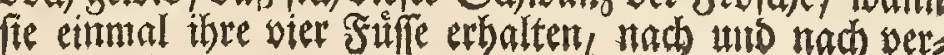
(c) 2

\footnotetext{
- Nat. Hift. Lib. IX. Cap, sI.
} 
axtsen $):($

omnium corporis fui partinm, in perfectas nunc, fi magnitudinem excipias, mutati fuerit rasas.

Haec fere illa funt, quae de rana hac terreftri furca, ratione incrementi ipfus ab ouo, vno eodemque in fpermate, fingulis obferuani diebus *. Poftquam vero gyrini mei in tantum adoluerant atque ex aqua prorepere tentabant, de alio, in quem eosdem transferrem, cogitari coepi loco. Aliquot hinc fumfi vitra cylindracea maiora, et poftquam eadem ad partem vsque dimidiam terra repleui, cefpidem huic fuperimpofui viridem in quo nonnullos dein collocaui ranunculos. Cefpidem ipfum aqua crebrius confperfi ne marcefceret, vtque cernerem vtrum ranunculi, poft ieiunium fat diuturnum, gramen fint deuoraturi. Sed abhorrebant ab illo, ita, vt multi fame enecati fuerint, donec ipfis mufcas aliaque infecta viventia minora porrexi, atque has non folum auidiffime ceperunt fed illico etiam deuorarunt. Difcebam exin, mutatis partibus externis internisque, illorum etiam ita mutatam fuiffe naturam, vt cibum, gratum antea, nunc naufearent; id quod tamen ex.parte etiam ori aliter iam conftructo, aliaque apertura hianti, adfcribendum effe mihi videtur.

Quum itaque eiusmodi ranunculi infectis nutriantur, eademque in terra potius quam in aquis quaerant, mirum non eft, cateruatim eosdem, vbi nihil impedit, ex aquis in terras prorepere: hinc etiam fit, vt fub finem Iunii, Inliiue initium, quo tempore ranae perfectae induere folent formam, in locis paludofis magno faepius numero, millenarium longe multumque fuperante, circumfilientes deprehendantur ; folent autem vefpertino praefertim tempore ex aquis prodire; iterque conficere quantum quidem vna nocte emetiri poffint. Sed inftituunt iter hoc noctu, tempeftate calida, quum interdiu multis obnoxii fint periculis, faepiusque coruis, fturnis, nec non aliis auibus in praedam cedant; hinc etiam eft, quod diurno tempore, in campis aeque ac in filuis, variis rebus tecti, immoti latitent; cadente tamen pluuia, eliciuntur ex latibulis fuis, atque tum alaciiores redditi, aeque ac tempore vefpertino nocturnoqute, tam copiofe vbique oberrant, vt per viam incedentes vix pedem ponere queant, quin plurimos eorum obterant, quum omnia huius fpeciei ranunculis vndique fcateant. Interdum tamen, plurimos bufones minores, certae cuiusdamfpeciei, qui cumranunculis hisce vno eodemque tempore folitam obtinuerunt formam, focios habent.

Ex hactenus dictis apparet, fuife ranam noftram terreftrem, antequam quatuor ipfius procrefcunt pedes, pifcis quantam fpeciem; ranunculos autem ilios, qui quatuor inftrueti pedibus caudam etian trahunt, pro monftro-

* Hinc p. 7.lin. 27, die duodecimo Aprilis, legendum, lie vigefimo quarto Aprilis.

\section{(2) $):(-56$}

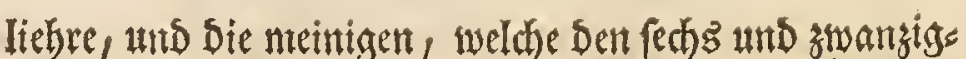
ften und fieben und zivanzigften Junti nod) vollfommen Dantit berfelen waren batten theils Den fieben und zwans sigften, theils aber Den adyt und swansigiten, mur noch Die Selffte Dason, wie Die 3 wey unt dreyfitste nebft Der orey und steyfigiten Siguv zetget, und nath $\mathfrak{B e r f t u s}$ et= licher Stutben latte er bereits miteder ntehr abaenom= ment ste swir an Der vier und dreyfigften fehen; ia nad) einem Ing war gar nidhts mehr Dayon wahrstmefintely

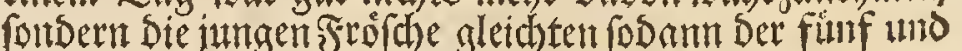

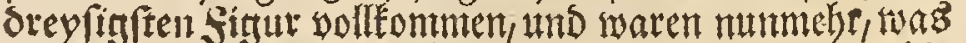
Die Structur aller ihrer librigen Theile anbelanget, bie

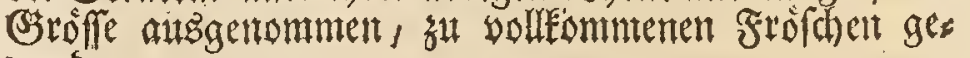
morben.

Diefes waire mun alfo basienige was ih sont tnferm

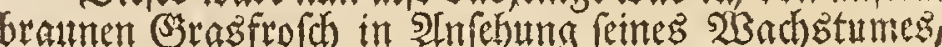
vom (E) an bis zur wolligent frofhgeftalt, an cinerlen

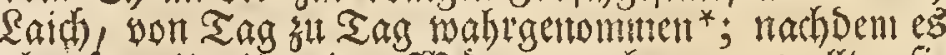
aber fo weit mit nteinen 2 Btirntern gefommen, wollten fie nid)t melye im 2 baffer bleiben, atmb allo war id auth bes Dadst ihten einen andert Drt zum S(ufenthalt fu vers

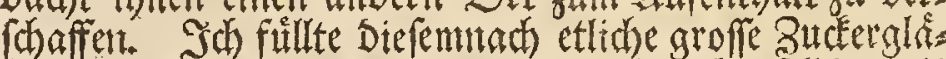

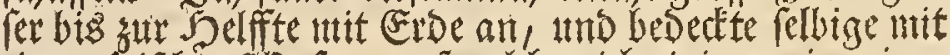
einem frifd)en 23 afen, anf welden idh cinige meitter ints

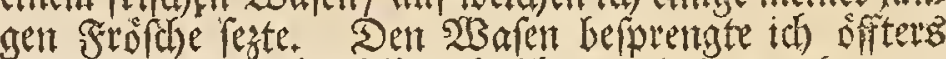

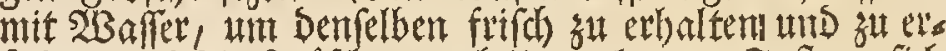
fahren, ob bie Froffhe, nach threm latigen Faften, fich

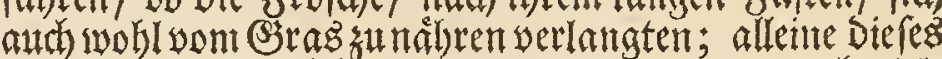
warihnen feine anfátubige Speife, Daber Dann auch viele

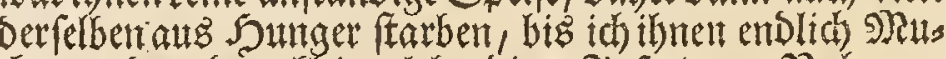

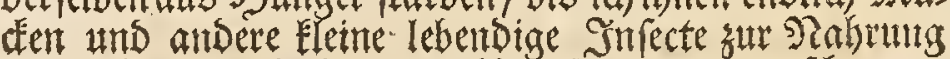

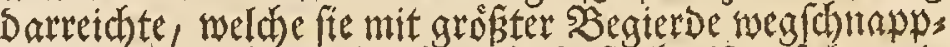

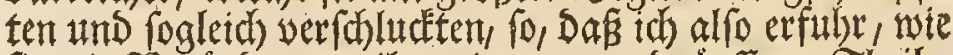

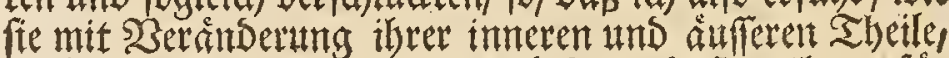

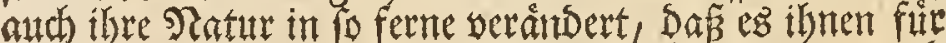
Der zuvor angenebmen Speife nummehr ectelte; wo zu audh ibr sint Der iest eime gans andere Structur und Deff; nung batte, vieles bensutragen fotente.

Da num alfo Diefe iunge Frofidhe fich you Infecten

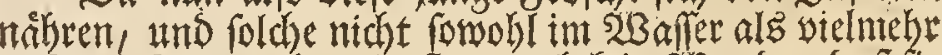

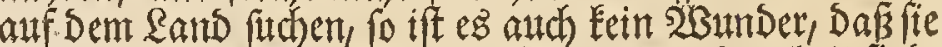

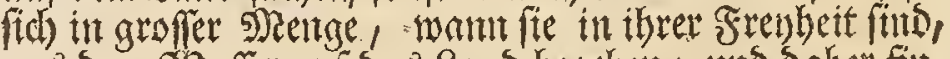
ans Dem 23 affer mif Das Rand begeben; tund Daher fits bet man fie audh in fumpfichten (3)egenden, ou Ende Des Junit, oDer IfnFang Des Jullii, Da fte eben thre bollfont, mene. Sseftalt betommen, wielmals su tauferoen auf ein, mal, fondertich aber bez 2 Thends, Da fie fich alts Dem $23 a f f e r$ begeben und fo weit forttried)en, als es ihnen it

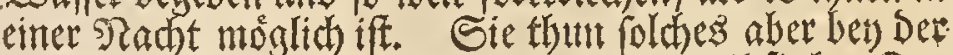
Pacht, Die noch Dast warm fenn mus, weil fie ber Ta: ge mehrere 2 erfolgung ausguftehent baben, und ronbers lich von Den Nad)ferlungen Der Raben, Stahren und antierer Boonel nidht ficher fint, Daher fie fid aud ant

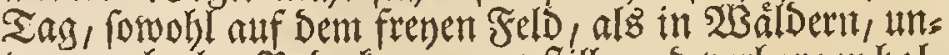
ter.manderlev Sedecfung/gang fitlle uns verborgen bals

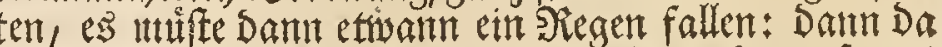
werben fie alle auf eimntal nunter, und wandern, fo gut

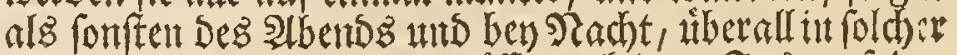
Skenge herun, Dấ man offters Eemen Fus auf bet Strafle fesen fan, obne felbige zul zertretten, weil alles

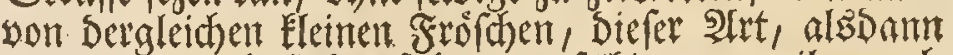
wimmelt; Dod fintot fid unter ferbigen sumeilen alth) cine Nenge junger Sroten, won einer gewiffen 2 ret, wels

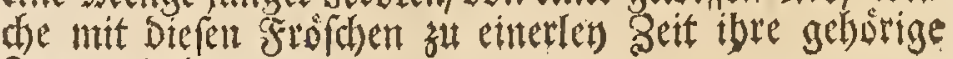
Form erbalten.

Ylus Diefem was bisher ergeblet worden, erkellet

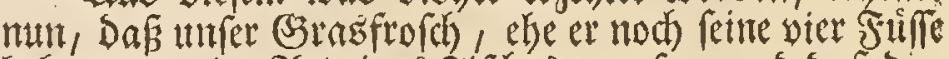

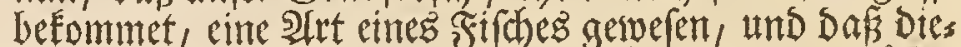
jertigent llemen Frofde, weldhe neblt ibren sier frilfen

* Daher mus es oben ouf ber 7 Ceite lin. 38, ftatt Den jmalffen 2lpril, Den vier und zroanzigften Spril, Geiffer. 


\section{(4)}

fis creaturis neutiquam effe habendos, quemadmodum aud einen Sdyang baben, für feine attferotsentlide

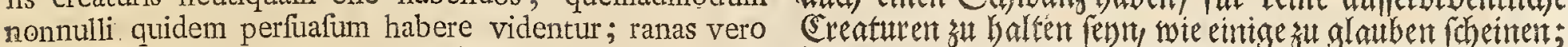

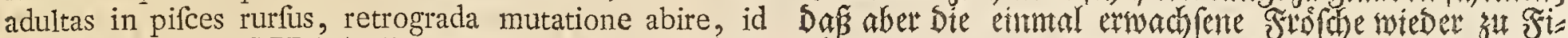
quod celeberrimus SEBA * affirmat, mihi quidem vix ac ne Chent werbert, wie Soert Geba * bebantet, Ean th sut vix quidem fit verifimile. Scribit ille fubire metamor- Zeit nod nicht glauben. (Er meldet zwar foldes mut phofin hanc ranas praefertim americanas, addit tamen, mu- fürnebmlich yon Den americantichen Frofichen, ferset aber tari eadem ratione ranas quoque europaeus; quin hinc rei boch auth hingu Daf folches mif bent europaitchen eben= certitudinem optime fe adftruxife putat **, quod binorum fals gefhehe; ia er methet aud Der Sache Ssentskeit

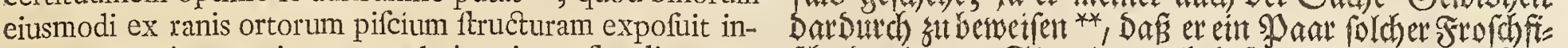
ternam, partiumque in corpore latitantium oftendit muta- fohe ber imment Structur nadh befhreibet, und Die şer= tionem. Enimuero licet pifces hi quoad magnitudinem anberning Der im \&eib entfaltenen Ibeile zeiget; alleme

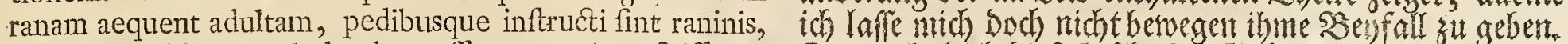

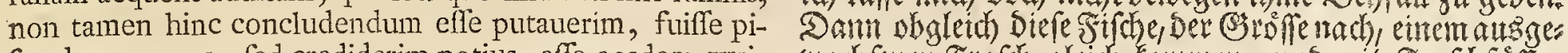
fces hosce ranas, fed crediderim potius, effe eosdem gyri- wachenten Frofd gletd Eommen, unto ntit Frofh finfen

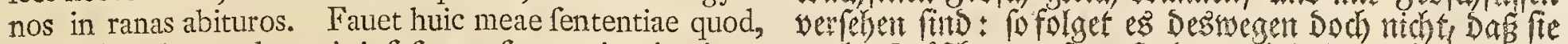
hoc ipfo in loco, de ranis ipfi fermo fit americanis, inter yorber frzofde gewefen; fonbern id balte foldhe stelmetye quas nonnullae tantam habent magnitudinem, vt folo cor- fuir Frofchwitumer, atts welchen erfe ited Frofthe wach=

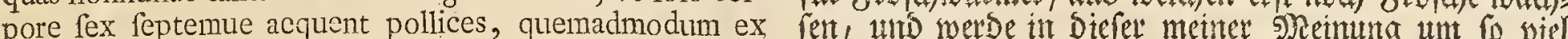

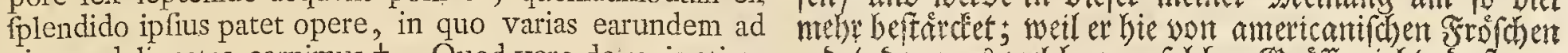
vivum delineatas cernimus t. Quod vero de ranis etiam rebet, Seren es wilche yon foldher Sroffe gtebt, Daf nut

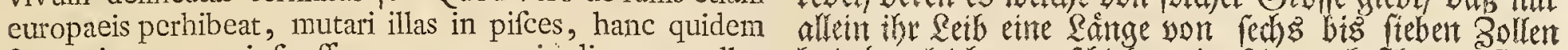

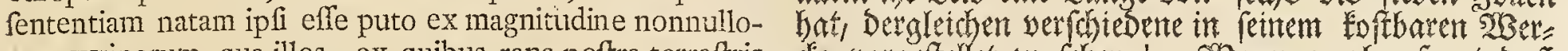
rum gyrinorum, qua illos, ex quibus rana noftra terreftris de vorgeftellet zu fehent. sobant er aber faget, Dafi

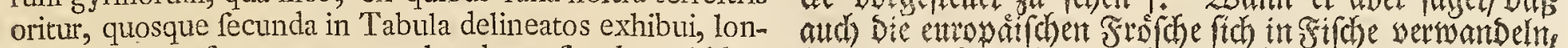

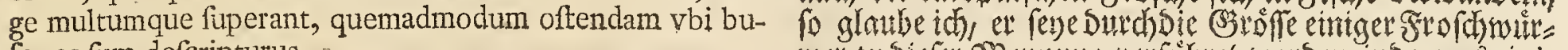
fones fum defcripturus. - met zudoter sNetming verfithet worden indem es etni=

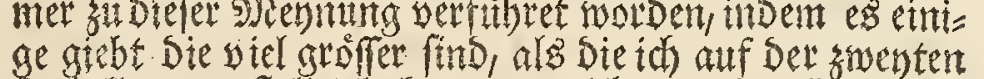
Eabelle vorgeftellet babe, aus weldhen unfer ersfrofd entipringet, uns want ith Die Aroten befdreibe, fo werbe ith felbige sat zeigen sselegenteit habert.

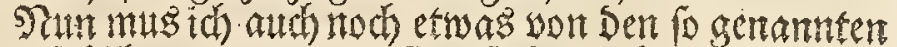

Sed monenda etiam funt nonnulia de ranis fic dictis temporariis, vel pluuiis. Legimus paffin, fcripfiffe veteres quod ranis pluerit, vel quod ex terrae puluere maioribusque imbrium guttis, fimulac hae terram tangant, ranae nafcantur; dantur et adhuc multi inter recentiores squi huic veterum fententiae adfipulantur, quin quum aliquando per arua ambularem atque ob pluuiam, derepente ortam, in proximam fecederem filuam, eandem fub tegmine fagi euitaturus, nec non quicquam in caput meum decidiffe perciperem, fimul vero omnia vndique ranunculis fcatere cernerem, ranunculos hofce pluiffe propemodum credidiffem: vifurus autem vtrum ranunculi in caput meum deciderint, in pileo aridum deprehendi furculum, quumque dein, redeunte fole, ardentioribus eiusdem radiis me fubducturus, pedem vlterius in filuam promouerem, multo plures confpexi ranunculos, qui tamen fub continuo folis fplendore ita prorfus euanuerunt, vt rediens ne vnicum quidem amplius cernerem. Difperiiffe fimul ac femel tantam ranunculorum copiam, quam initio quidem fumma cum admiratione contemplatus fum, vix erat credibile; curiofius itaque illos quaeritans fub frondibus, virgultis lapidibusque latentes eosdcm deprehendi. Data fic occafione vlterius in repentinum horum ranunculorum inquifiui ortum, poftquam autem ranae terreftris examen me docuit, prorepere illam, vbi in perfectam abiit ranam, derelicta aqua, in terram, elicique eandem, decidente pluuia e latibulis fuis, fententiam illam de pluuia ranarum prorfus repudiaui, ita, vt nunc cum illuftri RAYO †† periuafiffimum habeam, fi ranis pluere verum fit, fieri etiam poffe vt vitulis pluat: quodfienim in aere rana nafci poffit partibus aeque internis ac externis pcrfecte inftructa, quaeque naturaliter non ante hebdomadam decimam et quartam, quemadmodum obferuationes meae docent, abfolutam ranae induit formam, nonne etiam verifimile eft, fieri polfe, vt eodem in aere alia fimiliter oriantur animalia?

RideRegenfipof

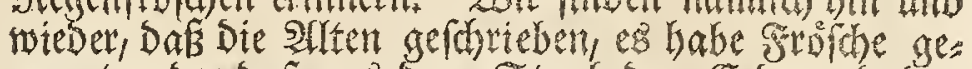

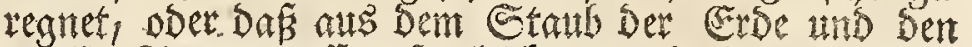

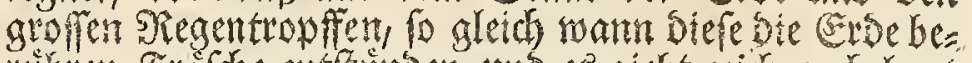

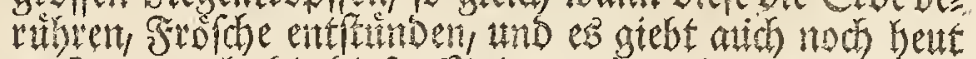

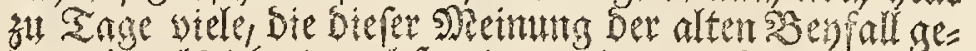

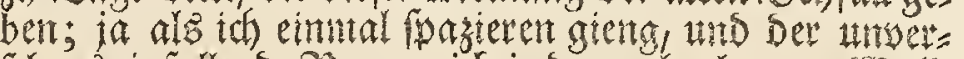
fehenseinfollende gregen mid inden mabgeregentenszald

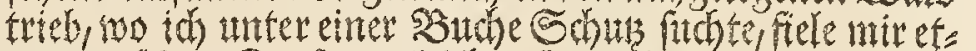

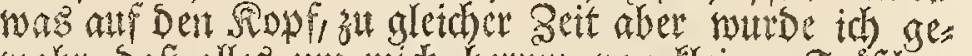
waher, Daf alles um mid hertum bon flemen Frofd on

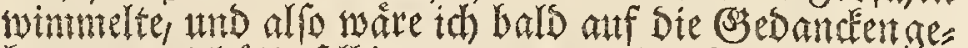
fommen, ez batte felbige geregnet; als id) aber nadfos

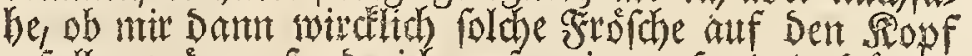
geforlen vairen, fande tith auf mettem Sut ein Durres şetslein, uno tadhoem die Somt bals wiedermat

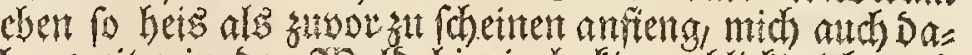

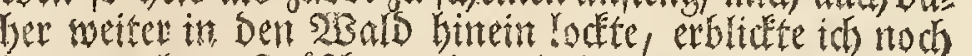

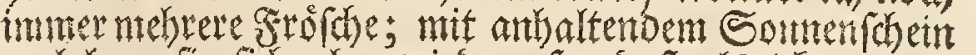
verlolyest fite fith aber wieber, fo, Dafís als id meinen

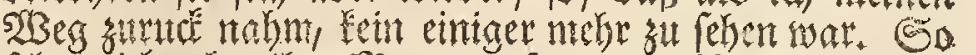

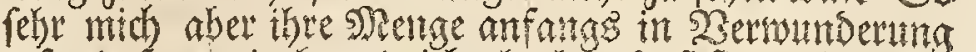
geferet, fo wentig fonnte id glauber, Dafsfe auf eimmal

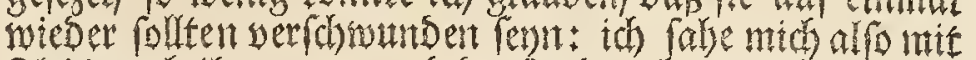

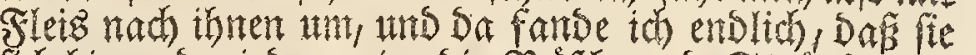

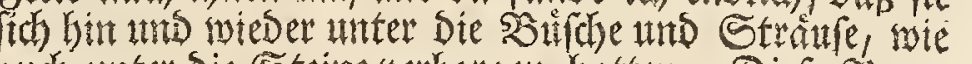
and unter bie Steme berborgen haten. Diefe Soge.

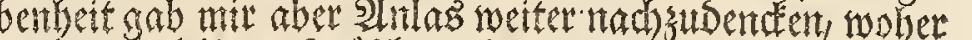
bod fo siel fleine feroche anf eimmal mogten getomnet

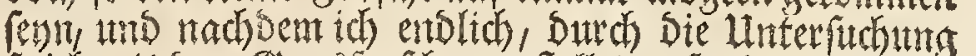
fo id mit Dem Grasfrofd angefteller, gefunden, Das fid

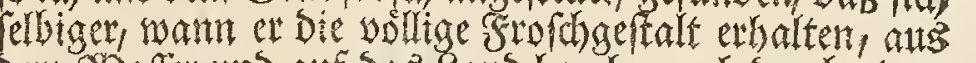
Dem sysafier und anf Das Samb begebe, aud Durch einen cinfallenden SRegen aus peinen Shlup fwittele heraus

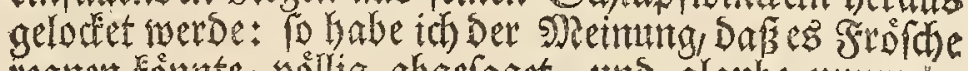

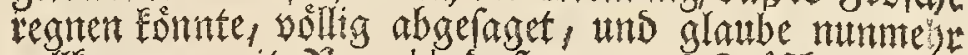

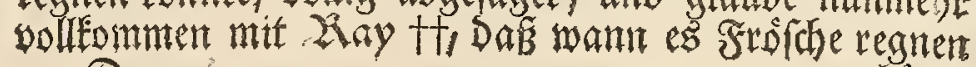

* Locupletifimi rerum naturalium Thefauri accurata defcriptio. Tom. I. p. 125. Tab. LXXVIII. Ephemerid. Nat. Cur. Ceut. Ill: \&IV. Obferv, CLXXI, p. 386, feqq. Valentini Amphitheatrum zootomicum, p. 1212.

** loc, cit. Tom. II. p. 127. Tab. CX.

† Tom. I. Tab. LXXIV. Fig. 1. Rana, Brafilienfis, orbicula. ris, Pipæ fpecies. Tab. LXXV. Fig. r. Rana maxima, virginiana, eximia, rara, fomina. Tab. LXXVI. Fig.
r. Rana, marina, Americana, rara, mas.

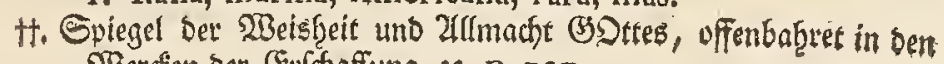
Wercfen Der E.rffaffung, 3.. p. 737. 


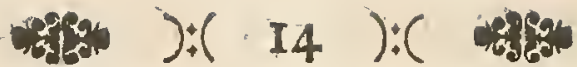

Ridebar nonnunquam ab illis, quibus hanc meam aperueram fententiam, perfrictaque illi contendebant fronte, fe plus fimplici vice vidiffe ranis pluere; quodfi vero ex ipfis quaerebam, vtrum ranae etiam fab eiusmodi pluuia in ipforum deciderint corpora? vel, fe eius rei non amplius recordari regerebant, vel, minus id factum effe, coacti confitebantur; illi vero qui affirmabant, vidiffe fe ranas pluere eodem illo tempore quo in vrbe pluerat, obmutefcebant, propofita quaeftione, qui factum fuerit, vt in vrbe nullae vifae fint ranae? Quod vero ad eorum attinet fententiam, qui autumant, nafci ranunculos pluzios ex imbrium guttis terraeque puluere, quum, fimulac gutta in terram ceciderit, exfultans oriatur ranunculus; nullo illa refelli poteft negotio, ex iam memorata perfecta horum ranunculorum ftructura, tardioreque eorundem incremento. Quodfi tandem fint qui regerant, vix fieri poffe, vt tot ranunculi ex aquis prorepant, quot poft pluuiam copiofifime per terras fparfos cernimus, his ego refpondeo, apparere ex hac illorum obiectione, ignorare ipfos, quod fupra iam indicaui, parere fcilicet vnam tantum ranam foemellam fexies, quin vndecies centena oua; quod quum ita fit, atque $a b$ vna foemella minimum fexies centena oua in aquam eiaculentut, quibusdam vero in locis quamplurimae ranae, atque adeo plures vna habitent foemellae, facile hinc fieri poteft, vt ex vno tantum ftagno vel vivario innumeri prorepant ranunculi ; prorepunt autem prae reliquis tenellae huius fpeciei, de qua hic loquor, tanae, quum in terris multoties verfantur.

Poftquam itaque vidimus quasnam rana noftra terreftris fubeat mutationes, donec perfectam ranae induat formam, ea nunc etiam fun enarraturus, quae ratione vlterioris incrementi ipfius a me funt obferuata. Nutritur rana haec femper, extra aquam vtpiurimum vitar degens, infectis, crefcit etiam prima aeftate in autumnum vsque magnitudine, vbi vero noctes frigidiores redduntur, frigusue ipfum ingruit, reliquis cum fociis, ex parte iain adnltioribus, in aquas recedit, atque tunc aquas praefertim petunt viuariorum pifcinarumque ftagnantes ibidemque fub limo latitantes, in vernum vsque commorantur tempus, illo enim appropinguante, ex hifce fuis eliciuntur rurfus hibernaculis. Sed prodemnt tunc iuniores tantum ranae atque ad fpeciei propagationem parum idoneae, aetate contra maioribus in aqua commorantibus, donec coierint foemellaeque oua pepererint. Illae, anniculae praefertim, de quibus hic mihi potiffimum nunc fermo eft, quaeque nunc rurfus in terra quaerunt de quo nutriantur, in eam interim excrefcunt magnitudinem, vt menfibus Tulio Iunioque, integro nunc, ranae fub forma, completo anno, fiouram 36 ฯab. III aequent. Appropinguante hieme, fub cuius acceffum maiores rurfus comparent, vt latibula denuo quaerant coguntur; proximo vero Iulio menfe, quo duos habent annos, ad Flvurae 37 accedunt magnitudinem. Hac atate deftituuntur adhuc externis fexum indicantibus fignis: omnibus namque alba tunc eft inferior corporis fuperficies; neque etiam rana bima fpeciei propagandae apta eft, quum ne vllum quidem ftimuli cu-

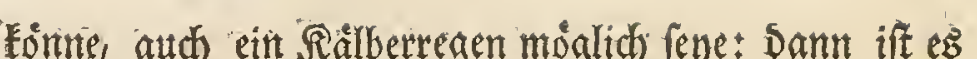
moglich, Dafi in Der \&ufft ein Frofch wach fe, Der mit

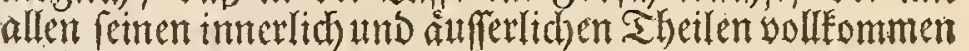
werfebert atmo sie neme Dbrerbationen zeigen ben, dierze

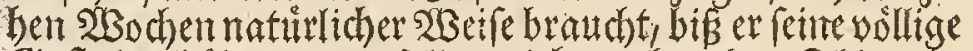
(S)eftalterbsilf, warum folltem nicht aud andere Iftere in eben Der Rufftregend erzeuget werden fonnen?

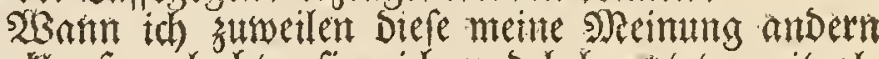

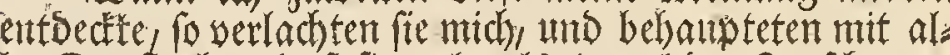
ler Dreiftigfeit, Daf́ fie mehr als cinmal Den Frofdrenen gefebèn batteit; wann ich aber Diefelbe fragte, ob ibnen Dann bey einem fold)en Riegen auch Fróche nuf Den

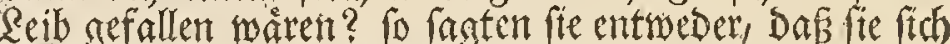

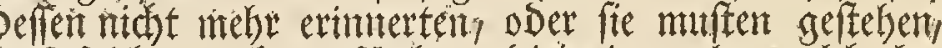

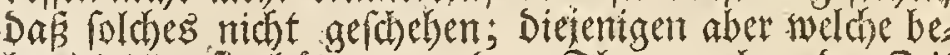
Gantetent fie bitten wor bem Zhor zat eben Der Zeit Frof́che regnen feheng Da es auth in ber Strot gereg= net; wuten mir anf Die Frage, warum Dant in Des Stadt Eeine Froiche wahrgenommen worden? Eeite Intwort zu geben. 2 Bas 1 tum aber Derer ibre snei.

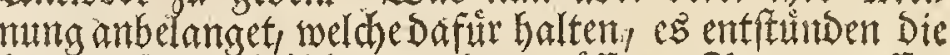
Elemen Segenfrofoche atts Den orofleren Regentropffen

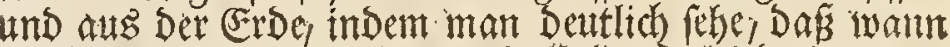
ein fold)er Tropife auf Die Erde falle; fogleth cin kupf:

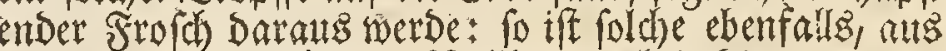
Ser bereits anaefuhrten 20 olfommentheit Dieler łleinen

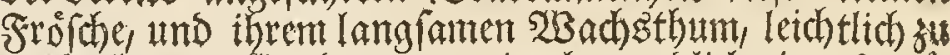
mieserlegen. sibendet man mir aber endich ein eB was

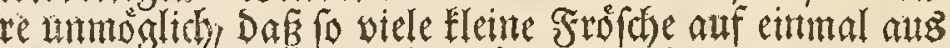

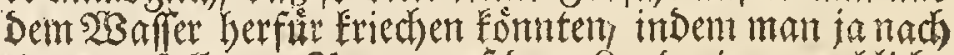
eitum gefallemen Regen auf bem Rand eite unzeglidie Denge wahrnehme: fo mus Derientige, der mit einen

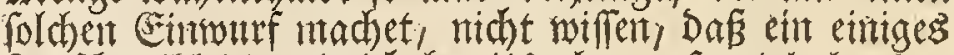
Frofhueiblem, wie th bereits oben gefanet habe, ber fechshunbert, ia ben eilfGumbert (Ever yon fich gebe, Da

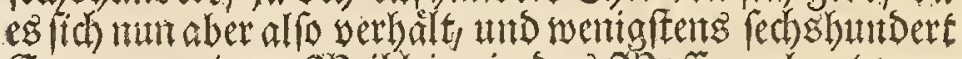
Ener, yon eitrem $23 e$ eiblem, in Das sisafer geleget wors Den in manthen Drten aber fich febr wiel Froiche unto alfo auth mebr als ein 2 seiblemt aufbalten: fo tif es

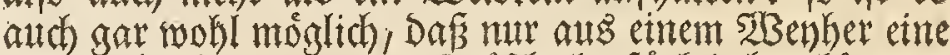

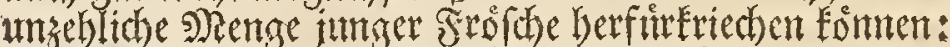

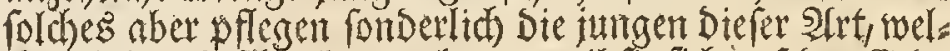

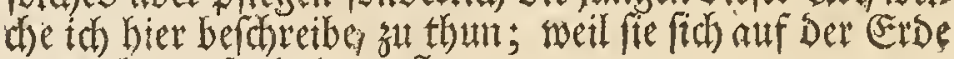
vielmals anfubalten pflegen.

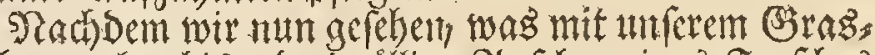

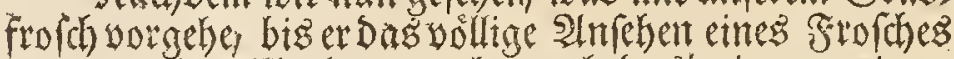
erlantget fo will idf nummebr auch Dasjenise anzeigen,

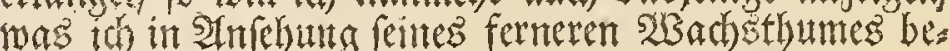
obadstet babe. (Er nobret fid als Frofd) allesett, 1mo

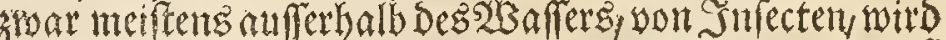
aud nod itm eriten Sommer tmb bis gegen Dent Serbit bith Im ein mercliches groffer, als er anfangz gewefen;

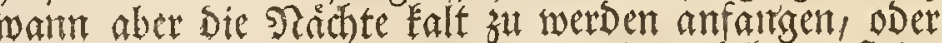
wann fich Der frofte eimftellet, fo begiebt er fich, neb/z fets

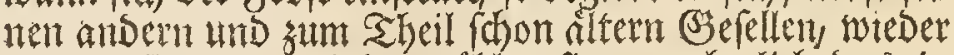

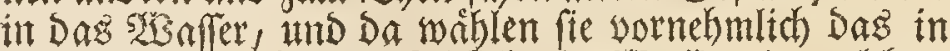
Seichen und Sumpfen fitllifehende $2 B a$ fifer, in weldhem fie fich anf Dem ßoben unter Den Shlam verbergen, bis ft. Der anbrechembe Frithling aus Diefem ihrem sBinter: Guartier wieder herwor locket. Doch gehen alsDautn nur Di: jungen atmo zur Fortpflangung thres (Sefh)lechtes noch untuiditiae Frofdie an Das \&and; Da bingegen Die nlten noch fo lange int sisaffer bletben, bits fie fich gepaaret und De SBeiblem gelaid)et baben. Sente, unt zwar fonders (id) Die jeshrigen, wou weldhen ieztetrentlid, Die SRede ift,

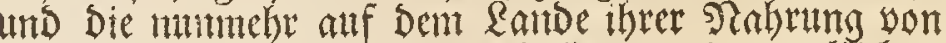
treuem angeben, wadb fen unterbefien um ein merdtidses,

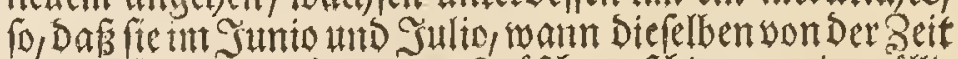

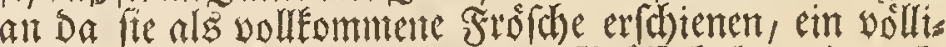

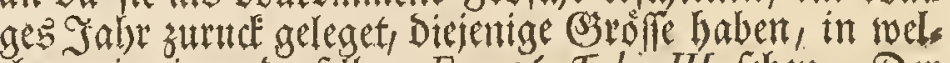
cher wir eimen Derfelben F:g. 36 Tab. III Febent. Der Darauf folgende 2 Sinter, bis zu toldches antunffit fie 
Tab.IV

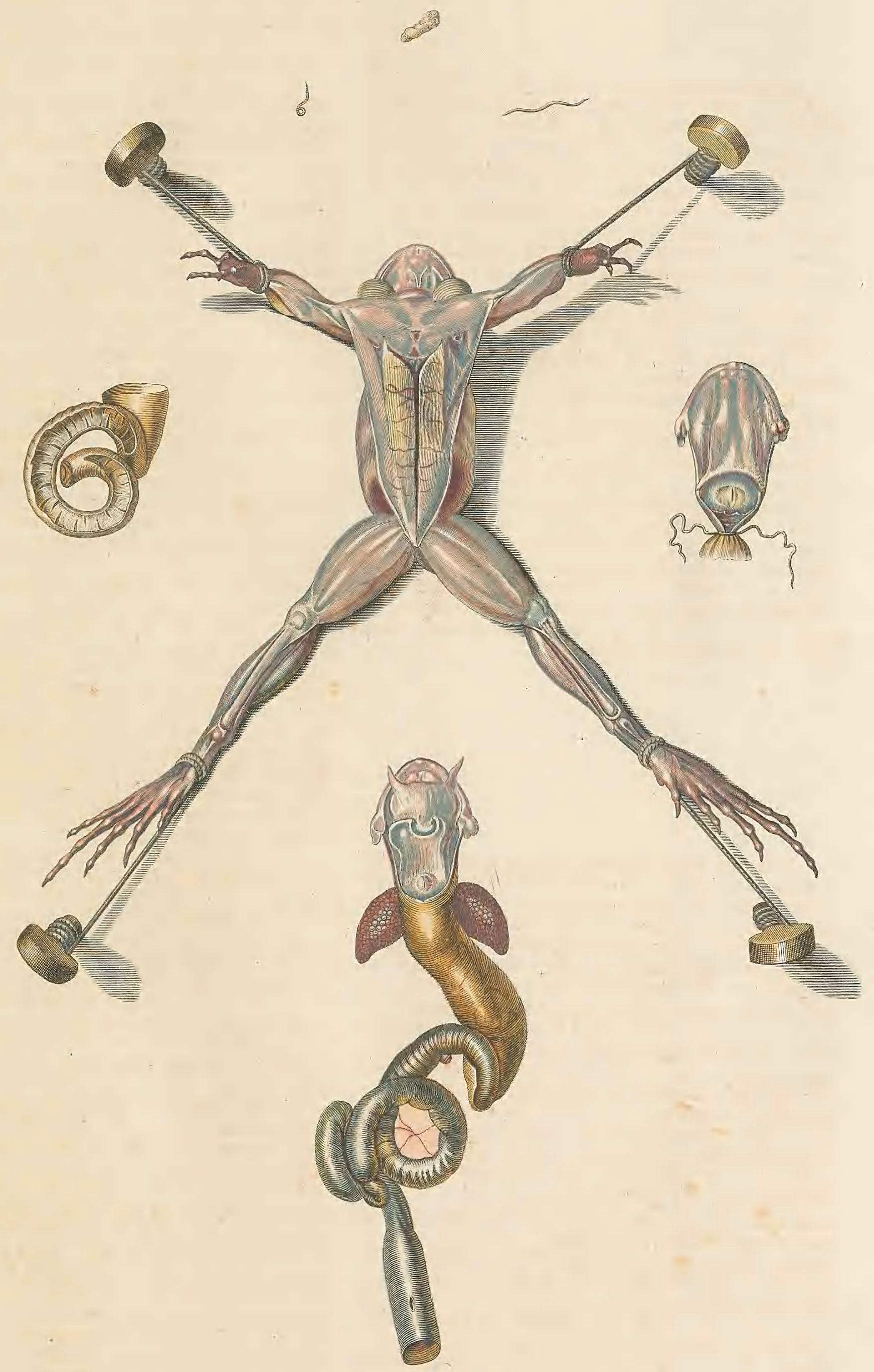

A. I. Rojet f er exe. 



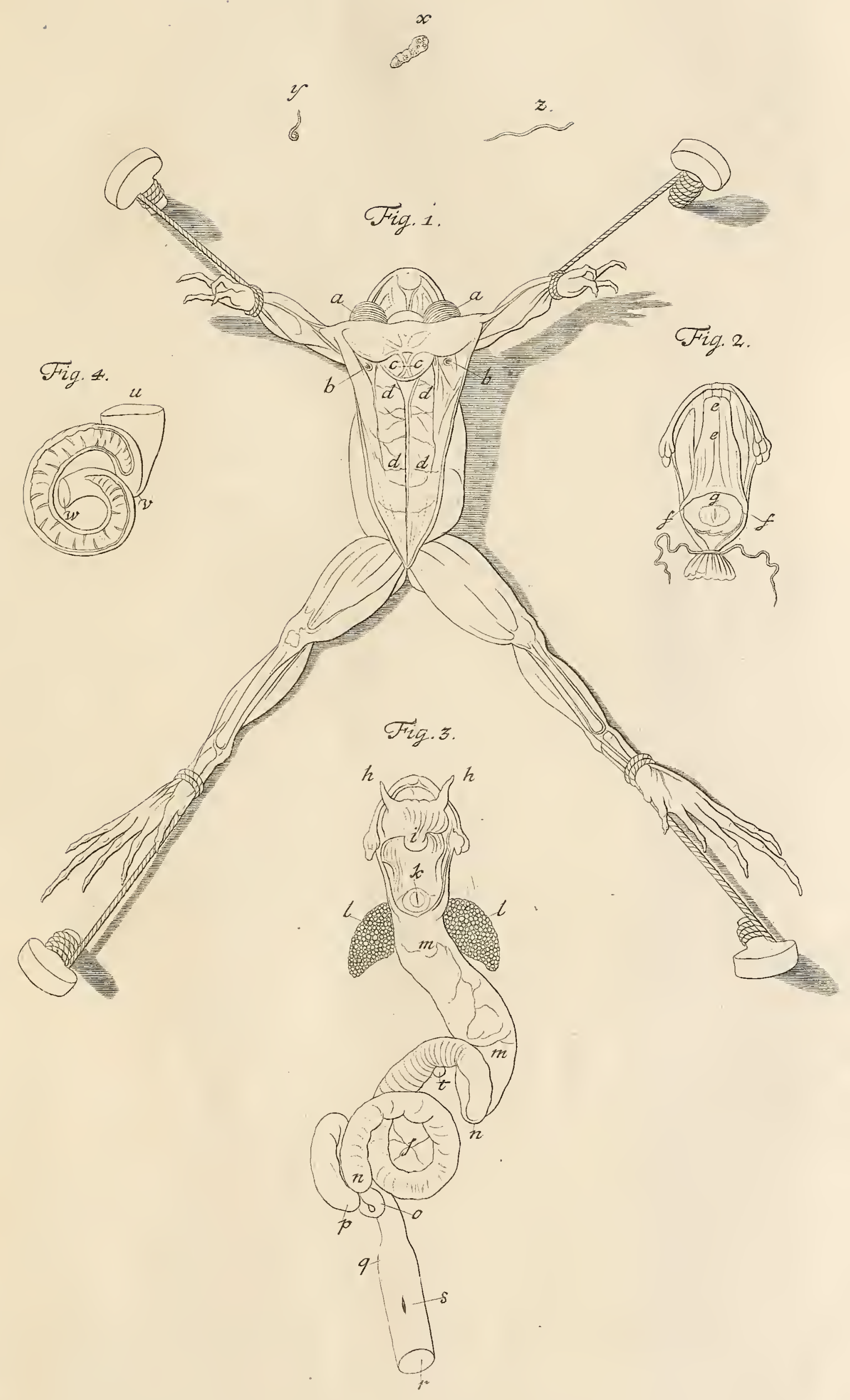





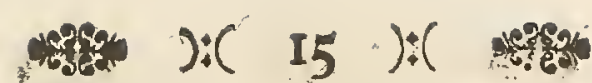

iusdam praebeat indicium, quin licet, tempore illo quo plurimae ranae adultiores coitum exercentes cernuntur, omni adhibita opera in rem hanc inquiras, nunquam tamen huius aetatis magnitudinisque ranam, coịu cum alia iunctam deprehendes, quippe quae non, nifi quartam poft hiemem, negotio huic apta euadit. Quemadmodum itaque animalia quaedam, vt oues, canes, lepores, capreae $\& c$, genus gallinaceum, anferes, anates multaeque aliae aues, primo aetatis fuae anno exacto, quaedam vero, vt equi, cerui, boues, pauones, ftruthiones, aliaeque aues peregrimae, nec non plurimi pifcium noftratium, tertium poft annum ad generationis ojus idonea cuadunt: 'fic etiam rana noftra, tertio demum aetatis anno, eidem negotio 'operari folet. Vbi vero quartum aetatis agit annum, fexus ex fignis externis, fiperius iam indicatis, dignofci poteft: tum enim albent mafculo abdomen atque gula, in foemella vero flauef́cunt partes eaedem maculisque confperfae funt rufis; in illo infuper tument nigrefcuntque, generationis tempore, anteriorum pedum pollices. Monftrant fijurae 38 et 39 binas eiusmodi ranas quadriennes, acfate, elapfo iam gencrationis tempore, a me delineatas fiftitur autem fisura 38 foemella, fis.39 mafculus. Ex acto vero quarto aetatis anno, nondum ranis hisce propius vitae fuae inftat terminus; videtur potius diuerfa earundem, quam paffim habent, magnitudo indicare, viuere easdem duodecim fere annos. Siftit figura 40 maximam, quam vnquam vidi, huius fpeciei ranam, quae vltra octauum aetatis annum vixiffe mihi videtur. Erat illa foeminei fexus, quumque tempore autumnali, quo ipfam delineaui, ouarium ranarum multis denuo repletum fit ouis, hinc etiam huius venter valde tum intumuerat. Depinx vero ipfam hanc ranam non folum ob fingularem eius magnitudinem, fed etiam ob colorem minus vulgarem, ex flauo quippe vndique rufefcens, maculis fere carebat ob fcurioribus; enimuero ea eft inter ranas hasce, ratione coloris varietas, vt centum inter, vix binas reperias prorfus fibi fimiles: quaedam enim fundum oftendunt fufcum quaedam ex flauo fufcum, quaedam ex rufo flauefcentem eumque nunc faturiatiorem nunc lucidioren1; quin dantur maculis fulcis, tigridis inftar, confperfae; aliae rurfus femora tantum eiusmodi maculis variata gerunt, atque onnem hanc varietatem, ipfis in fisuris lil Tabulat, quantum quidem fieri potuit, ob oculos ponere ftudui. Rariore funt ranae $f i s$. 40 magnitudine aequantes, ita, vt vix vigefima quaeque huic fimilis deprehendatur, praeter enim ci conias, aues quoque aliae, pifces, nec non mures ranis infidiantur, plurimas earun dem quotannis deuorantes, ita, vt exiguus earum fit numerus quae mediam fuperent aetatem.

Quum rana noftra fufca terreftris infectis nutriatur volitantibus aeque ac ferpentibus, id quod fupra iam indicaui, hinc etiam, finito generationis tempore, cibi cauffa in terram fefe conferens, maximam veris aeftatisque partem. ibidem commoratur, atque proin ranam fufcam terreftrem nod mebr ant Groffe zugenomment sningt fite wieber fich

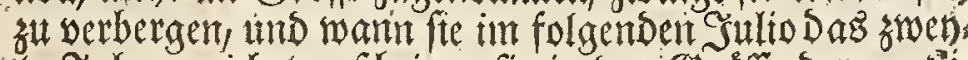

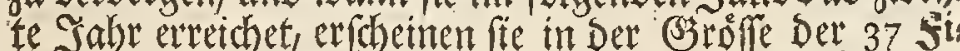

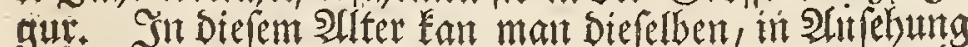

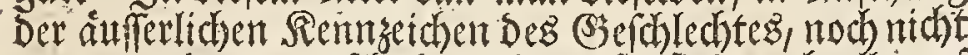

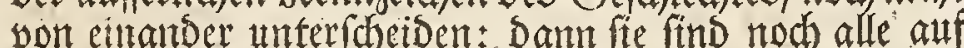

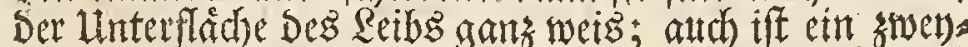

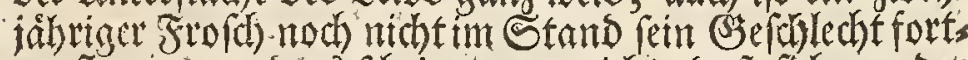

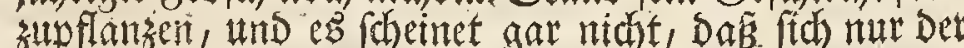
geringfte Zréb Dazu bet ím finde; ja man mag gleidh zu Dertenigen Beit, Da man Die ålten Frofohe in senge sepaaret antifft, nodf fo genau auf fe 2 (a) geben, fo wird man sod niemalen einen Frofd won Diefem aller, und bon biefer (Srófe gepaaref finden; fondern fiemuls fen noch swen sBinter uberleben, ehe fie Dazu tud th

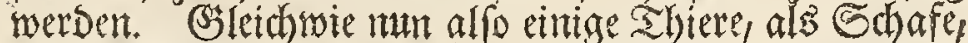
Sumbe, Safer, Rebe, Suner, Săne, Enten, und viele anvere sogel, nad) Berflus cines Sabres zut Paarming tuchtig werbely etmige aber auch em Dreniafriges Suter barsu nothig baben, als note zum Exempel Die sp ferde

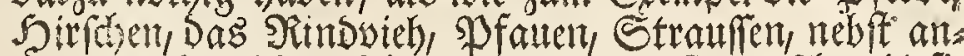

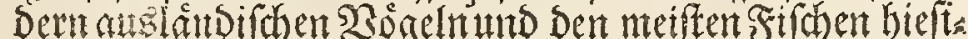
ges Sanses: fop flegt aud uner Frofd erf trad) Dem Drit. ten Sabr Diefem Seforffte obzuliegen; hat er tun aber fein viertes Sabr fait erreichet, fo fan man an ifm Das

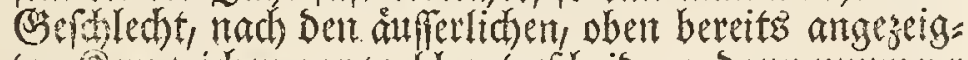

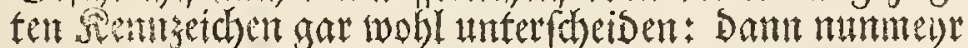

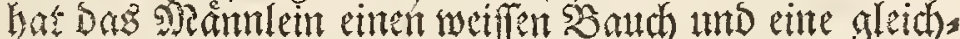
fribtge Reble, Das 5 Beiblein aber ift an Diefent sheilen gelbliobs, und rothbraun befprenget; and fint bentenent

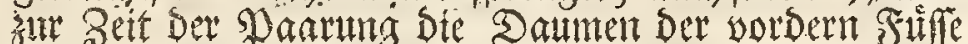
Conary und aufgelauffer. Die 38 und 39 sigur ftel.

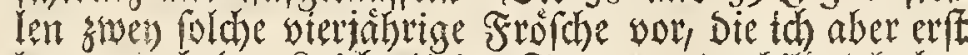

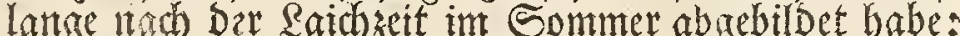

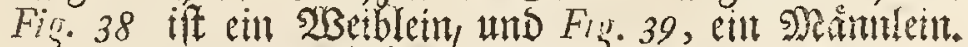

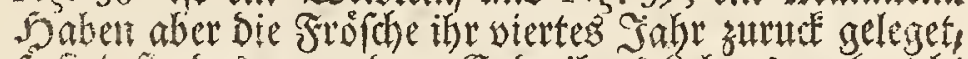
fo find fe Deswegent Dent Ende ifres sebens nod nidht

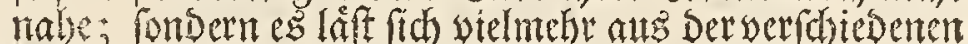

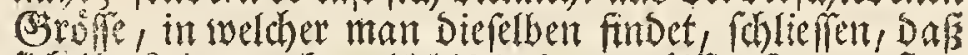

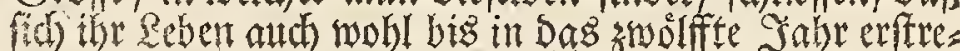
de. Sin ber 40 sigur habe id emen ber grofen fo mir noch zu Gefidgt getomnter, worgeftellet, weld er wobl cin Suter bon inehr als adst Sabren nag erreidet baben.

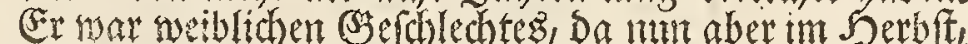
als gut welder Beit id felbigen abgentablet, Der (Ever.

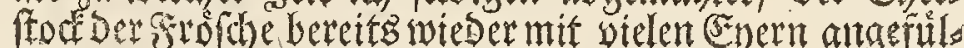

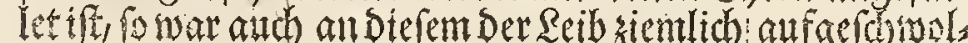
len. (Es bewegte mich aber nid) allem ote befombere Srofle

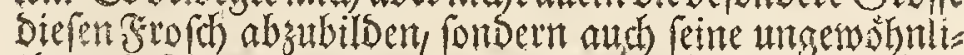
we unto ferene sarbe, indem er namlid uber unb uber gelblich totbbraun ausfabe, und wentg sunde frleden geigte; wienobl aud Diefe Frofhe Der warbe nad fo uns

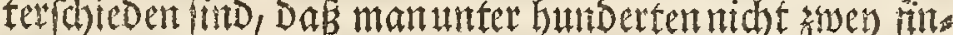

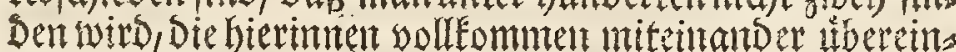
fámen indem eintge cinen Dundelbraumen, eintge einen gelblichtbraunen, unto eintge einten rotblich zelsen Struto fubren, weld er ebenfals bals dunder bald belle: aus. fállt; ja etlidbe find uber und uber gletd einem siger mit bundelen Fleden befprenget; und ben andern zeigen fidh Diefelben mut an Den Diden Sdbendeln, wie foldses an Den funf Figuten unferer IIT Tab. fo sid mógltd) alts gezeiget worDen. Die Fródhe fo Die (Strofre Der 40 Si gut baben/fino etwas feltery und mantwirs toobl ebent Der zwangis andere als einen foldben antreffen, intom felbige, auffer Den Stordhen aud andere 2 ogel, firthe

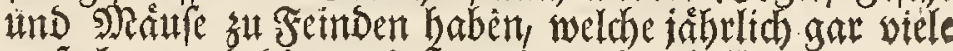
anfobren mo sie wertigfen alf werden lafen.

Da Die rabrutg unferes braunen Strasfrofoses, atts verfobiedenen fliegenden uns Erted enton Snfecten befebet, wie beretts gemeldet worden, fo bált erfich aud,

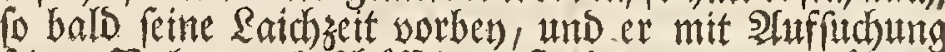
feiner $\Re$ abrung befhaffiget ift, Den gansen Frubling 


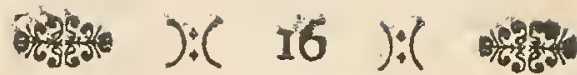

eandem appellaui. Praedam vix v̀enatur, eandem potius praeftolans, nec vllum vnquam deuorabit infectum motta deftitutum. Quodfi vero infectum quoddam confpiciat, immota fedet, vbi vero illud propius ad fe acceffiffe ipfi vide tur, fulguris inftar ad pedis dimidii longitudinem in illud inuolat, linguamque mire conformatam, nec non praelons gam exerens, infectum arripit, integrumque deuorat. Qua ratione hoc peragatur Figura indicat 38 , vbi et lingua apparet, quam mire conformatam effe dixi, quod in ore ranae pofteriora verfus reflexa, anterius ad inferiorem adhaerefcit maxillam $c$; hinc vero eft, quod rana linguam fuam non folum longius quam reliqua animalia exferat, fed eft eadem fic quoque comparata, vt et longitudine et latitudine augeri minuique poffit, humore infuper fcatet adeo glutinofo, vt quicquid ea tangatur illico adhaeref́cat. $\mathrm{An}_{\mathrm{n}}^{\mathrm{m}}$ terius in duas illa diuiditur breues acuminatasque partes $b$, quibus ipfis rana praedam arripere videtur, quae heic quidem eruca eft $a$, quam geometram dicunt. Reliqua hac de lingua dicenda in fequentibus, data occafione, propone. mus.

Porrexi facpits, non fine oblectamento, eitusmodi ranis, quas gramineo cefpidi infidentes in vitris feruabam, mufcas aliaque infecta viuentia, quumque aliquando vn ex illis araneam mediocris offerrem magnitudinis, deworauit eandem rana fimulac illa mouebatur, nèque ipfam illam faftidire obferuare potui. Alii cuidam vefpas apesque porrexi, licetque vefpam illico hauferit, haud tamen ipfi grata erat: iterata enim anxiaque pedum anteriorum agitatione eandem ex ore remouere tentabat, acfi vefpae aculeo laefa fuiffet; quin inueni eandem poftridie in vitro mortuam atque proin vomitu redditam. Ope conuexorum prominentiumque oculorum, facle omnia illa cernit rana, quae vel ante vel poft ipfin fita funt, proindeque praeda aeque ac hoftes illico ab illa conficicintur. Nares anterius fupra os pofitae indicantur Fig. 39 lit. d Pone oculos, inferiora verfus, vbi fufca illa vtroque in latere comparet macula, pedes anteriores verfus extenfa, fedem fuam habent aures, quarum alteram Figura 40 ad $e$ fiftit. Sunt illae tam planæ, vt, nifi diftincto cingerentur circulo, vix cernerentur. Pedes poftici ranae noftrae, natatores aeque ac faltatores dici poffunt: eorum namque ope et natatui et faltui apta redditur. Salti diftinguitur etiam ex parte a bufonibus, quibus quoad colorem haud abfimilis eft: bufones enim vix faliunt, rana contra haecce faltu in altum aeque ac longinquum fertur.

Quum.rana haecce terreftris bufonibus aliquatenus fimilis fit, non mirum eft, multos dari qui eandem virulentae indolis effe putent, licet experientia contrarium prorfus doceat. Notum quippe eft cedere crura pofteriora ranarum in cibum, quamvis vero eum in finem ranae tantum aquaticae eaeque virides eligantur, minime tamen illud curant homines eum in finem ranas captantes, quippe qui et crura ranarum terreftrium, nec non bufonum quorundam, cure detracta, in foro venundant. Accedit huc unt Sommer Gindurd in Dem (B̧ras auf; Diefes abet bat midh berwogen ifm Den Namen bes braunen Sragz frofhes beysulegen. Seme Bette pflenet er nehr zu er:

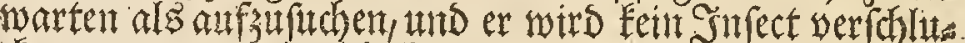

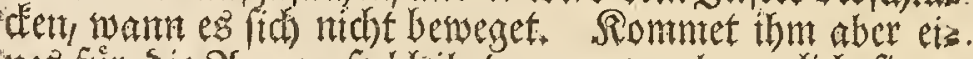
nez fur Die stugen, fo bleibet er gans unbeweglich fiser. bifis er foldes nabe gems zu fenn glaubet, und Da fóbret er auf felbiges, offters einen halben Schub wett, wie cin

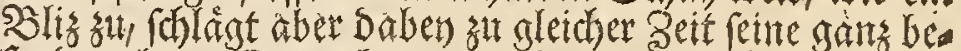

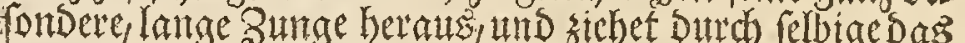
Infect in fetnen soratjen; weld)es er fobann auf emnal werfoblinge. Diefe SIrt Den Shaub su fangen felletuns

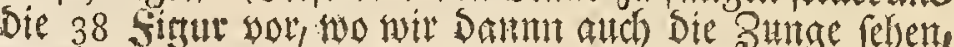
welche ich Destuegen befonder nente, weil fie in Dent sha chen Des Frofthes medewoints lieget, uns yornen ber $c$, an bem untern Siefer angewachfenift; Diefe Eimrichtums

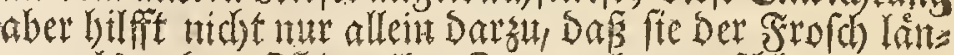
ger als andere Shiere ihre Zungen herausichlagen fan,

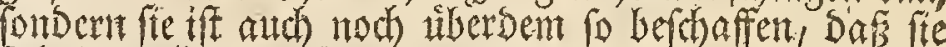

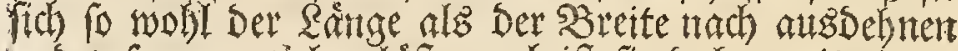

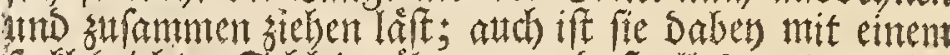
fo flebrichten Shleint libersogen, Das alles was bon rels beger berubret wird, fo gleich Daran berangen bleibet. Sonnen ben b theilt fie fich in zwen Eurze Spizen, tuns mit felbigen fohemet ber Frofó feine seute zut umfafien,

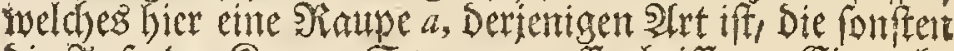

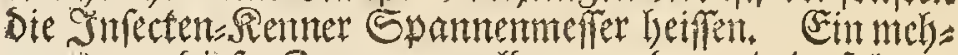

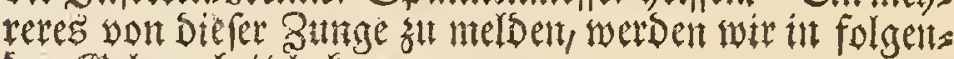
Den Seleacnheit bofomment.

Jah babe mir offers Das Dergmigen gemadyets

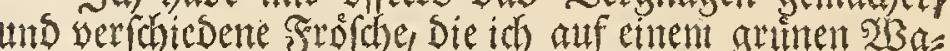

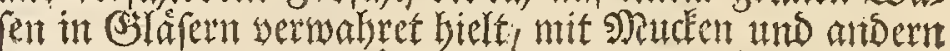
lebenten Jufecten geftittert. (Einzmals reidete the einent Derfolbian atch eme mittelntiofige Spime Dar, weldhe Der Frofd fo gleich), als fie fich zat berwegen anfieng, bers

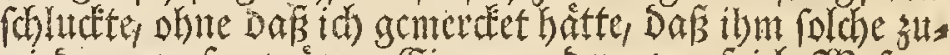

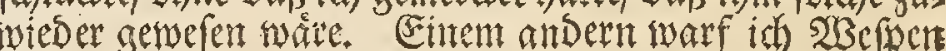
unt SBenen yor: Die $23 e$ fipe aber wollte felbigen, ob er fie gleidh werfhludte Dod nicht anfteben: Dann er bes

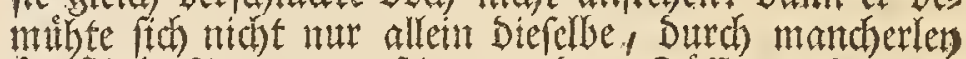

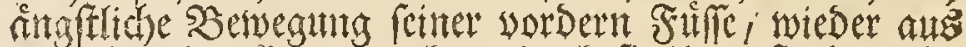

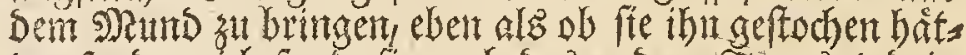
te; fondern th fandefie ald bes altoern sages tod in

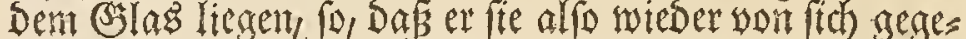
ben batte. Durd Soliffe feiner erbabenen und frare

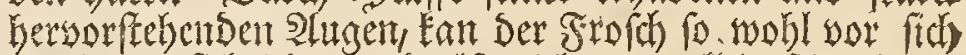

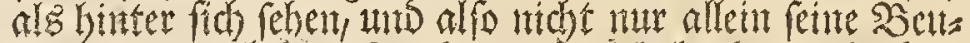

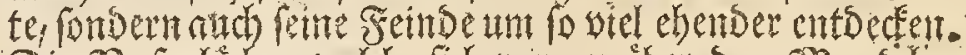

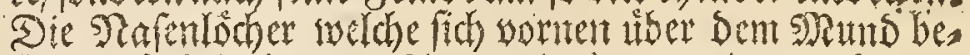
finoen find int ber 39 Fitur ntit $d$, angezerget. Sinter

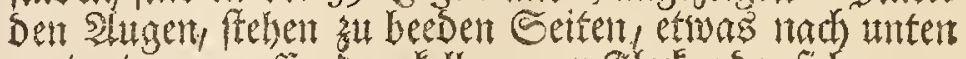

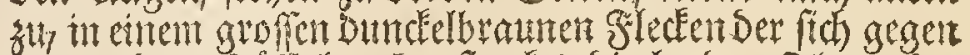
die botbern sinte herab erftreftet, Die beeden Dhren Des

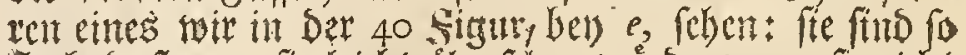

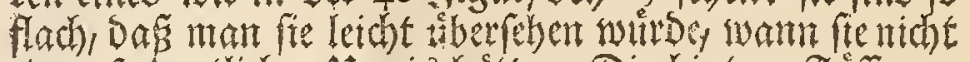

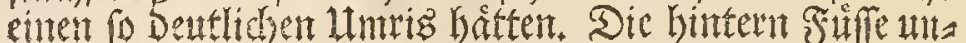

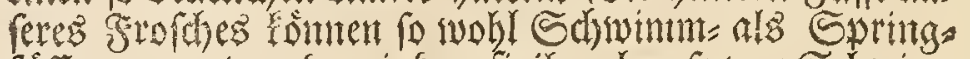

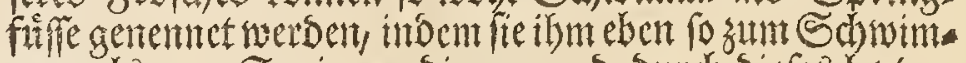
men als zum Exringen Sienen uns Durdh Diefes lestere untericheroct or fich auth entiger maffen you Den Siro= fen mitweld en er fonft ber Franbe nad siemlich liberein: Eonmet: Daun biefe pringen faft gar nidgt, unfer Frofh hingegen madht rehr hohe into weite Epringe.

Da Diefer (S) tasfrofo Den Sroten in etwas gleichet,

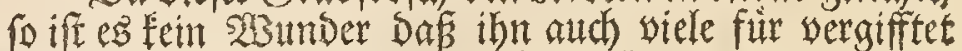
halten; unterdefiten lehret Dodh Die Erffahrung ein gants

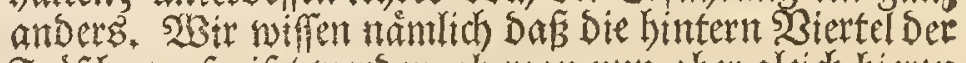

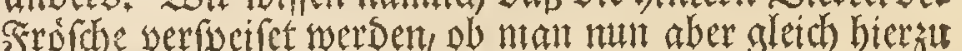

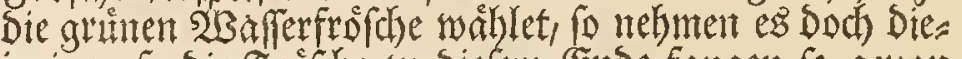
jentigen fo bie Frofeche zul biefem Ende fangen fo genta

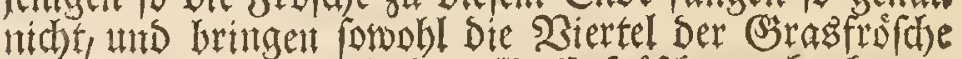

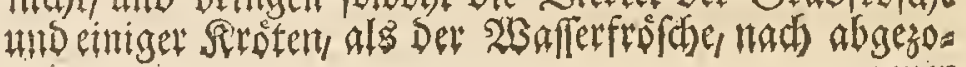




\section{2.}

quod verno iam tempore hoc utamur cibo, quo ipfo rana aquatica, in aquis adhuc latitans, nullibi apparet. Vidi id hoc quoque anno: quum enim Martio iam menfe, ob foles continuos, calidiore fruerenur tempeftate, plurimae e latibulis fuis eliciebantur ranae terreftres, noftroque in foro vendebantur, nunquam tamen audire me memini, quemquam ex efu illarum damni quicquan cepiffe; quodfi vero venenatae effent, comeftae vomitu filtem reiicerentur. Id porro hac de rana notandum eft; illos qui gammaris fluuiatilibus captandis operam nauant, cumque in finem ranis vtuntur excoriatis, ranas tantum adhibere terreftres, quum gammari non nifi has appetant. Quod reliquum eft, ranam noftram terreftrem, ranam appellant mutam, quum non aeque ac rana maior aquatica, etrana viridis, canora fit; quam tamen ob cauffam prorfus muta dici non poteft: qucmadmodum enim mares tantum ranarum vocalium, \& alio tempore, \& illo quo coeunt, vlulatum eiiciunt, atque hinc, PLINIO * referente, ololygones vocantur, fic haec quoquefpecies, coitus praefertim tempore, nec non vbi turbatur vexaturque, vocem edere folet; quae tamen parum clara eft, atque ab aliarum ranarum -voce facile diftinguitur, quum non coaxcnt fed potius grunniant. Nec mares tantum hanc mittunt vocem, nam et foemellas eandem nonnunquam, rariorem tamen fubmisfioremque, edere notavi.

Haec erat fumma mearum hac de ranarum fpecie obferuationum, quun et partium internarum, earum praefertim quae ad generationis negotium pertinent, ftructuram curatius eram examinaturus; fed ranam eum in fincm apcrturus, incifa cute, eandem a mufculis fubiacentibus facile ex parte feparari animaduerti, atque hinc onnem detraxi. Hoc peracto non nulla obferuaui notatu digna, quae; vtranamhanc ab inferiore fuperficie depictam quart $a$ in Tabula, nunc perluftranda, exhiberem, me permoverunt:

Siftitur autem hacin tabula Fig. $r$ delineatio ranae maris, quem quoque binae illae indicant veficae ad inferioris ma xillae latera pofitae et litteris a a fignatae, quae non nifi in rana vlulante, vel vbiaere per os naresue impulfo fufflantur, in confpectum venitnt. Quodfi cute detracta propius confiderentur, ex fibris carneis transuerfalibus compofitas esfe patet, quumque rana vlulans easdem inflet, illam in emittenda voce omnino iuuare videntur. Foemina tame quae, quemadmodum iam dictum eft, fimilem vlulatum eiicit, iisdem caret, vt itaque marem tantum veficulac hae indicent. Nulla ceterum alia ciusmodi in rana, cute detracta, cernitur, quod ftructuram attinet externam, differentia, fi pedes excipias, anticos aeque ac pofticos, in rana mafculo torofiores.

Quum prima vice ranae foemellae hujus fpeciei cutem detraxiffem, in vtroque Thoracis latere, fingularem quandam eamque paruam, non fine admiratione, obferuaui

aper- gener Saut zu SRardét. Dazu tommt auch noch Dafi man Diere Speife bereits im fruthling genteffet, Da boch

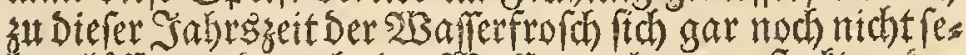

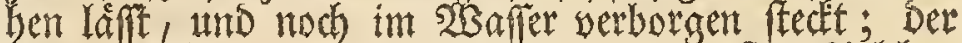

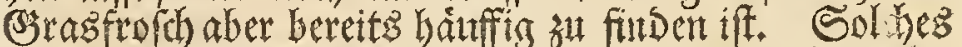
babe id) audh in Diefem Sabr wabrgenommen: Dann ba

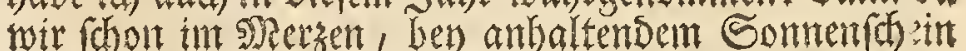
stemlich warnez sBetter hatten, fo Eamen Dte Srabf:

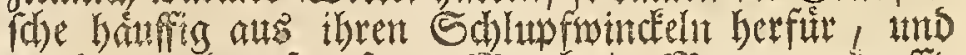
wurben and anf tnferem sidardt in soenge vertauff, unterbefien aber weis ich nitch nitht zu erimern, tentalsges

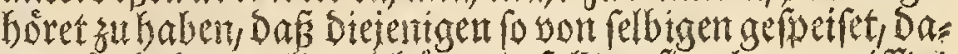
bon Sobaden gelitten hatent follen fie aber bergiffet (e) it, fo mifte fich folches, ben Dententsen bie won Der= gleiden frofoden genofen, wentgftenz Durch etn Erbre=

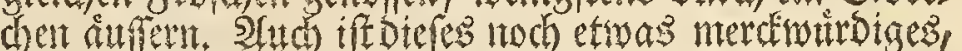
Dafis Dieientgen welde Den Serebsfang treiben, ant fith zu Derem Ende ber Froffhe bedienen, Denen fe borker

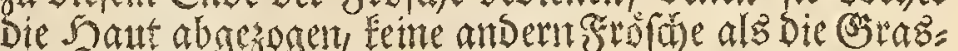

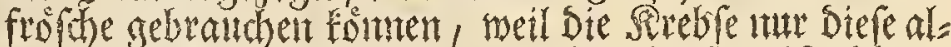

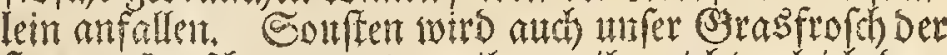

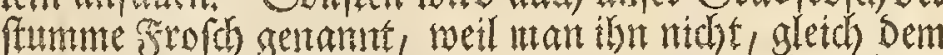

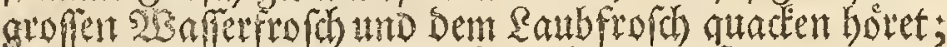
allene er ift Desiwegen Doch ntht gant ifuntm; Dann

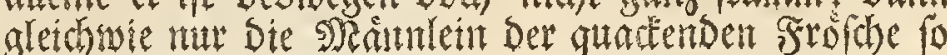

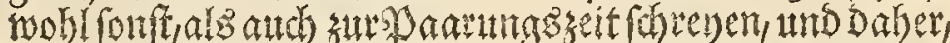
wie plinins * faget, Ololygones genamtwersen, fo plegt

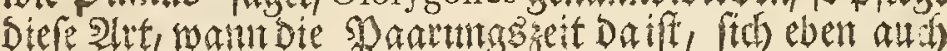
uns want fie etwann forft beuntulgtget witrs, hoven su

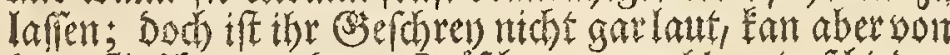

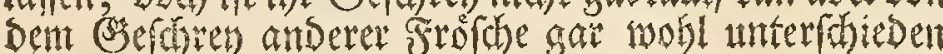

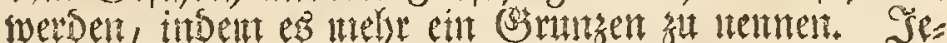

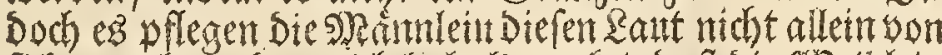
fich st geben: Dant idh habe bentertes, Das bie sibeiblent

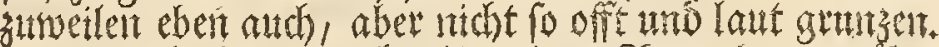

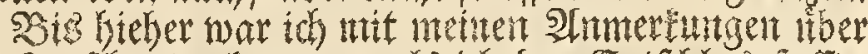

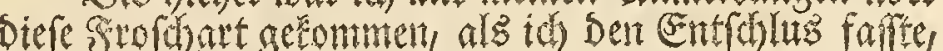
and bie minem sobile, fonberlids aber biejentgen fo

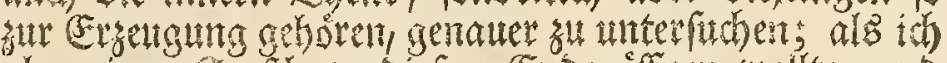

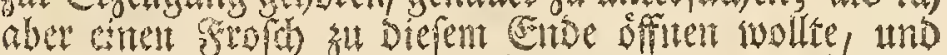

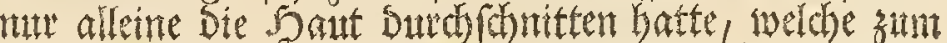

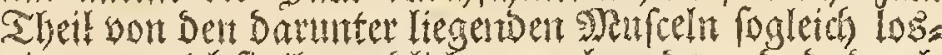

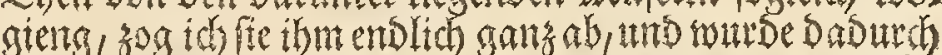
eit tun antors gewahe, welches befonoers angenterter zu werden serdientet, Daber habe id audh Diefen strofd yon Der mtern Sláthe, auf Der $I V$ Cabelle, in oev eriter Figur abgebildet, unt Diefe wollent wir nut betradien.

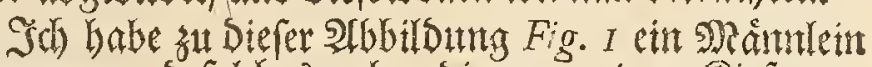
gentummen, und folches geben bir ant uttern setefer zH becoen Seiten befinoliche smen gla en zu ertemen, Die mit a a beseidonet fitto, fich aber foutfen ant stofoh mint zeigen, als want er forenet, doer utan ibn in Den Inumb, ober and Durd etn Seafentoch, Eutfe emblafer. Setrachtet man fie, fo aufgeblafen, wab abgezogente

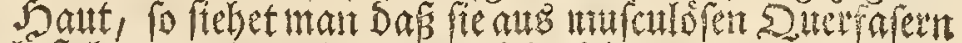

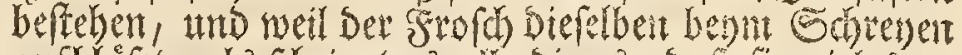

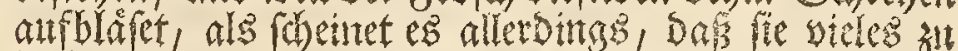
Dierem saut bettraben, wiewold fie ant bent SBetbleit, weldbes, wie oben gemeloet morben ebenfals sumeilon

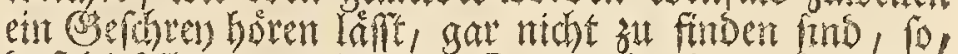

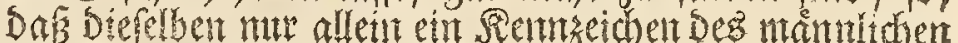

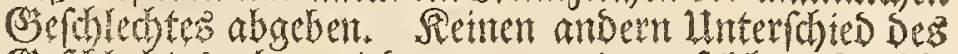
(E) efoledites aber wird mant an einem foldhen Strofh nad) abgezogeter Sout, was die åtferliche Structue anbelanget, ntd) wahritebmen, aufer Daf am Nains

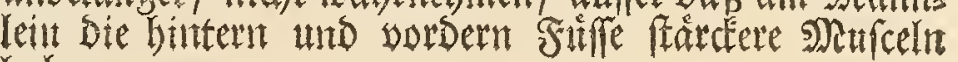
habent.

218 ich Das erfental eitem fold)en Frofth, welcher ein 23 eiblein war, bie Saut abgezogen batte, bemerces. te id an beeden Seiten Der Pzrufteme befondere fleine

"Nat. Hift. Lib. XI. Cap, 37. 


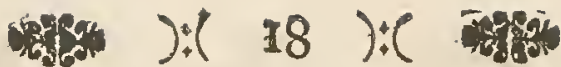

perturam, quam litterae $b b$ indicant. Cogitabam illico quum illas confpiciebam, numne illae fortaffis effent aperturae, per quas, ex eorum fententia qui nobis perfuadere fatagunt, concipere ranas per thoracem, femen ex pollice maris tumente, quem ipfi huic loco apprimit, in foemellae corpus transeat. Res itaque haecindagatione dign mihi videbatur; licet vero eum in finem plures ranas excoriauerim, multaque opera canalem illum quaefiuerim, qui hoc in loco, vti quidem credeebam, aperiretur, femper tamen vidi, mufculis illis qui aperturam hanc cingebant feparatis, effe illam nil nifi ipforum horum mufculorum interftitium, non folum in rana foemella, fed in mafculo etiam femper confpiciendum: quin nulla prorfus aderat apertura; tegebatur enim interftitium hoc tenui illa membrana, qua omnes mufculi generatim obducuntur. Quodfi Auctor fententiae modo relatae, hoc aperturam mentiens vidiffet interftitium, nullum eft dubium, quin eo ipfo ad firmandam illam fuiffet vfus: adeo enim de hoc fuo inuento gloriatur, vtomnia illa quae alii hac de re, quam ipfo curatius rimati funt, fcripfere, tanquam mere falfa prorfus reiiciat: quum enim non ignorabat, extendi huc vsque in ranis foemellis vteri tubas, vel ouiductus, practereaque perfuafum habet, inferi illos thoraci, nil nifi aperturae corum deerant.

Indicant litterae $c c$ in prima bac figura, fternum, quod vnacum carti lagine fuia dimidian circuli aream refert, in cuius medio os ipfum fterni crucem format. Ambo itli ab offe fterni, os pubis verfus excurrentes mufculi $d d$, $d d$ fignati, funtmufculi, quos rectos vulgo dicunt; reliquarum partium mufculofarum, hic quoque confpectui fe fiftentium enumeratione fuperfedeo, quum mufculorum ranæ defcriptionem minus fim daturus.

Quemadmodum vero in rana, cute non detracta, ne tantillum quiden membri genitalis in regione pubis cernitur: fic etian detracta illa nullum eiusdem adeft indicium; hine autem natae videntur fingulares illae de generatione ranarum, fub initum ftatin huius hiftoriae, relatac fententine, quas auctores illarum vix fuiffent propofituri, fi cogitaffent, plures dari creaturas, nullis genus diftinguentibus et ad generationem feruientibus partibus externis praeditas, vt lacertas, ferpentes, pifces omnesque aues; quae tamen interius iisdem omnino funt inftructac, aeque ac ranac, vtiamiam pofteriori in capite fumus oftenfuri, in quo infuper Lector beneuolus, et reliquarum hac in tabula exhibitarum figurarum inueniet defcriptionem: quas namque repraefentint, ad internas ranae referendae proprie funt partes, de quibus eo ipfo in capite fermo mihi erit. Prius tamen quam hunc inftituam, tres addendae funt obferuationes, ad hoc caput fpectantes, quasque habui, prioribus huius Hiftoriac naturalis foliis iam impresfis. Prima ad generationem attinet ranarum harum terrefrium; fecunda ad oculos; tertia ad appendices iilas fimbriatas gyrinorum, quarum fuperius, p. 8 et 9 , mentio fuit facta.

Quod ad primam, gauifi fumus fub initium huius 1750 anni, ob foles continuos tempeftate fic fatis calida,

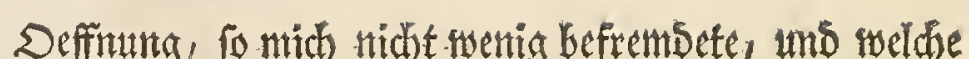
Durch Die Southftaben $b$ angebentet wirb. Es fiel mie bev Erblictung Derfelbigen fo gletes eitt, ob fie nicht ets

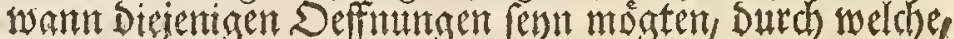

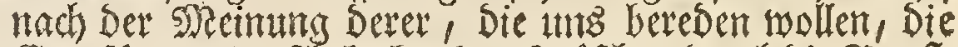

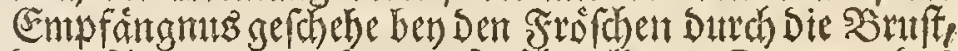
ber Saame atts Den allfarenindlenten Daumen Des Marnteins, welche es eben an Diefem Drt anleget, in Des 2 Beibleins Reib Fomme. Die Sache mar alio cimet genäuern Unterfitchung werth; alleine ob ich Deswegen gleich ntehr als einem Frofh Die Saltt abgezggen, hind

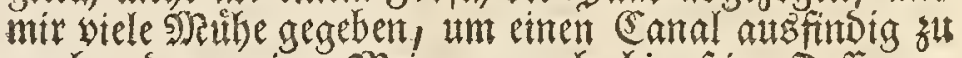
machen Der, meiner Meintng nach, hier feime Defintng hatte, fo fants idf Dod alleset, nach 2tbronderung Der

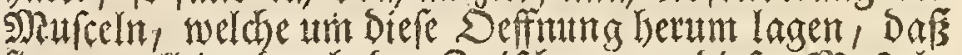

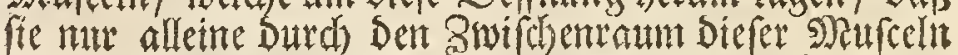
formiret wutroe, und Dafi fie Dem 2 Beiblein nicht alleine

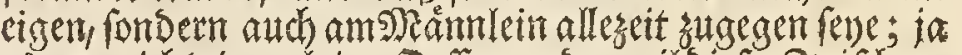
es war nid) teinntalcine Deffinung Dajweil Diefen 3 wifhens

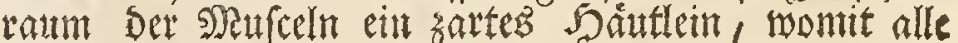
Noufelin 1iberbaupts cibersogen find, bebecte. Shatte Der Sluctor obiger Neinuth Diefent eithe Defintmg wors

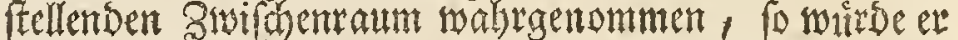

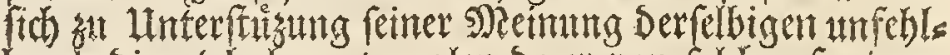
bar bedienet baben, zumalen Daer yon foldher fo einges

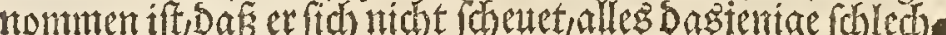
teroings alz falfón su vermerffen, was anbere Das yon gefhriebent Die viel befer als er bie Sadhe unterfita

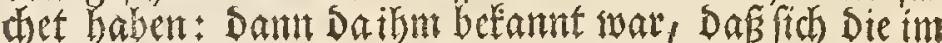
Frofohweiblein an Der Mutter befindliche Ẽyergânge bis bieker enfereden, fa felbiger nod) Dagut glaubet Das fie in Die Soutt Der SBrutit giengen, fo fellte ifm mur nod) inge Deffintmg.

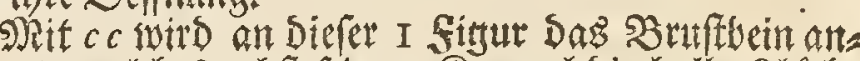
gezeiget, welches nebfit feinem Antorbel bie halbe Fladje

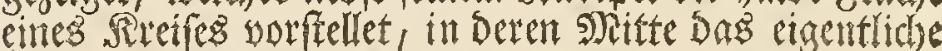
Seit eit serfboben Sircts formiret. Die won Diefen S3rutbein bis an baz Sdambeinfich erferectende beebe nit $d d, d d$ beseidntete Nufeelit, fims Die fo geriann ten geraben s)ufeln; Die ubrigen fich bier zetgente mus

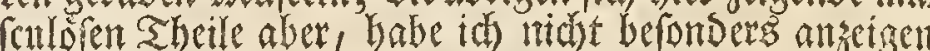

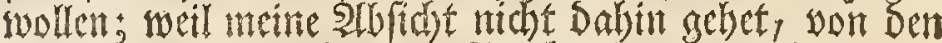
Nufceln Des frofdes cine sechreibung zu geben.

ED wettio mon fonften all eimem erofor Der feitte Saut noch hat, ttm Die Segend Der Schant, etwas son einent Sentungsglied wabrnimmt: fo wentig fielset mant aud yon ferbigen nad) abgesogener Saut; Diefes aber nag wobl sut cintgen, Gleid anfangs anteftibrten

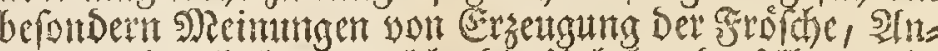
lns gegeben haber, weld)e de unbeber Derferben nicht fo fuledst him mirson worgetragen haben, mann fie

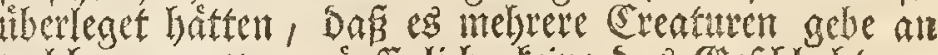

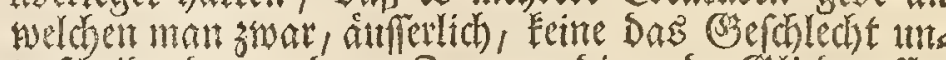

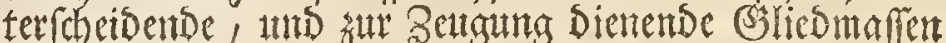
findet, suie zunt Exempel an Den Enderen, Sdylangen,

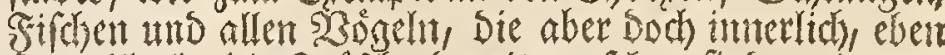

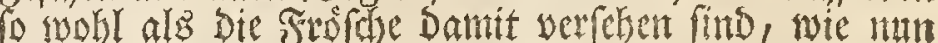
rogleid in Dem sweuten Capitel folf gezeiget werden, in

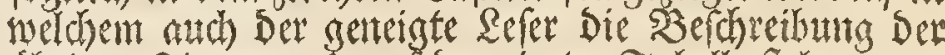

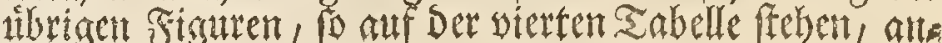
treffen with, weil fie eigentlich zu dent innern Sheilen Des frofhes gerbert, wott welchen ich mit in felbigent

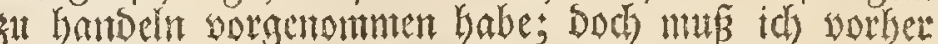

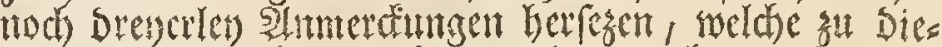
fem Eapifel getoren, atmo yon mir gemadyet worden, ba bie erften sogen biefer nafurlichen Siftorie beretes abs geduttet waren. Die eine betriffe Die \$aarung Diefer

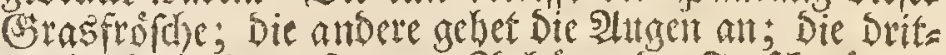

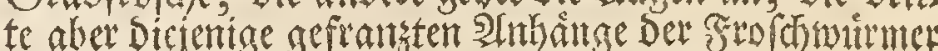
won welchen oben $\mathfrak{B l}$. 8 1t. 9 Neldumg gefhehen.

2Bas Die crfte betrifft, fo haben wir in Diefem 1750 Sabibals anfange,ben anthaltendem Sonnenfocin 
Tab. V.

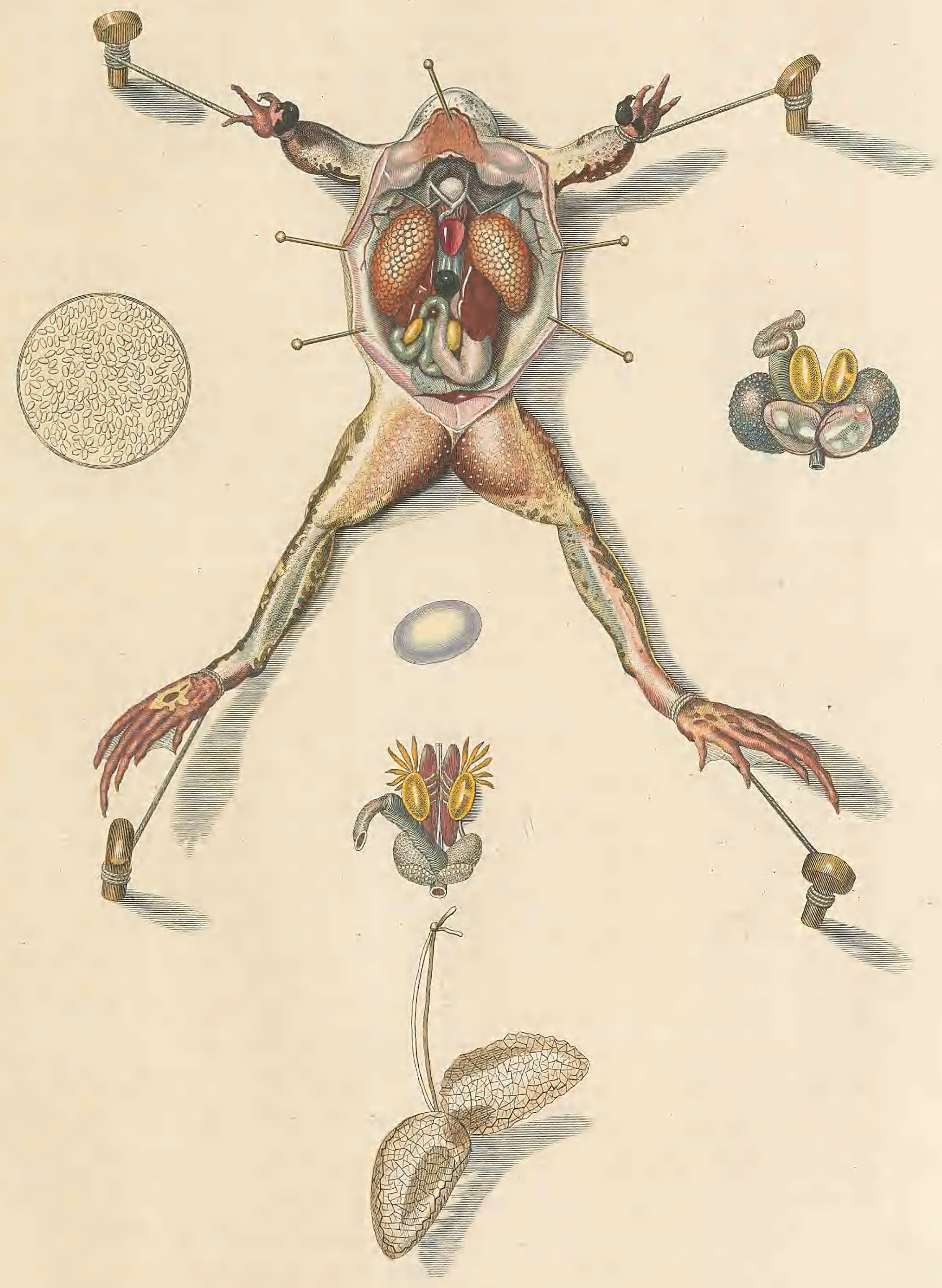

A.T. Rojel f.et exc. 

Tab V

Fig.1.

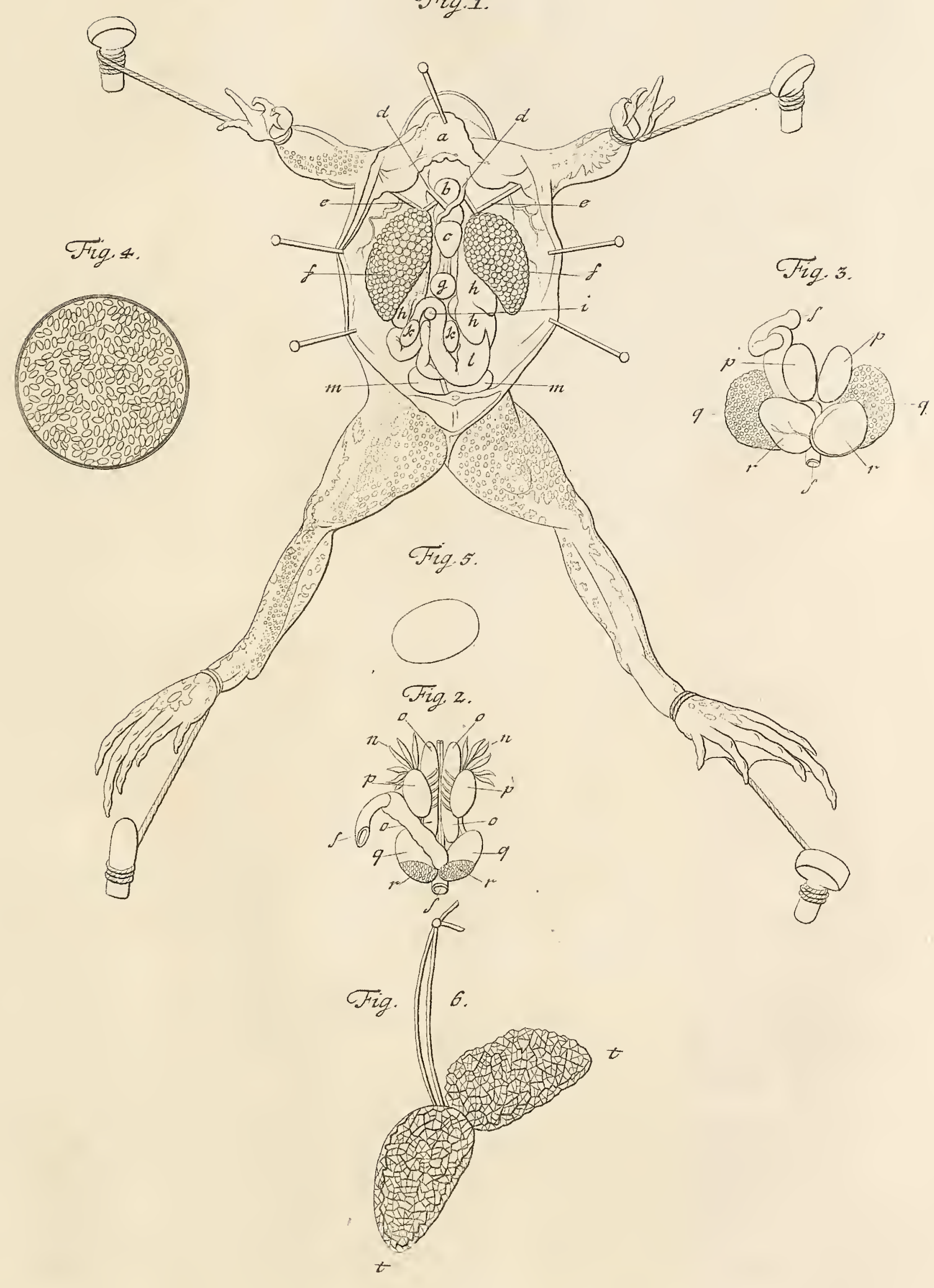





\section{-}

quumque hinc rānae noftrae terreftres, folito citius exhibernaculis fuis, vel limo aquarum, elicerentur, eas iam die quarto quintoque Martii menfis copulatas non folum inueni, fed vidi etiam, die feptimo atque octauo, fperma illarum aquis innatans. Data fic occafione denuo omnem impendi operam, vt, qua ratione generationis perficeretur negotium, diftinctius cernerem. Vidi itaque iterum, foemellam pofticam corporis fui partem nonnihil motantem, mafculumque officii fui quafi commonefacientem: hinc defcendebant copulati adhuc in fundum, quumque hoc facto mafculus pofticam corporis fui partem iteratis vicibus ad foemellac anum admouiffet, mox haec fperma fuum emifit, ita vt momenti fpatio omne illud, maflae inftar, fundo vafis incumberet. Dereliquit tunc mafculus foemellam, amboque celerrime ab inuicem feceffere. Solent nonnullae foemellae fperma ad digiti craffitudinem fimul ac femel eiicere; interquiefcunt aliae, horae fpatium partu confumentes.

Qui auem propius confiderauit, non potuit non videre, inftructum efle oculum eiusdem membrana tenui, qua omnem oculi globum, quaqua patet, cooperit, quamque membranam nictitantem, germanice cum celeberr. ZORNIO * das Winckbaeut leiri, appellant. EAt ranis finilis fere membrana, quoad ftructuram tamen paulum diuerfa, quam, aquae immerfae, ab inferioribus fuperiora verfus mouent, oculoque fuperinducunt, quemadmodum, in rana in vas vitreum aqua repletum immiffa, quilibet facile cernere poterit. Eft vero nembrana haecce adeo pellucida, vt rana fub aqua etiam, vifu fuo, quantum quidem eo indiget, vti poffit: quae enim in aquis propius ad illam accedunt, ea facile euitat.

Dixi fupra quum de appendicibus fimbriatis gyrinorum agebam, quas in branchias abire SW AMMERD AMMIVS autumat, me non concipere, quennnam branchiae hae, quas meis in gyrinis non reperi, ranis, pulmonibus minus carentibus, praeftarent vfum. Nunc aliter de illis fentio: inueni namque aeftate elapfa in gyrino butonis, adeffe, praeter veficas pulmonum, branchias hasce; de quibus tamen alia occafione, praefertim vero in ipfa bufonum defcriptione plura fum dicturus.

\section{SECTIONIS I.}

\section{CAPVTII.}

\section{PA}

PARTIVM RANAE FVSCAE TERRESTRIS INTERNARVM, EARVM PRAESERTIM QVAE GENERATIONI INSERVIVNT DESCRIPTIO. cet priori in capite multis oftenderim, coire ranam noftram terreftrem poftica corporis fui parte, haud tamen fuperuacuum crediderim, fi et partium internarum generationi inferuientium deferiptione id ipfum confirmauero, quum CHARLETONVS, aeque ac MENZIVS, ad confirmandam fententiam fuam iisdem vfus fuerit argumentis. Quum vero bini hi viri ea tantum in ranis diffectis quaefiuife videntur quae fententiae fuae giemlich warnes SBetter gehabt: Dasurth abet wutben

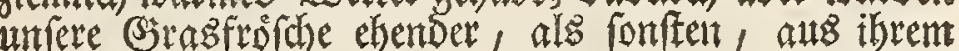
IBinterquereter, ich meine aus Dem Sd) lam unter Dem WBafer, heratte gelocket, wie id fie bann nicht nur Den bierten und funfen Ners bereits gepaaret fand, fon: Derit ich fabe ritch fechon Den fiebenden und achten then

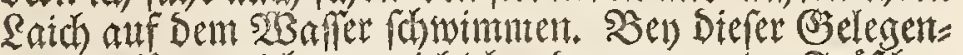

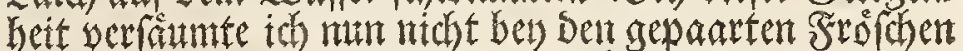

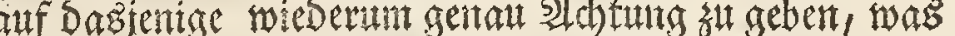

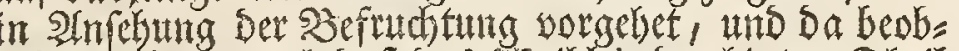

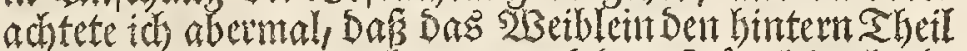

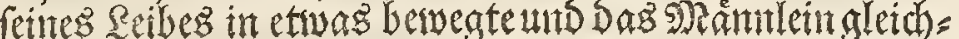
fan feines simtes erinturte bierauf begabent fie fid fo

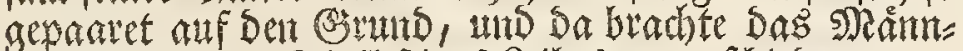
lein Den hintern Theil retnes Reibes zat yerfhiebentenntas

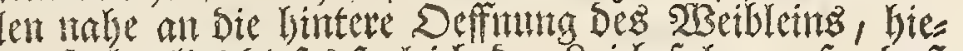
rauf aber lies Diefes fogleich Den Saich fabren, fo, Daf er imterbalb einer SDimute aller auf Dem 30 bett, in ei= nem Rlumben benfammen las. Nadhoem Diefes gefdes

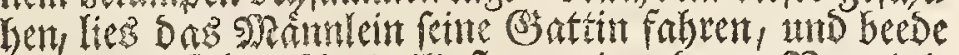
entfernten fich auf Das eiliafie soneinatioer. Bon einte

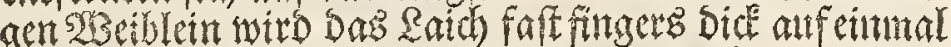
aus Dem Reib heraus getrteben, andere aber fesen Da zwifhent aus, und britget foft eine Stunde Damit zu.

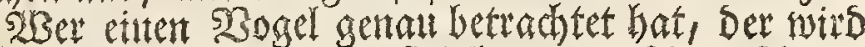
malurgenonment haben, baś felbiger an feiten 2 lngen

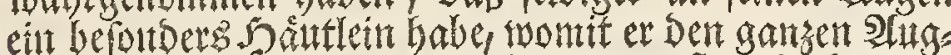

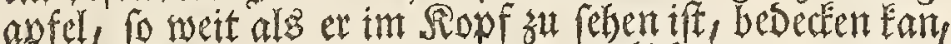
welches Serr כorn * Das WBintharutleit nemet:

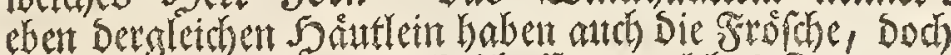
iftes hier etruas anders befthafien, welches fie, want Diefelben unter Dent $283 a f f e r$ fito, wont unten gegent dbent

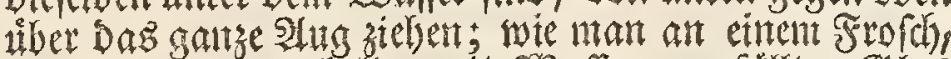

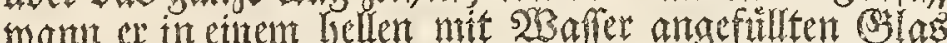

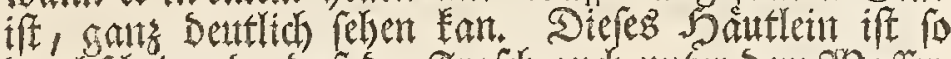

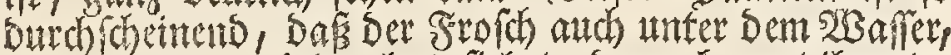

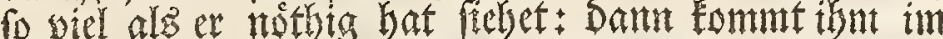

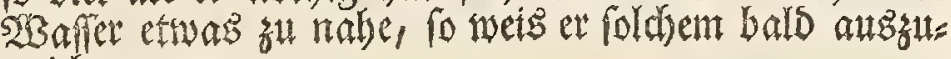
weidbert.

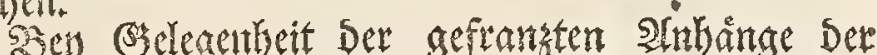

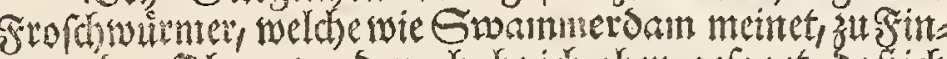
then ober Shien werden, habe tó obent gefaget, Dasich

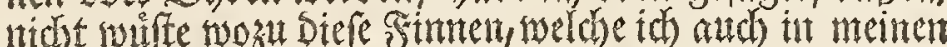

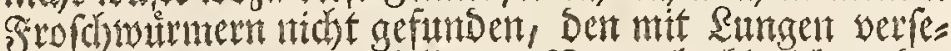
benten frofdien bienen follten. Sammebr bin id andes rer sneimutg: Sant als idh in biefem Sontumer einenets

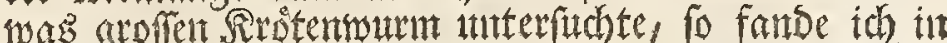

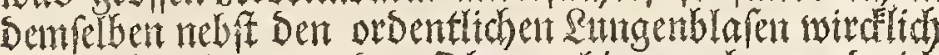
Dergletchen finnen ober Dhren, Gieson aber werbe ids

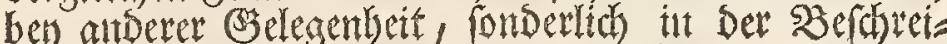
bung Der firoten, utt metrerm battelin.

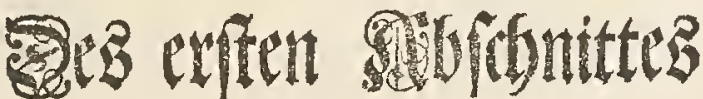

\author{
sweytes Copitel.
}

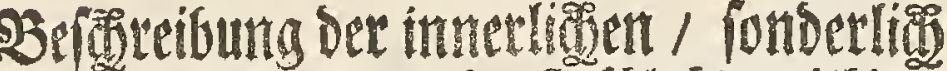

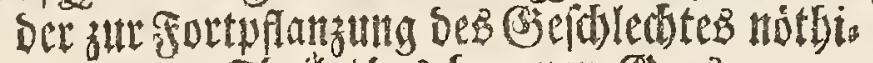 gett Fbeite/ DeB branten Stabs. fropdices.}

ith gleich mit nteinen im sorigen (5apitel exsebls ten Sbferwationen germafam erwiefen habe, Daf Die s)anuma unfers Frofhes mit Dem Ginterit

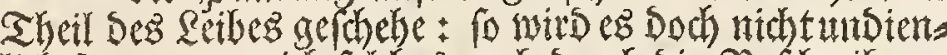
lich fend, want id foldhes aud surch bie Serchreibung Der inmert Theile, Die Das ithrige zar Fontpfanzung

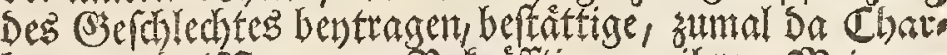

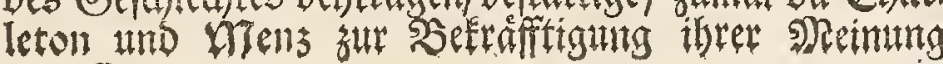




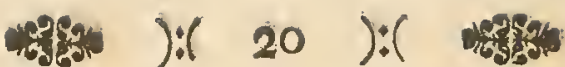

fauebant, infuper habito accuratiore examine, eosdemique erraffe mox patefiet; SWAMMERDAMMIVS contra rem hanc diligentia atque circumfpectione fumma tractauit: ipfum etiam hic fequutus fum, fic tamen, vt figuras ab illo exhibitas minus depinxerim.

Monftrat itaque Figura 1 Tabula $V$ mafculum ranae terreftris apertum. Littera $a$ fternum indicat eleuatum retractumque; $b$ laryngem ; $c$ cor; $d d$ bini maiores funt trunci arteriae aortae, fubclauiis aliorum animalium fere fimiles; e e par maiorum neruorum ad brachia vel pedes anticos tendentium; ff binae pulmonum veficaé, $g$ veficula fellea; $h b b$ hepar; $i$ lien; $k k$ tefticuli; $l$ ventricuIus in SWAMMERDAMMI figura*, calcographi errore, dextrorfum pofitus; $m m$ veficulae feminales. De fingulis his partibus iam non fum acturus, quum easdem minus examinauerim, de quibusdam tamen ea fum traditurus, quae mihi notatu digniora vifa fuerunt. Ventriculum quem ad $l$ cernimus cum inteftinis vnum eundemque formantem canalem, in 3 firura praecedentis Tabulae $I V$ vnacum pharynge, larynge, pulmonum veficis atque inteftinis iam exhibui, hanc itaque tabulam denuo vt infipiciamus neceffe eft, linguam ranae, quam iam in tertia Tabula fig $38, b c$ vidimus, diftinctius fimul referentem. Sifttur lingua haec in fecunda pariter eiusdem Tabulae IV fi, ura, vbi maxillam inferiorem a fuperiore feparatam, vna cum partibus carneis cutaneisque, nec non pharynge delineavi. Quemadmodum vero in omnibus, quae quidem novi, animalibus, linguae radix pofteriora verfus cum pharynge aliisque partibus connectitur: fic in ranis eandem tam cum maxilla inferiore in parte antica, quam aliis cum partibus intra illam fitis, adee, cohacrentem cernimus pars eiusdem reliqua, latior eaque maior, extenditur femper poftica verfus, libera ceterun, ita, vt rana eandem pro lubitu exerere poffit, inque binos abiens apices $f f$, intra quas larynx eiusdemque apertura $g$ confpiciuntur. Componitur lingua haecce tenera mollique carne, quam rana, quantum quidem opus eft, nunc longiorem nune breuiorem, nunc latiorem nunc contractiorem reddere poteft. Repraefentat figura 3, IV buius tabulae eandem rurius maxillam inferiorem, cui lingua eleuata et antica vertus protracta incumbit. $b$ b bini illius funt apices, ad $i$ vero firma haeret radicis eius pars poftica, a qua membrana quaedam lunata, cauitatemque formans propius abeft. Ad $k$ laryngen rurfus cernimus, cui vtroque in latere pulmonum adhaerent veficae collapfae $/ \%$. Nunc ad ventriculum accedimus proxime ad oefophagum orientem quum enim rana collo fere careat, oefophagum quoque breuiorem habeat, neceffe eft. Quo vero cernerem in quantum ventriculus extendi poffit, eundem aeque ac inteflina aere repleui, atque hinc eft, quod partes hae, inprimis vero ventriculus in figura folito maiores compareant; poffunt tamen aere amplius adhuc extendi. Eft ventriculus ab $m$ ad $m$ vsque eiusdem amplitudinis, froucturaque gaudet mufculofa, ftructura reliquorum inteftinorum robuftiore; indigebat autem pars haec et amplitudine et robore, quum rana praedam integram deglutiat; vbi autem ventriculus ad $n$ contrahitur, inteftina, proprie fic dicta, initium capiunt. Scatet tenue illud inteftinum proxime ad ventriculum ortum, aeque ac inteftinum ieiunum in homine, plurimis valuulis conniuentibus eousque vbi littera $n$ fecunda vice occurrit, ceu quarta nionftrat figura, quae intclinum hocce, vnacum ventriculi parte $u v$, inflatum, ficcatum apertumque $a b v$ ad $w$ vsque exhibet. Retardant valuulae hae chymi, in ftomacho ex cibis praeparati, per inteftinum hoc tranfitum, atque fic chyli quoque iuvant feparationem. Vbi valuulae hae conuiuentes difpa- eit gleiches gethan babert. Da es aber foheintet,

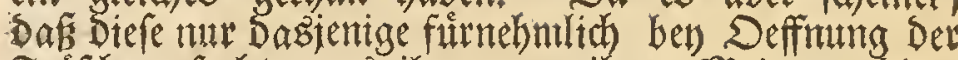
Frofthe gefucht, mas ifsnen zat ihrer Meimung bients

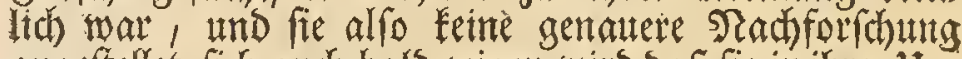
angeftellet, fid) auch bald zeigen wird Dafs fie in ifrer Uth terfiuchung geirret; Gwanmerdan bingegen bierimm biel vorfichtiger za 2 berct gegangen fibloffen Denfelben in Diefer Sirbett fitrnebulich zut fols

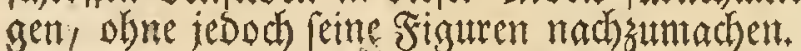

Es zeiget uns alío Die I firgur Der V Tabelle ein s)ännlein Des braunen Grasfroiches mit anfgechtitte: nem Reib. Das aufgebabene und in bie Sobe gezogente

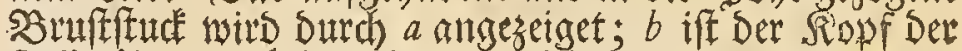

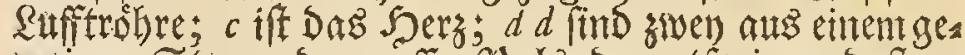
meinem Stamm der groflen Wullbaber entipringendeftar:

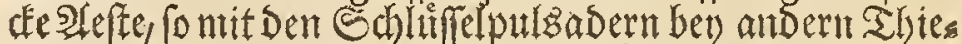
ren wergliden werden formen; e e find gwen fitarte in

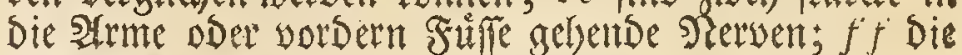
zwey Sumsenblaren; g Die Sallenblafe; b b bie Seber:

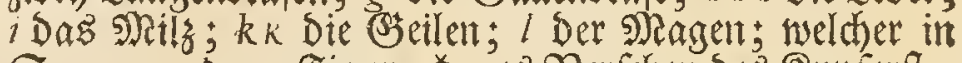

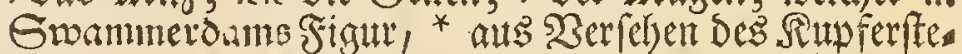
(h)erz, rechter Samb liegret; $m m$ die Saamenbläzlein.

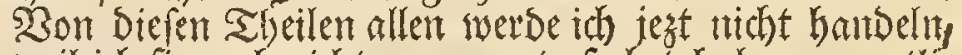
weil id fie noch nicht gemtg unterfuchet babe; bon eflit chen aber will ich dasientige meldent was mir merctivir. Dig gefditenen. Der Miagen ben wir bier bey $/$ fehen uno Der mit Den ŠeDárment einen einigen Canal attżnas het ift auf Der vorbergehenden $I V$ Cabelle nebrt Der Deffmung Des Solunbes, ben Rungenblafen unt Dendas ran hangentoen S3edarmen, in Der 3 Finut bereits bor aeftellet worden baber wir dann eben Diefe Sabelle noch eimmal anferyen wollen, auf welcher wir auth bie Bunge

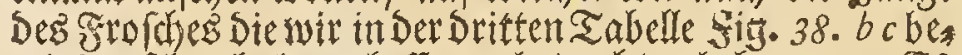

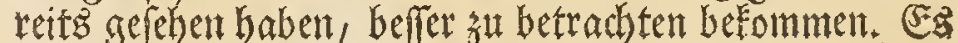
zeigt fich aber Die Bunge altch in Der 2 Sigur Der námli. d)en vierten Cabelle ro ich) Dent won Dem obern Riefer

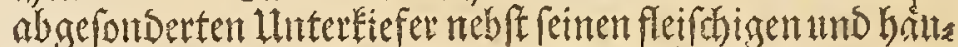
tigen Shetlen unt dent 2hnfang des Schlundes abgebils Det babe. Da nun aber bel allen ntiv beranten shies ren bie 2Burzel Dek Bunge alleseit binten am Schlund und andern sheilen wefte if, fo lyat bingegen ber ben

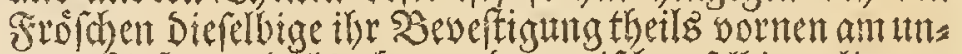
tern siefer, theils aber an Den zwirthen relbigen liegens Den Sheilen ee; Der librige breite untis grofte sheil Der= felben aber erftectet fich ordentlicher 533 eife hinterwarts

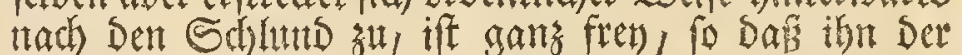

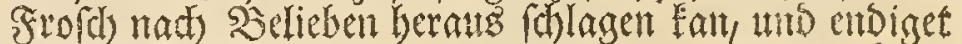

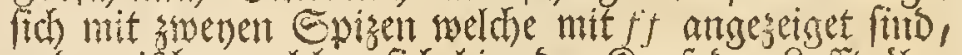
umb swifhen welden fid bier Det Ropf Der Ruftuble

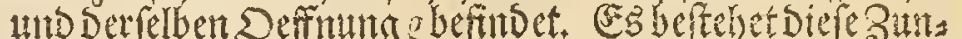
ge aus einent zarten unt weid)en Gleifh, focldes Der

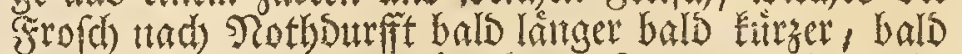

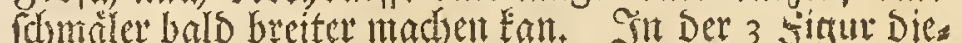
fer IV Cobelle iff ber metere Niefer abermals zu fehen, anf weld sem bie anfigebabene Zuntgeson binten sorwants gezogen lieget; bh fits Die beeden Spizen Derfelben unto

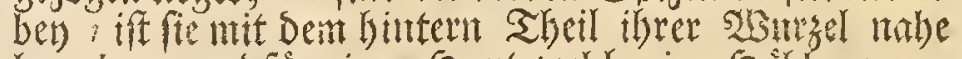

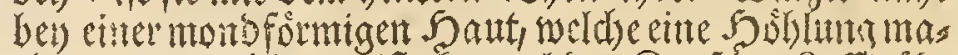

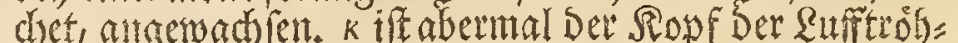
te, tmo nabe Daran bangen zat beedent Seiten die Sunts genblafenll, weldye bier zulaumten gefallen fints. Nun

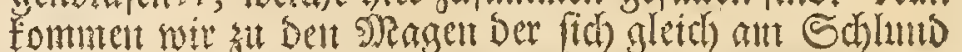

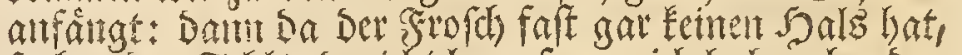

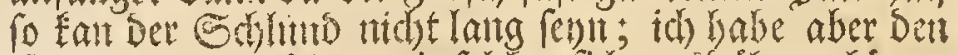

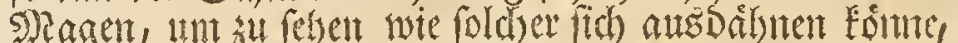
anfgeblafen Da Daut Die Ģedarme cbenfals mit \&ufft

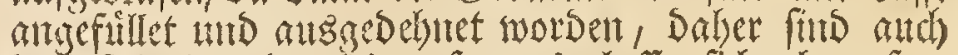
biele Theile in Der šisut lo gros, lafent fich aber, fon:

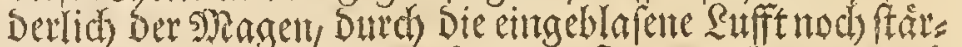

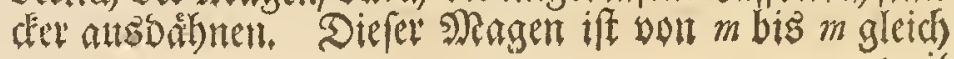




\section{* :}

rent, arctior quaedam inteftinorum occurrit pars o; fed
dilatantur rurfus $\mathrm{ad} p$, dein eandem feruant amplitudinem ad $q$ vsque, initium fcilicet amplioris multo inteftini recti, cuius extremam aperturam $r$ indicat. Quum hic inteftina haecce, mefenterio $\int$ adhuc connexa, a parte poftica fiftuntur, ads parua confpicitur fiffura, per quam in rana foemella fperma, vel oua potius, ex vtero in inteftinum tranfeunt rectum: incumbit namque, quemadmodum ex fequentibus patebit, inteftinum hoc ipfi vtero; in rana autem mare hac in fede alia adeft pro femine excernendo apertura. Corpus illud paruum rotundumque, eadem in figura $t$ fignatum, fplen efteolore carneo obfcuriore tinctus.

Sed infpiciamus denuo $V$ Tabulam in qua et aliae quaedam confideratione dignae occurrunt partes, in abdomine ranae maris contentae, tunc demum vero vifui fefe fiftentes, vbi ventriculus inteftinaque ablata funt. Oftendit easdem figura 2 huius tabulae, eo in fitu, in quo femper fub inteftinis inueniuntur. Indicant $n n$ partes quasdam foliaceas, renibus tefticulisque cohaerentes. Renes litteris 0000 fignati funt; $p p$ binos monftrant tefticulos, $q q$ veficulas feminales; $r r$ vefica eft vrinaria bifida, hic quidem euacuata; $\iint$ inteftinum rectum. Eædem hæ partes, foliaceis illis renibusque exceptis, 3 quoque fiftuntur figura, fed omnes majores.

Vt partes hafce binis repræefentarem figuris, earum præfertim, quæ ad generationem pertinent, me permovit, varia qua diverfo funt tempore conditio. Menfibus namque Martio atque Aprili, quibus ranae vtplurimum coire folent, maximae comparent; aeftate multo funt minores; autumno vero magis magisque rurfus extenduntur. Hoc autem, dubio procul, hinc contingit, quod ranae femel tantum in anno coeunt generisque propagationi operam nauant; atque eo ipfo tempore tefticuli non folum, fed veficulae etiam feminales, genitura adeo turgent, vt majores omnino fefe oftendant; poft coitum, femine fcilicet omni ejecto, multo culadunt minores; vbi vero ranae vires per xftatem collegerunt, fenfim fenfimque replentur confpectioresque euadunt. Exhibet itaque fisura 2 partes hasce ea forma, quae minima fere eft, 3 vero illa in magnitudine, quam paulo ante coitum habent quamque laepius obferuaui in mafculis, qui cum foemellis jam quidem copulati, femen tamen nondum emiferant.

Partes illa foliaceae in figura 2 litteris $n n$ fignatae, renibus tefticulisque cohaerentes, lutei funt colo- weit unt bat eine biel ftarceere mufuldofe Struttute

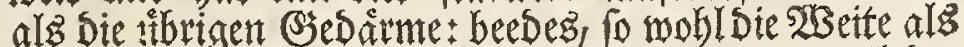
Die farde Structur, ifit Deswegen bier nothig/ weil Der

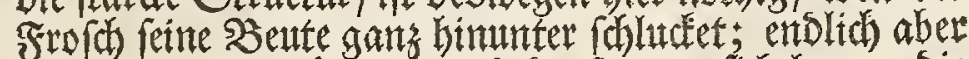
miro er wieder buinter, uns Da fangen fich bet $m$ Die eigentltchen (Ses arme ant. Der gletch auf Den Mzagen folgende Dunte Darm, ift intenher, wie Der leere Darm ben Dem sentchen, nit sielen Duterfalten, bis Dahin wo Das zwente $n$ ftehet, werfeben, wie aus ber viertent Fiaur erbellet, wo Diefer Darm nebit etnem Thet Des s) blaren, getrodnet und hemadh geoffitet worben, vors aefellet ift. Diere Fralten Dienen Dasu, Das Der aus Den

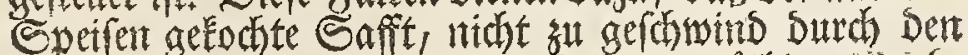

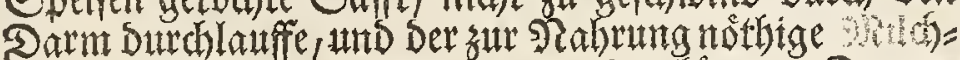
faffe, beffer Dason abgefondert nerben Eome. $2 a_{l}$, wo oie Fralten aufhoren, hat bie Darmrobre ber o einent Ditment Theil, bals Darauf aber erwettert fie fid niteder

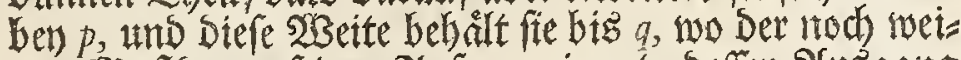
tere SRaftsarm fettert श्रnfang unme, Deflen 2lusgang Durd) $r$ antgezetget wirs. Da Diefe Bjedarnte, weldhe nod) Dutrch Das (Szefrófes an einanter bangent, fich Giet

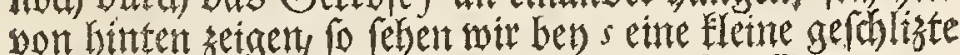

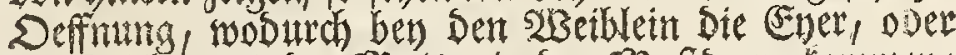
Der Saich, aus Der Seuter in Dent Naftoarm Eommen: Datti ber SDafts arm liegt, wie wit it folgentsem ferjen

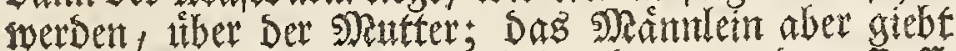
um eben Diefe S3egend, jeDoch Duth eine andere Defî"

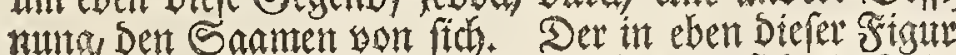

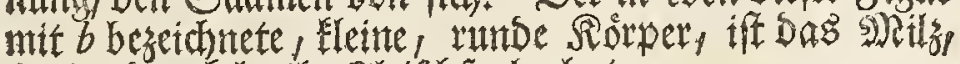
fo eine Dundelrothe Flet for farbe hat.

Sest wollen wir unts wieber, sut $V$ Cabelle wenbert, noo alth nod eintge andere Theile za betrachent find,

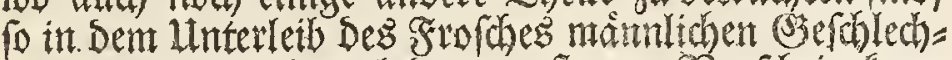

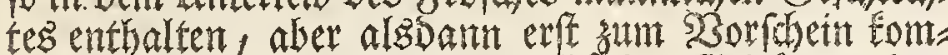

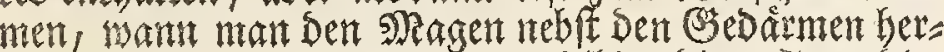
ausgenomment. Es geiget uns felbige bie 2 Jitut bies fer Fabelle, in Derientigen Sage, in weiber man fie alles zeif unter ben (3edärnten findet. Durch $n n$ werdent in felbiger eintige blatterfóntige Sheile angebentet, Die

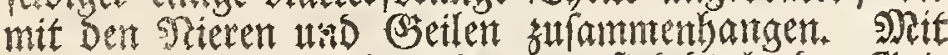
oooo ftnd Die SRieren beseidnet; pp find Die beeden Ëet= Ien; 99 Die swen Sannenbläsletr; $r r$ if Die alts zhet gleithen Ibetlen beftehenbe, leere Samblate; $\iint$ aber

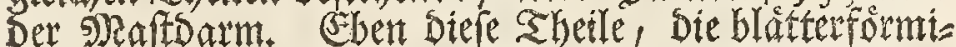
gen, nebit Den sieren anggenommen, fitllet and Die

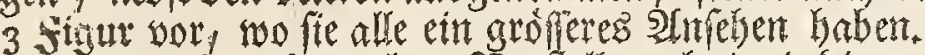

Su Diefer geboppelten 2 sortellung hat ntiv Die bers

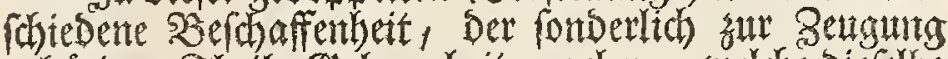
gehortgen Shetle Selegentheit gegeben, weldie Diefelbe

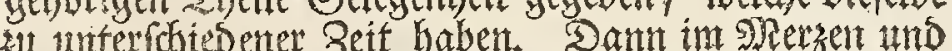

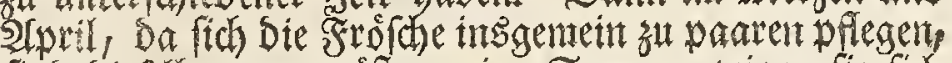
fint Diefelben am grofiten; im Sommer zeigen fie fted siel Elenter; im Serbit hingegen fangen fie fohon wieber an fich meth unt mefr auszudefnen. Deefes aber Fomme forter Zweiffel Daher, Das fith Die Grofohe Des Jahts intre etmmal begatten uns the (Serdiledtsermebren, "Da Dant nicht nut Die (Seilen, fondert aud Die Saanten= blasletm von Saanten angefitlet, atnd folglid) auth

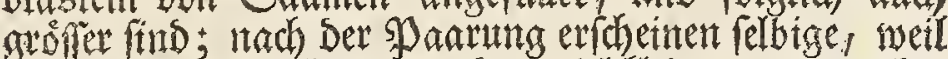

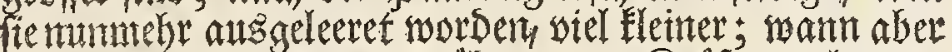
Der Frofo, Den Sommer tiber, thene Rraffen erlanget, fillen fie fich nach und nad wied er antumb fallent alfo methe in Die Singen. Dite 2 Sigur fellet Demnad Diefe Sheile fo soot, wie fie ansfebers went fie faft am telemfent find; int

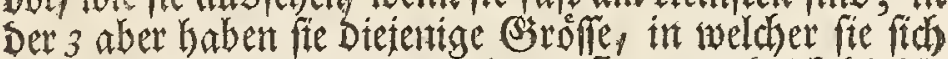

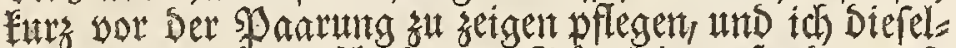
ben offters in verfhiedenen snamlein gefunten, to swat ichon mit ihen Esattintmen gepaaret waren, Den Saamen aber noch nicht won fich gegeben hatten.

Die itt unferer 2 Sigur mit $n n$ bezeidhetete blatter=

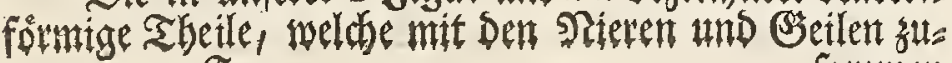




\section{4.}

riś, dưosque fórmant fafciculos, quorum alter dextro, alter vero finiftro incumbit tefticulo. Numerus harum partium variat; interdum enim fex tantum, interdum plüres in quolibet numeraui fafciculo: nonnullae earum fimplices funt, nonnunquam vero binae, ternae pluresque ex eadem quafi oriri videntur radice; quoad formam autem graminum foliis fere fimiles, pinguedinem referunt oleofam, tenui membranae inclufam. Inueniuntur eaedem etiam in foemellis, in quibus tamen renibus ouarioque cohaerent. Neque carent partibus hifce oleofis foliaccisque alia animalia aquatilia, vbi easdem varii iam viderunt. auctores; quis autem verus earundem fit vfus, nullus quidem, quantum noui, hactenus indicauit. $\mathrm{Ob}$ feruauit easdem SWAMMERDAMIVS quoque, qui illas appendices appellat luteas fimulque addit, oriri easdem exminimarum particularum, fphaericarum, etmembranacearum, oleofa ac flaua materie repletarum, congerie, de vfui autem earundem altum, apud ipfum eft filentium. Non ignoro adduci hic poffe, habere partes hafce pinguiferas eandem illam vtilitatem, quam pinguedini aliorum animalium adfcribunt, in qua renes ipforum fepulti fere iacent, quaeque vrinae temperat acrimoniam; tunc vero, cur certo tempore fuam mutent magnitudinem, vix intelligo. Peracto coitu non majores funt, mafculis aeque ac foemellis, quam in ecunda easdem delineaui figura, vbi vero poftnodum tefticuli veficulæque feminales denuo in mafculis replentur, in foemellis contra ouarium rurftus excrefcit, eum in modum augefcunt, vt haud exiguam abdominis occupent partem. Nonne itaque verifimile videtur, iuuare illas in maribus quidem feminis, in foemellis autem, materiei illius glutinofæ tenacisque fecretionem, qua oua circumcinguntur? Non enim folum renibus, \& tefticulis mafculorum, fed ouluario foemellarum, easdem cohaerere iam indicauimus.

Incumbunt renes o o o o fpinae dorfi ranarum; colorem habent faturate carneun; aequalis infuper fempe funt magnitudinis, nec non formae gracilioris oblongiorisque. Obferuaui praeterea in fuperficie corundem plieas atque inaequalitates quasdam; vtrum vero hae ipfae vafcula illa fint feminalia, quae, quemadmodum SWAMMERDAMIVS fcribit, e tefticulis femen auchunt, trenesque percurfantes in vafa deferentia fefe inferunt, ipfe quidem minus indagaui.

Tefticuli $p p$, eius funt, nonnullis in ranis, poft coitum, magnitudinis, quam in 2 habent figura; non ita multo poft autem aeque parui inueniuntur ac illi, quos 1 in figura $k \mathrm{k}, V$ tabulae vidimus; ipfo vero coitus tempore interdum multo funt maiores, quam tertia eosdem $p p$ fiftit. Quibusdam in ranis vnicolores flauique, in aliis cineracei et nonnunquam oliuarum inftar colorati, punctulisque atris confperfi cernuntur.

Veficulas binas feminales $q q$, exhibet figura 2 ea forma, quam poft coitum, femine omni exculfo, obtinent, atque tunc quidem dificilius, quin ab iis tantum, deteguntur, qui ranarum anatomen crebrits iftituerunt. Multo contra maiores funt in figura $3 q q$, femine quippe, quo coitus tempore turgent, repletae.

Aeque difficulter, ac veficulae feminales inanes, reperitur velica vrinaria duplex, fi yt 2 in fioura $r r$ con- fammen bangen, find won gelben Faube und madjen stwen

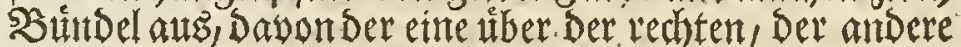

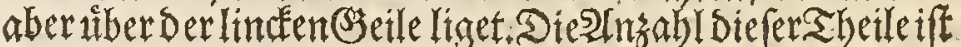
untgleid), indem ted) Derfelben mandimal nur fect) fe, mand)= malenaber aud mebrere in jedent Bitndel gezehlet; zunt Theil fitto fie nut einfad, zum Theil Eommen aber auth zwen und melorere gleidf fam ats einer SButzel, und Der Form nach Eơnen fie faft mit G3rasblåttern verglichen

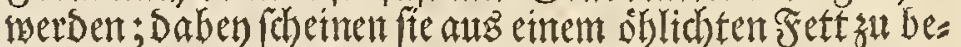

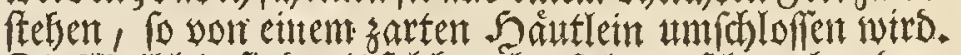
Die 2Beiblein find mit folchen ebenfals yeriehen, bel) Dens Felbentaber bangen fie mit Den Nieren 1 tho Dem Ever. fod zufammen. Esfinden fich Diefe fette unt blätters. förntge Theile auth in andert in 2 Baffer lebenden Thies ren unt fint bereits yon ver d) tedenen Scribenten bemerfet worden; worim aber eigentlich ibt Nathen bes

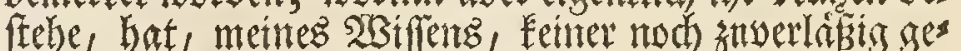
setget. Gwammerdam hat felbage swar aud bemer"

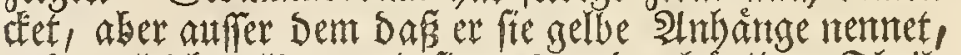
uns sugleid meldet, wie fie aus runben hâttigen The th d)en befteben, fo mit einer ofhlichten unt gelben soates rie angefilllet find, lebret er uns fonft nidhts won ihnen. EB fonnten swar einige fagen, Diefe fetten Ibetle hätten hier eben ben Nuben, Dent Das Feet ben andern IStes ren hat, Deren Nieren gleith) fam Darimen begraben lie=

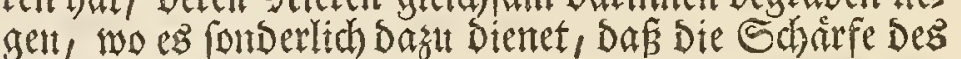
Sarnz badurch ges antpfet werde; alleine warum yer=

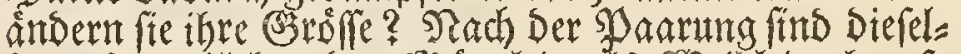

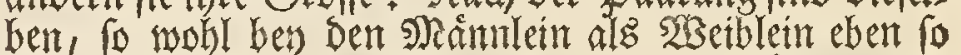
flem, als fie bier in unferer 2 figur vorgeftellet wor:

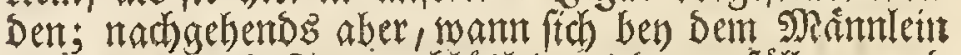
die Bjetlen und Saamenbláslein wieder anfillen, unt ben Dem 2 Beiblein Der Enerftod yon nethen su wach) fen anfoungt, fo find fie fo gros, das fite einen grofen sheil

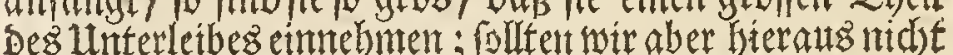

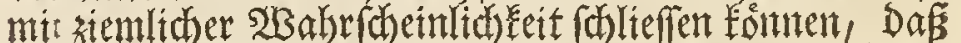

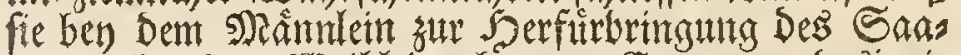
mens, ben Dem 2 Seiblein aber zut Ersengung desjents. gen Schleims, womit Die (Ever umgeben find, wieles bentragen, sumal Da fie, wie beretts gemeldet worden; nicht alletme mit Den Siteren, fondern aud mit Den Set: len, ben Dem Sianmlein, und mit Dem Everftodé bey Dem 2 Beiblein, zufammentangen?

Die Nieren o 000 liegen hinten am SRutchrad des Frofches ; fie fuben eime Dundte Fleifhfarbe, haben

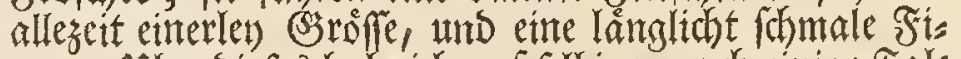

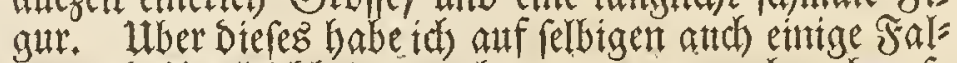
ten und Itmgletch heiten wahraenonmen, aber ebent io genau nicht unteriudet, ob folches dietentigen Saamens gefốpe feren, welche, wie Ewammerdam fagt, Dent Saamen mats Den Eseilen fithren, tiber bie Nieren hit:

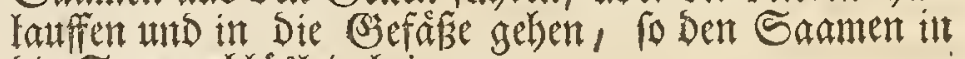
Die Saamenbläslem bringen.

Die Steilen pp haben ben eintgen sroidsen, thach ber Saarung, Die Erofife in welcher fie hiter in Diefer 2 Figut vorgertellet fins; etwas pater findet man fie vielmals fo flein, swie nitr fie in Der I fitur Diefer V Cabelle bey kk gerehentaben ; zur Paartngzzeit felb: fen aber fitto fie atth mandhmalen wohl grotler, als fie bie 3. Sigur ben $p$ seiget. Sin eimigen Frofochen fint

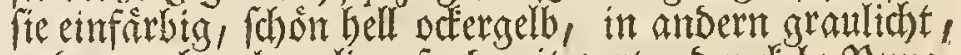

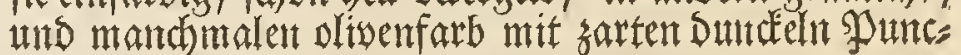
ten beiprenget.

Die beeden Saamenbláslein $q q$ fint in Der zwen= ten figur fo yourgefellet, wie fie nad Der. Paamm be= chaffen, wann felbiae yon Saanten leer finto, da man fie Dant nidht foletdete findet, want man nidht foholt etwas in Berglieberung ber Frofd genibt ift; in ber 3 . firtur himgeren $q g$ find fie viel groffer, weil fie die zut

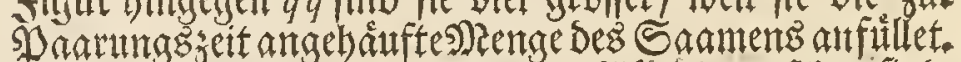

So fhwer die leeren Saamenbläslem zn fehen fitts,

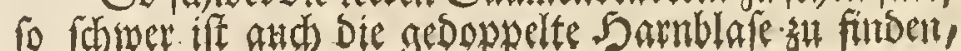


Tab.VI

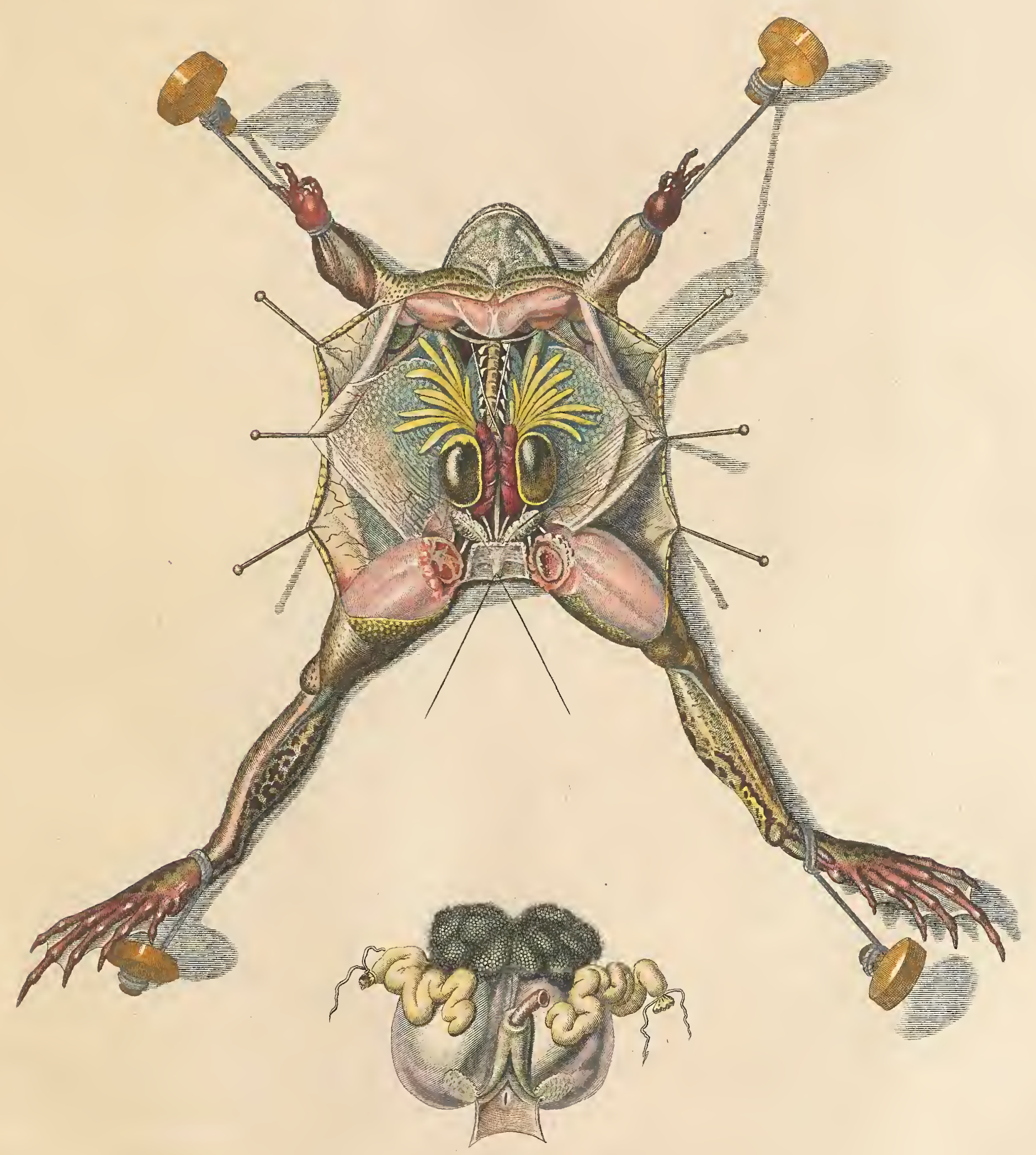



Tab.VI

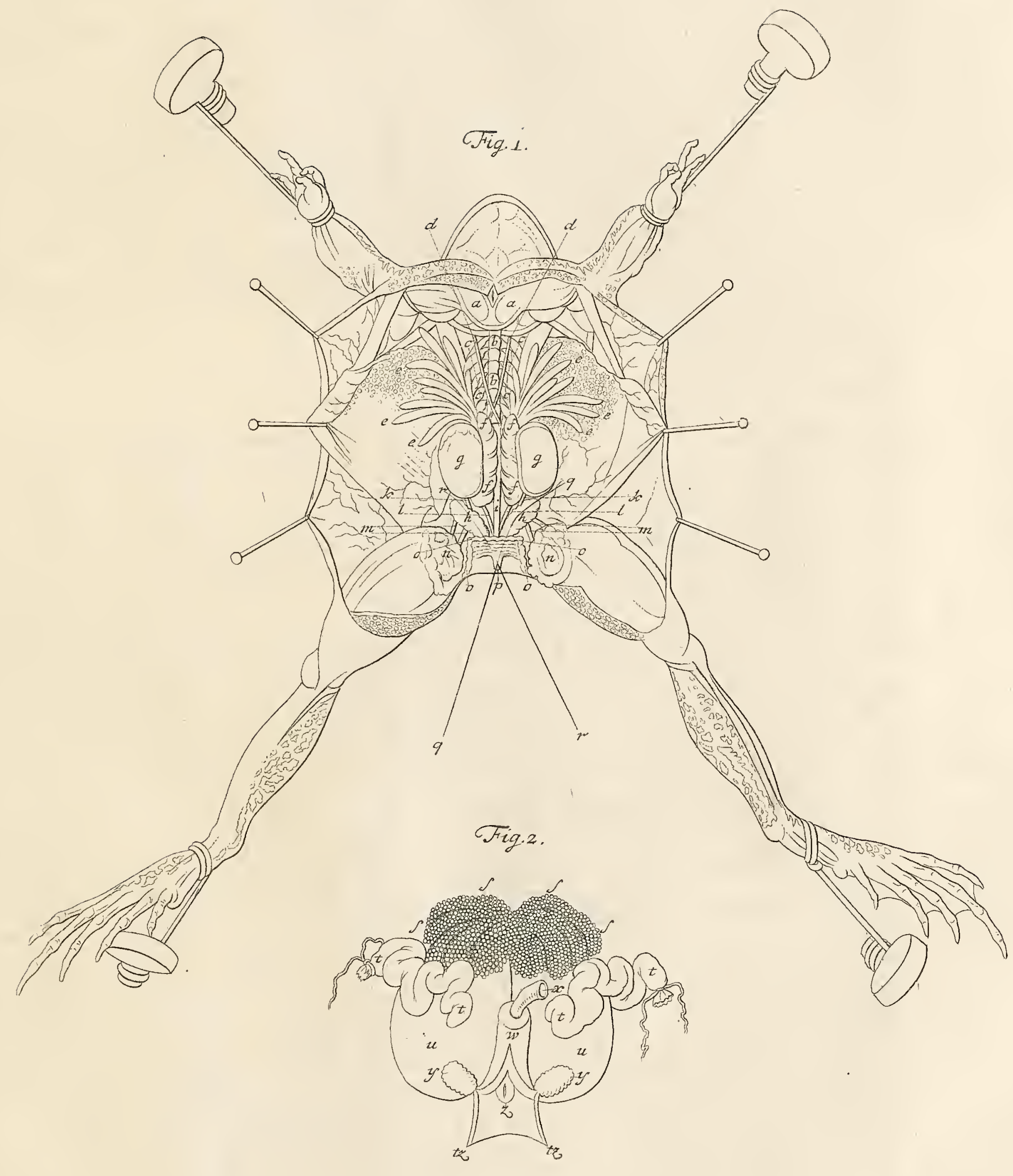





\section{(4)}

tracta fit. Tertia in figura r $r$ diftentam eam cernimus, aere fcilicet per inteftinum rectum, tubuli ope, repletam. Incumbit illa inteftino recto $\iint$, renes fupra tefticulosque femper decurrenti, quod autem, vt partes hae confpici queant, ex féde fua hic remoui. Abfcidi illud $\mathrm{ab}$ inteftino cui cohaeret ad litteram $\int$ fuperius pofitam, eadem vero littera $\int$ fecunda vice inferius occurrens aperturam illius indicat, quam anum appellant. Saepius veficam hanc vrinariam diffectis in ranis limpida repletam. inueni aqua, quae ipfa illa eft, quam interdum in vexatores infidiatoresque per anum eiaculantur. Si de bufonibus fermo fit, mictum, eiaculationem hanc, appellant, quem venenatum effe putant; fed quemadmodum nec ranarum vrina nec teftudinum, quae eandem fimili ratione eiaculantur, venenum habet, fic etiam, bufonum mictum eodem carere, certum eft; falfam tamen, eidem, vt plurimorum aliorum animalium vrinae, ineffe acrimoniam, inficias non eo. Addendum ceterum eft, defcendere, in ora externa renum, canalem quendam, vrinam non folum e renibus in veficam, fed etiam femen e tefticulis in veficulas feminales deducentem, et a SWAMMERDAMIO iam indicatum, quem vero alia occafione fum inueftigaturus.

Quum noffem, vidiffe celeberrimum LEEVWENHOECKIVM in ranarum femine vermiculos vivos (*), vtrum in femine hoc eiusmodi inuenirentur animalcula, et ego videre volui. Eo itaque tempore, quo veficulac feminales fpermate turgent, guttulas quasdam huius fpermatis, humorem turbidum potius quam limpidam referentis aquam, ex iisdem defumfi opeque microfcopii, quod manu tenetur, confideraui. Vidi tunc, haud fine ftupore, innumera ouata corpufcula, quae non poteram non pro viuis habere, quum quaquauerfum mouerentur, fibique occurrentia, fecederent. Mouebantur illa celerrime, quoad formam vero, omnia fibi fimilia, ouum, vti iam dictum eft fisuraque 4 monftrat, referebant. Differunt hinc ab illis vermiculis quos LEEVWENHOECKIVS depinxit, quique capillares funt; hoc ipfo vero impulfus iteratis vicibus idem tentaui experimentum femperque vidi vermiculos qui in ranarum femine inveniuntur, non folum canda carere qua illi inftructi funt, quos in aliorum animalium cernimus femine, fed effe cos quoque his multo majores. Vt vero omnem adhiberem circumfpectionem, femen hoc etiam ope microfcopii folaris, a me confecti, contemplatus fum, atque tunc vermiculos per lentem mediae magnitudinis millies feptingenties vicies octies quoad diametrum auctos obferuaui. Erat illis eadem tunc quoque forma: namque corpuscula pellucida, ouata, motu continuo tamdiu agitata, donec humor cui innatabant, id quod in eiusmodi microfcopio facile contingere folet, ob folarium radiorum calorem exficcaretur. Effe vero formam horum vermiculorum ouatam, hinc quoque conuincebar, quod obferuaui, oftendere objecta plana, in microfcopio folari, marginem fuum diftinctum, conuexa vero rotundaque, id quod ex s figura apparet, iridis cingi coloribis. Quum ceterum propria edoctus experientia, plurimorum eruditifimorumque virorum non potuerim non hactenus accedere fententiae, reperiri fcilicet in animalium femine innumeros vermiculos, nunc quoque femen ranarum tantum huic fententiae apud me addidit ponderis, vt vermiculos hofce moleculas vel partes tantum effe organicas, cum D. de BUIFF ON credere neutiquam poffim. Si quis vero vermiculos hofce obfervaturus eft, vt femen ipfis ex tefticulis vel veficulis feminalibus fumat, requiritur : liquo- want fie, wie in Der 2. figur $r . r$, zuamment gefallen iff; in Der 3. Sigur feben wir fie ausgebelynet, wetl celbige bermittelfi eimes in Den snaftDarm geftedten Robuleins aufgeblafen worben. Ez liegt Dieje Sarn blafe utber Dem siaftsarm $\int$ S Der fonftert uber Die Nies

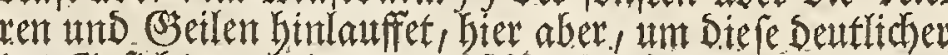
ins Bjeftchte zu bringen, auf Die Seite geleget worben. ber bem obert $\int$ habe ich ith won Dem Daran hangen Dent Darm abgechnitten, ber Dem untern $\int$ aber, ifte Dieienige Deffitung Desferben, fo Der 2lfiter genentet

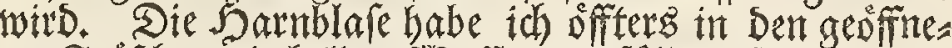

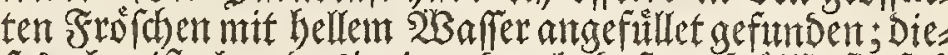
fes aber ift eben basientge, Durch Defien Sulffe fie fich mandinalen Der 2 erfolgung zuentziehen pflegen, mann

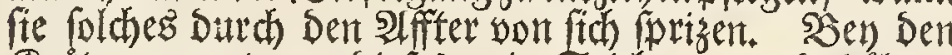
Aroten nemter man biefes, ein Seichen, und bălt es für vergiffet; fo wenig aber Der Sarn Der Froof che unt

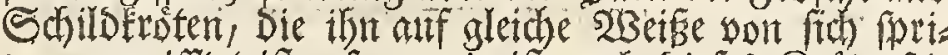
zen, vergiffet ift, fo wertig ift and Diefes Rrotentei

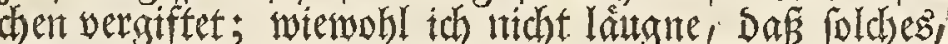
gleich) allem 5 arn bieler andern Shiere, eine falzige Scharffe habe. Utbrigens mus ich auch bier noch mels Den, Dấ an Dem âtlfern ober Gintern Rand Der Nies ren ein Sanal herablaufe, Der nadh Grammerdams Sertut fowohl Den Sart átuz Den Nieren in bie Љ̧lâe, als auth Den Saamen auż Den (Szeilen in Die Saamenblatsein fintret, weld)es ich nod) bet anderer Selegenheit unterinchen merbe.

Da mir nicht unbefannt war, Daf Der berûthmte Seenwenboet in Den Saament Der Srofóne lebendige 2Burner gerehen $\left(^{*}\right)$, fo habe ich ebenfalls eiten $23 e r=$ (itch machen wollen, ob ich Deraleichen Shierlein in Die:

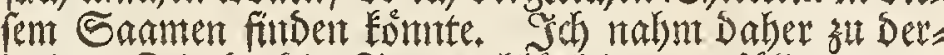
jertigen 3ett Da Die Saamenbläslein angefúllet maren,

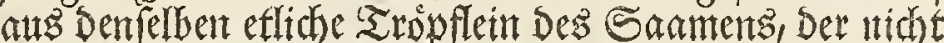
fowohl einem hellen SBaffer, als wielmethe einer truben Jendfigfeit gleid) (ahe, und betrach tete folche Durdh ein

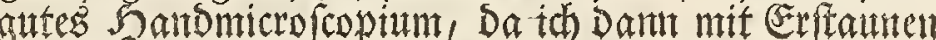

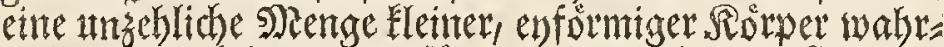
nabm, Die ich Deswegen fuir lebentig balten mufte, weil fie fid nad) allen Seiten bewenten und want fie nahe zufamment famen, einattoer auswichen, Ihte secwe: gung war febr fohteell, ber Form nad aber fament fie alle mit einander tiberein ; fie matem, fise ids bereits ge= fagt babe, enformig oder opalrund, wie fie die 4 sigut zetget. Siertmen mut find fie zmar von Denjenigent

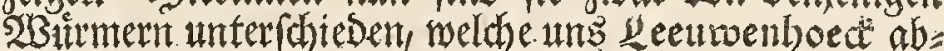

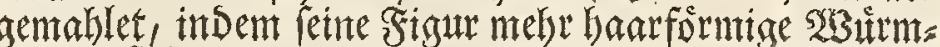
lein oorftellet; eben Deswegen aber habe ich Den 2 eritth zut yerfohiedenennalen antgeftellet, unt allezeit wahrge: tommen, Dấ Die in Den Saamen Der Froíche befindit:

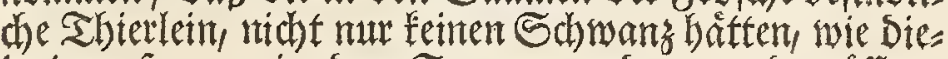
tentigen fo mant in ben Saamen anderer und grofferes Thtere fintoe, fondern alth noch um vieles aroffer als biefe

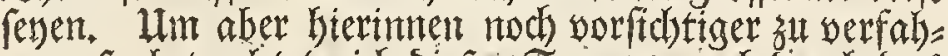
tent, fo betraditete id Diefen Saament aud Dumd Das won mir felbft verfertigte Sonmenmicrofcopium, weldhes mir Diefelbe, Durdh Die nutetlere 刃ergroffertutg, um $1>28$ mal grofer im Durdymeffer vorftellte, als fie son 5 Ratur waren, inere (3)eftalt aber blieb Die sorige, und th fahe

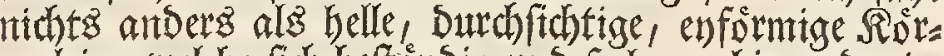
perlein, welche fich beftandig und fo lange bit und wie:

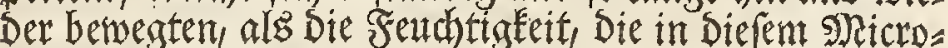

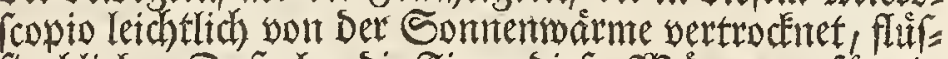

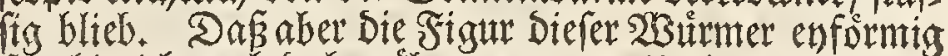
fen, bin tith atth baher uberzetuget, weil ith wahrgenont: ment l)abe, Daf fith Die platten Dbjecte in Dem Sontren:

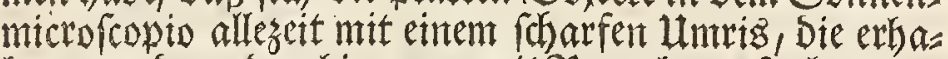
benen unt runden bittgegen, mit Regentbogenfarbent un: geben, zeigen, wie Dies Stgur bor tellet. Da id aber $\mathfrak{F}^{2} 2$

bisher

* Anatomia et contempl. P. I. p. sI. 


\section{*3: $):(24):(x)$}

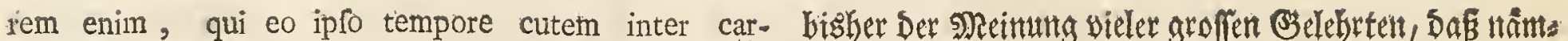
nemque haeret, cuius fupra iam p. 3 mentio injecta eft, fich in Dem Saamen Der Thiere unzehlid) lebendige

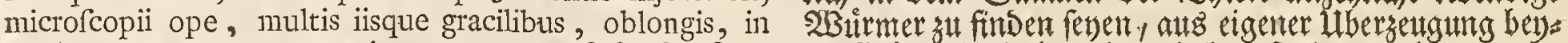

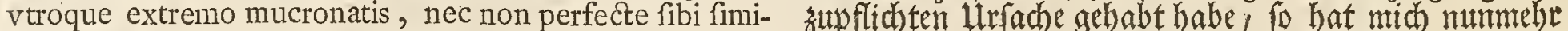
libus fcatere cernimus corpufculis, quae tamen, quum Det Saamen Der Frofche in Diefer Neinung ant Das

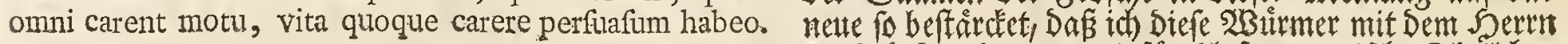
D. 23irfon Eeineswegs fir blofe organifhe Theilchen balten tan. 2 Bill man aber Diefelben zat fehen betom=

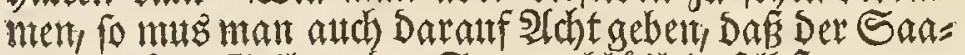
me aus Den Şeilen doer Saamenbläslein felbit genom=

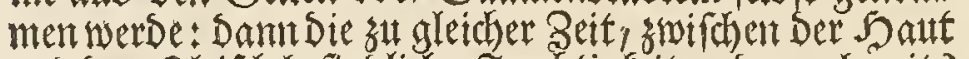
und Dem Fleifh befindidhe Fenchtigent, Deren bereits nben p. 3 gebacht worben, enthălt, wie Das Nicros fcopitm ebenfals zeiget, eine Mrenge rd maler, länglich: ter und an beeden Enden zugépizter fleiner, Rorper, twels

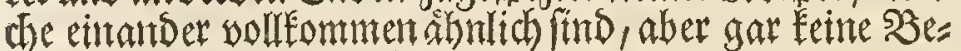
wegung und Reben baben.

Vidit etiam LEEVWENHOECKIVS in Rercore anarum tot animalcula, vt illi non nifi his ipfis conftare vidcretur; hæc ego minus quidem obferuaui, fed in ranis binas alias vermiculorum viuorum inueni fpecies. Obferuaui easdem in inteftinis non folum, fed etiam in vtero foemellarum, in vefica vrinaria, nec non, maximo numero, in inteftino recto. Altera illorum fpecies nonnihil lata, hirudinis vel limacis inftar, corpus fuum longius breuiusue, gracilius latiusue reddere poterat. Refert ejusmodi vermem figur a IV Tabulae littera $x$ fignata naturali in magnitudine, coloris erat albi multisque punctulis fuicis confperfus. Latiffima in parte, quam prae reliquis maxime mouebat, quatuor notaui foraminula, quorun nunc hoc, nunc illud, aperiebat claudebatue, ita, vtinterdum duo tantum, interdum tria, rarius vero quatuor confpicerentur. Alterius fpeciei vermes, anguiculis fimiles, inaequalis erant magnitudinis : quidam enim eorundem vix aequabant figuram IV Tabulae y notatam, quae eosdem repraefentat fufcis punctulis, fquamas referentibus, confperfos; nonnulli toto corpore albi, duas tertias habebant digiti partes, vti figura $z$ oftendit. Mouebantur hi ocyus illis, vtramque tamen fpeciem ad termites refero, quorum multi in terra etiam habitant inque paruas mufcas mutantur; quid vero de latiore illa fpecie dicam, vix habeo. Vidit etiam SWAMMERDAMIVS in ranarum pulmonibus binas vermium fpecies, quarum alteram lumbricis, alteram vero tenui fetae fimilem effe ait*, atque in hac plurima inuenit ouula, de quibus viuos exemit vermiculos; quum vero pulmonum hica me facta fit mentio, de his quoque vt nonnulla proferam moneor.

Seeumenlyoed hat auth in Dem Roth Der Frofdhe

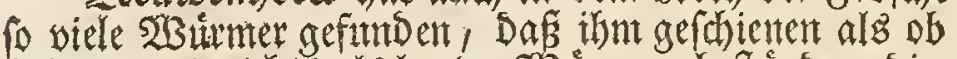
felbiger aus nichts als lauter 23 intmern beftunde; Dies ce habe ich swar nicht aefehen, hingegen find swenetlen

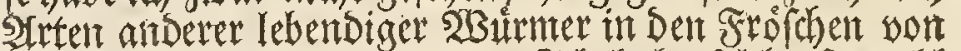
nir wahrgenommen worben. Sob habe oldhe fo wohl

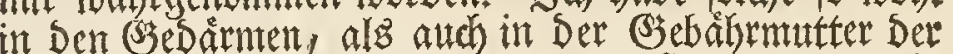

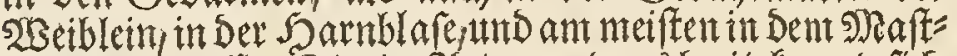
Darnt angetroffen, Die eine? Irt war etwas breit, Fonntefich

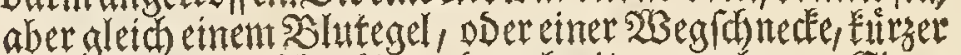
ober långer , fdumeller doer breiter madhen. Einent

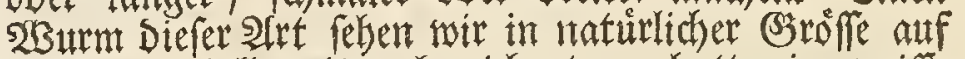
Der IV Tabelle mit $x$ bezeichitet; er batte eine weiffe Farbe umb war Daben mit vielen flemen braunen splinte lein befprenget. 230 er ant breiteftent par, lies er Die

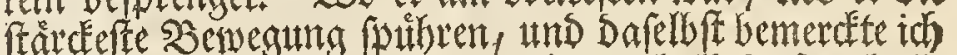

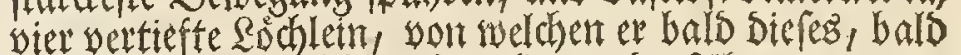

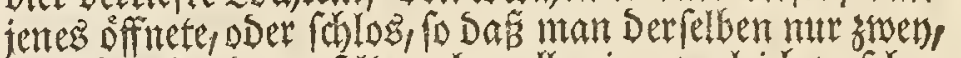
manchmalen Dren, felten aber alle siere zugleich zut fehet Gefan. Die andere 2 re Diefer 233 intmer felliten Heine Schlanglein ungleicher Stoffe sot: Dant eimige Deriels ben waren fanm fo gros als fie auf ber IV Tabelle ben y zu fel)en, unt mit brauter SJinctlein befprenget, bie wie Schuppen attsiahen; andere aber waren gans

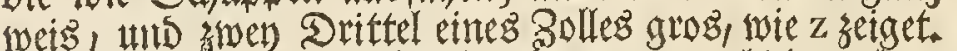
Diefe hattent cinte siel fontellere SBerwegutty als tene; bee:

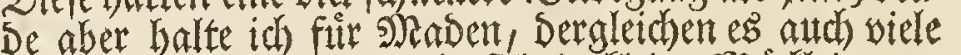

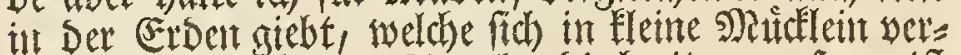
wanoeln; was fir eine 2Irt aber Die breiteren $x$ fenen, ift mir sut Beit nod) unbefannt. Gwammerdam bat aud in Den Sungen Der Frofiche sweterlen SWituter gefunden,

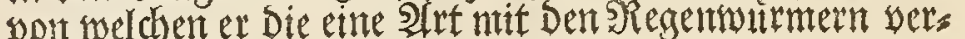
gleichet, bie andere aber borftenformig nenter; und in Diefen lesern bat er auth fo gar Die jungen aut Dem En rebendig Gerausaenommen ${ }^{*}$; : Da id) aber her ber Eungen Dez Frofchez gedentêe, fo erimere ich ntich), Dafi ich auth son Diefen nod) etwas ztt melben babe.

צBir baben Die Rungen bereits in Der 3 Sigur $/ l$

Vidimus iam pulmones fig. $3, I l, T a b . I V$ et fig. I $f f, T a b . V$, in explicatione vero harum figurarum eosdem veficas pulmonales femper appellaui; hoc autem nomen eam ob cauffam ipfis indidi, quod nil nifi binas veficas referunt, quae quidem externa in fuperficie plurimis veficulis conftare videntur, intcrius vero cavae funt multisque cellulis angulofis, diverfae formae atque magnitudinis, praeditae, quae interna tantum in fuperficie cernuntur, quemadnodum ex 6 figura tt tabulae $V$ apparet, vbi altera harum veficarum ea fiftitur forma, quam habet, fi aere repleta filo conftringatur, exficcetur apcriaturque. Singularis haec pulmonum ftructura eo perduxit celeberrimum SWAMMERDAMIVM, vt crediderit, non valere fempcr fententiam illam, qua ftatuunt, euchi fanguinem in pulmonibus ad extremam vsque perfectionem Der IV Cabelle, unb in Der a Der funfften $f f$ gefehent und in Der Ereterunt Diefer Sabellen fint fie allezeit volt mir Die Suntgenblafen gentennet worden; Diefen sias men acbe ich ifnen aber beswesen, weil fie eigentlich nicht: anders alE zwen Blafen fut bie zwar ånfertid

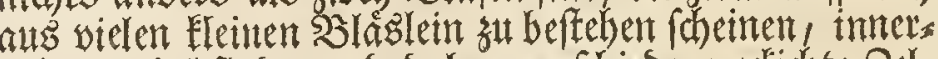
lid aber hol fins, und Daber) verfidiedene edfichte Bel= len woit ungleicher Form unts OJrófe haben, weld)e fich

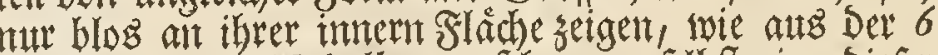
Situr $t$ ber $V$ Cabelle zlt erfehen, worelbit eime Diefer beeden 2 la fen foworgeftellet ift, wie fie fich zeiget, want

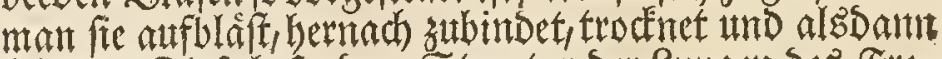
offinet. Diefe befondere Structur Der \&ungen Des Fro= (c)es bat Gwammerdam auf Die Gedanten gebrad)t, 


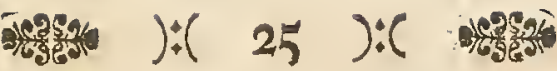

nem fuam; fed habere etiam hepar fuas in fanguificationis negotio partes $\left(^{*}\right)$ : hæc vtrum fefe ita habeant iam quidem non difpician; contra vero non poffum non illi fubfcribere fententix, quam Socii Regia fcientiarum Acaderice Parifine in anatomica teftudinis indicae maioris defcriptione propofuere $(* * *)$, quaque ftatuunt, nihil prorfus negotii effe pulmonibus amphibiorum cun circulari illo fanguinis motu, fed iunare cosdem potius, aere repletos, ranarum in aquis defcenfum afcenfumque, quemadmodum pifces ope veficæ aerex, qua inftructi funt, in iisdem pro lubitu furfum deorfumue mouentur: poffunt namque rane veficas fuas pulmonales non folum ampliores reddere quam quidem in fisura 3 tabule $I V$, nec non in I tabula $V$ a me depicta funt; fed fi femel eafden aere implerunt, illum etiam pro lubisu retinent; neque vlla hinc in cordis, vel fanguinis per vafa, motu oritur retardatio. Obferuari hoc poteft in rana viua aperta: ablatis namque pectoris atque abdominis mufculis, mox prorumpent binæ vefice pulmonales acre replete, quem interdum diutius retinebunt, interdum vero collapfae propellent, mox denuo attracture; nonnunquam etiam, altera earundem fefe contrahente, altera aerem inclufum feruabit, nulla interim in ipfo fanguinis motu notata mora.

Sed reuertamur illas ad partes, quæ ad generis faciunt propagationem: licet enim easdem in $V$ jam viderimus tabula, intra tamen corpus atque in fitu fuo natutali ut illas infipiciamus, necefle eft. Vt easdem omni repræfentarem accuratione, vnam ex maximis huius fpeciei felegi ranis, apertoque abdomine eiusdem, cuteque cum mufculis remotis nec non acicularum ope, ne mihi impedimento effent, firmatis, veficas pulmonales, cor, hepar, ventriculum \& inteftina omni adhíbita cura feparaui atque ex corpore abftuli, ita, vt partes tantum generationi inferuientes, cum renibus, portioneque inteftini recti reftarent. Inftitui autem partium harum examen menre Septembri, quo ipfo tempore maxime vtplurimum effe folent; ipfius vero ranæ hac ratione apertæ diffectæque imaginem I tabulae VI refert figura.

Cernimus itaque in $I$ hac fiour $a$ ad $a$ fternum; $b b$ fpina eft medium occupans dorfum, ad cuius latera intra litteras $c c, c c$, præter mufculos, fingularis quædam alba occurrit fubltantia, que vti quidem reor, ipfá illa eft, quam SWAMMERDAMIVS natiuum \& colliquefactum appellat falem (***) qui, ipfo referente, cerebro æque ac medullæ fpinali ranarum, intra tunicas conclufus, vafisque fanguineis intertextus vsquequaque adiacet, atque fub forma nodulorum, iuxta vertebrarum tractum, in dorfo, difpofitus eft; $d d$ bini funt neruuli prope renes fefe decuffantes; с еe, e e e luteas illas, pingues foliaceasque indicant partes, qux, vti iam in explicatione tabulae $V$ indicatum eft, variam ob magnitudinem, ad generationis negotium facere videntur, atque hic admodum magnae comparent, $f f, f f$ bini funt renes rubri, proxime fibi adiacen- als ob Die Neimutta, Daf́ Das BSeblute in Den Puntgen

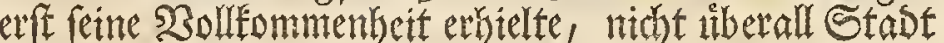
finde, und die Reber Das ibrige allerbings Daju bets: trage $\left.{ }^{*}\right)$ : wie ferne er literinnen SRed th habe will id nicht unterfuchen; wann aber Die bitieglieser det 210 . niglicben Zardomie der DDiffenlohaften ju Paris, ben Gelegenheit Der anatomifhen Derdreibung cinter grof:

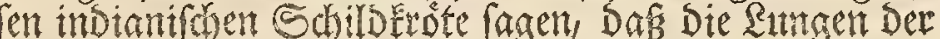

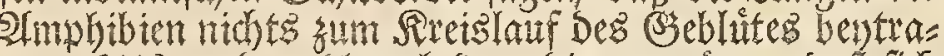
gen, (**) tnd wohl atd basu bienen mogen, bas fich

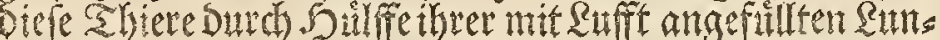
senblafen bals unter bag sBafer, bald aber ulber bafs furbige begeventomen gleth ben firchen, welde Debs weren mit cinet befondern suftelafe verfelien find: lo Eant idh nidge anders als ibnen Sbegfall geben: Damn bie

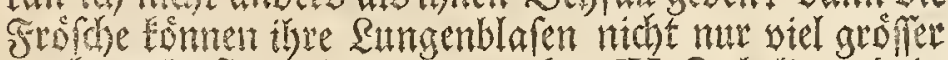
matien als fie in Der 3 situr Der IV Tabelie unto in Der I Der $V$ yon mit borgeffellet morden, fonbernt want fie siefelben einmal mit $\mathcal{L}$ uffe angefullet baben: fo Eonnent fie folche fo lantge Darimmen behalten als $\mathrm{ez}$ if $=$ nen belieber, obne Dafs Deswegen Dir Berwegung Des Set:

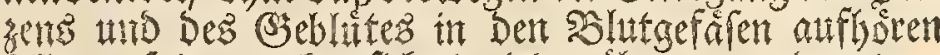

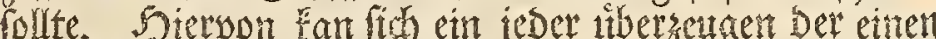
rebendigen Frofh offinen will: Dann fo bald als cr bie smufein Der Sornt und Des Interleibes auf Die Seite ranmet, fo werben Die zwen Sungenblaren aus felbigem

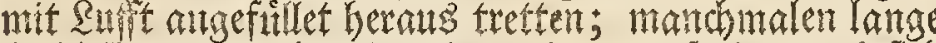
fo bleiben; mandimalen aber zufammen fallen, this fids bernadh wieber aubdefnen; sumeilen aber wirb fich aud

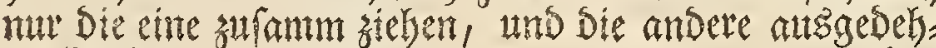
net breibery obne Daf man Daben in Der SBewegting Des (Bseblitez cinen Stillfand wahntelmen follte.

Dodh wir wollen uns mieber zu bententigen Theilen

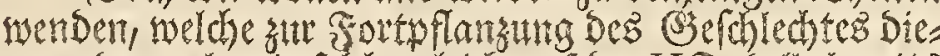
nert: Denn ob wir folche gletes au Der V Tabelle bereits

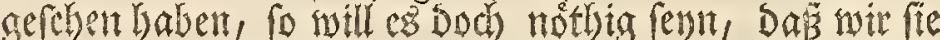
and imerhalb Des Reibes in iner naturlichen Rage be= trachen. In relbige num o viel Deutficher yorfellig zu

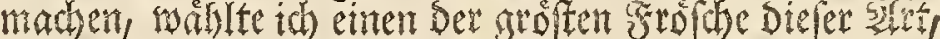
uno nachoent ich felbigen am unterleib geoffitet, aud bie Sant nebft Den 9 Matceln auf Die Seite gebradist und, Danit fie mir nicht hinderlich waren, mit Stects nabeln angebeffetet, fonderte ich, mit aller Sorgfale, bie Rungenblaren, Das Sers, Dee Rebev, Den Jeagen uno Die (s) edcirme ab uns nabm folche aus Den Reib beraus, fo, bas mur alleine die zut Bunung gerjortge Sheile,

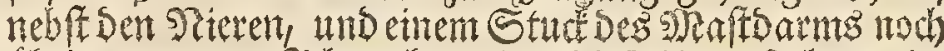
tibrig waren. Sch nafm aber biefe Lunterfuthutg in sonat September vor, um weldhe get eben bie shet.

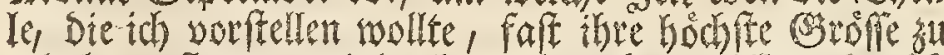

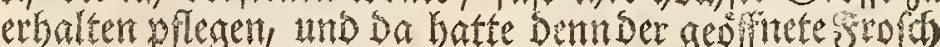
Das Intehen, Der auf Der VI Cabelle vorgeferlten I Sigur.

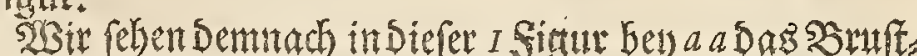

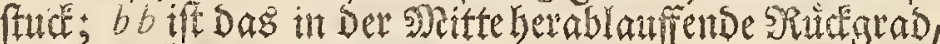
att befen beeden Seiten fich sinifhen $c c, c c$, nebphen 9) Receln eite befondere weiffe Subftans zeiget, welche ich fin Dietenige balte, fo Etwammerocm ein natirlis d)es fingiges Sals nemtet (***), Das wie er faget, fo

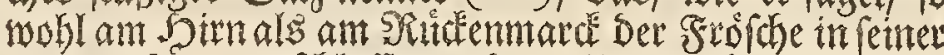

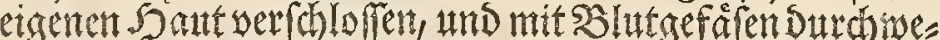

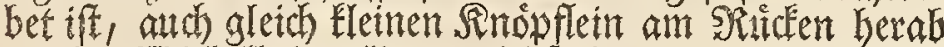
um Die 2 Birbelbeiner lieget; $d d$ fins zwen zarte ?erven weldiefth ben Den Nieren Erensen, eee, e ee seigen Dies ienigen gelben fetten und blatterformtigen Sheile, wel the wie berets in $\mathfrak{B} e$ fdreibung Der $V$ Cabelle gemeldet

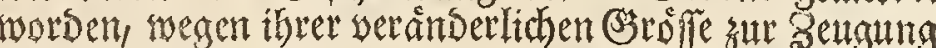
nothig su fenn foctiten, und fich bier fonderlich gros (S)

* Bibl, Nat. T. II. p. 830. requ.

**) Mem, de l'Academie Roiale des fciences depuis 1666 . iufqu' à 1699. p. 193. \& 197.

(***) Bibl. Nat. p. 838 . 


\section{(4)}

iacentes, qui, quamquam ad generationis organa non pertiheant, hic tamen, ob cohæfionem cum his ipfis partibùs fervari debuerunt. $g . g$ tefticulos monftrant, menfibus Septembri atque Octobri vtplurinum valde magnos; b $b$ veficulàe fúnt feminales, fenine hoc quidem tempore minus repletie; $i$ vafa quædam ; hactenus a me nondum examinata, quæ vero in 2 fisura, VTabule gemina vidimus, $k k$ bini funt canales e tefticulis prodeuntes atciue in veficulas feminales fefe inferentes, $/ /$ bmi alii vrinam e renibus in veficam, hic minus confpicuam, deferentes, $\hat{m} \dot{m}$ in vtroque latere duo funt nervi craffiores, ad neruivi cruralem conftituendum concurrentes, quem ipfum, quod omnino notatu dignum mili videtur, fi volfella forte vellicaueris, totum crus illico mouebitur, ipfa etiam ab rina ian feparatum; quin fi omnes illae partes a rana auferuntur, quae e rana hic depicta a me ablatae funt, non tântum ditu adhuc viuet, fed, habenis libera, faltu quoque fugan capeffere tentabit.

Partes hic defcriptas omnes celeberrimus fimiliter vidit defcripfitque SWAMMERDAMIVS, ranarum vero mares fingulari quodam inftructos effe ad procreandam fobolem membro, non indicat, hoc tantum dicens, inferi veficulàs feminales vafaque deferentia, infra fundum vefice vrinariae, in inteftinum rectum aperirique in illud duobus ofcillis: quod quum \& ego examinaturus ef fem, aperienda erat pars inteftini recti extrema, id quod tamen vix fieri potuiffet, fi illam e rana extraxiffem; in fitu potius naturali feruari debebat, quumque ipfa illa pars, quam infpecturus eran1, fub offe pübis latet, ope acut cultri illud difcidi, cautiusque inteftino recto, quod hoc fub offe fitum erat, feparato, diffecui illud, binailla veficularum feminalium vifurus orificia. Sed nulla aderant orificia eorum quippe loco, non fine fumma admiration'e, paruam iuteni papillam carneam, quumque, quid de ea fentiendum effet, mecuin voluebam, ell inuifit apud me D. D. HVTH, poftquam autem ipfi, quidnam thic quaererem indicaui, illo fuadente, alteràm ex veficulis feminalibus leui aperui incifura, inque eam per tubulum a'erem immifi: monftrauit nobis, hoc facto, aer in veficulam immifius non folum viam, quam perneauerat; fed eleuabatur quoque dicta papilla, atque tunc nihil obftabat quo minus facili negotio, tenuem, per viam inuentam, transmittcremus fetam, quin, quum per eandem illám aperturam, per quam feta in papilla prodierat, aliam in veficulam feminalem alteram effemus introducturi, hoc quoque ex voto fucceflic. Mododicta, I fimiliter $V I$ hu jus Tabule exhibet foura, $n n$ fcilicet os pubis eft difciffum, o 0 0 o pars inteftini recti quæ fub eo latuit atque, in fuperficie illa qua os pubis tangit, diffecta fuit; $p$ papillam indicat carneam, quæ, vt eo diftinctior compareret, paulo major delineata eft quam ipfa illam finxit natura; $q 9$ feta illa cft quam primam in veficulam apertam immifimus, $r r$ altera, quam per papillam introduximus.
Darftellet. $f f$, ff find bie beeben nalie benfamment lies gende rotbe siteren, die ob fie folyon eigentlid nidht zu ben Seugungstheilen gehoren, Dodh wegen ibres Bufam= mentanges mit felbigen hier baben mufen benbebalten werben. og weifen uns die (Seilen, weld)e in s)ennt September tho Detober gemeiniglich fehr gros eridhet nen. $b$ b find Die sur Beit noch leere Saamenblablein, $i$ aber eintge (stefrife fo idh noch itdit genan unterfithet Gabe, und die in Der 2 figur Der $V$ Cabelle Doppelt ers cheinen; $k k$ find zwen Cancle fo von Den Steilen in Die Eaamenblizlein, unt $/$ l zwen andere, fo son Dent Tie: ren in Die Sarnblafe geben, weldhe aber bier nidbe zu feben if: $m \mathrm{~m}$ zeigen zu teser Seite zwey farfe Rerben, Die Dent groffen Echendfelnersen ntnchen belfen, bon weldem tol bier als etwon befonders anzumerten babe, Dấ wam ntan felbigen etroant mit einem sanglent er: greiffet, Det ganze Schendel Des Froddes pogletd in sewegung gebracht werde, follte er aud fort yout Frodd abgeloret revn; aud mus idh nod bey diefer (S3es legenbeit erintern, bafs want man einem Frofd gleid) alle biejentgen Sheile wegnimmt, die Demt biar borge= ftellten bon mir weggenommen werben, felbiger nidst nut alleine nod lange lebe, fondern aud fogat, want man ibm feine Frenbeit läbt, zu entprinsen fuche.

Die bisber beforicbene sbeile bat $G$ wammersam

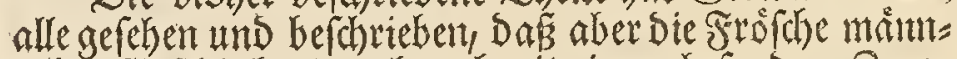

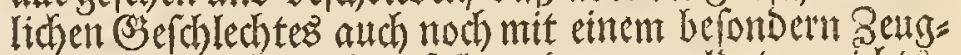
ungsalies berfeben fenn follert, Davon meloet er nichts; fondern faget nur, Daf́ Die Saamenbläslein nebf Den zufuthenben Sefaren, gleid unter Der Sarnblafe in Den 5) Daftoam gienget, uns fich infelbigen mit zmen shins Duntren offineten; 1 tm tun aber aud Diefes ou unterfus

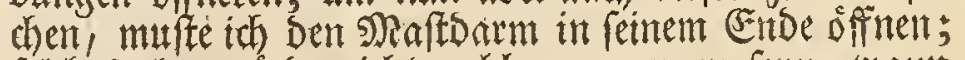
folches aber wurbe nidht wohl angegangen fenn, mant the ifn aus dent Frofó berausgenommen batte, fonsert et mufte in feimer natinfiben Rage bleiben; weil aber eben Derienige Stheil Deflelben weld en id insbefondere st betrachten hatte, unter Dem Sd)lof = Doer Shant bein verborgen lieget, als tremete id saffelbe sermits telf eines (d)arfen Seffers yon eimander, und nach Dem idf Den Dartuter liegenden spaftoarm mit aller SBot: fisht Davon abgefondert batte; sffnete idh, felbigen, $1 \mathrm{tm}$ in feinem hintern Sheil Die beeden sumbungen Der Sanmenblälein, als wofelbit id fie fuchen mut te, auss fittig zumadien. Sier fande id num aber zu meiner groften 2 serwumberung, fatt zwener Deffiungen, eint fletnes fleidsernes 23 ärslein, als id aber eben bin und bet Dadite was idh Daraus ntadjen follte, fam Serr Suti) zu ntr, und nadbent idf Demfelben, was ich bier fuchte, angezeiget, gab er mit Den SRath in cintes Derer Saamenbläblem sine Deffinth zu machen, und ver: mittelfteines sobbrleins Rufft bitein zu blafen: als num aber Defes gefdahe, zeigte uns Die Durd Das Samen=

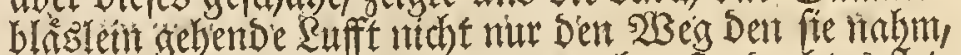
fonbern es wurbe butch felbige aud enfiged achtes fleis fornes 5 Barslein in Die Sóbe geboben; and lies fids bernad, Durd Den einmal entbedten sbeg, eine zars

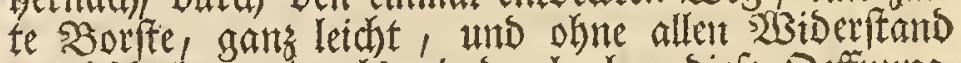
Durch fhieben: ja als wir Durch eben biefe Deffitng;

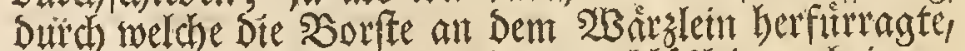
eine anbere in Das zpente Saamenbláslein zu bringen

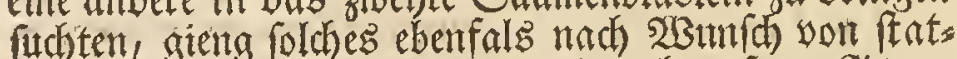
ten. Srles diefes zetget uns auch nod) unfere 1 Sigur: hn iff namlid Dab won einander setrente Sd) Smbeily o000 aber Der unter felbigem werborgen gewefene Reft bes Snaftoarms welder ba wo er am Schambein ans lieget entswer geróniften worden; $p$ beutet auf Das flei: fherne sisarzlent welches bier um metrerer Deutlich feit willen etwas (d)etnlither, als es wirelid) ift, borgeftel: let worben; $q q$ if die zu erft Durd Das geoffnete San=

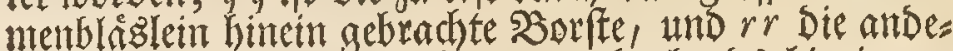
re, fo wir Duth Das 2 barbletil nadhgebends binein ge: fobobn babent. 


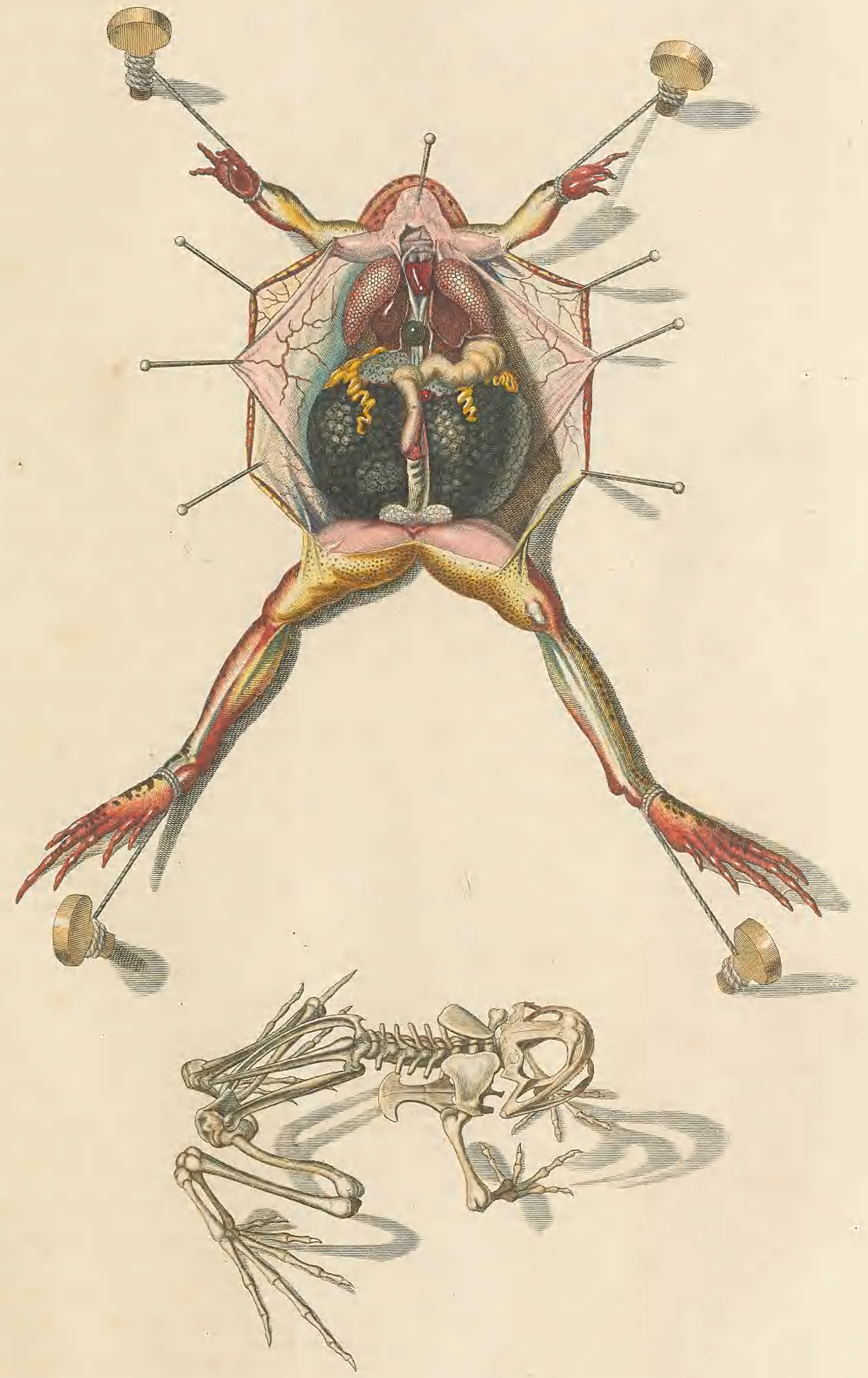



Jab. VIL

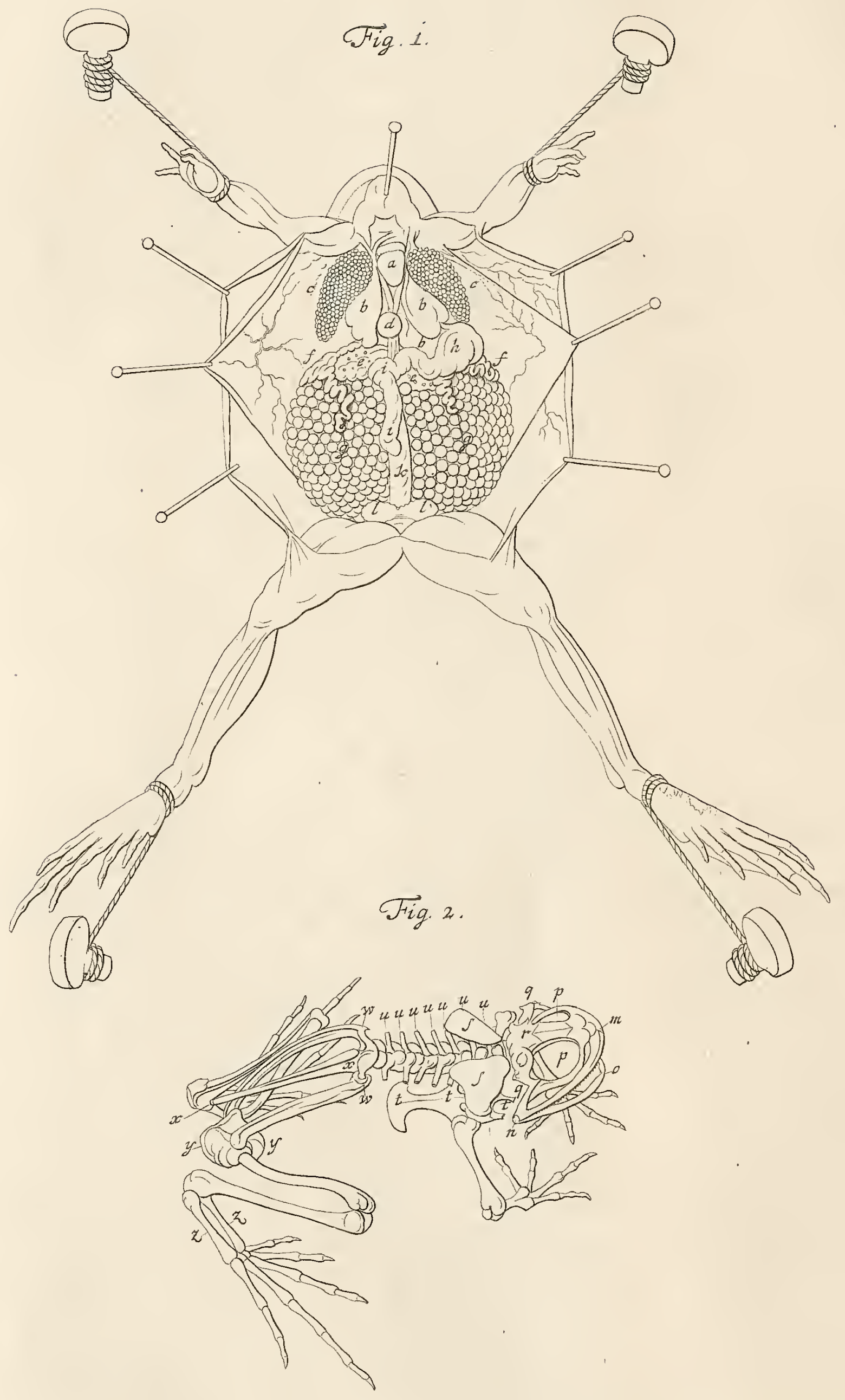





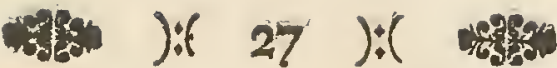

Non vidit itaque, occulatiflimus alias SWAMMER DAMIVS papillam hanc; tantum tamen abeft vt de illius exiftentia vllum apud me fuperfit dubium, vt illam potius, in aliis poftea ranis femper inuenerim; atque hinc in eam fere deducor fententiam, vt credam, ipfum SWAMMERDAMIVM rem hanc minus exacte examinaffe, præfertim quum, quemadimodum fupra jam notaui, infupe fcripferit, deduci per vnum idemque vas deferens vrinam in veficam vrinariam, nec non femen in veficulas feminales, quum tamen illa, in rana cui abdomen apertum eft inteltino recto incumbat, hae vero infra illud fitæ fint Sed eftne quaefo papilla haec carnea, a me detecta, penis dicenda? Mihi quidem fic videtur: licet enim non obferuauerim, reddi illam, tempore eo quo rana femen emittit, maiorem; licet etiani eodem illo tempore eam minus confpexerim: conftat tamen dè auibus, quae fimilite pene vifibili carent, inire easdem foemellas ope prominentis cujusdam partis carneae, id quod in anate praefertim mare apparet, ex cujus parte poftica, vbi foemellam iniit, caruncula femper quaedam properidet, quae fen fim fenfimque decrefcens, tandem omni ex parte euanefcit Sed quicquid fit, habet certe rana partem quàndam pen haud diffimilem, atque hac in re, contra diffentientium objectiones, mecum pugnantem habeo virum, quem præter MENZIVM, multi alii eruditionis laude confpicui viri, oculatifimum \& experientifimum rerum minimarum, in naturalibus, indagatorem appellarunt. Eft is celeberrimus Lipfienfium Profeffor A. Q. RIVINVS, qui eandem illam papillam carneam, quam præter omnem fpem atque opinionem in rana iuueni, multo prius detexit $\left({ }^{*}\right)$ quemadmodum jam nominatus D. D. HVTH mihi poitmodum indicauit. Licet itaque primus ille papillæ huius fit inuentor, me tamen, ipfius inuenti prorfus ignarum, eam ipfam partem fimiliter reperiffe, valde gaudeo; pate vero etiam exin, parum fidendum effe examini ranarum a D. MENZIO inftituto, multumque ipfum a veritatis tramite aberraffe, quum fequentia contra celeberrimum RIVINVM fcripfit: Nibil vero, guod a fe teftes injra demittent, quavis intenta acie, licuit exquirere, ot adeo nimium fibi confifum credamus au\&torem objeruationum anatomicarum circa congreflum, conceptionem, geItationem, partumque ranarum, quo ipfo iam laudatum innuit RIVINVM, qui vaja baec deferentia tabula efficta dedit, er nec minus veficulas feminales iufto, fere, pro mole animalis, ampliores, quarum nec vola, nec veftigium a nobis, seduio indagantibus, confpedum eft, neque ab aliis repertae funt, viti nec penis ille ex concur $f_{u}$ vaforum eiaculanitum exfurgens, extra picturam vifu eft, quem ranae alii denesare nulli dubitant. Haec vera effent, falfus fuiffem in omnibus illis quae hactenus oftendi; aft videtur D. MENZIVS non folum ranas eo tempore non diffecaffe, quo celeberrimus RIVINVS easdem examinauit, fed caruiffe illum oculo anatomico omnia profecto docent. Patebit id ex illis quoque, qua de partibus in foemella ranae noftrae fufcae terrreftris generationi inferuientibus dicenda fuperfunt.

Age itaque $I, V I I T a b u l a e$ infpiciamus figuram, foemellam, cuivus abdomen apertum eft, repræfentantem, quae, 'quoad'ftructuram externam, graciliora ipfo mare

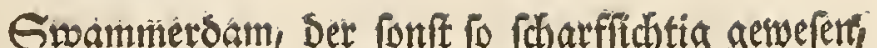

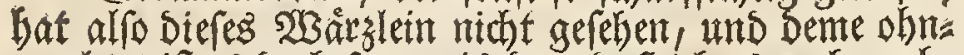

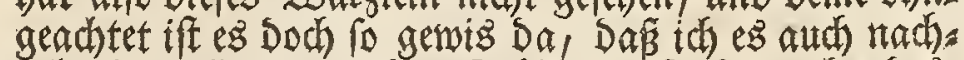
gehents, allezeit in andern Frofichen gefunden; ebendes: wegen aber follte id faft glauben, er muffe hier fich ets was libereilet baben, fonderlich Da er aud faget, wie

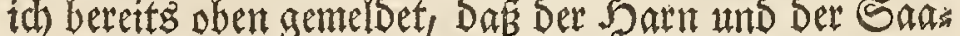
me Durch einen (Eanal, jenter int Die Sarnblafe, und Dies fer in Die Samenbläslein gebradhtwande, badodi Die Soarnblafe, in einemam \&eib geoffneten Fro/h, uber Dem SRaftsarm, Die Saamenbláslem aberunter felbigemlie: gen. $23 i e$ aber, iff wohl Diefes yon mir gefunderte flet:

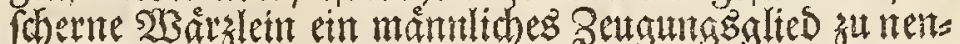
nen? Ich follte es faft glauben: Dant ob id gleid

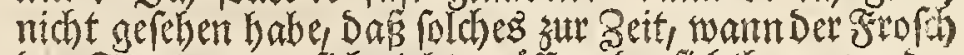
Den Saamen wonfth giebt, groffer oberfithtbarer nerde: fo ift Doch von Den SRogeln betant, waldhe eben anth Eein fichtbares måntlides Bjlied haben, Daf fie ben Det Naanuth fid mit Dem 2 Beiblein burd) einen etwas bers firragenbent fleifhtgen Theil veretnigen, wie fortberlich an Dem Enterich ober Eittsogel zu chen, ant welohem

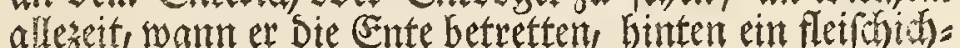
ter Sheilherabfanget, Derintmer wieder fleiner wit's unto

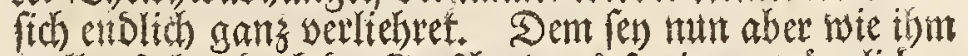

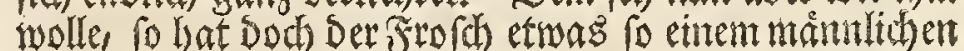

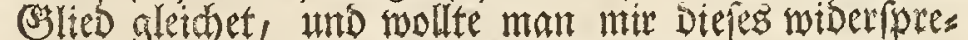
chent fo babe ith einen soman ant ber Sette, ben auf fer Serrn onersen, viele grofle Buelehrte für emen Der

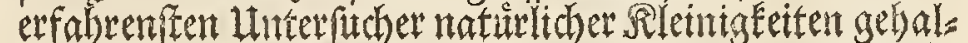

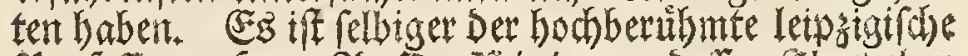

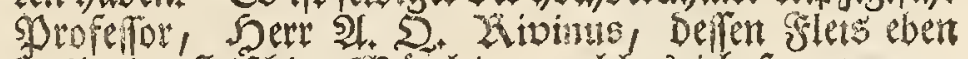
bazientige fleifhige 23 inesteits, welches ith fo unvermus thetentbedtet babe, bereits lange vor mit gefunden $\left(^{*}\right)$, weldes mit Sert D. Suth, enft nadherbends antgesets get. Db mum alfogletch felbiger Der ente estrinter Deefes

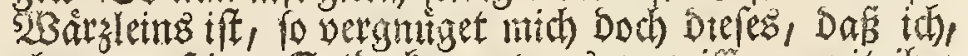

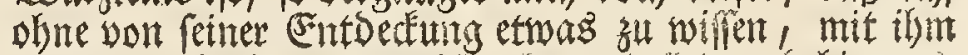

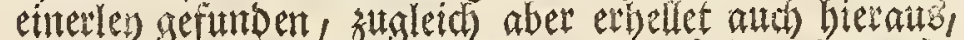

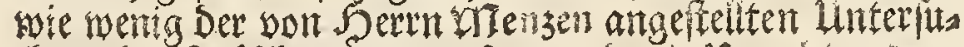

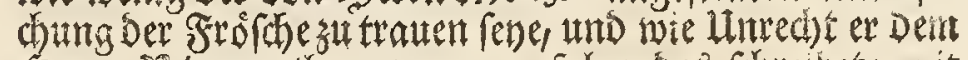
Sern Rivuno thue, want er folgendes fdyelbet: wit aller Gcharffichtiglent aber babe id nidat entsectent

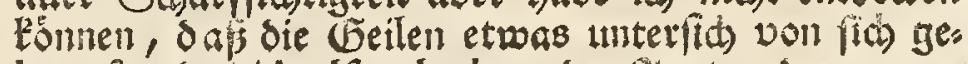
ben, fo, dabich alfo glaube, der Zutros der amito:

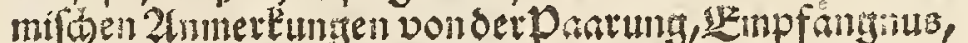
ber Crabtigleit und Geburth oet stoldse, weldher eben belobter Serr Rivinus ift, habe fidh 3 w vel be. taus gentommen, wann er die zufuldendern befafe auf feiner abeille vorftelligg gemahet, nid t weniger and o oe Gammenblaslein troffer abbiloet als eB fici) 341 Grof

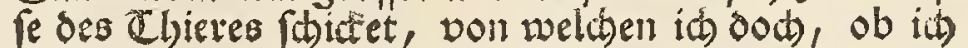
fie gieid now fo fleiffits gefudhet, nicht das geringite gefelen babe, wie fie dem anch andere eben 10 wenig tgefunden; aud ift das aus Dereinigung bet ausfub. teiben Gaanengefófe entftandene manmlicbe Glieo,

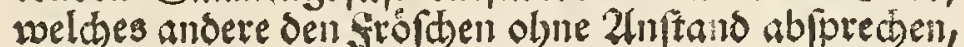
antfer dem Gentibloe niemals tefehen worden. Stimms ten Diefe 230 rte ntit Der 23 aherheit libercin, fo wurbe Der grofte Theil won Demientigen was tch bisher gezetget Gabe, einleerez 2 orgeben fenlit alletne Serr thenb hat,

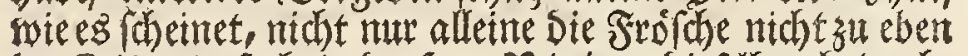
Der Beit unterfuchef, Da Serr Zivinus Diefelben betratis: fet, fondern es musibm auth Das anatomifore 2 lug ges mangele haben. Da ner erbellen, wann wir mun auch bie'sur zeugung gefori:

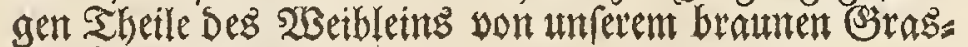
frofd betractiten.

Bu biefem Ende wollen wir Die erfte Sigur ber VII

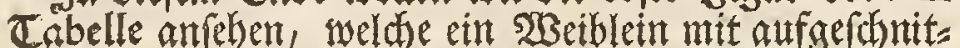
tenem Reib vorftellet, Das Der áuferlichen Structurnads (S) 2

wiel

(*) Vid, Act. Erudit, loc, Supra cit. 


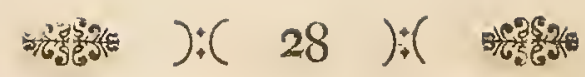

habet crara. Quemadmodum vero in hoc partes generis propagationi inferuientes, non omni anni tempore ejusdem funt magnitudinis formaeque: fic \& in foemel lis partes hasce nutari obferuamus; elegi hinc ad examen a me inftituendum, eiusmodi foemellam, quam mafculus iam aliquamdiu amplexu fuo fouerat, cuiusque vterus, maximam partem, ouis nondum impraegnatis repletus erat, a monftrat in $I$ hac firura, VII Tabulae cor in pericardio aperto; $b b b$ hepar, $c c$ veficas pulmonales ex parte tantum aere repletas; $d$ veficulam felleam orbicularem; e e ouarium ex quo quotannis tot in vterum deducuntur oua; $f f$ tubae funt vterinae ex vtroque latere vtero fitperius adhaerentes; indicant litterae $g g$ tam vterum ouis, vel fpermate, repletum, quam fedem illam in qua tubae in ipfum hiant. In latere finiftro furfum verfus ventriculus $b$ fitus eft; $i i$ tenuia funt inteftina; prope literam $i$ vero quae fuperiore in loco eft conficicitur lien; $\mathrm{k}$ inteftinum rectum ita cum vtero nexum, vt illum in duas quafi diuidere videatur partes; / vefica vrinaria bifida.

Atque haec eft conditio nonnullarum harum partium, in foemella fperma mox editura; quodfi vero tempore autumnali eiusmodi foemella aperiatur , nullus fere in illa reperitur vterus, ouarium contra multo apparet maius; immiffo tamen in vterum aere, et hic inde repletus in confpectum fe dat, formamque habet 2 firurae, Tabu!ae VII, in qua per $\iiint \iint$ ouarium vtero incumbens atque cohaerens defignatur, quod Septembri femper menfe huius magnitudinis atque, ob oua nunc increfcentia, ex nigro cineracei coloris effe obfertauli. In varios illud diuiditur lobos, tunicaque conftat tenera \& loculata. Ex vtroque latere vteri aere repleti $u$, tubae $t t, t t$, multo quidem longioris, pars dependet, filo in loco quo eandem difcidi, conftricta atque $\mathrm{ab}$ aere quo diftentitur amplior reddita. Uterus inflatus ouatam habet figuram, geminusque eft, in duos quippe loculos diuifus, membranaque conftat tam tenui atque pellucente, vt collapfus vix a reliquis abdominis partibus difcerni queat, of inteftinum eft rectum, q́uod ad $x$ a tenuibus inteftinis feparaui; $y y$ vefica vrinaria duplicata, hic quidem, ob inteftinum rectum a $t z$ $t z$ ad $n$ vsque diffectum, diuifa, ea vero in fede' vbi inteftino recto cohæret, in hoc aperitur. Indicat $z$ hians vteri orificium, per quod facile aere repleri poteft, ita, vt aer etiam in tubas tranfeat; per hoc vero orificium oua quoque, antequam foemella eadem excutit, vt mihi quidem videtur, imprægnantur.

Ex D. MENZII fententia tubæ pectus verfus directæ in illud etiam aperiuntur, fcribit namque: admittere illas aerem ita, wt totus canalis impleri queat, ad infertionem vsque, quae fit in pettore, vbi ala vtraque anneEtitur, Er exilitate fua effugit videntis aciem, ad exteriora tamen videtur tendere; de HEIDE contra feribit: barum tubarum vinum extremum circa pulmones patulum iacet in abdominis cauitate, fere infundibuli inftar ex latiori orificio in auguftiorem canalem defcendens: deinceps aliquanto amphor euadit; tantum vero abeft vt clariff-

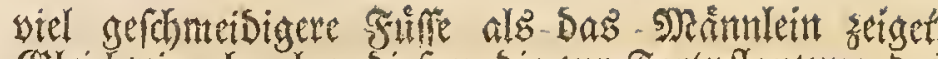
(SIletchivie aber ben Diefem Die zur Fortpflanzung Des

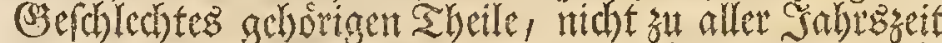

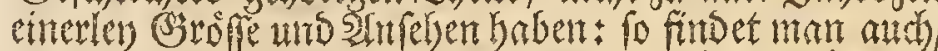

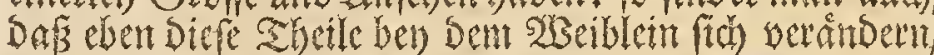

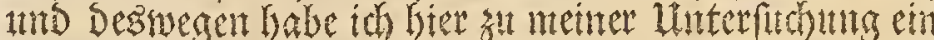

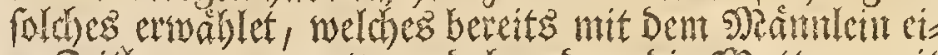
ne Beitlang gevarret, amb ber bem bie snduter, mit

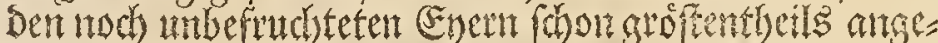
fillet gewefen. a zeiget in Diefer erften Sigur Der VI Cabelle Das 5 bers in Dem geofineten Sertbentel; $b b b$

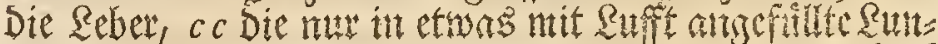
genblafen; d Die munde Ballenblafe; ee Den Syenfod

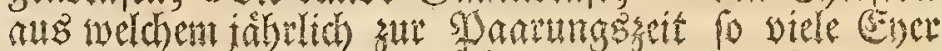
in Die sjutier Eomment f f ftro die an troer Seite Der Nonfter obenther liegende Energange; go getgen fo wohl

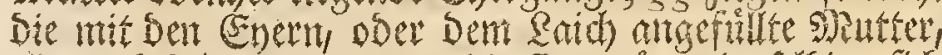

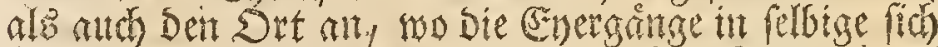
offrten. But lintent Seite liegt oben ber sengen $b, i i$ find Die Shumen (Sebarme into bev) Den obern $i$ if Sas

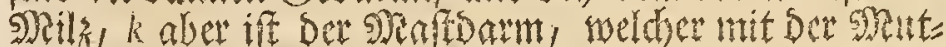

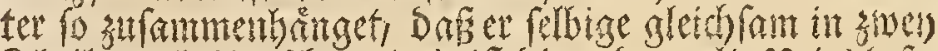

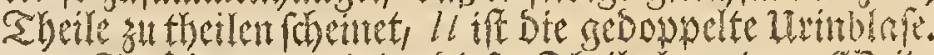

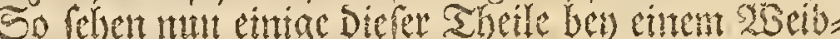
leit aus, waldyes Den \&aich jest bald vonfidi gebentoll:

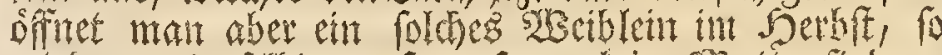

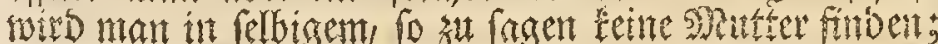

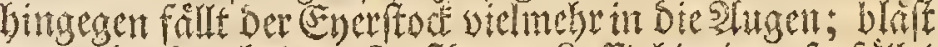

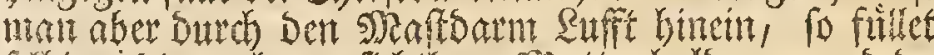
felbiget bie vorker unfidbtbare sNatter balb an, amb da zeiget fie fich fo, wie folche in Der 2 signt Der VI Cs.

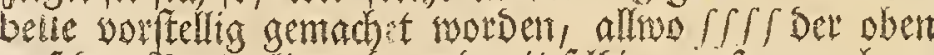
anf Der souter liegende unto mit felbiger sufamntenthan

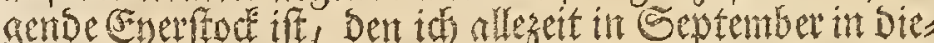
fer Sroffe gefunden, Da er Dammanth yon ben in ibmbe=

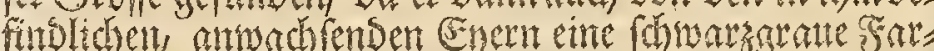

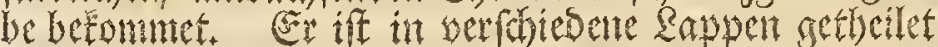
and beftehet ans einer zarten fídjerichen somt. 2 in

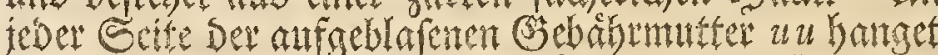
nochein Sheil $t t, t$, yonden fonft fertr langen Eyergan gen welde bier etwas Dide erfobeinen well fie alth mit

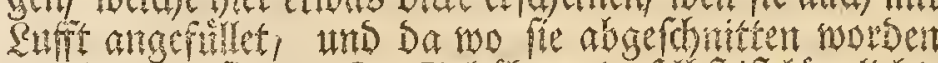

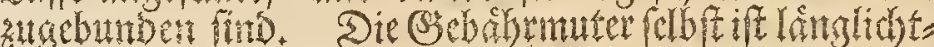

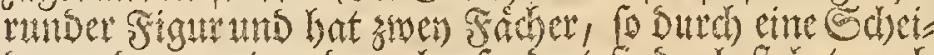
Devants yon einamber abgefondert fins, beftess at ad

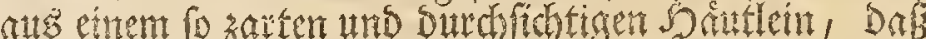
want fie sufammengefallen it Dem Reib lieget, fie nidist

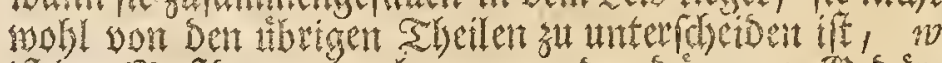
if Der Jaftsarm ber ben $x$ bon Den Dirnterten (Sebir:

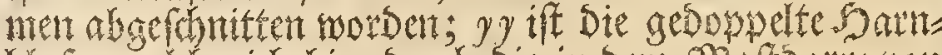

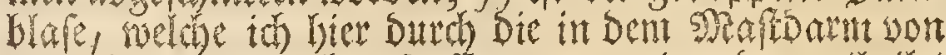

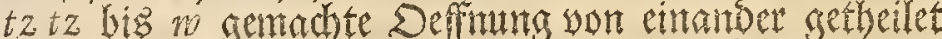

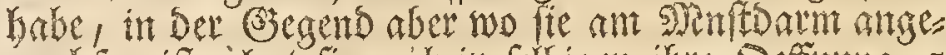

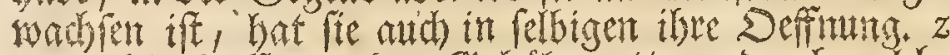
seiget bie Defintung Der (S3ebahrmutter, Durch welche

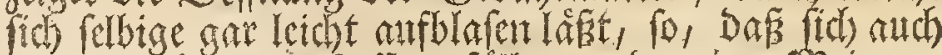
Die Evergentige mit Luffit anfitllen und meiner soeinuts

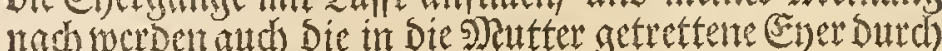

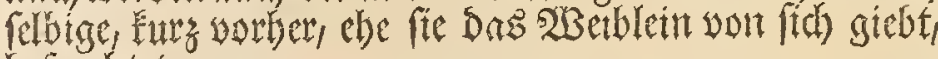
befuthtet.

Die Energintge, Durch welche Die Ener in Die Nut ter fommen biften fich nach Sorr miensens speinung

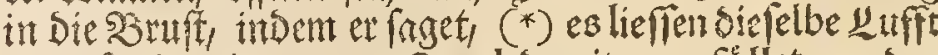
ein, 0 , oat; ber ganze Cancl oamit angefinllet weeden tönte, bis oabin wo er in oer 23 ruft, oa wo die $2(d)$ filn fund, eingepflanset ift, und felbitger fo jart woito,

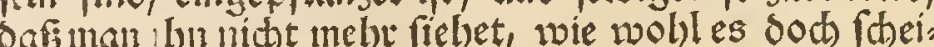
tie oaf er nadb anfen gebe; Kingegen faget de Seide

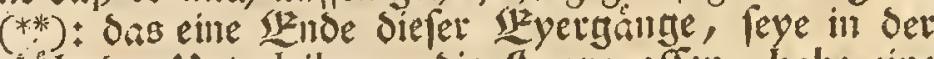
Sóle bes L binterleibs un die Sunge offen, babe eine wocite 


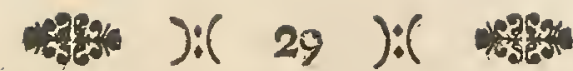

clarifimus MENZIVS verbis hifce fidem adhibeat, vt po- weite (1) ffinunty uns werbe bernach gleid cinen Crid, tius contra oculorum euidens teftimonium dicta putet, tet enge, alsdeun aber wieder weiter. Serr Mensglants quin addit, quot verba, tot negligentiae argumenta, $\pi$ a bet Diefen 230 rten nicht, und mennet fiemårendemelaren

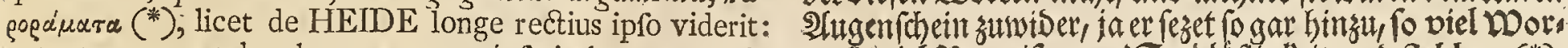
patent namque tubae hae reuera eo ipfo in loco quem de te, fo viel Zeweife von Ladaleffigteit und fehlevn (*), HEIDE indicat, id quod nos propior fivurarum VIII Ta- obgletch de betse viel beffer als er gefehen. Dennes has bulae infpectio iam nunc docebit.

Oftendit figura illa VIII huius Tabulae quae nunieris $I$ et 2 fignata eft, vterum, ouarium, partes foliaceas huic cohaerentes, tubas euolutas nec non cor, circa quod fuperius illarum eft orificium. Defumfi partes hafce ita fibi cohaerentes, ex rana foemella admodum magna huius fpeciei, illique fere fimili, quam figura 4 o tertiae Tabu. lae fiftit. Seruaueram.illam ad menfem vsque Ianuarium, vifurus vtrum omnem per hyemen viueret; quum vero mutationem illam, cuius modo mentio facta eft, quaeque certis anni temporibus in partibus ad generis propagationem pertinentibus fieri folet, obferuaturus eram, dicto menfe ranam hanc incidi, quoniam tempus coitus, quem ranae menfibus Martio et Aprili exercere folent, propius aberat. Partes ablatas afferculo impofui humefacto, ne iufto citius ficcefcerent, dein vero tubas, valde femper concrifpatas inflexasque, vtero incumbentes, quemadmodum ex 5 figura Tabulae buius B C cernitur, euoluere tentaui, quo longitudinem ipfarum commodius oftendere poffem: tenui enim membranae, eundem fere in modum quo inteftina cum mefenterio cohaerent, annexae funt, atque hinc etiam eft, quod multum concrifpatae, tot forment flexus, $\mathrm{Ab}$ hac tamen membrana illas vix potui liberare, donec easdem aere repleui; fed et ne fic quidem omnem illam, absque tubarum laefione, auferre potui varios hinc in figura noftra adbuc oftendunt flexus, licet easdem ita euoluerim, vt omnino, cum SW AMMERDAMMIO credam, fuperare eiusmodi tubam duorum pedum longitudinem. Nectuntur tubae hae anterius cum vtero, quem prima refert figura $d d d$, inflato, in quem etiam ad $c c$ hiant, dein vero ad 2 fiuram vsque extenfae, cor a verfus tendunt. Quo propius ad hoc accedunt, eo etiam magis redduntur anguftae, quoad craffitudinem fimiliter decrefcentes; pellucent hinc, indeque oftia earum cordi proxima $b b$, atque hic, quum iam ficcefcerent, quam reliquis in figuris anguftiora, vix ac ne vix quidem inueniuntur. Indicant litterae $e e e e$, in $I$ hac fisura, ouarium, hoc iam tempore mole ctum; pone illud pars confpicitur renum, fuperius vero partes foliaceae $f f f, f f f$, hoc pariter tempore multo, quam alias, maiores. $g g$ vefica eft duplex aereque diftenta $; b$ inteftinum rectum, cui fuperius pars adhaeret inteftinorum tenuium, filo hic eum in finem conftricta, ne vteri tubarumque repletio, per aerem in anum $i$ immisfum, impediretur, qua facta ipfum etiam rectum colligaui inteftinum.

Dixi iam fuperius, diuifum effe vterum fepto intermedio in binos loculos; licet vero id adfpectus iam fatis fuperque doceat, rem tamen curatius examinaui, vifurus obgletch be setoe stel befier als er gevehen. Dennes ha ben biefe energannge wirdtich in Der volt de Seide anges

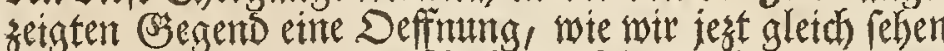
werber, went mir Die verfdhtedenen Figuten Der $V$ ill. Tas belle genåter betrachten.

Dieinige Figur Diefer VIII Cabelle weld) mit I und 2. beseichinet it , ftellet Die Mutter, Den Enerftode, Die mit Dentelben zufammenthangende blatterformtge Sheile, Die

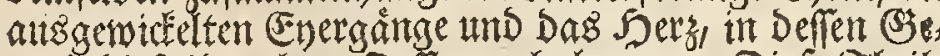
getts Diefe ibre obere Deffmung haben, wor. Diefe sheile

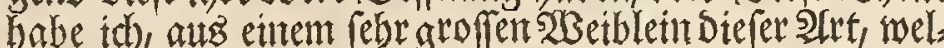
d)es Dem anf Der oritten Tabelle in Der 40 Sigur vorge

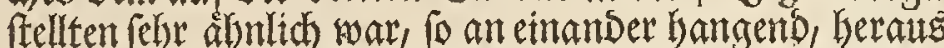
genommen. Sob Gabe folches bis in Den Nonat Jamtas

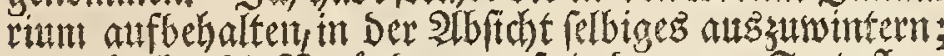
wetl id aber Dte Seranderung, fo in Denen sur Fortpflan

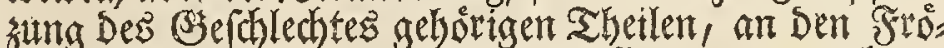
ichen zu getwiffen setten vorsugehen pfleget, wowon ich nut

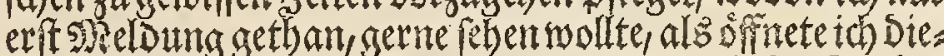

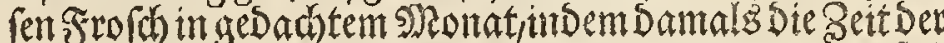
Saarung, welche im Monat Martio und 2 (prit bor fich

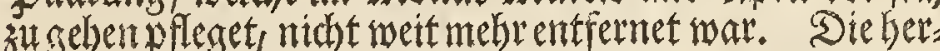
autgenommenten Sheile legte ich foDann anf eim malles Bret, Damit fie nidyt fo bald yertrodfreten, uns Gernach (utd) th Die Energange, weldhe proentlider SBetfe viele seugungenmachen nno gefrummt uber Der șutter, wie in Der 5 štgur Diefer Cabelle bey $B C$ bedanmen liegen, aus emanber zu widfelit, um ibre Rånge beffer zetgen zu Eommen. Diefesgients aber nicht fo letcht won fattem als manther wohl glauben mógte: Denn fie hangen an eitter

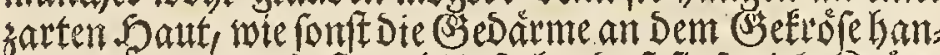

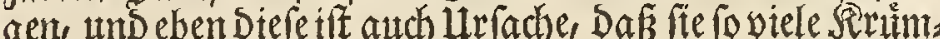
mungen und Sengungen madent; fie waren aber won fel biger nicht ehender los zubringen als bis ich fie aufblies?

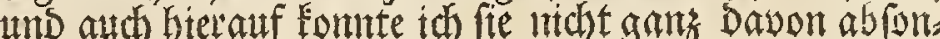
Dern, wemt ith fie nitht berlezen wollte, Daber fie Dann

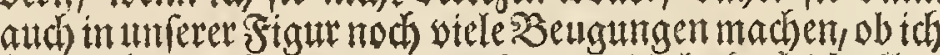
fie gleios in fo ferne aus einander geniuelt, bais id alles. bings mit Gwammerdanm glaube, ez eritredfe fich Die Range emes foldhen Energanges tiber zmen Sthuhe. Die= fe Energânge hangen mit ber in mererer s figur vorgeftell ten uns etivas aufgeblafenen SDutter $d d$ a vornen zujantm

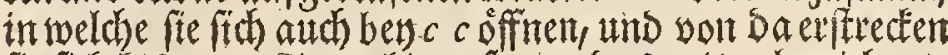
fie fich bis gttr 2 Sirtur himauf, an Das mit a bezethnete Sors. Te náber fte zu Deferm Eontmen, je enger werdenfte auth, and in Der Didte nebmen fie um Diefe (jegents gletd) falls ab. Daher fie Dem auth gan' Durdfitd tig find, und

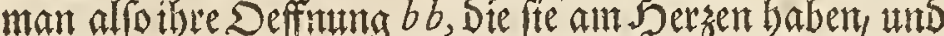
welche bier, weil fie bereits trodeen sut werden anfiengent ef was enger als in ben itbrigen stguren vorgeftellet wor: ben, nidht fo letdit ausfindis madhet. Die sitchitaben

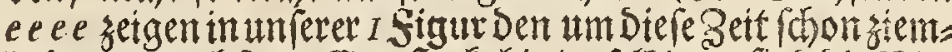

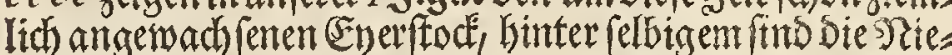

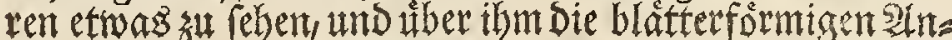
bànge $f f, f f f$, welche ebenfalls zu Diefer Beit viel gropler als ponften erfhemen. Baeng $g$ feben wir Sie gedoppelte uns burch sie Rufft althier ausgedehnte Sarnblare, $b$ ift ber bicke soaftsarm, an welchem obenter nod ein llemer

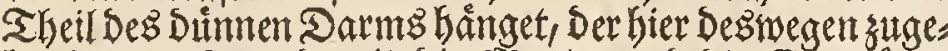
bumben worden, Damit Die Nutter und Die Energange Durch Den 2 fffter $i$ un fo wiel beffer aufgeblafen werben fonnten, worauf th) auth Den saftsarm felbften zuband.

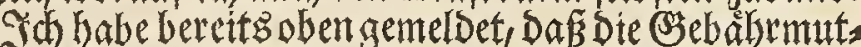

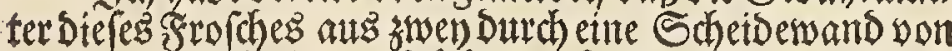
einanber abgefonderten šä) ern beftehe und ob aud gleich 5

(") . c. 5. XXI. p. 87 . 


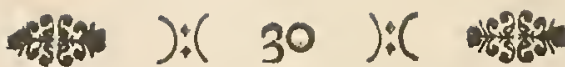

fimul, vtrum apertura, qua tubae in eundem hiant, valvula claudatur nec ne; notaui namque, aerem difficilius per vterum in tubas propelli. Diffecui eum in finem foemellam, quae iam pepererat, cuiusque adeo vterus nullis amplius repletus erat ouis, hunc ipfum aere extenfum, exficcatumque aperturus. Hoc vt ex voto perficerem, auferendus e rana erat vterus, quum alioquin vix exficcari poterat; quodfi enim non ficcatum aperuiffem, fuiffet collapfurus, ipfe vero vix quae quaerebam inueftigare potuiffem. Aft enimuero connexio ipfius, cum dorfi cutaneis carneisque partibus, non poterat folui: non folum enim, viti iam dictum eft, valde tenui ille conftat membrana, fed peritonaeo etiam arctius cingitur atque ad dorfum alligatur, quodfi itaque cultro feparetur, et peritonaeum incidatur, tunc illico tenuis vteri prorumpit membrana vix rine laceratione feruanda; hoc igitur vt euitarem, fuafu D. D. HVTH rem fequenti ratione perfeci. Filo primo conftrinxi partem illam tenuis inteftini, quae recto cohaerebat, nec non ipfas tubarum vteri narum partes extremas; tum vero per inteftini recti orificium vterum ipfum eatenus aere repleui, quoad id fine ruptura ferebat, hocque facto rectum fimiliter colligaui. Difcidi tum ofla pubis; inteftinum rectum a partibus illud cingentibus feparaui, vterumque ipfum a rana ita abfcidi, vt quaedam fpinae, nec non maxima offium lumborum pars, ipfi adhaerefceret: his enim peritonaeum arctius illum connectit. Hoc peracto vterum fufpenfum tamdit libero expofui aeri, donec ficcaretur, atque tunc demum eundem et aperire, et interius potui perluftrare. Quac vero inuenerim 3 foura VIII huius Tabulae oftendit. Indicant $k k$ vtroque in latere partem extremam tubarum filo confrictarum, $l$ pars eft fimiliter colligata inteftini tenuis recto cohaerentis, $m, m I, m 2$ vero inteftinum recum pracftrictum, inflatum maximeque extenfum. Numerus 3 partem exhibet tenerrimi mefenterii, cuius ope inteftina et inter $\mathrm{fe}$, et aliis cum partibus cohaerent $n n$ loculus alter eft vteri apcrtus, nec non aliquatenus reflexus, o o feptum intermedium inferius foramine ouato $p$ pertufum, per quod vtroque in loculo contenta oua exvtero in inteftinum propelluntur rectum, cum in finen pariter apertum, id quod iam in 2 figura VI Tabulae ar $z$ oftendimus. In parte illa vteri reflexa $n n$, indicat $q$ locum illum in quo tubae eft oftium. Scribit quidem SW AMMERD AMMIVS (*) orbiculare adparere tubarum ifthoc foramen, ficubi inflatae prius et exficcatae difjecantur: at vero in minus exficcatis, quippe ideo concidentibus, figuram id ouatam prae fe ferre; in mea contra rana oblongum illud erat, et altera in parte malginem habebat circularem, pars altera incurua, antrorfum ferebatur, et in acumen abibat; inucni infuper, obturar illud tenui membrana, quae, ceu videtur, valuulae in ftar oua e tubis in vterum admittit quidem, reditum vero ipfis praecludit; huius autem membranae SWAMMERD AMMIVS nullam iniicit mentionem, atque hine coniecturae locus eft, illum eandem non vidiffe; fed nec ego diftinctius potui videre, qua ratione valuula haecce aperiatur, fuerat namque exficcata. Comparent infuper hac in figura offa vtero cohaerentia, a quibus eundem, quemadmodum iam indicaui, feparare non potui; quoniam vero vterus admodum pellucidus eft, tam diftincte oculis illa patent ac fi prorfus nuda eflent. Eft itaque $r$ medium, $\iint$ vero vnum ex lateralibus illis offibus quibus lumbi in rana componuntur. Ad $V$ tandem ouarium cernimus, in foemella hac vacuum, atque hinc, vt et ob exficcationem, valde exiguum.

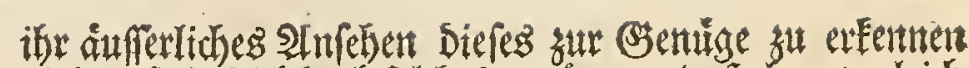
giebt: fo hab ich Doch folches genâter unteriucher, zugleich aber fehent wollent, ob bie Energange, ber ibret Deffinttig

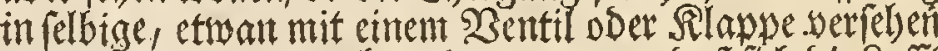
fern no nicht fo leicht Durd) Die soutter in Die Energaintge treiben

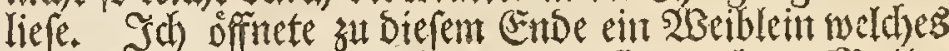

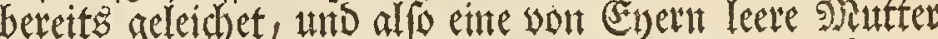

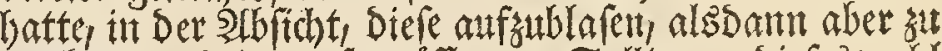
troditen, mo hierauf zu offinen. Sollte mun diefes wohl

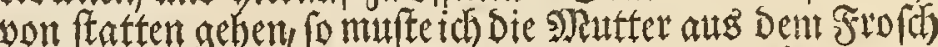

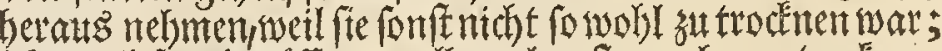
batte ich fie aber offinen wollery obne fie vorber zutrodinen,

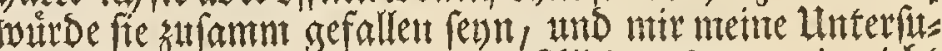

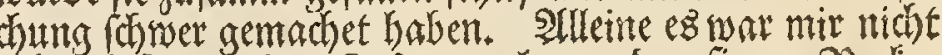
moglich fie vont Dent Bufantmentang, ben fie an sitten mit Dem Dafelbit liegenden hantigen und fleifhichten Sheilen batte, absuloren: Demn fie beftebet nibst mat allein, whe ich bereits gemelbet, ans einem fehe zarten So wutlein, fondern tie aud noch oon Dem Darmfell ibersogen, wels ches Diefelbe hinten ant suteden beseftiget; fo bald mant fie

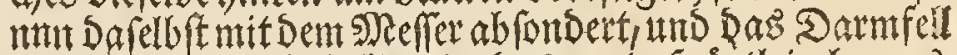

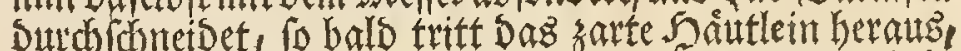

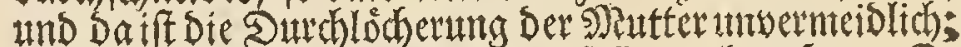
Diefenmach berfulye id enblich auf (Eimratben Sperth D. Sutbs folgender mafien. Job bant nantlich erfflich ben

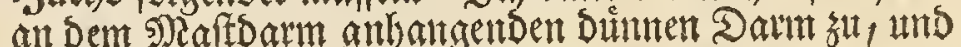
mit bett beedert nodh an Der \$nutter hangenden Sheilett

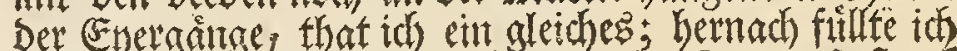
Ditch Sie Defintutg Des SRafto arms Die Nutter fo ftarce mit Eufft an, als es fich, shine Berfprengutg Derfelbert, than lies, unt hierauf band ich foldenebenfalls zu. Tads Diefem trente ion Die Sd) antbeine ntit Dem Neffer yon eint

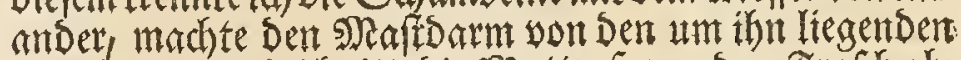

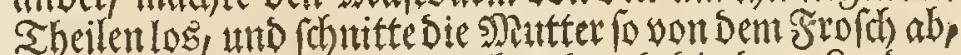

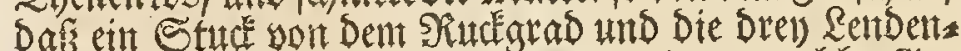
fnodien arditentheils Darat blteben, als unt weldhe (St) gent biefelbe Durd Das Darmfell wefte gefaltent wird.

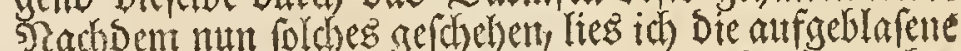
9) utter folange in ber freven Rufthangen, bis fte trodeer

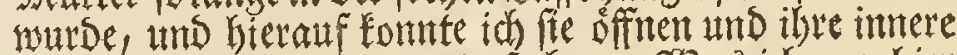

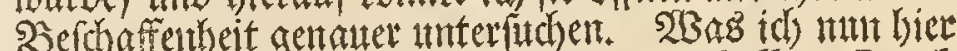
entoecter, zeiget Die 3 Sigur Diefer VIII Eabelle. Dutrón $k k$ wird ant teber Seite Det zugebundente Reft Der Evyers

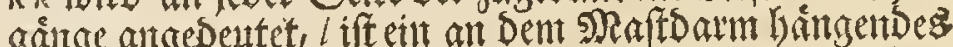

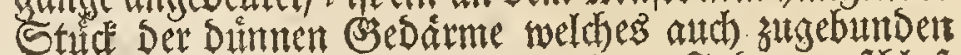
worsen, unt $m$ Der gleich fals mit einent Faden yelf chlofs

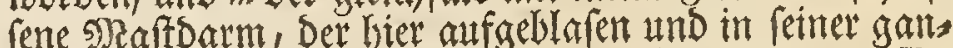

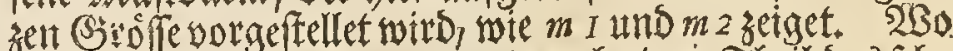

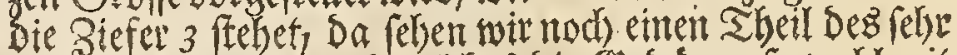

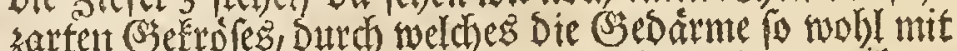
einatber folb t, als mit andert Sheilen sufamment baits gen. Das eine geoffinete uno etwas zuntud gelegte Fad

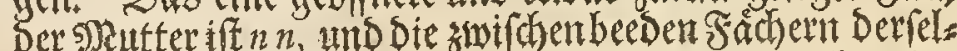
bent befindiche Sheibemano o o, in weldher witenther eine

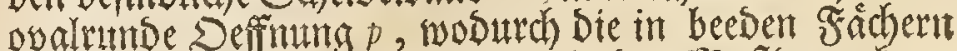

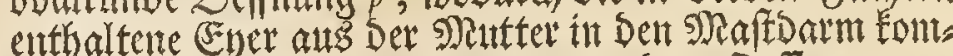
men Der'besivegen wieser ntit einer andern Deffmung bet: fehert iff, Die wir bereits it Der 2 Sigur Der VI Cabelle ben

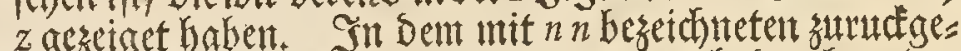
legten SThil Det (Sebábrmutter witb auch Durd) a Der Drt angezetget, wo Der Energants fith in fellige offnet.

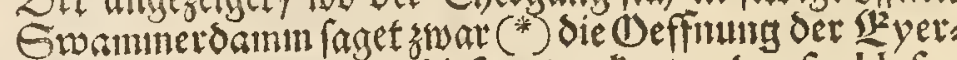
tgantre seige (idh, wann biefe getrodtnet und aufgeblafen worden, itulo; waten fie aber nidt getrodinet, fo fies len fie 3 lanm und oa feye felbige oval; in meinem Frofch aber war fie ablang, unb ant einer Seite rumb, alt Der alidert lief fie Erunt ttad) vornen zli, und enbigte fich tit eine Spize + Daben fand ich folche mit einter zartent Saut

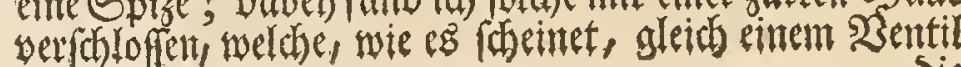
Reli-

(*) Bibl. Nat. p. 799 . 
Tab.VIII.

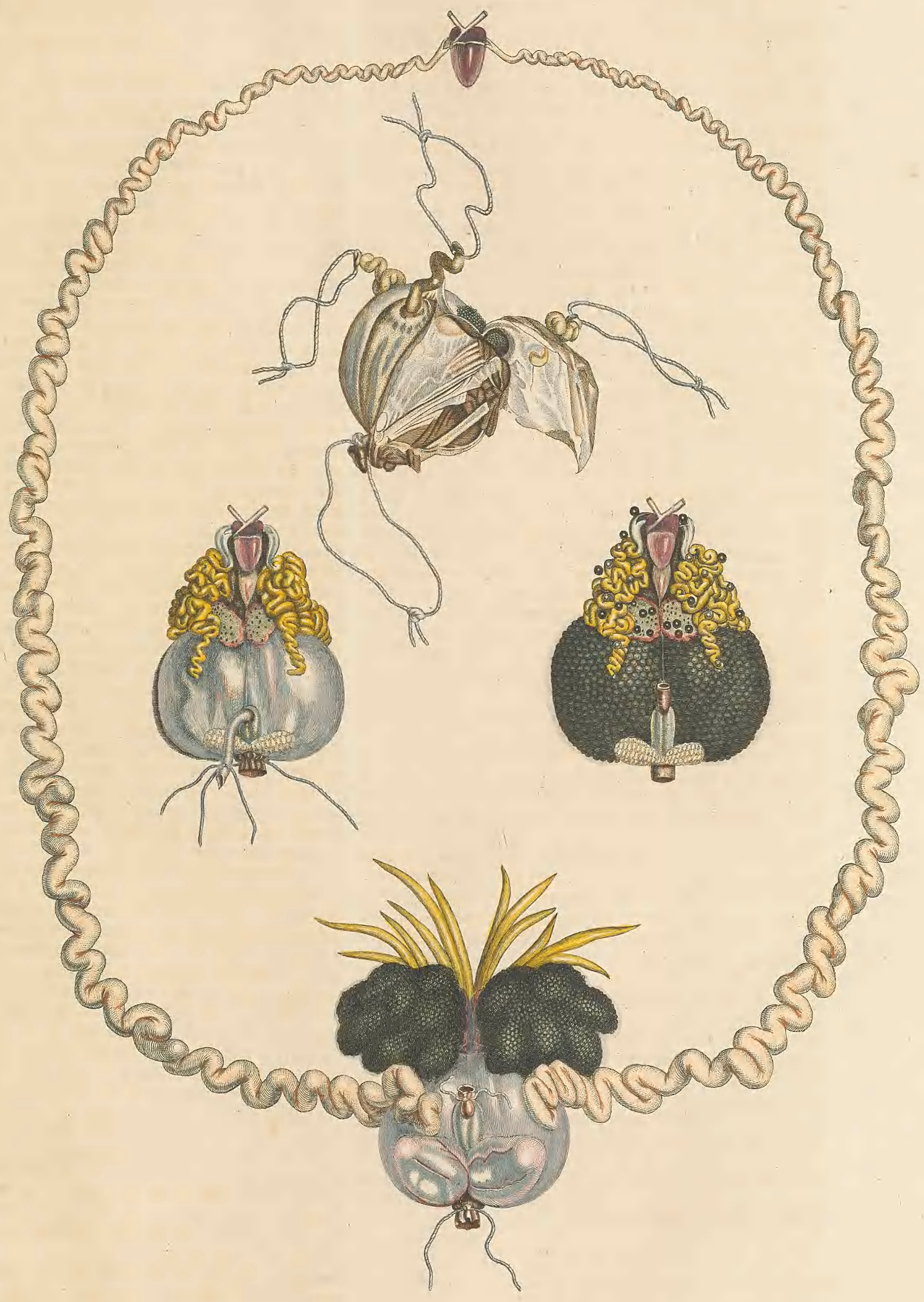



Jab. VIII.

Fig. 2.

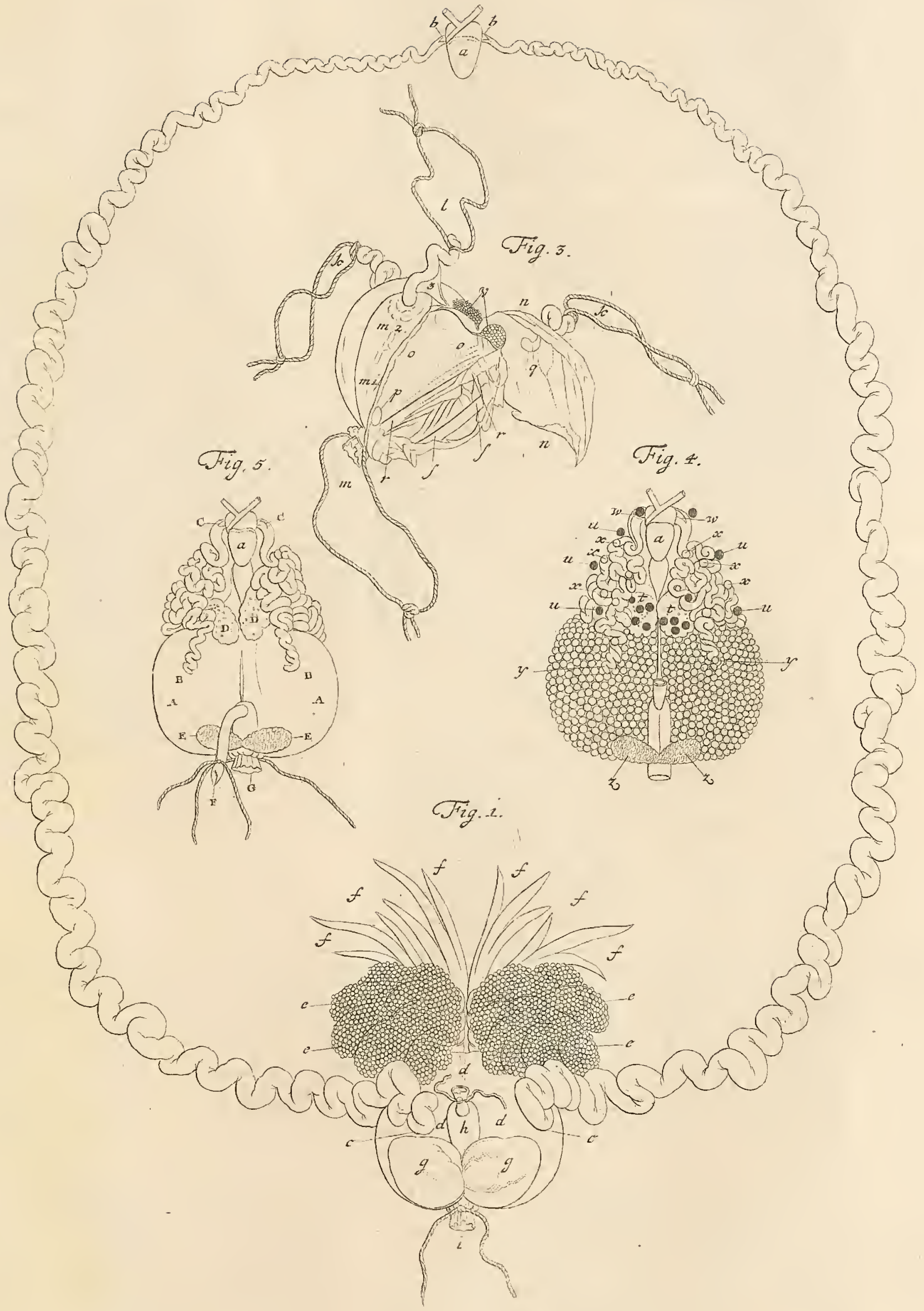





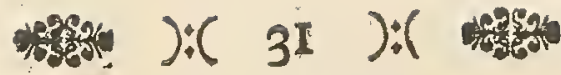

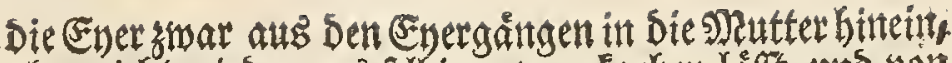
aber nicht wieder ats felbiger surtudgehen láfit, und von Diefer Sout gebendet Gwammerdamm nichts, soraus

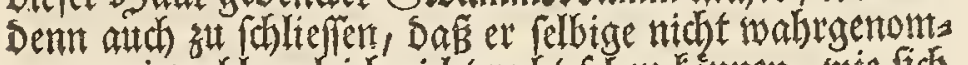
men; wiewohl auth ich nicht recht fehen fonten, wie fich

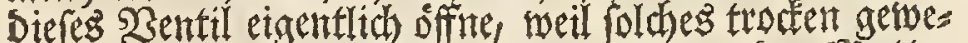
fen. Horigens seigen fid alld nod Die an Der soutter

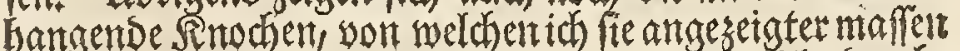

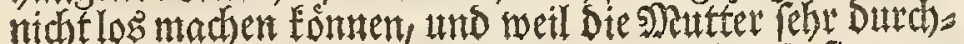
fid)tig ift, fo fiebet man fie fo Deuflid), als ob fie gaits blos warent $r r$ if alo Das mittlere $\iint$ aber etres Der smey Seifentseine, woratrs Die Renten bey Dens Frofoh befteken. Endich fehen wit aud nod ben $v$ ben Enerftoe, Der in Dierem $23 e$ ibleit antsgeleetet und Daber fehr Elem wat, atth wegen Dez Trodnens nod) Eletner ges worbert.

Reliquae VIII huius Tabulae binae figurae, exhibent partes, de quibus hactenus egimus, eo in fitu, quo ipfa in rana inueniuntur, fi hepar veficaeque pulmonales ex illa fuerint ablata; delineaui vero easdem hac ratione, quia, fi ipfam quoque appinxiffem ranam, numerum tabularum, praeter neceffitatem, auxiffem. Siftit itaque 4 figura hafce partes, quales illas in foemella quadam inueni, quae iam cum mafculo copulata erat, quamque ab eo feiunxeram, rationem illam inueltigaturus, qua oua ex ouario in vterum defcenderent. Aperui eum in finem plures vna foemellas, vidique in nonnullis earum omnia oua ouario adhuc conclufa, vterum vero inanem; inueni in aliis non folum oua quaedam in vtero et tubis, fed et in ipfo paffim abdominis cauo; in aliis rurfus, quae vero diutius copulatae fuerant, maximam ouorum partem in vtero deprehendi; haerebant nonnulla etiam hinc et illinc in tubis; quaedam in abdominis cauo difperfa reperi, nec non pauca ouario adhuc cohaerentia: id quod 4 figura ob oculos ponit, $t$ t ouarium eft, in quo pauca tantum haerent ouula, quodque vtero plurimis iam ouulis repleto incumbit. $u u u, u u u$, indicant vtroque in latere illa ouula, quae ab ouario foluta, tubas verfus tendunt, binaque alia $w$ to prope orificium tubarum iam fita; $x x x, x x x$ oua funt quae tubam iam intrarunt, $y y$ illum monftrant locum quo tubae in vterum hiant. Gemina, aft vacua inteftinoque recto incumbens vefica vrinaria litteris $z z$ eft fignata.

Quod tandem ad 5 fouram attinet, repraefentat illa partes iam faepius memoratas, quales fefe in foemella quadam, quam poft emiffa ouula aperui, inflato vtero, exhibuerunt. $A A$ vterus eft aere diftentus, $B B$ pars extrema eaque inferior tubarum, $C C$ orificium earum in fitperiori extremo, quod femper proxime a corde $a$ abeft; $D D$ oularium vtero incumbens, quod fingulis fere annis, poft oua emiffa, tot rurfus fere repletur, quot antea edi. dit; $E E$ vefica vrinaria vacua; $F$ pars inteftinorum tenuium; $G$ inteftinum rectum.

Enumeratis fic harum figurarum partibus, haud difficulter ea iam indicari poterunt, quae ipfo fub coitu ex parte foemellarum fiunt. Patet ex illis quae iam p. 28 de 2 fisura YI Tabulae, modo vero de I, VIII p. 29 diximus, increfcere autumno atque hyeme ouarium, oua, partesque foliaceas ouario cohaerentes; circa illud vero tempus quo ranae coeunt, augentur oua quotidie mole, donec maturuerint, vernoque tempore, quo ranae hae terreftres coeunt, $a b$ ouario, ipfo fub coitu, fecedant, fur-

Die auf Diefer. VIII Cabelle nod) tibrige beede Sights rent seigen uns Die Theile won welchen wir bisher gehalts Delt baben, in Derientaen Rage, in welder man fte in Dent

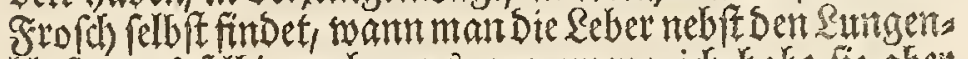
blafen aus felbigem herausagnommen; id babe fie aber

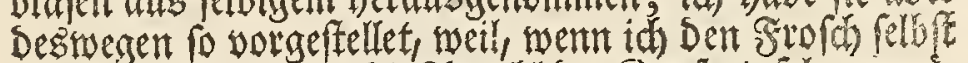

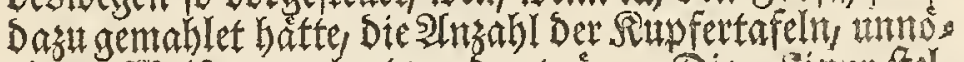
thiger 5 Beife vermebret worben waire. Die 4 Sigut fell

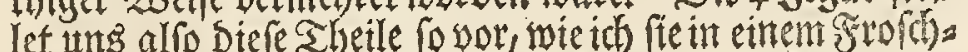
tweiblein gefunden, welches bereits mit einem snentinem aesaaret war, ich aber bezimegent yon biefem losgemanthet

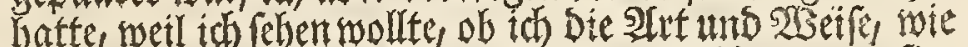

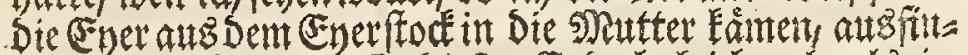
Digmadien fonnte. Ztt Diefem Ende bab id mebralsetr

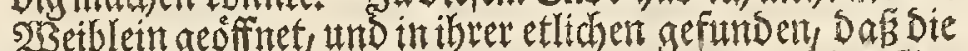

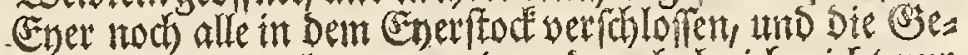
bäbrmutter gants leer war, in andern babe th nicht nut

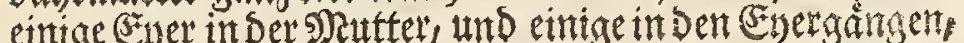
fortoern aud hin und wieder in Dem holen Leib angetrofs

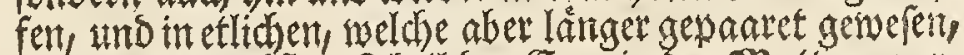
Gahe ich Den arofiten Theil Der Ener in Der Inutter; vers idjesene ftaden bie und Da in ben Energangen ; etliche fand ich hin und wieder in Dembolen \&etb; und einige we: ntge hiengen nod an Dem Enerfock, weldies alles unere

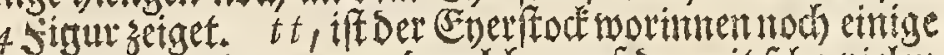
wentge (st)er bangent, und welcher auf Der nit fehr bielent

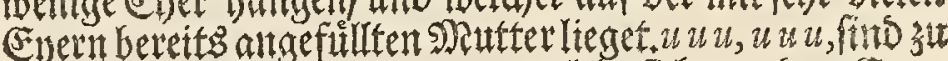

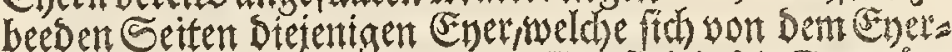

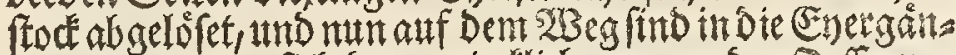
ge st gehen, wie fich Dent wireflich swey ant Der Definumg

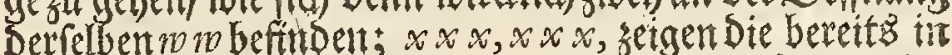

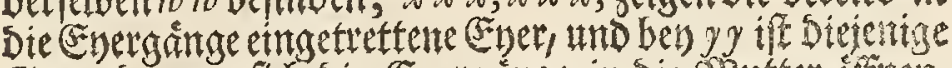

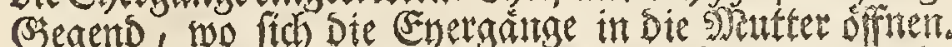
Die geboppelte, aber leere, auf Dem s)artionern liegends Utrinblafe tif mit $z$ z besetdinet.

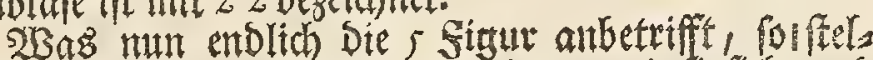

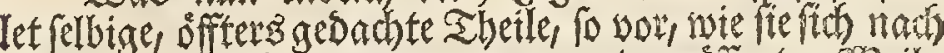

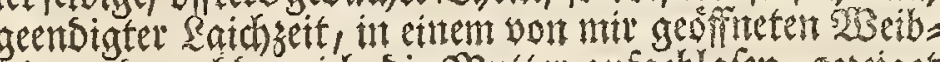
lein, und nadbem id sie sutter aufgeblafen, geseigé

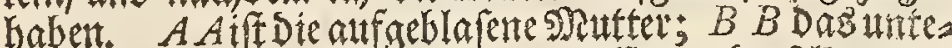
re Ende Der Energange; CC Die Deffinung Derfelben ant

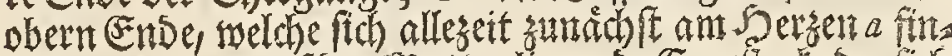
Det: $D D$ Der auf Der Dutter liegense Enerfoct, Der fíd

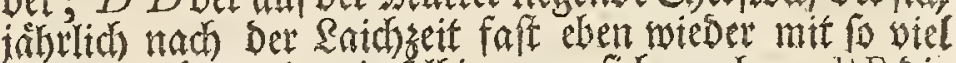
Enert anfillet, als er in felbiger bon fich gegeben, $L E$ Die leere Sarnblate; Fein Thet Der bunnen Sedarme; $G$ Der siaftbarm.

Fachbem wir alo Diefe Figaten betrahter haben:

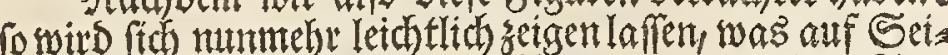

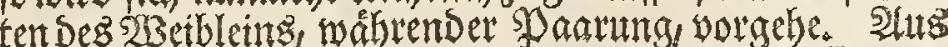
Dem was wir p. 28, won Der 2 Sigm Der $V I$ Cabelle, Itth mut erif won Der I Figur Der VIll p. 29 gefaget habert ers

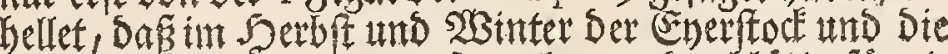
Ever, neb fen mit thm zufammbangenden blátereformis gen Shetlen, grofler werben, gegent De Bett Der Spaartits bit aber nesmen Die Ener noch inmer sit bis fee end lith su 52 


\section{4:}

fum afcendant, intra tubas ingrediantur, perque illas in vterum tandem fenfim fenfimque defcendant. Quomodo hoc fiat SWAMMERDAMMIVS fe ignorare fatetur $(*)$; rem tamen fic fe habere certum eft, nec magis mira illa ipfi videri potuit,quam mihi, quum quae de ea fcripfit legerem, figuramque quam ad illuftrationem addidit $\left({ }^{*}\right)$ infpicerem, donec tandem omnia illa ipfis etiam in ranis confpexi, ouaque non folum in abdominis cauo, fed et in tubis haerentia deprehendi, id quod in 4 firura huius tabulae iam oftendi. Reiicit haec omnia cl. MENZIVS, quumque eadem in de HEIDE etiam legerit obferuatione, eundem fequentibus refutat verbis: errat autem a regia ouorum via, et tubarum fabricae connexionique contrarium conceptionis modum confinxit HEFDIVS: quanto tubas altera parte patulas, libere fuitantes per abdomen, infundibuli forma finxit, quae oua in caunm ventris lapfa arripiant, atque per anguftiorem canalem, iterum latius extenfum, in vterum praecipitent $\left({ }^{* * *}\right)$. Quamuis vero hic regeri poffet, alia haec quam de HEIDE effe verba, hoc tamen omifo, oftendemus potius MENZII exemplo, facillimum, eorum, qui fibi folis fapiunt, effe lapfum. Quum femel ftatueruat foecundari oua ranarum per thoracem, non poterant non tubae eo etiam tendere, aliam namque, qua femen ferretur ad oua, non nouerat viam, licet de HEIDE eam illi oftenderet, ipfique BLASIVS notus fuerit, cuius in opere, SWAMMERDAMMII figura fupra citata fimiliter exhibetur $(t)$. Dicit de HEIDE, transmitt oua per tubas in vterum; tantum vero abeft vt MEN ZIVS hic ipfi affentiatur, vt potius fcribere maluerit, demitti ouula occulta via in vteri marfupium $(\dagger \dagger)$; lice infuper fatcatur, reperta effe oua in ductu, vel tuba, perfuafum tamen habet, vrgeri illa ex vtero in tubam, vi, quam patitur animal, dum viuum inciditur abdomine, quo motibus conulliuis agitur, et viterus contrahitur violentius Esc. (t+) Nonnehic meliore iure dici pofient quae ipfe dixit: quot verba, tot negligentiae argumenta,

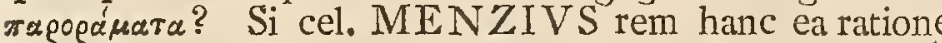
tractaffet, qua ego illam aggreffus fum, a veritatis certe tramite non tam longe aberraflet. Quum prima vice ranarum fufcipiebam anatomen, $M E N Z I I$ aeque ac IACOBAEI $(*+)$, CHARLETONI( $\left(^{*}\right)$ et SWAMMERD AMMII ad manus mihi erant figurae. MENZII ct CHAR LET ONI figurae parum exprimebant naturam, neque etiam ea inuenire potui vafa defcrentia, quae ex fententia CHARLETONI, in maribus, a teiticulis, vt tubae pars in foemellis, ad fauces tendunt; vas vero illud deferens MENZII $\left(\dagger^{*} \dagger\right)$ fuper teftibus afcendens fimiliter latuit. IA COB AEI figurae illis ex parte fimiles erant, quas SWAMMERDAMMIVS dedit; hae vero tam perfpicue omnia referunt, vt fingula, maximam partem, mox inuencrim, fi veficulas feminales mafculorum, fuperiusque orificium tubarum nec non vterum in foemellis, et in vtrisque veficam vrinariam excipias, quae cuncta ob pellucidatem diutius confpectui meo fefe fubducebant. Quum vero reliquas partes, quas fuis in figuris depinxit, adelfe cernerem, ea ipfius apud me erat auctoritas, vt plures non tantum ranas aperire, fed et partes nondum vifas, omni adhibita opera, quaerere contituerem. Atque fic inueni primo in mafculo, quem tempore quo ranae oua emittunt diffecui, veficulas feminales, quippe quae femine turgentes, prae reliquis partibus confpectui fefe fiftebant; quumque hac ratione fedes ifrer Reiffe gelanget, und im Frribling, Da fith biefe

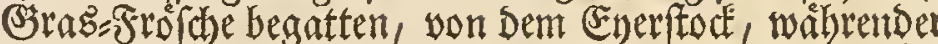
\$aarung, losgethen, in Die Şokefteigen, in Die Evergåth getretten und Durd folde, nad ind nad), in bie soutter tommen. WBe Diefes zugehe weis Gwanmerdamm nach feinem eigenen (Seftånonis itidht $\left({ }^{*}\right)$; unterdeffen geidhies het es Doch, and fo wunderbar thm biefe Sadje vorfam fo fwumberbar fohien autch mir Dieferbe zu fenm als ich Das. lenige las, waser Davon gefarteben, und Die Figur bes trad)tete, Die er Deswegen nitisgetheilet (**), bis idi) end, lich alles int Den Frófden aleich falls fahe, mo nicht nutr Die

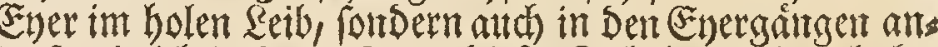
traf, wie ich in Der 4 figur Diefer Tabelle gezetget babe. Serr v17ens will hievon gar nichts wiffen, und Da er ein gleiches bey de Seyde gefunden, fo wiederipridht ex ify

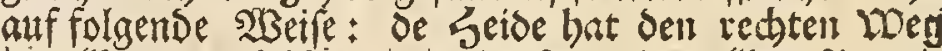

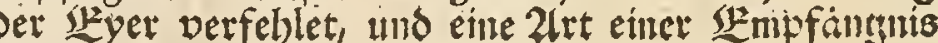

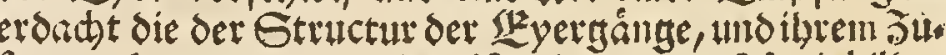
fammenthants tans jundoer if : indeme er fich énbildet

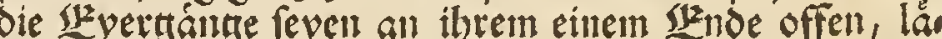
gen in llnterleib frey, und bätten die Sorm eintes Tridy. ters, ergriffen die in denbolen Reib gefallene Kzyer, und bräbten diefelben, outed einen entreren Canal, der hers Inad) wieder weiter wiurde in die mituter (***). Db wir num zwar hier eimwenden Eonnten, Dấ Die SBorte Dez de Seide anderft lauten, fo wollen wir unz Dooh hieber nicht unnotbiger 3 Beife auffalten, fondern aut Dem Exempel Serm kltenzens zeigen, wie leidht Diejenigen irren, Die fich alleine weis zu fern bumden. Da er einmal Die Mens. nung angenommen hatte, Die Befrudstung Der Ener Der

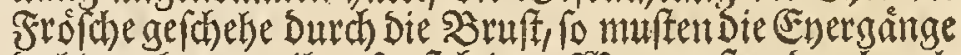
Dahin gehen, weil er fonft keinen 23 eg wafte, Durd) wel. chen Der Saame zat Den Enern fomment lonte, ob ibit gleid de seyde ein anders lebrte, und ihm aud 23 lafius itid)t unbefanntwar, in Defien $2 B e r d f$ Die son Swammer. Oanmm mitgeffeilte und bereits oben angefúbrte Şigut

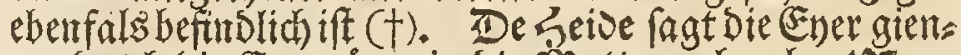
gen Durd Die Energange in Die פisutter; else aber bitens

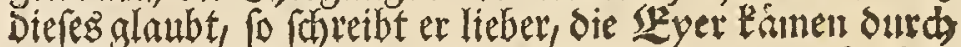
einen verborgenen toeg in die MTutter $(\dagger)$, und ob er (ch)on eingeftebet, Daş Die Evyer in Den Evergangen gefuns Den worben, fo meinet er Dod), es wirtoen diefelben aus

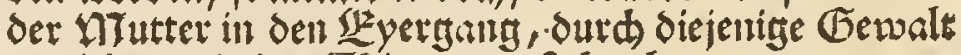
tetrieben, die das Thier ausulfteben hat, wann mantes lebendig offinet, oa es krampfhaffe 3 ewegunger Keiden unus und fich die Mintter gewaltfamer DDeife suf commen

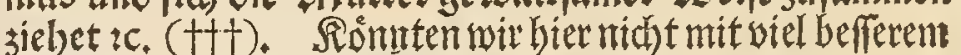
SRedit als er fagen: fo viel গBorte, fo viel 20emeife von

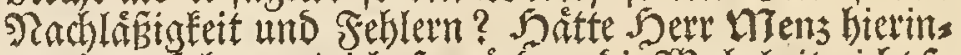

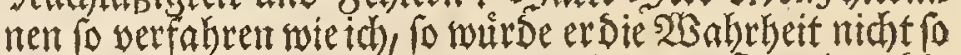
Gehr verfeblet haben. $2(13$ ich midh Das erftemal an Die

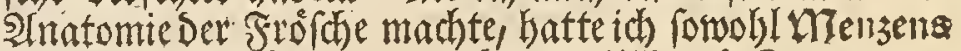
als auh Jacobai $\left(^{*} \dagger\right.$, Charletons $\left(t^{*}\right)$ unt Swammer: damms Ftiguren ber ber Sand. MTensens and Charles tons Şiguren famen mit Der Natur wenig kiberein, aud fonnte id Dieienigen (S)efáfe nidht finden, welche nad Charletons Neinutt in Dem Manntein non Den (S) eilen, wie ein Theil Der Energänge in Dem 2 Beiblein, nach Den

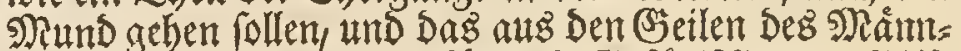
leing nad oben gehende zufúkrende mar firt meinen 2lugen ebenfals verborgen. Jacobái Fitguren Eamen theils mit Dentenigen atbetein Die wir bon Gwanmerdoumm haben; Diefe lezere aber find fo Dents

(*) Bibl. Nat. p. 807

(**) Bibl. Nat, Tab. XLVII. Fig. s.

(***) L. c. p. 20. §. XXVI.

(†) Ger. Blafii Anatome Animalium Tab. LV.

$(t+)$ L. c. \$. XX. p. I r.

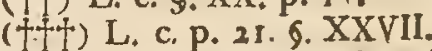

(1i) Ol. Facobei de ranis et lacertis obferuationes.

( $\left.{ }^{*}\right)$ 1. c. Mantiffa anatomica p. 20. und 92.

(t*t) 1. c. p. 13. S. XV. 


\section{4)}

quam femper occupant, mihi innotuit, nunquam non easdem poftea, vacuas licet, inuenire potui. Ope tubuli in inteftinum rectum immiffi, fufflando mox vacuum atque collapfum detexi vterum; illico namque ab aere extendebatur; vefica contra vrinaria tam diu delituit, donec tandem tubulum, quo vterum fufflaueram, nonnihil retrahebam atque illam inteftini recti fuperficiem verfus dirigebaim, quae, vbi rana dorfo incumbebat, faciem meam fpectabat; nunc vero eandem cuilibet quocunque monftrare poffum tempore. Maior nauanda erat opera in detegendis tubarum orificiis. Aere easdem repleturus, faepe incaffum laboraui, tandem vero vi aerem in illas impuli, parum curans, fiforfan vterus hinc dirumperetur; tunc vero fenfim fenfimque $a b$ aere diftendebantur, ad partem vsque haud adeo magnam, quae, quantum quidem videbam, non poterat non furfum, cor verfus, excurrere, atque hinc vifui fefe fubducebat, quod, quemadmodum iam dixi, tubarum pars extrema eaque fuperior, fic extenuatur, vt pelluceat. Quum vero hactenus aere per tubulum immiffo non fine fucceflu vfus eram, eius etiam ope me orificium fuperioris huius extremitatis reperturum, vix dubitabam, atque hinc, in rana cuius vtcrum acre non repleueram, fequenti id tentaui ratione. Tubae illae in quas iam antea aerem immiferam, docuerant me, exporrigi extremitatem earum fuperiorem in ipfa dorfi regione furfum verfus; vt igitur hanc vacuam redderem, ventriculum e rana abftuli, veficas vero pulmonum ea ratione remoui, vt cor omni ex parte nudum confpicerem: verebar enim ne, fi illas abfcinderem, ipfam tubarum extremitatem, quam quaerebam, laederem. Poftquam itaque SW AMMERD AMMII figuram, qua fuperius ille tubarum oftendit orificium femel atque iterum intentis oculis acerrime contemplatus eram, locumque illum, quo, ipfo indicante, aperiuntur, probe notaueram, tamciu illum verfus per tubulum aerem immifi, donec tandem aperturam aliquam infimulque translucentem et ad litterae s formam propemodum incuruum, confpexi canalem, quem vbi detexeram, maiori vi aerem in illum impuli, atque fic omnem non folum tubam, fed tandem etiam ipfum aere repleui vterum. Hac itaque ratione de tubae apertura certior redditus, facile nunc intelligebam, hinc tantum illos, qui tam miras de ranarum generatione fouent fententias, erraffe, quod eam ignorauerant; quodfi vero quis eandem eft quæfiturus, hic, fi ratione a me indicata rem tentabit, illam certo certius inueniet; me certe eandem omni tempore cuilibẹt oftenfurum, fpondere audeo.

Adefle itaque tubarum illud orificium, quod in 4 figura ad $w w$, et in quinta ad $c c$ cernimus, certum eft; quum vero illae earum partes, quae apertae funt, in ipfa cordis regione firmiter accretae, ad ouuarium vsque defcendere, et matura oua arripere nequeunt, qua ratione haec ipfas intrent tubas, difficilius concipitur; eam tamen fequentem in modum aliquatenus explicari poffe, perfuafum lich, Dafs ich balb Den groffen Sheil Desjentigen fant was fie yolftellen; nur fonnte ith Die Saamentaleslein in bent

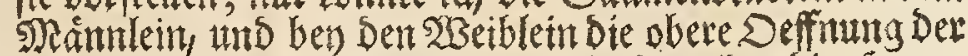
Enetgange, nebit ber sutter; in beeden aber die Sarn. blafe, wegen Det Duth fichtigfeit aller Diefer stheile lans

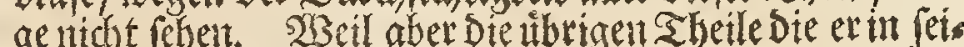

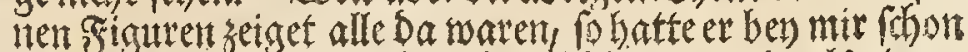

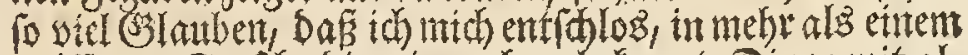
gedfiteten Frofh, Die mit nod unbe Eante Dinge mit als lent Fleis zu fuchen. Diefemnach fant therith die Saas

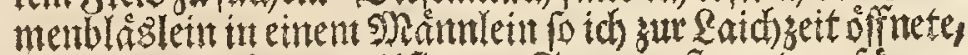
in welchem folbige, weilfie son Saamen froseten, fit ans

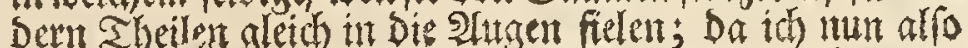
Die (Segend enmal gerdben batfe wo fie orbentlid) liegent fo Eomte id fie nach gebenss alleset ftinden went fte aut gleich san' leer waren. (sin in ben sleaftorm gebrach)

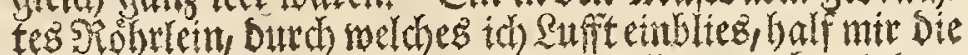

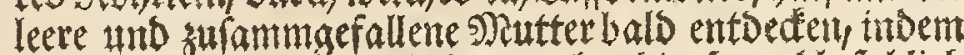
fie bie Ruft fogletdi ausbefnte; aber sie Samblare blieb fo lange verborgen, bis id) mir einmal eintallen liez, oas Sobrleit womit to Die sRutter aufgeblafen hatte ettwas

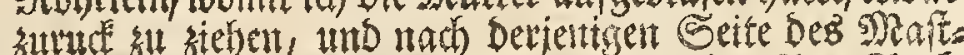

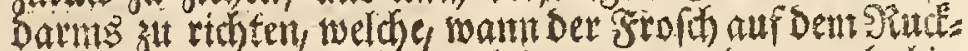
ent las gegen mein (Seftat gefebret war; and numers bin tch alleste tm Stand fie enem feden ftl zeigen. Snebr

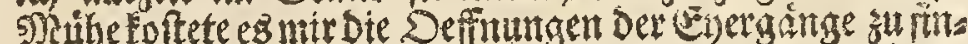

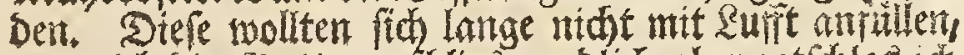

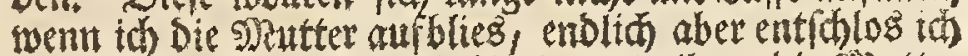

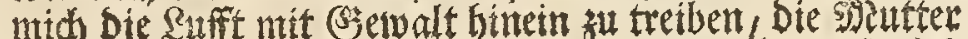
mogte Dariber bớten ober nidst, unb da fillten fie fith nad tulb nad mit Rufft an, bis auf einen tlemen wokil, Ser, fo viel id feben fonnt: oben nad Den Serzen fid er: freden mute, aber besivegen faft unfid tbat wax, weil Die Energange, wite id beteits gefaget bab, an theent oberen

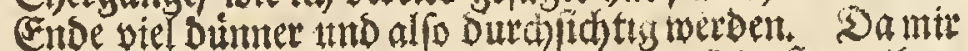
Dos Cinblafen Det Ruft bisker fo gute Diente gethait

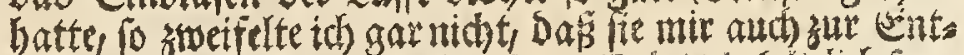

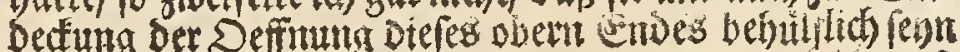

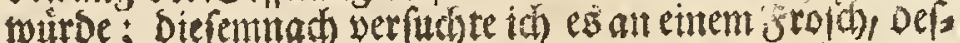
(en s)

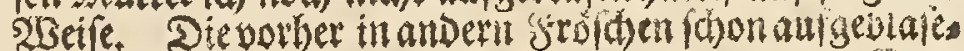

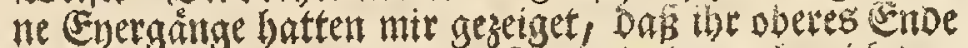
binten an sem soutten binauf ltef, Daber nabm ith Den.

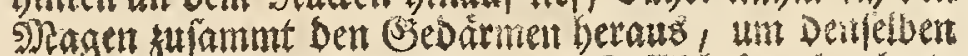
frei su betommen, Die Sungen ooer Ruffeblafen aber leste to fo auf Die Seite, bafs Das serzyalstren Dalag; abs

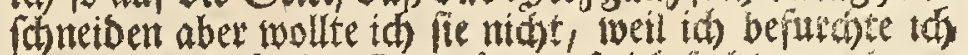
mơgte bas Bnde ber Finerginge, fo id futhte, veriezen.

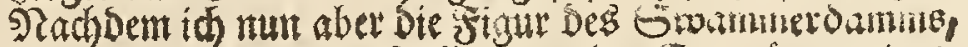
in weld)er er bie obern Deftungen Der (Et)ergonge geiget,

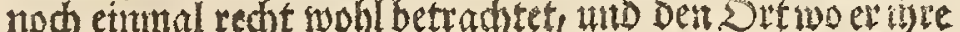
Deffunth wetfet, genau bemerdet batte, blies id fo lattge ganz fad te nad felbigen ourd mein arobrlein su bis idf

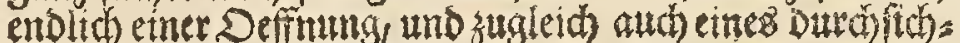

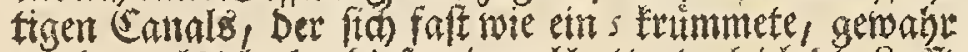
wurbe; als id aber diefen einmal hatte, trueb id ote suft

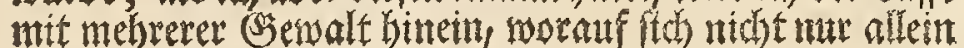

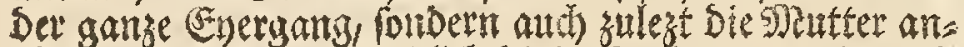

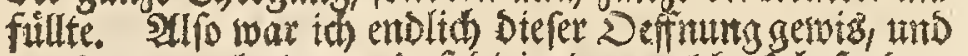
wurbe nunmehr innety Daf Diejentgen welche fo befombere Deimunaen son Erzengung ber Frofde haben blos Des: wegen gefeblet hatten weil ithen wolde nid tbetannt war:

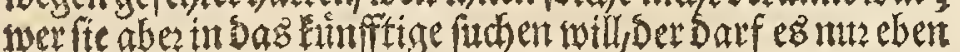
fo wie id madsen, fo wirb er felbtge ganty gewis finden; ich wentgfens getraue fte mit allezeit jeglidiem zu zeigen.

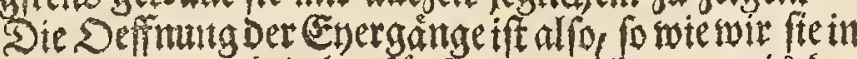

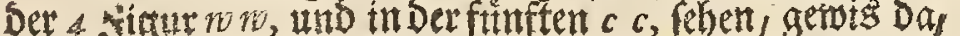
meil aber Diefe Sheile Derfelben, worinnen fie befindids find, un Die (Segeno Des Serzens seft anthangen: fo fonnen fie fith niogt bis su Dem snerfoct herab begeben und die reifen (Ever auffaften, Daber es dem aud foweht zubigreffen wiefoldie in die Energangebinein fommen; 


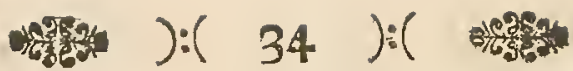

habeo. Portquam oua in outrio confuetam obtinuerunt magnitudinem, ouarium, mole admodum auctum, a tubarum aperturis parum fere diftat, atque hinc breuis etiam eft via ouis emetienda; vbi vero pars eorum in ipfum defcendit vterum, hic ipfe fenfim fenfimque repletus, magis magisque furfum verfus afcendit, ita, vt oua in inferiore ouarii parte haerentia propius ad tubarum accedant orificia; inferiora autem verfus, $a b$ ouario aeque $a c$ ab vtero, ouis via praecluditur: fi itaque hoc vel illo, mihi quidem incognito, modo, oua in motum cieantur, fuperiora verfus vt progrediantur necefle eft; qua vero ratione in tubas ingrediantur, vtrumque ope mufculofarum fibrarum, quibus illae inftructae funt, per ipfas promoueantur inque vterum deuoluantur, quae SWAMMERDAMMII (*) fententia eft, me quidem nefcire fateor; mafculum tamen ftrictiore fuo amplexu ingreffum otorum in tubas adiuuare, verifimile videtur.

Autumat modo citatus SWAMMERDAMMIVS, generari in tubis gluten illud, vel albumen, quo oua cinguntur : non folum enim gyrinos tuba minutim concifa enutriuit; fed euadit etiam tuba ipfa, in aquam coniecta fenfim vel octuplo craffior $\left(^{* *}\right.$, id quod et I A COBAE VM notaffe memini $(t)$. Tentaui et ego idem, tubam autem intumuife, non vidi, id quod tamen hinc fortaffe factum eft, quod partem eiusmodi fumferim tubae, quae huius glutinis nihil amplius contineret; atque hinc haud eo inficias, oriri ouorum albumen in tubis hisce, quum praefertim eam ob cauffam in tantam exporrectae mihi ef fe videantur longitudinem, vt pro tot ouis fufficientem glutinis continere queant quantitatem; obferuauiattamen, oua ab ouario foluta, nondum tamen in tubam delata, albumine etiam fuifle cincta; in aquam quippe demiffa, diftincte id monftrarunt; atque hinc eft quod credam, id quod fupra iam innui, iuuare partes illas foliaceas ouario cohaerentes, huius quoque glutinis generationem: faceffere namque pinguedinem earum, tempore quo ranae in latebris degunt, in harum nutritionem, quae IACOBAEI eft coniectura $(\dagger+$, hinc mihi non fit verifimile, quod eo ipfo tempore, magis quam alio increfcant, pauloque ante coitum maximae fint.

Poftquam fingula oua in vterum ingreffa funt, magis quam antea foemellae turget abdomen, fi vero quis ranas copulatas faepius attentiusque confideret, videbit ille, exporrigi tunc foemellae corpus plus in longitudinem altiusque attolli : hoc ipfum etiam mafculus percipere videtur, ac fi foemella illum moneret, adeffe nunc tempus, quo oua iamiam ex vtero per inteftinum rectum eiaculanda, femine fint foecundanda. Atque haec illa funt, quae hactenus circa coitum generationemque ranarum, in ranis terreftribus obferıaui ; finem itaque huic nunc imponere poffem fectioni, nifi icon fupereffet, de qua prorfus nil dixi. Exhibet eam Tabula VII, exprimiturque illa ranae noftrae terreftris fceleton, quod addere volui, licet hac in Sectione reliquarum huius ranae partium anatomen minus tetigerim, ratus fore, vt easdem in rana viridi aquatica, quae hanc magnitudine fuperat, faciliore fim examinaturus opera.

Cerni-

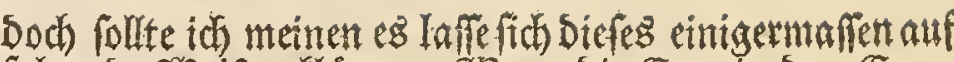
folgende 2 Seife erflären. SWent Die Ener in Dem Ener

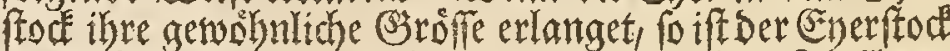
jiemlich ausgedelynet, uns alfo mit jemem obern Theil won Der Deffinug Der Enerainge fo weit utid) entfernet, Die entrach if aud Der šber Den Die Ever zu nehmen baben Eury; wamt aber ein Theil Derfelben in Die Nutter getrets tem lo hebt fich biefe, wiefie nadh und nadh angefiflet wird mmer mehruns mehr in bie 5 obke, und alro fint and bie im untern Theil Dez Enerftockes befindiche Ener naher ben Dem Eingans ber (Evyergånge; nad) unten zu aber wird Den Enern Der Wises, fowohl yon Dent Eneritoce als Der sontter felbft, werfdrlofien: went fie alfo auf ente ober

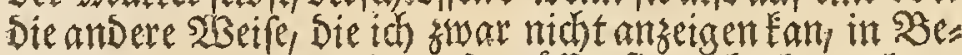
wegung gebracht wersen, fo ntuffen fie nach oben geben. wie fie aber in bie Evyergange fommen, und ob fie butrh Sullfe Der in Diefent befindlichen fleifdigen Farert Durdh felbige Durd und in bie Nutter getrieben werben, wie Gwommerosmm meinet (*), Ean id) micht fagen; Dod) follte ich meinen, Daś auch Das sámlein, welches

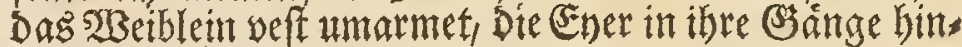
ein treiben helfere.

Enft angefuibrter Gwammerdamm hålt aud Dafü Die Ener erhielten Den Schleim, ober Das szeiffe, Don wel, chem fie amgebenfind, in ben હinergängen; inbemer nicht nut Die Frofdywtimer nit eintem in Hleine Studklein zers fonittenten Energang unterhalten, fortsern auch bie Evergånge, wann man fie ins 2 Baffer leget, nad) und

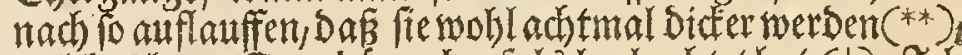
welches lezere Jacobatus ebenfals beobadhtethat $(t)$. Id babe foldhes swar audh eimmal serfuchet, alleine nidd ges fehen, baf polche aufgequollen; Doch mag folches stels reicht Saher gefommen fenn, Dafich ein Stude yon einem folden Evergang genommen, Der bereits son Diefem Edhlem leer war, baber id) aud) gar nicht laugnen will,

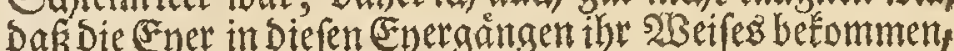
zumalen Da fie mir beswegen folange zu feon foheinen, Das mit fie gemugfamen 5 chletm fir fo viele Ever enthalten

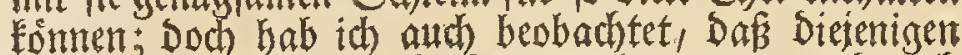
Ever fo son Dem Everftod bereitz los waren, und nods nidit in ben Eyergang gefommen, eben auch mit Den sbeifen ungeben fenm, weldhes fid, wann id felbige, ins 2Bafier leate, ganz Deutlich zeigte; Daher id Demn aud glaube, wie beretfs oben son mir gemeldet worden, Daf Die am Enerftock hangende blatterforntige Theile zur Erzen= gum dieres Schleims etwas bentragen: Denn daś bas in innen enthaltene Sett Dem Frorh, wahrend Der Beit ba er. fid in șerborgenen hålt, zat siabrung Dienen follte, wie Trcobrus meinet $(t+$, Eant ich Deswegen nich)t slauben; weil fie zu eben biefer aeit gróner als fonften werben, unt furs yor ber Saarung am groften find.

grent nun Die (sner alle in Die S) utter getretten, fo

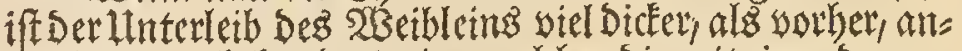
zureben; aud Ean Derienige, weld)er Die mit cinander ge= paartent Frófde offters, und genau betractitet, gar wohl wahutebmen Dafis Das 23 eiblein alsoenn einen geftrectes: ren 2 eib mache, unb Den binteren Iheil Deşfelben mehr in die

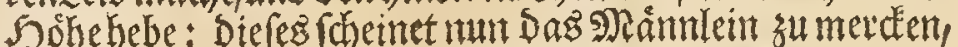

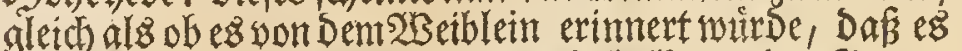

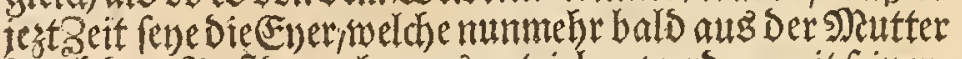
Durch Den Mattsarm heraus actrieben werben, mit feinem Saamen zubefrudten. Ulnd fo viel habe id) zur Beityon Der Saarung und Erseugung Der Frófthe ant Den Grabs=

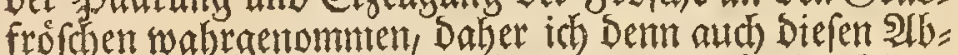

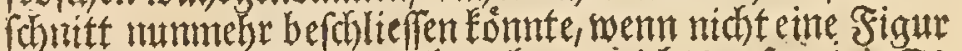
librig ware, won weld der id nod) gar nidhts gefaget. Es ift relbige auf Der $V I I$ Cabelle befind lich, und ftellet Das (S)erippe unreres (3)asfrofhes vor, weldhes ith her mit benfugen wollen, ob id) f(d)on mich mit Der 2 (ntatomie Der

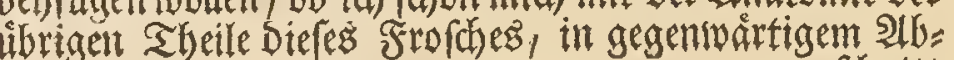

(d) $n$ itt

(*) L. c. p. 806 (**) Loc, cit. p. 806

(t) L. c. p. 75. (tt) L. c. p. 71. 
Jab.IX.
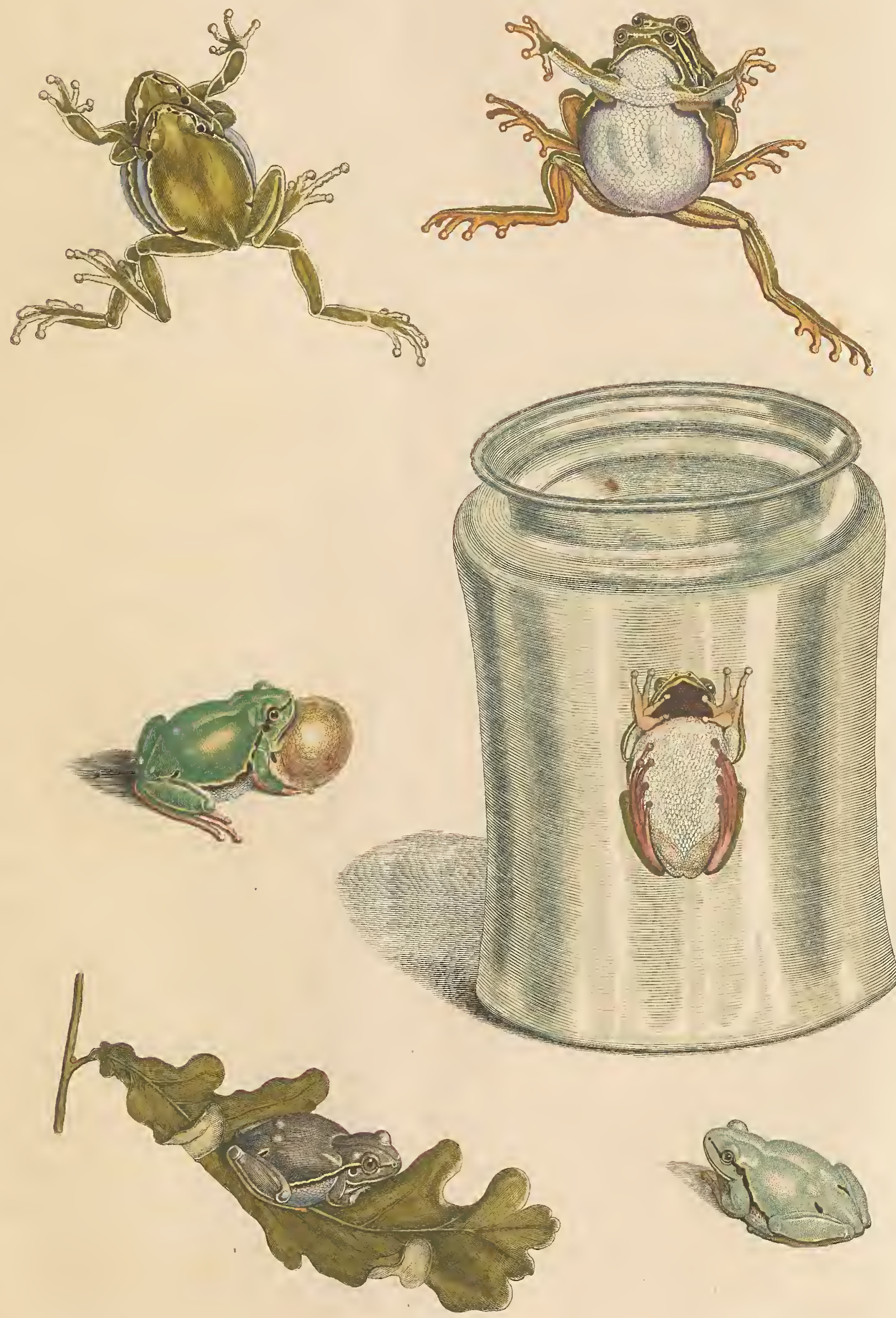

A. J. Röfel fecetext. 

Tab.IX.
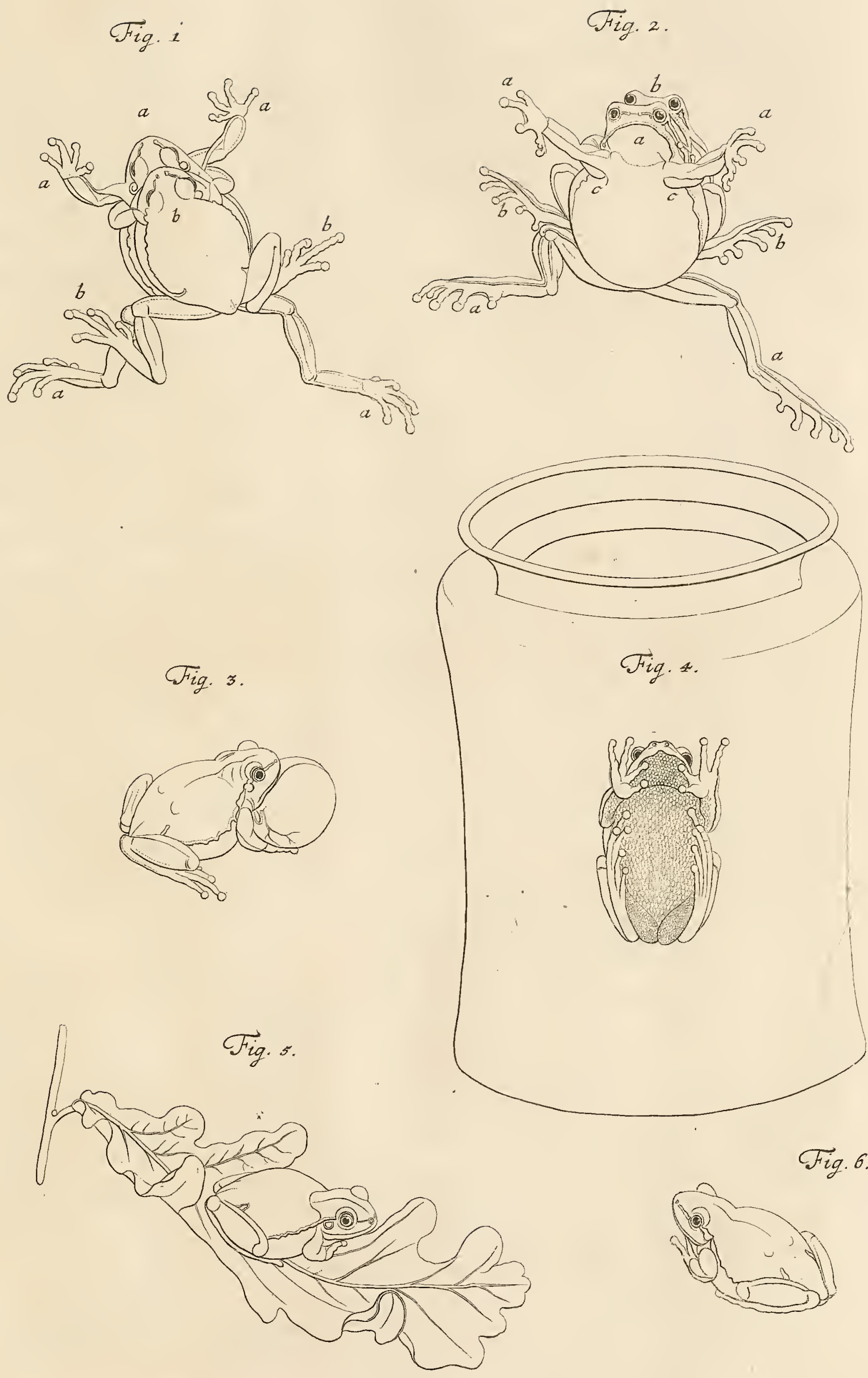

Fig.6.

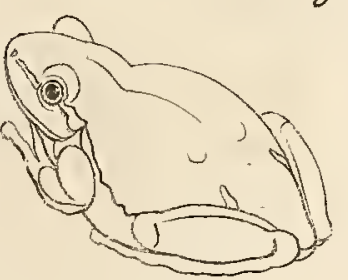





\section{4:}

Cernimus itaque in 2 figura VII Tabulae, fceleton ranae referente, maxillam fuperiorem $m$, multis exiguis acutisque confitam effe dentibus, ad modum ferrae fubtilioris qua frondium ornatus in afferibus formantur; maxilla contra inferior $o$, eaque tenuior, ex integro laeuis, nullis exafperatur dentibus, fed etiam viua in rana mollis eft : atque hinc patet, eiusmodi ranam neque mordere, ic quod tamen nonnulli affirmare videntur, neque rodere poffe; ore itaque cibum, infecta nempe, quibus, vti ianl fupra diximus, praefertim nutritur, tantum comprehendit, integrumque dein deuorat. $n$ mobilis maxillarum ef commiffura vel articulus, debiliór quidem quam effe deberet, fi rana morderet roderetque. p $p$ maiora oculorum funt foramina; $r$ caluaria anteriora verfus ad finem vsque foraminum oculorum pertingens; licet autem ranae cerebrum mole fit paruum, caluariam tamen vndique replet. $q$ q regio aurium eft, quarum vero in fceleto nil confpicitur. If binae funt fcapulae quae cum fieno $t$ t t ope alius offis plani, clauiculae locum occupantis, cuique os humeri inferitur, ex vtroque latere committuntur. Os pectoris anteriore in parte acuminatum, in margine laterali finuatum, in parte poftica lunatum eft. Huius nec non fcapularum ope, cor veficaeque pulmonum in thorace haerentes, tutantur, ne, rana poft faltum in
terram delabente, laedantur. Quum ranae nullum fit collum, ceruicis etiam caret vertebris, ipfunque caput fpina excipit dorfi, ex nouem conftans vertebris. Defunt in prima harum vertebrarum proceffus laterales, qui tamen fequentibus tam longi funt $u$ u $u и u u u$, vt coftarum vices, quibus rana caret, fubire videantur. Exporrigit autem fefe fpina haec vix vltra medium ranae dorfum, reliqua vero illus pars, aliquanto longior, nullis componitur ex vertebris, fed ex tribus Iongis gracilibusque conftat offibus, quorum quidem bina lateralia $w w$, lumborum offa appellari poffent: iunguntur illa fuperius cum la. teralibus vltimae vertebrae proceffibus, dein, parum incurua, congrediuntur, inferiusque offi committuntur, quod aliis in animalibus pubis vel pectinis os appellant; medium vero illud rectoque ductu excurrens os $x x$, ex mea quidem fententia, coccygis os dici poffet: in gyrinis namque cauda eidem cohaeret. Inferuntur in pubis os $y y$ crura faltatoria ex tribus partibus conftantia: ex offe nempe femoris parum incuruo, ex tibia minus inflexa neć non ex pedis offibus. Bina priora pedis offa, ad tibiam inferiorem pofita, litteris $z z$ fignata funt: excipunt haec aliquot offa minora, atque ab his digiti oriuntur. Conftat extimus digitus ex quatuor officulis, proximus huic quinque habet, tertius quatuor, quartus et quintus, qui breuiffmus, tria. Breuiora multum funt crura anteriora, aft ex duobus tantum conftant ollibus teretibus, nec non ex illis quibus pes componitur. Gibbum eft primum illorum in priorem partem, reliquaque longitudine fuperat; huic adhaeret os in fine leui diuifione dehifcens, fuccedit dein carpus nec non quatuor digiti, quorum extimus cum fib proximo ex quatuor, bini reliqui vero ex tribus componuntur officulis.

\section{FINIS}

HISTORLE RANE FUSCE, TERRETRIS. fibnitt, nidht eingelafien babe, insem ith geglaubet, id

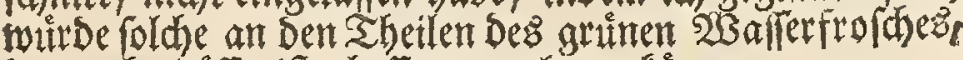
Der noch groffer ift, beffer bornebmen Eontuen.

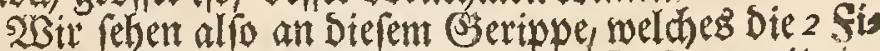
tur Der $V$ ll Cabelle zeiget, Da

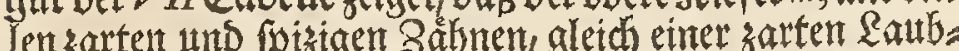

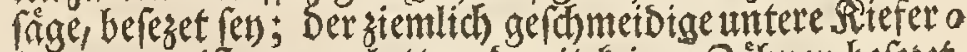

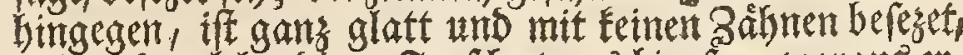
uno an bent lebendigen Frofi etwas biegram, worauser

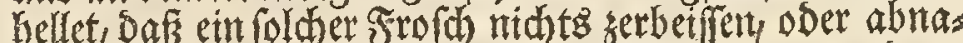
gen Eónne, wie Dod einige meinen wollen; Daber er bent antof feite Speife, welche, wie oben gemelbet worbert, gros= ftentheils aus Sinfectenbeftebet, nur mit Dem ) and wefre hail, uns hernads gant berfaludet. $n$ ift bie beweglide

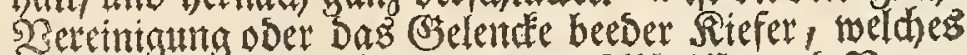

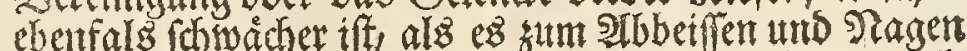
erforbert wirb. p p tand bie swey groffen \&odher in wels

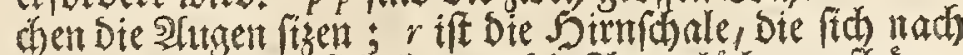

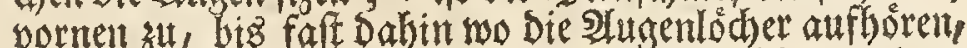
enfrectet; ob aber gleth bas Sirn Des Frofohes geringe

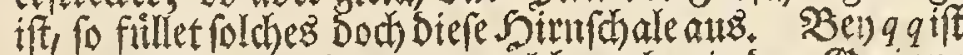
Die (S)egend Der Shrem won weldhen aber in Dem SJerippe

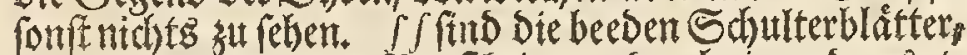
unt biefe find mit bem 8 ruffbein $t$ t $t$ Durch ein andereset.

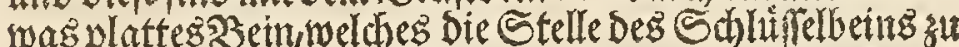
vertrettent fheinet, sut feber Seitevereiniget, und in felbiger hat Das Sdulterbein reine Einlenting. Das 20 rufthein

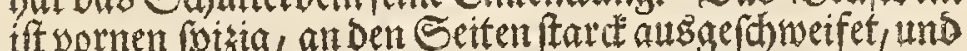
hinten mont formig. Durch Diefes, wie auth Duth Die beeden Sobulterblatter, werben bie in Der \$Bruf neb/t Dem Sers enthaltente Rungenblafen befhiszet, Das fie in Sprisgent

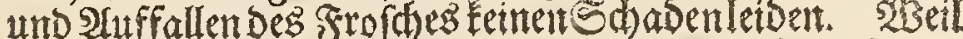

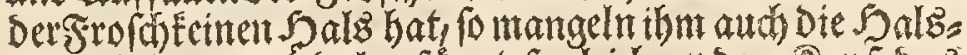
wirbelbeiner, umb Daher fangt, fo gleid an Dent alopf, Das

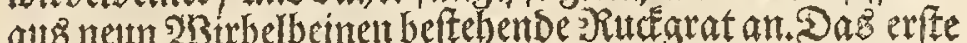

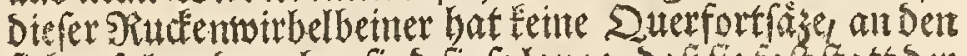

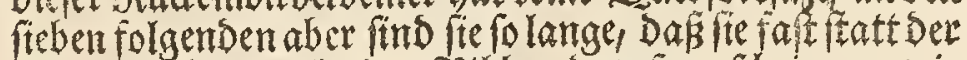

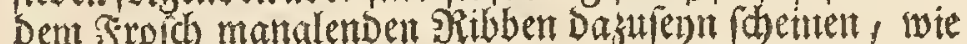

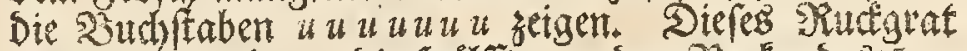

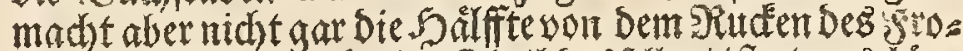
fores aus, und ber tibrige Theil Desfelberi it etwas laits aer, beftebet aber aus Eeinen 23 irbelbeitern, fondern aus Dren Langenund Dúntmen Rnothen Davon Diean Den Sets ten fethende und mit to to bezethinete, Die Lendenteine ge nennetwarden fointen: ezgeremigen fid Diefelben obeits ber mit Den Duerfortfázen Des lezten W3irbelbeins, be: nac Erimmen fie fich etwas in ibrem sortgang, fomment untennåber zuraunn, und wereintgen fíd) mit einem SBein, weldes Dasientge ansmad)et, fo lonftan andern Sbieren.

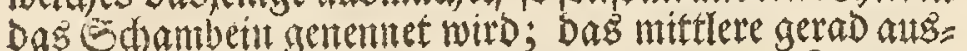
lattifende \$Bein aber $x x$, ift Deswegen, meiner SNemung nach, Das Schwambein su nennen, weil an felstgent bes

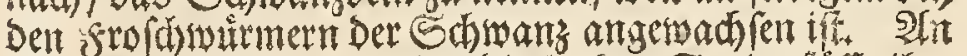
Sem Sdambein y $y$ baben bie beeden Springfinfe ibre Eintenctung; biefe aber befteben aus Dren Theilen: aus Dem etwas gefrummten Dberfhendfellein, aus Dent ge: ras anslautenden Sdientein, und aus den Susbeinent.

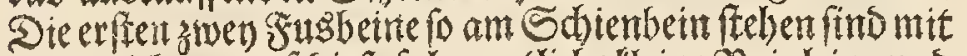

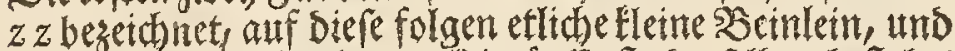

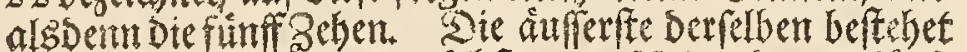

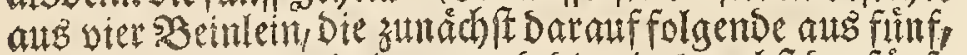
Die dritte wieder nus vierelt und Die dierte neb ft Der finf:

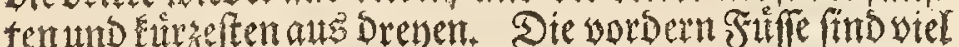

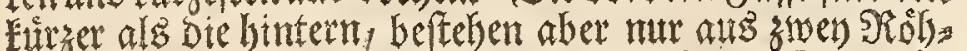
renveinen unb Den eigentlichen Fugknod)en. Das erfte SRofrentein it etwas tiber fich getrimment unben Das lángfe, Das Daran ftehende rhetnet unten etwas getheilet

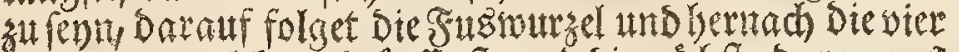

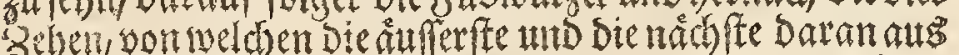
wiersbetnletiy bie beeden ibrigen aber atts Drenenzufams men gefezet finto.

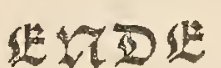

Der SBe[ (4) 


\section{ERRATA.}

Q hanc Sectionem varii irrepferint error obfante in primam rum fenfum turbent, eosdem, addita emendatione indicare hic ncceflarium effe duxi.

Pag. 1. Lin. 7, ante finem bracchits, lege, bracbios. - 2- 37 , ititemque, lege itidemgre.

- 5. 1, poft partern, adde aguis.

- 6 - 32, vndeutgt frncque, lege ctvigefino primo.

- 7 - 8, idem occurrit error.

_.. 27 , duodectmo, lege vige imo quarto.

- $9-38,24, \operatorname{lege} 22$.

- in - $7, b$, lege $\mu$.

-. $\quad$ - 19,, , fcribe

- $\quad$ - I4, ante finem, dereliquentes lege derelinguentes.

- 12 - I, partinm, lege partium.

- - 2, fuerst, lege fucrint.

- 13 - 7, europaess lege europaeas.

- $\quad$ - 4 , in fubiecta nota, Ceur. lege Cerst.

- I6 - 25, mouxbatur, lege lefe monebat.

- 17 - 32, nonnulla, lege nonnulla.

- 18 - 9, credecham, lege credebam.

- 19 - Is, ante finem, poft defcriptiosie ponatur,

$-20-16$, - - veritrablus - ,.

-23 - 26, - - vidi

$-28-5, \quad-\quad-$ tendere

\section{Selder.}

8

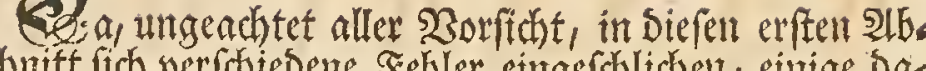

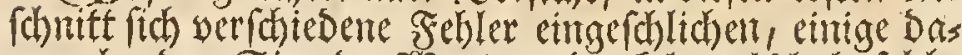
won aber Den Sinn Der sorte verdinteln; als babe folde

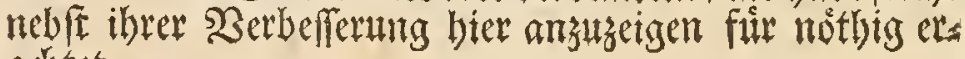
adi)tet.

Stite 2 Sin. 28 , Linnanus, lies Liunåtts.

- 3-16, einemt, emen.

- 4-12, von unten, nach Deiblein mache cin, .

- $7-38,3$ wodfften, lies vier uno 320anzigften.

- $10-11$, fur $b$, rese pa

- II- $14, \mathrm{~mm}$, lies, in.

- 12 - 10, gleidbren, lies, glidben.

- I4 - 32 bon unten, Eónnen, lies tónne.

- - 6 bon unten, angeben, lies nachgeben.

- $16-2$, brauneu, lies braunen.

- 20 in ber legten Sinie, aubodbnen, liso ausbebnen.

- $21-30,6$, feje $t$.

$-24-14$, von unten, 2 fese 1 .

$-26-22$, werden, lieg, wordent. 

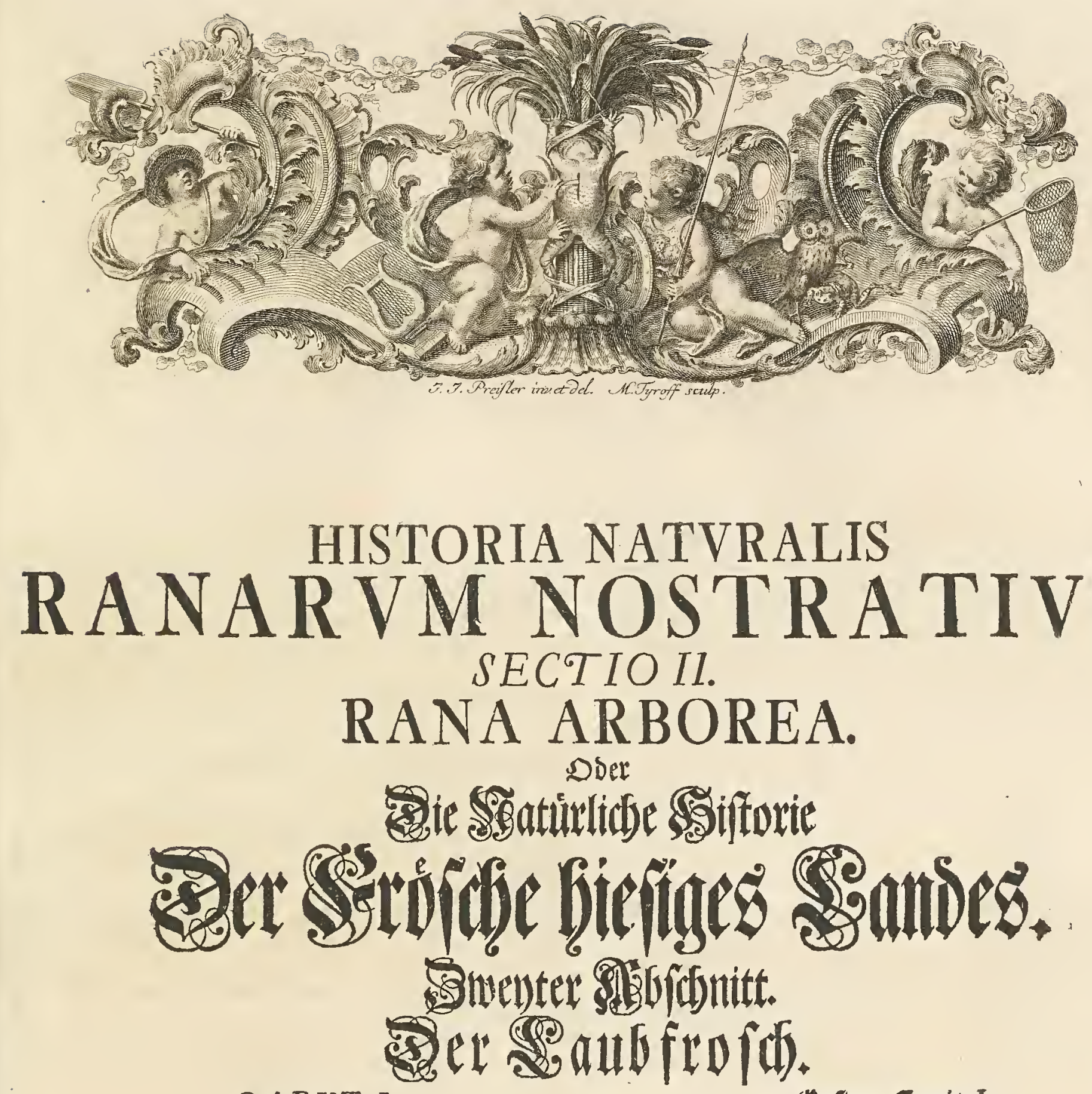

CAPVT I.

Enites Capitel.

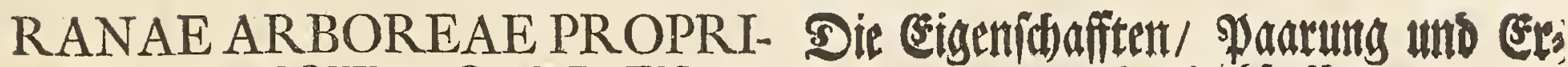 ETATES, COITUS, GENERATIO. zeuguth Des Qquibfroides.}

I

$\mathrm{n}$ fecunda hac, Hiftoriae naturalis ranarum noftratium, Sectione, de rana fcripturus fum arborea, quamuis enim in examine atque in notandis proprietatibus ip. fius multum operae laborisque fit confumendum; in huius tamen ranarum fpeciei perfcrutatione magis profperam, quam in reliquarum, hactenus expertus fum fortunam; eo ceterum gratiorem hanc Le\&foribus beneuolis futuram fpero hiftoriam, quo minus eorum explorata eft veritas, quae hac de rana in aliorum Auctorum notata legent fcriptis.

Effe ranam arboream fingularem ranarum noftratium fpeciem, ipfa externa eiusdem fatis fuperque indicat forma. Superant eandem ranae noftrates reliquae magnitudine, et licet longiorem ducat aetatem, nunquam tamen ranam terreftrem triennem aequabit magnitudine, atque hinc merito, minimam eandem ranarum elfe fpeciem, affirmare poffumus. Differt illa etiam a reliquis fpeciebus colore: laete namque viret fuperficies eiusdem fuperior, inferior autem, fi in maribus gulae regionem, in foemellis vero, aeque ac in illis, pedes excipias, albet fere; accedit huc fingularis notatuque omnino dignus character, flauefcens nempe linea, binas hafce fuperficies difcriminans: haec prope nares orta, vtroque in latere per caput corpusque extenditur; prope femur vero furfum afcendit, defcriptoque ibidem angulo acuto, per pofteriores excurrit pedes. Monftrat margo maxillae fuperioris fimilem fe-

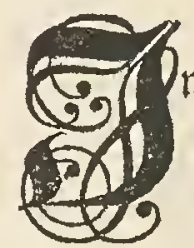
nd diefent sweyten 2abfhnitt, Det naturlichent Siftorie Der Froofhe biefiges Sandes, hab it mir sout Dem Saubfrofich zu handeln vorse nomnen; indent id in Hnterfichung Defielbis get unt in Entbectung feiner Etgenthaffert

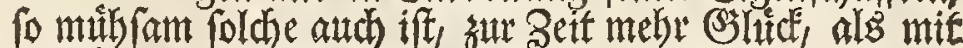
Den tibrigen Frof(charten gehabt; auth) boffe ich, es wers De Diefe Befitretbung Dem geneigten Sefer un fo viel

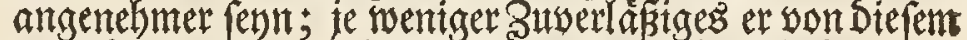
Frofh ber andern Scribenten anfgezetchet finder.

Dấ Der Raubfroid unter Den Fróchen hiefiges Lantos eine befondere 2 (nt ausmache giebt fogleich feint

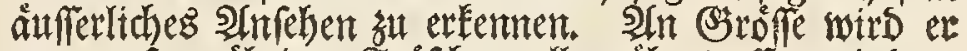
yon unfern itbrigen Frofohen allen utbertroffen, indem felbiger, follte er auch gleich noch fo lange leben, Doch nies

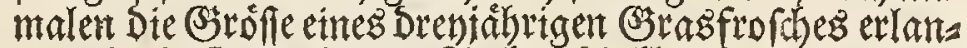

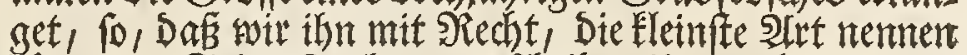
fonten. Seine Farbe unterichetbet ibn auch yon Der librigen Sorten: indem er auf fetner obern Fláche reché anmuthig grim, anf Der untern aber, Die ßeble ber Dent

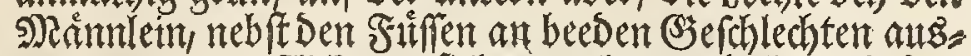

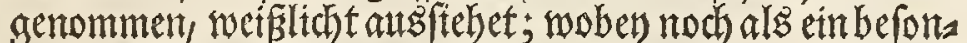

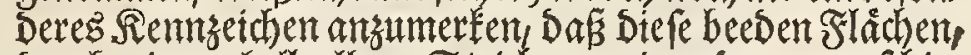
Durch eimen hellgelben Strid) yoneinatber unterfichs Den werben, welcter fich yortten bet Den Nafentódhern

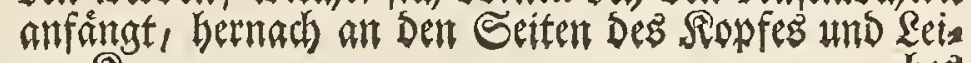


re lineam flauefcentem, fed pallidiorem anterfioresque ambientem pedes. Eft et in pedum digitis ranae arboreae Inta iphi foli propria: quilibet namque digitus, tam anteriorum quam pofteriorum pedum, quorum in quolibet illorum quaterni, in quolibet vero horum quini numerantur, in parte extrema fingulari, rotundo carneoque inftructus eft globulo; inter ipfos vero digitos pedum faltatorum, parua vel nulla prorfus illius membranae cernitur pars, quae aliis in ranis adeffe natatumque ¿auare folet.

Dum dixi deeffe digitis aliarum ranarum carneos illos rotundosque globulos, de noftris tantum id dictum volo ranis: plures namque vna dari fpécies ranarum exoticarum, eosdem gerentes, ex pretiofo illo SEBAE opere fatis fuperque mihi innotuit $\left(^{*}\right)$; notatu infuper dignum mihi videtur, alere etiam Virginiam atque Carolinaml ranas arboreas, noftris fimiles, quas CATESBY $\left({ }^{*}\right)$ defcriptas dedit depictasque.

Vtrum plures vna, noftra in regione, quin vniuerfa in Europa, dentur ranae arboreae fpecies, eft fere quod dubitem. Defcripferunt quidem GESNER VS, ALDROVAN DVS, IONSTONVS, atque LIBAVIVS binas eiusdem fpecies, quarum et veteres meminerunt; differentia tamen, quae ipfis referentibus, inter illas intercedit, nullius mihi effe videtur momenti. Alteram earum ranam appellantarboream, quod in arboribus; alteram calamiten, quod in arundinetis et herbis maxime vivit; illam, addunt, clamofam, han mutam effe; vtramque porro venenatam perhibent, calamiten tamen magis quam arboream; quodfi enim forte hauriatur, ventres boum diftendit, vt etiam inde nonnunquam rumpantur. Haec fi vera fint, ranas eiusmodi noftris in terris liabitare, vix verifimile eft, hunc namque effectum noftris quidem temporibus incognitum prorfus esfe, omnes confentient. Licet vero, ranam arboream venenatam effe, vix penitus negauerim; hinc tamen, vt ea de re dubitem, fere adducor, quod ranas eiusmodi comprehenfas per horas integras manu geftaui, nullo et ne minimo quidem exin percepto incommodo. Quemadmodum vero, quod reliquum eft, AGRICOLA affirmat, fcandere ranam calamiten arbores quoque, neque mutam eam effe addit; fic ranam etiam noftram arborean, licet arbores vtplurimum habitet, interdum in arundinetis herbisque

mora- bes binlauff; nicht weit aber bom Schendelbein in sie Sobe gebet; Dafelbit gegen oben einen fpizigen 23 indel machet und hernach fich Durch Die hintern suiffe erftre: ceet. 2lm Siand Des obern Rieferz zeiget ftch eim glet= cher beilgelber, aber etwas blafierer Struch, unt Diefer gehet in Die sordern Ftuife. 2(nt Den Beben Deg \&aubfro. iches finbet fich anth etroas, fo inme allein eigen iff: ins Dem rowohl Die wiere bie er an jebem Borberfus hat, als auch Die finffe welche an jebem Sinterfus gezeblet wers Den, zu ăferft ntit einem befondern runden und flets fhernen Anopfleit verfehen find; zwifhen Den Beben bet Springfuife aber, wirb von berientaen Saut, wel, dhe alt altoern Frofthen zugegen, und Die ithen Das

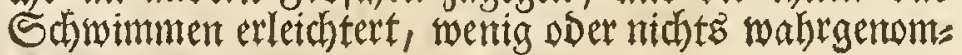
ment.

YBenn ich gefagt, Dafs fich an Den Beben anderet

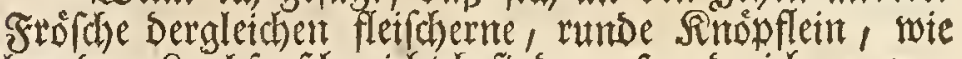
bey Dent Raubfrofd, nicht befinden; fo rese idh nur won unfern Frớchen: Denn Daś es mehr als eine Sorte uns ter Den auslantithen gebe, woranfth foldhe zeigen, it mit ats Dent fortbaren 2 Berd Des Serrn Geba mebe

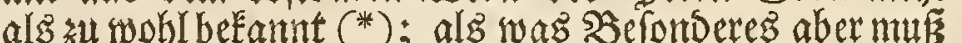
ich) nod) anmerden, Da rolina Raubfrofche gebe, Die mit Den unfertgen tibereits Fommen, und von Catesby (**) befdrieben und abgez bilbet morbert.

Dafis in unferm Sand, ia in gants Emopa, melte als eine Shrt Des Saubfrofches an finden fen, follte ich faft zweifelin. Gesmet, 2llorovandi, Jonfton und Libavins baben zwat zweterlen befthrieben, welche wie attch ben Den åltern Scribenten finben; alleine Der Lin= terfoted Dent fie von benden angeben, foheinet nir yout Eeiner 2Bidtigket zu fenn. Die eime 2irt nement fite Den Batunt= ober Laubfrofo, weil er fich auf Den 3 âtument autfuthaltent pflegt; Die andere aber Den $R$ Rohrfro/ch),

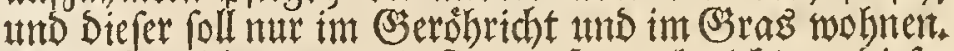
Sener fan fortenen, wie fie uns ferner berichten; Diefer bingegentif gans futmm; beebeaber follen vergiffet fetsm

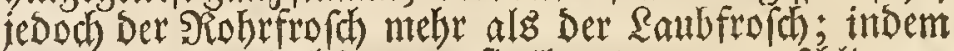

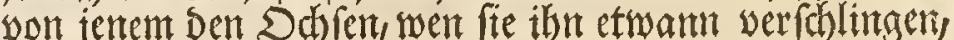
Ser Leib auflauffe ja aar zerberffet. Juf Diefe leste

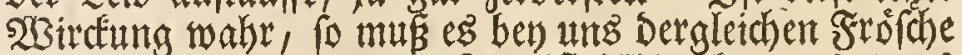

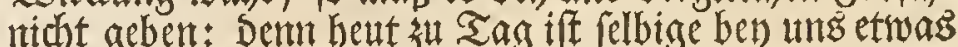
unbe Eanntes. Db ichaber aleid Denienigen nidst (d) led)= tersings wiberiprechen will, welche Den Saubfrofh fur vergifftet balten: fo follte ich ood Daher faft Daran swei= feln, weil id Dergletchen Froithe Stumben lang in Der Sand getragen, dhe Das geringfte wibrisge Daven bers

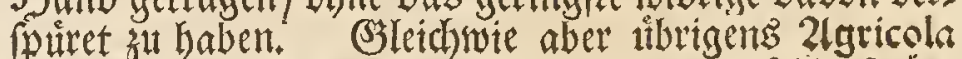
$(t)$ faget, daf ber Robrfrofd, auth auf bie 23 ă.

(*) Locupletiff, rer. natural. Thefauri Tom. I.

(**) The natural Hiftory of Carolina, Florida and the Bahama Islands etc. Vol. II. P. 7 I.

(t) GEORG, AGRICOLAE de re metallica Lib: Xll. Bafil. 1556. P. 535. vel potius 495 . 
$\sigma_{a b}, X$

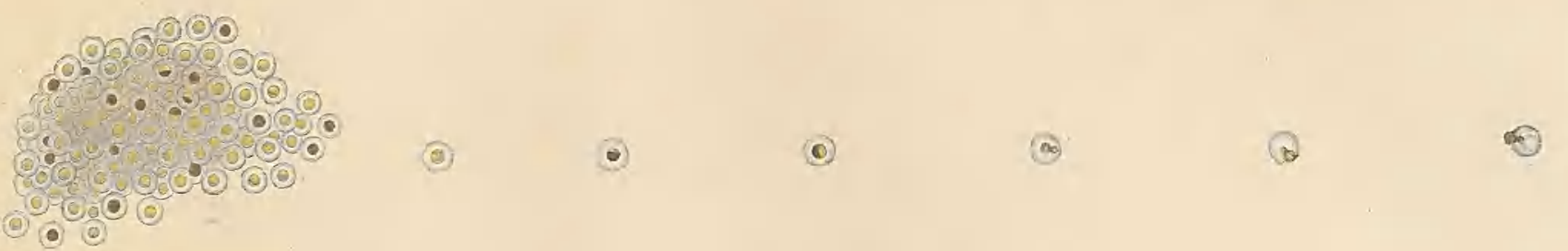

(2) क क क क क

ค. $8=9$

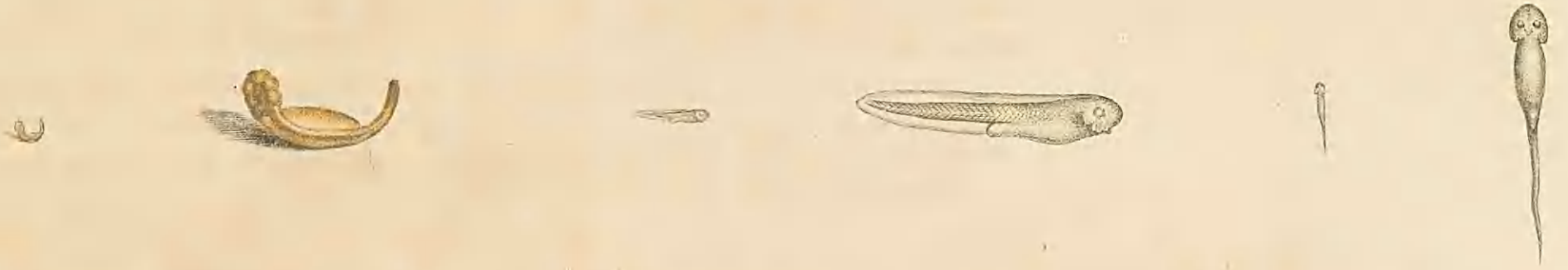
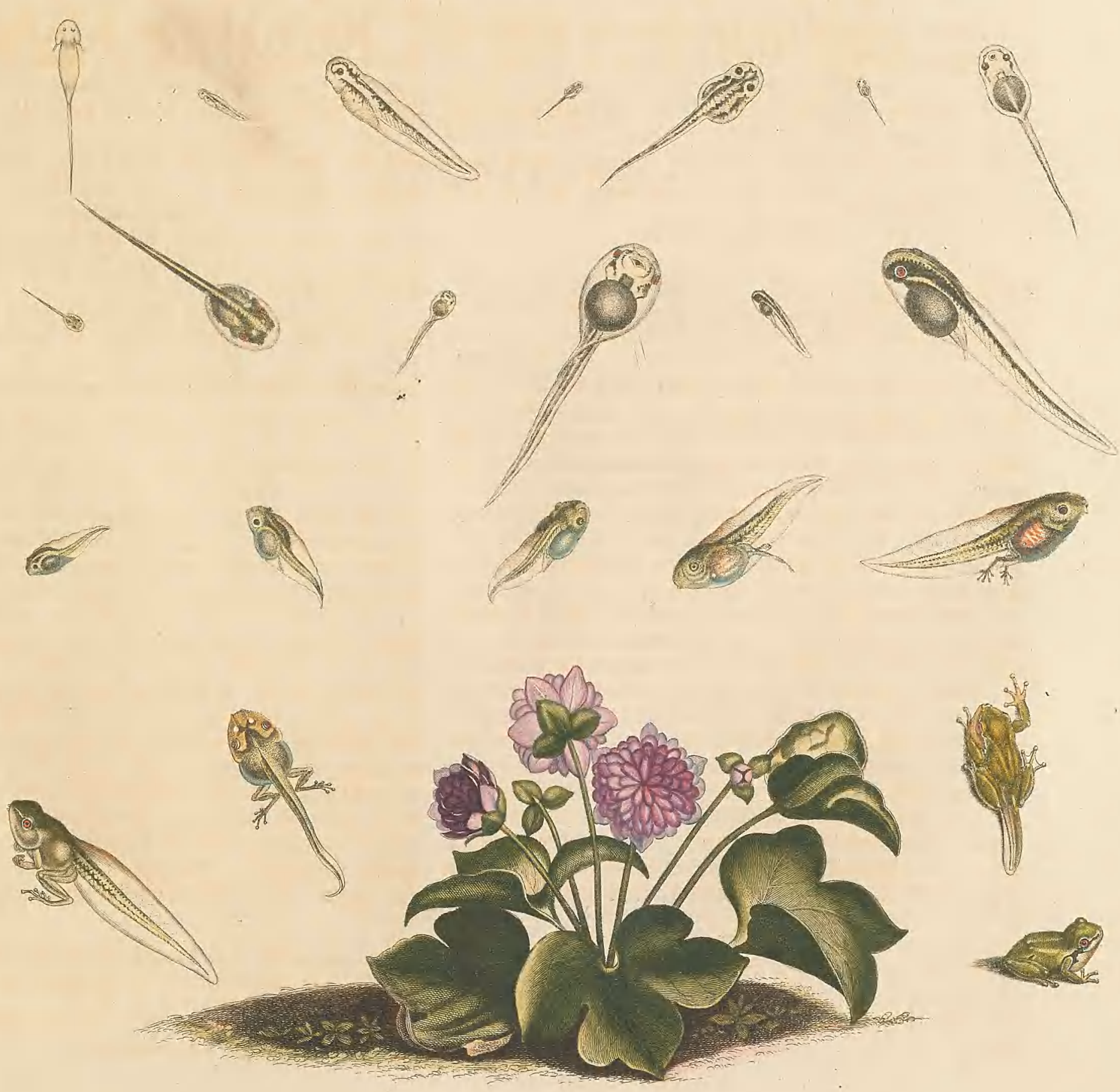



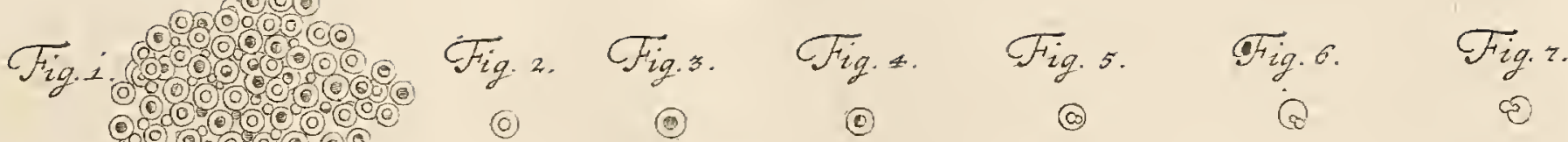
001000
0.000

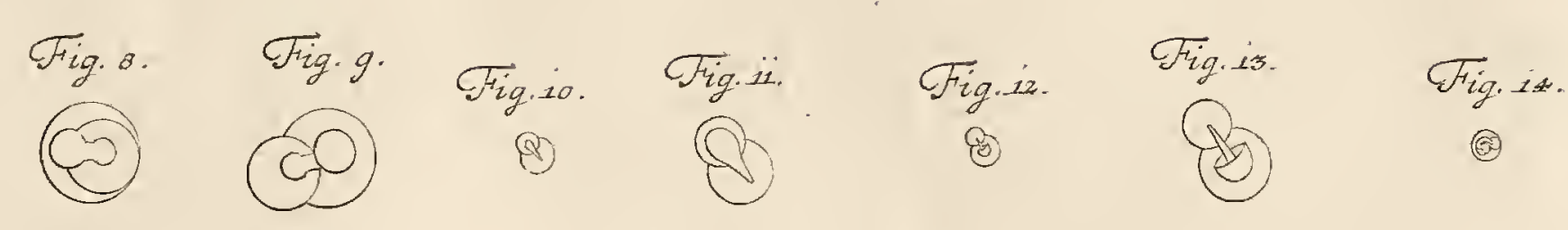

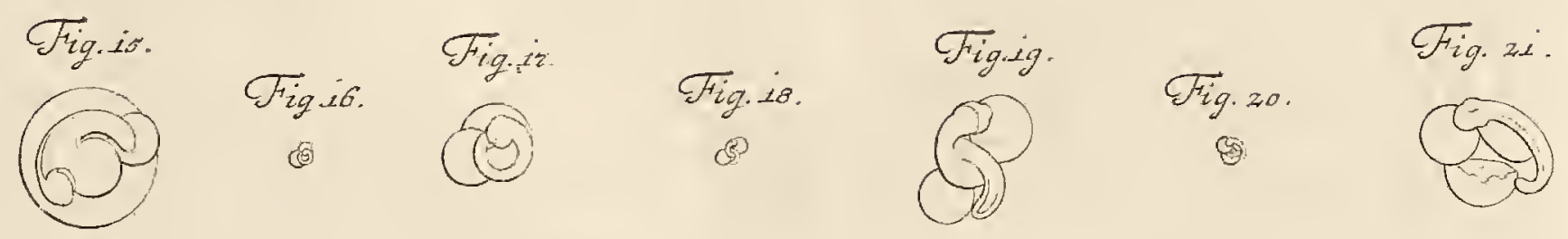

Fig.z2. Fig.25. Fig.24 Fig.26
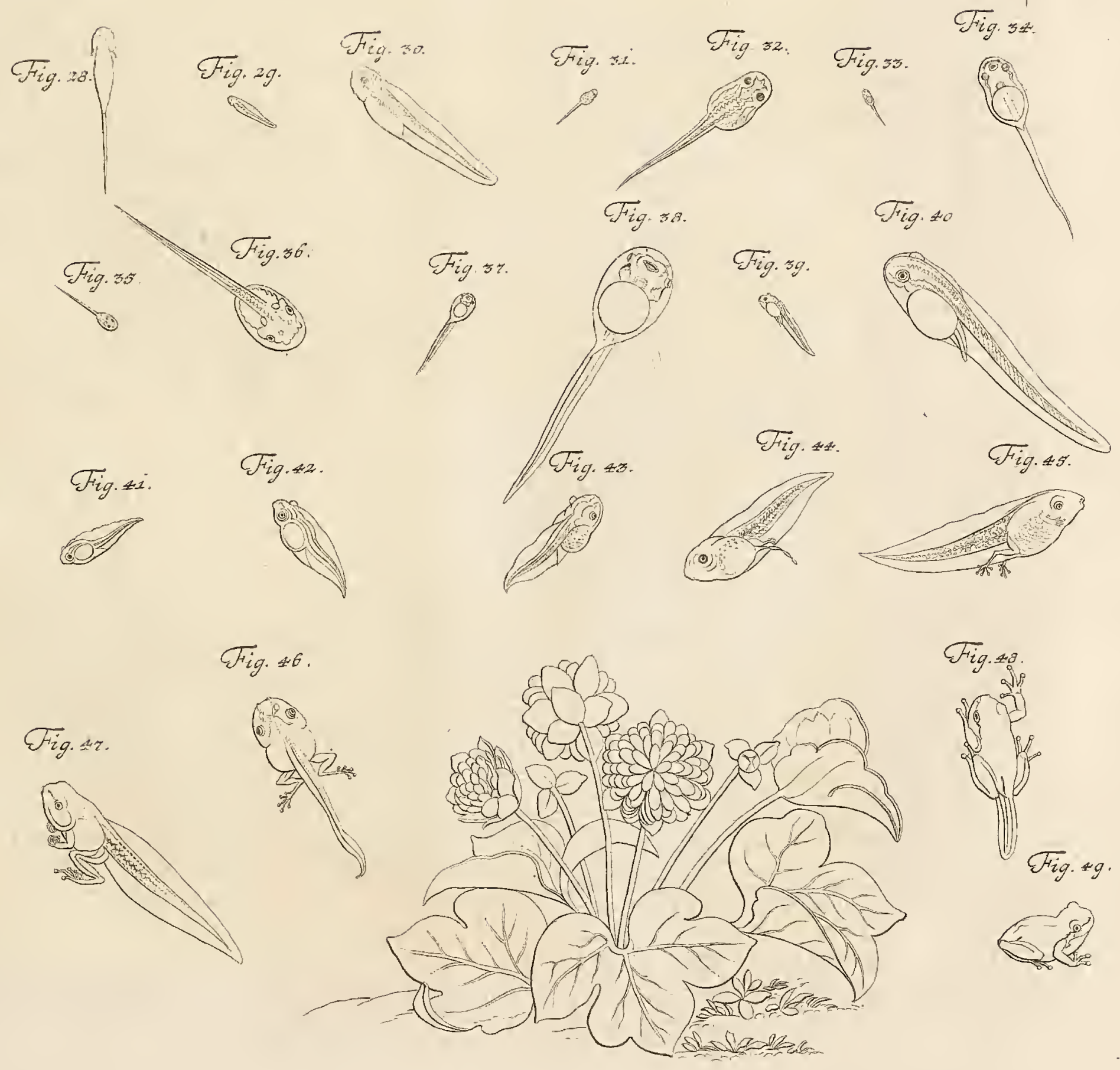



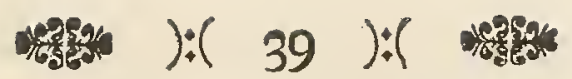

morari perfuafum habeo: atque adeo vnicam tantum, noItris in terris, ranae arboreae dari fpeciem firmiter credo.

Scribit GEESNERVS, habuiffe se inter diuerfas ranarum piduras, ab Argentinenfi pidore miffam, fubuiridem quandam paruam, non ita pulcbro calore wt calamites eft, fed fubobfcuro; eamque fi non ad calamitas, forte ad temporarias referri debere. Fuiffe ranam hanc ex arboreis credibile eft, licet colore nonnihil difcrepuerit; ranas namque arboreas non femper vnum eundemque feruare colorem, curiofior earundem me docuit confideratio, id quod tamen alii minus obferuaffe videntur; plures namque vna fpecies exiftere ranarum arborearum credidiffent; et nifi rem hanc curatius examinaffem, in eandem quoque juiffem fententiam.

Seruaueram aliquando, in vitro quodam, plures ranas arboreas, quas quum forte contemplatus eram, nonnullas earundem colore a reliquis differe obferuaui. Vifum autem hoc mihi fuit eo magis notatu dignum, quo minus fimile quid antea confpexeram; fufpicabar quidem vernationem forte diuerfitatis huius effe cauffam; vt autem certior redderer, attenta requirebatur contemplatio in pofterum inftituenda. Factum vero eft non ita multo poft, vt aliae harum ranarum me, quod indagaturus eram, docerent: vidi namque reddi ipfas, elapfo coitus partusque tempore, primo quidem fubfufcas; dein fubcinereas faepius furcisque maculis varias; poftea ex cinereo albefcentes; tandem vero antequam priftinum illum nitideque viridem induant colorem, ex caeruleo virides. Subeunt vero mutationem hanc mares non tantum, fed et foemellae; atque hanc ipfam coloribus expreffam, Tabula exhibui $L X$. Siftitur itaque Fig. I. rana naturali colore; monftrats fubfufcam; 6 ex cinereo albefcentem; 3 denique ex caeruleo viridem. Vbi vero haec colorum contingit mutatio, vernat rana, atque hoc fingulis quatuordecim fere fit diebus; is vero, qui incipiente hac colorum mutatione, ranas hafce attentius confiderat, videbit, diebus nonnullis elapfis, exuere ipfas tenuem vifcofamque cuticulam, in aqua tantum, extra ipfam vero minus, confpicuam. Rem hac fe habere ratione, didici ex contemplatione ranarum quas domi feruaui; fubire vero eandem etiam mutationem, forte tamen minus crebram, ranas liberam agentes vitam, nullus dubito.

Quum rana noftra in arboribus, et ex nonnullorum fententia, in arundinetis etiam vivat, appellarunt eandem ranam arboream calamitenque, eandem vero ob cauffam dicitur etiam Germanis der Laubfrofcb; habitare namque ipfam omnem per aeftatem in arboribus frutetisque frondentibus, certo certius eft; verno vero tempore aquas incolit: iure igitur meritoque a clariffumo LINNAEO Amphibiis annumeratur, argumentumqueillud celeberrimiKLEINII; ranam nempe arboream nunquam ingredi in aquam, nullum eft. (**). Vbi vero frigida ingruit tempeftas, varia illa, quibus rana arborea nutritur, necans abigensque infecta, limo conditur; verifime itaque fcripfit AGRICO. LA $(*)$, me gelle und nidt fitumm fey: fo glaube auth ith, bafi

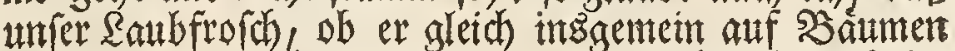
wohnet, fich auth manchmalen im (Sterofhricht und int

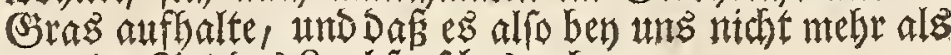
nue eine 2lrt Des \&anbfrofdes gebe.

Gesner meldet, safj er wnter andern gemablten frófben, auld emen Lohrfrofth, von einem Gtras. burtger Mmabler gefdidt betommen, Ser zwar grius lidt, aber nidt lidón, fondern etwas duntel gewefen;

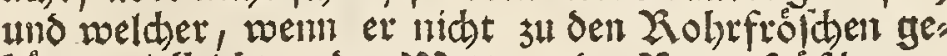

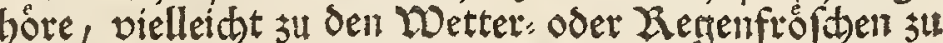
rechnen fey (*). Diefer Frofo fan gar wohl ein \&anb.

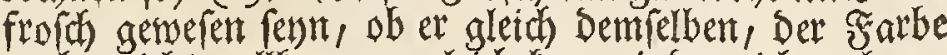
nach, micht sollemment gletch fam, indent ich wahrges nommen habe, Dase Die Latbfrofche nicht immer cintes lè) Farbe belialten; yon andern aber if folches fonder

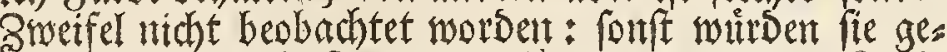

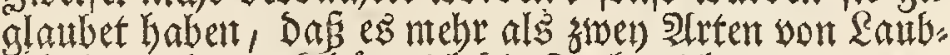

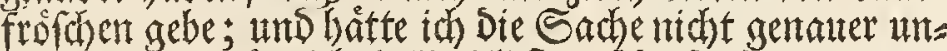

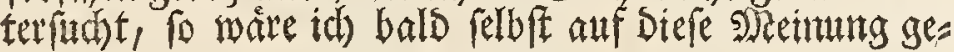
tommen.

Sid) batte nimlich cinmal etliche Raubfrofiche in eis

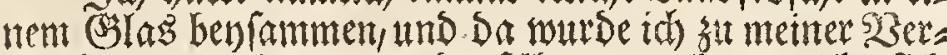
wutndertug eintger unter Dentelben gemahr, welche fich yon Den andern Durch itgre Farbe unterférieden. Dies fes Eam ntir um fo siel meremtirbiger wor, te wentger ich fonft Dergleichen gefehen hatte; eben beswegen aber fiel

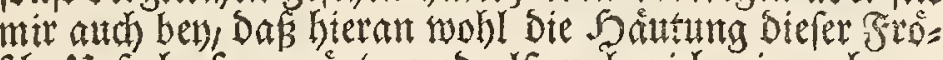
fore unfache fern moigte, und alfo nahnt id nir aud por hierauf it Das fintitige genau acht zli geben. Tch Dweft= te aber nitht lange warten um hierimen zu einiger (Se= wisheit zugelangen: Dent id wurbebals hernach an alt

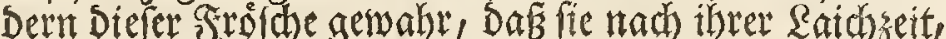
enflich braumlicht, bernach effeters graulidyt umb braun gefledt, alsoenn aber gratlidtwets, und endlich ebe fte tod ithe forone gruine Farbe mieder erhalten, etwas blaulichtgruin werben. Diefe Serainderumg ereignet fith aber ntet alleine an Dent saltmlein, fombern aud an Den 2 Beibleit, uno in Der $I X$ Tabelle Gabe ich folche nach Den Farben ausgedondtet. Die I Sigur frellet Den Frofth in reiner naturlid)en Farbe bor; in Der 5 fehen noir einen braunlichten; cinten graulichtsoifent in Der

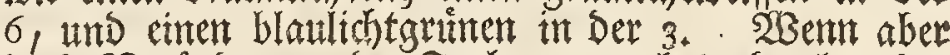
Defe :Beränderung Der Farben yorgebet, Da lege Der Frofh feine Jaut ab, welches faft alle wierseben 'Tage gerd, ebet; Derjentge aber melcher Diefe Frofthe, went fich ihre sarbe za andern anfängt, genall beobachtet: wirs nad etlichen Tagen gewabr werden, bafis fie ein zartes unt fobleimiges Saintlem ablegen, welches fith nut im 2 Baffer, aufferbalb Deffelben aber ntebt, Dentlid zeiget. Das ez fich hiemtit po verbalte bab ich an benter von untr za 5 aus aufbehaltenen Fróchen wahrgenoms mett; $D a \tilde{s}$ aber anch ein gleiches, obfhon etrwann ntobt fo ofit, gechehe, wenn fie fich in ther Frenheit finden, ztweifle ich feintesmegs.

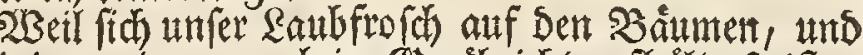
wie eintge meinen, auth im (Serobricht aufhâl, fo if er

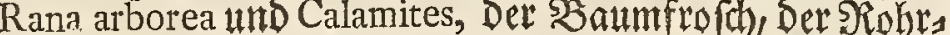
frofth genentet morden; und eben Daber fubret er anth ber) unt Dentichen Den Famen Des Raubfrofhes, wie er Dentr altch wirdflich, Den gansen Sommer himburch auf Den belaubten જ̧aumen und ß̧łifhen wohnet; int

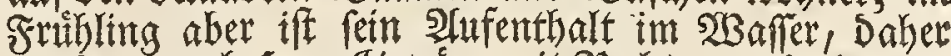

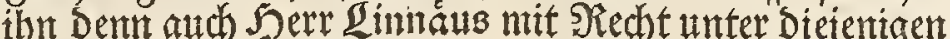
Thiere rechntet, Die auf Den Santo fowohl, als in $23 a$ f

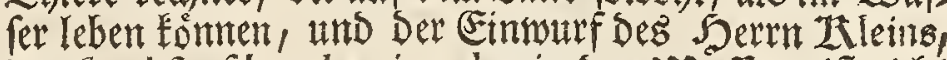
der Laubfrofh gebe niemalen in $\delta a B$ Dafler, if nicht gilttig (**). 2 Benn aber Die antmabende Ealte 2 Bittenung $\Re 2$

itim

$\left(^{*}\right)$ De Aquatil. L. IV. Hift. natural. animal, p. 95 r.

(**) lo. Theod. Klein Summa dubiorum circa claffes Quadrupedum et Amphibiorum in celebris Dom. C. Lya. naei Syltemate naturae p. 27. 


\section{4.}

LA (*), latere bybernis menfibus in terra ranas omues; quae vero addit, eminere ranam arboream verno tempore faepenumero ex terra mediam, mediam adbuc in ea late$r e$, nunquam vidi.

Vix vero arbores habitatura effet rana noftra, nifi glutinofiore vifcidioreque, quam reliquae ranarum fpecies, inftar limacum, tegeretur cute, cuius ope omnibus corporibus facile adhaerefcit. Vtitur eundem in finem fuis quoque digitis; quodfi enim faltu, quo reliquas fpecies, habito ad magnitudinem ipfius refpectu, multum antecellit, pofteriore anteriorene pede, folium vel et tenuiffimum furculum attigerit, illico eidem adhaerefcet illumque fcandendo eft perreptura. Cutis porro glutini adfcribendum quoque eft, quod in politiffimum fpeculum infiliens, illi ipfi, fiue erectum fit, fiue antrorfum propendeat, firmiter adhaerefcat; hine infuper ex vitro, in quo feruatur, minus tecto, facile non folum prorepit, fed vbique etiam pro lubitu in eodem moratur; quin haeret integros interdum ad vitri latera dies, id quod 4 Figura IX Tabulae, expreflum cernimus.

Durante tempore illo quo rana noftra in arboribus frutetisque moratur, crebrius etiam ex iisdem vociferatur; quum vero, hoc vbi fit, non raro tempeftas oriatur pluuia, vociferationem hanc pluuias certo portendere, vulgo credunt. Quodfi igitur quis viuum exoptet hygrofcopium, ranam is vitro includat arboream mafculum (foemellae namque minus funt clamofae), atque fic, omnem per aeflatem, inftantis pluuiae habebit nuncium. Diutius infuper in vitro feruatur rana eiusmodi, fi in eodem cefpes ponatur viridis, ipfi vero ranae mufcae aliaque, quibus vefcitur, praebeantur infecta; nullus etiam dubito, quin multis eiusdem vociferatio aeque grata, ac coturnicis cantus, fit futura. Aluit chirurgus quidam Vratislauiae eiusmodi ranam plures per annos, tandem vero outaua byeme, cum muscae penitus deficerent, ipfa contabefcens interiit (**).

Ait PARACELSVS, referente fic LIBAVIO $(t)$, in firmamento efferanas, a quibus fui generis nafcantur aliae, et deiiciantur impetu tempeftatis: et jperma menfe Maio decidere, ex quo fiant ranae arboreae; quemadmodum vero hanc eius opinionem, noftris temporibus, omnes fummo excepturi funt rifu; fic illi quoque derifu digni mihividentur, qui de eo difputant, vtrum ranae arboreae fpontaneo oriantur prouentu: coire enim easdem, genusque fuum, ranarum inftar terreftrium, propagare, explorate noui. Hac tamen de re vt certior redderer, multam navaui operam, donec tandem cafi, quod diu incaffum quaefiueram, didici. Ignoraui olim, aeque ac alii, fubire ranam arboream aquas quoque, atque hinc in filuis frutetisque me eandem coeuntem deprehenfurumperfuafum habui; quum vero aliquando ranam viridem fluuiatilem cum foemina copulatam quaererem, ipfis in aquis ranas cepi arboreas easque copulatas, $a b$ eo vero tempore, faciliore quam olim opera, ea quae in actu generationis fieri folent, potui indagare, atque haec ipfa iam fum enarraturus.

Coeunt ithm feine Nabrung nimmt, weldhe aus allerband Infe: cten beftehet; fo verbirgt er fich itt Den Schlanm, fo,

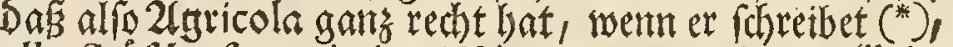

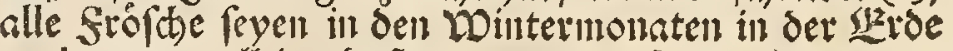
verbortten; alleine Das man, wie er ferner faget, den Laubfrofh, in frublinty, offters loalb aus ber 迎: se bervortagen, und halb datim fteden felse, habe idf nod niemalen wabrgenommen.

Es wurbe aber ber Raubfrofh forwerlich atf Den Boonmen wobnen fơnen, wann er nidbt, fity allen ans Derit Frofdharten, gleich Den Erdofdneden, eine fchlet: ntichte und flebichte Sallt batte, bermóg weldher er fids leidftlich an alle Rorper anjangen Eant; Liber Dent weis

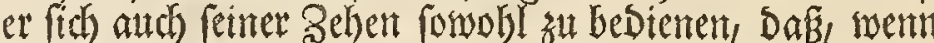
er im Springen, mortitnen felbiger es allen andern Sorten, nach Shoportion feiner Srrofle, zutworthut int reinen bintern dober yodern Fus ein Blat, ober aud

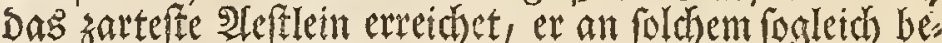
bangen bleibt, und Daran gans leidht berum Eriechen

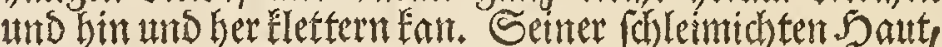
if es auth zusufdreiben, Dafis werm er ant Das glattefte Epiegelglas (printget, felbiges mag aitch gleich aufred)t freben, Doer fich worwarts netget, er bod an foldhen bes bangen bleibet; und eben Deswegen if es ifm alth eit Icichtez, aus cintem G3las, worimn mant ihn berwahret hailt, went es nicht bebectet wirb, herang zat Erted)en, ober an felbigen, liberall swo er will, hantgen sateiben; wie ex Dern auth wirklidh an Den Seiten Des BJlares? wie Die 4 Sigut Det IX Cabelle zeiget, offters gange Ta ge fitzet.

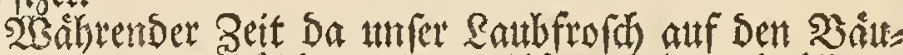
men unt int Bseburiche wolinet, lâf er fich auch offers mif feinem (3efdren horen; wetl aber hierauf tnsgentein eitt segen zu folgen pflegt: fo wirs fortches auth fit eir geniffes Zethen eines bevorftelsenben Seegenwetters ge

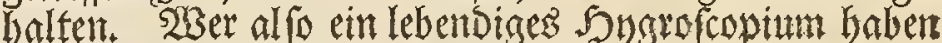

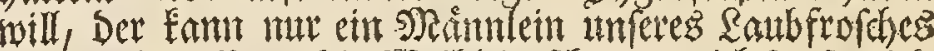

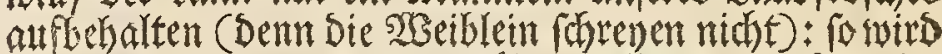
that folches , Den Somnter tiber, allezet oon sem bes

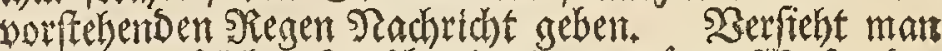
aber eimen foldhen Frofdh mit einem grumen 2 Ba fen, Der

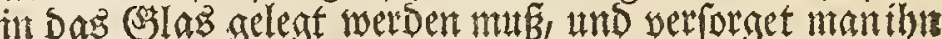

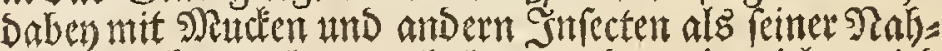
rumg, io fan er lange erbalten werben; ja vielen wirs feit (Steichren eben io angenterm fenn, als Der Schlag einer 2 Badtel. In Breslan hat ein 2 Bumbarst einen folchen Frofd efliche Sabre erbalten, Da ihm aber in adsten 2 Binter bie Netiffent mangelten, fo werdorte und ftarb er enditich (**).

Paracelifus fagt,nach dibwiigericht $(t)$, es feyen ant

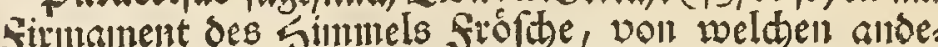
ve erjeutet whiben, die, wein es fintunet, herobfielen: alld folle der Said in Mraymonath berab, und dars

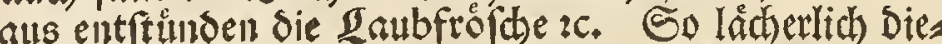
fe Neintung jesermann beut za Tag yorfommen wirs; fo lädserlich fheinen mir auth Diejentgen zu fenn, welche

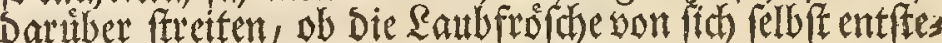
ben; weil idh gewis verfichert bit, Dẩ fie fich paarent

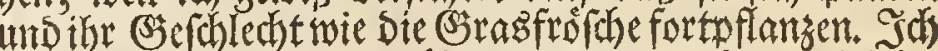
habe mitch aber, hievon tibersenget zut werben, viel be= mithet, biśs mich endich ein ungefährer zufall Dastenis ge lefrete, was id lange umfonft gefuchet. (5s wat mir neinlich ehedent eben fo wentig, als andert, befant,

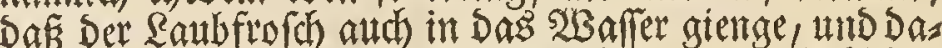

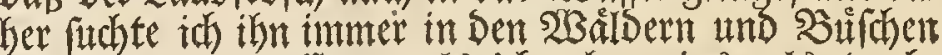
gevanret ansutreffen; als ich aber eimsmals trachs tete ben grinten 2 Baflerfrofd gepaaret zut finden, traf

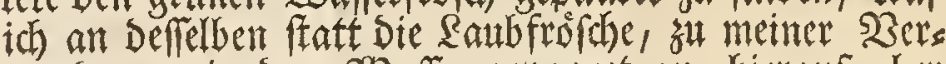
munderung in Dem $\mathfrak{x a f f e r}$ gepaaret an, hierauf aber

wat:

(*) Loc. cit. (**) Ephemer. N. C. Dec, II. An. VI, p. 32I. (†) Libau. Batrachior. Lib. II, p. 848. 


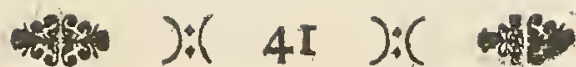

Coeunt ranae arboreae, reliquarum more, femel tantum in anno, neque vnquam prius, quanı rana fufca terreftris oua peperit fua. Morantur tunc in aquis quietioribus pifcinisque $\mathrm{ab}$ arboribus parum remotis, mafculis multum clamitantibus. Eft vero parua haec rana magis vocalis maxima etiam rana fluuiatili; coaxat yefpertino praefertim tempore, et interdum integras etiam noctes, atque vbi in pifcina quadam copiofior earum eft numerus, clamor ipfarum, firante prafertim vento, in locis etiam duas horas diftantibus, percipitur: coaxantenamque vna, reliquae omnes fimul coaxant, et licet ruftica gens, quaenam ranarum fpecies hos edat clamores, ignoret, ex iisdem tamen, ante vel poft diem St. Georgio facrum, perceptis, de fterilitate fertilitateue futurianni vaticinantur. Eft autem rana arborea prima ranarum quae verno tempore vociferant : licet namque rana terreftris prius ipfa coeat, atque adeo more ranarum tempore illo fimiliter vocalis fit, furdum tamen potius edit grunnitum quam clamorem, quemque ad diftantiam quindecim pafluum vix percipimus.

Vtrum mafculi ranarum arborearum clamores fuos, eo ipfo tempore, adeo ingeminent, $\mathrm{vt}$ iisdem foemellas alliciant; an vero temporis verni amoenitate ita exhilarentur, vt indefinenter fere vociferent, jain quidem non examinaturi fumus; notatu vero dignum eft, quod, dum vociferant, gulam ita inflent, vt faccum referat membranaceum aere repletum, vinde fingularem in modum externa ranae mutatur fpecies, id quod 3 monftrat firura. Quemadmodum vero membranaceus hicce follis, quem femper ipfo fub clanore expanfum feruant, mafculorum conftituit characterem: fic ipfa etiam gula, licet eandem contraxerint, a foemellis diftinguuntur; fufci namque in ipfis eft coloris, id quod 4 Fioura indicat, quum contra ipfa illa regio in foemellis (a Fig. 2), vt integra, earum aeque ac mafculorum, inferior fuperficies, alba fit; in pollicibus vero anteriorum pedum huius ranarum fpeciei, difcrepantia illa, quam in rana terreftri notauimus, minus occurrit: nunquam enim mafculorum pollices nigra illa obfiti funt carne, quam coitus tempore terreftrium ranarum mafculi monftrant.

Quod vero ad ipfum ranarum harum attinet generationis negotium, anno 1750. fub finem iam Aprilis eidem operam illae natiarunt. Prodierant nonnullae quidem ex limofis fuis hibernaculis vigefimo jam huius menfis die, erant vero illae mares tantum, quos, poft dies aliquot, foemellae demum fequebantur ; tum vero easdem mox etiam vidi copulatas. Vt itaque quae durante coitu fierent, diftinctius cernerem, aliquot illarum cepi paria, eademque domum transtuli, vbi quodlibet eorum in vitrum immiff cylindraceum fat amplum, et ad dimidiam vsque partem aqua repletum. Singula vitra reti circumligavi anguftiore, ne ranae, finito coitu feparatae, elaberentur, quum, vt fupra dictum fuit, nullus vitri laeuor impediat, quo minus facili opera ex eodem prorepant. $\mathrm{Ne}$ vero pro inftituendo viteriori examine ranae deeffent, fufficientem etiam non copulatarum quantitatem domum meam curaui deportandam.

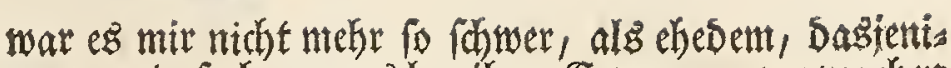
ge sut unterfitchert, was ben ifrer Erzengung vorgugeben pfleget: und foldhes will tch test beforreiben.

Es paaren fich Die Eanbfrofothe, gleith andern Fro: chen, Das Tahr nur einmal, aber niemal ehember, als

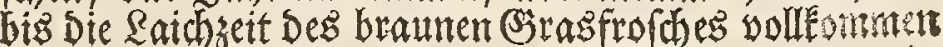
vorbey ift. Sie halten fich zat Der Beit ebenfalls nur in

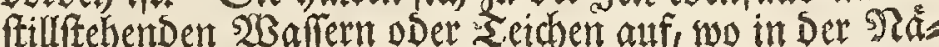

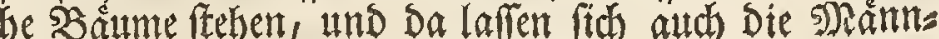

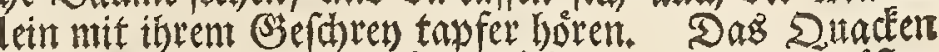
Dieres Eleinen strofhes ift siel ftâder, als Des grofiten rafferfrofches (eines, fonderlich aber wirb foldhes des शlbends, und ntandimalen ganse Nädte lang vertoms men; finden fich aud viele biefer Storfhe in eittem Teids benfammen, fo hoset man fie wobl ztwey Stunben weit, sunten ant foldhen Drten, wo Der simb hintwebet:

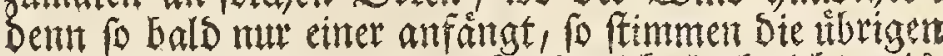

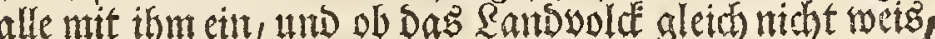

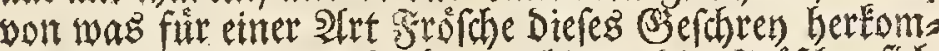
me, fo glaubet es Doch, nachoem Die Frofthe fits bor ober nach (Seorgii Tag horen laile, machoem folge auth ein fohledtes ooer ghies jabr. Es ift aber Der Raubfrofh Der erfe unter Den Froforen, bet mont int Fribling quadeen horet : Demn ob fich gleid Der Seras: frofo elsenter als er paaret, umb alfo nath Der Srofiche 2lrt ebenfals, zat Diefer Zeit, eimen Ratit vout fin giebt

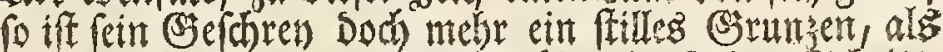

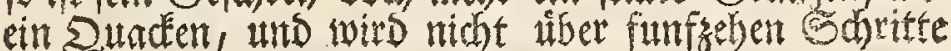
gehoret, wie in Deffelbent Siftorie beretts gemeldot wor bett.

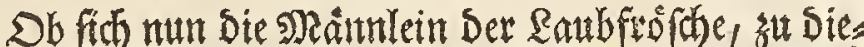
fer Peif, Deswegen fo ftarde horen laffen, Dar baburb

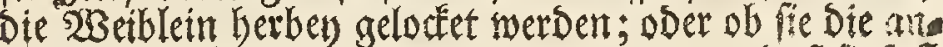

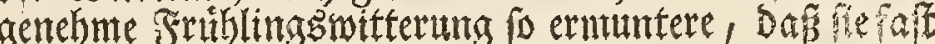
unaufhorlidh guaden, wollen wir jezs nidet unterfuden; Diefes aber baben wir ben itrem (J3efhren als twa bes

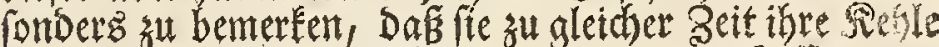
ftarck aufblafen, fo, Daf felbige einen mit Suffet antse= firllten bautigen Sade porffellet, Der Dem Srofa) ein gans

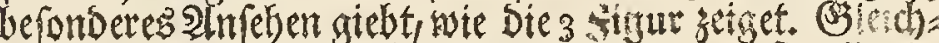
note mun aber Diefer boutige slabbalg Den fie allugut

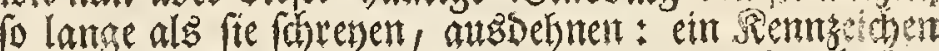

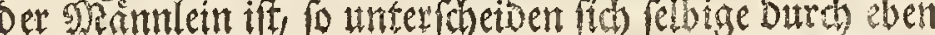
Diefe Sehle and yon Den sgerblem, twent fie folche eint

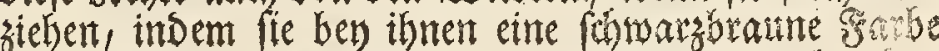
hat, wie an ber 4 Sigur zu fehen, da hingegen bey ber 2Beiblein biefe Begend (a Fig. 2.) eben fo weiz ife, als

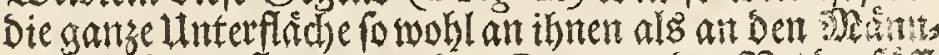

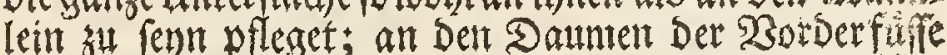

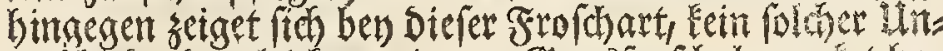
terfiched, Detgleichen wir am (Bjagfrofd bentertet ba: ben, indem bie 5sRännlein niemalen an félbigen ein of

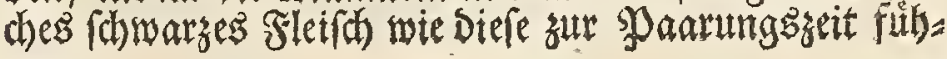
ret.

NBas mun aber die \$aarung Diefer Frofdhe antres

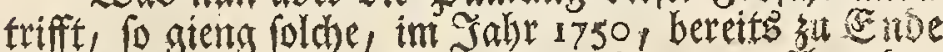
Des Iprils vor fich. Eintge berliefen zwat fôn ben

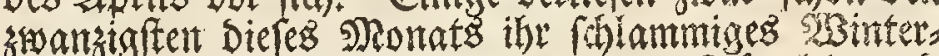

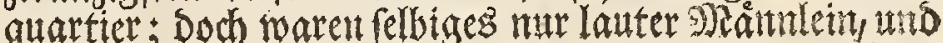
Die 2 Beiblein lieffen fich enft nad) einigen Tagen rehet. Gierauf aber traf id fie bald mitemutinser gepartet an. Damit ich mul alles mas wähend Diefer sparung odes

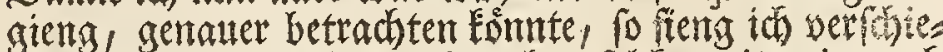
Sene spare Derfelben und nahm foldse mit mir mab Gaus, rounte auch einem teben ein befonderes geraus miges Buderglas ein, Das ich bis zur Salffite mits $3 a f_{1}$ fer anfullte und mit einem engen 3 arm veriahlos, $D a s$ mit mir, nach vollendeter saarma, die einzelnen Sros fhe richtentgeken mogten, weil, wie wir oben gehoret

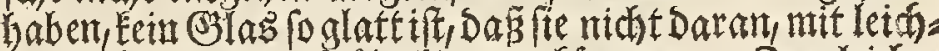

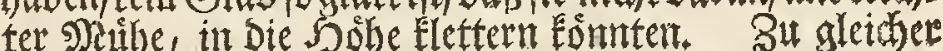
zeit aber lies id mir aud), eine genugfane sisenge, 


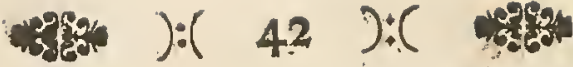

Ipfo in coitu mafculus femper foemellae infidet dorfo, id quod fimiliter fieri folet vbi terreftres ranae coeunt; fed non amplectitur rana arborea mas foemellam eadem etiam ratione, quemadmodum ex binis prioribus figuris $I X$. Tabulae apparebit, quarum prima par harum ranarum a fuperiore fuperficie, fecunda vero ab inferiore fiftit. Indicant in vtraque earum litterae a aaa $a$ foemellam; $b b b$ vero mafculum; ex fecunda etiam figura patet, liberum prorfus foemellae pectus a mafculi effe amplexu, hunc vero pedes fuos anteriores $c c$ ita in foemellae alas adigere, vt omnino lateant, ipliusque brachia detruncata videantur; retinet tamen his ipfis foemellam tam firmiter, vt ipfi vix ac ne vix quidem eripi illa poffit. ' Quodfi igitur femen mafculi foecundans per pollices excerneretur, ad alas vsque foemellae, vt ouiductus exporrigerentur, neceffe effet; rem zutem fic fe non habere fequentia docebunt.

Durat interdum harum ranarum coitus, donec ipfa fiat foecundatio, per tres dies totidemque noctes, nonnunquam tamen omne hoc negotium viginti quatuor tantum abfolvitur horis, fi praefertim tardius coiuerint; fed determinat potiffimum rem hanc citior tardiorue ouulorum foemellae in vterum ingreflus: hunc namque ante ipfam femper fier: foecundationem, ex illis didici foemellis, quas non ita multo ante aperui. Mergit foemella mafculo juncta fefe iteratis vicibus in aquam, atque tunc, antequam emergant, diutius fub eadem morantur: notaui eodem etiam tempore in omnium foemellarum abdomine expanfo, crebriorem, fortiorem prorfusque fingularem motum, ita vt viuum in eodem latitare videretur animal, nunc fuperiora, nuncinferiora, nunc etiam latera diffupturum; moleftam tamen hanc ipfi foemellae abdominis fuiffe diftentionem, praecedens eandem inquieta arguere videbatur illius agitatio, quae tamen magis magisque increfcebat, quo propius ipfum oua pariendi tempus inftabat. Tantum vero abfuit vt, haec dum fiebant, mafculus quiefceret, vt potius extremam corporis fui partem eidem parti foemellae, repetitis vicibus admoueret; quem tamen motum, fub ipfa ouorum per inteftinum rectum eiaculatione, haud fegniter iterabat.

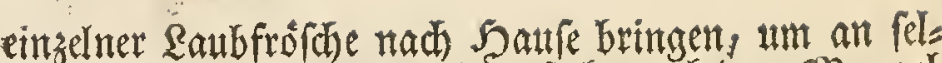
bigen, bet) anzuftellender Unterfuchung Eeimen Nangel zuk haben.

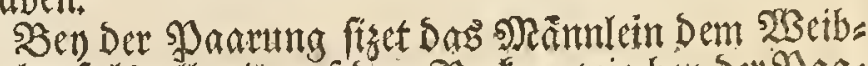

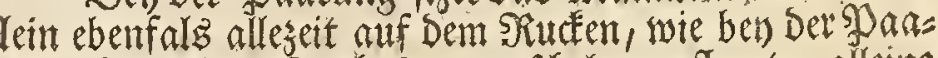
rung Des Grasfrofhes zH gefhehen pfleget allewe

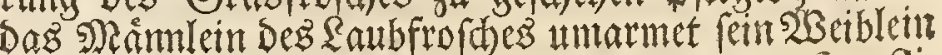
nicht anf gleiche 2 Beife, wie uns Die becoen erften fits guren Der $I X$ Cabelle zeigen werden, als nogfelbfit bie I. Figure ein paar folcher Frofche yon oben, Die 2. aber son unten Darftellet. In beeden ift Das 2 Beiblein mit

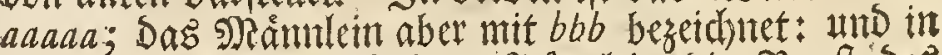

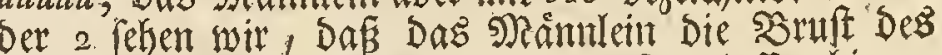
Weibleing ben Der llmarmung ganz fren laffe; binges aen aber feine borbern spfoten $c c$, fo bef unter ben SIdjell einorucke, Daft man won felbigent nichts zat ${ }^{e}=$ ben befommet, unt feime beeden 2rrme mur ein sjane Stumpfen borftellen, mit weld)en es aber Dod, biz Die Sefruchtumg vor fich gegangen, Das W3eiblein fo wefte bålt, Dafís man ihm foldhes nid)t leicht entreiffen Ean. Rơme aber twut Der zut Befruthtung nótbige

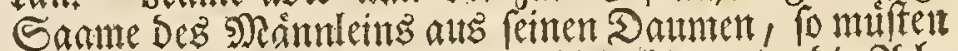

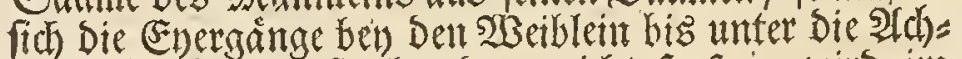
feln erftreden; Dafi aber Deme nidht fo fere, wirs int Folgenden gezeiget werden.

Diefe sparung Dauert mandimalen wobl Dren Tas ae und eben fo siel Nind te, bto Die Befruchtung yor fich getset mandhmalen aber wabret fie nut vier atmo ziwanzig Stundeny und zwar fonberlich bet) Denjenigen fo fid etwas fpat gepaaret haben; Doch fommt eg hies rimen wortelimlich Darauf an, ob bie ever Des 23 eibs

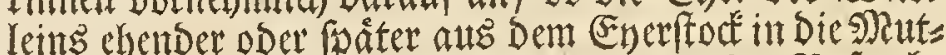
ter getreten : Dent Dấ foldhes allezeit yor Der Befruch).

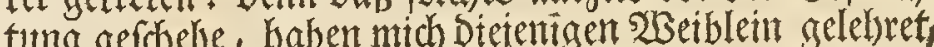
weld)e yon mir Eurs yor felbiger geoffnet worben. SBåth= render \$aarung gehet Das şetblein zufammet feinem (Satten offters unter Das $\$$ BBaffer, Da fie Dent ehe fie fich wieber ant bie Dberfliche begeben, ziemlid) lang ttts ter felbiaem bleiben: aud babe id) za gleidher Bett an allen 23 Betblein wahrgenommen, bas fid in ihrem Dis den unterletb, mebrntalen, cine farde unt gans bes

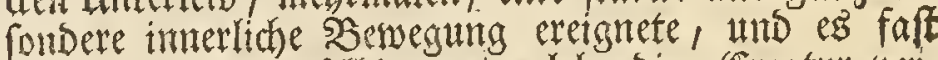
foriene, alz ob in elbigem eine Iebendige Ereatur vers borgen maire, welche bald oben, balb unter, bald aber auth on Den Eeiten Durdytubrechen futhte: anben batte

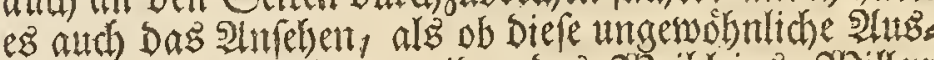

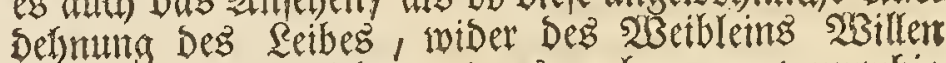
gefherbe, indem foldhes, etwas vorker, gant untubits iwnobe; He naker aber bie Beit zum Saichen heran rudte, je offter und ftrinker noar auch biefe Berwegung wabry nefmen. Das Månnlein blieb fieben nted trubig; fons Sern toótherte fich vielmebr, su wieberbolten malen, mit Dem Sintertheil reines Reibes Dem nåmlichen Theil Des YGeiblems; biel offter aber gerdhahe foldhes, went bies fes fich feiner Ener Durch Den snafts arm enteledigte.

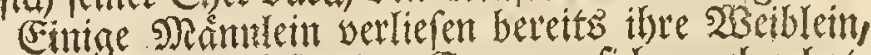

Dimifere mafculi nonnulli foemellas fuas, dimidia vix dum ouorum parte exclufa; alios contra tamdiu dorfo ipfarum, donec omnia ouula eiecerint, infediffe vidi. Licet vero eo tempore, quo foemella ouula eiuculabatur, duodecim quin plura harum ranarum paria, crebrius contuitus fuerim, omnique cura foemellam aeque ac mafculum confiderauerim, nunquam tamen in hoc membrum genitale me vidiffe memini; vtrum vero ad impraegnanda oua liquorem aliquem emiferit, quemadmodum de terreftri notaui rana, aeque minus obferuare potui. Pepererunt nonnullae foemellae omnia fua oua binarum horarum fpatio, nonnullae vero, illaeque praefertim quas mafculi derereliquerant, quadraginta octo horis idem perfecere: operae hinc precium me facturum putaui, fi ouula, tam illa quae breuiori tempore partu edita fuerunt, quam ea in quibus excutiendis foemellae diutius laborarunt, feorfim feruarem, nec non ftudiofius obferuarem examinaremque; hanc etiam cautio-

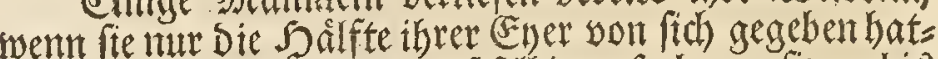
went andere aber blichen auf felbigen fo lange fizen, bis fie alle heraus waren. $D b$ ich aber gleich offter mebr als zwolf SSaar, zu Derientgen seit, Da Das 2 Beiblein laichte, aetra betrachtete, und auf felbigez fo wohl, als auf Die Berrichtung Des SRánnletns Die forgfamfte

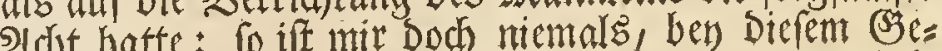
2ld)t batte: stl (S)efichte gefommen; atth babe id nidst, wie ben

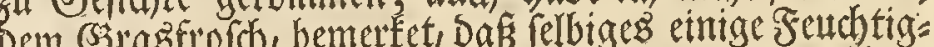
Eete, Die etwann jur Sefruch tung Der Ever Dienen fonn= te, son fid) gegeben botte. Shit Dem Laid)en felb/t Grad) ten einige sBeiblein zwen Stunben zu; einige aber,

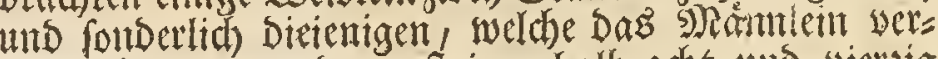
laffen hatte, wurden erfitimerbalb acht und vierzig Stumbendamitfertig/und diefes madte midh fo vorlud = 
Tab, XI.

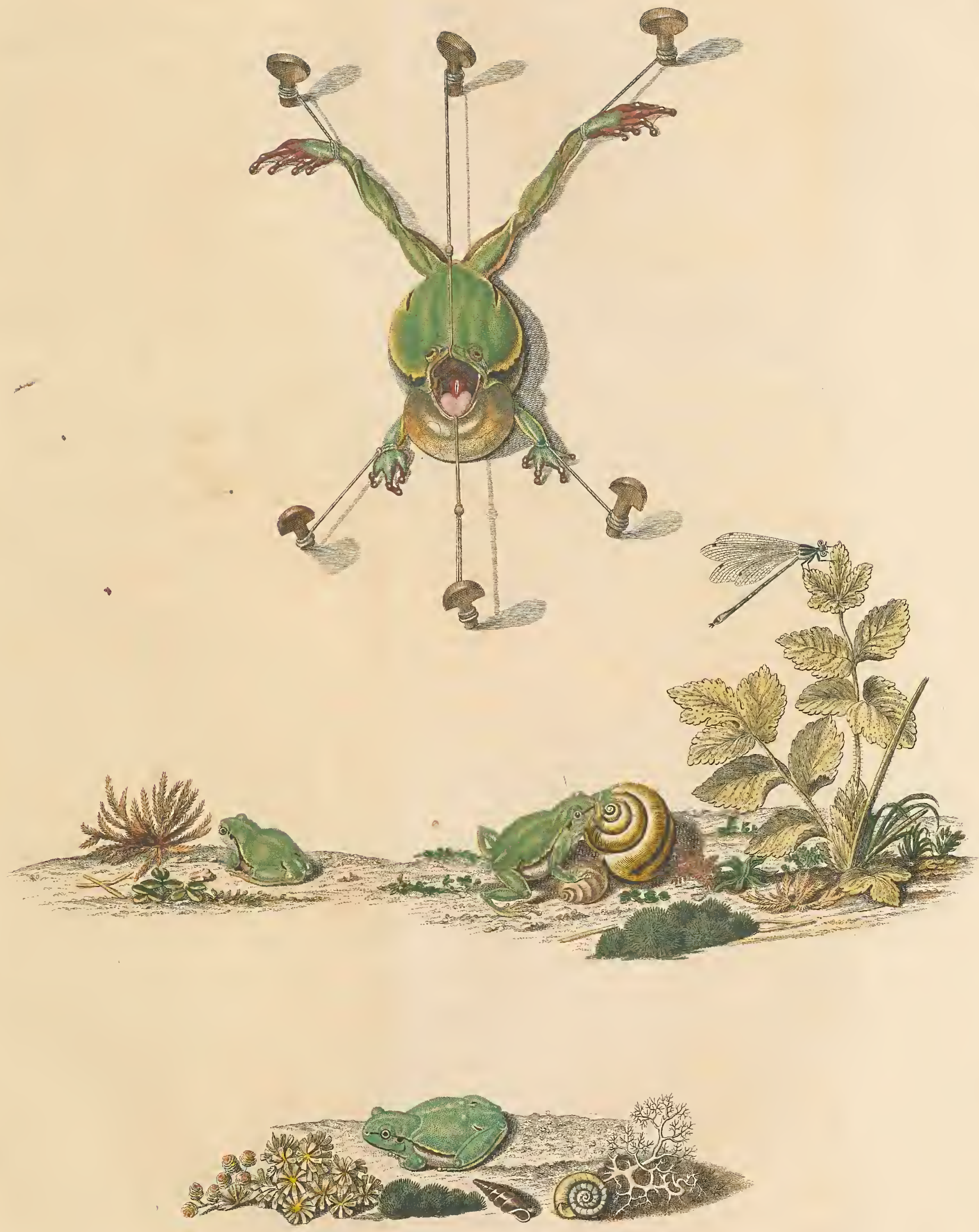




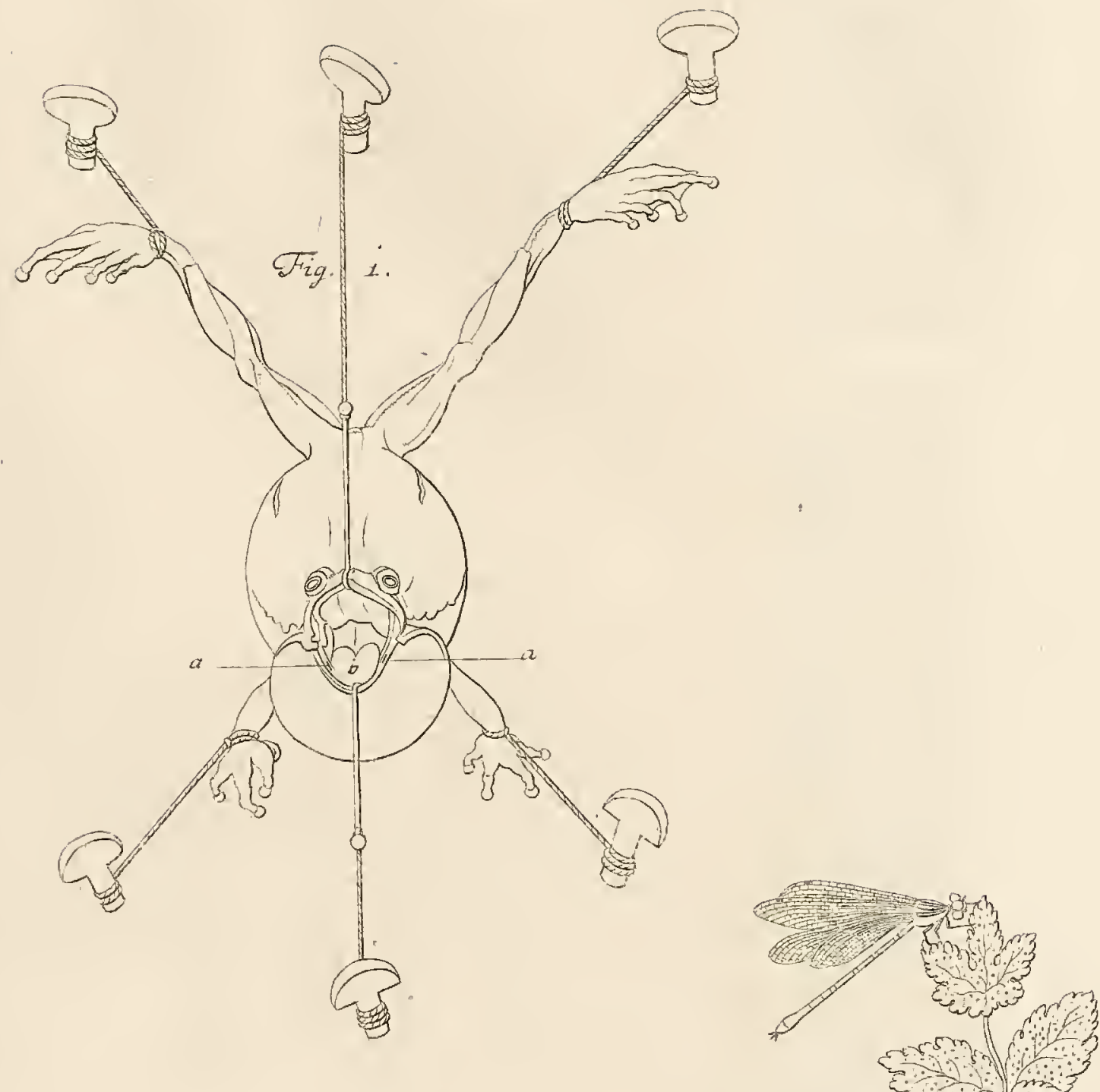

$$
\text { Fit. }
$$

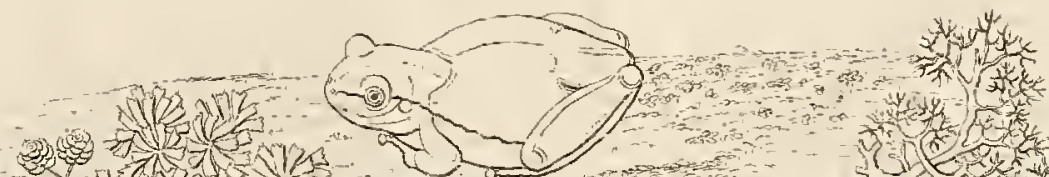





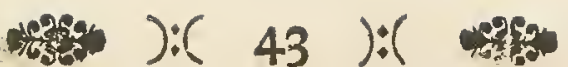

nem non fruftral a me fuiffe adhibitam, jam jam videbimus!

Quamdiu vero ranae hae generationi incumbunt, tamdiu etiam in aquis habitant; peracta autem illa, citius tardiusue ex iisdem prorepunt; prout nempe amoenius vernum tempus citius tardiusue ingruit; $v t$ plurimum tamen fub finem menfis Maji humida fua linquunt habitacula, atque tunc haud raro in terris herbisque inueniuntur. Sequent vero tempore frutices magis arboresque incolunt, tam diu in iisdem commorantes, donec frigida appetente tempeftate, vt in fua limofa redeant latibula, cogantur.

Sunt oua ranae noftrae arboreae non tantum, ouis ranae terreftris, minora, fed eft ipfis quoque color magis dilutus. Licet autem initio ftatim nulla materia giumofa cincta effe videantur, in confpectum illa tamen tunc demum prodit, vbi oua per duodecim horas aquae fuerunt immerfa, atque tunc aequat quodlibet eorum, cum glutine illud cingente, vulgaris viciae granum, cuius diameter decimam pollicis partem non fuperat; ipfum vero ouum vix habet magnitudinem grani finapis. Cernimıs horum ouorum, vel fpermatis huius, in I Figura, $X$ Tabulae partem aliquam, qua tamen tricies maiorem quantitatem vna tantum emittit foemella. Quia vero glutinofus oua haec cingens liquor non fimili ratione, ac ille qui oua ambit ranae terreftris, increfcit, ponderofius etian ipfum hoc eft fperma, atque adeo ab aqua minus eleuatur, fed vel in fundo iacet, vel ad herbas plantasque ipfa fub aqua adhaerefcit. Quum praeterea quodlibet horum ouorum ex parte pallide flauum, ex parte vero fufcum fit; folent hinc etiam pro diverfa ipforum pofitione, nonnulla eorum alba, vt in 2 Fisura, alia fufca, vt in 3, alia yero partim flaua partim fufca, vt in 4. , comparere; atque proin maior horum ouorum congeries varii etiam $\in \mathrm{ft}$ coloris,

Dixi iam fuperius, duplicis generis a me afferwatum fuife fperma; alterum emiferant foemellae binarum horasum fpatio; alterum vero, elapfis demum quadraginta octo horis, ab illis editum fuit foemellis, quas mafculi ante abfolutam ouorum exclufionem dereliquerant. Licet vero illud foecundatum, hoc minus foecundatum effe crederem, dubium tamen id ipfum adhuc erat; vtrumque hinc aequali confideraui attentione, nec coniectura me aberas fe, tandem etiam vidi: quamuis enim et hoc etillud fenfin mutaretur, attamen ex altero tantum vivos obtinui gyrinos, ex altero nulli prodierunt.

In fpermate quod, vt mihi quidem videbatur, foecundatum non fuerat, notaui die vigefimo octauo Aprilis mutationem aliquam, qua quilibet vitellus in bina globofa diuidebatur corpufcula, quemadmodum ex s. Figura patet. Die vndetrigetimo trigefimoque Aprilis non haerebant amplius vitelli in medio albumine, quumque altera pars ipforum altera minor erat, pyri nunc fere habebant formam, cuius crafius extremum marginem exteriorem, tenuius centrum albuminis fpectabat, id quod 6 Figura indicat. Eminebat die fexto Maii extra albumen craffior vitelli pars ad modum $7 \mathrm{Fi}_{\text {gurae }}$, atque tunc videbatur etiam albumen in. binas fphaeras, quarum altera alteram magnitudine

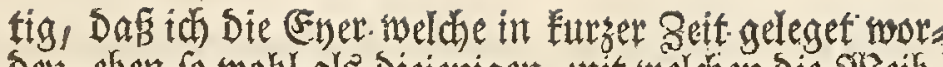

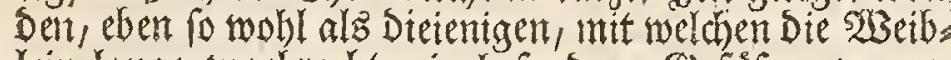
lein lange zugebrad)t, in befondern (S)efáfen, zur ge=

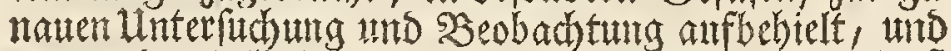

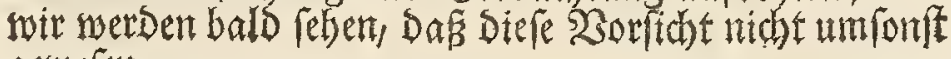
gemejent.

So lange mun Diefe Froofhe mit Fortpflangung ity.

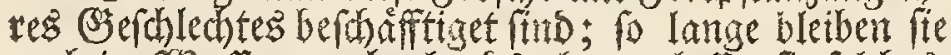
auch im şafer, nad)gebends aber verlafen fie folches,

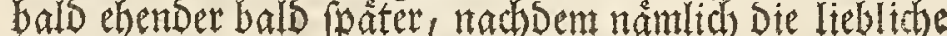
Frublingswitterung fich ehender ober fpater einftellet; Dod Eommen fie inggentein erfiz Diefer ifrer nafent 230 hnuth hervor, Da man fie Dem auch offters auf Der ErDe und im (Szas antrifft. SRad)=

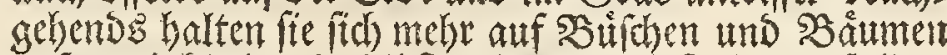
auf, und bletben Dafelbit fo lange, bis fie Die einfallen: be froftige 2 Bitterung, Den Shlamm, als ithr sBinter= quartier wieser fu futhen zwinget.

Dete (3iner unferes Raubfrofhes find nicht nut allein Hetner, als Dietentge fo Der Bjtasfrofich von fid gitebt, prover and won sarbe stel beiler. Itro ob fie gleich anfontgs nit Feneing blem umgeben zu fentr fochent:

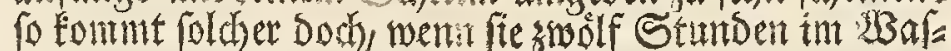

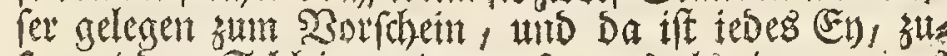
famme Den Sd)lem, etwann fo gros als ein gementes

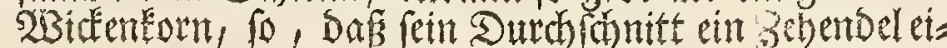
Hes Solles ausinadhet, Das En felbif aber fommt faum einem Senfforn an Srófe aleich. S2Bir fehen eimen Theil Diefer Ener, ober Diefes Ratches in Det I. Sintu, Det $X$. Trbelle, und ein eintges TSeiblein giebt wobl orenfiamal megr won fich, als hier yorgeftellet worden. Wetl fich aber Der Schleim, welcher Die Ever Diefes Raiches umatebt, nidut fo ftardét wie an Dent Evern Des Srasfrofhes ausbrettet, fo bleibet auth Der Rath ferb= ften fchweer; Daher er Dem altch bon Dem 5 Baffer nicht in bie Soble geboben wird, fontoent entweder auf Dem

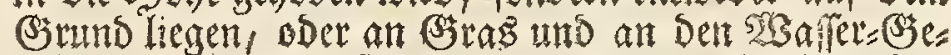
vatulen, in der Tiefe behangen bleibet. Ein tedes dies fer Ener if halb gelblicht, balb bratm, und baber fes. ben fie nach therer verfhied enten $\mathfrak{L}_{a g e}$ thetls gants bell, swie in Der 2 Fitur, theils Dundel coer braun, wie in Der 3.; theits aber auth halb bellgelbletst und halb

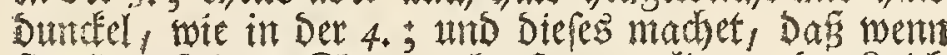
fie alle auf einem Rlumpen bey anmen liegen, ber Lath

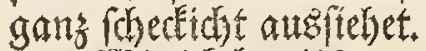

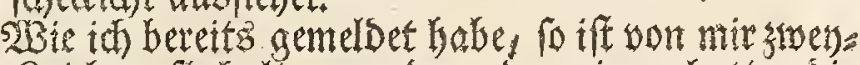
crley Saich aufibehalten worben: Den eiren batem Die

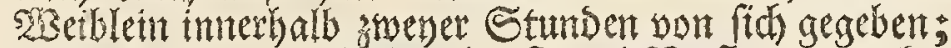

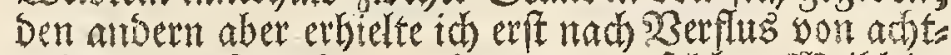

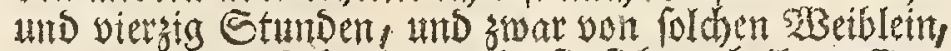

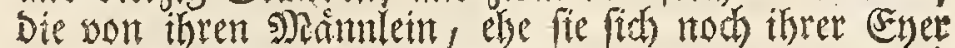

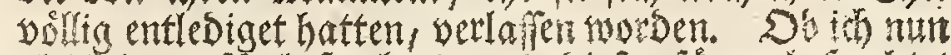

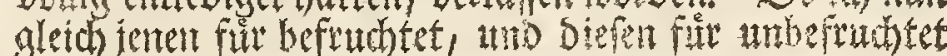
bielt: fo war foldes bod noch ungerots; eben beswes gen aber betarbete th beebe mit glether atufmerufam teit, uns fand enslich, bas ich redit gemuthmalet hat:

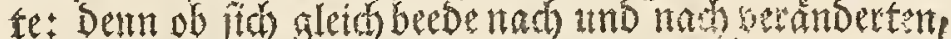

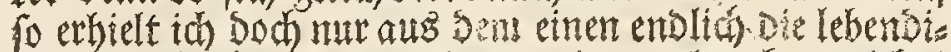
gen Grofinutrmer, aus Dem andern aber fam nidhts sum sonthetit.

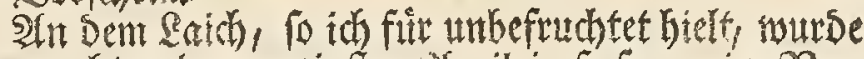

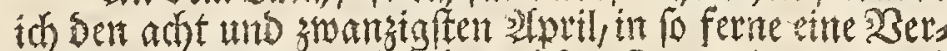

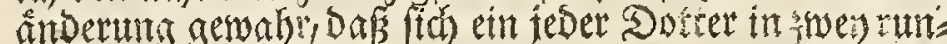
De Rorperlem theilte, wie aus Der 5 . Bigur su erfehen. Den neun und zwanzigften und Drenfigften Itpril, was ren Die Dottern nidht mehr in Der STitte Des Shleims; und weil Der eine Theil Derrelben flemer als Der andere geworder, fahen fie mebr bintrormig aus; ihr bickes

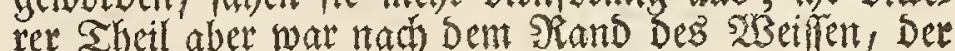
Dinnere binaegen nad Dem SMiftelpunct Defielben ge= Eebret, mie Die 6. Sigur zeiget. Den erifen glats ragte

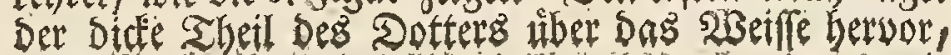




\section{(4) $):(44):(4)$}

fuperabat, diuifun, cingebatur etiam hinc tenuior vitelli pars, aeque ac craffior, nunc proprio fuo albumine, ipfe vero vitelli color nullam hactenus fubierat mutationem : oftendunt namque figurae 8. et 9., quae eundem magnitudine auctum repraelentant, fuiffe illum adruc ex parte pallide flauum, ex parte vero furcum.

Quum hactenus nullum in ouis hifce quoad formam notaueram vitium, ex iisdem gyrinos mox prodituros fperabam; fed mutabatur, praeter fpem, forma ipforum fimul cum colore, ita, vt in magnitudine naturali Figurae 10 , per microfcopium vero vifa Figurae 11 . fimilia esfent, parsque altera illorum priftinam craffitudinem atque rotunditatem haberet, altera vero extenuata nec non acuminata prorfus effet. Die vero tertio quartoque Maii tantam fubierant mutationem, it fungum potius petiolo fuo inftructum, quam gyrinum referrent, quemadmodum 12 . et 13 Figurae oftendunt, quarum illa naturalem, haec autem naturali maiorem eorundem fiftit magnitudinem. Bina albumina nullam tunc quidem paffa erant mutationcm; fed difparebant tandem, eoque facto omne hoc etiam periit fperma.

Mira valde vifa mihi eft haec ouorum minus foecundorum mutatio, quamuis enim non negen, fuiffe eam ex parte $a b$ aqua, in qua haeferunt, productam; potuit tamen illa in albumine tantum, non autem in vitello effectum aliquem edere. Quaenam itaque eft cauffa mutationis in hoc etiam factae, magnitudinisque ipfius auctie? Videtur fane animalium ouis plus fudimentorum foetus ineffe, quam quidem hodie nonnulli credunt; praefertim quum et in mufculortim atque cochlearam, vere tantum coeuntium, ouariis, ipfo iam altumno, conchas domosque, ope boni microfcopii confpexerim. Quodfi infuper fint, qui oua haecce minus quidem foecundata, incremento tamen aucta, cum molis comparent, $a b$ his ea in re, me vix diflentire, lubens fateoro

Fuerant quidem in fpermate foecundo, oua noninulla, quorum vitelli dicta fimiliter mutabantur ratione, ea vero quae mafculi foecundata erant femine, fenfim fenfimque aliam prorfus induebant formam. Initio quidem augebantur mole tantum, vitelli autem renem figura referebant; die vero primo fecundoque Maii confpiciebantur gyrini in iisdem jam fat diftincte, atque tinc illa ipfis erat forma, quam I4Figura delineaui, 15. contra vnum eo. rundem ope microf́copii magnitudine auctum oftendit. Prius tamen quam in hac ouorum confideratione vlterius pergam, indicandum eft, inftituiffe me contemplationem fpermatis ranarum arborearum longe maiori attentione, quam fpermatis ranarum terreftrium, atque proin non mirabitur beneuolus Lector, fi plures hic indicauero mutationes. Vbi gyrini horum ouorum in confpectum prodire coeperunt, maxima pars illorum conftabat ventre, fic tamen vt cauda finrul cum capite iam diftincte appareret. Natabat quilibet gyrinus in albuminis medio, craffitudo vero ventris debebatur potiffimum vitello, ex quo caput caudaque, ad modum germinis nec non radiculae ex femine plantae cuiusdam, prodire videbantur, quique merito fio placenta etiam dici poffet. Obferuabam nunc quoque haerere ad caudam gyrini aliud quoddam corpus globofum, quod magnitudine tantum a reliquo albumine dif ferebat, cui tamen tertio atque quarto Maii die fimile fere erat; fed diftabant tum magis, venter vero gyrini perdiderat nonnihil ex craflitudine fua, vt ex I6 et 17 figuris patefcit. Mouebat fefe nunc etiam gyrinus pernici mo- wie in Der 7 Sigute, Ind $\delta a$ thien es als ob fit bas WBeife in zwen Sitgeln getheilt batte, Davon bie eine

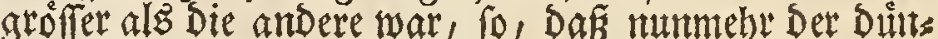
nere Theil Des Dotters, eben fo wobl als Der Dickere, fent eigenes Weiffes hatte; Die Farbe Dez Dotters abee war zur Beit nod miche verănert: Dent wir fehen auts Der 8. uni 9. Sigut, Die uns Denfelben vergróffert yors ftellen, Dafi er noch zum Sheil bellgelblicht zum Theil aber braut geweren.

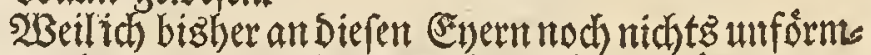
lidhes wahrgenommen, fo vernuthete id bald Die Frofthwirmer aus felbigen sum 20 orfheinfom: men; alleinfie verlohrèn ihre Sorm neb fít Der braunenfarbe auf einmal, uns erfhienen Den zwenten Nay in Derie. nigen (Siefalty in weld)er fie Die 10. Sigur ber nattirlis chen (Sroffe nadh, Die II, aber bergroffert yorftellet, Da Der eine Sheil Derfulben nod) Didf und rand, Der andere aber gand Dume utto foizin war. Den britten und biers

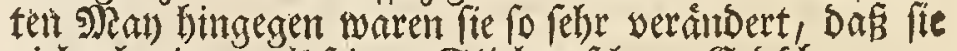
sielmebreinem mit feinem Stiel serfehenenङ̌rbfhmamm als einem Frofthinum gleich fahen, welches die 12, unt 13. Signte, und ziwat jeme in natirlicher, diefe aber in melir als naturlicher E3róffe zeiget. Interdefien batten

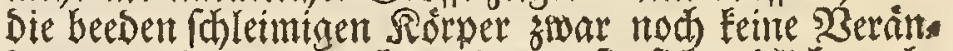
berung gelitten; Dod serlobren fie fich entlid auts, Ints fo verdarb Diefer \&aich miteinander.

Die Berninderum welche fith in Diefen anbefructes ten Eivern ereignet, bat mich nidht wenig befrembet:

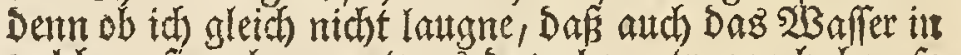
fweldhem fie gelegen, etwas Dazu bevgetragen habe, fo hat folchez Doch nur in Daz 5 zeiffe Der felben, nidyt aber

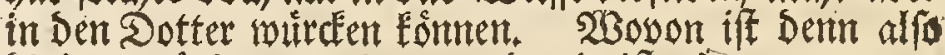
Dieler veraindert worden, und wie ift es stigerantisen, Daf er grófier gerworden? Fafít follte id glauben es ftes

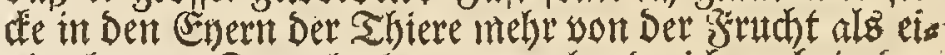
nige heut zu Sag glauben; sumalen ba idh aud in ben

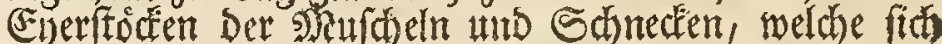
nut im Fraibling zu begatien pflegen, bereits in Sperbit

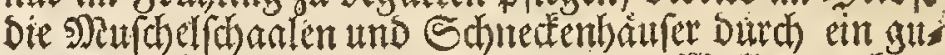

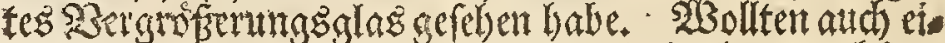
nige dieke unbefrudteten Ener, weldhe Dod gewadrien, tmo alt Bstóffe zugenommen haben, mit Den sNonofáls bern vergletchen, fo bitte id wider Diefen Bergleith nidhts einzunenden.

Inter Dem befruchteten $R$ aich fanben fid swarauth einige Ener, Deren Dottern fich auf obige Weife verain. Derten; Dieterigen aber welche Durd Den Snanen Des" Mannleins belebet worden, befanten nad) und nad ein

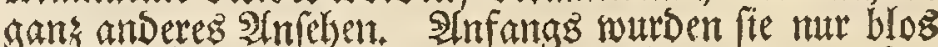
etwas groffer und ifr Dotter nierenforntig; Den erften und andern $\mathfrak{M}_{a}$ aber Eonnte man bereits in felbigen bie 23 inrmer gans eigentlich erkenten, utnd Da faben fie fo auts, wie id einen Derfelben in Der 14. Sigur sorgeftel. let babe; in Det 15 . lingegen find fie fo von mir abge bilber worben, wie fie mir Das SBergrofferungaglaz ge.

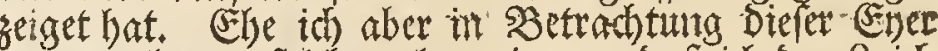
weiter gebe, mus th worber erimern, Dafich ben \&aich Des Eaubfrofhes biel genauter uno forgfáltioer als ben Saich Des Brasfrofhes betrad)tet babe, Daher fid Dent Der geneigte Eefer nicht wundern- mird, menn ex bies

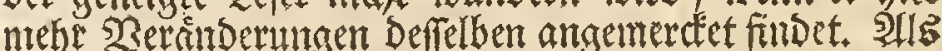
fich Die 2 Birmer in Diefem Raich zu zeigen anfiengen ; mad) Der 3 aud Den groffen Iheil Derfelben aus; Doch Eonnte man bereits aud Den Sownans nebrat Dem

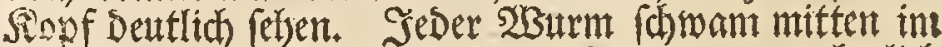
WBeifen, Die Diffe feines Reibes aber war vornebmlich Dem Dotter zHzthdretben, aus weld hem Der Sopf uno Der Shinanz, wie Der Siem und Die WHursel aus Demi

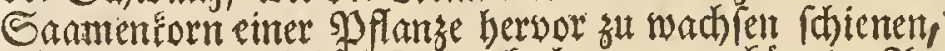
atid Den mant aud Den Nutterkud)en nement Eonnte. 2 (n Dem Shwanz murbe ich mut aud einte andern rumber

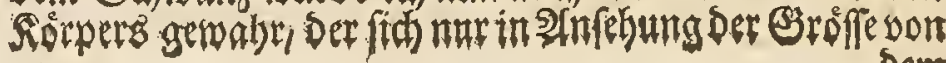




\section{(20)}

tu : mutabat namque non folum fitum, fed percutiebat etiam caput cauda fua, quo vero facto aliquamdiu immobilis prorfus jacebat. Quinto fextoque Maji nulla amplius inter binas veficas glutine plenas, erat connexio; altera quippe capiti adhaerefcebat, altera caudae, vt ex 18. et ID: figuris apparet; ipfe gyrinus flauefcebat, venter vero eiusdem nunc fenfim fenfinque decrefcebat. Septimo octauoque Maji aderat dimidia tantum pars albuminis cum cauda cohaerentis, quod et apertum videbatur; quum contra illud quod capiti junctum erat, integrum claufumque effet, quemadomodum figwrae 20.et 21. indicant. Difparebat vero vtrumque nunc quibusdam in gyrinis, fub ipfo intuentium confpectu; quia, ceu quidem veri fimile erat, ipfe iam gyrinus alimenta fibi quaerere potis erat. Nutriri gyrinum ex anteriore vefica, haud vana eft coniectura, quis vero polterioris fit vfus, me ignorare fateor.

Poterant nunc gyrini hi flexuofo pernicique motu huc illuc natare pabulaque quaerere, quae ipfis etiamnum pars illa ex materia glutinofa fpermatis reliqua praebebat, mox tameñ folidiore cibo mutabant. Oftendit figura 22. eiusmodi gyrinum; extra materiam glutinofam, in natural magnitudine, 23. vero refert eundem in magnitudine ope microfcopiiaucta; erat autem haec plurimis eorundem forma die nono Maji, cauda nunc tenuiore minusque craffa exiftente. Maiorem multo fubiuerant mutationem circa decimum vndecimumque eiusdem menfis diem ! color quippe illorum lucidior non tantum magis fiauefcebat, fed ambiebat etiam caudam eorum tenuis et pellucida pinna, quae prope ani aperturam orta, ad extremum caudae apicém extenfa circaque ipfum ducta, per dorfun ad caput visque excurrebat. 'Ipfo in capite bina nunc comparebant puncta oculos referentia, in inferiore autem illius parte, oris locos duae eminebant papillae, cauda vero valde iam pellucida, multisque inufculis inftructa, intortis foeminarum crinibus fimilis erat, id quod tamen ex fioura 24. non aeque diftincte, ac ex 25., adhibito microfcopio delineata; apparebat.

Augefcente hinc gyrinorum meorum magnitudine illorum eciam augebatur alacritas, qua furfum deorfumque per aquam natando ferebantur; quiefcentes contra vel vitro, vel aliis corporibus, capite affixi haerebant., Quemadmodum vero ipfos incremento augeri laetus cernebam: fic follicide nunc circumfpiciebam, qua ratione illud cibis neceffariis promouere poffem : licet namque reliquiis materiae glutinofae adhuc vefcebantur, ne tamen, iis confuintis, fame mox necarentur, verendum erat. Iteratis hinc vicibus aquas illas adiui ftagnantes, in quibus ranas arboreas iam copulatas ceperam; atque nunc gyrinos, ex fpermate ipfarum ortos, plurimos offendebam. Ex his varias in ipfis germinantes collegi plantas, quarum nunc hanc, nunc illam, gyrinis quos domi alebam porrexi, vifurus vtrum ipfas appeterent, an vnam faltem earundem prae reliquis eligerent, inuenique amare illos maxime viciniam ranunculi aquatici capillacei, cui etiam cateruatim adhaerefcebant; obferunui tamen poftmodum, gratum etiam ipfșisfe cibum lenticulam paluftrem, herbasque alias aqua-

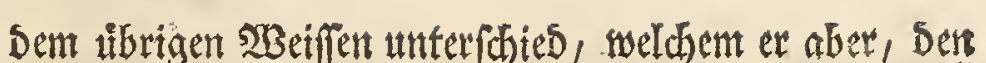

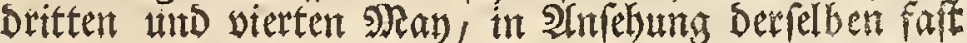
gleich fam; Dod waren fie Damals mebr von eithatider abgefondert, und ber Reib Des 234 ms hatte an Dite etruas abgenommen, wie aus Der 16 . und 17. Sigur zut erfehen. Sounmers fienger aud an fith Dann uns want

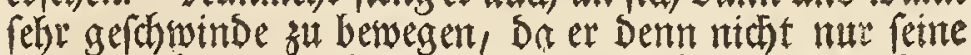
Eage berånderte, fortdern aud manchmalen mit Dem

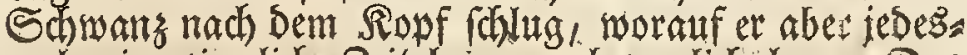
mal, eine siemliche Beit lang, unbeweglich lag. Den

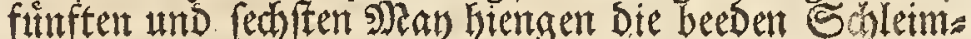
blafen gar nicht mekr miteimander zufammen: Dent biocia mewar nut am siopf, Die andere aber am Schmanzbefitos lich, wie Die 18. unto 19. Situr zeiget; Daben fabe Der 233 trm gelblichtwets aus und lein Seib nafun immer mebr und methr ab. Den fiebendent unts athten $\mathfrak{N a y}$, seigte fid

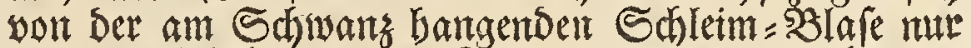
nodb die Salffte, die am Ropf bintgegen war noch ganz anto verichlofien, ba jente offen zu fern foriene, wie die 20. und 21. Sigut weifet, unt beede verlobren fid test an einigen

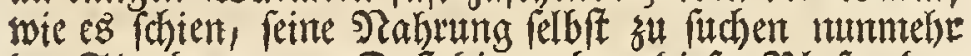
im Stand war. Daf Die sorbere Diefer Slafen ben

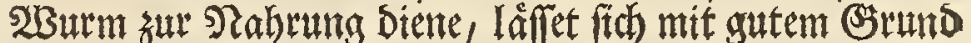
muthmallen, von ber Gintern aber wets tch feinen Sits zen antzugeigen.

Sest waren biefe 2 Burmer aud im Stand fidh, Durd) ente fonelle fichlainglente Bewegung, won einen Drt zu Dem andern zu begeben, und iher Rahrults nach stmehen, Die fie sur Zeit noch von Dem Reft Des Schleintes aus dem Iaich nafmen, Doch aber bald hers itad) mit einem ftärfern frutter verwedffelten. Die 22. Sittur ftellet einen foldhen 23 urnt, auferbalb Des Sd)lei: mes in feiner inaturltiben (Groffe, Die 23. aber vergróf: fer't yor; unto Diefes 2 (njehen hatten Die meiften Den

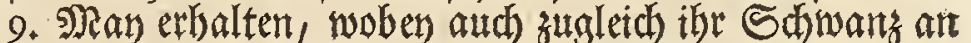
fetner. runden Didfe etwas abgentommen und gefdimetois ger geworben. Bis gegen bent zebenden und eiffitent

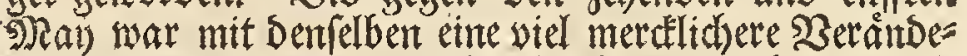
runtg vorgegangen: Dent ibre Farbe war nidht unt hel: ler uns gelblichter, fondern es zetgte fich and um inten Schwans eine Durdhfichtige zarte Sloffe, Die unten bet Der Deffung Des afffers anfieng, nad) Der aufferftert Spize Dez Schwanzes bintief, um felbige herunt gieng

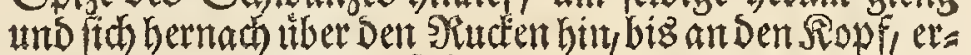
frecter. Yluch zeigten fich jetso an Dem Sopf Die beedent Singenpuncte, unt unten ragten an felbigem, Da wo Der

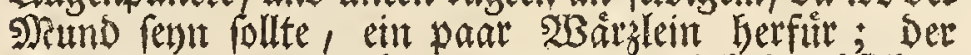

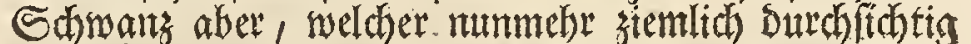
war, ftellte wegen feiner vielen situfeln einen geflochte: nen Sharzopf Der 2 Beiber firr, weld es aber it Der

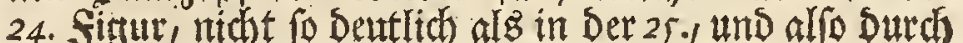
Das 2 Jergrofferungsglaz, beobachtet wurbe.

Nit zunebmenter Srofie nabmen bierauf aud meis

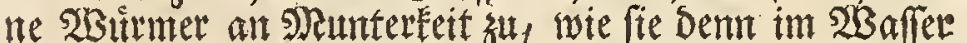
offers auf un ab fohwamen; went fie hingegen sweber rutbeten, fo hiengen fie fich gerne an Dem BJIas, oDer ald att andere Rorper mit ifrem Ropf an. BHetdinte id

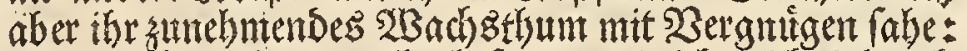
fo war ith aud nummekr beforgt, wie id poldes Durd Darreichung Des mothtgen Futters ferner beforbern móns te: Denn ob fie fich jest gleit) von Dem noch dibrigent Schletm nâbretert, fo batte id Doch Jat befurchten, fie

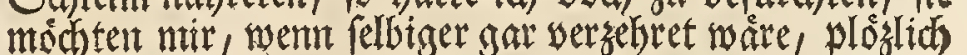
fuir Sunger fierben. Th, gienge alfo offters an Die fte: herben soafler, in weldent th) Die berrits gepaarten Raubfrofiche gefangen hatte, und wo ich nummebr aud

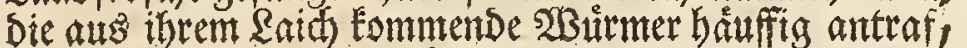
unt fammlete nir verfochiebene in felbigen wads fentoe Pflansen, yon weldhen id Denen bey nir in Der Rof rebenden. WBitmern etne nad) Der andern Darreichte, Itm

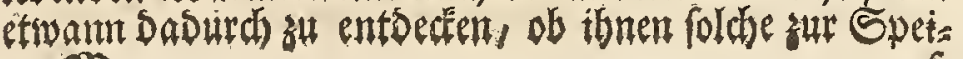




\section{*}

ticas; fed age in ipfa eorum confideratione vlterius pro"grediamur.

Exhibet foura 26. inferiorem corporis fuperficiem il lius gyrini, quem 24 . in naturali magnitudine a latere ftitit, figura 27. vero repraefentat eundem magnitudine microfcopii ope aucta. Cernimus hic, practer binas illas papillulas oris vicibus fungentes, feparatum effe caput a corpore, nec non hoc a cauda, interftitio quodam. Quum vero modo dictae papillulae inter fe diftent, atque a fede illa, quam os in adultioribus gyrinis occupat, remotiores fint, dubium videbitur nonnullis, vtrum illae oris vices praeftent; quoniam vero eo ipfo tempore in ipforum capite'nulla alia ádeft apertura, reliquaeque gyrinorum internae aeque ac externac partes, fenfim fenfimque, varias admodum fubeunt mutationes, aliter ut fentiam, dubium hocce vix me mouet.

Monftrat ficura 28. Tabula $X$. gyrinum noftrum eodem in fitu, quem in 27. habuit, fed nonnihil nutatum. "Eminebat namque in omnibus gyrinis mess, die duodecimo decimoque tertio Maii, pone caput vtroque in latere, tenuis quaedam pars, tubulum potius hauriendo aeri aptum, quam appendicem ciusmodi fimbriatam referens, quales in gyrino ranae terreftris Tab. II. fig. 8. vidimus. Sed difcrepent licet partes hae, verifimile tamen eft, effe in vtraque hac gyrinorum fpecie vnum eundemque ipfarum vfum; euanuerunt certe, in hac aeque ac in illa, eodem prorfus tempore. Aft mutabantur nunc etiam gyrini mei quoad colorem: fundus namque illorum, qui hactenus flauefcebat, varius nunc fiebat, vt ex figuris 29. et 30. apparet, ob plurimas obfcurioresque lineolas. Aderane adhuc binae papillulae oris, ociuli vero magis nunc nigrefcebant.

Diebus decimo quinto et decimo fexto Maji maiorem multo in gyrinis meis notabam nutationem : augebantur namque non folum in fundo flauo obfeurae maculae; fed induebat eciam omne illorum corpusaliam prorfus formam. Non diftabat amplius capur a corpore, yefica potius ouiformi, pellucida et aqua plena ambo cincta effe videbantur, id quod fiourae 3 I. et. 32. fuperiorem fuperficiem, 33. et 34. vero inferiorem referentes, ob oculos ponunt, vbi vero monendum effe duco, indicare minorem figuram naturalem, maiorem vero, microfcopio auctam gyrini formam, id quod tamen in pofterum non monebo, perfuafus Lectorem beneuolum huius non amplius egere admo nitionis. Monftrat figura, quae inferioren fuperficiem corporis repraefentat, obfuram efle pofteriorem illius partem cum linea quadam ex ipfius medio elucente; pars vero anterior pallide flauct, aeque ac capur, in quo iam praeter oculos nigricantes, os quoque et nares diftincte comparent; voraciores infuper effe gyrinos meos facile nunc videbam. Alia rurfús illorum erat facies diebus decimo octauo et nono Maji : obfcuriorem namque fuperioris fuperficiei, quae paucas tantum oftendebat maculas lucidas, caudaeque redditum fuiffe colorem, oculos autem aurantii coloris circulum cingere, fisurae indicant 35 . et 36 .
Te Dienlitch fent mógtent, ober ob fie nut eine Derfelben

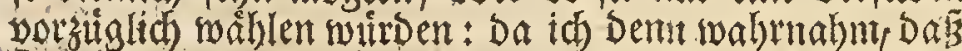
fie fich an Dem foreitanten Silitgras ober boaflerfens bel an liebfen aufbielten, und an folden baufentwets

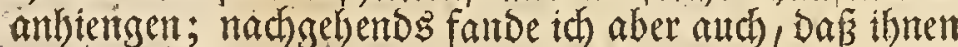

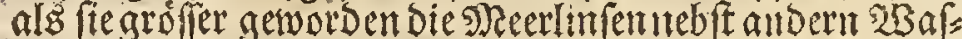

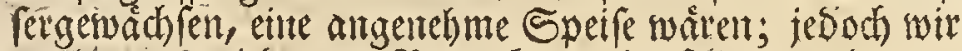
wollen uns twe der zur Setrachtung Derfelben wenten.

Sin ber 26. Sigur fehen wir Dent in Der 24. in ntatir lid feiner untern Flåche, und Die 27. Figur zeiget cben Den= felfen veraroffert, Da wir Dem, auffer Den swei) Die Stels

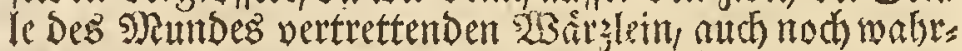
nebmen, Dá̃ Der Sopf yom Reib, Dirfer aber yom Schwans abgefondert fene. Da enft gedachte smen WBárzlein etwas voneinander entfernet, uno Daben siems

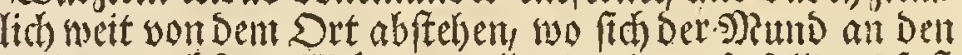

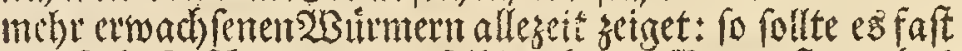

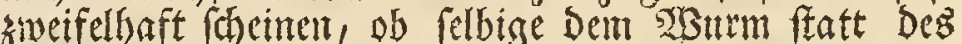
Sumbez Dienen; alleite weil zu Diefer Bett an Dem Sopf Defierbigen Eeme andere Defium zu finden ift, tmo fid

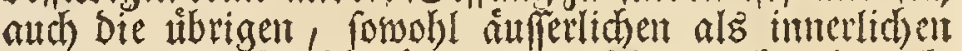

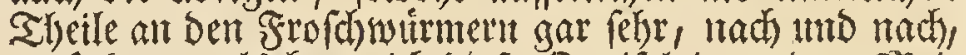

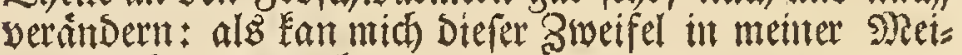
nung iricht irre machen.

Die 28. Sigur unferer $X$ : Tabelle, weifet umfern Frofthwurm in eben Der Rage, in weldyer uns folden bie vorbergehende 27. onrgeftellet, aber mif-einiger $2 \mathrm{Ber}$ ănberuitg; inden meine 2 Burmer inşgefamme ben

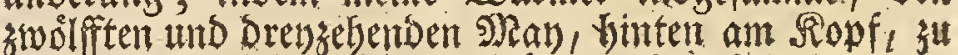
feder Seite; einen zarten herfirragetiden Sheil hatten Der inehr einem zum Lufftholen beftimmten Röhrleim als

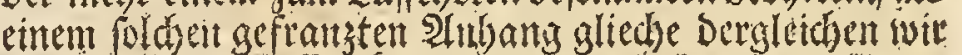
auf Der 71 . Tabelle ain Der I8. Sirtul, bey Dem Y3um

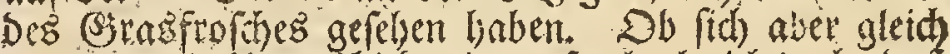
bierinnen ein Linterihted zeiget; fo glaube id) Doch, Das Diefe Sheile, ben Der einen פirt Diefer. 2 Burmer eben Den Nutsen, wiebei Der anbern baben, wentigfens fitt fie bey gegegentwartiger fo bald, als ben jener, wiber bers

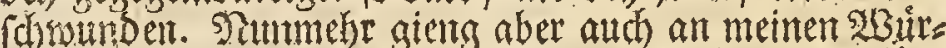

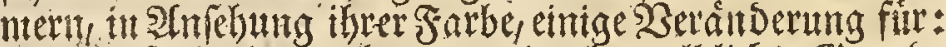
Dent ba fie bisher nody immer einerley gelblid te Ejund farbe bebalten, ro fiengen fie tegt an felbige zu verâns bern, indem fie wegen ver foiedener Dundfler und Eurzee Streife, ein fordetiges altefen befamen, wie aus Der

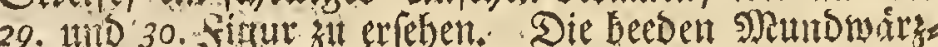
leit woren an felbigen mun auch nod sugegen, Die 2 th gen aber fiengen an fowárzer zu werbent.

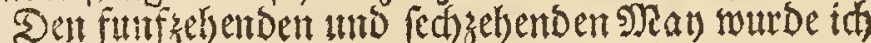

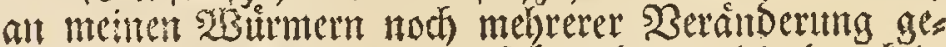
wahr: Dem es yermelorten fidh nicht nur bie Dinnceln Flecten int gelben Ssrutb; fondern es nahm nuch Der gange Rorper eine anbere Form an. Der Ropf war

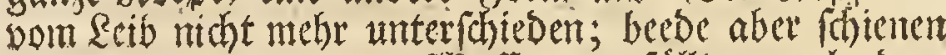

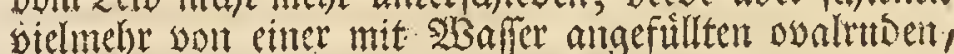

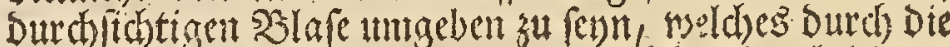
3I. und 32. Sigu: nadh Der obern Fláche, Durd Die 33. uns 34 , aber mad Der untern vorseftellet wird, woben id zutaleich erintere, Dafie Die fleinere Figur Die natirlis d) , Die groviere aber Die Durch ein 2 ergrofierungsglas vermehrte Sertalt Des. SButrnts anzeige, welches ich aber in Das funftige unterlaffen werbe, weil ich boffe bas

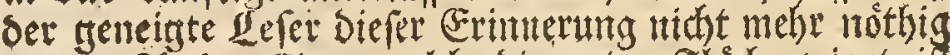

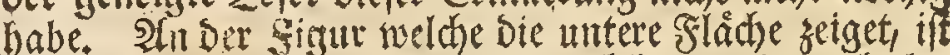
Der hintere Sheil Des Reibes Duntel nit einem hellen

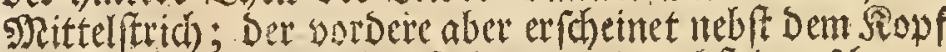

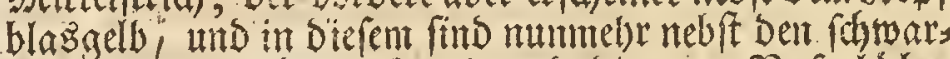

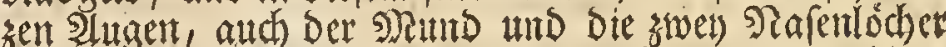
beutlid) zu erfentmen ; fonften war auch jezt gar wobl zh merffer Dafs biefe solinmer ziemlich zu frefen anfientgen. Den ach tzebenden und neunzebenden g) ay aber bekanten 
Jab.XII

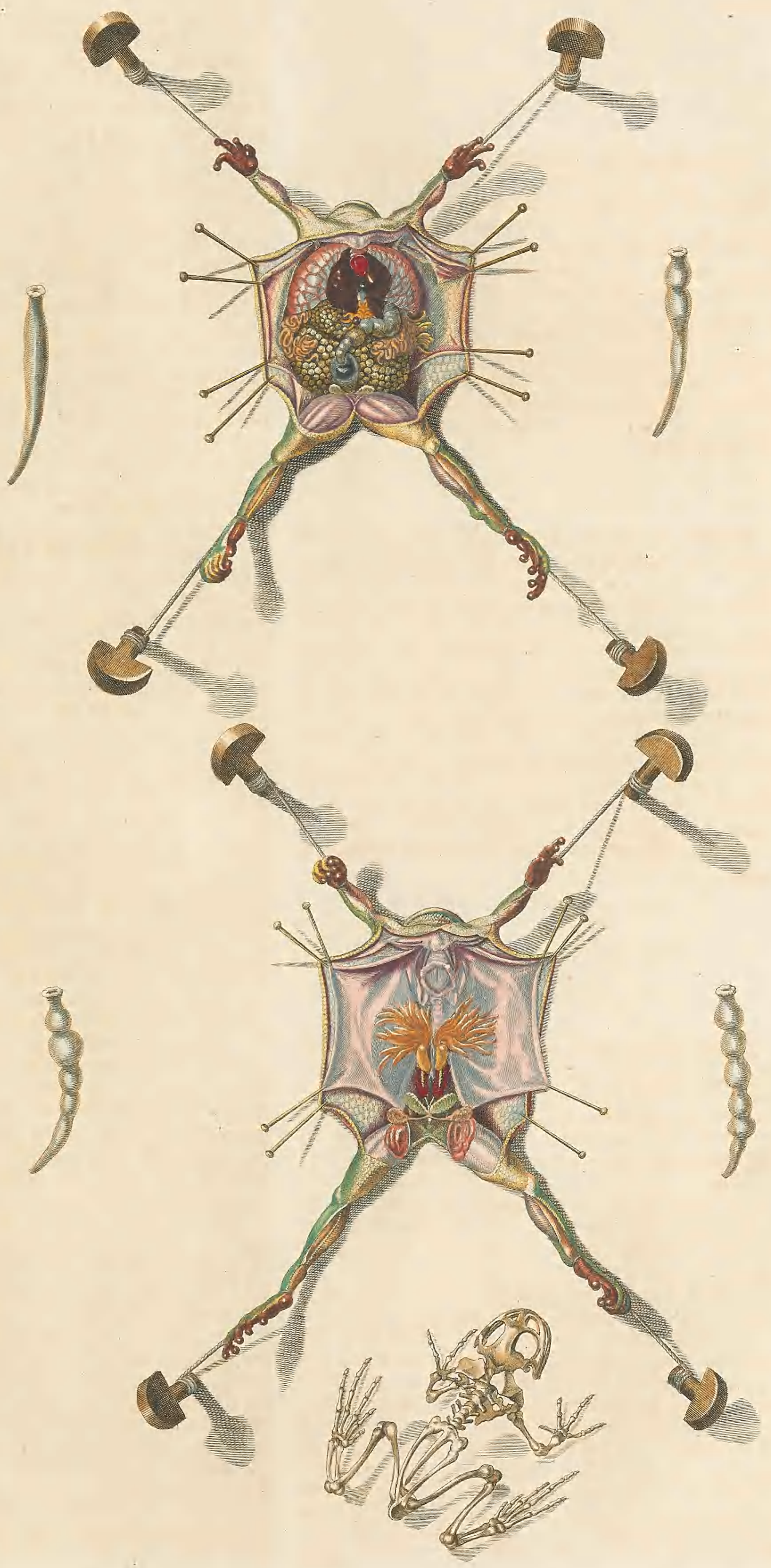

A. 3. Röpt fec et exc. 

Jab, XII.

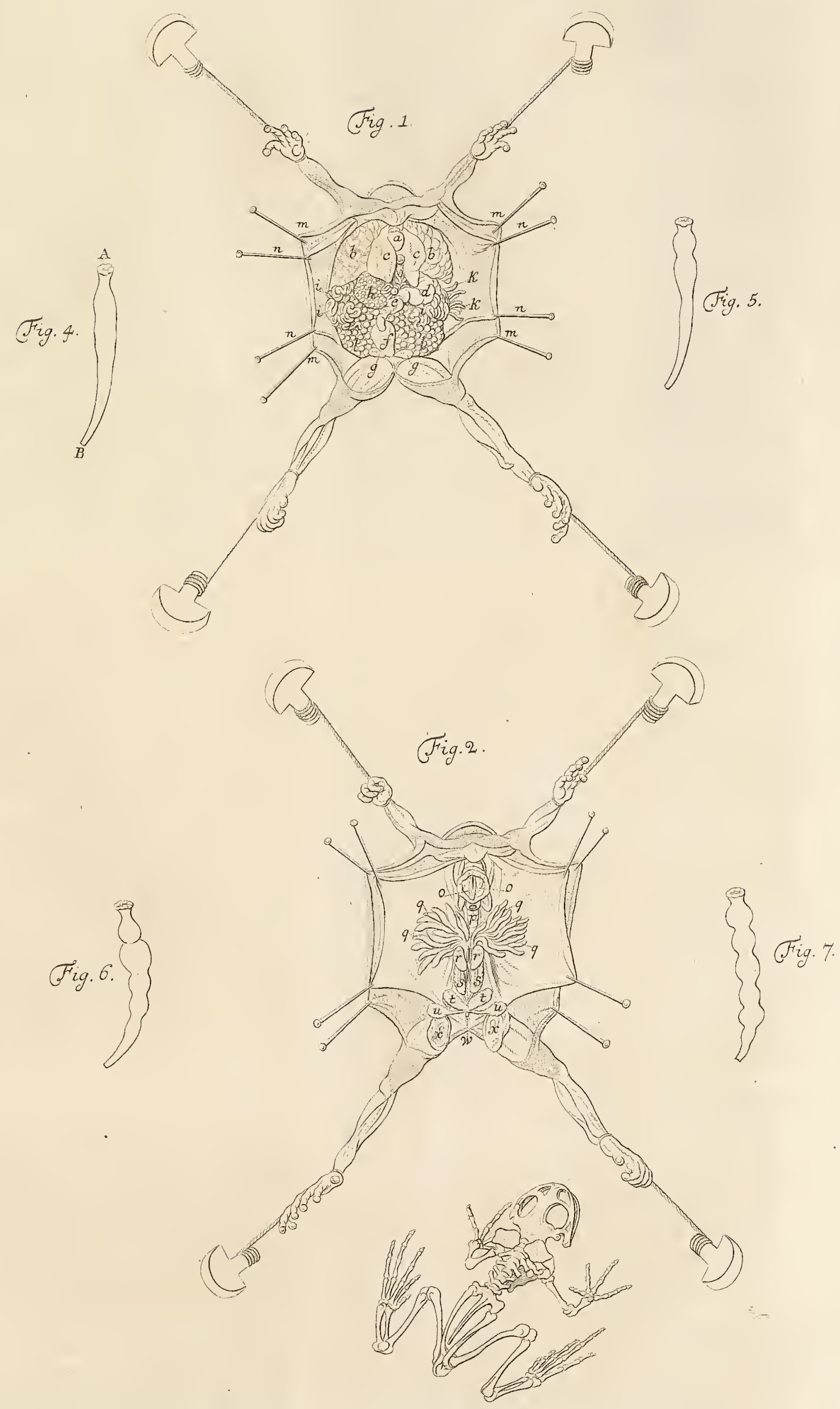

- Fig. 3. 



\section{$4): 47 \quad):(2$}

Similes erant gyrini mei, a die vigefimo ad vigefimum quartum vsque $\mathrm{N}$ aji, quoad formam, figuris 37 . et 38 ., quae tamen fuperficiem tantum inferiorem gyrini monftrant; quum eodem tempore in fuperficie luperiore nihil notatu dignum occurrebat, tenuis vero illa gyrinum cin gens et aqua repleta pellicula, clare hic diftineteque cernebatur. Referebat nunc pofterior corporis pars globum ex cinero fufcum, prope illam vero aderat in parte anteriore flauefcente, ea in fede quam cor occupat, macula quadrata. Os rima erat oblonga atque transuerfa, a naribus vero protendebantur pelliculam extimam verfus, parum ab ipfis remotam, bini canaliculi. Carebat os huiusmodi canaliculo, quum ipfa pellicula margini ipfius affixa effet, id quod gyrinum a latere, vt in fisuris 39. et 40 , intuentibus facile patet. Cerciorem ceterum me reddebant excrementa, quibus inteftinum rectum, diftincte hic confpiciendum, repletum erat, quaeque ex eodem nonnihil, plus vero aliis in gyrinis, quemadmodum figura 44. oftendit, propendebant, non indigere gyrinos meos nutrimentis, quin plena femper erant reliqua quoque inteftina, vnde. venter ipforum adeo diftendebatur, vt magnitudine caput fiuperaret, nullusque dubitarem, me in nutriendis isdem operam non effe iriurum.

Excreuerant iam gyrini mei eam in magnitudinem, vt nudo oculo eorundem accurata inftitui potuerit confideratio, reprefentant hinc reliquae omnes figurae eosdem, ea forma, qua mihi absque microfcopii ope confpicui erant. Amiferant onnnes die vigefimo nono Maji tènuem illam pelliculan, qua antea cincti fuerant; quoad forman vero finiles erant $j i$, urat $4 I$. Flauefcebat eodem tempore, caput verfus, pinna, in maiörem nunc latitudinem expanfa, ipfi vero tardius nunc increfcebant, vnde die denıun vndeuigefimo Maji magnitudine 42. figurae comparuerunt, quoad externam figuram parum, quoad colorem vero, nunc magis ex viridi fufcum, multum mutati. Ob tardius hoc eorum incrementum, jufto fere diuturnior praeftanda mihi erat patientia, donec crura pofteriora, quae auide nunc expeEtabam, apparerent, id quod tandem in nonnullis eorum, die vndetrigefimo Iunii factum fuit, poftquam 43. fizurae magnitudinem nacti erant. Vix quidem initio difcerni poterant crura haec ob paruitatem, quum prima tantum eorum pars in confpectum prodiret; hoc tamen non obftante facile notaui, procrefcere illa eadem in regione, in qua ipfa in gyrinis ranae terreftris $\mathscr{T}_{a} b . L_{0}$. prodeuntia mon. fraui.

Die decimo fexto fulii propius aberant gyrini mei, a fumma in quam excrefcere folent magnitudine, mutatum etiam nonnihil eorundem fefe oftendebat color: ventris namque craflioris latera magis magisque lucidum cupri induerant colorem ; fuperficies illus inferior ex pallido erat cineracea; caput ex flauo fufcum, in fuperficie vero. fuperiore, aeque ac dorlum, obicurius apparebat; flauebat cau'da obfeuris maculis notata, pinna vero ipfius inferius alba, fuperius flaua, nigrefcebat caput verfus. Crura po:fteriora erant nunc altera parte longiora, quinque vero .ipforum digiti magis confpicui. Singula haec refere $f i$; ura 44 , in qua infuper eo in loco, in quo pifcium funt branchiae, vefica conf́picitur alba, qua magis conuincebar, :fententiam: SW AMMERDAMMII, habere fcilicet rana $\because \cdots$

felbige soieder ein anderes Snfehen, insem ithe Dber flache nebft Dent Schwans noch Dundeller geworben, und anf tener.nut noch etnige belle Flecten sut fehen waren Die 2 ugen aber ente orantenfarbe sinfafing betoment wie Die 35 . uno 36 . Sigut jetget.

Som swangigften bis su Den vier und swansigften Man Eamelt meine meifte 2 burmer Der (B)eftalt nadh mit Der 37. Ints 38. Sigur tiberein, welche aber einent Derfels ben ture auf Der untern Jfladbe yorftellen; weil fich auf

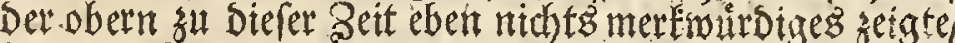
Die Den 23 itrm ungebende und mit 2 Baffer angefullte zarte 5 ant aber bier am beutlid ffen su fehen war. Der bintere sheil Des Seibes fahe nutmehr etuer graulith braunen rumben Sugel ábnlich, oben aber war nabe at felbigem in Dem gelben 20 ordertheil ein bietedigter f̧les

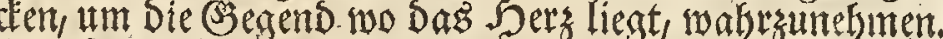
Der Matmb ftellte einen länglithten quer ftehenden Spalt vor, und yon ben beeden Nafentodern erftecteten fid

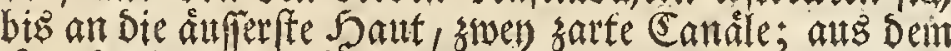
Nound aber gieng Eein folder Eanal, indem Diefe zarte Saut um Den Siand Deffelben herum angewach fen war. welches fich Deitlith setgte, wernt man Dent 2 Burm vor Der Seite itach Der 39. und 40. Sigur betradjtete; Der unrath aber Der Den bier gans Deutlid) zat erfennenden g)aftsarm anfiulte, auch aus elbigen etwas, mehr abet an allderit wite Die 44 . 5 igut zetgetiberausgetretten war,

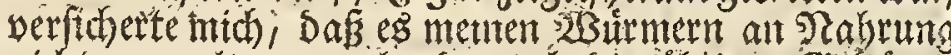

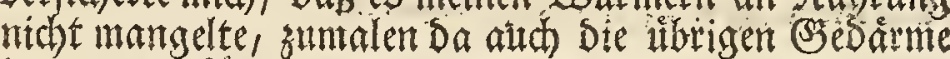
inmer angefillet blieben und Den bintern 'Sheil Des Reis bes fo ausgefpaunt erbielten, bas er beftaitstig groffer als Der Ropf ausfate; eben Diefes aber lies midh auch an fernerer gludflicher (Erstebung berfelben nidht sweifeln.

Tezt waren meine Frof fowirmer fo gros geworden, Dafis fie mit blofen 2litgen gar wohl betrad)tet werden Eonnten Diefemuach zeigen uns Die folinemben Finitren

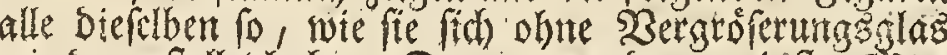
mir bargeftellet baben. Den neun und zwanjigften j)an batten fle alle Die zarte Saut, won welcher fie borther unt geben waren werlobeen, Der Gertalt nath aber Eamen fel. bige nit Der $4 I$ Stgatr uiberein. Itnt Diefe Seit serfärb.

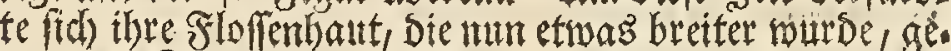
gen Den Sopf zu in bas Belbe; mit inrem şad) stum aber gieng es etwas langfamber, indemfie erft den netins zehenden Jinti fid in Der (S)rolle Der 42. Sigur zetatery Der atuletichen Structur nad aber gar nidst, in 2 lnt

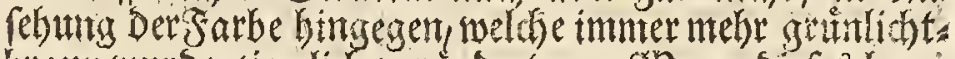
brann wurbe stemlith veranderten. sæB egendefes lang.

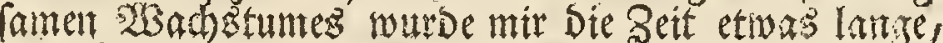
bis ich Die bintern Sitipe erblifte, worauf ids mun mit - Berlangen wartete, ind Die enditid cit etitigen Den neun

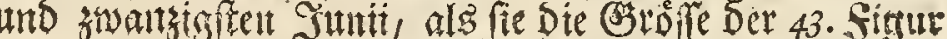
erbalten batten, zum 20 rfacin Eamen. 2lirfangs wa, ren Defelber, negen ibrer Rleinigkeit Eaun zu erEemen; indem fich nur Der erfte Theil Derfelben fehen lies: Dob

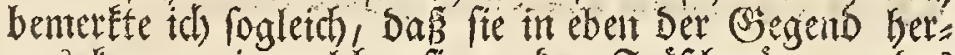
aus Eamen, in weld)er fte an Den Frofothlirmern bes Sragfrofdes auf Der Il. Cabelle von mir gezeiget worbert.

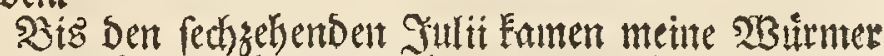

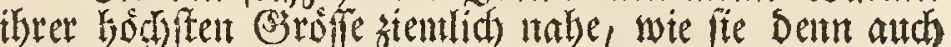
ibre Sarbe eintger mafon serambert batten: Deun thr ois der $\mathcal{E}$ etb wutro an Den Seiten immer meth hell Eupfer. farb; Die untere Stád) fabe hellgraut aus; Der Ropf gelblichtbiaun, auf feiner Dberfládje aber war er, wie ber

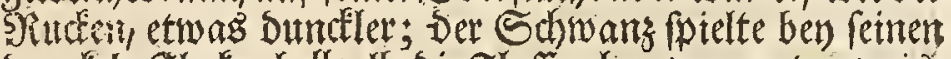

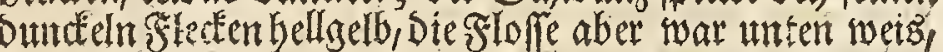
obent gelblicht und gegen Den Ropf zu, Dundel. Die bin.

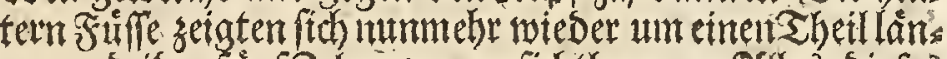

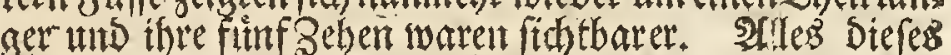
int an Der 44. Firut wabranebmen, wie auth eite weifs fe Slafe, welthe Da, wo fonft an Den Fithert Die Dhen

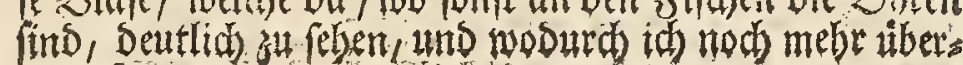




\section{(6)}

rum gyrinos fuas etiam branchias, veritati minus effe concrariam. Ceffante tandem, circa diem vigefimum quintum Iulii vlteriore gyrinorum meorum incremento, apparebat, inftructa nunc effe pofteriora illorum crura parte etiam tertia, in ipfis vero eorum digitis, cernebantur iam diftinctiffime proprii huic ranarum peciei globuli; mutatum etiam ipforum fuife colorem monftrat figura 45 , in qua et crurum anteriorum quaedam comparet adumbratio. Prius tamen quam haec integra prodierunt, nonnullas adhuc paffi funt gyrini mutationes: non folum enim obfcurior eorum reddebatur color, fed oriebatur etiam, ad latera, circa branchias, tumor quidam, id quod figura 46. die vigefimo octauo Iulii a me delineata, indicaui. Die tandem huius menfis trigefimo perfecta erant crura anteriora, quae tamen non uno eodemque tempore in vtroque latere prodierunt; dextrum quippe in omnibus gyrinis meis prius apparuit finiftro, retraxerunt etiam illa primo die iteratis vicibus ita, vt penitus abfconderentur. Iam vero erat.color eorum in fuperficie corporis fuperiore fubuiridis, in inferiore autem nec non in cruribus flauefcens, cauda contra perdiderat, fpatio dimidii diei, cum priftina forma colo. rem quoque. Naior infuper in ipfis nunc videbatur aeris hauriendi neceflitas, quum iteratis vicibus ad aquae fuperficiem enatarent; exercebant porro oris etiam vfum, quod crebrius et aperiebant et claudebant, quiefcentes vero adeo contrahebant digitos pedum anteriorum, vt pugnum formarent in figura $47^{\circ}$ confpiciendum.

Decrefcebat tandem etiam gyrinorum horum cauda, vnde factum vt illa die trigefimo prino Iulii, nec non primo Augufti, dimidia iam parte minor effet; aquae etiam, vt videbatur, nunc pertacfi gyrini, prorepebant ex illa partique fuperiori vitri adhaerefcentes admodum diu quieti manebant; mutabatur porro color eorum, quippe qui ex flauo grate virefcebat; ad latera vero refiduae partis cernebantur fuperius binae breues nigraeque lineae, quas 48. figura diftincte monftrat. Perdiderant die fecundo Augufti gyrini illi, in quibus crura citius quam in reliquis procreuere, omnem prorfus caudam, atque tunc aderat parua quidem, fed-quoad coloren et formam omni ex parte perfecta rana arborea, quam figura 49. repraefentat, et inter cuius digitos pedum pofteriorum membrana illa cernebatur, fi rana vndam innatabat, quae natatum iuuat, et de qua, fuperius quidem, fcripfi, adeffe eius paruam vel nullam prorfus in ranis arboreis partem, vbi addere debuisfem, fi extra aquas morantur. Quum vero parua hae ranae non folum optime faltare, fed et efcam fuam, varia fcilicet infecta, captare potes funt: hinc aquas derelinquere et arbores atque frutices, praedae caufia, quam hic fat copiofe vtplurimum offendunt, petere folent.

Poftquam itaque de incremento ranae noftrae arboreac expofuimus, quo illa ex ouo egrediens fenfim fenfimque, donec perfectam ranae induat formam mutatur, atque id ipfum in Tabula $X$. ob oculos pofuimus, reliquae nunc etiam indicandae forent ipfius quoad magnitudinem mutationes; ante tamen quam id ipfum agamus, dicenda quaedam funt de I. figura, $X I$. tabulae, quae in eadem, concinniorem ob ordinem, fuperiorem occupat locum. Refert illa mafculum huius ranarum tpeciei, cuius fauces, ope binorum hamulorum, quantum quidem poffibile fuit, diductae funt. Cur autem hoc in fitu illum depinxerim, caufa fuit maior ille follis, cuius

zengt morben, Dafí Die Meinung Des Swammerdans yon Den in Den Frofthwirmern befinslidgen Ohren, nicht falfich feise. Den finf und swatsigfter Jutlit waren ents

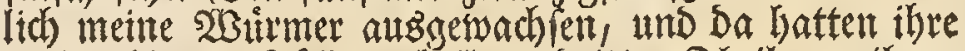
beeben hintern Stife aud ibren britten Theil, an ibren Zeben aber zeigten fich Die Diefer Fro (chart eigeite Sinopfs

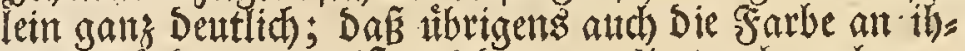
nen veranbert war, ift aus Der 45 . Stigur abzunebmen, an welcher iber biefes Die vorbern Fưfe, wie in Schat: ten bereits zu feren. Ebe aber Diefe sollig Durchbrad)en,

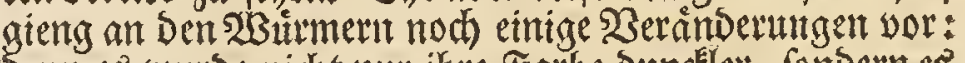

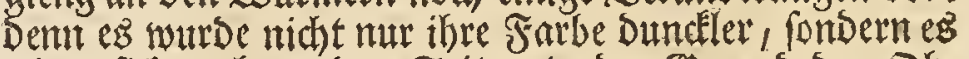
zeigte fich auch an Den Seiten in Der ESegend Der Dh=

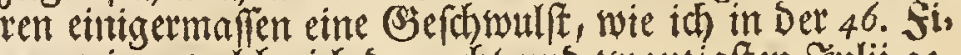
tur zeige, wellhe ich Den acht und swangigften Sullit ges machet habe. Den Drevefigten Diefes seonats waren

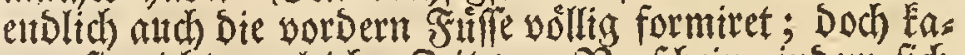

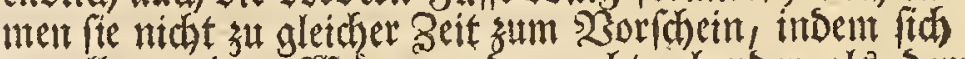
an allen meinen $\mathfrak{W}_{\text {inmern }}$ ber rechte ehender als Der lintefe rehen liefe; und mandomaten sogen fie biefelben am

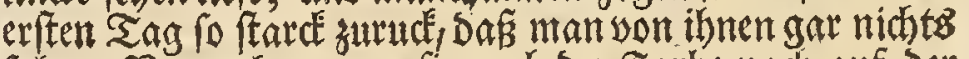
fabe. Natnmefts waren fie aud Der Farbe nad auf Der obern Fláche bes Reibes grunticht, an Der wuttern aber

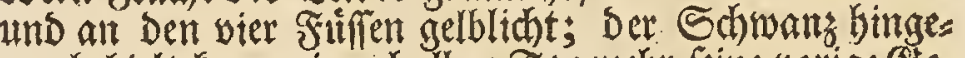
gen behielt faum einen balben כagntehr feine vortge Jes falt uns Farbe. Lubrigens fotiene es aud jegt als ob

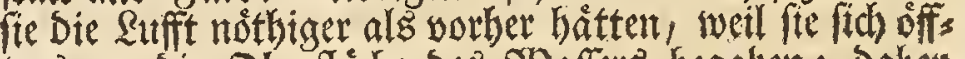
ters an Die Dberfláche Des $23 a f e r 8$ begaben; Dabea

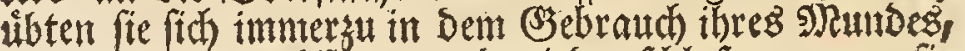
ben fie vielmals offineten nns wieder fdilofen; want fie fich aber ftill und ruhig bislten, fo sogen fie bie Beben Der vorbear Fuffe fo sufantmen, Das fie eine gefololiente Fanft worftellten, wie an Der 47 . Sigut wabrzutuefinten Endich fittin auth Der Sdimalts an Diefer 2 But

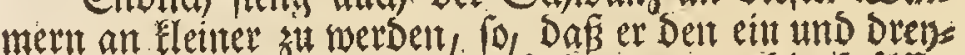
figften Julit uns erften 2luguft bereits um die 5 álffte

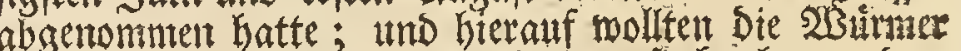
nidht mebr im sybafer bletben, fondern fie frochen an orm Slas in Die Sobe, und blieben an felbigen aufjerbalb

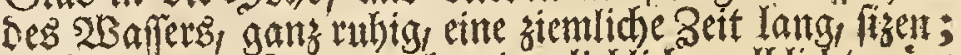
auc befanten fie munmebr eine lieblidje gelblidstgraine Farbe, und an Dem Reft Des Sdmanzes feigte fich oben ant $\Omega e i b$, zu feser Seite, ein Eurser fowivarzer Strich, wic Die 48. Hitur ausmeiret. Den swerten 2luguft mar an Dentenigen SBurnern, weld) zuerft Die Füfie betomment,

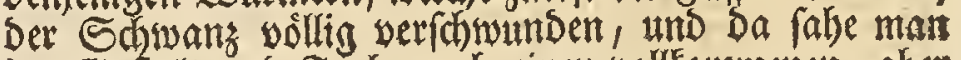
ber Seftalt uno Farbe nach eimen sollfommenen, aber noch Elemen \&autb froid, ben bie 49. Sigur vorftellet, an weld)em aud im saffer, swifhen ben Behen ber bin: tern Finfe, Diejenige Jaut zal fehen war, weldhe Dett

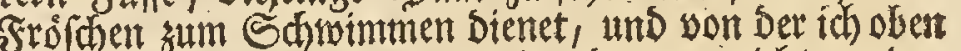
gefaget, Da Saubfrofohen gewahr werbe, wo ich zugleid Diefes Gat

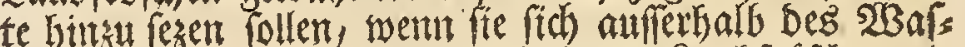
fers befinden. syet aber biefe junge Laubfrofche mets fterlich foringen unt ibren Pantb, Der aus lauter Intes cten beftehet, behenbe erhafichen tonnen: To verlaffen fie in Diefer Sroffe insgemein Das $23 a$ fer, uno begeben fit

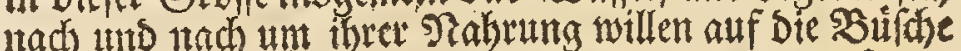
und 3 Batunte, wo fie biefelbe insgentein in genugfamer senge antreffen.

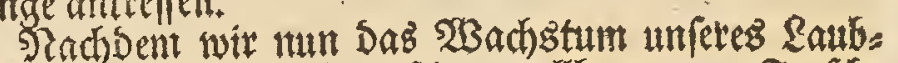

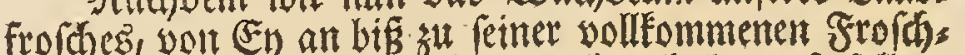
geftalt, mad Der $X$. Cabelle betradhtet baben: fo follten

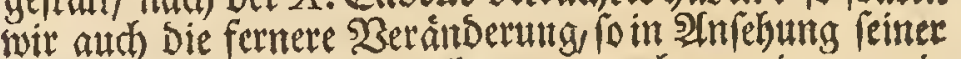
Srroffe mit felbigem vorgebet, nummelys anzetgen; wir muffen aber fold)es nur fo lange unterlafien, bis ids son ber 1. Figur ber $X I$. Tabelle, alz weldher id um befierer Oromutg willen ben oberften Dlas einraumen meiffen,

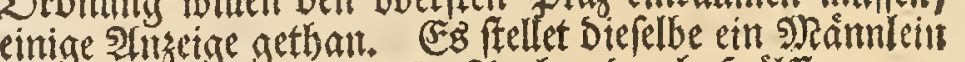

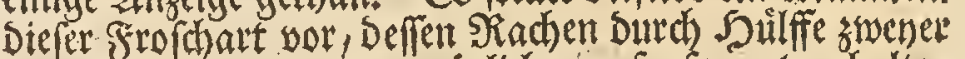
Sadktein, fo weit als móglid, aufgerpernet ethalten witp. 


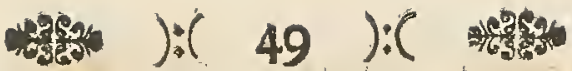

jam fupra p. 4t. aliquam inieci mentionem, quique femper in mafculis ranarum arborearum, vbi vociferant, in confpectum prodit. Noffe fcilicet auebam, quanam via aer, faccum huncce expandens, in ipfum intret. Si tubulum in ranae os immittebam, illudque dein firmiter claufum tenebam, et per tubulum aere replebam, facile quidem follis expandebatur; vbi vero aperto rurfus ore, oftium illud quaerebam per quod aer in follem penetrauit, inueniebam femper, ipfam oris atque follis cauitatem inter, parietem, quem linguae fubiacens cutis formabat, nullo foramine pertufum; tandem vero obferuabam adesfe ibi, vbiparies cum maxilla cohaerebat, vtroque in la. tere rimam, per quam aeri et ingreffus et egreffus patebat. Signatae funt binae hae rimae, in figura noftra, litteris $a a$, atque per has pro lubitu nunc poteram, frepius iam dictum follem illum, aere replere; quum vero hoc iuuita rana fiebat, faepius eundem, aere expulfo ipfa contraxit, donec tandem, crebrius aere a me immiflo, las faretur, follisque diutius aere turgeret. Conftat ille ex fufca, pellucida admodum tenaci membrana, quae vbi, rana non vociferante, contracta eft, vt gularipfius, id quod iam indicaui, fufci fit coloris, efficit. Inter binas illas follis rimas, confpicitur in figura noftra lingua $b$ no. tata, quae licet parua hic videatur, habito tamen ad proportionem refpectu, latior longiorque eft quam in rana terreftri, fi ipfam rana arborea, infectum quoddam arreptura, exerat; de fitu vero illius cadem quoque valent, quae iam in hiftoria ranae terreftris a me fint dicta. Pone linguam comparet medio in ore rima quaedam, quae laryngis eft apertura; poft hanc vero hiant fauces.

Ante autem quam quartum, rana arborea mas, aetatis agat annum, nunquam ille follem fuum eft inflaturus clamoremque editurus: atque tunc etiam fufca eiusdem fit gula, certo indicio, effe illum nunc ad fpeciei propagationem idoneum, cui foemellae quoque hac ipfa demum aetate aptae euadunt. Docuit me hoc diuturnior experientia, atque hinc etiam eft, quod nouerim, agere ranam arboream, magnitudine 2 figuram XI Tabulae aequantem, alterum aetatis fuae annum; hoc vero elapfo fimilis eft $f^{\text {s }}$ gurat 3; tertio exacto anno magnitudine ad 4 . accedit; licet vero tunc viribus ad generationem requifitis non deftituatur, figna tamen illa, quibus mafculus a foemella diftinguitur, fat diftincte nondun apparent, quamuis ipfo etiam in gyrino huius fpeciei adultiore, omnes eae iam cernantur internae partes, quae vtrique fexui funt pro priae. Ornamenta illa Tabutae huius, cochleae fcilicet herbaeque, eorum gratia hic fuerunt appicta, quibus Ta. bulae meae vacuaenimis fuerunt vifae, ad rem vero, quam tracto, minus pertinent. Parum itaque refert, fi illi, quorum opera in Tabulis hifce pingendis vtor, hic vel illic eadem viuidiore obduxerint colore, quam ipfe quidem in archetypo feci: namque hofce errores, vt ipfis condonem, cogor, ne praecipuis in rebus naturae imitationem negligant, wirb. Das ich aber felbiges in biefer Stellung aboes bildet babe, Dazu bat mir Der grofe silafebalg Seles genteit gegeben, won Dem id bereits oben p. 4. e etwas gemeldet habe, unts weider fich allezeit an Den Deanz ein ber Saubfrofoche, neent fie quaden, zu setgen pfles get. Sch war namlich begierig su wifien, wie Denn bie Sufft, wenn fie Diefen Sadk ausDefnet, int rolden bits

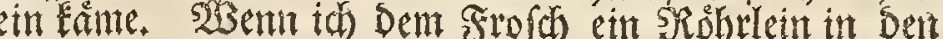

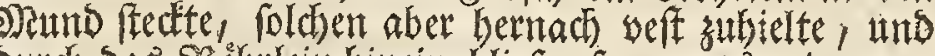
Dutrdy Das SRohrletn binein bliefe, fo war es mir swat

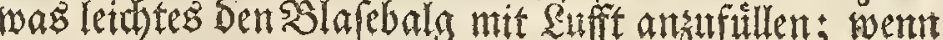
ich aber Gernad ben s)dund wieber offinete, und inth nach Der Deffinung umfabe, Durch weldse Die Sufft it

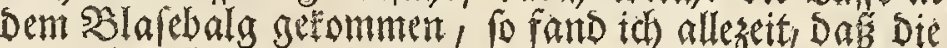
unter Der aunge befindliche saut, swirthen Der 5 ole Des s) Jutbes und Dent SBlarebalg, eine Sd)eidenans

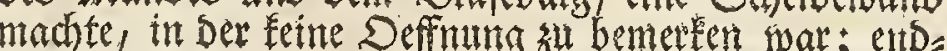
lich aber fand idh Doch, Da wd Diele Sdhetoeswand ait Dent untern alerer angemadfert, an jeber Seite eine lainglidhte Deffinung, Durdh welche bie Rufft leidstlich aus und ein fommen connte: Diefe beeden Deffunngen

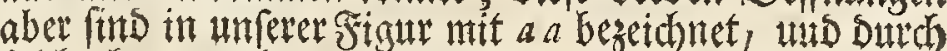

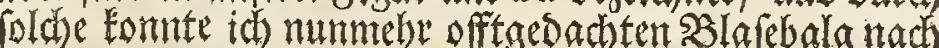
Selieben mit Ruffit anfitllen meil Diefes aber wiber Des

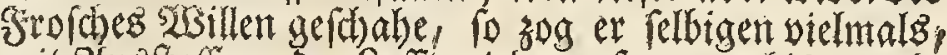

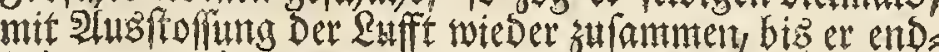

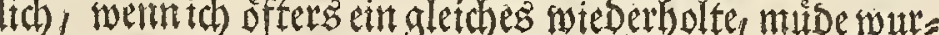
De; Da Dem berfelbige länger angefiullet blieb. Es be= febet aber foldher ans einen gerbbraunen, etwas burch

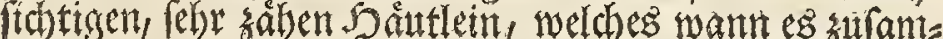
gezogen ift, und wenn Der Frofd nicht quadet werut fas

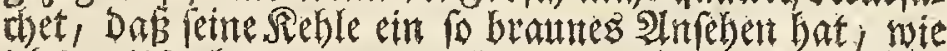
ich bereits oben angezetget babe. Snifhen Den beebent

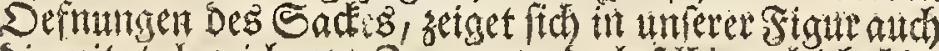
Die mit $b$ bezeichnete Bunge, itnd ob pelbige gletch biek

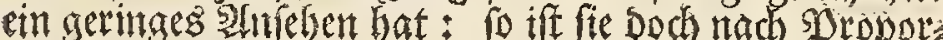
tion breiter und langer, als ben Dem Şrasfrof th swent

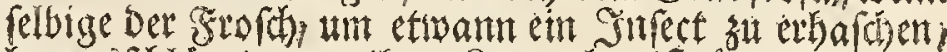

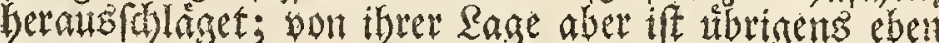
Das zu bemertem, was id) in sjefdreibutg bes ongers. frofdes Dabon gemeldet babe. Somter biefer 3unge,

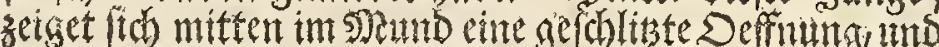
roliches if Die Deffrung Des Ropfes Der \&ufferobre, bin ter wels

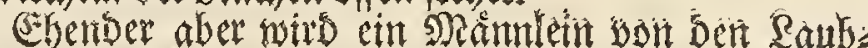
frofchen Diefen SBentel nicht aufblafen, und Daber aud nidht guaden, als bis es in bas wierte Salje gebet, uno alsoben laest fich auth erif eine brame sierle an thm wabrtebmen, weldhes roDentm ein richtiges Rentseident

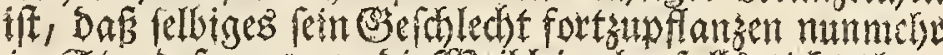
im Stand fen, wozu Dieskeiblein ebenfalls nidte eben

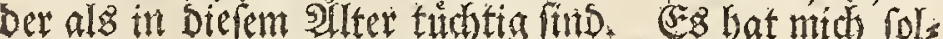
thes eine lange Erfahtung gelebrety uns eben Daber weis

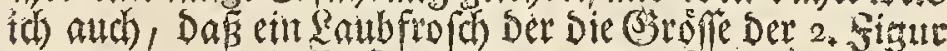
unferer $X 1$. Tabelle bat, im zwenten Jabr reines

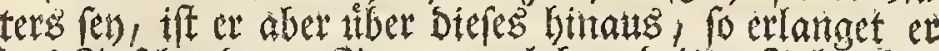
Das 2nreben der 3. Sigur; nah Dem Driften Jabr aber

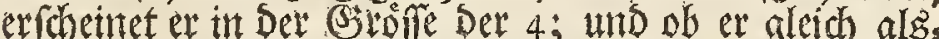
Denn zut Fortwflansung Die notbigen Siräfite erlanget:

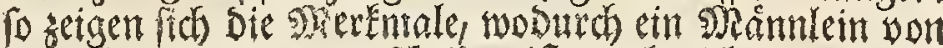

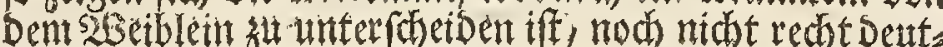

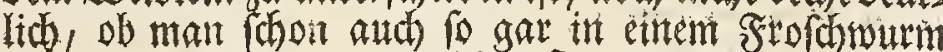

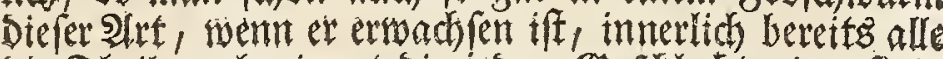

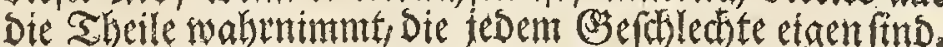
Die 2lusgiernngen melde fid auf Diefer Sabelle befin ben, idh meine Die Sdineden und Siräuter, find un Der zentgen Riebhaber willen bimst geferset worben, benen meine Sabellen zat leer ausfeben, und geborent etgentlid nicht zur Sauptfache, Daber man es bent and ntdet tu genalt nebmen mus, wern etwann Die STluminifent umaefábr cine frifthere Farbe bier und Dar angebrachet baben alsich ifnen sorgemablet; indem ids gesmungen 


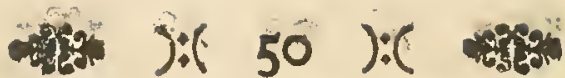

Si rana arboreae praedae inhiat, exdem id perficit ratione ac rana terreftris; gratius tamen illa eo ipfo tempore nobis praebet fpectaculum : felis enim inftar muri infi diantis, praedam intuetur, atque tunc eum feruat pofitum, quem 3 monftrat figura, vbi eandem libellae infidias ftruentem cernimus. Quando itaque praedam fib non euafuram zutumat, fulguris inftar, ad pedis altitudinem longitudinemue interdum exfiliens, in illam inuolat, eandemque glutinofa fua lingua arripiens deuorat. $\mathrm{Mu}$ tari ceterum in iunioribus ranis arboreis, aeque ac in fenioribus, viridem femper colorem, obferuatu haud ef difficile: fingulis enim quinque fexue diebus alius ipfis eft; quin fi plures earundem eidem vafi inclufas feruaueris, hanc coloris mutationem, v1no eodemque videbis die, id quod vero hinc contingit, quod, vt fupra iam dixi, cutem crebrius exuunt.

Sunt qui ranae arboreae virtutem adfcribunt fudori manuum, malo multis perquam molefto, medendi. Sua dent hinc vt vtraque manu ranam arboream tamdiu comprehenfam teneant, donec tandem moriatur ; ipfum vero hunc effectum frigidiori ranae tribuunt fanguini : quodfi tamen res fic fe habeat, aliae etiam ranae, nec non in aquis habitantes creaturae aeque erunt efficaces; quum frigidus ipfis fimiliter fit tanguis, licet ille ob motum fuum, non poffit non certo caloris gradu gaudere. Videtur ceterum rana noftra arborea, inter reliquas ranarum fpecies, fi ita loqui liceat, effe ftupidiffima, propius namque licet ad ipfam accedas, vix tamen loco ết ceflura, vel in fugam fefe coniectura.

Omnia atque fingula quae hactenus de rana arborea, Ipfiusque dixi proprietatibus, tam funt certa tamque vera, vt haud verear, fore quenquam, qui in examinanda eadem operam fuam fit collocaturus, qui me accufet, fcriptum hic effe quicquam veritati minus confentaneum Quum autem fint qui dubitent, vtrum rana haec aquas incolat, non poffum non, pro adftruenda rei veritate, $\mathrm{fe}$ quentia addere. Seruaui ex gyrinis illis, quos prìma vice c ranae noftrae fpermate obtinui, quatuor modo, poftea vero quam in tantum increuere, vt crura obtinuerint pofteriora, et hi morte interierunt. Sed erant ill crebra contemplatione mihi adeo cogniti, $v t$ ipfos in aquis etiam, ope fummae qua gaudeo vifus aciei, $a b$ aliis diftinguere potuerim : cepi hinc etiam nonnullos eorundem, quos mecum domum deportaui atque tamdiu alui, donec perfectas, ex illis obtinui ranas; neque defunt qui id factum effe teftentur, ego vero quotannis idem me praeftiturum fpondeo: vt adeo non fine ratione affirmare audeam, coire non tantum ranas arboreas ipfis in aquis; fed habitare etiam gyrinos earundem in illis tamdiu, donec quatuor cruribus inftructi, caudaque amifla, faltui aptae facti fint ranae.

Quum propofitum mihi fit, omnium fpecierum ranarum noftratium hiftoriam eadem tradere ratione, ac illam terreAtris ranae confcripfi: vt de internis nunc etiam ranae arboreae partibus agam ordo requirit. Quuum vero illae isdem ranae terreftris partibus fere fint fimiles, fuperua. cancum

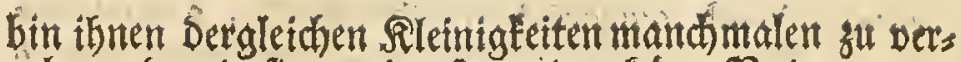
gebell , Damit fie nur im Sauptwert Der Satur genau folgen.

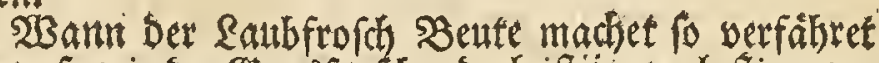

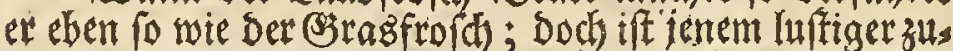

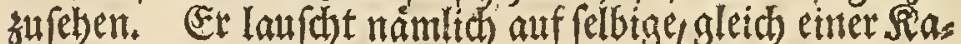
ke welche eine saans fangen will, wobet er Dietentige Stellung madht, in welcher wir ibn in ber 3 . Figur ies

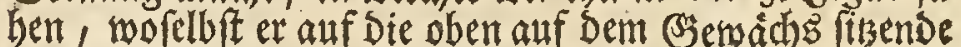
Qibelle lauret; twenn er mun aber feiner Beute genots zat fenn glaubet, fo fäbret er auf relbige gletcheinem Slits su wober er benn offters tuber einen Shut weit in Die Soble oder länge fpringet, tmo fodenn mit feiner fles

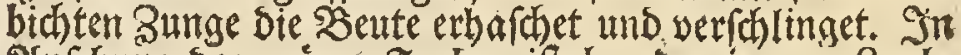
श्रrebung ber grumen Farbe, if beis Den jungen \&aubs frófhen fowol, als ben Den alten, immer einige Beräts

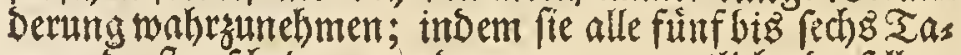
ge anderftericheiner, uns man, wern etliche Serfelben in einem (s)efás bevfamnten find, aud an eittem und Dem nảmlichen Tag, biere Merfhiedenheit beobachten fan, welches aber ebent aud, wie ich bereits oben geras get babe, won ihrer offtern Săutung herfommet.

Sonften wird Dem \&aubfrofd) aud) nod) Die Siraft

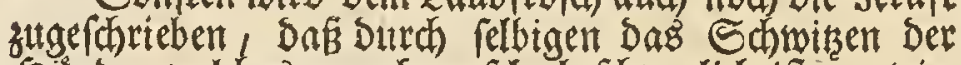
Sande, welches mandem fehr befdwerlid iff, vertries ben werde. E\&s wird baber Dergleichen sperfonen ange. ratben, Das fie in ieder Sand folange eiten \&aubfrold) tragen follent, bis felbiger endich ftirbt; Diefe XYBirtung aber foll Daber Fommen, weil Der $\mathfrak{E} a$ abfrofd ein Ealtes Geblite hat. Jif mun aber Die Sache richtig; fo wers Den auch andere Fröthe und im 2 Baffer lebende Creatu. ren hiegu eben fo wohl Dienlich fenn; weil felbige gleid).

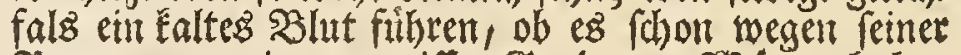
SEenesuna , einen gerwifien Srad pon 2 Bärme haben mus, Ubrigens facinet Der Raubfrofh unter allen uns

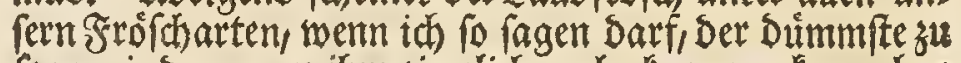
fenn; indem mant itm fiemlich nahe fommen fan, obne Dafi er fogleid austweiden, oder fich Davon maden follte.

Iflles was id bisher won Dem Saubfrofid und rets

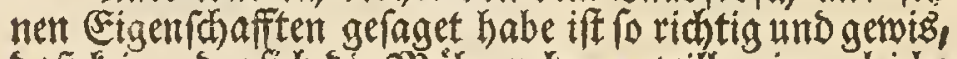
Daf Eeiner Der fich bie \$dulbe nebmen will, eine gleidhe unterfud)ung anzuftellen, mid) bef(huld igen wirb; id bátte etwas, fo Der 213arbeit zuwider wäre, gef́chrieben. Da man mit aber wegen fetmes 2Ufentbaltes tm 2 Bafs fer nod einigen Sweifel gemadhet: als will gu einem fers neren 23 eweis Deffen, was ich bereits davon angezeiget

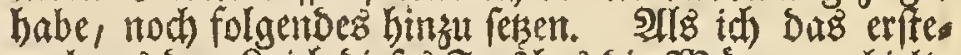

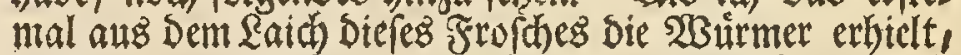
blieben mir siere Davon am Reben, und nachdem Diere

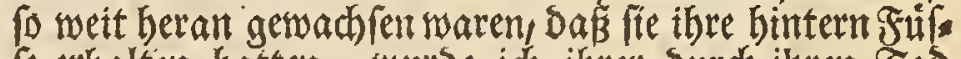
fe erbalten hatten, wurbe ith ifrer suret ibren Sod ebenfal: verluftig. Durch Die offtmalige Betrachtung Derfelben habe id fie aber fo wobl Eemen gelernet, Das ith fie aud int SBaffer, vermóg meines fharffen Sefths tes, won andern zu unterid cetben mufte, Daher id Dem anth wirflich einige berfelben gefangen, mit mir nach Saule genommen, uno hernad aus felbigen vollétus

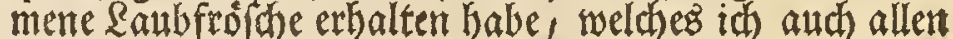
falls nit Beugen berweifen Ean, uns mirnod jåbrlich ins

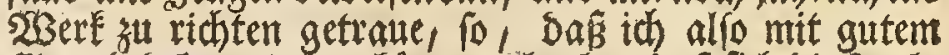
Şrund behaupten zu Eónnen glaube, Dafi fich bie Laub. fröfthe nicht mur alleine im $2 B a$ fier paaren, fondern Das aud ithe Sungen fo lange Sarimen bleiben, bis fie nad) erhaltenen veter Fuffen, und nach abgelegtem Sd)walt: şum Supfen und Springen tridtig geworben.

Sa ith mir etmmal bor genomnen habe, alle unfere

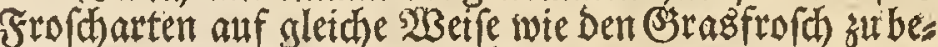

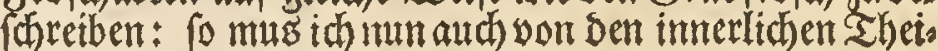
len unferes Raubfrofthes etwas melsen; meil aber bies relben mit eben Diefen Thetlen Des Grasfrofdes fehr viel

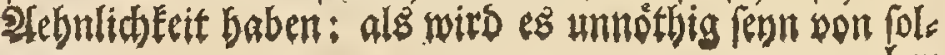



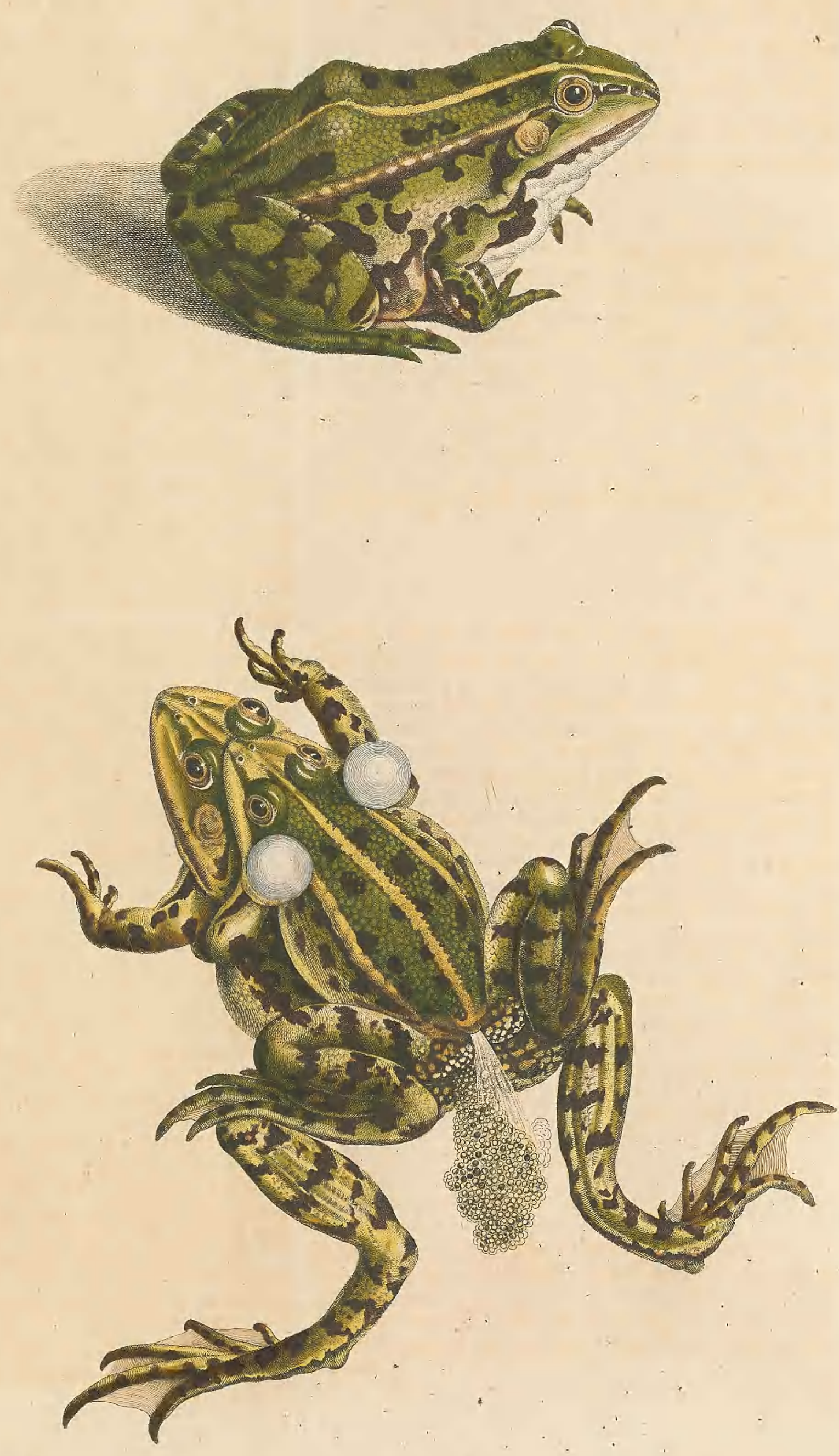

Tab. XIII.

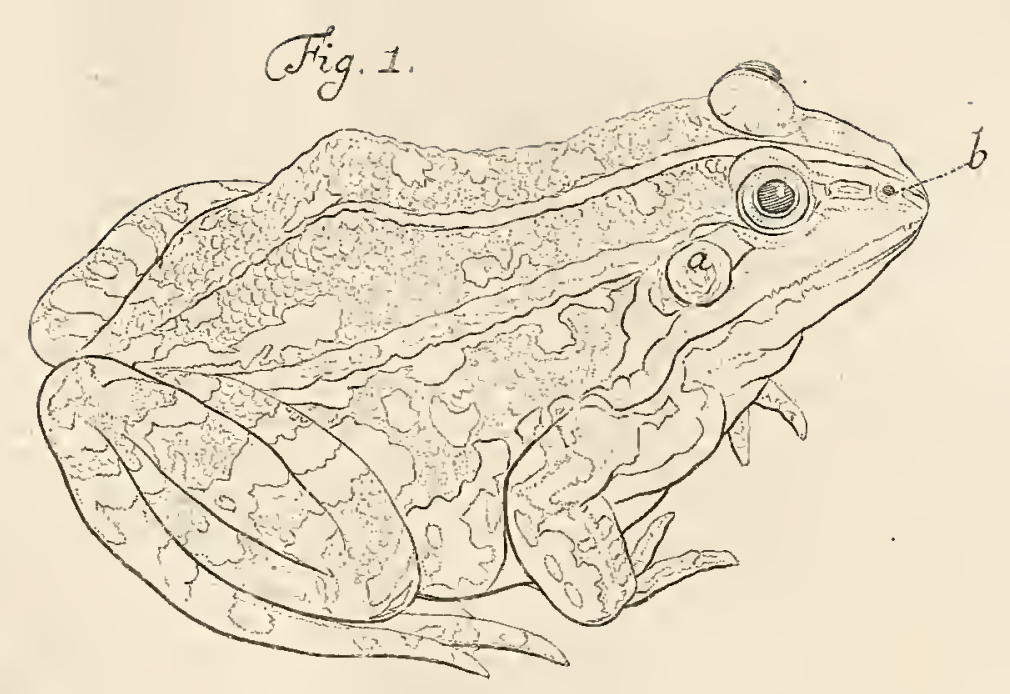

Fig. 2

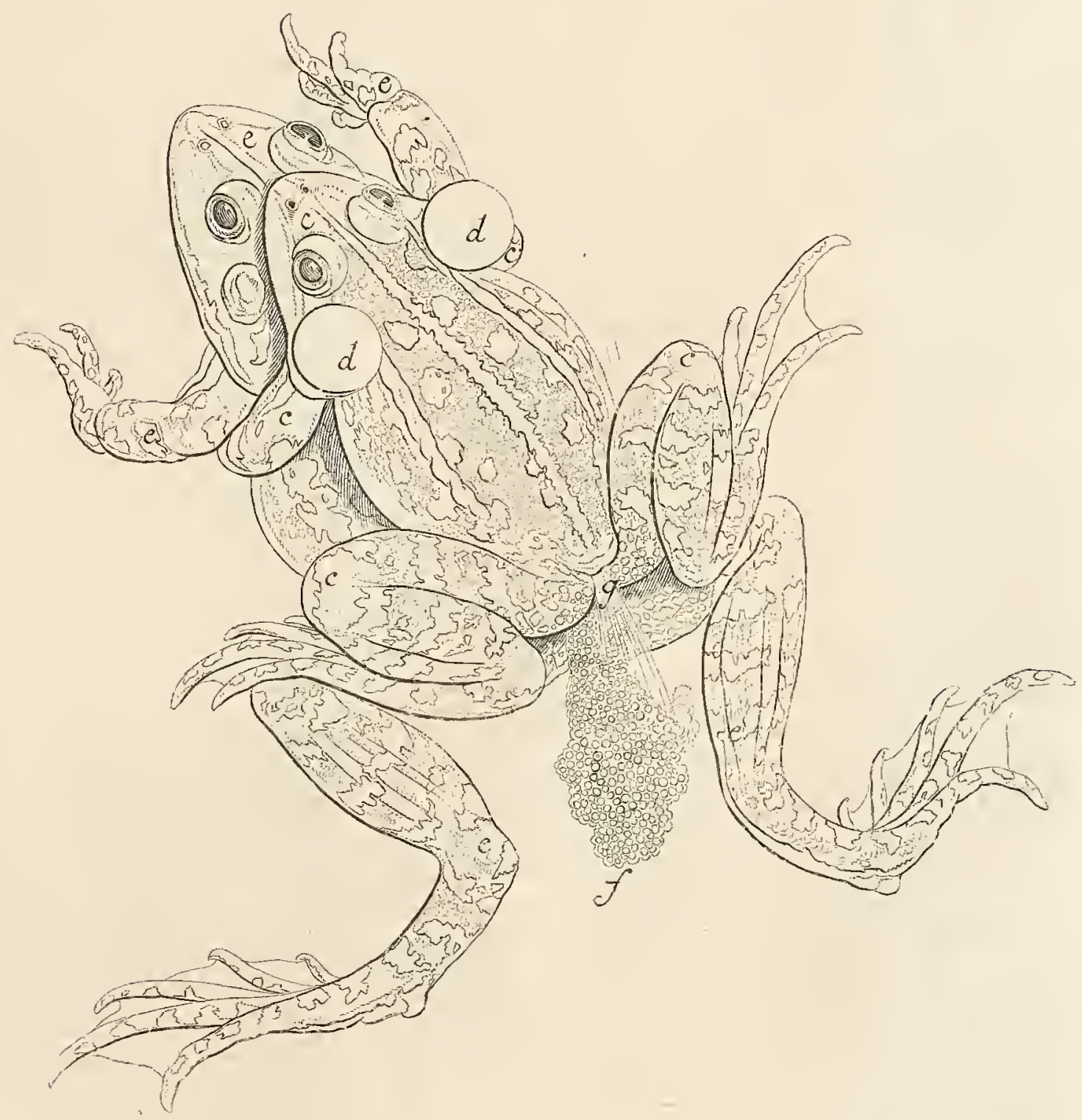





\section{H}

caneum foret, fi fufiorem earundem exhiberem deftriptionem.

Contemplemur itaque partes hafce fivuris XII. Ta bulae expreffas. Siftit $I$. ranam arboream foemellam thorace abdomineque diffectis, fic, ve partes eius internae in fitu confipiciantur naturali. Ope acuum $m \mathrm{~mm}$ m cutem externam, ope vero illarum $n n n n$ panniculun carno. fum, vel abdominis mufculos, ad latera retinui remo tos expanfosque. Cor in medio hepate fuperius fitum $a$ eft notatum. In rana recens aperta rubicundus ipfi eft color; prout vero ex difciffis vatis plus minusue fanguinis effluit, fenfim fenfimque in pallidiorem mucatur ; ipfum autem cor, in rana hac ratione diffecta, per dimidium fere diem continuo agitatur motu. Veficas binas pulmonales litteris $b b$ fignatas, ampliores multo reddere poteft rana, quam quidem hic apparent, differunt vero a veficis pulmonalibus ranae terreftris, ob cellulas angulofas maiores, nec non ob colorem carneum, ex pluribus vafis fanguiferis per ipfas difperfis, ortum. Hepar $c c$ duobus conftat lobis, atque ex his finifter in binos diuifus videtur, quorum alter altero multo eft minor. Color ipfí eft obfcure fufcus. Non longe a corde, cernitur inferius, globus faturate viridis, atque is ipfe fellis eft veficula. Ventriculus $d$ ad $e$ vsque pertingit, ibi vero, vbi terminatur, fitus eft fuperius lien, paruum nec non carneum referens globum. Inteftina tenuin exigua funt longitudine : ab $e$ enim orta non vltra $f$ procedunt, vbi inteftino recto cohaerent. Accumbit huic inferius vefica vrinaria $g g$, quae hic duabus conftare videtur partibus; vbi camen aere vrinaue turget, formam fere eandem ac in terreftri monftrat rana. Habent fefe lingulae hae partes eadem etiam ratione in mafculis. Quod vero ad partes generationi dicatas attinet, cernimus in $I$. hac figura, dextrorfum ad $b$, fat magnam ouarii partem, reliqua ventriculo partim, partim vero hepate tegitur; apparent autem in illo iam fat diftincte ouula, ad generationem futuro anno peragendam, neceffaria. Indicant litterae $i$ i $i$ i vtroque in latere tubam vterinam, cuius tamen ea tantum pars confpectui fiftitur, quam reliqua vifcera minus operiunt. Prominent in latere finiftro ad $k k$, nec non ven. triculum inter heparque, apices fic dictarum foliacearum lutearunque appendicun, quae tamen maximam partem fub vtero ouarioque latent. Vterus litteris // eft fignatus, multoque maioribus hic repletus ouulis, quam quidem illa fuerunt, quae in ouario vidimus.

Depictum exhibet figura 2. ranam arboream marem, cuius thoracem atque abdomen fimili rationeac in foemina aperui, ex quibus vero partes illas quae mafculo cum foemina communes funt, omnes abftuli, ita, vt partes tantum igenerationi dicatas in naturali fitu cernamus. Comparet fuperius ad $o o$ afpera arteria, cui alias binae cohaerent veficae pulmonales, quaeque, quoad ftructuram, ab afpera arteria reliquarum ranarum, ipfiusque huius fpeciei foemellae, aliquatenus differt : non enim folum longior eft, fed conftat etiam aliquot cartilagineis annulis ; atque hine forte fit, quod rana haec reliquis fit vocalior, iplaque eius foemella nullum edat clamorem. Cernimus in hoc canali rimam, quae ipfa laryngis eft apertura, quam in I figura X. Tabulae fumiliter vidimus. Canalis ille fub

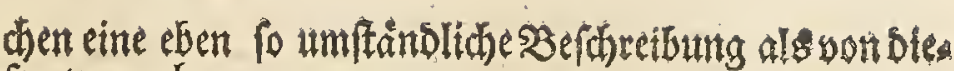
en su madien.

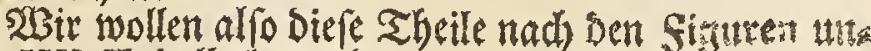
ferer XII. Cabelle betrahten. Die 1. Rellet sinen Ranb.

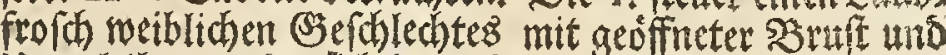
Unterleib yor, Da fich Denn bie innerlidhen Sheile bes: felben in ibrer matiutlichen Lage zeigen. SNit Den vier Nadeln $m \mathrm{~mm}$ ift Die auffere Saut, uns mit ben itbris gen vieren $n n n n$ Diesletidhaut, ober Die Shufeln bes Interletbes aแรgepannet, und auf Die Seite gebradit morden. Das Sers fo oben zwifhen Der Reber in ser Nitte lieget ift mit a begeichnet. Selbigez hat ben eis nem frifh geofneten Laubfrofh eine bodbothe Farbe, wito aber nad) und nach immer blaffer, nadbem năm (ich Durch Die bet gemaditer Deffnung gerifonittene (S) fáfe mebre oder mentger Beblute verlobren gebet; Daben bebalt es auch bey eimen auf diefe sBeife aufgejonttees nen Stofd, wobl hod cinen halben Tag lang feine $B$ e. wegung. Die beeden Rungenblafen, weldie ntit $b$ b. bes mertet find, Ean Der frofh viel mebr ausbehnen, als fie fich bier zeigen ; find aber yon ben \&ungenblafen Des

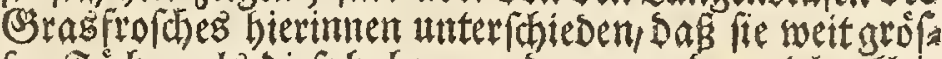
fere Fäd)er als Diefe haben, uns wesen Der vielen flets nen şlutgefäre fo fich in felbige bertheilen megr fleifh. farbig ausfeben. Dite Reber $c c$ beftehetbier aus smenen

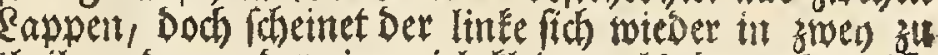
theilen, bavon bet eine siel Hletner als Der andere ift. Shre Farbe iff Dumfel braumroth. BJleich unter Dem Sers, zeiget fich zwifhen ben Rappen Der Rebet eine

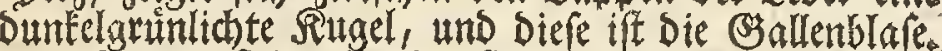
Der Nogen if bend und erffrectet fith bize, gleich abet Liber Dem EnDedesfelben lieget Das פRils als eine Eleine runde fleidf farbe Rugel. Die Dunnen Esedarme fins you geringer lénge, indem fie fich nut von e bis $f$ et frecten, wo fte fich mit Dem Meftoarm vereinigent. 2in Diefem liegt untenlyer bie Sarnblare g $g$, welde biet aus swen Sheilen zit beftehen formet, aber wenn fie mit Sarn ober Rufft angefullet if Sorm mie benm (Srabfrofh hat. Salle Diefe Thetle has

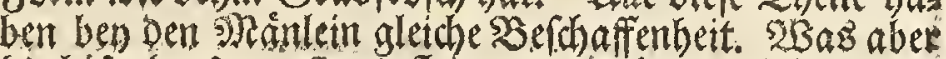
Die befonders zut Fortpflanzung gefoorigen Sheile bes 2Beibleins anbetrifft: fo fehen wir in biefer I sitgus

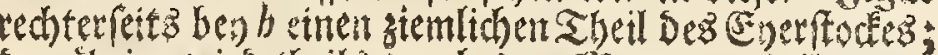
Der ubrige wirs theils Durd Den s)eagen; thells aber burd bie leber. beseffet, uno in felbigem fino allbier Die zur Fortpflansung auf Das funftige Jahr befimmte

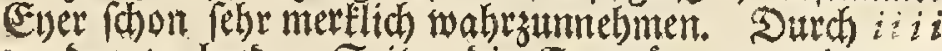
werben zul beeden Seiten Die Energannge andesentet, volt weldhen wir aber bier nur dententigen : Theil peben Ser vort ben librigen Eingeweiden nicht bederter wits. शluf Der lindeen Seite finden fid bet) $k k$, wie alld in Der Mitte zmichen Dem Magen und Der Reber Die hers worragenden Spizen Der fogenannten blätterfơrmigent

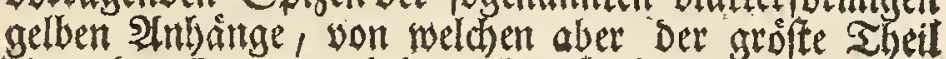
binter Der s) Nutter und Dem Everftod verborgen lieget.

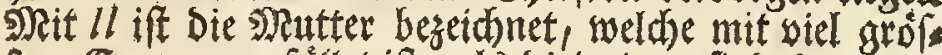
fern Enern angefillet if, als Dieientigen find of wir it Dem (Everftod gereben haben.

In ber 2 tigur babe id ein sannlein vom \&aubs

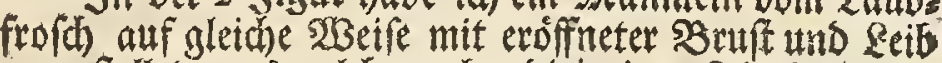
worgeftellet, aus weldem aber Diejentgen Theile fo ith mit Dem 2 Beiblein gemein find, herausgenummen wors Der, fo, Dafís wir Die zur Fortpflanzung nothigen Thet. le nur alleine in ibrer naturlichen $\mathfrak{E} a g e$ zut fehen betsonts men. Oben zetget fith in Diefer Ftigur sie \&uftróbre $100_{2}$ an welcher Die beeden Sungenbla len ankangen, und bie hier etwas anders als ben ben anbern Frofcharten , uns

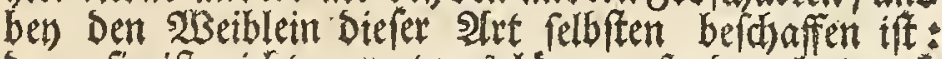
benn fie tif nidst nur ettwas lánger, fondern bat aud etlidbe Enotplidte Ringe, woher ez Denn aud tommen mag, Dafs diefer Frofh cinen fo farden Laut im Sdrenen

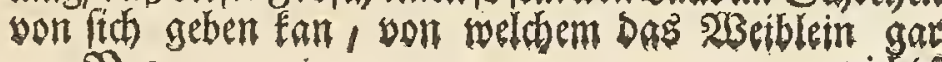




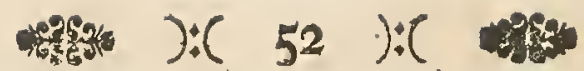

afpera arteria prominens $p$, oefophagus elt, a quo ventriculum feparaui. Indicant litterae $q g, q q$, luteas appendices, quae in foemellis aeque ac in mafculis aurantii funt coloris, atque tempore autumnali, antequam coeant, maximae, poftea vero minimae funt, et in mafculis teftibus, in foemellis, ouario co. haerent. Bini tefticuli litteris $r r$ funt fignati, his vero fubiacent renes ss. Sunt hi coloris fufci, illi vero flaui, Habent tefticuli oui fere formam, renes vero, quorum maxima pars latet, magis funt plani, Veficulae feminales $t t$, nullo, quum iconem hanc delineaui, turgebant fernine, hoc tamen non obftante fat diftincte vifui patebant. Binae partes veficae vrina riae valde hic funt diftractae; hoc autem inde factum eft, quod os pubis $x x$ fuerit difciffum; quumque hic vrinariae veficae fecerim mentionem, indicandum etiam eft, eiaculare ranam arboream, aliarum etiam ranarum more, fi capiatur, interdum vrinam fuam. Difcidi os pubis ranae huius eam ob cauffam, quod vifurus eram, vtrum in recto illius inteftino fimilem re. perirem papillam carnean, ac in rana terreftri detexeram. Aderat quidem illa $v v$, fed in propurtione ad ranam admodum parua; potui tamen per eandem, ope tubuli vitrei capillaris, veliculas feminales genitura vacuas, commode aere re. plere.

Delineaui icones iam defcriptas ad exemplum ranarum arboreanum, quas eo anni tempore cepi, guo coire folent, idque eum in finem, vt oua in vtero iam reperirem. Soluenque eum in finem, vt oua in vtero lam reperirem. Soluen-
di hinc erant dulces plurium parium amplexus, atque vbi foemellas aperui, vidi plus fimplici vice, afcendere oua, ab ouario foluta, cor verfus atque intrare ibidem, quemadmodum in hiftoria ranae terreftris iam dixi, tubarum oftia, quae fimiliter in cordis vicinia hiant. Quodfi vero oura omnia atque fingula in vterum hac ratione defcenderunt, non ita multo poft, a foemina partu edita, per mafculum foecundantur; quum vero hic omnem fiepius emifit genituram, prius qtam foemella cun cta pepererit oua, citius etiam hanc ipfam derelinquit, atque tunc pars ouorum in vtero remanet. Aperui fic aliquando, menfe Augufto, foemellam, in cuius vtero haud exiguam ouorum inueni partem, id quod argumento effe potelt, multum iuuari foemellam, mafculi complexu, in ipfo ouorum partu. Poteft vterus vacuus, aeque facile, ac in rana terreftri, im. pulfo aere diftendi, atque tunc patet fimilem huic quoque esfe itructuram.

De tertia quid dicam figra, quae fceleton ranae ato boreae repraefentat, vix habeo: quodfi enim magnitudinem excipias, fimile eft omni ex parte ranae terreftris fceleto: quae igitur de hoc dicta funt, pro tertiae huius figurae explicatione inferuire fimiliter poffunt.

Agitantur ventriculus nee non inteftila omn:um animalium geque ac in homine, perpetuo motu, ita, vt munc contrahantur, anc dilatentur: vnde non folum cibusatque potus probe mifcentur, fed etiam fuccus nutricius ex isdem exprimitur, reliqua vero minusque vtilis pars e corpore expellitur. Appellant Phyfici motum hunc periftalticum, ipfe vero vidi eundem in ranis, praefertim vero arborea in rana, obferuauique durafe eundem, licer ventriculus e ventre iam fuerit exciffus, integram etiam horam. Contrahuntur motu hoc ventriculi fibrae eadem ratione, ac fibrac vermis contrahuntur, vbi alim migrat in locum: induit tum ventriculus fingulis momentis aliam formam: fi enim nunc planus atque aequalis frerit, quenadmodum four a eundem monftrat, in qua $A$ fuperius, $B$ vero inferius illius indicat orificium, non ita multo pofts referet fouram, mox rurfus fimilis erit fourae $\theta$, tandemque $\%$ Obferuari quomox rurfus fimilis eric, microfcopii ope, in pediculis atque pulicibus; aft in erucis nudo etiam confipicitur oculo, inque his eundem pro motu habui fanguiuis, donec me ranae cafu certiora docuerant. Sed fufficiant haec: nunc enim ranam exa. minabimus viridem aquaticam, in cuius hiftoria addifcenda hactenus elaboraui, cuiusque omnes optime mihi reddidi no. tas proprietates.

Finis Hiftoriae Ranae arboreas:

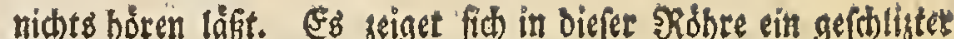
Spalt, welcher bie Deffnung Der Suftrohre ift, fo wir aud in ber I gigur ber XI Cabelle gefehen haben. Der unter Diefer

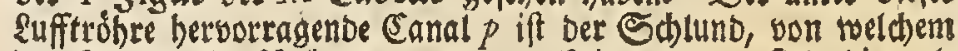
Der Magen abgeftuitten rvorden. Sgrit $q q, q q$, find bie gel

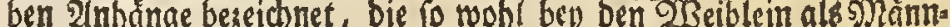
lein Diefer Frofdart hod oranienfarb fino, unt fich im Serbfe vor ber Wakrung ebenfals am gróften, nach fetbiger aber am Eleimfters zeigen, uno die bey Den Mnentein mit Den (Beilen; bey Den 25 cibs lein aber mit Dem Eyerfod jufammbangen. Nhit $r r$ fino die bees Den Bieilen temerket, und unter Diefen liegen bie Nieren $s s$. Dise fe fuikren eine brauneothe, iene aber eine gelbe Frarbe. Die Beis len find faft enformig, bie Sierten aber von reelden Der groffte Sheil bier bebeclet ift, fino mebr platt. Die beeben Saamenblăss lein $t z$, waren zwar Damals als ich Diefe \&abildoung maüte ven Saamen leer, aber bods fehr beuttid ju reben. Die becoens Sheile Der Saarnblafe u u fino bier ziemlich von einanoer gejogen, reeldbes aber Daher getommen dá Das Sa)ambein $x x$, entyroen gefdonitfen worben; weil ich aber bier Der Sarnblafe groencfe, fo

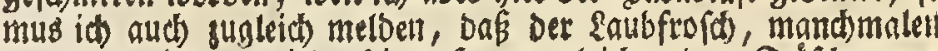

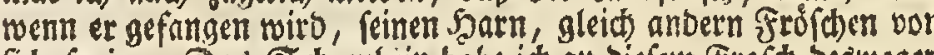

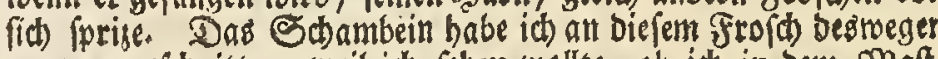

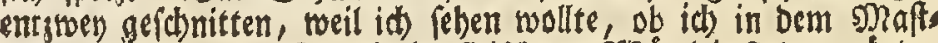

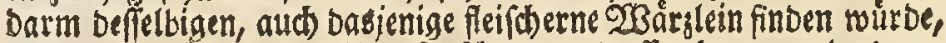

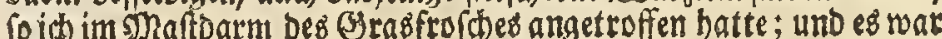

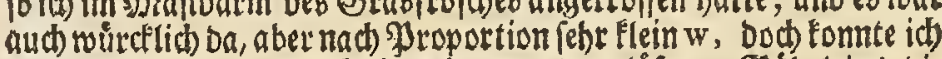

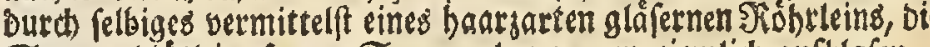
Eaamentláslein, fo von Saanen leet warem, jiemlich aufblafen.

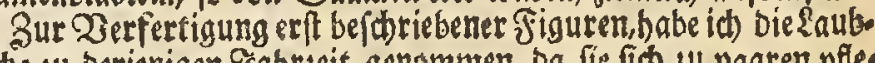

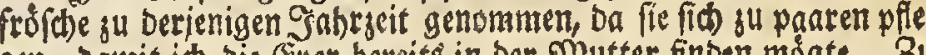

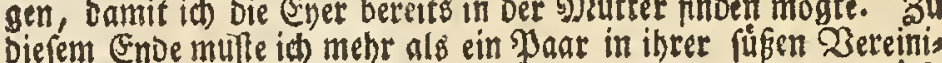

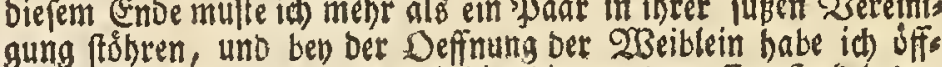
ters inabrgenommen, bafi auds bier bie von bem Eyerfock losges

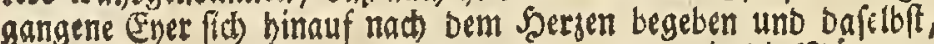

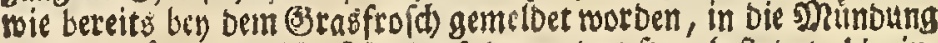
Der Energénge weldhe fich eberfals um bas shers befinbet, bincins tretten. Sino num aber alle Ever auf Diefe 263 eife in bie श2utter gefonmen: fo werben fie balo Darauf, inbem folde bas asciblein bon fick giebt, burd Das siánnlein befrudstet; meil aber Diefes mandimalen ben Saamen bereits fabren laffen, ehe bas 2 beiblein

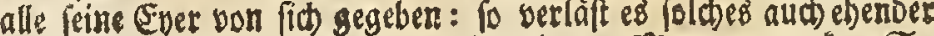

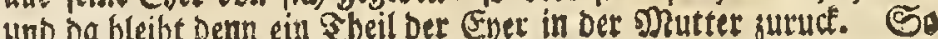
habe id) eimmal ein 23 eiblein im 2Auguftmonat geoffrnet, unto in ber SMutter Defferbigen, cinen guten Theil von Enern angetroffers

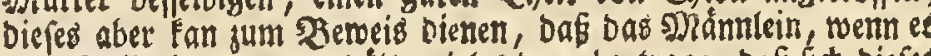
oas 2 Seiblein umarmet hált, vieles Daju bentrage, Daß fich biefes feiner Ever entledigen Édnne. Die von Enern leare Mutter láfit

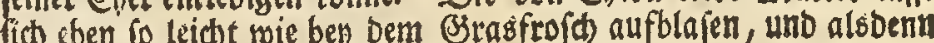

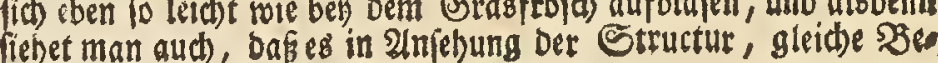
(c) afferbeit mit int habe.

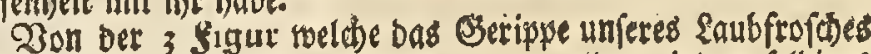

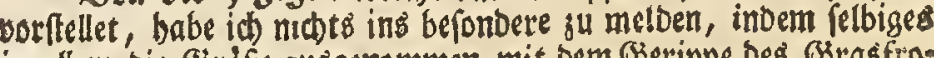
in allem, bie Sirsfe aubigenommen, mit Dem Serippe Des Brasfro: fors úbereintommet, uno alfo die ßejchteibung bon biefem, aud bier zutt Eretåtung Dienen tan.

Ben allen Sbieren bat Der snagen nebft Den Gsedármen, wio

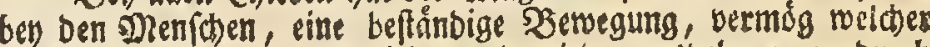
fie fid immertu surammenjichen und wieder ausobbnen, woburd benn nict nut Speife und Srand red)t miteinander vermifhet,

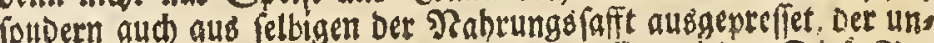
nothige lieberteft aber aus Dem \&eib gefthaffet wiro. Dieje Djes nothige lieberteft abet aus bem \&eib geftaffet wiro. Sieje babe felbige auds an ben Frojichen, (onberlid aber an bem faubfer fo

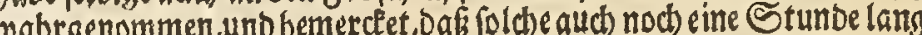

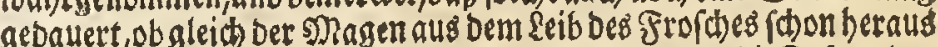

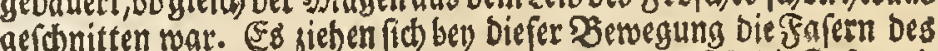

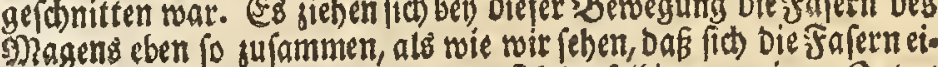
92) agens eben fo sufammen, als wie wit feben, daf fid die Jalern eibem andern begiebt, unb Dabetomnt bet Sagen alle sininuten eine an.

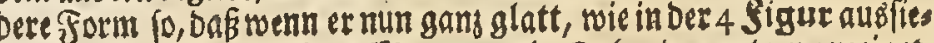
het, in walcher $A$ ben obern Magenmund, $B$ aber Den untern anseiget, fo befommt et gleiđh Datauf Daš 2nreben Det s Sigur, bald aber glei.

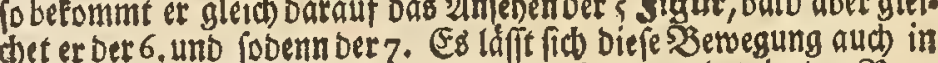

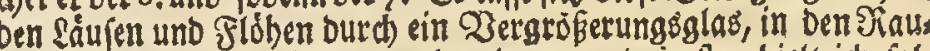
pen aber mit blofen 2 lugen wabrnebmen, uno jonflen bielt ich fol

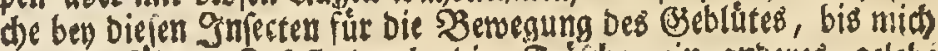

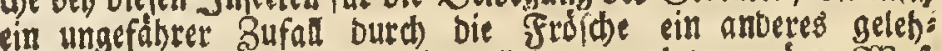
ein ungefabrer sufal but : wir wollen nun aud den grunen $23 a$ a ret. Sebod genug bievon: wir wollen nun aud den grunen

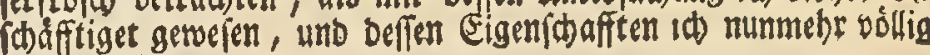
ennen gelernet.

Kunde der Zefhreibunts des Laubfioftes. 


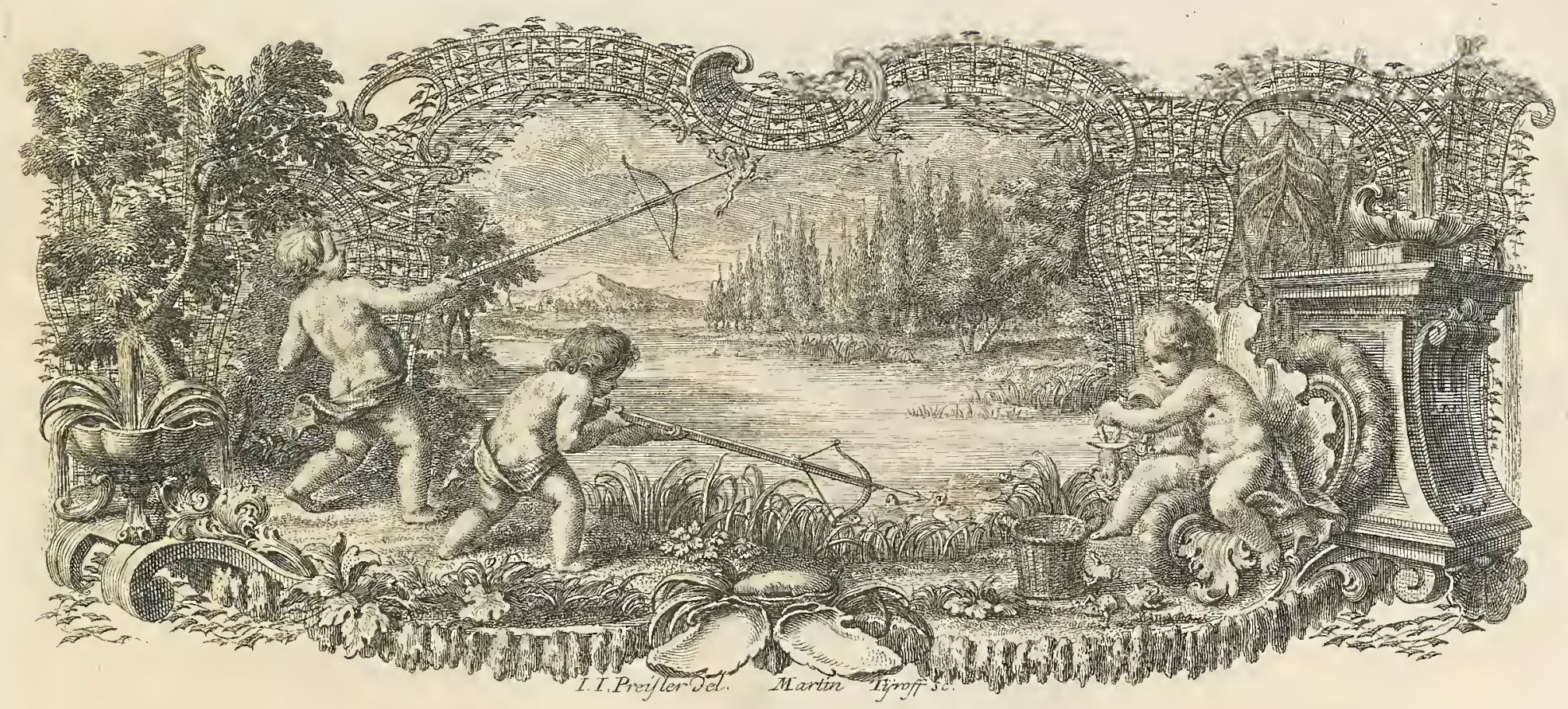

\section{HISTORIA NATVRALIS RANARVM NOSTRATIVM. SECTIO III.}

Dober

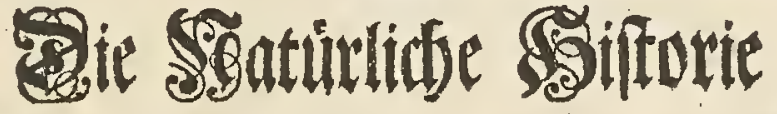

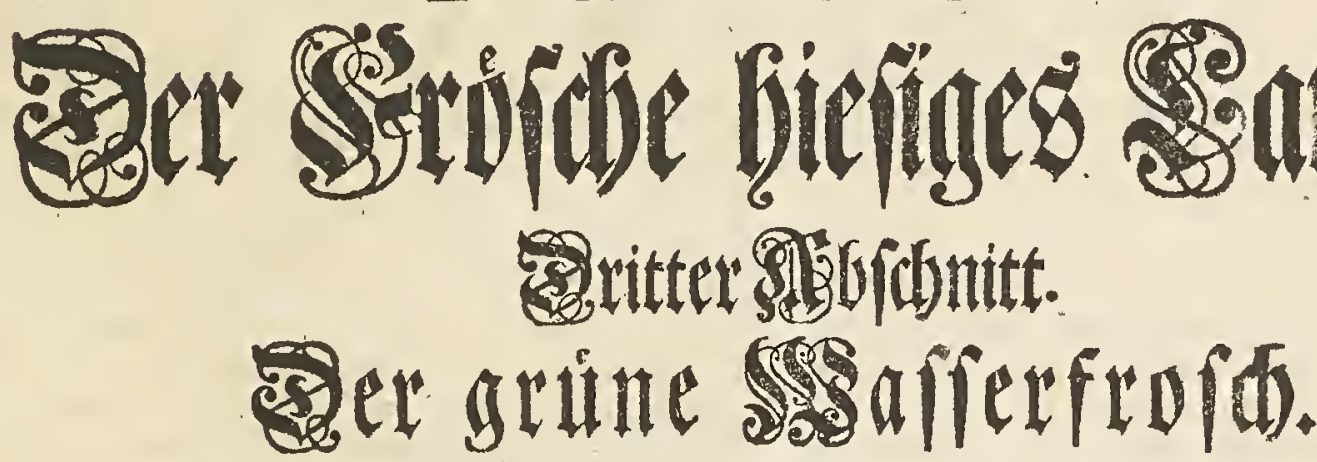

C.APVT I.

(Errites Capitel.

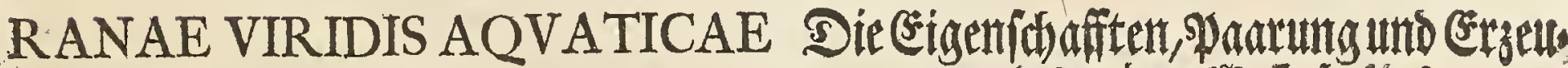 PROPRIETATES, COITVS, GENERATIO.

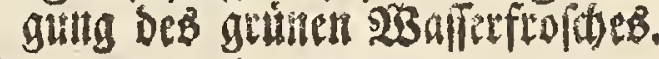

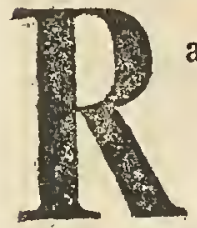

ana viridis aquatica tertia illa eft ranarum noftratium fpecies, cuius nunc fimiliter dare posfum hiftoriam. Inditum ipfi iam dudum quidem eft ranae viridis aquaticae nomen, quippe quae crebro multumque in aquis verfatur, ftagnantesque prae fluuialibus amat; quum vero inter reliquas ranarum fpecies, omnem per aeftatem in arundinetis atque ripis gramineis plurimum moretur, rebusque quibus nutritur inhiet, rana etiam appellari poterat calamites : licet namque haud ignorem, auctores illos, qui hifce de animalibus fcripfere, aliam prorfus fpeciem ranam vocaffe calamiten; illam tamen vel nullibi, vel faltem noftris in regionibus vix, reperiri perfuafum habeo. Multum vero ranam viridem aquaticam in ripis verfari facile omnis ille videbit, qui aeftiuo tempore, fole praefertim radios fuos emittente, quos rana noftra valde amat, ad ripas pifcinae cuiusdam propius accedit : illico namque ranae magna copia ibidem latitantes, longo arcuatoque faltu, multam fimul per pofticam corporis partem limpidam ejiculantes aquam, in ipfam fefe immittent pilcinam, ex qua tamen fecuriores redditae, mox rurfus in ripas funt enataturae. Aliud ranae huic in Saxo-

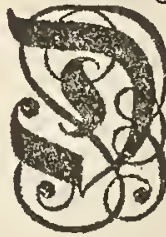

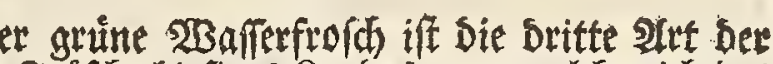
Frofore hieftaes Lanbes, won meldier ith fest ebenfalls eine ßerthreibutitg mitzutheilen in Stano bin. Ses iftellbiger zimar finon vor lan:

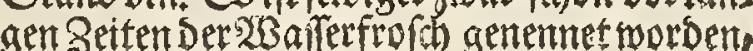

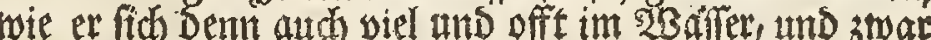
mebr im ftebenden als faifenden aufbâlt ; alleme ba es

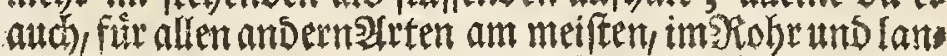
gen Szras Der llfer, Den ganzen Sommer bindurch, fis set und auf Dasienige, was zu feiner Nabrung Dienet,

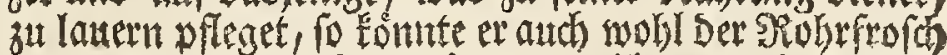
heiffen: Dent ob ich gleich gar wobl wets, baf bietes ntgen Scribenten, fo von Diefen Sreaturen gebandelt

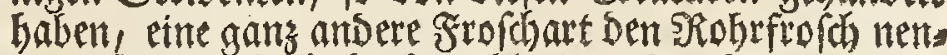
nen, fo wits folche Doch wohl nirgend, oder atm toes ntgeften ben uns nicht, zu finden fenn. Da ́a aber unfer griner $23 a$ ferfrold fich siel am ufer aufbalte, Ean jes Dermann letchflich erfabren: Dent man Darf fich nur im

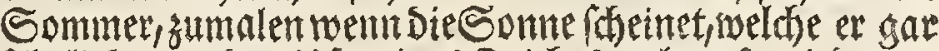

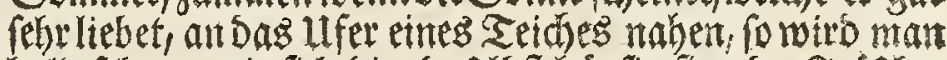

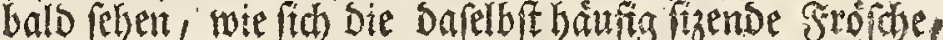
mit eintem grofen Sogenforung, wober fie aud eine 
nia nomen eft; ibi enim eandem Markgeker vel Quarkgeker vocant, atque hoc, vt verifimile videtur, ob ipfius, quem edere folet, clamorem, iteratum Quark Quark, crepriusque repetitum Gek Gek Gek fonantem.

Efie ranam noftram aquaticam fpeciem ab iis, quarum iam dedi atque adhuc dadurus fum hiftoriam, omnino diverfam, curatior ejusdem non poteft non docere contemplatio. Licet namque primo intuitu ejusdem cum reliquis ranis effe videatur ftructurae, valde tamen caput ipfius differt: non folum enim procerius longiusque, fed anterius magis etiam eft acuminatum. Quod ad colorem, mafculi aeque ac foemellae virides vtplurimum funt, ita tamen vt nigris etiam confperfae fint maculis. Finito illo quo coire folent tempore, color hic viridis fumme eft floridus, poftea vero pallidior nunc, nunc faturatior, et in quibusdam fubfufcus etiam euadit. Pertinet infuper ad harum ranarum characterem, lutea illa, ab ore medium per dorfum ad extremum corpus vsque excurrens, femperque obferuabilis linea, nec non vtroque in latere confpectui fefe fiftens fimbria fimiliter lutea, vt et binae illae globofae veficae, quas mafculi clamantes, ad oris jatera ex angulis ipfius propellunt; quibus vero foemellae, leuem tantum grunnitum cun quadam gulae inflatione mittentes, omnino carent.

Cernuntur binae hae: veficae in XIII. Tabulae, 2.Fi* gura ad $d d$; quemadmodum vero his ipfis mafculus a foemella facile difcernitur: fic etiam, eo quo copulantur tempore, in illo pedum anteriorum tument pollices, cuteque teguntur furua et afpera, minus vero nigra quam in rana fufca terreftri, et generationis tempore elapfo, aeque ac in hac, rurfus euanefcente. Sunt et foemellae propriae quaedam notae; in fuperficie namque corporis inferiore plures quam mafculus oftendit maculas cinereas; in vtroque vero cutis inter digitos pedum pofteriorum magis eft confpicua, quam in reliquis ranarum fpeciebus.

Superat rana noftra aquatica reliquas-fpecies magnitudine in tantum, vt, fi fpeciem quandam bufonum excipias, omnium maxima, mihi quidem, videatur. Hinc
פRenge helles $23 a$ fers hinten son fich foritisen, in Den Setid) ploszlich binein fturzen; weld)en fie aber, went fie wieber ficher werben, bald yon netem verlafen. In Sadhen futhrt Diefer Frofh nod einen andert Nas

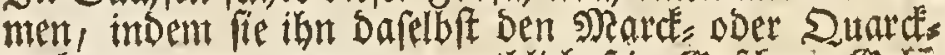

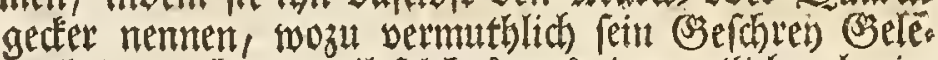
gentyeit geaeben, weil folches ans einem effichmal wies Derlyolten Duarck Duara beftebet, woranf allezeit ein

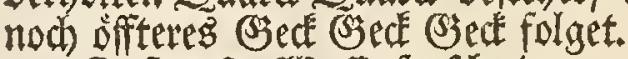

Dafis unfer 23 afferfrofh eime, won Den bereits bes dhriebenen und nod folgenden andern frofoften, une

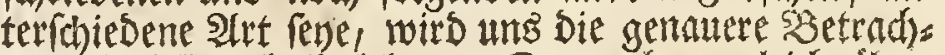
tung Defielben bald lehren. Denn do. er gleid) riber. bmots feinerstructur nath, nidht anders als Die tibri

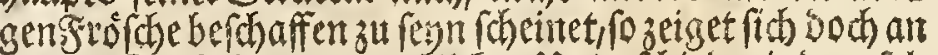
einem Ropf ein gar merclicher Linterftied; indem fols

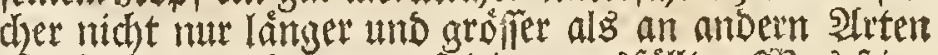

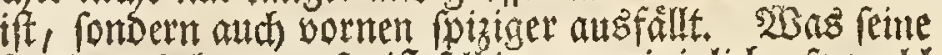
Farbe anbelanget, to ift relbige gemeiniglich), fo wobl

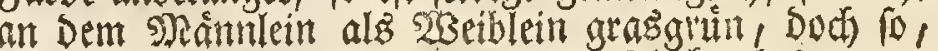
Dafe fie Dabery alleseit mit fobivarzen flecten beporentget ind. Diefe arazgrume Farbe if nach gefhebener 1 aas ruma am fobonfen; auffer foldser aber seigt fie fich bals fotwacher und balb Dundeler; und ben einigen and wohl gar bellbraun. Ferner if alli biefes als ein befonderes

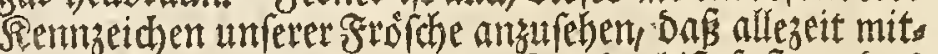

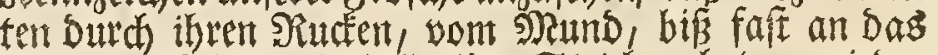
Ende Des Reibs, ein bellgelber Strido gehet, an jeder Seite aber fich ein gelber erbabner 23 ul zeiget, und

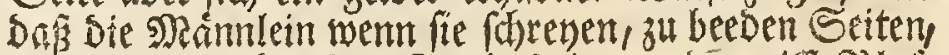
aus Den 2 Bindeln beg sounbez eine runbe weife Slaic heraustreiben, weldye Den פJeiblein nangelt, indem felbige nut in etwas grunzen, und Dabey bie Seble ein wertia aufbleben.

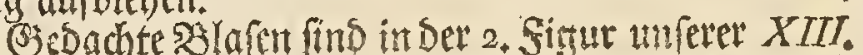

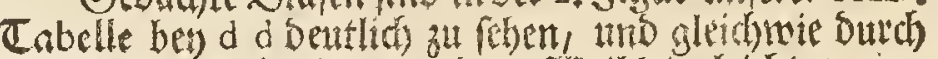

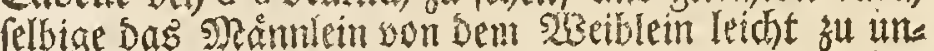
terfareiben ift, fo zeiget fich aud on ben Daumen ber worbern Pfoten Des erfteren, zur \$aarungszeit, baj retbige gans aufgefthoullen uns mit eimer oundéln,

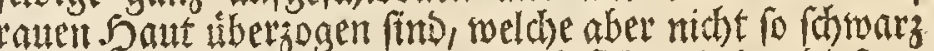
als am (S3rasfrofh erfobetnet, und fid), wie bey biefem, nach Der Daarung wieoer berlichtet. Daz abeiblein hat aud noch Dieres zum befondern Rennzeichen, Dafs eS auf ber unterfláche feines Reibes mekr bellgraue fles den als Das SRannlein finhet; an beeben aber if Die

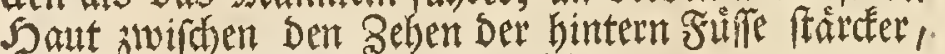
als ant anbern ftodd)arten zu relyen.

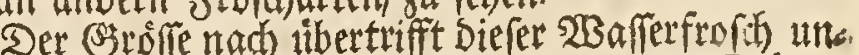

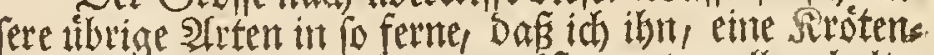
ant alsigenommen, fur bie grófte unter allen balte. 

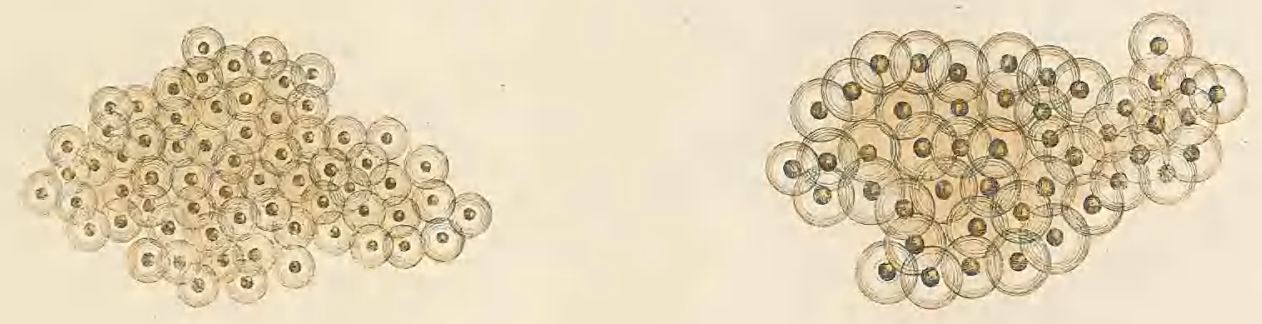

(c)

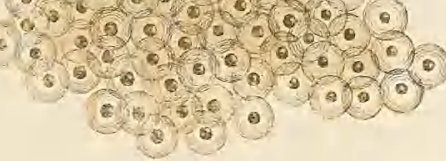

c)

(ब)

(1)

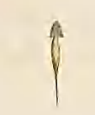

1

(8)

$$
2-\infty
$$
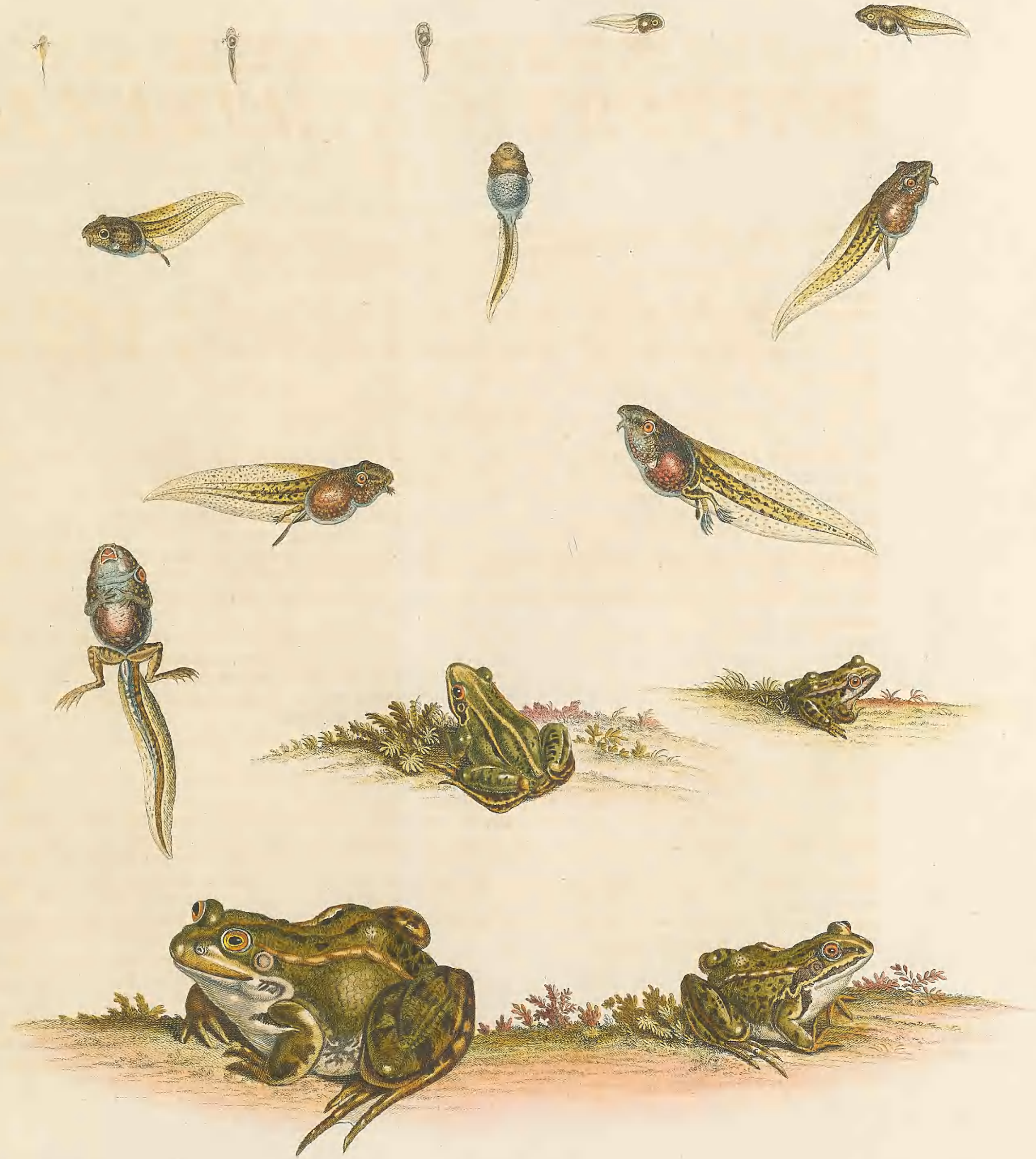

sig.

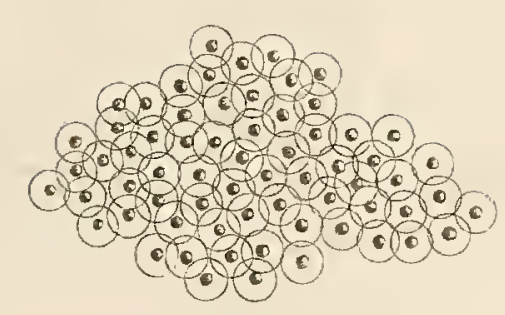

(9) Dig.t. (e) Th.

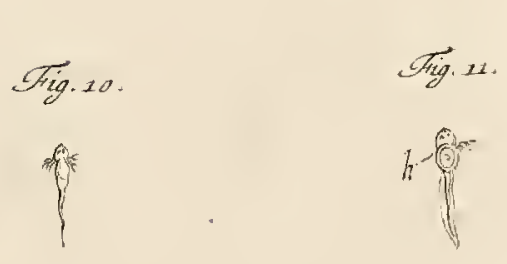

Sig. $25^{\circ}$.

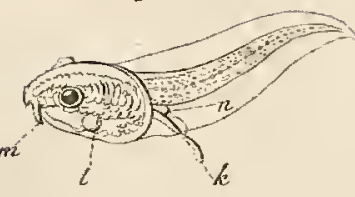

Stig. 2

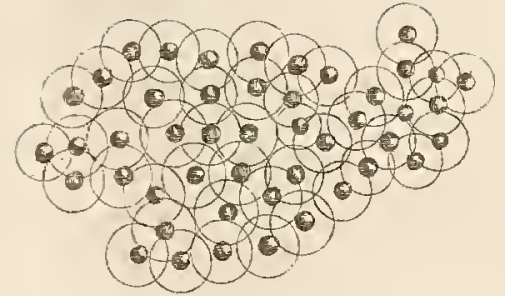

S<smiles>[CH]C</smiles>

5 Sig. 13

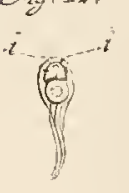

Tig. 3.

$$
\text { b. (a) } a
$$

Jig.

f

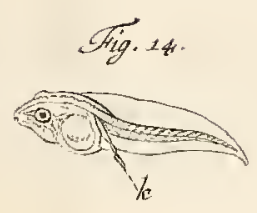

㱙. $f$ fig

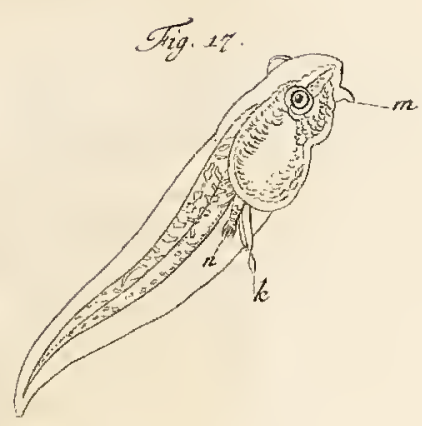

STig. 10
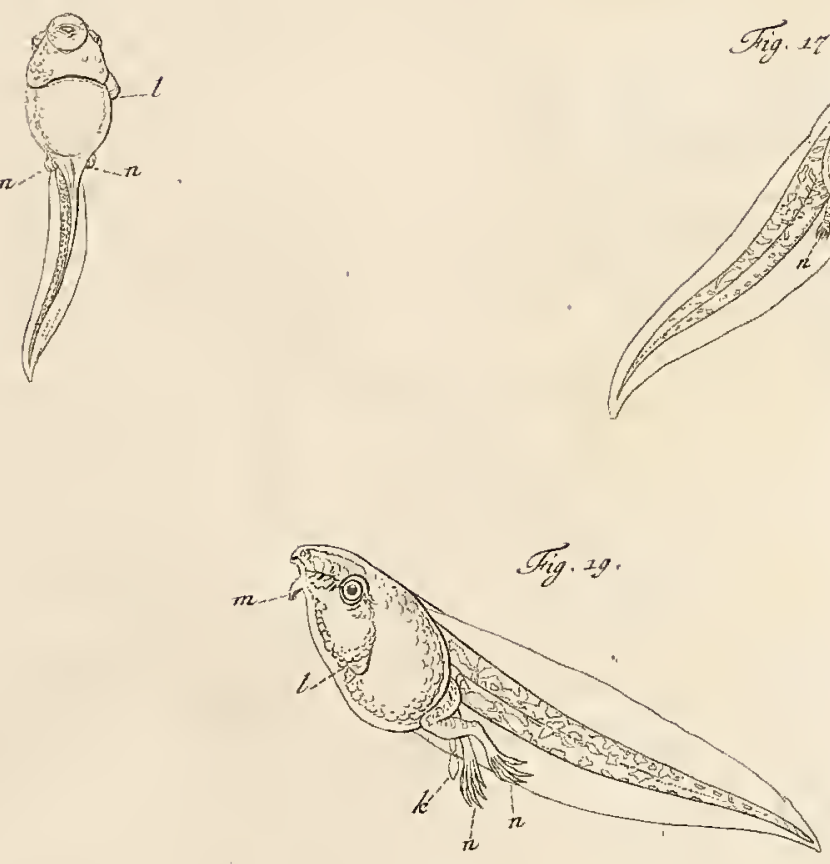

sig. 20.

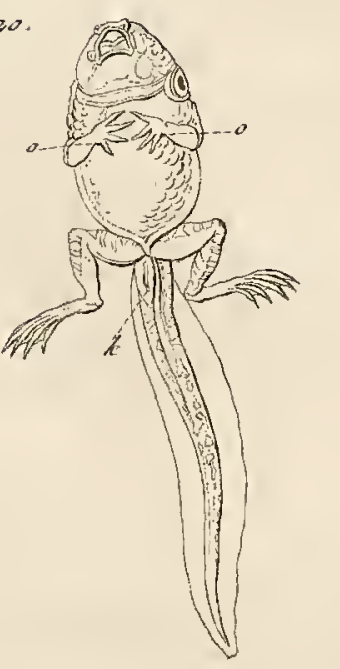

原 28

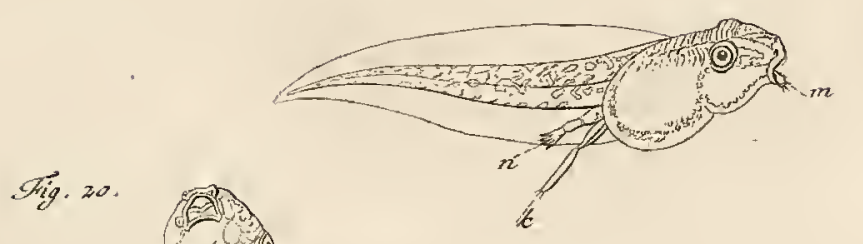

Sig. 27

Ty $2 x$

(6)

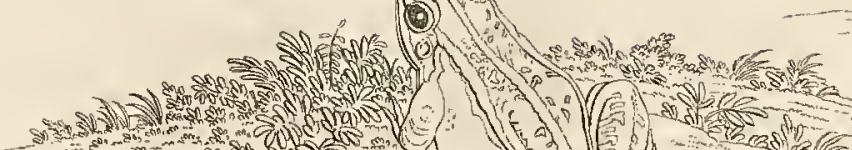

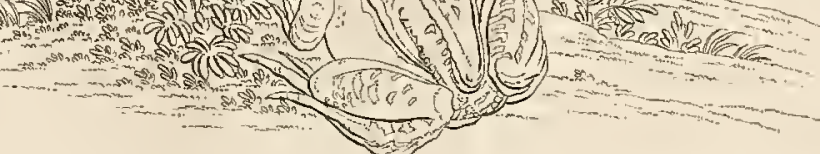

$\rightarrow 32$ har

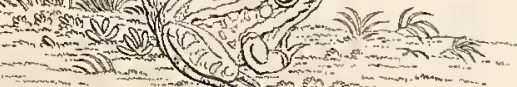

(a)

Jig. 23

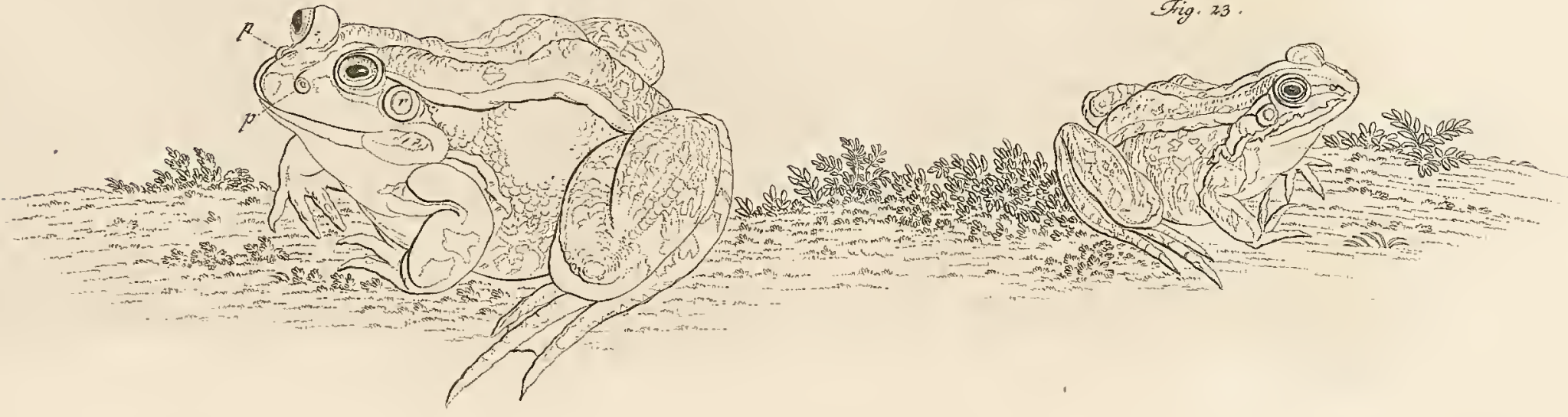





\section{(4) $):(55):(4)$}

2ùtem perfuafum habeō, crefcêrè eandem per decem pluresque annos; fed quum verifimilie fit, producere ipfam vitam fuam vltra decem et fex annos, hac in re quid affirmem vix habeo. Foemellae ceterum majores ipfis euadunt mafculis, foemellaque illa quam I figura. XIIITabulae fiftit, multis certe earum cedit magnitudine.

Probant, quae hactenus dicta funt, fatis, vt puto, fuperque, effe ranam noftram aquaticam fpeciem $a b$ aliis omnino diftinetam, atque hoc et reliquae vlterius funt indicaturae eiusdem proprietates.

Eft ex proprietatibus hifee, vix ranam aquaticam ante menfem Aprilem, fuis ex hibernaculis effe proditu$\mathrm{ram}$, nifi forte calidior tempeftas eandem citius eliciat. Teneriores quae primum, fecundum tertiumue aetatis agunt annum, vno quidem menfe prius ad ripas iam comparent; adultiores vero funt femper tardiores: quodfi ergo quis easdem ante illud quo prodire folent tempus, cernere cupiat, in limo quaerendae forent, in quo et ego easdem maturius confpexi, quum e pifcina quadam in quam pifcium foetus immitti debebant, aqua emittebatur; ob fufcum tamen colorem quem e limo ipfis adhaerente contraxerant, bufonibus quam ranis erant fimiliores.

Quum itaque haec ranarum fpecies ferius ex latibulis fuis prodeat, omnes illi falluntur, qui fperma illud, quod primo iam vere aquis innatat, fperma viridium ranarum aquaticarum effe putant: coëunt namque Iunio demum menfe, ante coitum vero nulla vnquam foemella, nifi ipfi vis inferatur, fuum emittet fperma. Hinc illi etiam fide vix funt digni, qui credunt, coire ranam aquatican1 cum aliis etiam ranarum fpeciebus; ii autem quibus ranarum efus in deliciis eft, quem in finem viridium praefertim crura pofteriora eliguntur, multum errant, fi ranas eas quae ante menfes aeftiuos apponuntur, virides esfe credunt: ranae namque illae, quae ante illos in foro venales proftant, merae funt ranae terreftres, quemadmodum in prima iam a me dictum eft fectione. Quicunque igitur eiusmodi adamat cibum, viridesque ranas aquaticas appetit, vt Iulio demum fequentibusque menfibus eaedem capiantur, iubeat neceffe eft, tum enim et ob generationis negotium peractum, et ob vberiorem alimentorum copiam, non poffunt non carnofiores effe fapidioresque. Data fic occafione, non abs re erit, fi de modo easdem capiendi nonnulla proferam. Vtuntur quidem vtplurimum hunc in finem hamis faccisque reticulatis, funt vero multi qui easdem ope arcus balearis fagitta transfigere gaudent, quem modum fectioni huic tertiae praemiffa icon apte fatis ob oculos ponit. Conftruitur vero inftrumentum, quod ad percutiendas ranas adhibent,duplici ratione: vel enim fagitta ferrea arcu propellitur ex chalybe confecto, vel filo ferreo tortili elafticoque.

Vbi tempus quo ranae hae copulantur ingruit, tancum mafculi earum diu noctuque edunt clamorem, vt etiam in locis vltra horam remotis audiantur. $\mathrm{Ob}$ id ipfum tamen non vt os earum adaperiatur indigent, quum neutiquam, quae rufticae gentis vulgaris eft opinio, neque in hac neque in alia ranarum fpecie, hiemali tempore claufum fit concretumue: licet enim ipfis illis quibus ranae filent menfibus, plures earum accuratius fim contemplatus, os tamen illarum, quamuis arctius fit claufum aegriusque fere foluatur, aperiri poffe, femper quidem deprehendi. Si quis vero fit, qui credat concreta hieme ranarum effe ora, quum ineunte vere tenuis ex iisdem propendeat cuticula, is certe falfus eft: vernat enim rana, vt plu-
Eben Deswegen aber glaube id and, Daber zu feinem volfommenen 5 Bachsthum mehr als zeben Sabre no: thitg habe; ba fich aber, wie es gar wahrfocinlid ift,

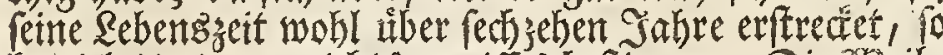

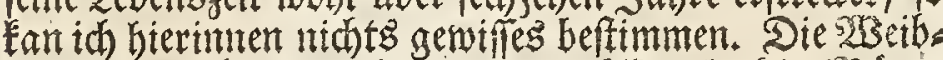

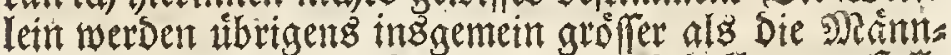
lein, und Das in Der I Sigur Der XII Cabelle vorgeftells te $\mathfrak{B}$ Beiblein, mus wielen Derfelben an (S)óffe wethen.

2fllez was tid bisher gefaget, bewetret genugfam, Das unfer $23 a f f e r f r o f h$ ente gans befondere 2 (rt feve: feine tibrige Eigenfhaffen aber, werden foldies noch mekr seigent.

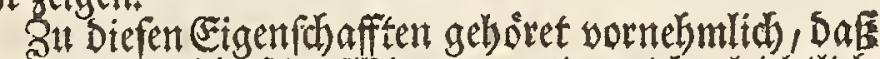
Der 2 Bafertrofh fein 2 Binterquartier ntw leidhtlith

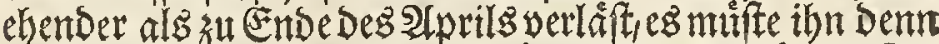
eine febr marme 2 Bitterung frither heraus lofen. Die itngen weldhe nur ein 2rlter yon einem, swenen ober

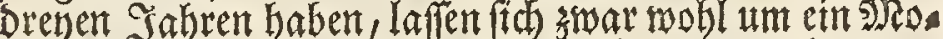
nat ehenter an Dem lffer fehen, die áltern aber fonmen

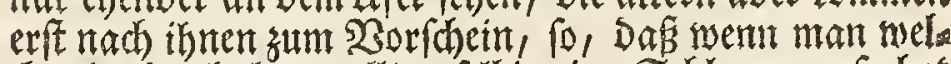
che ehender haben wollte, felbige in Schlamm gefuthet

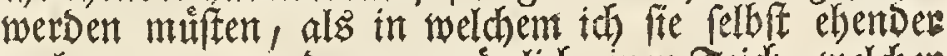
wabrgenommen, ba man námlich einen seidh, weldher befesetwerden follte, abgelaffenthatte; wiewobl fie Damals

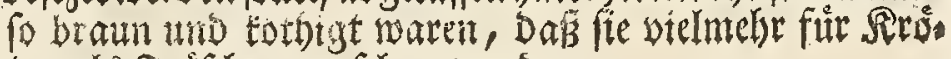
ten als frofdhe angefehen wumber.

Do num aber Diefe Frofhart fo for erfcheinet, fo betritgen fich alle Dielenigen melche glauben es fene Ders jentge Saidh, Den man fhon ebenter im Frubling auf

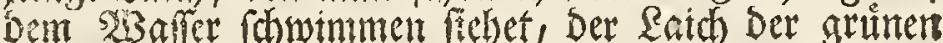

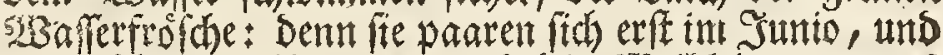

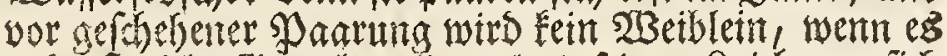

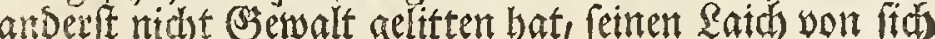
geben. Eben Destwegen berdienen autch Diefe feimen

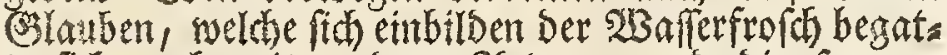
te fich aud mit andern 2(rten ; unto Die fo gers

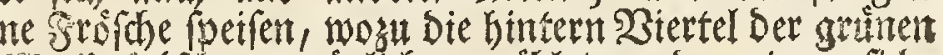

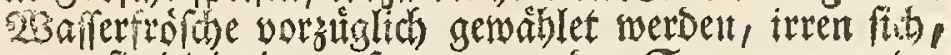
menn fie Dieienigen, fo man wor Den Sommermonatert zu Fishe bringet, Dafur halten: Demn Die Frofobe fo

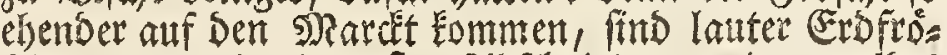
(d)e, wie bereits im erften $2(b$ fhnitt won mit gemeloet morden. 2 ser alín zu Dergletchen Sperfesseliebentraght,

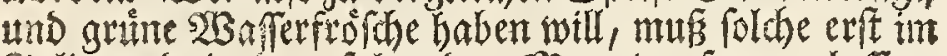
Sulio und in Den folgenten ononaten fangen lafer,

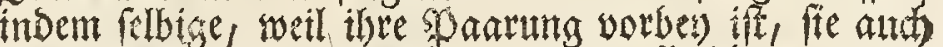
mekr Dabrang betommen, alsbean fletfóthter unto

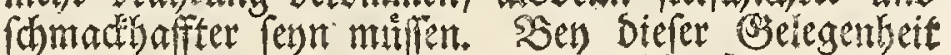
mus ich Doch aud etmas bon ber Slrt fie su fangen melden. Insgemein bedient man fich zmar biešl Der 2ingel uns Samen; viele wadien fith aber aud ein be:

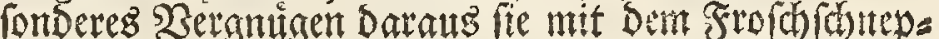
per zat fhiefien, und foldhez ift in ber sor diefem brits ten 2ibronitt befindichen Infangsleife worgeftellt wo:

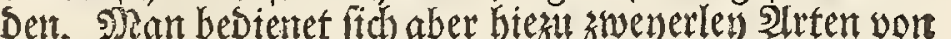
Sthneppern, indem ber Dazu gebórige aus Eiren ver: fertigte $\$$ fetl, auf einigen Durd einen fíablerren $\mathfrak{B O}$ gem, auf andern aber bureh eite auts Drat berfertigte Šeder getrieben wiro.

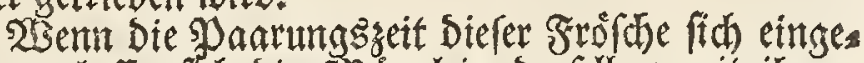

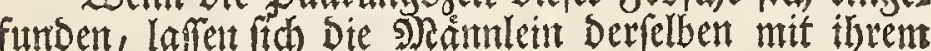

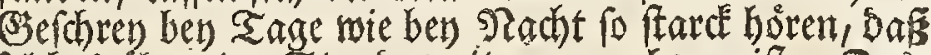

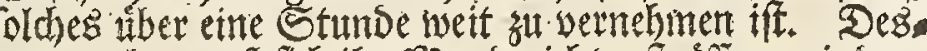

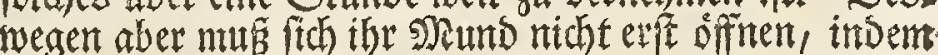
felbiger Eetmesimegs, weder an Diefer nod) an einer ant Dern Frofhart, wie die Sanbleute inggentein glauber, Den swinter uber weridhlofien ober zugewadhen ift: Dent ob idh gleich zu Derientigen Beit Da Die Frofoche insgements forwetgen, werfdiedene beswegen genau betrad)tet, fo

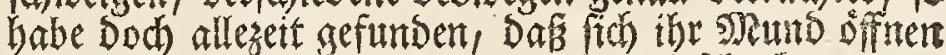
lafie, wienobl foldses, weil er allemal fehr inapp ges (d) loflen iff, einige sube Eoltet. Sollte aber femand 


\section{(4) $)\left(5^{6}\right):(10$}

Hes per aeftatem, fic hoc etiam tempore, ita, vt vifcofam omnino exuat cuticulam. Si itaque rana hiberno tempore cibo indigeret, os fuum pro capiendo eo aeque posfet aperire, ac naribus, (Fig. $I . b$.) fi volupe elfet, serem attrahere, quum hae fimiliter ipfo illo tempore minus fint claufae.

Audit non folum 'rana noftra aquatica clariffime fed ea etiam vifus gaudet acie, vt reliquas ranarum fpecies fagacitate multum fuperet. Sitae funt anres ad latera pone oculos, id quod ex I figura, XIII Tabulae apparet, in qua dextra auris littera $a$ eft fignata; clariflime aurem ranas hafce audire hinc patet, quod, vbi magno numero congregatae fortifime clamant, percepto tamen fono minus noto, illico conticefcunt. Bini fulgentes, aureo circulo ornati globofique oculi ea prominent ratione, vt rana, quaecunque circum ipfam agantur moueanturque, facillime percipiat; accedit huc eorum etiam mobilitas, qua non folum retrahi fed et propelli polfunt. Nullo hinc negotio omnia ea, quibus vefcitur, ab illa arripiuntur, praefertim quum viridis color eandem vix prodat, ipfa vero immota maneat, donec illa quibus inhiat, proxime accedant neque amplius effrugere poffint. Nutritur autem non tantum variis infectis, fed aliis quoque animalibus, quibus vincendis deuorandisque par eft. Quae vero motu carent non inuadit, nec etiam plantas arrodit; vbi autem ex hamo pendentia corpora mouer cernit, tunc quidem omnia, nec folum animalia mortua, fed varios etiam arripit fructus; quodf tamen quidquam, ipf minus gratum forte deuorarit, id vomitu mox eft redditura. Quod reliquum eft, admodum ranae hae funt voraces, quumque ipfis os et fauces valde hient, rana eiusmodi adultior tenellum pafferem, aliamue auem, nec non murem, haud raro adoritur, quemadmodum olim ipfe in Saxonia vidi, quum illis faepius huiusmodi animalia obieci. Quin ipfae etiam tenellae anates, a matre forte longius remotae, vix huius ranae effugiunt infidias. Saepius etiam in ventriculo harum ranarum duas tresue minoris fpeciei inueni lacertas aquaticas. Quidquid autem capiunt, id etian integrum deuorant, aeque namque minus ac reliquarum fpecierum ranae, vel arrofione, vel morfu, ex re quapiam abripere quidquam poffunt. Singula haec quilibet, pro lubitu, propriis videbit perfpicietque oculis, fi tempore illo quo gregatim in aquis commorantur, murem pafferemque, volatui nondum aptum, ipfis objecerit,

Vbi ranae hae coeunt., infidet mafculus $c c c c c$ nunquam non foemellac e ece e dorfo, quemadmodum 2 figura XIII Tabulae monftrat, ipfo vero fub coitu femper mafculi gek gek clamabunt; fimulac autem foemella oua fua $j$ per anum $g$ emittit, mafculus eadem fuo confperget femine, id quod ipfe domi meae non folum vidi, fed iteratis etiam vicibus fieri, non fine admiratione, obferuaui, quum, quemadmndum poftea videbimus, in hac ranarum fpecie yeficula feminales minores multo fint, quam in rana fufca terreftri, atque adeo non eadem feminis turgeant
Desmegen glauben, es fere im winter ben Froflden sex ) Xund sugervach fen, weil mait manchmalen im Fruth. jabr an felbigem eine zarte Sout lozgehen fiehet, fo trret er: Denn es pfleget Der Frofó um Diefe Beit aud feine alte 5 aut, wie ben Sommer wiber mebrmalen ges fhitehet, âlze einen Salleim abzulegen. Soitte er alfo

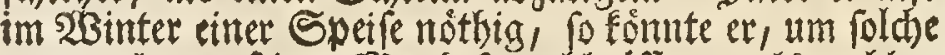

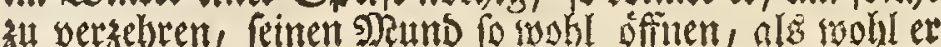
im Stand ware, wann er Rufft holen sollti, biefelbe

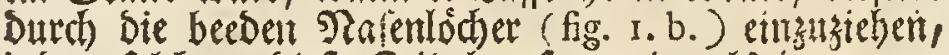
intom folde zu Diefer Beit eben fo wenig/ als jenty wer= fi)loffen fino.

Das BSebor if nebfe Dem Sbefiot bey unferem

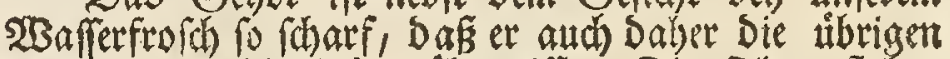

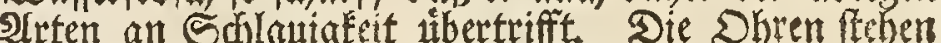

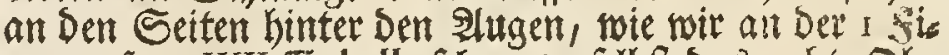
gur unferer XIII Tabelle Tehen, wofelbit Das recise Dhe

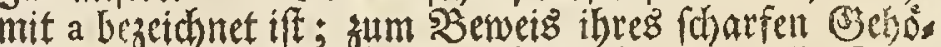
res aber Dient, Daf wern aud gleid eine grofe Ne Rens

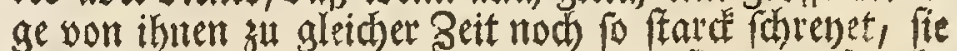
Doch auf eimmal fille fchweigen, went fie einell fremb. ben Schall verttefmen. Die beeden bellen uno mit (S)ds eingefaften $\mathfrak{Y}$ ugen fins fo runs und erhaben, und fteken am Ropf fo ftarce heraus, Daf Der Srofh alles was unt ihn berum vorgehet, and fich berweget, leichtlich wahrnimmt, wosu nod) vieles bentriget, bat

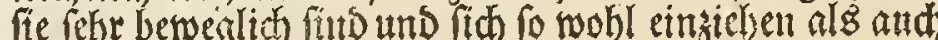
heraustreiben lafien. Daher nun Ean er Dasientige, mas er zu feiner sabrung notbig bat, aud leidtlid erba fhen zumalen Da ihn feitte grume Farbe nidgt forleich verrath, und er ganz unbemeglich fizen bleibet, bis ith Dasienige, woraaf er lauert, recht nahe getommen, duto nidgt leidt ment entwishen fant. Es beftehet aber ret. me siabrung nidht alleine aus mandherlen Sinfecten, forts Dern aud altz anbern Thieren, Die er zu bezwingen und zu viruduluen im Stand ift. Doeh padet er midits an wemn ez fith nicht beneget, und won \$flanzen beifs fef er aud nid)ts an, ausgenomment wern man nit ber Altgel etwas fir feinen 2uaen beweget: Denn Da fonap. pet er Dod nach allem, es mag num gleid ein todes Thier ober aud) eine Frudbt feun; follte er aber yon ungefä́s

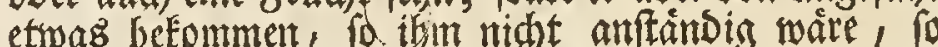
fuenet er felbiges bald wieder aus. Es find uibrigens Diefe Frofoche rebr gefrásig, und ibr weiter Sadben und

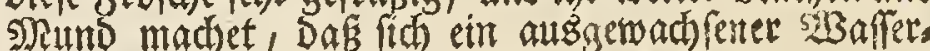
frofd mandmalen auch an einen jungen Sperling, oper andern Bogel und an eine Maus waget, weldaes if felbiten ehedent in Sadhen gerehen, Da idy isnen viels mals Dergleidien Thiere yorgenorffen. Ja wons noch

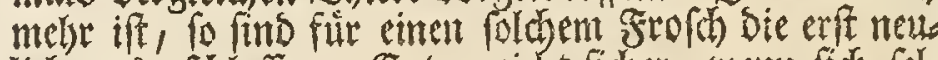

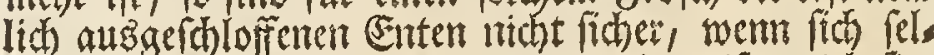
bige von ibrer s) Jutter etwann gu weit entfernet befint Den. Bielmals habe if auth in Dem soagen biefer Frofche zwen bis bren $\$ 3$ afferensexen yon Der flemerer

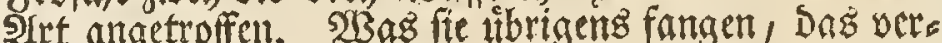
fohlucter fie sans, indem fie eben fo wentg als andere Frofharten etroas zu benagen, doer abzubeifen im Etano fino. SClles biefes, fan ein teder, Der Luft Das zu bat, felbft mit anfehen, soentr er Itur za Derienigen Beit Da fie fid in songe in $3 a$ fer beneinander auf halten, eine snaus ober einen jungen Sperling, ber now nidb) fliegen fan, ifinen sumerfen will.

พ3as Die \$aarung Des Wafferfrofhes anbelantgef, fo fizet ben felbiger Das Dảnnlein c c c c Dem 23 ciblein e e e e auf Den 5 Ruten, wie in Der 2 figur unferer XIII. Tabelle su feken, und wáhrems felbiger láfiet jenes ims meren fein Gisegeffer boren; fobals aber Das $2 B$ eiblein Den Raich Durd Den Ifffer $g$ von fich zu geben anfängt fobald fangt and Das saannlein an Denfelbigen mit feinem Saamen zt beforengen, wie id ben Diefer 2(rt Celbften in meinem Simmer gerelsen habe; wobes in zugleith bemertet, Dap foldes zu wiederboltenimalen 


\section{4):(5):( 57}

copia, infuper vero etiam vnus interdum mafculus duarum triumue foemellarum oua foecundet; huius autem fpeciei foemella, maiorem multo ouorum, minorum tamen, gerat copiam, quam ranae terreftris foemina. Addendum infuper eft, complecti ranam aquaticam foemellam fuam eadem prorfus ratione, ac rana terreftris, eandemque ob caufam obductum effe pollicem ipfius, coitus tempore, afpera illa, cuius fupra mentionem inieci, cute, qua quidem rana arborea minus indiget, quum foemellam anteriorum crurum pedibus fub alis comprehen. fam teneat.

Sperma, vel oua potius harum ranarum, coloris magis eft pallide flaui quam fufci : pars enim altera ouorum flauet, altera vero fufca eft; queniadmodum autem ouis ranae terreftris magnitudine cedunt, ita etiam minori glutinofa cinguntur fphaera. Simulac autem rana oua hacece emittit, in fundum illa defcendunt aquarum, vbi dein ad algam aliasque aquaticas plantas adhaerefcunt neque amplius in aquarum fuperficem afcendunt. Verfantur hinc plurimae harum ranarum, tempore quo generationis negntio operam nauant, mediis in aquis ftagnantibus ibidemque fecurae prorfus oua fua pariunt, Hanc iplam vero ob cauffam paucifimi harum ranarum norunt fperma, illique qui pharmacopoeos permate tantum aquaticarum viridiumque ranarum vti credunt, falluntur: qui enim fperma hunc in vfum colligunt, aquis ftagnantibus innatans fumunt, quod ipfum tamen ranarum terreftrium, quin aquaticorum bufonum eft fperma. Autumaui fic ego fimiliter olim, fluitare oua ranarum aquaticarum; quum vero ex eiusuodi ouis nullam vnquam ranam aquaticam, fed vel ranas terreftres vel butones obtinui, in eam deductus fui cogitationem, abfcondere ranas aquaticas fperma fuum; tandem vero ex hujus fpeciei ranis, quas domi in vitris feruaui, didici, cadere oua ipfarum in fundum ibidem poftea permanfura,

Refert fpermatis huius imaginem Figura prima $T a$ bulae $X I V$. Sunt vero oua haecce, fi proportionem fpectes, multo minora ouis ranae terreftris, licet rana aquatica hac ipfa longe maior euadat: quin cedit exiam quodlibet horum ouorum magnitudine ipfius ranae arboreae ouo; vix itaque cuiquam mirum debet videri, maiorem quotannis ranarum aquaticarum nafci copiam, quam terreftrium arborearumue: omnino namque fir verifimile, maiorem multo foemellan ranae aquaticae in vtero gerere partuque edere ouorum munerum, quam binarum illarum ppecierum foemellam. Vix albet giuten oua ex flauo fufca cingens, fed flauefcit potius; crefcit auten illud, aeque ac ouum, fenfim fenfimque mole, et poft tres dies formam fecundae habent figurae; duos alios dein poft dies, fimilitudine ad tertiam accedunt firuram, atque intra fphaeram glutinofam $a$, qua initio oua cincta erant, alia comparet eaque minor $b$, quae tamen vtrum vacua fit, an materia quadam repleatur, me quidem latẹt.

Pepererunt oua haecce ranae, quas domi in cylindraceis feruaui vitris, anno 1752. a duodecimo ad decimum fexcum vsque, Junii diem; iam vero vlteriorem, quạn poft-

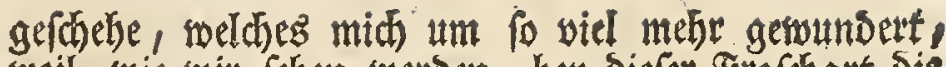
weil, wie wir fehen werden, bey Diefer Frofhart Die Saamenblåslein viel Eleiner, mito also nad) sDropor. tion nidst fo ftard mit Saamen, als bey Dent Erofrofor, angefuillet find, uns liberbent ein Mämulein mandimas

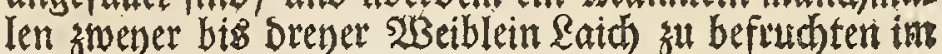
Stand ift; ein foldhes 2 Beiblein aber eime viel groffere

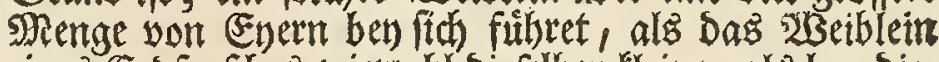
eines Erofrofhes, wienohl Diefelben fleiner alE ben dies

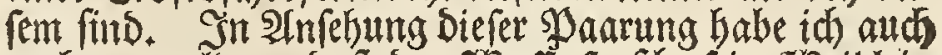

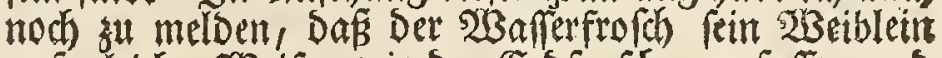
auf gleiche 2 Beife, wie Der Erofrofich, umfafe, uns DaE er eben Deşwegen aud), an fémen Daumen, zut Sparungéseit, Die oben angefíthrte raue 5aut babe weid)e ben Dem Raubfrofdi, wie bereits gemeldet wor Den, nitht nothig ift; weil er Das 2 Beiblein in bee Soble Der 2lfheln, mit Den Futfen Der vordern Shen dél, verte bålt.

Der Raid, ober wielmehr Die Eyer Diefer Frofód Gat eitte mebr bellgelbe als brame Farbe, indem die (5oer an Der einen Salfte gelblidit, an Der andern aber et.

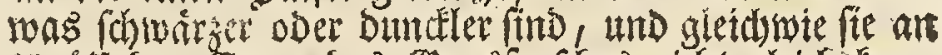

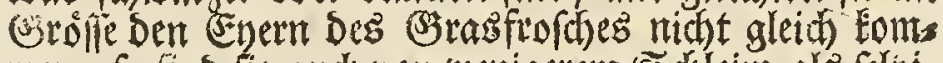
mell: fo find (te aud) von wenigerem Shlletm als felsis ge ungeben. Soball aber ber frofh Defen \&aids won

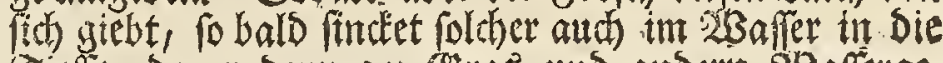
sieffe, Da er Denn am Bz'as und andern $23 a$ fiferge.

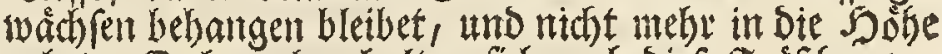
gebet. Daber aber balten fith aud Diefe srofohe, sut

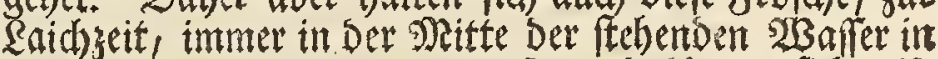
grofler gienge beysammen auf, uns Eonnen fid alfo gans fidser und ungeftóber ibrer Ener entlebigen. Ebent

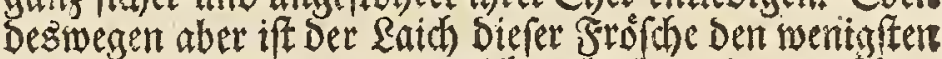
betamnt, und biejentigen weldje glautben, in Den श्रीpos theten wirbe Eein anderer Frofhlaid) als Der grinten

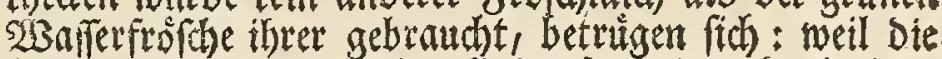
Reute fo foldhen zu Dierem Sinde fammlen, Denjenigent

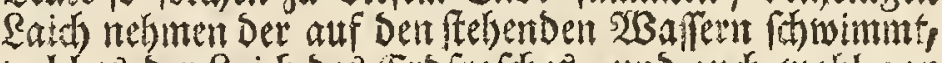
weldies ber Raich Des estofrofhes, und anth woh! gat

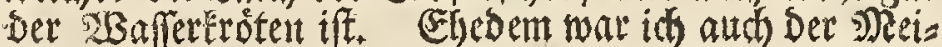
mung, Der Satb Des 2 Baferfrof fes fhwintme auf Dem

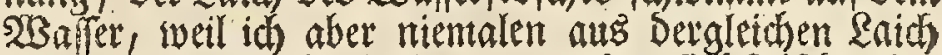
einen 23 afferfrofh, rombern entweder Erofrofdse obee Rrotent erbalten, fo Eain ích auf Die Sebanten, Die

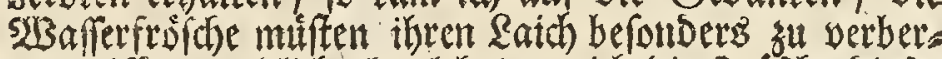

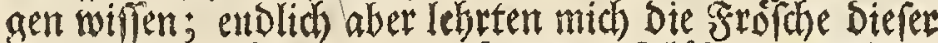
Irt, welche ich bey mir zu Saus in Şláfern unterbiel=

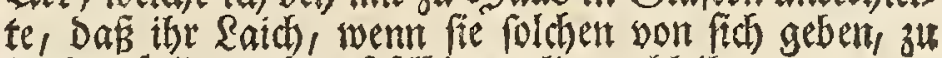
Boben falle, uns auf felbigem liegen bleibe.

İie Diefer \&aich eigentlich ausfehe zeiget bie erfte Sigur ber $X I V$. Cabelle. Er if liach 9 roportion viel Heiner" als Der Raich Des Evofrofhes, Dbgleich Der 23afferfrofd wiel groffer als Diefer wird; ita ein jebes Ey an uns yor fich ift aud mobl Heiner als ein En Des Raubfrofhes; Daher aber if es nicht an wunbern, Daf

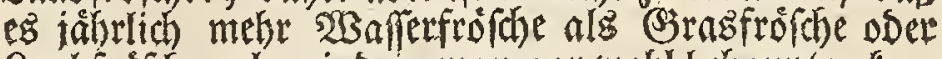

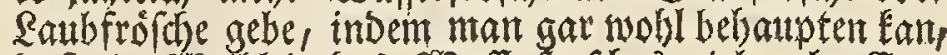
Dấ ein 23eiblein Dez 2 Bafferfrofthes viel mebr als bie beeden andern Sorten tit feinem Seib fuhte, uns son fich geben foonte. Der Shleim weldher Die gelblichtifhwarzen (E)er umaiebt, if bier nitht fo wold tweis als vielmethr galblichtbraut, beede aber werden nadi und nad grofier, uns erbalten innerbalb Drenes Tagen Das 2inesen Der sweyten Sígus, und nach bem

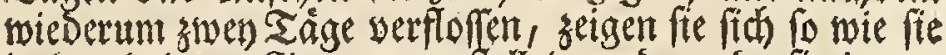
in Der sritten Figur yorgeftellet werden, Da fie inmers halb Dev erften Sablemtugel $a$ eime Kleinere b haben, von weldher id aber nidbe bebaupten fan, ob fie leer ober gefulllet ferye.

Den Laid woran id Diefes beobadtet, habe ic

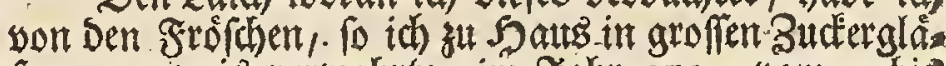
ferm parweis verwabrte, im Jabr $1752,40 \mathrm{~m} 12 \mathrm{bis}$ 
modum,ipfa aequeac gyrini inde nati, fubierunt mutationem, breviffimis indicaturus, non ipfos, quibus hoc vel illud obferuaui, notabo menfium dies, quemadmodum in hiftoria binarum praecedentium ranarum a me factum fuit: verendum enim foret ne hinc lectoribus taedium creetur. Poftquam itaque interior oua ambiens fphaera comparuit, reniformia illa euafere Fig. 4 ; non ita multo poft vermis eadem induerunt formam Fig. 5. ita, vt et caput et cauda confpicerentur, vermis vero minus extenfus incuruum feruaret fitum. 'Apparuit iam quoque, fitum effe, in ea ouorum parte quae flauebat, vermis ventrem, in fufca vero contineri caput, dorfum atque caudam: atque hos ipfos colores vermis poltmodum quoque diutius retinet. Interior fphaera quae tum adhuc cernebatur, mox poftea euanuit, ipfe vero vermis motu iam agitabatur. Poftquam fextae fimilis factus erat fiqurae, quae ipfum a latere refert; exteriorique glutinofae fphaerae adhuc inclufus haerebat, fortiori illum cieri motu notaui, licet caput $c$, nec non cauda $e$, obtufiora effent, venter autem flauescens $d$ admodum tumeret. Vbi tandem gyrini a glutine liberi aquae innabant, graciliores erant redditi, id quod figura feptima cum oftaua fic quidem monitrat, ve illa inferiorem gyrini fuperficiem, haec lateralem fiftat. Erant tum etiam caput caudaque fufci adhuc coloris, venter autem flauebat, et praeter baec jam quoque caudan cingens comparebat pinna.

Confumita nec non ex parte colliquefacta reliqua illa glutinofa materia, quae antea oua circumfuderat, huc atque illuc gyrini mei in vitro ferebantur natatu, fic, vt mihi nunc alio indigere viderentur pabulo. Paluftres igitur ipfis praebui lenticulas, quamuis autem vix animadverterim, eosdem hinc quicquam abrodere; femper tamen iisdem adhaefere, ipfum vero, quo augebantur, incrementum, teftimonio erat, fat ipfis lenticulas praebere alimenti: non enim tantum crefcebant, fed prodibant nunc etiam, vt in gyrinis fpecierum iam defcriptarum, in vtroque latere pone caput, fimbriatae illae appendices. Quemadmodum autem in rana fufca terreftri alius, quam in arborea, fuerant formae, fic heic quoque illas ranae terreftris nec magnitudine nec ramorum numero aequatunt; ab appendicibus autem ranae arboreae, quae tubulum fimplicem referunt, multum difcreparunt. Non ortae funt appendices hae fimul ex integro, nec etiam eodein tempore, fed prodibat viplurimum finiftra $g$ prior dextra $f$; licet autem initio parua tantum effet, maior tamen femper erat dextra, ceu nona indicatur figura; vbi vero magnitudine aequales factae funt, vt in figura decima, vix vltra viginti quatuor horas integrae manferunt: euanuit namque, elapfis illis, vt in figura vindecima, nunc dextra, nunc vero, et quidem crebrius, finiftra. Hoc facto innge alia gyrino erat forma, craffius quippe caput dilutiorem monftrabat colorem, venter veso contractior magisque globofus ex cinereo in nigrum vergebat, cauda contra longior a corpore magis erat diftracta. Videbantur infuper caput atque corpus tenui pellicula vel vefica potius cincta effe, quae aliquot poft dies melius difcerni poterat, atque etiam fusura duodecima ob oculos ponitur. Pellucebat pellicula haec ita, vt integrum gyrini corpus cerneretur; apparebant iam etiam in capite oculi non tantum, fed infuper litteris $i$ i fignatae, binosque paruos tubulos referentes nares: Quum vero iam paluftres lenticulae gyrinis meis fufficere vix viderentur, lactucam ipfis dedi, qua quidem, vt cibo ipfis gratifimo, plurimos eorundem tamdiu alui, donec hunc cum alio, quem ranis regnum fuppeditat animale, commutarent.
Den I6 Sunii erbalten, uno nun will id bie tibrigen Beraindertungen Deffelbent und Der Darauz Eommenden פBitrmer, fo viel moglid, auf Das firzefte befhrieber, ofne allezeit bie \$lonatztage Daben za bemerden, wie ich ber B Befdreibung Der beeden vorbergehenden Frofd arten gethan; weil id befurdste, cs mogte foldses Den Refern serontiflich fallen. - Rachdem num allo an mei. nen (E)ert Die innere Rugel jum SBordhein geFommen, warben fic nierentormig, Fig. 4. balb Darau aber zeig.

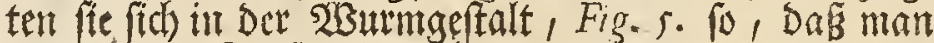
bereits Den Sopf und Sthwans erfennen fonnte, Dev

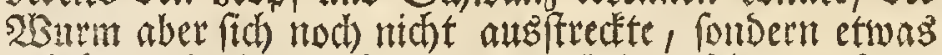

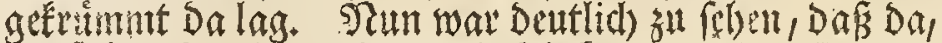
wo fich in Den Eyern Der gelbe Stecte zeigte, Des 230 urms Saud) Sene, Der Duntele aber yon Dem Ropf, STuten

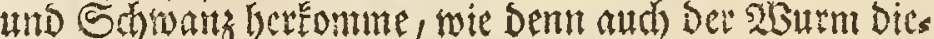
fe beeden farben nod lange nadher behált. Die innes re Jugel, weldhe zu Diefer Beit tod zu feben mar, yers

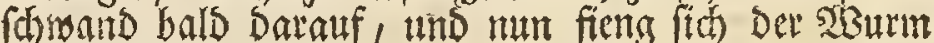

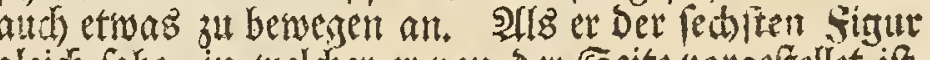
gleid fabe, in welther er yon Der Seite vorgeffellet ift, und noch yon Der áuferen Schleimkugel umgeben war,

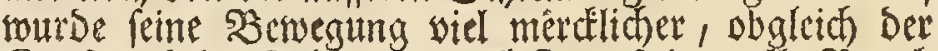
Ropf cumo Der S fimanz enod) ftumpf, Der selbe Zand aber $d$ zienlid bicf gemefen, went er fid aber nid)t bes

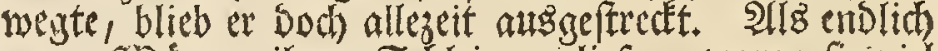
meme sistrmer ifren Shleim berliefen, waren fie viel raliniger, wie bie fiebende unto adte figur zeiget, yon welchen fente Don 5 surm nach feiner untern Slàd)e, uns Diefe von Der Scite vorfterlet, und Damals war Sopf mnd Sdiwan; แod) Duntel, Der Baud aber gelb; aud rabe man bereits Die Den Edwanz umgebende Floffe.

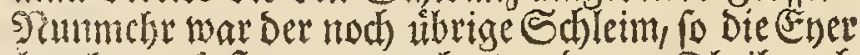
umaeben hate, fort ganz yerzebret und zum Theil aud

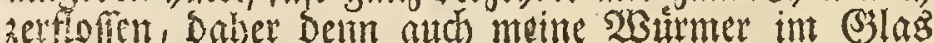
Gith und ber za fchminnten anfiengen, unto tine andere

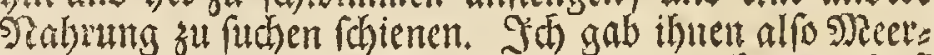

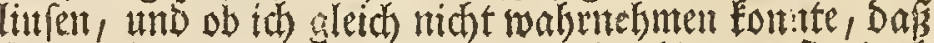
fie bou felbigen etrob abnagten : fo biengen fie Doch immertu an ibnen, und ifr zunehmentes 23 ad 3thum

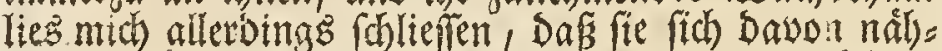
reten: Deim es vermeterte fich) nicht nur ibre (Stroffe in etwas; ( fondern fie befamen nut aud), gleid) Den siburs mern Der beeden bereits befhriebenen Sorten, an jeder

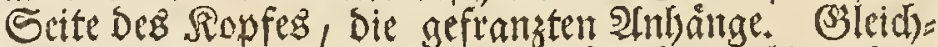
wie aber Diefelben ant Dem Eerdfrofh) anbers als ant Dent Enubfrofd ausfaten, fo waren fie auch hier wieber et. was Eurger als alt Dem Evofrofh, und hatten ibers Dem wentigere 2lefte; mit Den 2infinangen ber Laubfrós fiche aber, wellise mur aus einer einfachen Rointe beftes

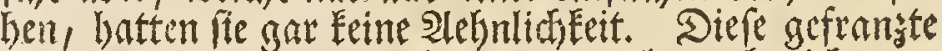

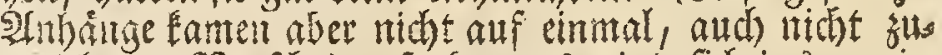

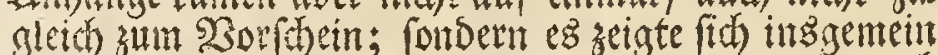
ber linate guerit und war anfangs gant Hlein, Gernad aber folgte erfit ber red)te; Dather Denn audh Der linde wie in der neuten Sirtur, allezeit groffer als ber red). te f war, und went fie emander, wie it ber jelenden Sisur, an Broose gleid fahen, ro blieben fie nicht mels iber viet und swantis Stunden in ibrer 2 Bollesmment. beif indem fid nach Berfus Derfelben einer Davon, and zwar mandhmalen ber red)te wie in Der eilften figur, offters aber Der linde, bereits verlohren Gatte; bicrailf aber erhielt Der 23 mm einte siemlid verinderte (S)eftalt intoen fid Der Ropf Deffelben nidst alleine Didfer nito heller zeigte; [ondern and Der $\mathfrak{L e i b}$ mefre zufnmmen ge Choben, rumber unt fitwarsbraun wurbe, Der Sd)wan aber länger und melse abgefezet war; aud) (d)tene eż, als ob Der Siopf zurammt Dem Letb mit einer zarten Shaut, wie mit eimer Blafe untgeben ware, weldes fich fonder: lich nach etlichen Tigen gan' Deutlid wiefe, wie Die 3wolfte Sigur auziveifet. Durch Diefe zarte Saut wat Der Rorper vollemmen su fehen, uns in Sem Siopf 
Tab. $X V$.

06
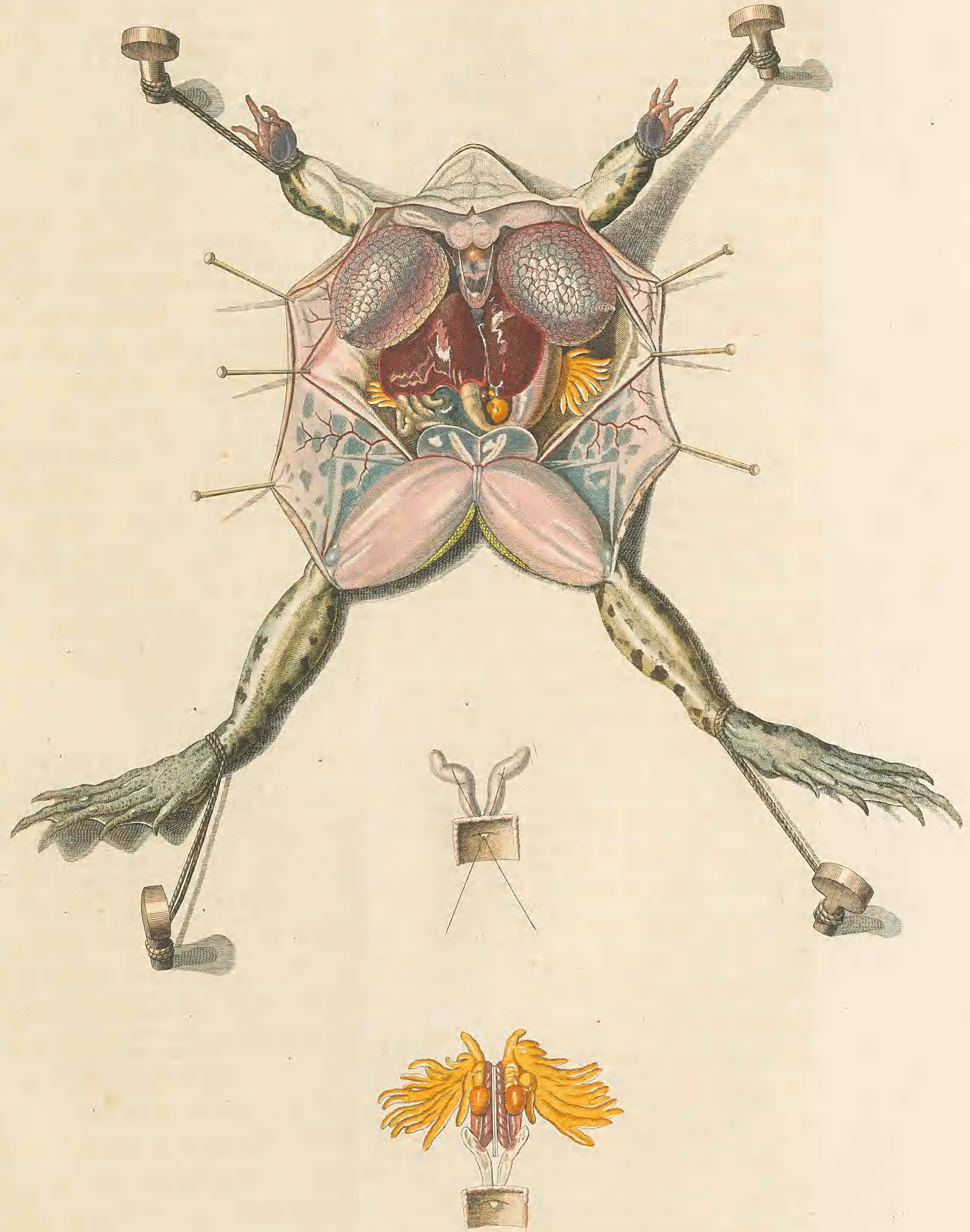

A.9.Rofel fec et exc. 

Frg. 4 .

setax

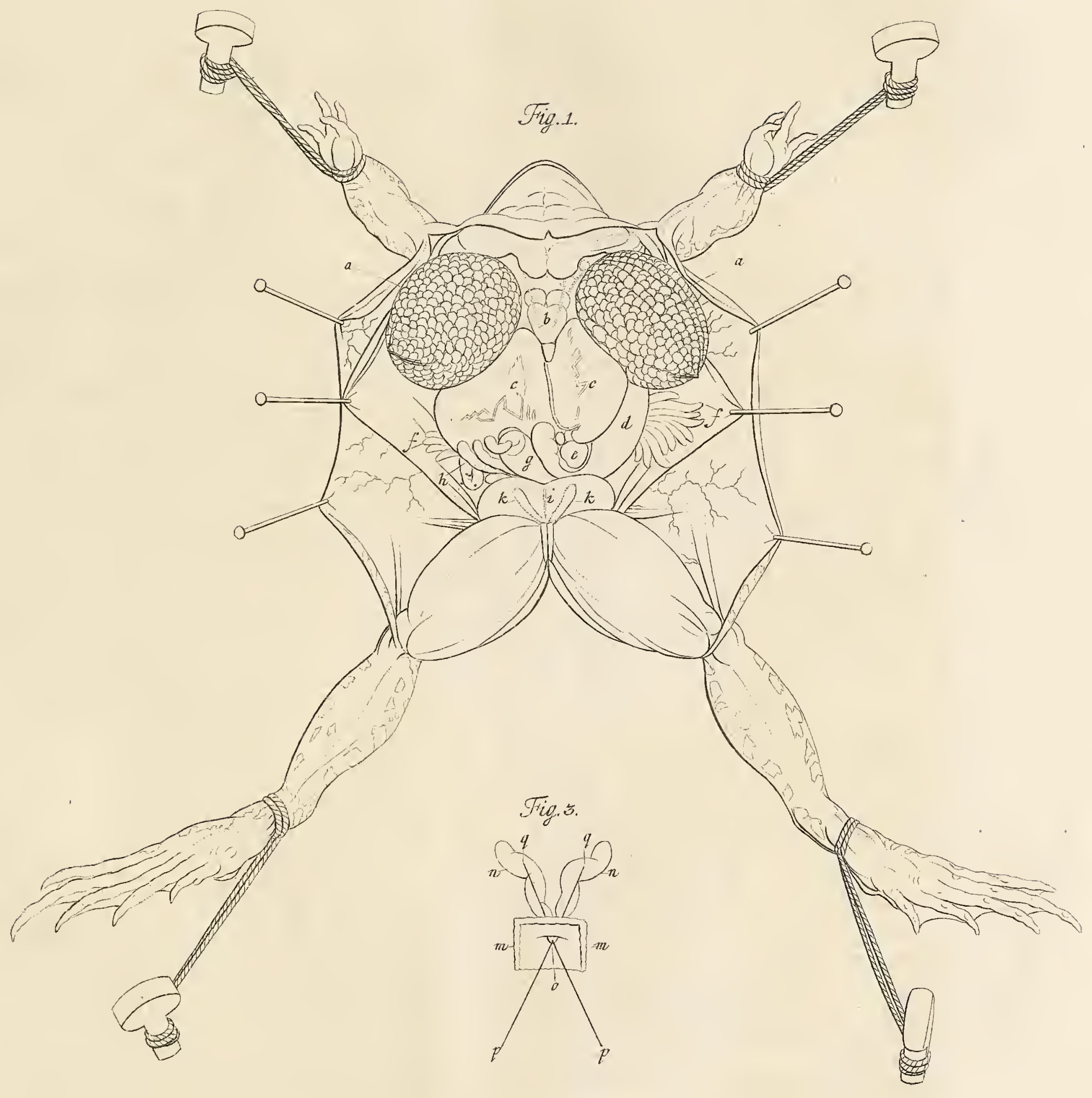

Fig.2.

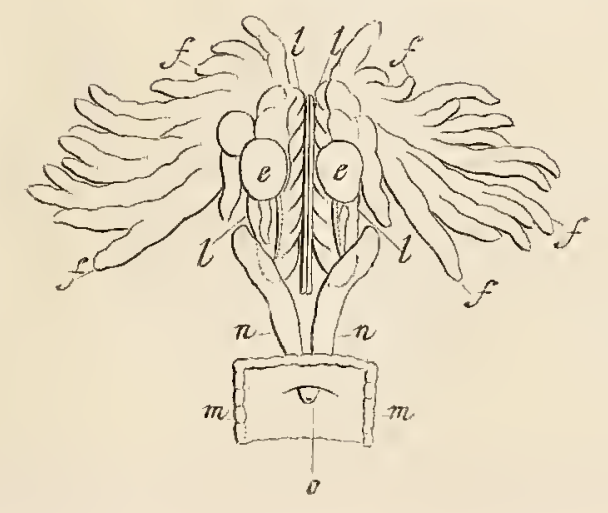





\section{4.}

Maximam quam poftmodum gyrini mei paffi funt mutationem, figurae fiftunt decima tertia nec non decima quarta. Monttrabant tum rutilantes oculi pupillam, inteftinumque rectum faecibus femper erat repletum; licet easdem crebrius gyrini emitterent. Vbi vero in magnitudinem fivurae decimae quintae et decimae fextae excreuere, quarum illa gyrinum a latere finiftro, haec vero ab inferiore fuperficie fiftit, quoad ftructuram ipforum fequentia in ipfis occurebant notatu digna. Praeter ipfam enim magnitudinem auctam, eminebat nunc, in finiftro tantum latere, in "dextro nunquam, pone oculum inferiora verfus, fingularis quaedam pars, paruam, candidam menbranaceamque referens veficam', fpiraculum potius dicendam, per quam gyrinus, aeque ac piicis, per branchias, aquam ore hauftam rurfus propellebat, id quod aquae hinc orta agitatio fatis fuperque docebat. Vix huius veficae patet orificium, nifi gyrinus caudam contemplantis oculos verfus habeat directam, tunc enim ipfum velicae introfpicimus fundum carneo, vt huius gyrini os, colore tinctum. Oftendunt figurae, decimia qun $a$, decima jexta \& decima nona fpiraculum hocce littera $l$ fignatum, illoque gyrini tam diu funt inftructi, dum quatuor ipforum procreuerint pedes. Iam etiam in inferiore oris labro aderat tenuis quaedam nec non acuminata pars, vid. Fig. 15. 17.18 . et $19, \mathrm{~m}$, cuius ope hi aeque ac illi priorum fpecierum gyrini, ad omnia, quae in aquis offendunt corpora, adhaerefcunt. Apparebant praeterea, fcabrarum inftar papillarum, pofteriora verfus, corpus inter caudamque bina pofteriora crura, $n$ Fig. 15. 16. maiora poftmodum, teftantibus figuris 17. I8. I9. fenfim fenfimque fumentia incrementa.

Licet vero gyrini mei initio quidem, dumque ad decimae quartae jugurae excreuerint magnitudinem, fat celeri augerentur incremento, tardius tamen poftmodum proceffere, tardius etiam perfectae ranae induerunt formam; quum itaque copiofiorem eorum numerum nutrire, nunc fere me taederet, tot tantum alui, quot meis obferYationibus continuandis fufficere videbantur.

Similes erant gyrini mei, Augufto menfe, figuris decimae Septimae decimaeque ortulute, menfe vero Septembri vndeuigefimae. Erant etian tum temporis pofteriora eorundem crura multo quidem maiora, hondum tamen perfecta. Fiebat nunc quoque color in fundo dorfi magis fufcus viridefcensque; ad latera flauefcebat; in fuperficie inferiore caeruleicebat; omnis vero corporis fuperficies, fubflauis, rubellis diluteque cineraceis confperfa erat punctis. Cernebatur porro in inferiore fuperficie ipfaque in regione thoracis, fub cute, cruda quafi caro, quam guidem anteriora cenfebam effe crura, nec fallebar: fub finem namque Septembris, fubque Oetobris initium perfecta illa, cute licet tecta, in plurimis gyrinorum confpiciebantur, quemadmodum ad oo ex vigejima patet firura. Verfabantur tunc gyriní mei circa fuperiorem potius aquae fuperficiem, quam in illa; vbi vero natabant, crutibus vtebantur porteriotibus, ad modúm adultiotum per- murbe man lest nid)t alleine Der 2 lugen getwahis, pribern

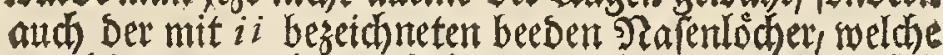
aleidfam swen Eleme SRóbren vorftelltent. Syeil fich aber meine 2 Burmer nummelir an Den seerlinfert alleine nidht begnigen wollten, fo legte idh ibnen and Sarten falat bor, welchen fie fich fo wohl fichecken liefien, Das this stele Derfelben fo lange Damit erzod, bif fie Diefe Speife mit Derientgen fo Die Frofobe fons in abierreid firden, verwechielten.

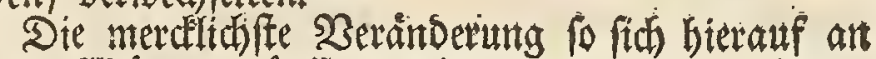

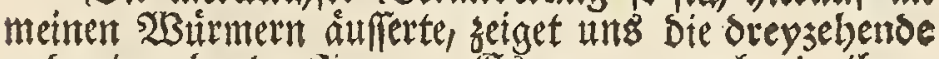
unt vierselyende Sigur. Es war nunmehr in ifrent

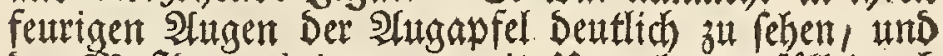

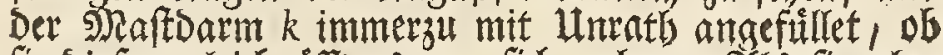

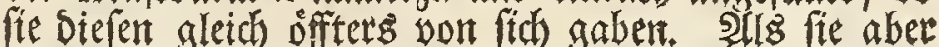
Die (s)rofie Der funfsebenden unt fechsebenden figut erbalten batten, son welcher jent ben SBurm yon Dee linden Seite, Dére aber won Der untern Fláche vorftel let, fo war in -2fnebung ifrer Structur folgenbes at

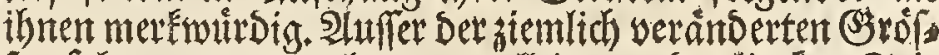
fe, fahe man numbers, mur alleine an Der linden Sei te, ntemalen aber an Der red)ten, Ginter Dem 9 Inge nad unters!", enen bejondern hervorragenden Theil, Der et. ne fleine, weine, biutige slare vorferlte, in ber That

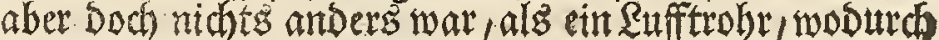
Der şurm, wie bie Sifhe Durdh ibre Dhren, Das eins gesogene wafler wieber von fith trieb, weldes bie in

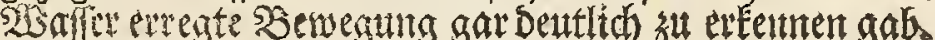

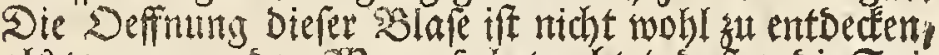

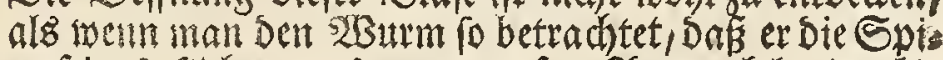

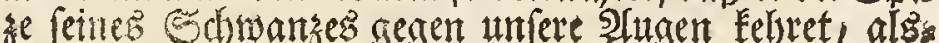

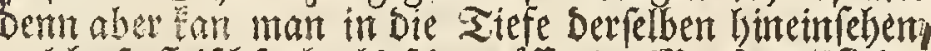
welche fo feifhifarb als fein geofineter s) and ansfiebet. ess if Diefs: Rufftloch an ber funfsehenden, fechselsen

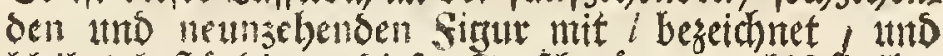

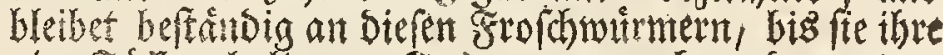
sier sine erbalten. Scerner war auth an ber untern Rippe Des shundes eine zarte Spize in, Fig. 15.17.18.

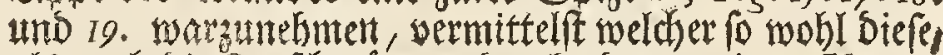

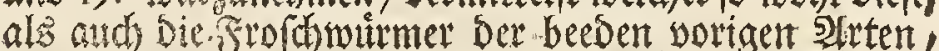

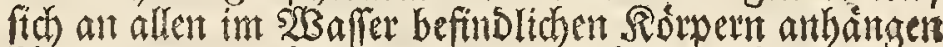
fơment. Uberdem fo Eamen mun aud Die beesen bintern

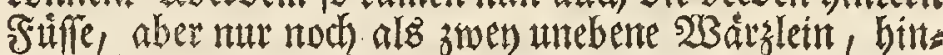

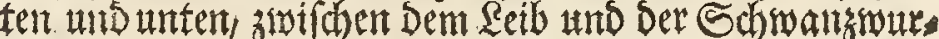

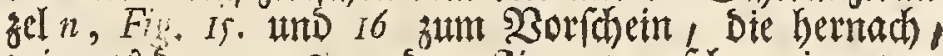
wie aus ser 17.18 . ant 19 Sigur zu erfeben, immtersu groffer und frourcerer nurben.

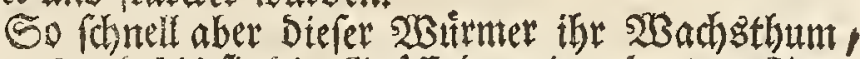
anfangs und bis fite Die (Sroffe Der viersebenden Sigut erreichet, oor fich uieng; fo langlam nalmen fie, nachs gebenos unt bis fte die vollige Frofchgeftalt erbalten,

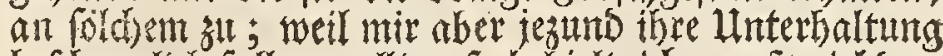
befowerlich fallen wollte: fo bebielteich mur fo stel Der: felben, als idc) zu meiner Unterfuthunts fưr nothis bitlte.

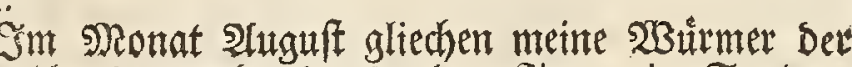
fiebensebridoen unt act tohenben finur, im Septem. ber aber Ser nenusebenden, ju weld)er Jeit Dann auth Die hintern Fuifie bereits siemlich. ftarce, aber Dodh nod

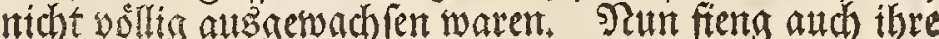

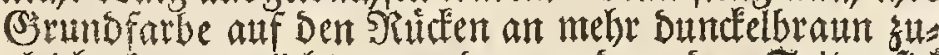
gloid aber graulicht za werben, dunt an Den Seiten fiel felbtae etwas in Das gelbe und róthlide; an Der untert Gládbe bingesen war fie blaulichtgrau, liber and liber aber zeigten fich an felbigen gelblithte, rottylidite unto hellaraue SDuncte. Iest fabe ntan aud an Der unters

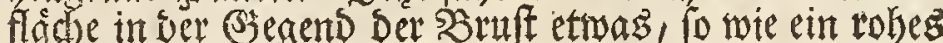
Sleifh Durdh Die Sonut fdimmerte, weldhes id) meinen Bermuthen nath fur Die swey worbern Fiffe bielte/ wo

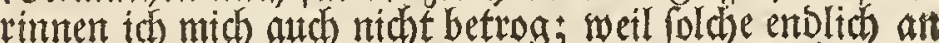

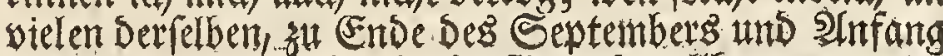
Des Sctobers, in eben Diefer Begend solleommen unter iD 2 


\section{(6) 60 ):}

fectaru mque ranarum; nec ulla iam indigere videbantur cauda. Die tandem vigefimo tertio confpexi in gyrino quodam, tempore matutino, crus dextrum anterius, atque hoc per eiusmodi prodierat aperturam, qualem in tunica manicata, altera manicarum ablata, cernimus; poftridie vero comparebat horis meridianis finiftrum quoque crus, et fic tes fefe habebat cum reliquis gyrinis, quorum dein cauda cum pinna annexa fenfim fenfimque decreuit, donec tandem a die trigefimo primo Octobris ad diem quar.tum vsque Nouembris prorfus euanuerit.

Patet ex hactenus dictis, gyrinos ranae aquaticae, licet initio citius augefcant, tardius multo crefcere tardius etiam in veras mutari ranas, quam illos ranae terreItris arboreaque. Quodfi enim obferuationes meas anteriores cum pofterioribus hife comparemus, deprehendemus, creuiffe gyrinos ranae terreftris a vigefimo et vigefimo primo Martii ad duodetrigefimum vsque Iunii diem; sanae vero arboreae, a fine Aprilis ad fecundum vsque Augutti, atque adeo binas hafee gyrinorum fpecies trium, et quod excurrit, gyrinos vero ranae aquaticae quinque fere menfium fpatio in ranam adoleuiffe. Quum vero amiffa cauda vix maiores effent quam tenella ter reftris rana : credibile eft, multum iuuari folis calore ranarum incrementum eundemque efficere, vt gyrigi ranae aquaticae initio quidem citius, poftmodum vero, et praefertim menfe Oetobri, tardius crefcant.

Poftquam itaque ranam aquaticam ab ouo eduxeram parum curabam tenellas meas ranas, atque hinc binas tantum per hyemem eram feruaturus. Indidi hine in vi trum, in quo degebant, praeter paullulum aquae, caefpitem quoque, vt fcilicet haberent vbi extra aquam commorarentur, nouamque quem ipfis praebebain cibum mufcas puta aliaque infecta, faciliore opera capere poffent. Quum vero iam hyems ingrueret, qua omni abftinent cibo, vix efuriebant. Corripiebar tunc atroci morbo, ita, vt nullam neque neceffariis negotiis, neque ranis hifce darem operam, factum vero hine eft vt hae, quum vitrum in quo habitabant extra feneftram pofitum effet atque ex improuifo maximum oriretur frigus, ab hocita afticerentur, vt mortuae effe viderentur. Vitro vero in hypocauftum calidius translato, reuiuifcebat altera earum, alter morti in praedam cedente. Illam poftea in cellam iufli portari, vbi totam hyemem, omni absque cibo, viva transegit. Minus interim creuerat, quod tamen nemo mirabitur, atque adeo fub veris initum maior non erat figura vigefima prima, eandem vero magnitudinem habuerat etiam autumno elapfo; inter illas autem aquaticas ranas quas eodem tempore ex ftagnis afferendas curaui, teneriores eilisdem erant magnitudinis. Enim vero augentur ranae hae lento generatim incremento, id quod reliquae Tabulac $X I V$. probant figurae, Siftit quippe vigefima fecunda ranam eiusmodi biennem, vigefima vero tertia quadriennem; illa contra quam figura vigefima quarta monftrat annos habet quinque, hac autem demum aetate generis propagationi aptae funt ranae haec. Litterae pp indicant hic nares hac in fpecie fat patulas, $r$ aurem. Si quis vero de varia harum ranarum aetate dubitet, hic fi verno tempore fufficienti ranarum numero captando operam
Der Saut zu feben waren, wie aแล ber 3wansigften fis guu ben 00 ertellet. 811 bierer Beit bielten fio meine

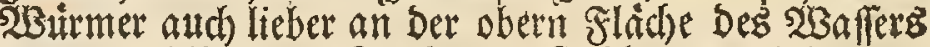
als unter felbigem auf, und went fie fhiwamen bedienten fie fich biezu ithrer hintern friffe, wie ein slter ausges

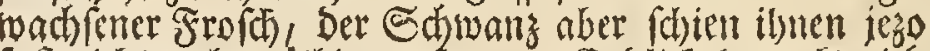

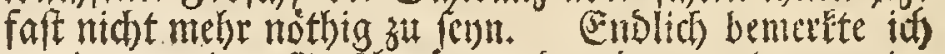

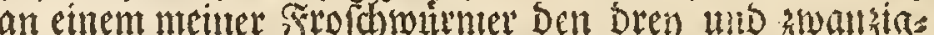
ften Detober, Des Sargens, Den rechten Doroern Stts, welcher zu ciner foldhen Deffnung beraus lann, Dergltie chen fich an einem SRodk zeiget aus weldhem ein Erntel getremet worden, und bes folgenden Sange nadjutt.

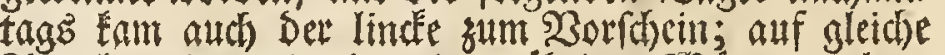
2lit aber gieng es mit meinen ubrigen 23 sirmern eben= fals zu, an meld)en autd) nod) won Diefer Beit an Der

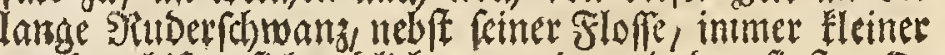
wutbe, bi er fid enolidy wom ein unt Drevfigften D: ctober bis ben vierten Nopember vollis verlohr.

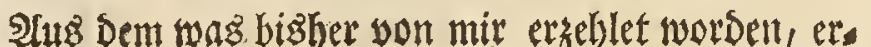

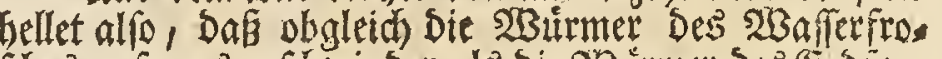

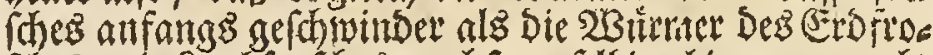
(h) gehenos viel langfamer zuntebmen, und baber aut pater ibre Frofhgeftalt erfalten. Denn bergletchen wir bie vorigen sseobat)tungen mit den hiet angefiblys. tell: fo werben wir finden, bafi bie 2 Butrmer Dez erd fros (c) es vont zwansigften uno ein uno zwanjigften Inartit biB Den adjt mo sivansigften Tunii; Des Laubfrofhes aber, wom Ende bez stprilz bis ben zwenten 2rugufti gewad) fen, unt da ás allo Diefe beede Sortent etwas uiber

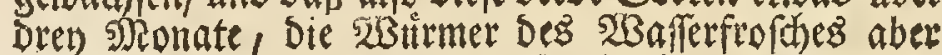

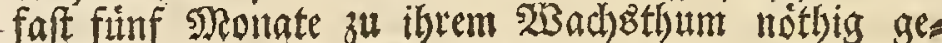
babt. Da fie aber Deswegen nach abgelegtem S dhwang

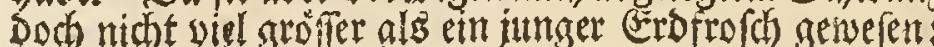
fo follte idh faft glanben, Das Das 23 ad) sthum ber Yro: (h) yon ber Somenmentrme vid befórbert werbe, umb

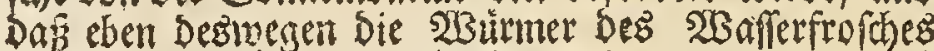
anfangs gefhwimb, nachigebens aber, und fonderlich in Detuber langlamer gewahien.

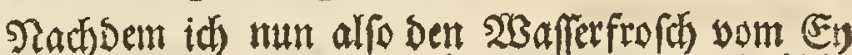
an ersogen batte: fo adtete id meiner jungen Srofotse eben nicht mebs uns bebielte alfo nux nod ein soar Derfellen mit Dem $\mathfrak{B o r f a t}$, fellbige Den 2 Binter bins Durd aufzuberjalten. Su Diefent Ende gab id ihnen in bas SJlas, worinnen fie fich befanden, nebit etruas SBaffer, audh einen $23 a f e n$, ber ibnen Dazu Dienen fols

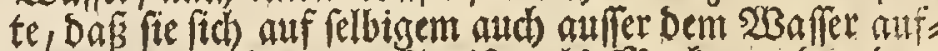

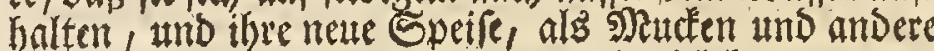
Gnfecte, womit ich fie verfabe, um fo viel beanemer er. bafchen fonnten; miewol fie nach foldher, weil bereits Der $5 \mathbb{B}$ inter, ben fie allezeit mit Faften zubringen, yor Der Shure war, eben feine groffe 3 enterde beseigten. Itnterbeffen wurde idb yon einer febiweren. Sirandbeit be

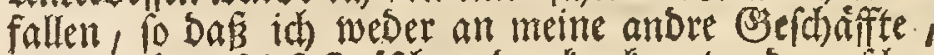
noch aud an biere seróche gedendten Eonnte, Da gefdias he es mun aber, baś bierelben, weil Das Glas worimen fie waren yor Dem senfter ftumbe, unb auf eimmal cine groffe Ralte einfiel von Dem froft fo mitgenonment wurden, Daŝ fie beede tod zu fenn fohienen; jebod) als Das Silas in die warme Stube geftelletworden, erfolte fich ber eine nieser, Der andere aber blieb tod. Jenen liế idh hierauf in Den Reller bringen, wofelbft er ben ganzen 23inter hinourh, obne alle Rabrung geblie. ben. Interdeffen hatte er, wie leidt zu wernutlen, nidht sugenommen unto twar alfo, nit anbrechendem

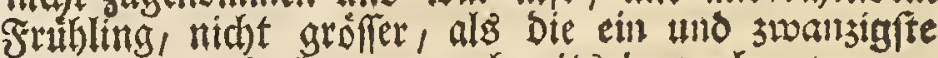
Finut, fo gros aber war er bereits int vorbergegange. nell Soebft genefen, atno unter Denienigen, welche ith

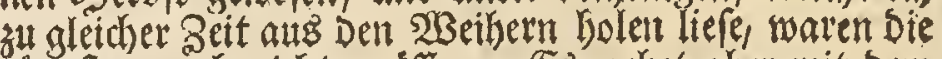
jungiten auch nicht grófier. Es gebet aber mit bem

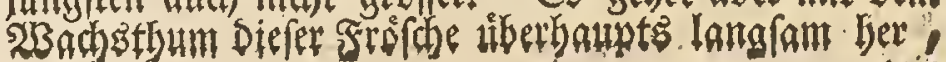




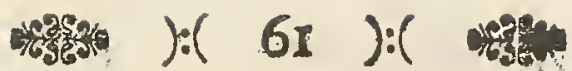

operam fit nauaturus, facile deprehendet, dari harum ranarum fex ad minimum, quoad magnitudinem, diuerfas fpecies: quodfi dein idem per aliquot annos fit iteratu* rus, magis adhuc de dictorum veritate conuincetur.

\section{SECTIONIS III.}

\author{
CAPVT II.
}

\section{Defcriptio partium internarum ranæ viridis aquaticæ.}

$\mathrm{P}$

oftulat Ordo quem hactenus obferuaui, vt nunc internas quoque ranæ viridis aquaticæ monftrem par tes; quod licet nonnulli fuperuacuum forte fint habituri, quum haud alias exhibiturus fim partes, quan quas in binis prioribus vidimus ranarum fpeciebus: hinc tamen operæ precium effe videtur, quod, quemadmodum rana viridis aquatica $a b$ illis quoad ftructuram externam differt, fic quoque internarum partium ftructura variat; præter hæc veroapparebit ex ipfa earum contemplatione, nec in hac ranarum fpecie alias, quam in illis, generis propagationi aptas adefie partes.

Aperui eum in finem, tempore quo ranæ hæ coire, partesque earum perfectiflima effe folent, mafculum aque ac fomellam; vifuri hinc fumus in quatuor illis $X V$. Tabule figuris, ipfas eas partes, quæ in mafculo præprimis notatu dignæ funt, non exclufis illis quas cum fœmella communes habet.

Siftit itaque prima fioura, XV. Tabule iconem maf culi in inferiore corporis fui fuperficie aperti. Prius tamen quam partes in eo contentas enumerem, monendum duco, notari debere hac quoque in figura cralliorem pollicum, anterioribus in pedibus, partem: non folum enim hoc tempore, menfe nempe Iunio, æque ac terreftri in rana, afpera eft, fed tumet quoque; attamen non, ut in illa, nigrefcit. Sat ceterum robufta funt, tam anteriora quam pofteriora crura, præfertim vero femnra pofteriorum adeo craffa circumdata funt carne, vt facile pateat, cur tantum ranæ hæ iisdem, præ reliquis, exferant robur; quin fit etiam verifimile, excitaffe opima hæc carnofaque femora, eius, qui primis ranis vefci aufus eft, appetitum, ut eadem in cibum adhiberet.

Partes internæ, quæ diffecta hac in rana, confpectui noftro fefe fiftunt, duplicis in genere funt fpecici: vel enim ad partes pertinent quas vitales appellare folent; vel ad eas quæ animali in corpore actionibus naturalibus funt dicatæ. Vitales funt cor atque pulnones; naturales he- wie die auf unferer XIV. Tabelle noch tibrige figuren beweifen. Denn die swey und 3wosnzigtie ftellet einen

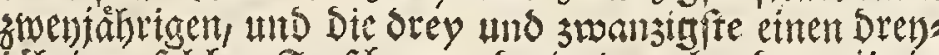
jabrigen foldgen Frod wor: Derienige aber Den wir in Der vier uno zwansigiten figur feben, ift volfemmen finf Sabr alt, uns in Diefem Sllter ift Der 2 Baflecfrofd erfin in Stand rein (Serdidedt fortzuflanzen. Die Şudhraben $p p$ zetgen in otefem Frofch, Die an Diefer

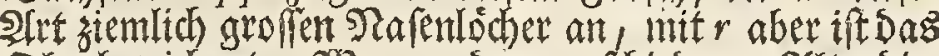
Obr bezeidnet. SBer an Dem yerfochedenen suter bie. fer Frófbe zweifelit wollte, Der Darf fid mat die Shibe Hebmen unb int Fribling eine gentgfame sinenge von

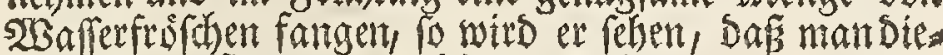
felben wentaftens yon fedjarlen Sroffie finde; follte er aber foldses efliche Sabre binter cinander thun, fo wird

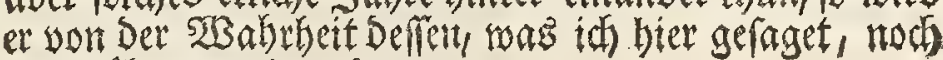
mely uiberzenget werben.

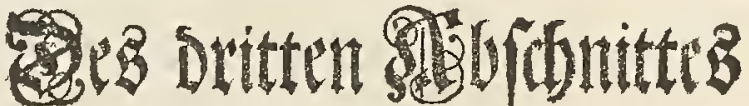

\section{.3weytes Capitel.

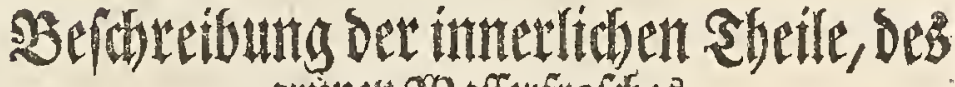 grituetits 2 afferficoides.}

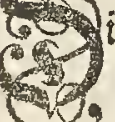
binmal angefangene Dromung heifhet bon mir, Dafi ich nun anth Die inmerent shetle Des gruiten sibafierfrofthes anzeige; ob nun aber foldhes gletd eintigent etwas liberflifiges zat fenn focturen mogte; in sem id feite andere Shetle werbe jeigen Eosmen, als

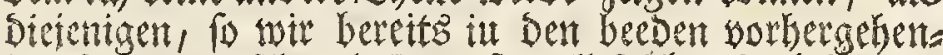
Den Sorten geiefen baben: fo will folches Dod Desme=

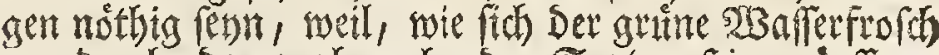
yon ben beesen sorbergebenben Eoten, fenter antferen

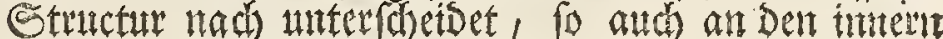

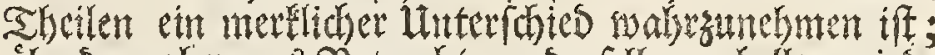
liberDem aber aus Betradtutung Derfelben erhellen wirs,

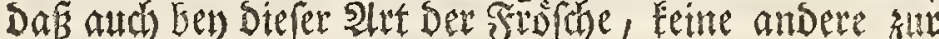

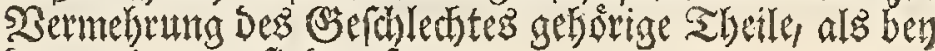
ben vorigen zu findent rewen.

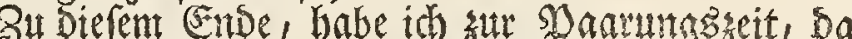
alle Thbeile Der frofoche ant bolleommenten ftro, fo wohl

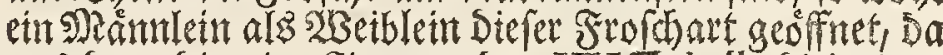
uns Dem Die viet Siguren Det $X V$. Cobelle Dieientgen Theile zeigen werden, weldhe insberondere alt Dem 5 sam lein bemertet zu werben verbienten, wober fedod anth

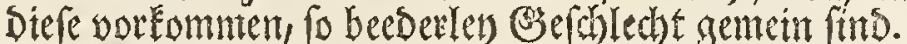

SBir feben alfo in Der erfent Sigut Diefer $X V$. Cas belle Die 2lbbildung eines an Der untern Fláche bes Ret bes aufachnittenen spantleins. (Ebe id aber die Theile felbft fo in felbigem enthalten fino, anzeige: fo

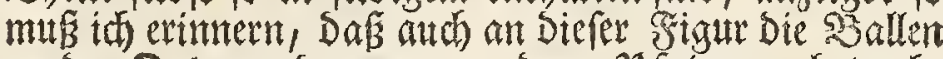

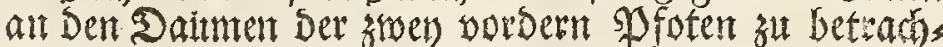

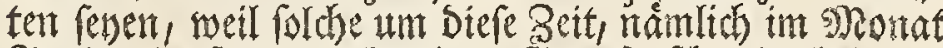
Sunto, ebenfals, wie bey Dem (Srasfrofd, siemlich rau

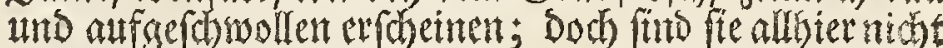

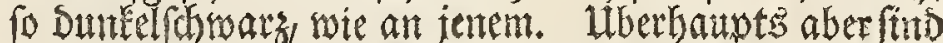
fo wohl stevordern als bintern Fufe an Diefem Frofb

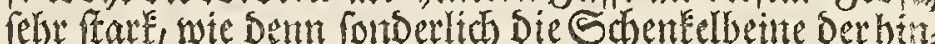
tern futfe mit Fleifh Did bewad) fen find, woher eg Dem nicht uttr alleine fommet, Dafí Derfelbe vor andern $2(r$

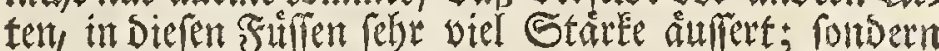

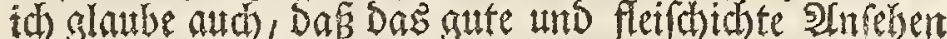
Diefer Stheneerbeine, bey Dem erfent Der fith Frofdhe zu effen geliffen Iaffen, ement 2lppetit zu Diefer Spete er: weder habe.

Die intern Sheile, welthe in Diefen autfgerdanitte. nen Frofh zum হorfhem Eommen, find iberbaupts

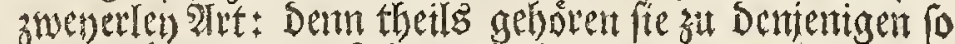
untumgånglich zum \&eben erfordert werden, theits aber

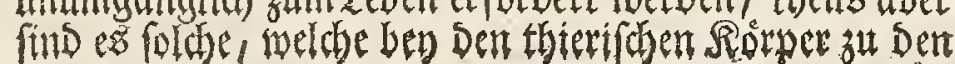
natur 
par, ventriculus, inteftina partesque reliqua in fequentibus indicandx. Pulmo, vel prioribus in fectionibus faepius a me ita dictæ veficæ pulmonales $a a$, quæ in rana, dum inciditur, ob infpiratum aerem ftatim valde extuberant, formam extremo apice imitantur papillarum, nierisque conftare videntur veficulis, quas plurima difterminant fanguifera vafcula; intra tamen, vt in rana quoque terreftri (Tab.V.Fig. 6.) monftraui, cauæ funt; veficulæ vero apum referunt fauos. Cor $b$, inter binas veficas pulmonales pofitum, atque integra in rana contra onines iniurias externas fterno munitum, inuolutum adhuc eft pericardio fuo, hinc etiam maiora vafa ipfi cohærentia non confpiciuntur. Minus ceterum rubet quam in binis præcedentibus fpeciebus, fed diuturnior in rana etiam aperta, quam in illis, ipfi eft motus, quin fi ipfi etiam ranæ euellatur, hæc tamen integram fere viuit diem, id quod $\&$ in hiftoria ranæ terreftris me indicaffe memini; heictamen repeto, quum id ipfum \& in illa \& in hacres mihi vifa fuerit fumma admiratione digna. Monftrat fefe ipfo fub cordis apice velicula fellis ex parte tantum, maximam namque partem hepate eft cooperta. Ipfum hepar $c c$, hac in rana valde eft magnum, hinc etiam haud exiguum corpotis replet fpatium, ceterum fufci ex rubro eft coloris. Ad d portio confpicitur ventriculi, pars autem maxima tegitur hepate nec non finiftra vefica pulmonali. Eft huic ventriculo, habito ad ipfam ranam refpectu, valde magno, quique pro magnitudine prædæ deuoratæ ampliatur, idem ille motus, quem in ranæ arboreæ ventriculo obferuaui, \& licet eundem e rana auferas, non ceffat ille, quin vidi duraffe illum binas vitra horas. Vbi ventriculus, prope globulum illum rubentem, lienem puta, terminatur, furfum atque pofteriora verfus hacce in figura inflecticur; ibi autem inteftina oriuntur tenuia, dextrorfum $a d b$ in confpectum prodeuntia, dein vero recto illa inteftino $g$ iungi cernimus. Signata eft vefica, non vrina, fed aere hic repleta, litteris $i k k$. Differt illa quoad formam a vefica ranae terreftris nec non arborex, in his enim magis bipartita binisque quafi veficis conftare videtur, in rana contra aquatica fuperius finuata tantum eft.

Quum hic veficæ mentio a me fuerit facta, eorum re cordor quæ inNouis litterariis Goettingenfibus huius 1754 anni No.5.p. 46. de vefica quadam ranae maris, foetus viuos continente, relata legi. Sed en, adducam hicipfa, quibus id narratur, verba, quæ fic habent: "affirmat $D$. " GAVTIER, vidiffe fe ranas clathris inclufas coeuntes, "incidiffe plures earundem deprehendiffeque tandem, in "abdomine mafculi, fplendentem pellucidamque vefi", cam, chorda quadam in binas partes diuifam. Repe"riffe fe hac in chorda viuos foetus atque adeo certuin "nunc effe, tenera animalcula non in matris fed patris ab", domine fuiffe generata; miramur obferuationem a no"ftris prorfus diuerfam. Minime tamen credulos nos "reddit ranarum, quam D. GAVTIER exhibet, anato"me, quum inito ftatim 11eget, effe animalibus hifce pe"nem, qui tamen diftincte fatis in iisdem cernitur,." "Pu-

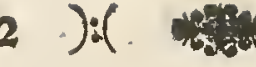

natitrlidien SBinfungen beftintmet fins: zu jentem-find hier die Runge und Das.5erz zu restnen, zu Diefen aber Die Reber, Der Sagen, Die SSedarme nebft Den úbrigen im folgenden zubenentenden Theilen. Die Range, dDer

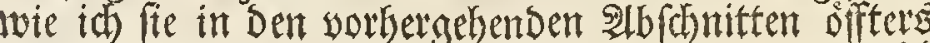
genennet babe, Die \&ungentalafen a $a$, weldhe Der Frold bey Deffnung feittes Reibez fogletch, Dutrch Dte eittgegoge. tre Sufft ftare herrus treibet, entigen fich bie in eine warzenförnige Epize, und fcheinen ebenfals, Dem åtr rerlichen 2Unehen nach aus lauter 2 liaglein su bettehen,

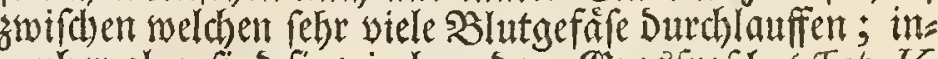
menter aber find fie wie ber) Den Saragfrofh (Tab. $V$. Fig. 6.) gezeiget worben Gol, und die bernteintlichen Blélein fehen faft Den Bellen Deg Wüfftigg ober Det WBaben Der Sienen áhnlid). Das swifhen Diefen Sunt: genblafen befinsliche und mit $b$ bezeichnete Sers, weldhes on aufen fonft Durd Das Dariber liegende Sruftbein

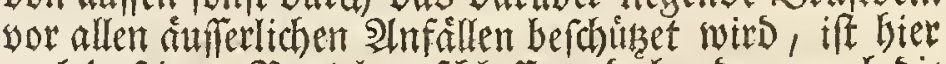
nod in reinem SBeutel verfhlofen, Saher Denn aud Die Daran hangende grofle Blutgefấe nicht zu fehen finto. In Infehang Der Fabe if es nitht fo roth als in Delt borrjergehenden Sorten; hingegen Dattert die Bemes gung Desfelben itt Dem bereitz aufgefhnittenen Frofh viel linger alb bev Diefen, unto weent man anth gleids Dasfelbe aus Dem Frofoh heraus nimm fo lebet foldhet Deme ungeadtet wob! noch einen ganzen Tag, weldhes

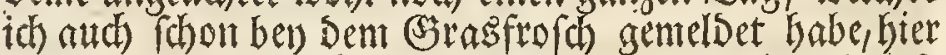
aber wiederum anfübe, weil es mir ben Diefent eben fo wumberbar als ber) jenem yorgefommen. (Błleich unter Der Spitse Des Sor'zens ift Die (Sallenblare, welche fid bier nut in etwaz zeiget; weil fie yon Der Reber gróftens

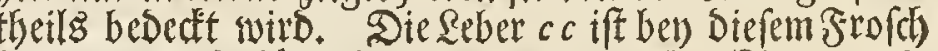
febr gros, und fillet Daber einen zienlidbett Raum aus, fuibret auch eine Dunfle rothbraune ratbe. $23 e 1) d$ les ben wir einen Sheil Des פiagens, Der librige grơfte Reft Desfelben aber ift yon Der Leber und lineen Lumgettblafe bebedt. Diefer sagen, Der nad Droportion Des Frt's (d)es fehe gros iff, und fidh aud nach Befdaffentheit Der eingefhluteten $\mathfrak{B}$ eute (ehr ausbehnen Kam berweget fich ebenfal', wie Der sRagen Des Raubfrofdes, ware er aud) gleich aus Dem Frof heraus gefdnittem, nod) ets me ziemliche lange Beit, und ich babe foldhe SBewegung uber zwey Stumben Sauren reben. Da wo Der Jnas gen ben Dem rothen Rigelein, fo Daz $\mathfrak{N i l}_{3}$ ift, zu Ende gehet, Erumme er fids in gegentwartiger Figur in Die 50 :

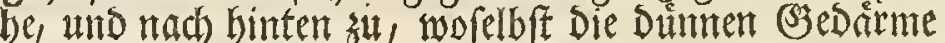
ibren 2 nnfang nebmen, welche hier redhter 5 ant sum Borichein fommen uns fich ber b zeigen, Da man benn aud fiehet, swie fie fich endlich mit Dem Maftoarm gers

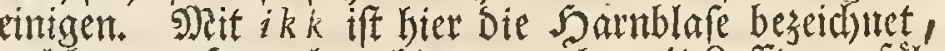
weldhe von Sam leer, bingegen aber mit Sufft angefitls let ift. $2 B_{0 b}$ ben wir anmerten, Daś felbige in Diefent

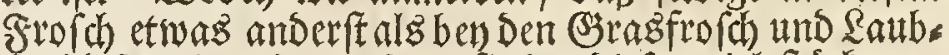
frofd formiret feye, indem fie bey Diefen viel ftarterges theilet if uns fort aus zwenen Blafen zu befteben ichei net; in unferem 2 Baflerfrofh aber ift fie oben mur ets was eingeborsett.

Da id bier sou ber Sarnblafe rebe, fo fállt mitr ein, was neultc) in Den Goottingif(t)en 2lnjeiften von ges Ielyrten Sndan, im 5. Stude Des jerigen 1754. Jahres pag. 46. von einer Blafe Der Frofhmainnlein gemeldet worben, in welcher lebendige Junge gerwefen teyn fols len. Jd) will bie Dafelbit befimbliche 2 Borte felbut her: resen, fie lauten alfo: , Serr Gautier verfid fert, er ha: "be Die Frofoche unter feriten 2 ugent in gegutterten ein:

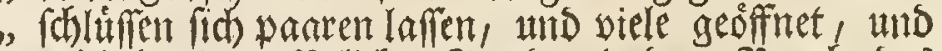
enslid mit unfräglicher Freube, in Dent Bauche Deß Naintchens, cine glânzende Durchfichtige Blafe atte getroffen, Die Durd etnen Strick (cordon) int jwen) Theile fith getremnet habe. Sit Defem Strict habe , er lebendige Sunge angetroffent, fo , Daß ntan mun "mebr gewis ware, Das bie jungen Shiere nidit in "Der 
Cab.XVI

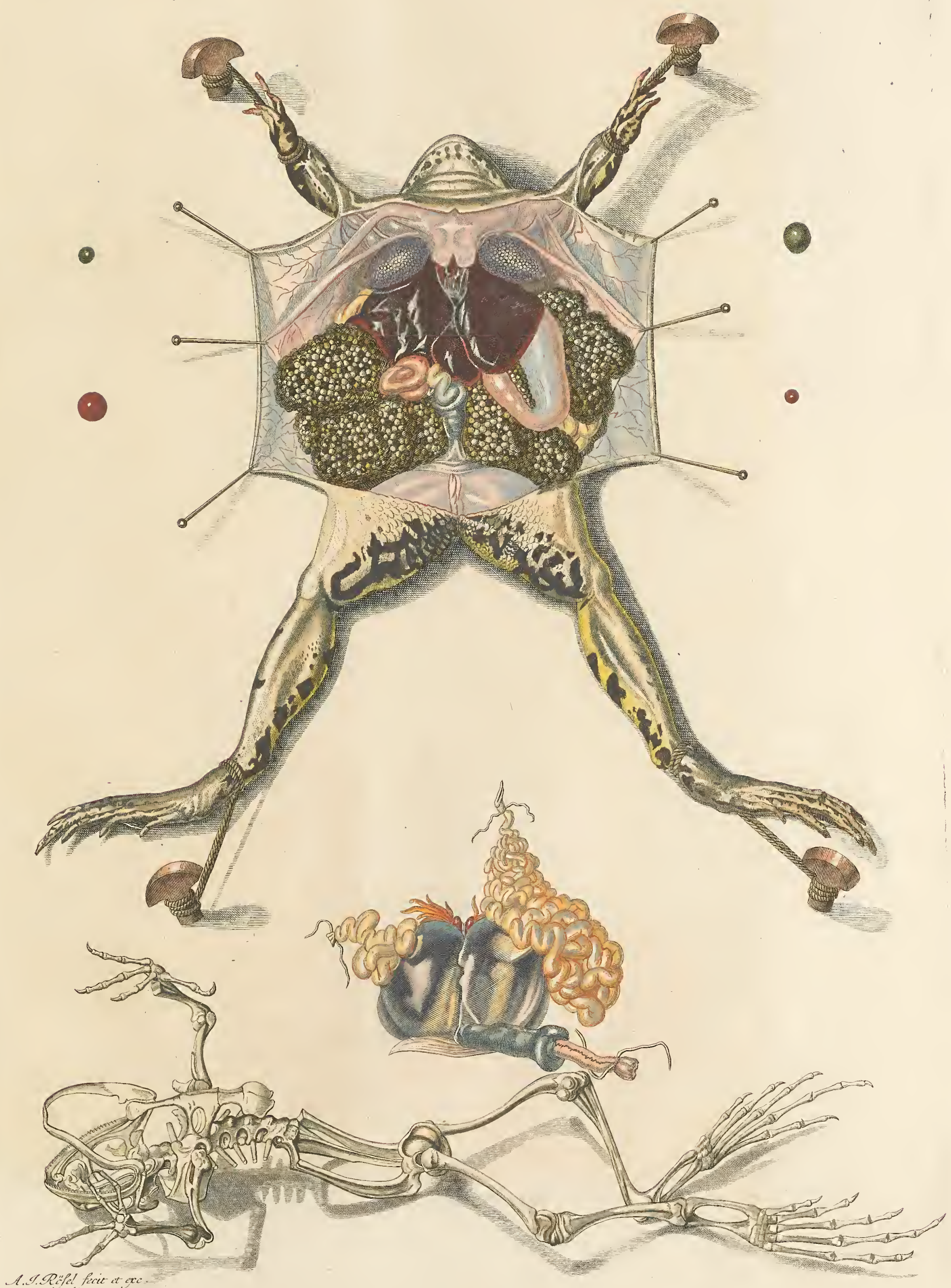



Gab.XVI.

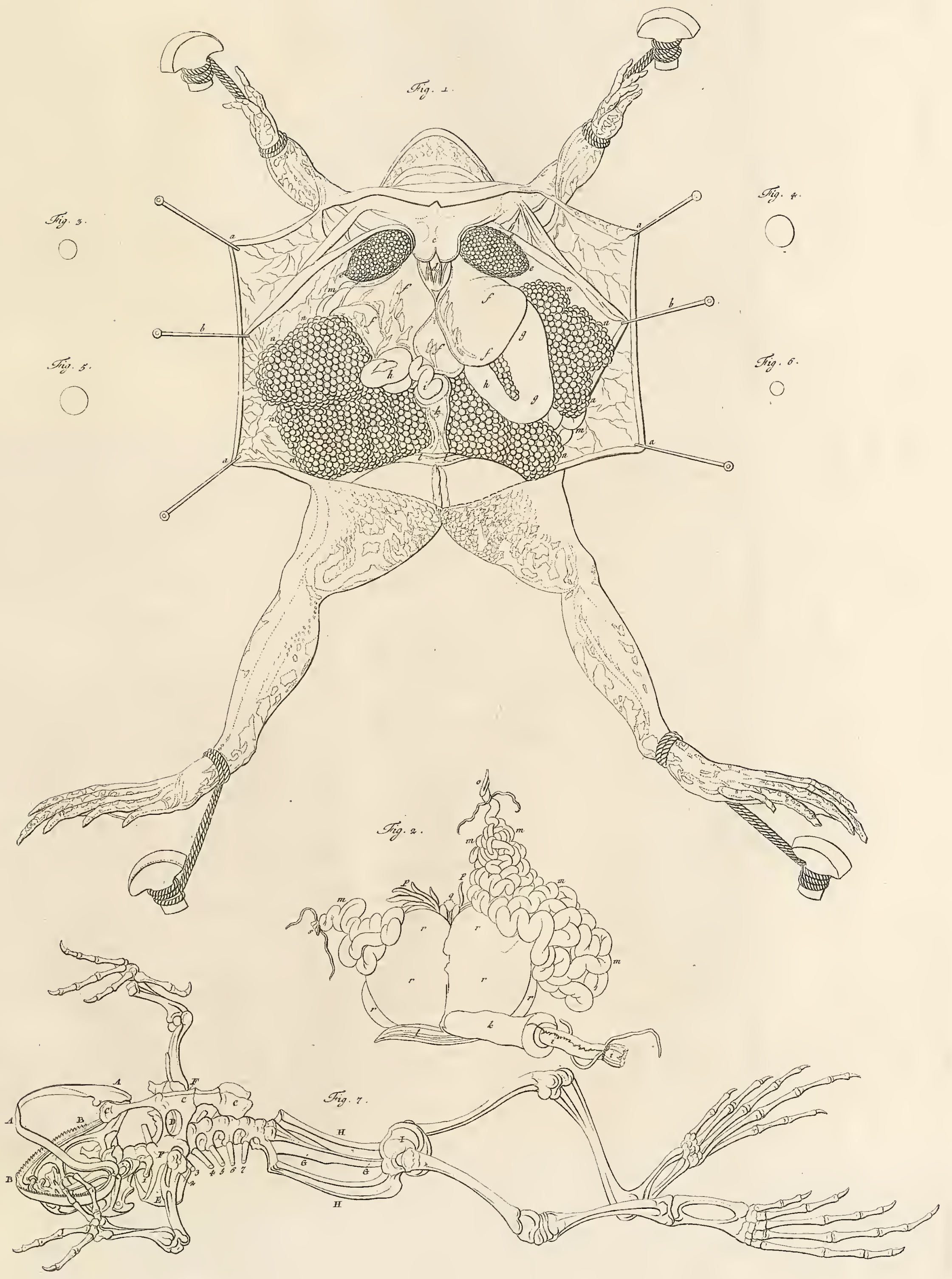





\section{-}

Publicauit haud ita diu nouum hoc fuum inuentum D. GAVTIER, Pictor Parifinus, in quinta, quas edit, obferuationum fuarum parte $\left(^{*}\right)$, fimulac vero illud mihi innotuit, fumma ardebam cupiditate ipfo in opere illud legendi, fed nondum, quod valde doleo, pars illa ad nos eft delata, ita, vt interim, quæ Noua Geettingenfia retulere, fufficere debeant. Quantum vero eruditiffimi Nouorum horum Auctores obferuationem hane mirati funt, tantum \& illa apud me, ob infolentiam, habuit admirationis. Scribit namque D. GAVTIER, vidiffe fe ranas coeuntes deprehendiffeque in mare tenellos fœetus, veficæ cuidam fplendenti pellucidæque inclufos; quodfi vero mafculus foetus in ventre gerat, quænam quæfo ipfo in coitu fœmellæ funt partes? Quodfi porro D. GAVTIER mafculum a fœmella diftinguere nouerit, non potuit non generationis tem. pore vterum fæmellæ ouis repletum inueniffe, hæc fi viderit, quid quæfo perfuadere ipfi potuit, generari fetum ranarum in ventre patris? Enimuero perparum mihi in ranarum profeciffe videtur anatomia: fin, quæ in mafculo fe vidiffe refert, vera funt, fplendens illa pellucidaque vefica, chorda quadam in binas partes diuifa, vera fuit vefica vrinæ colligendæ excernendæque dicata, viuos vero quos in eadem inuenit fœtus, eiusmodi fuiffe vermes verifimile eft, quales in rana reperi terreftri, quorumque in I. huius Hiftorie Sectione, Cap. II. p. 24. mentio aliqua fuit iniecta. Sed forfitan plura hac de re dicendi nafcetur mihioccafio, vbi ipfum D. GAVTIER peruoluero librum. Iam, quæ fuperfunt, partes ranæ noftræ aquaticæ generationi inferuientes, contemplemur.

Coopertæ illæ funt in prima firura $X V$, huius Tabu$l_{\mathcal{E}}$, ventriculo, inteftinis nec non vefica, ita, vt fupra ventriculi flexuram, prope lienem, tefticulum cernamus finiftrum littera $e$ fignatum. Eft ille aurantii coloris, neque vnquam, eo etiam tempore quo partes ranarum funtperfectifime, maior euadit, quam heic depictus eft. Vtroque in latere ad $f f$ pars confpicitur appendicum lutearum, per veficam vero translucentem cernuntur, pone ipfam fitæ, veficulæ feminales albentes. Quæ vero hic ex parte tantum confpectui noftro patent, ea fingula tertia in $f$ gura plene ob oculos nobis ponuntur: fiftit enim illa partes hafce eo in fitu, quent ipfo in corpore feruare folent, $\&$ in quo fefe, ablatis partibus quibus teguntur, offerunt. Indicant litteræ $/ I / l$ binos oblongos, gracilesque renes, carneo colore tinctos; e e bini funt tefticuli; fffff vero appendices luteæ. Veficulas feminales litteræ defignant $n n$, quæ quum in hac quoque ranarum fpecie in papillam abeant in inteftino recto hiantem, addita eft pars huius intertini diffecti $m m$, in cuius medio ipfa hæc comparet

papil.

(*) Integer libri titulus fic fonat, Obfervations fur l'Hifoire nsturelle, fur la Phyfigue of fur la Peinture. A Jiore nesturelle, Planches imprimsees en couleur. Cet Ouvrage renferme les fecrets des Arts, les nouvelles découvertes, \& les difputes des Philofophes \& des Artiftes modernes, Année i7 12. Tome premier, I. II.III. Partie a Paris, chez Delaguette, rue S. Jacques, à l'Olivier. Avec Approba. tion \& Privilege du Roy, Les Planches en couleur fe di. tion \&uent féparément chez M. Gautier, Penfionaire dis Roy, rue de la Harpe.
, Der Mutter, fondern in Des

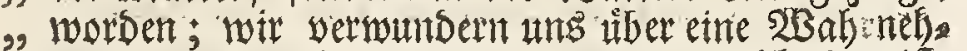
$\Rightarrow$ mung, Die von Den unferigen gans unterfutedent if. "Die Zergliederung aber Der Fróche, Die Eautier lies " fert, macht uns eben nicht leichtglaubig, indem er $\Rightarrow$ gletich anfangso as ziemlich fichtbare mânnliche EJlice "Diefen Thteren ablingnet.

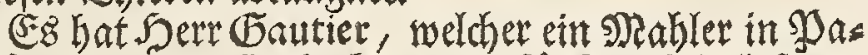
ris ift, Diefe nette Entodecking im finften Sheil feine Obferuations $\left(^{*}\right)$ unlanafí vorgetragen, und fie erwect.

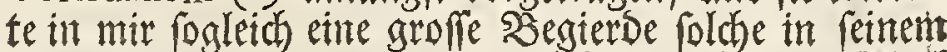

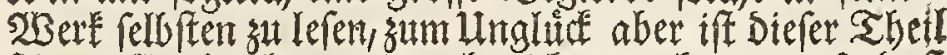
feines SBerkes ben uns noch nidht angeEomnten, fo, Daf ich al fo mit bet gottingifchen Nad)ridht zur Beit zu fries Den fern mus. So febr fich aber Die Serren 3 erfaffer Der gottingifhen Inseigen uber Diefe 20 abrnehmung werwutsern, fo fremb iff felbige aud mir borgetommen. Demt Sorr Gautier faget, er babe Der so arang Der Frofbe sugerehen, und findet in Dem shantem Die Sun gen in einer glanzenden Durch fichtigen Blafe; wentmath Das Mannlein Die Sungen in Reib triogt, mas madjt Dent mohl Das SBetblein bey Der Daarung? Sat Serr Gautier Das Niannlein von Dem $2 B$ eiblein zu antet. foriden gewatit, fo mus er ja wohl die sutter ben Dem sibeiblein zut sobarungzzeit mit Evern angefullet ges

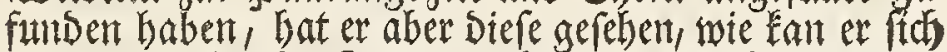

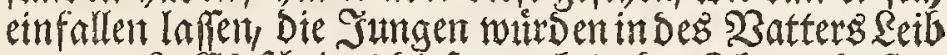

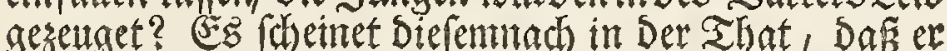

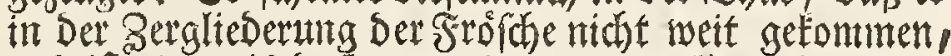
unt ift es gewis Da er, was er uns meloet, in einem

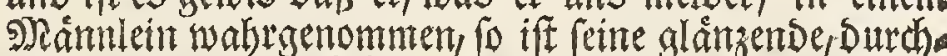
fid)tige SBlafe, Die fidh Durch einen Stride in zwey Theis le getheilet bat, nichts anders als die Sarnblafe gewe. fen, uns Die lebentitgen Sungen fo er Dartinen ge feben mogen ivobl 2Btirmer gewefen fern, Dergleichen ich it Dem. Srasfrofó gefunden babe, und won weldhen yout

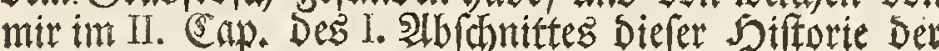
Frófhe S. 24. bereits einige 2 (nzeige gefthetsen. Sie. Doch ich werbe sielletest bieson ein andermal, und wobl

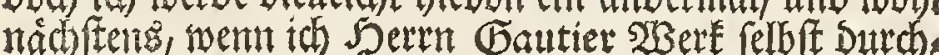
gegangen babe, ein mebrers zu melden (S) elegenteit fits Den. Segt wollen wir nod Die zur Beugung gehorigen mànliden Sheile unferes 2 Bafferfrof

Sin Der eriten Figur Diefer $X V$. Cabelle fint fel.

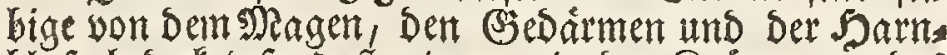

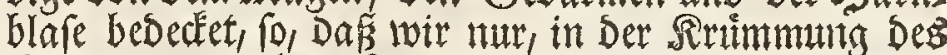

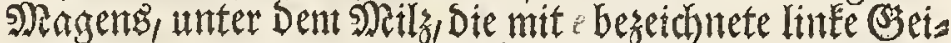
le gul feben betommen. Es fuhret felbige eime orantens gelbe šarbe, and ift, aud zu Der Beit Da biefe Sheileben Den Frofchen am vollemmenften fino, niemalen aróflec als fte bier abgebildet worben. In ben beeden Seitent

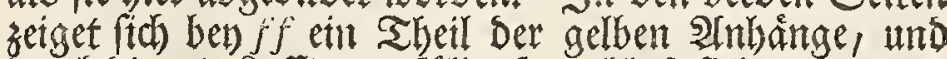
Durch Die mit Rufft angefillte 5 arnblare fiehet man swis

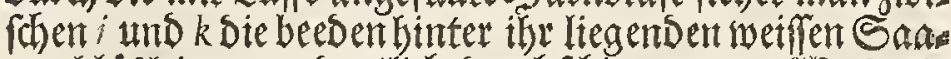
ntenblésleit gans Deutlitch Durch fch tmmern. S2Bas wit aber bier nur sunt sheil betrachten Eormen, $D$ as finder wir alles in Der zweyten Sigur Deutlich yorgeftellet, als in weld)er Diefe Sheile fo abgebildet worben, wie fie na

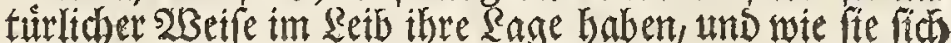
zeigen wenn biejenigen, ro fie bededen, hinweg genom

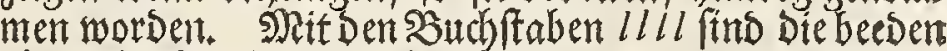

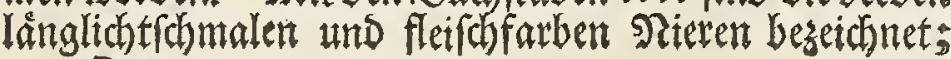
2. 2

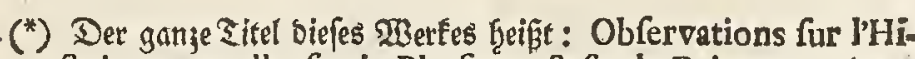
ftoire naturelle, fur la Phyfique \& fur la Peinture, Avec des Planches imprimées en couleur \& 


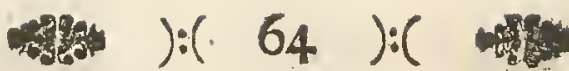

papilla o, quæ, vt ego quidem reor, penis dicenda eft, li- e e find bie beeden (Setlen, ff fff aber Die gelben \$tt: cet D. GAVTIER eodem ranas carere perhibeat.

bainge. Die Saamenblóslein werben Durch $n n$ anges Deutet, und Dafte auth in Diefer Frofohart fich Durd ein

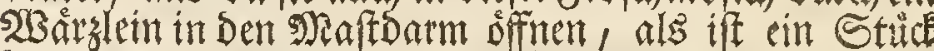
Des entswen geichnittenen SMaftoarms $m m$ hier benbe. haltent worben, und in beffen Nitte fehen wir bey o dies

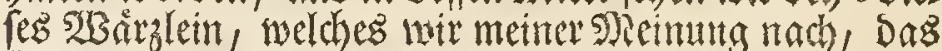
Seugungsglies nennen Eormten, obsletd) Serr Gauticr foldjes Den Frófhen abfpred en will.

Tertia in figura easdem rurfus delineatas fifto vefi-

In Der oritten Sigut habe ich Die Samenblä: culas ferninales $n n$, cum parte illa inteftini recti $m m$, vt ipfas ea monftrem in magnitudine quam habent, fi femine turgeant vel aere fint repletæ. Repleri vero. hoc ipfo poffunt, fi orificium carneæ illius papillulæ quæratur \& ope tubuli aer infuffletur, facile infuper idem per orificium binæ immitti poflunt fetæ $p q, p q$, vt hic factum eft. Veficulæ hæ ita turgentes non in longitudinem excurrunt, fed varie curuantur, quo ipfo multum a veficulis feninalibus ranæ terreftris differunt, quas Set.I. Tab.V. Fig. 3. ea magnitudine delineatas dedi qualem habent vbi perfectæ funt: veficulæ namque ranæ aquaticæ partem magis referunt canalis inteftinalis multoque funt minores; hinc vero fupra iam dixi, mirandum effe, poffe eiusmodi mafculum numerofá illa fæmellæ fuæ oua, quin binarum trium. ve fœmellarum fœcundare.

Quodfi quatuor a tempore generationis elapfe fint hebdomades atque eiusmodi rana incidatur, is, qui neque formam neque fedem veficularum feminalium nouers, easdem fruftra eft quifiturus; omni namque femine emisfo collabuntur, ita, vt ob exilitatem vix confpiciantur. Eaclem ratione habent fefe fimiliter tefticuli Juteæque appendices: priftina namque magnitudine amiffa, quam ad ee \& $f f$ in fecunda figura habebant, partes quarta nunc æquabunt figure, in qua tefticuli $e e$ minores non folum, fed \& graciliores comparent, appendices vero lutew of fibras referunt flaccidas. Appendices hx, nifi in foemellis quoque reperirentur, fimiles milhi viderentur florum ftaminibus, quæ ad femen foecundandum adeo funt neceflarii, vt planta, quæ illis caret, maturum nunquam ferat fructum, id quod, inter alia, illud etiam probat experimentum Berolini nuper cum palma dactylifera inftitutum, quæ ope fpacidis mafculos flores ferentis, Lipfia allati, foecundata, maturos reddidit fructus.

Sed mittamus ian mafculum ranæ aquaticæ, fœmellam eiusdem contemplaturi, quam prima fivura XVI. qabule nobis offert. Indicant in hac litteræ $a a, a$ cutem excernam, quam femper primam incidere atque ad latera acuum ope firmare foleo, vbi ranam, quam viuam diffeco, quatuor illis clauiculis minori affi hunc in finem adaptato alligaui. Ipfam cutem vel ad $c$ fub fterno, vel prope os pubis incido. Vt autem eandem eo facilius ad latera remouere poffim, illam, facta fectione in longitudinem, transuerfa quoque diuido. Dein ipfos fub cute fitos difcindo mufculos, eosdemque, quo minus mihi impedimento fint, ad latera reductos acubus $b b$ figo; his vero factis internæ ranæ partes, ceu in figura noftra, omnium patent oculis. Cor littera $d$ fignatum eft, $e e$ vefica funt pulmonales multo heic minores quam in proxime pracedenti figura, pauco quippe aere diftentæ; $f f f f f$ hepar eft magnum furuumque, quod hac in fæmella mafcili hepar magnitudine multum fuperauit, id quod in aliis quoque vidi fæmellis. Ventriculus $g g$ ob inanitatem minor heic comparet; $b b$ tenuia funt inteftina ad $i$ vsque extenfa, mal abgebildet, unt jene fo gros zu zeigen, als fie twirk lid) find, wenn fie nodh woll Saamens fteden, ober mit Ruffit antefullet worben. Diefez letsere fan gefthehen,

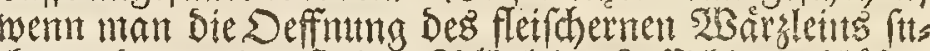

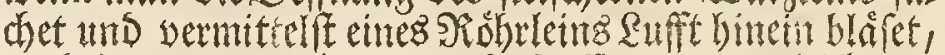

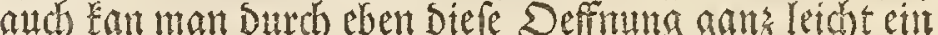

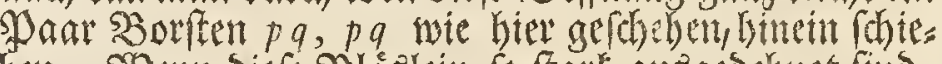

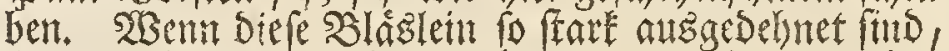
fo achen fie niche nadh Der Range fort, fondern madien berfotiedente Sertimmungen, eben Dadurd aber tnters

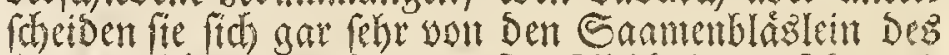

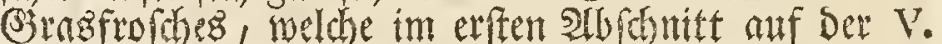

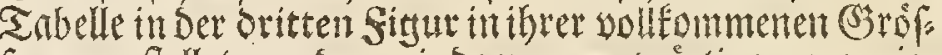
fe solgeftellet worben, indem gegenwaitige gegen jes

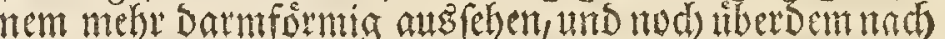
Sroportion biel Eleiner find, wesmegen idh benn auth

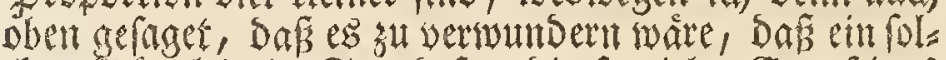
bes Norinnlein im Stand fene Die fo stelen Ener rentes 2Beiblems, ia aud wohl zmener bis srener 23 eibleit zu befrudbten.

Definet man enten folchen Frofd etwann sier 230 s

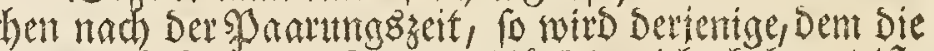
Form und Eage ber Saamenbląglein nitht betamt ift, oldhe umfonft fuden; weil fie alsoem won Santen leer find, uns allo zufammen gefallen und gant Eleft ausfehen. Eben Diefes aber gilt auch yon Den Steilent tmb gelben 2infingen: Dem Da fie yorkel fo groz was cen, wie wir fie in Der zweytert figur bey e e and $f j$ ge. rehen habent, fo werben fie fich nummebr fo seigen, wie fie bie vierte firmur Darfetlet, in weld)er Die Breilent ee nicht mur flemer fondern auch långlichter ausfehen, bie gellon 2inhainge aber $f f$, gants furge und welfe Fafern

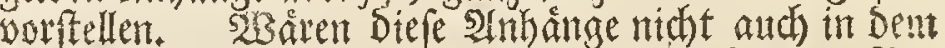
Weiblein zu gegen, fo foimten felbige mit Den sur $\mathfrak{B e}=$ futhtung Des Eamens fo notbigen Staubfáden Der

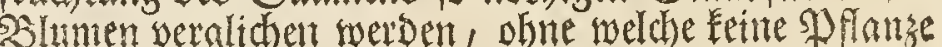
cine reife Srucht trágt, wie unter andern Der vor Ettrs zem mit einem Dattelbaum in 2 erlin angeftelle $2 \mathrm{c} r=$ fitch beweifet, weldher Durch einen yon Reipaig Dabin ges cendefen mainnlichen 2Jlumenzweig fo weit gebracht wor Der, Daf er reiffe Frühte getragen.

SBon Dem SRånnlein wenden wir uns mun stt Dem

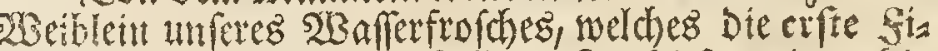
sur Der XVI. Tabelle yorftellet. Sn Diefer zeigen Die Suchetaben $a$, $a$ a die ânfere 5 ant an, welde alleseit wenn ber Sroich, Den id lebendig effore, mit feitent vier Stiffo, yermittelft Der vier Bwedte auf einem Dazul be= reiteten Eleimelt Shet weft gemachet worben, an erfent von mir ents(ven gefdnitten unt mit Nadeln an ben Seiten beveftiget wird. Die Deffitung Diefer Saut fange ich aber entweder ben $c$ an $B$ ruftbein, oder inten

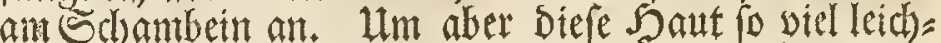
ter auf Die Ectite bringen ju Eónmen, wird foldhe, went fie nach Der Ránge gesffnet worben, auch obent an Der Bruft in Die Duer entswen geidhnitten. Nachgehends

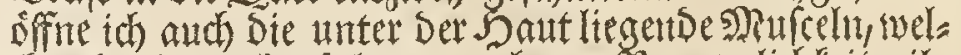

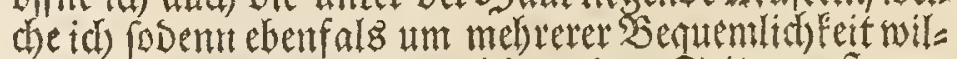

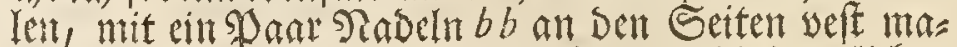
die; wem aber befes geftheben fo liegen bie immerlichen

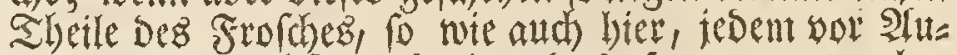
gen. Der sudf fabe d jetget bas Sher an, e e aber 


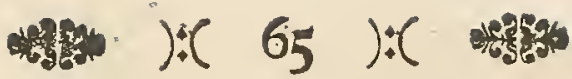

-bi admodum gracilefcunt. "Inteftinum rectum littera $k$ bie beeden Iungentafen, welche bier biel Eleiner, als

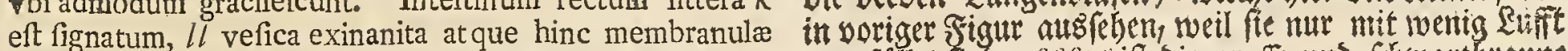
complicatæ fimilis. Ad $m$ dextrorfum æque ac finiftror- angefillet find; fffff iff bie groffe unt (d)

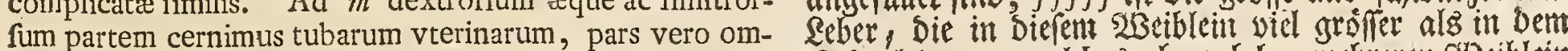

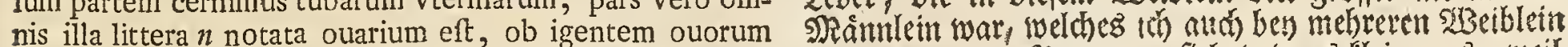
numerum adeo expanfum, vt vterus ac reliqua genera- bemerker. Der 5 Ragen g g fieh et etwas flein all tioni dicatæ partes ab eo contegantur, quas vero eam er you Speife gan leer if: $h b$ find Die Duinten Dirme, ipfam ob cauffam in fecunda hujus Tabule figura fepara- Die bis $i$ geben, wo fie am Duintiften find, $k$ aber ift Det tim delineaui.

Vt autem partes hærecte perfpicueque oculis fittantur, easdem aëre repleui atque ex abdomine dein abfituli. Notata eft litteris $i$ i portio inteftinorum tenuium cum recto cohærens, ea in parte qua abfififa fuit filo conftricta. Indicatur littera $K$ inteftinum rectum; $l$ vefica eft vrinæ colligenda dicata, nunc vacua complicataque. Tubævterinæ $m \mathrm{~m} \mathrm{~m} \mathrm{~mm}$ eandem prorfus habent longitudinem magnitudinemque ac in fremella ranæ terreftris, fed hic finiftram tantum ab orificio fuo $o$, poftquam aëre immifơ eandem colligaui, ad locum eum vsque vbi in vterum hiat, integram reprefentaui; dextræ partem tantum cernimus, fimiliter ad $s$ filo praftrictam. Littera $q$ renes monftrat, quorum tamen portio tintum confpectui fefe filtit, quum maximam partem vna cum luteis appendicibus $p p$, fub vtero lateant. In vtroque vteri $r$ r r r latere fimbria quædam cernitur, littera $r$ fimiliter fignata, quam initio quidem ex lefa exteriore vteri tunica ortam putabam, quum vero eandem in pluribus hujus fpeciei formellis poftea femper confpexi, propriam hanc vtero ranarum aquaticarum effe configurationem didici. Parum ceterum quoad ftructuram internam vterus hic $a b$ vtero ranæ terreftris differt; vbi vero omnia in eundern defcenderunt oua, major fere euadit, \& in tantum diftenditur, vt durus tactu fit.

Quod reliquum elt, obferuaui quoque in hac ranarum Ipecie, veficulam felleam mafculorum, habito re'pectu ad lienem, valde effe magnam; fuperare vero hunc in fomellis illam magnitudine, ita, vt veficula fellis Figuro tertice Tabule XVI., lien vero quinte fimilis fit; in mafculis contrailla Figuram quartam, hic autem fextam referat. Vix ceterum funt quæ hifce de ranis addam, at que hinc earundem nunc contemplemur fceleton: quamuis enim in hiftoria rane terreftris promiferim, me, reliquas etiam internas ranarum partes, in rana viridi aquatica effe examinaturum, morbofa tamen corporis mei difpofitio hactenus, quo minus promiffa preftiterim, impedimento fuit.

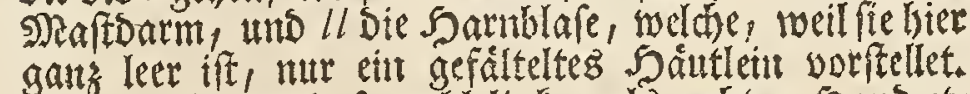
Sen $x m$ fehen wie fo wolyl linker als vechter Saln ets was von Den (E) ergángen, a!les aber toas mit $n$ bezect)= net if gehoret zu Dem Enerftock, Der um Der in ifsm bes finblichen vielen Ener willen fehr gros erfheinet, unt

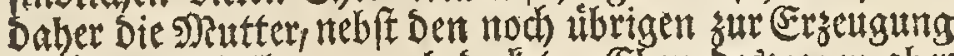

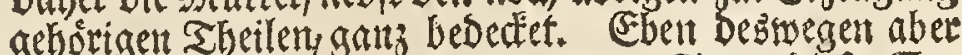
find felbige oon mit, in ber stweyten Sigur Diefer Cas belle, beronders vorgeffellet wordent.

Th babe aber Diefe Thetle, Damit fie befier und Seutlither in Die 2 tugen fallen, aufgebla fert uns nachges benos aus bem Reib heraus genommen. SNit it fif ber an Dem Naftsarm batgende ubrige Reft Der Dúnten (S)edirme bereichnet, welcher Da, wo er abgefonittert morden, zugebunten ift. Den siaftarm zeiget $k$ an, und $l$ if Die leere zufamgefaltente Sornblafe. Die (E) gânic $m \mathrm{~mm} \mathrm{~mm}$, find bier ebent attch fo longe und fo Gros, als in Dem 23 eiblein des (STrasfrofd)es, Dod has

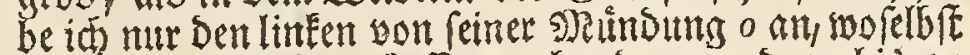
er nad cingeblafener \&ufft zugebutnden worden, bis sus feiner Beretnigtng mit Der sidutter, ganz yorgeftellet" yon bem rectem aber zeigt fid nut ein sbeily fo ebenfals be!) : mit etmem Faben zthebunden worben. Nit a find bie broben Siteren bemerket, yon weldhen aber bier ntur

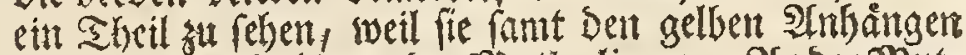

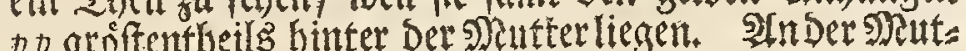
ter felbit rrrr, zeiget fich zu yeber Sette, eint befondes

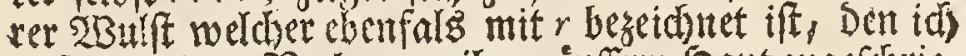

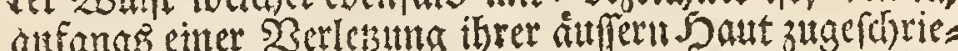
ben, als id aber foldsen in mebreren sibelblett biefer sete allezeit fand, fo sumbe ib tiberzenget, Dafs bie Natfer

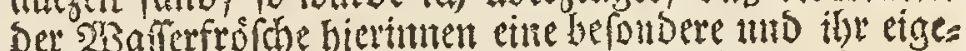
ne Structur kabe. Surferdem iff biefe Nenter Der its nem Befdaffentbit nach, won Der Soutter Des (STras: frofhes nicht viel unterfohies ent utto went in felbige alle Ener cingetretten, fo ift fie faft nod grofer als bier,

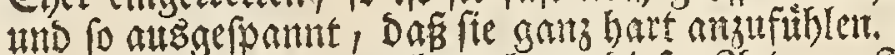

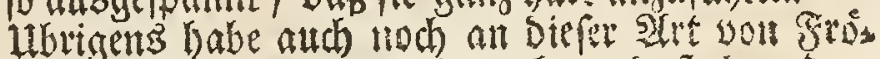

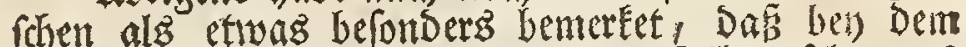

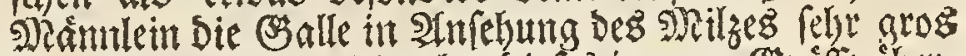

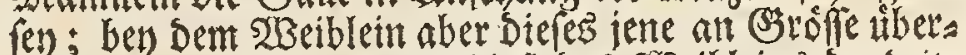

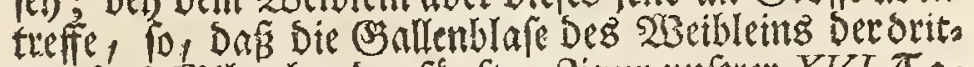
tell Das sonils aber ber finften Gignt unferer $X V I$. Cra belle gletdet; bey bent Deannletit aber iene mit Der vierten und Diefes mif Der febften libercinfonme. Sonften habe id won Diefen Frofidy nidhts weiter su melden, Daber wir Denn mar nod ife (Sterippe bes trachten wollen: Denn ob th wohl in Ser Berchreibung

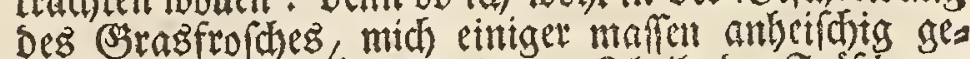
machet, auch Die ibrigen innern Slyetle ber Frofde alt Dem grumen $23 a f f e r f r o f h$ gencuer gu unterfucten, fo

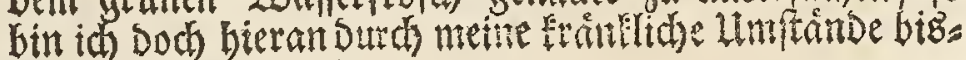
her werfindert worben.

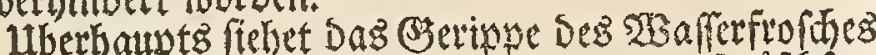

Simile fere eft fceleton ranæ aquaticæ, Tceletis bina. rum jam defcriptarum fpecierum, quippe qua fimilitudo in ipfa harum ranarum externa quoque ftructura obferuatur; in hoc etiam feeleto neque major necque minor quam in illis fingulorum offum eft numerus; quod vero ad eorundem attinet ftructuram, differunt inter fe, id quod præfertim ipfa capitis oftendunt offa. In fceleto namque ranæ noftre aquatice, quod in Septima Figura XVI. Tabule dorío incumbens atque in longitudinem diductum exhibui, majus magisque acuminatum eft caput, quam reliquis in

fpecie.

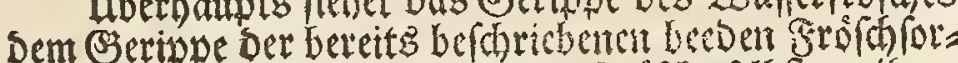

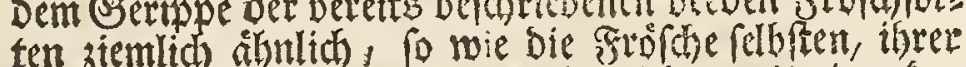

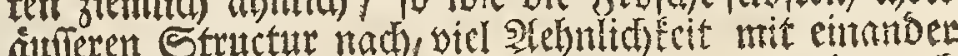

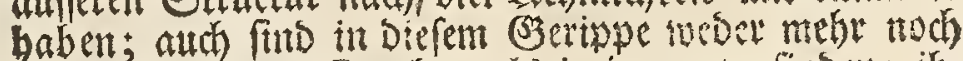

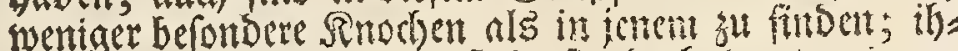
rer Structur nad aber find fie dod in etwas won

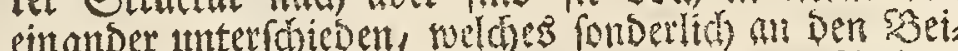

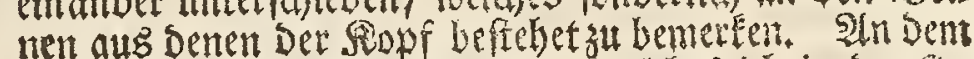

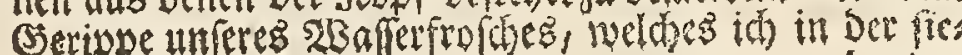




\section{\%) $:(66):(4)$}

Speciebus; fed protuberant etiam paullo plus, cum cranio, benden fignt Der XVT Tabelle auf Dem SRuten liegens ipfi juncta narium offi. Indicant $A A$ gracilem inferiorem maxillan, $B B$ vero fuperiorem; quemadmodum autem illa acuto in margine glabra eft., hæc contra multis exiguis acurisque faret dentibus. Refert os fterni $c c c$, cum partibus lateralibus, crucem fere, $\&$ in his ad $D$ ouatum adeft foramen. Scapula $E$, offi cohærens fterno, nectitur in dorfo altera cum fcapula, ita, vt ambæ cum lateralibus fterni partibus annulum quaff forment, cui ad $F F$ crura anteriora inferuntur. Septem proceffus transuerfales vertebrarum $1,2,3,4,5,6,7$, non funt paralleli : tres namque priores diuaricantur extremis fuis, quæ contra in reliquis quatuor propius ab inuicent diflant. $G G$ os. coccygis eft vertebræ vltim: junctum, extima vero parte liberum. HH bina notantur lumborum offa, qua inuicem junct $x$ os formanc pubis $I$ : nulla enim hoc inter atque illa cernitur commifura. De quatuor cruribus nihil dicendum rcftat, quum cruribus ranæ terreftris fere fint fimilia; notandum tamen cit de pedibus pofteriorum, effe illos ranæ aquaticæ nulto majores, quam in reliquis omnbus ranarum noftratium fpeciebus.

Sed licet jam hiftoriam ranæ viridis aquaticæ ad finem perduxerim, eundcri tamen huic fectioni imponere nondum poftum: en ramque affertur mihi hoc ipfo momento Secinam Doumen Obleruationum GAVTIERII, in quo novam fuam, fupra jam memoratam, de ranarum generatione propofuit fententiam; quum vero premiferim me plura de eodem effe allaturum, fidem nunc fum liberarurus.

Sed indicandum inprimis eft, communicaffe jam GAVTIERIVM, in priore volumine, nouum de generatione inuentum, quo ipfo edoctus afferit : contineri jam joetum in mafculi jemine, atque hinc credit: fuppeditare j:ngulorum animalium mafculos foetum jam formatum, effe vero famellarum matrices tantum receptacula qusdam, in que ipfi foetus deferantur, ot in iisdem or nutriantur Ef increment a fumant.*) Pro vlteriore vero hujus fur fententiæ confirmatione, quæ cum ranis inftituit allegat experimenta, atque hinc ea refert quæ fuperius jam ex $\mathrm{No}$ uis litterariis Goettingenfibus adduxi. Tunc quidem minus intelligebam, quæ ipfe de fæetu in patris abdomine nato dixerat; jam vero inuenio, explicare illum rem hanc fequenti ratione: vbi mafculus fceraellam confcendit eandemque firmo tent amplexu, expertat donec oura fua emittat jomella, to if fo vero momento edit fuos, quos vidi, foerus. Gabarcut illi tunc ouis, atque to iisdemper dies aliquot nutrime at a capiunt, donec firmiori ferendo pabulo apti reddantzir. Retincut ifli formam, quam in patris ba. buerunt vefica, integrum menfem, dein vero eandem, bombycum in chryalidim mutalorum inflar, exuunt. Euoluunt poftea diuariccintoue crura pofieriora, qua ipla in foctu jundta gyrini fomant coudam. $\dagger$ ) Exhis vero atque ex illis, quæ jam fuperius attuli, ipfum GAVTJERII con-

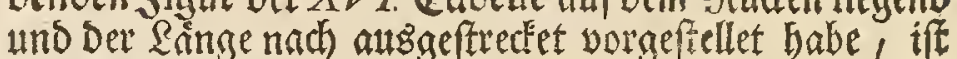

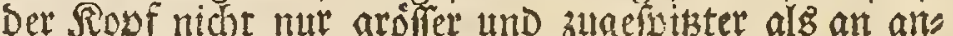
Dern Sorten; fondern es ift anch Die Jjimfchale nebit Dem Daran froffenden Nafenbein viel erbabener und ges woilbter. Der Duinne Lnterfiefer miro Durd $A A$ ange: zeiget, und Der obere Duth $B B$; gleichwie aber jener an

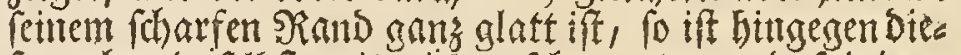
fer, eben bafelbft, mit sielen ferer zarten uns fotzigen.

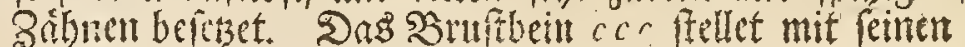
beesen Seitentheilen gleidy fam ein Sreuts vor, und in

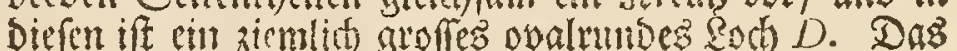
tuit Dem 2 ruftbein fich vereinigende Shulterblat $E$, hanget auf Dem Rutern mit Dem ihm gegen uiber fteben: Den Sd)ulferblat zufammen, fo, Dag fie beeve mit Den Seitentheilen Des 2 ruftebeines gleich fam einen SRing formtren, in weld em ben FF Die vordern Shentel ibre Einlentung baben. Die fieben Duterfortfáse Der SBit. belbeiner $1,2,3,4,5,6,7$, lauffer nicht mit cinander pa: rallel: Dent bie brety erftern find mit ifren ernoen aus einander gefpreiset, und Die thbrigen bier fathen mit fel. bigen nơber beyfammen. $G G$ ift Das Swhangbein, weldhes mit Dent lesten Futénwirbelbein furamment banget, an reinem Enoe aber fren iff. HH fitto Die beeben Senoenbeine, Die Durch ifre ßereinigung Das Sd)ambetn ! ansmadien, indem jowifhen Diefent uns

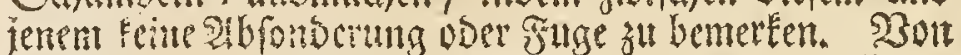
Den viev Echenteln babe nichts befonderes zu melden, weil fte mit Den Sd)enteln Des Grasfitorthes itbereth foumen, soch nus ich noch von Den Fuifen Der bintern. erimern, Dafs felbige an Dem 23 afferfrofd, nach Pro= wortion gibofer, als an allen ubrigen Sorten umferer srofiche fener.

Eo batte ich nun zmar die 5 iftorie Ses grimen $23 a$ ferfroiges vollendet, Ean aber Doch hiemit diefen slbronnite nom nidjt endigen: Denn ebent jete erbaltetch Den 3weyten 3 ano you Den Obfervations Deg Serrn Goutter, worimen Derelbige feine oben angefúthrte neue Neimnng sont Der Erafengung Der Fróphe vorges. tragem Da id) nun ober von felbiger ein mebretes zu mels. Den veriprodsell babe: als will id . auth jeted mein set: fprechen erfullen.

3or allen muticich melben, Dof reits in fernem erften Sheil eine neute bie Erzentung bes treffende Entbeckung mitgetheilet habe, bermoge wels cher er bebaudet, dafi un dem Gamen deb mianis leims bereits oie juntre frudt entlyalten feye, und die: femnach glaubt er, Saf bey allen Thieren der Dattet alleine de bereito vólligse formitte frubt lyergebe,

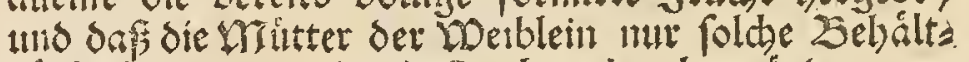
minfe feyen, worein die find gebtad)t warde, um

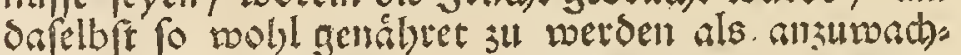
fen*). Itm nun biefe feine Deinung yon neuem zu

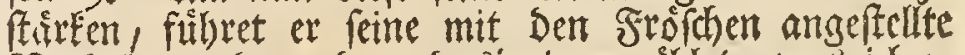

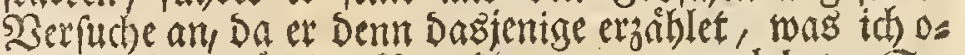

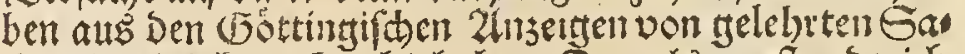
(hen bereits beysebradht babe. Damals berfunde ich nicht was er nut ben in Des Jungen wollte, iest aber finbe idh), Dafí er foldies fols gender maffer erflare: Traboem das miannlein fón Weiblem beftiegen und felbiges veft bölt, wartet es

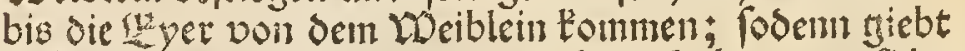
co bie Jungen, fo wie ith fie gefelen babe, von fich,

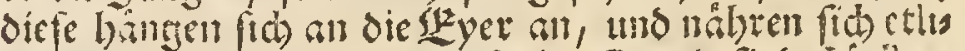
de cage lam davon, bis fie im Gtand find ifaricte

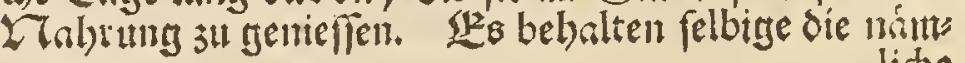

*) En ipfa Auctoris verba: Que le pere feul dans tous les anir avix fournit le foetus rout formćs, \& que les ma. trices des femelles ne font que des réceptacles, oùces

fretus lont dépolés pour y prendre leur nourriture \& leur accroiffement.

†) La Grenoville Miale montée \& fortement attachée fur la Femulle 
Tab. XVII
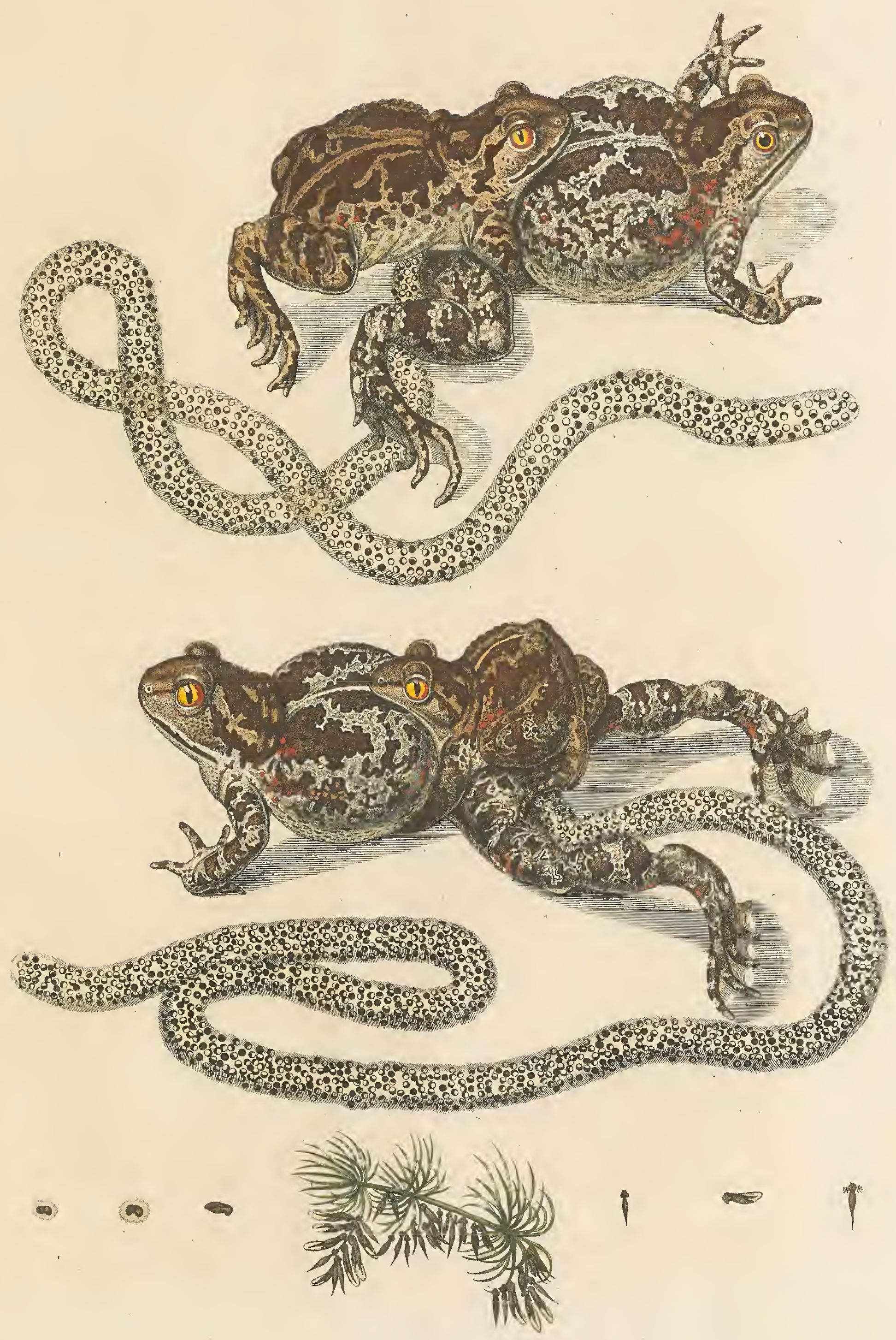

Tab.XVII

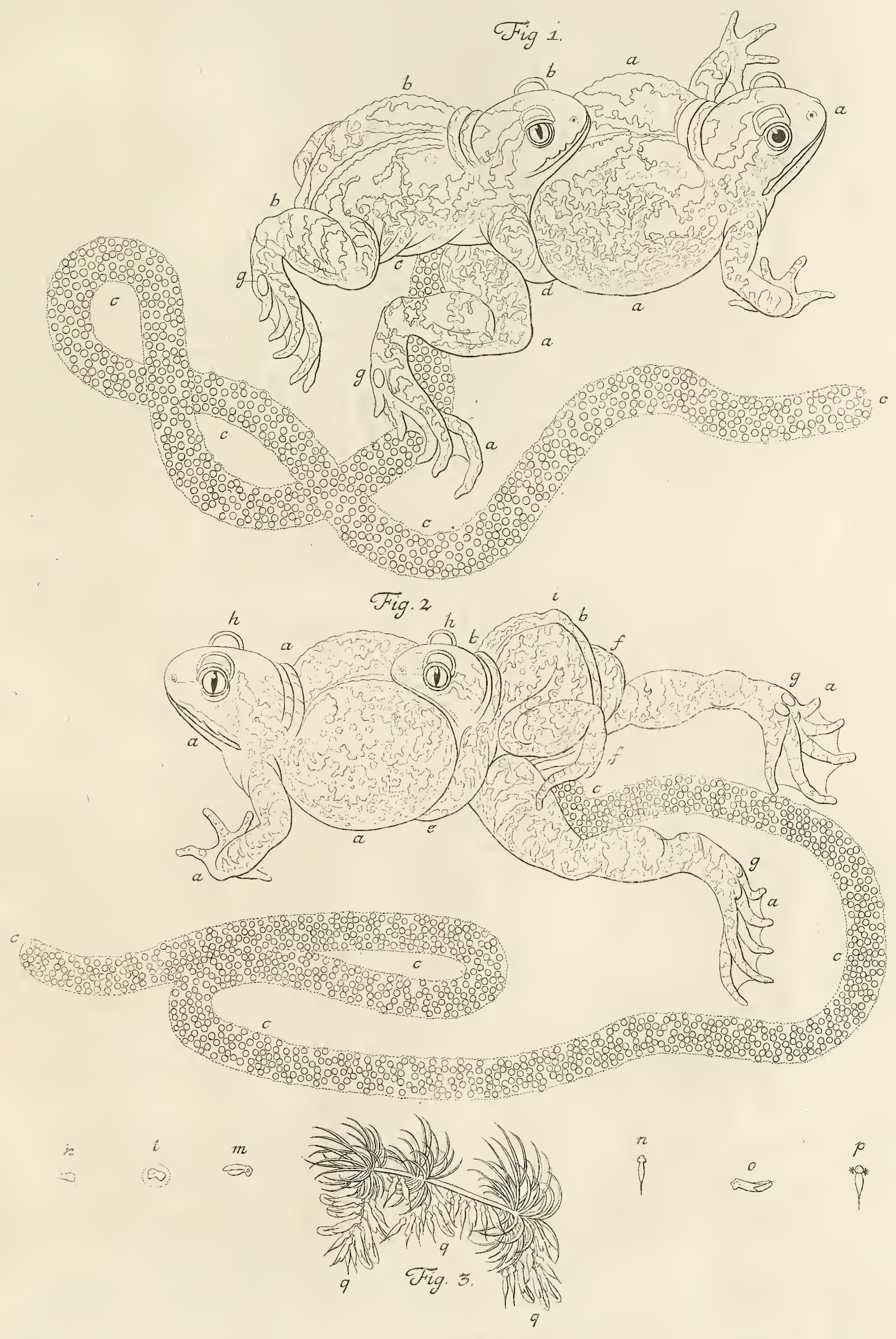





\section{(6)}

tat inuentum, de quo adeo quidem gloriatur, vt periuafum habeat, PY'THAGORAM, fi idem illud inueniffet, denuo Diis hecatomben fuiffe facrificaturum; ego vero crediderim, fi fieri poffet, vt GAVTIERIVS PYTHAGOR IE, quæ inuenerit, enarraret, hunc ipfi non filentium biennii vel quinquennii, quod difcipulis fuis imponere folebat, fed perpetuum effe injuncturum.

Adhærere gyrinos ouis atque ex is per dies aliquot nutriri; retinere eosdem formam vnam eandemque integrum menfem; formare pofteriora crura illorum caudam afferta func GAVTIERII, quæ fatis fuperque probant eundem \& ranas \& generationem earum nulla prorfus adhibita obferuaffe attentione. Eandem veficam, in qua in mafculo foetus inuenit, vidit ille etiam in fomeilis, quas vtero carere afferit; figuræ vero, quas hifce de partibus dedit, oftendunt, effe ipfam hanc veficam vrinæ colligendæ etiam dicatam: in fexta namque figura, foemellam repræfentante, veficam eandem appellat, in figuris vero tertia, quarta \& quinta, quas pro demonftrando nouo fuo inuento affert, veficam dicit vtrique fexui communem clara limpidaque aqua repletam; veficas aquofas; veficam aquofam; ex his vero ipfam Auctoris de inuento fuo titubantem apparere puto mentem; $v$ autem objectionibus obuiam eat, veficam vrinariam in mafculis inteftino recto cohærere dicit; fed nou:m fuum enarrans inventum, veficæ illi maris in qua foetus invenit, eandem in offe pubis effe fedem ait, quam noftra etiam habeat vefica. Licet autem hoc ipfo Lectoribus perfuafurus fit, aliam effe veficam quam ipfe inuenit, aliam veficam vrinæ colligendæ dicatam; hæc tamen $a b$ illa plane non eft diuerfa; foetus vero quos in eadem vidit, fi modo viderit, ejusmodi fuiffe vermes, quales \& me vidiffe jam fupra feripfi, omnino fit verifimile. Non folum itaque afferere audeo, parum in anatomia ranarum profeciffe GAVTIERIVM, fed addere etiam non ambigo, ipfas ranas eundem vix habere cognitas. Verum esfe vtrumque hoc meum affertum, fequentia infuper docebunt. Profert ille aliorum quoque de ranis obferuata, hinc vero narrat, fcribere celeberrimum SEBAM diuerfas tanarum effe fpecies : dari enim quæ in fruticetis verfentur; dari qua in locis paludofis atoue arundinetis habitent; dari qua in fluuiis ftagnisque viuant; de ranis autem fruticetorum addit nofter : credo fermonem hic effe Auctori de bufonibus; atque exin, non noffe GAVTIERVM ranam arboream, facile patere puto. Afferit dein, BLASIVM de ranis minus vera fcripfiffe, quum vafa fpermatica fomellarum, quæ ex noftri fententia ouis, nefcio quid, fuggerunt, tubas appellet; fed fi hæc, ipfi dicta, vafa fpermatica curatius examinaffet, BLASIVM certe hac in re non vituperaffet. De is referens, qua ipfe ex ranarum diffectione didicit, linguam earum anteriori margini palati cohærere fcribit; quum vero palatum pars fuperioris

Femelle, attand les inftans que les Oeufs s'écoulent de la Femelle; il jette alors fes Embrions tels que je les ai apperçûs, ils s'attachent aux Oeufs, \& s'en nourisfert pendant quelques jours, jusqu'à ce qu'ils foient en ét de fe nourrir d’ jimens plus orofliers Ces Embrions confervent $l_{2}$ même Figure qu'lls avoient dans line Geftalt to fie in Sem Stáslein bes Datters ges habt haben, ein Monat lang, wornuf fie biefe Ges ftalt wie die Beitentwirmer in ber "Pupe versindern. Gie bringen ihte bintern Beine sum Dorfhein, die fie endlid von einander thun, uno diefe Zeine madsen, wem fie now in dem. Intugen vereinitget find, ben Edwans des frofdrourins aus $\dagger$ ). Shierimen aber wie auth in Demienigen was ich oben angefithet habe,

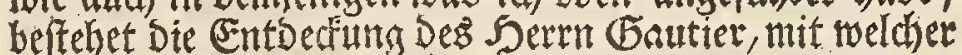
er fich fo viel neis, Dafier glaubet, went pytbatgotras felbige gemachet batte, to wuirde er Deit (Sottern noch einmal humbert Dhfen geopfert haben; ich aber follte meinen, went. Serr Gautier Dem Dythatgoras feine Entbectung erzeblen fonnte, whirbe er felbigem nitht, bote er mit feinen Sthillern zu thut pflag, ein Stills forneigen yon stwer) ober funf Jabren auflegen, fons Dern ibn auf beftundotg fotsweigen beiffert.

Daf fich Die Frofhinitmer an Die Ener anhartgen und von felbigen etliche Tange nathen follten; Dafis bies ferben ein s)ona lang einerlen Beftalt behaltent; Dafi Die hintern Ffiffe Den Schlvatz Der Frofhivurner nus: machen, wie 5 t. Bantier faget, find lauter $53 e r w e i f e$,

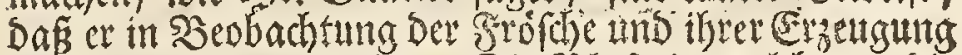
fehy untachtam geweren. Die Blafe in welcher er bie

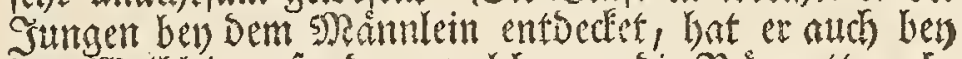

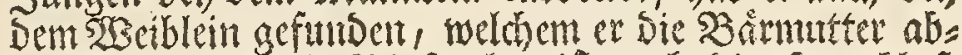
pricht; eben biefe Slafe aber if aud Die Somblafe wie fetre Sabbildungen ausweifen: Dem in feiner fectiftert Giour, weldhe ein $23 e i b l e i n$ yorftellet, nennet er fe bie Silare (la Vefie), in Der Diften, victen uns finften gur aber, welthe er zum şeweis foiner nenen Ents

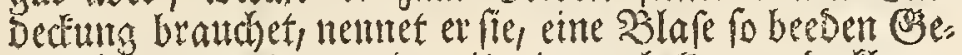
folecten gemein, uno mit enem hellen uns Elaren

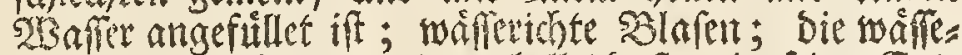
richte Blafe; hicraus aber erbellet ots er in feiner Ents

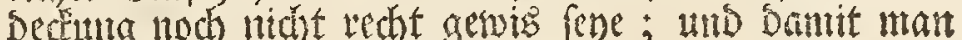

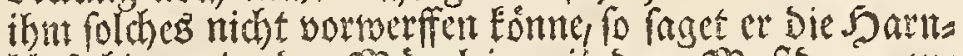
blafe bienge in Dell Sorantletil mit Dem SMaftoarm zas fantimen, Da aber wo er feine neue Entseckung beforets

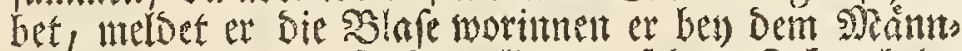
lein Die Jungen gefunden, liege au Dem Shjamberit, chen an Demtentigen Drtall, wo ben uns Die Saublare fith befinde. Db er mun alfo oleid heburch ben Qefer

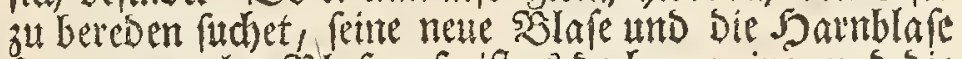

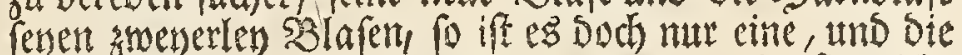
Sungen bie er Darmuen gefeben, wemn er amberfi melde Darinten seeteren, merben mohl nichts alloers als foldie sistirmer gewefen fent, won benent thl bereits oben ges

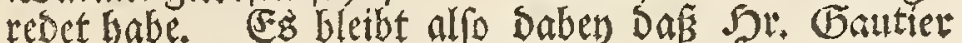
in Der Berglteberung oer frofothe nicht weit getomment

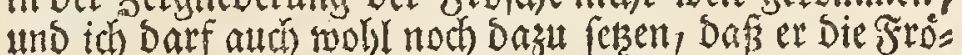
fche noch wenti fenne. Sseedes erkellet noch ferner aus folgenbem. (Ev fifiret audh anderer ibre 23 abrnelimuns gen von ben Fróficin an, mb Da meldet er aus Dem

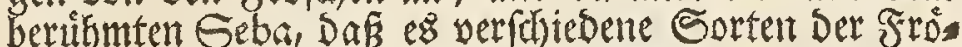
fobe gebe: als namlich einige fo im S3ebitich and im Bes frratre wohnen; andere fo fich in Stmpfen mo (Serób

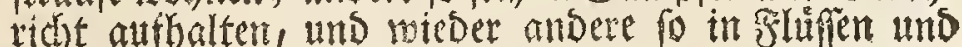

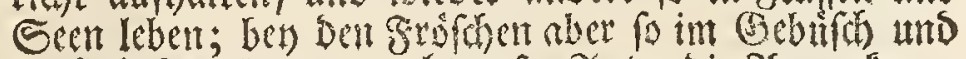

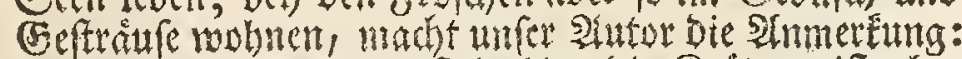
ich glaube Der 2rator berfetye bier Die Sroten ; ift abet

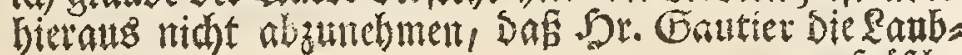
Sर 2

frofoche

Véfrcule du Pere, pendant l'efpace d'environ un mois, tems auquel ils quittent cette Figure, comme font les Vers - a. foye dans le Cocon. Ils développent leurs pattes pofter éures quils écartent erfin : ce font fes pattes oui, units dans l'Embrion, furment la queue du Tétard Enbrion de la Grenouille. 


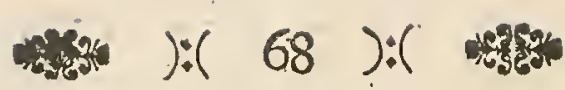

rioris fit maxillæ, credere quis poffet, linguam ranarum cum eadem nexam effe, quod vero falfum protfus foret. In figurarum explicatione veficularum meminit feminalium, in fua tamen ranarum anatome de iisdem filet; illas infuper fub vefica, in qua foetus raninos vidit, fupra os pubis fitas effe dicit, qua tamen in fede easciem nunquam invenies. Tefticulos renes appellat; ipfos vero renes, in quinta figura depictos, minus nouit. Figuræ ipfæ ranarum nec non partium earundem, fic funt effigiatw, vt mirum omnino videatur, pictorem qui \& phyficum fe profitetur, \& nouis inuentis gloriatur, easdem in publicum edere, non potuiffe. Paucis vt rem expediam, ipfum illius inuentum nuilius omnino eft momenti; miffum hinc illud faciam, quippe quod meis prius jam refutaui obfervationibus, quam mihi innotuit. Finem igitur ranarum a noftris ita dictarum hiftoriæ impono, eam nunc illarum, quas bufones appellant daturus.

\section{F $\quad I \quad N \quad I \quad S$}

Hiftoriæ ranæ viridis aquaticæ.

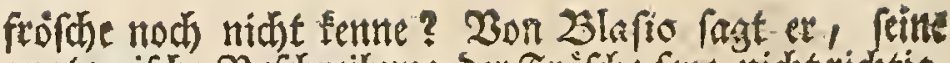

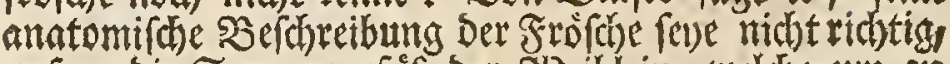
et laage Die Saamentgefáfe Der 23 ciblein, welche, um an

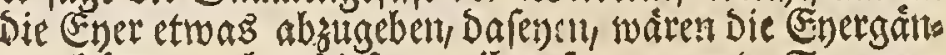
ge; bátte ex aber biefe son ifm fo sellannte Saaments gefare redst unterfuchety fo weitse er 3 lofium nicht ta:

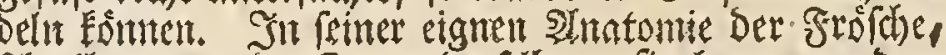
6hreibt er von Der Bunge Derfelben: fie hange an Dem Rand Des sorbern Theilez Des S3muten an, Da mun aber Der Baume im obern Riefer ift, fo follte man ja

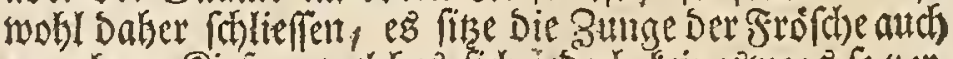
an obern Riefer, welches fich feood feineswegs fo ber.

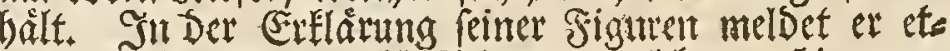
was yon ben Saantenbläblein, won weldhen er hingegent in Der 2 efchreibung feiner 2 tnatomie gar nid) ts faget er ferbet fie aber unter bie 2 lafe worinn er bie Sumgen ges feben gleich uber.Das Sd)ambein, wo fie Dod ibre Las ae gar nidt haben. Die Seilen nemtet er Nieren, und bie sieren weldie ex in Der fünften Figar sorftellet, fennet er nicht. Die Figuren felbit fo er uns yon ben Frófhen und ifrer Serglieberung mittheilet, fitid fobes (c) affen, bafi man fith allerbings watntoent mufí, wie

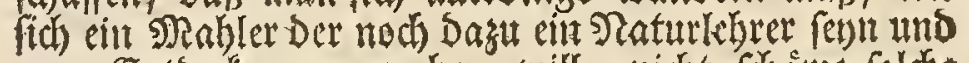

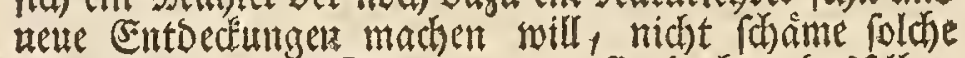
heraus zu geben. Surz, Die ganze Entbeckung Desfelben heifit nidhts, baber swill id mich and) nicht länger bas

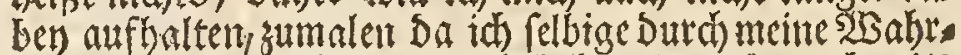
nefmumigen, che fie mir nod) befannt worden, bereits wiederleget habe. Schendige alfo hiemit bie Siftorie ber biefigen insigemetit fo gettannten Fróphe, und wens

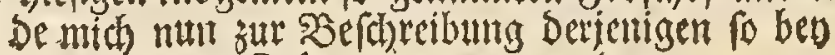
แnz Rróten genenmet werden.

\section{せ $\mathfrak{D}$}

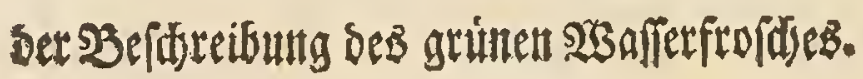




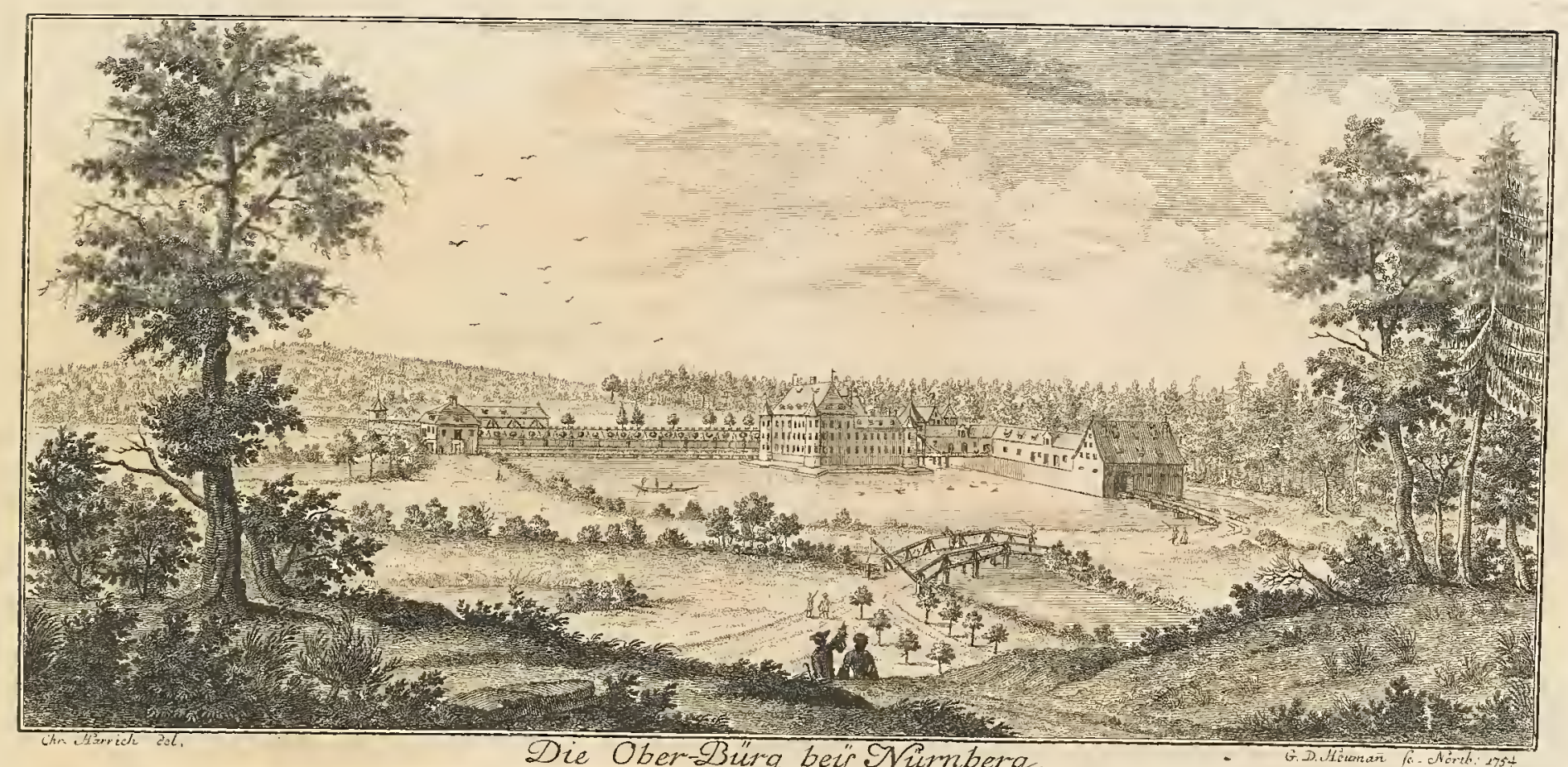

Die Ober-D̈urg beis Sirmberg

\section{HISTORIA NATVRALIS RANARVM NOSTRATIVM. SECTIO IV.}

\section{BVFO AQVATICVS, ALLIVM REDOLENS, MACVLIS FVSCIS.}

DSe

(2)

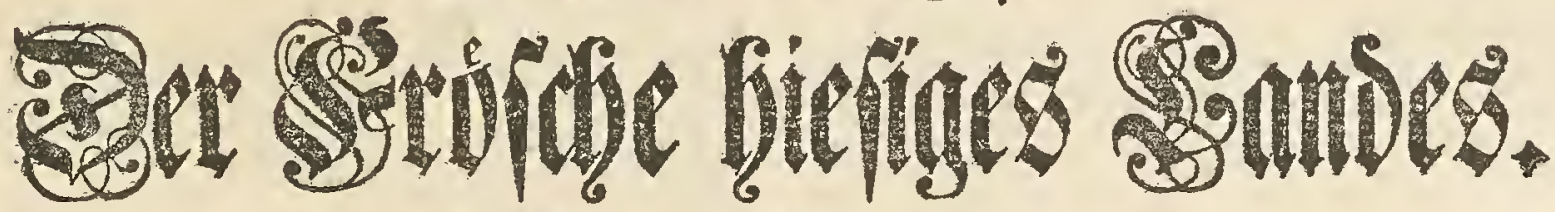

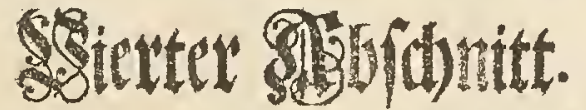

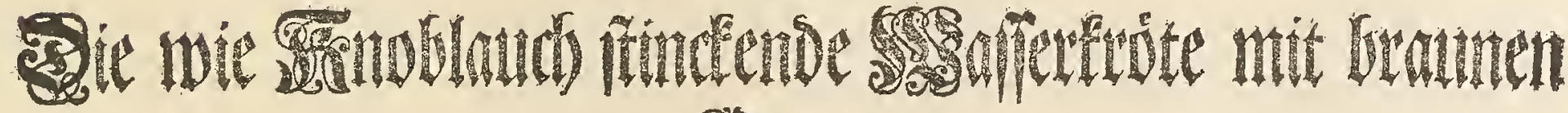
getertitn.

CAPVT I.

Bufonis aquatici, allium redolentis, maculis fufcis, externus habitus nec non aliae proprietates.

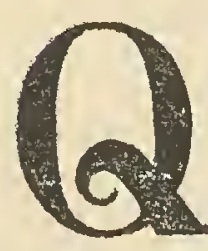

uifeculo decimo fexto nec non decimo feptimo magnum inter medicos aeque ac chemicos adeptus eft nomen, ANDREAS LIBAVIVS, ranas in genere, in binis illis libris quos de ranarum natura et vfu etc. confcripfit $(t)$, in blandas atque turpes difpertitus eft: blandas illas appellat, quas vulgo ranas, turpes, quas bufones dicimus.

(t) Singularium ANDREAE LIBAVII Pars quarta \& vltima, continens Hiftoriam \& inueftigationem fontis medicati ad Iubarim fib Rotemburgo: Libros Batrachiorsm
Suteres Coptitel

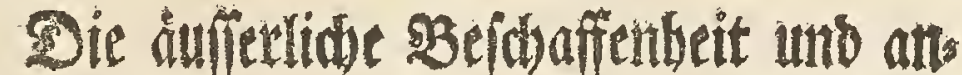

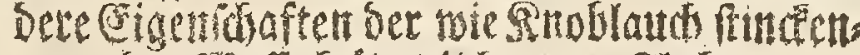

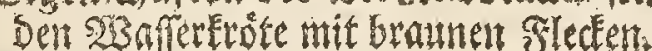

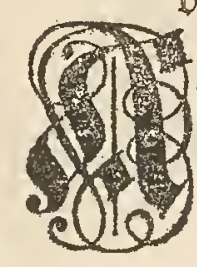

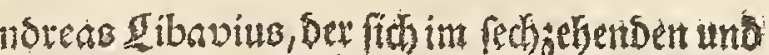

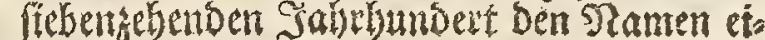

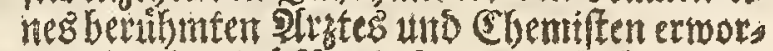

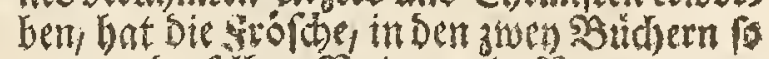

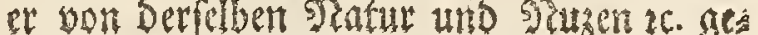

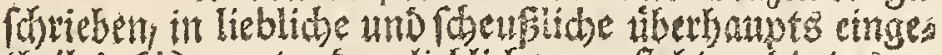
thetlet $(t)$ : anter ben lieblition verfeft et bie insges (5

thetris

duos de natura, vfu \& Chymia raßarum vtriusque gene: ris \& $\mathrm{c}$. 
Annumerandas effe ranas, in tribus fuperioribus fectionibus a me defcriptas, blandis, omnes credo mecum fentient, quippe quae gratae potius quam turpes fint afpectu; quim vero praeter has nullam nouerim noftratem quae blanda dici poffit: ad turpes jam noftrae regionis, quas vulgo bufones vocamus, progredior ranas, quae, docente fic celeberrimo FRISCHIO, (*) ab antiquo verbokr. ten, repere, nomen fuum germanicum Kroeten traxere. Atque hac in re, quantum ego quidem video, FRISCHII potius quam illorum fubfcribendum eft fententiae, qui vocem Krotte fiue Kroete a Grotta, antro vel fpecu quodam deriuant, licet nobis conftaret, hanc vocem non a gallica illa Grotte, fed a germanica noftra Grube originern fuam habere. Quamuis enim bufones ejusmodiantra, rudera nec non obfcura, tenebricofa atque vliginofa ament loca, mas tamen reptatu quam habitaculis hisce a ranis differunt. Hae, ob crurum pofteriorum longitudinem, grandi faltu facile de loco feruntur in locum; hufonibus contra pofteriora crura funt breuiora, ita, vt licet faliant, ipforum tamen faltus ranarum faltui nunquam fit aequalis.

Aft enim vero ca non folum bufones inter ranasque eft differentia; fed funt illi etiam afpectu adeo horribiles, vt eosdem confpicientes, magis, quam vbi ranam forte afpicimus, obftupefcamus; folent praetera bufones, prae ranis, fi propius quis ad eosdem accedat, vel timore perculfi, vel fefe defenfuri, lotium ejaculare; virum re venenati atque adco ipfis ranis fint nocentiores, ego fere dubito, quippe qui ex eorundem examine nullam omnino paffus fim noxam. Ét vero et hoc bufonibus proprium, vt noctu potius quam diu efcam quaeritent, viuisque vtplurimum infectis inhient, atque hanc ipfam ob cauffam haud facile iidem, ve ranae, diurno cernuntur tempore, folo illo quo coitum celebrare folent excepto.

$\mathrm{Ob}$ loca quae bufones habitant, vel terreftes dicuntur?, vel aquatici: latent namque illi in cauis quae accliui

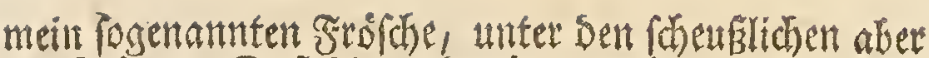

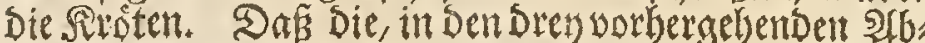

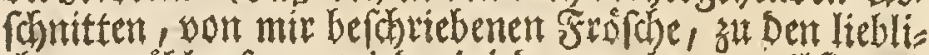

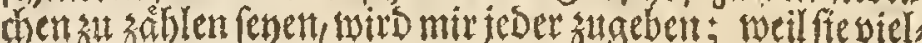

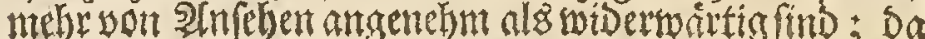
mir aber aufer Diefen Dren Srofohen, font feiter be:

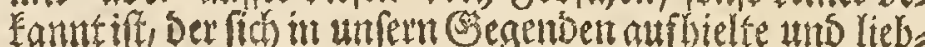
lich sententet werben Eonnte: fo conme tob nun su ben

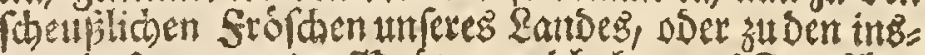
aemein fo genannten 2 ro otem, welche bey uns Dentichen wie Jert stifh leftet (*) von bem alten Zeitwort tru pen, für Eriechen, allo genemtet werden. Sierinmen aber verbienet 5 err frifi, meiner (sinfiont nadh, aller. Dinges mekr $23 e n$ fall als Diejertige, welde Das syort

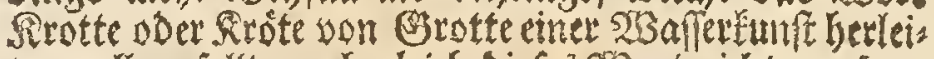

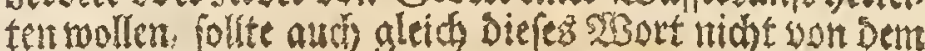
Granzofiffifen Grotte fondern von unferent Deutfoth OStubebertominen: bent ob fich fifon Die Siroten ger.

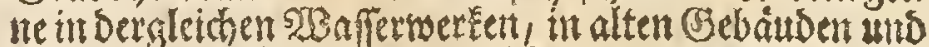

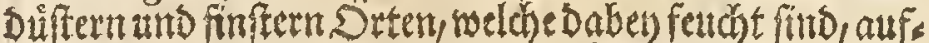
zubaltet pflegen, fo unterfectiden fie fich hieburch Doch midht fowohl, ald Durd ibe Rrtedien, you andern Fros. foren. Diefe foimen, sermittelft ihter langen Silters füfe, wort einem Drt jum andern zientich weit Gupfen;

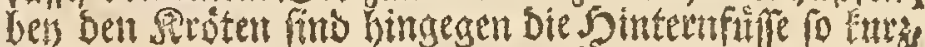

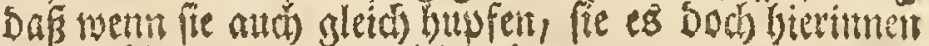
Den Frófhen niemalen gletdi thun.

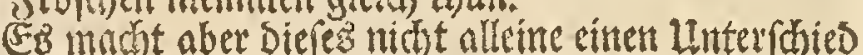

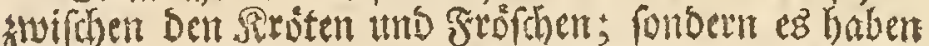

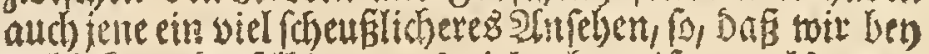
Evblidung Der felbigen uns sielmeht entrezen, ols wenn

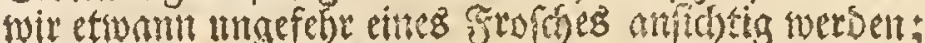

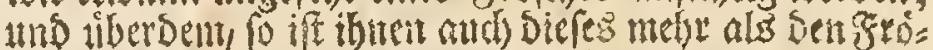

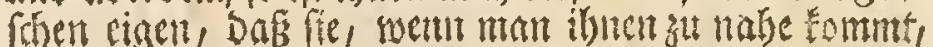

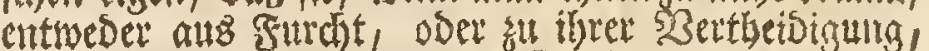

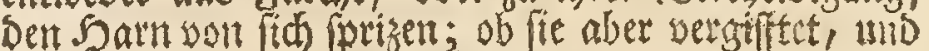
alfo idneslicher als bie srobche feten, baran folle ich

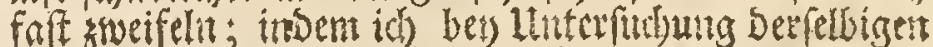

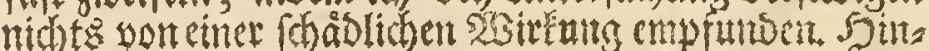
geaen babenfie betinten wieder cine eisenfohaffe, mels d) an Den Frófhen nicht watirgettomment wird, bafis

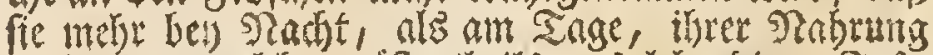
machehen, welche grofenthetls aus lebentigen Juthe cten beffeliet: eben deswegen aber wird man ibler, wernt wil bie Beit $D_{a}$ fie fid pareit nusinebmen, nu

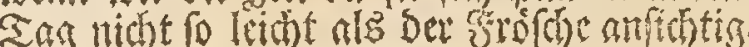

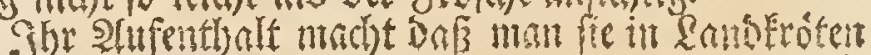

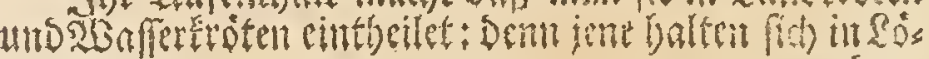
(b)ert

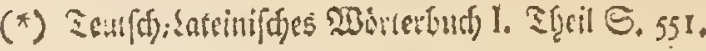


Tab. XVI
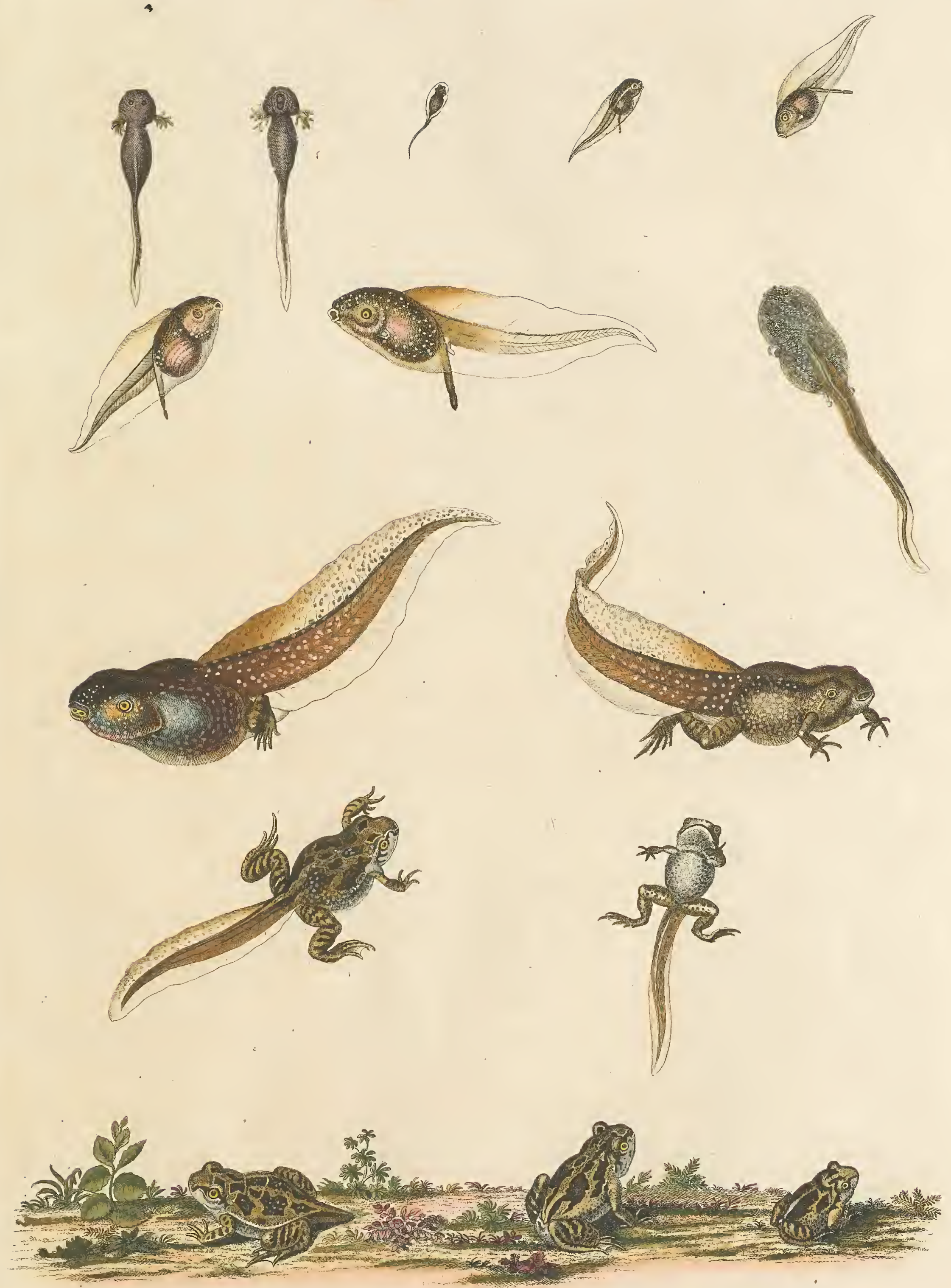


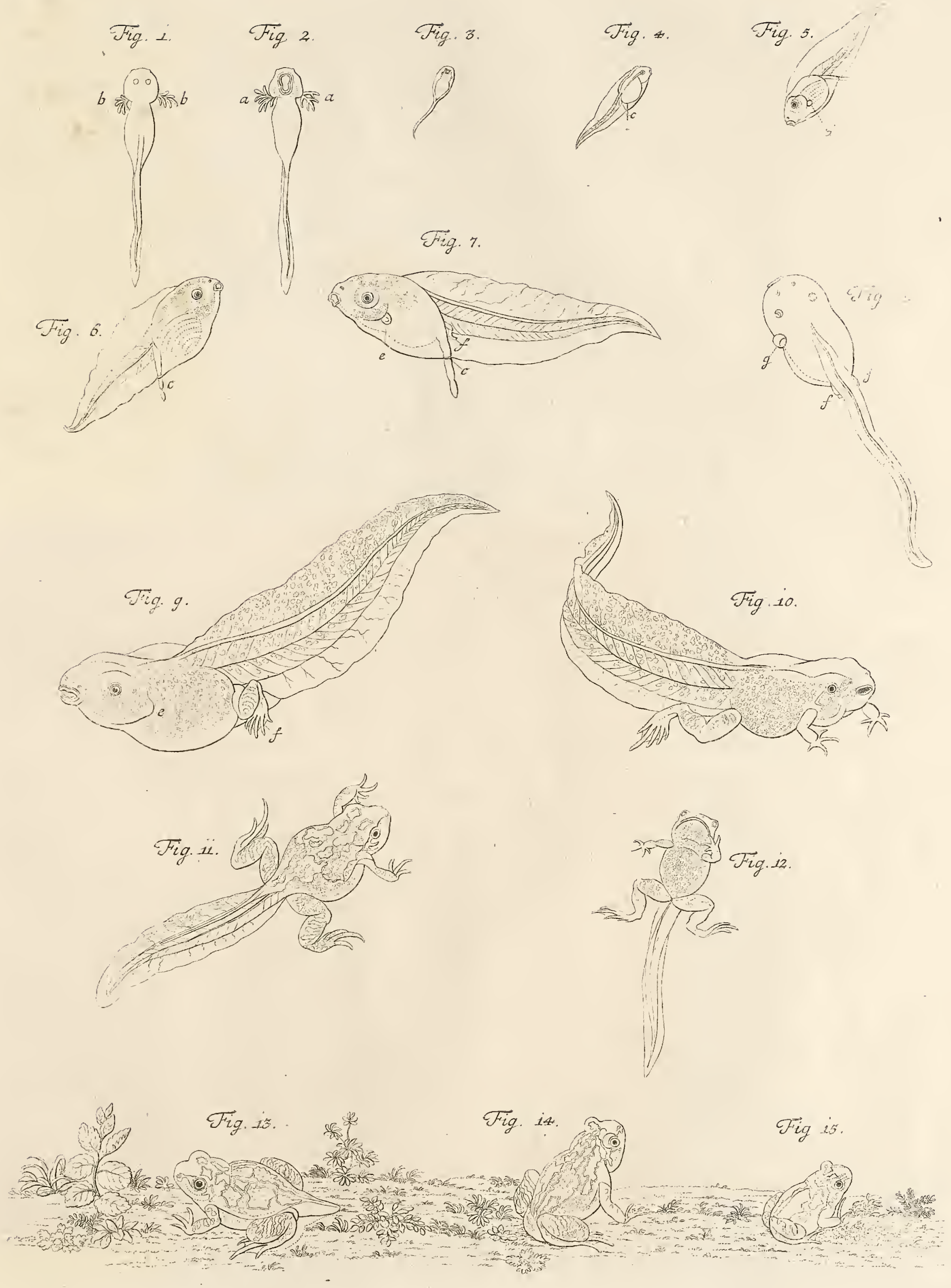



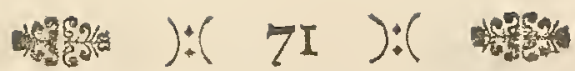

hioco, plano in campo vel fub ruderibus eum in finem effodiunt, vt non folum a folis calore, quem omnes bufones minime ferunt; fed etiam a miluo cauda hirundinina; a ciconia atque $a b$ aliis auibus tuti fint. Addo autem hic inimicis bufonum ciconiam: licet namque alii fcribant, nullos illam deuorare bufones, ipfe tamen contrarium his meis vidi oculis. Amant contra bufones aquatici vliginofa loca, ficca vitantes: vt vero frigus hibernum ipfis minus noceat, in fluminum limum vel vdam in terram fefe abfcondunt; bufones contra terreftres, per hiemem quoque, in ficcis fuis commorantur cauis. Licet autem eam ipfam ob cauffam, ceujam dictun eft, bufones difcrcpare putent, uterque tamen verno tempore, quo coeunt, qantum ego quidem noui, ipfas fubit aquas ouaque fua in iisdem relinquit, atque hinc fit, vt illo etiam tempore in aquis, vtut rarius, confpiciantur. Ceterum hiemali tempore bufonum latitantium ort, aeque ac ranarum, minus effe claufa vel concreta, affirmare audeo.

Quotnan noftra in regione bufonum dentur fpecies, me quidem ignorare fateor; interim tamen tres earundem cognitas habeo. Primus eft bufo, mihi fic dicrus, aquaticus, allium redolens, maculis fufcis, qui rarius fere cernitur. Alter vulgaris ille neminique non notus eft bufo dorfo cuberculis exalperato, qui quidem vtplurimum noctu, nonnunquam tamen durno etiam tempore, e latibulo fuo prodit. Tertius eft bufo fic dictus igneus, qui hoc nomine exin forte appellacur, quod in inferiore corporis fui fupcricie aurantias vel rutilas gerat maculas, in fuperiore vero ater potius quam fufcus fit. Rarius hic, quam bini priores, offenditur, quin vidi ego eundem heic loci femel tantum, licet vero eo ex tempore octo jam elapí fint anni, nusquam tamen eundem amplius reperire potui, ita, vt hinc dubitem, vtrum illum hoc in opere fim defcripturus.

Sect quod jam primam horum bufonum attinet fpèciem, quam Tabsia XVII depictam dedi cujusque hiforiam jam fum traditurus, appellandam illam effe ratus fum, bufonem aquaticum, allium redolentem, naculis fufcis. Nomen bufonis aquatici hine ipfi competit, quod et ante et poft coitum in aquis reperitur; quum autem, quemadmodum jam dixi, id ipfum rarius contingat, verifimile eft, eundem parum effe cognitum et a nemine, quod fciam, curatius defcriptum. In terris femel tantum, dum hifce animalibus inueftigandis operam do, eundem offendi. Eram aliquando, autumnali tempore, in pulcherrimo illo praedio, quo hujus fectionis frontifpicium exornatum cernimus, cujusque nobilifimum DOMINVM vt fummum veneror fautorem, quum cjus conceffu ildiden pro arbitratu meo commorari poffim, ita, vt hinc ipfius beneuolentiae plurima mea, ad infecta aeque ac ranas noftrates attincntia, debean inuenta; heic igitur verfans, contuli me aliquando matutino tempore, ante lucis ortum in locum a praedii domicilio haud longe remotum, in quo leporem me forte offenfurum effe credeban, quumque durante diluculo omnia fefe mouentia objecta diligentius obferuabam, non longe a me diftans vidi corpus a reliquis dificilius diftinguendum, irrequietum quidem attamen vnum eundemque conftanter occupans locum. Illucefcente aurora filentibusque ventis illud ipfum fefe moucre, certior quidem reddebar, fed ipfo oriente fole mutabatur corpus, quod leporem effe putabam, in lappaceum fruticemi, ad editiorem ri-

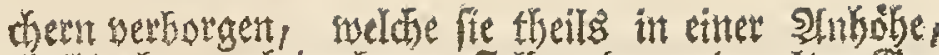
theils aber auth in ebenem Seld, ober unter alten Se= miner ausaraben, um nicht mu alleme fitr ber Son

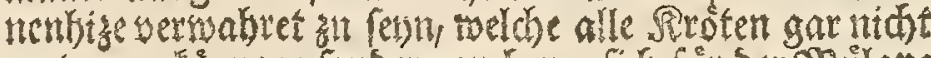

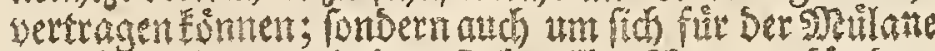

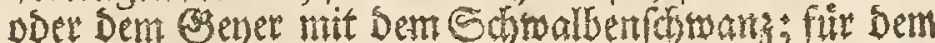

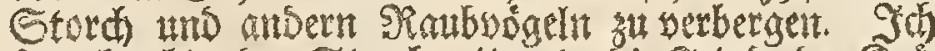

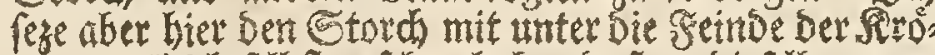

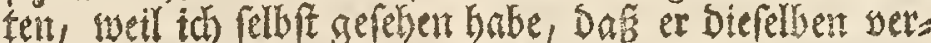
3eljret, wenn gletd motse Das (segentheil behauten

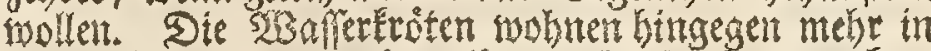
fumwfithen Orfen uns metsen vielntebi bas trodente

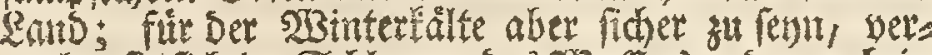
grabenfe fich in Edhlamm des Syafers, oder auth in feutite (EvDe; Da Gingegen bie Randeroten fioi) aud) Den

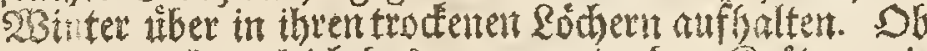

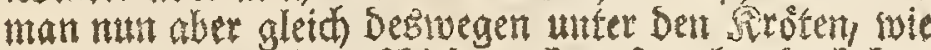

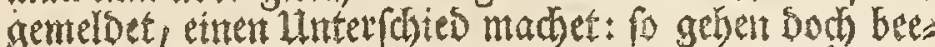

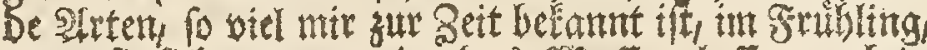

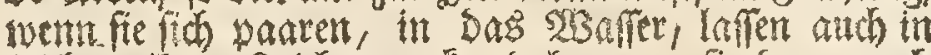

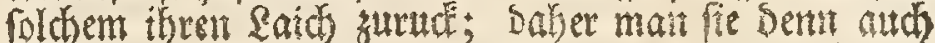

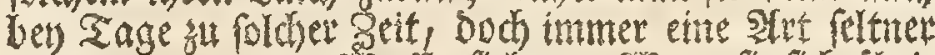

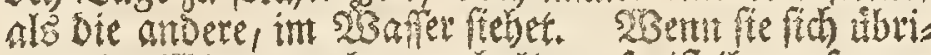

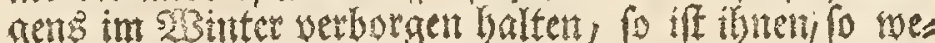

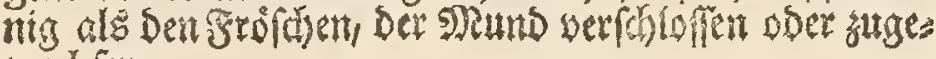
wachert.

WBie sielerlen Tretn son Rrotent es in unferem

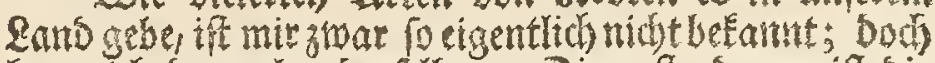
Eeme id Drebetlen Derfelber. Die erfte Datont ift bie

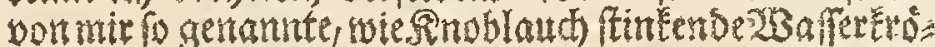

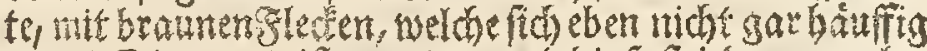

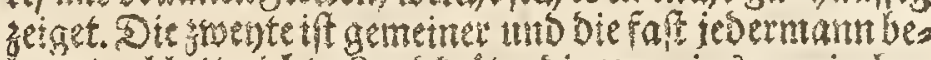

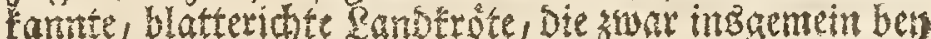

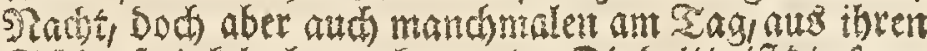
Ed)lupininteln beroortentmet. Die britte if bie foge namte Fenertrote, welche ifeen samen vielleid t baher

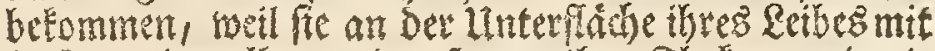

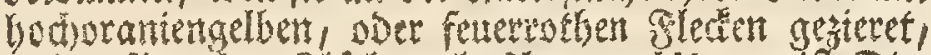

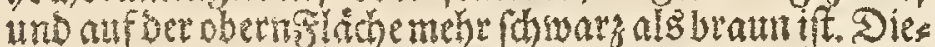

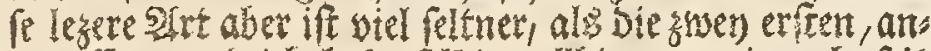

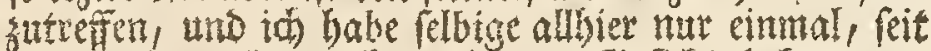

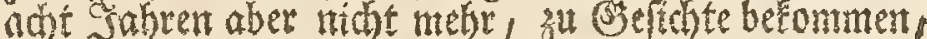

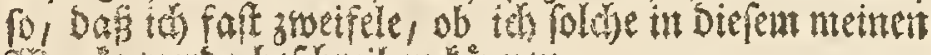

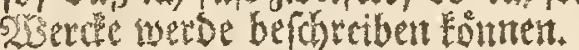

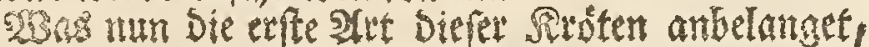
welche wir auf Der XVII. Cabelle abgebildet fehen,

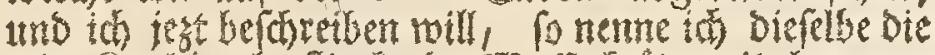
wie sendolaum fincrende smafertrote mit brament Flethen. Sie fam aber beswegen eine 53 a fiertrote beif

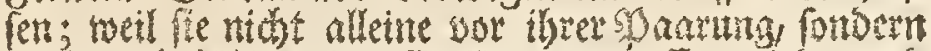

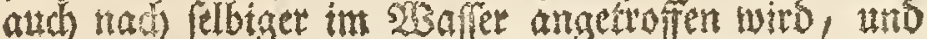
Da foldes, wie bereits genteldet wordent, felten gefintes bet; fo mag fie soobl nidbt viel betannt fersm, twie fee

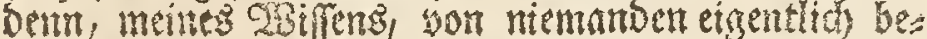
fobrieben worbent. Suf Dem Sande babe ich Diefe Rros te, fo lange iof mich mad) Dergletdien (Sreaturen um:

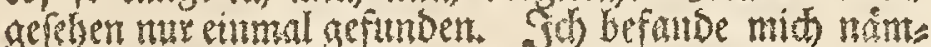

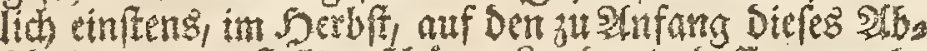

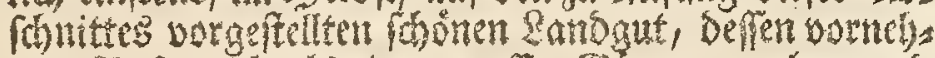

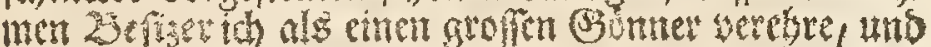

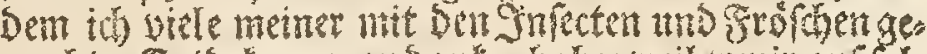

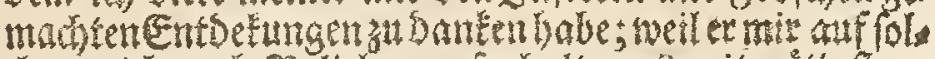

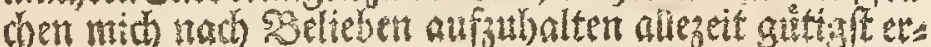

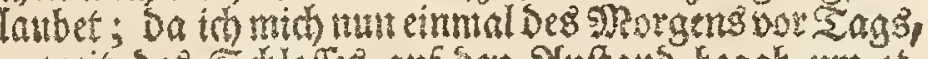

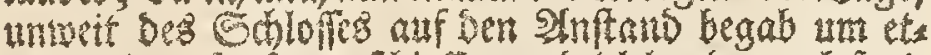

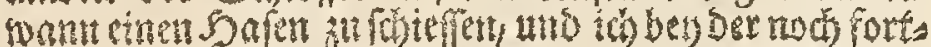
Daurenoen Dismmertitg auf alle fich bewegende Segen:

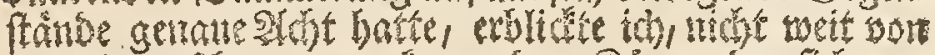

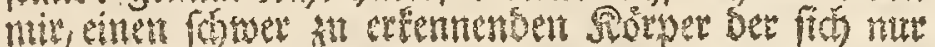

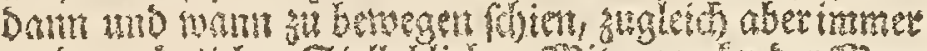

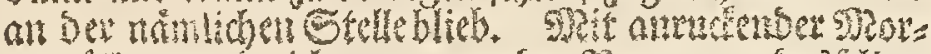

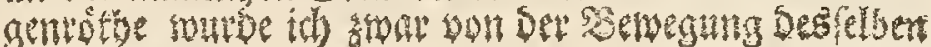




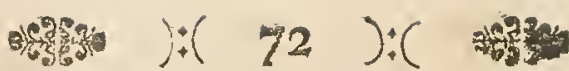

pam colliciarum procretum. Indignabat quidem, me tam turpiter fuife delufum, omnemque fpem necandi leporis, ob diem magis magisque illucefcentem, nunc effe inanem; quum vero denuo folium quoddam hujus fruticis vi quafi quadam moueretur, curiofior redditus, propius ad illum accefii. Vidi tum folia diuerfis in locis ef fe arrofa exefaque, atque hinc fufpicabar, fore vt erucan aliquam minus mihi cognitam hic deprehenderem hanc autem dum quaero, minores quosdam inueni limaces, fimul vero teterrimum allii percepi odorem, ita, vt allium pedibus me conculcaffe autumarem inque it lud inquirerem; fed detexi tunc, non fine horrore, bufonem nunquam mihi vifum, quem tamen mox craffiore fcloperi parte occidi, poftea vero eum in finem diffecui, $v t$, vtrum folia lappae arroferit, cernerem: illo enim tempore pabulum bufonum minus noueram; aft rullas, in ventriculo ejus, foliorum hujusmodi intieni reliquias, fed nonnullos modo memoratorum limacum, nec non.alias quasdam infectorum fpecies.

Fufius haec narraui, indicaturus me fimul ac femel tria reperiffe didiciffeque: bufonem puta, antea minus mih notum, quemque pofthac nusquam amplius in terris, femper vero in aquis inueni; pabulum efcamue ejusdem, non plantis, vt quidem falfo putaueram, fed infectis conftans, tandemque fingularem illum allii odorem, quem tum bufonem fundere minus credebam, poftea vero, vbi ranas curatius examinaui, eidem omnino adfcribendum effe, edoctus fum. Quum enim aliquando varias inter ranas, quas domum deportandas curani, nonullos etiam bufones hujus fpeciei obtinui, atque hos a reliquis fe paraturus, feorfim in vitrum quoddam indidi, in vicinis hujus vitri ingratum femper allii percepi odorem, qui agitatis forte bufonibus fortior reddebatur, quin vix ac ne vix quidem ferri poterat; quum propius ad vitrum accedenti naresque admouenti lacrimae ex oculis manarent, perinde ac fieri folet vbi raphanum majorem vel cepas olfactamus; interdum videbatur quoque huic allii odori vapor, quem accenfus pyrius puluis emittit, admiftus effe. Hinc vero indidi huic bufoni nomen bufonis allium redolentis: quin eam ipfam ob cauflam turpibusannumerandus eft ranis, licet ceterum afpectu haud adeo fit turpis reliquisque bufonibus altius faliat. Sed indicandum infuper eft, percipi etiam tetrum hunc odorem, licetipfe bufo extra aquas verfetur, vbi vero eundem diffecui illiusque partes ftudiofius examinaui, minus me illum fentiiffe. Vnde igitur oriatur, me quidem latet. Obferuaui tamen, tollere bufonem hunc, fi tangatur, pofteriorem corporis fui partem praefertim fi ex aqua fucrit protractus, atque hinc verifimile mihi videtur, prodire foetorem hunc ex ano, feu ex ipfo inteftino recto; quum vero non folum vefica, fed et in mafculis veficulae femen continentes, in foemellis vero vterus in illud hient, nihil hic afirmare audeo. Cur autem in bufonis hujus denominationefufcarum meminerim macularum, effigies illius facile oftendet: cerminus namque fuperiorem ejusdem fuperficiem plurimis inaequalibus, irregularibus fufcisque, in fundo dilucidiore, fcatere maculis, quarum illae, quae majores funt, dorfumque vtplurimum occupant coloris funt faturatioris. imner mely uns mebe senfthert, zumalen $\mathrm{Da}$

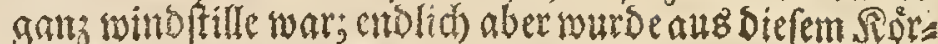

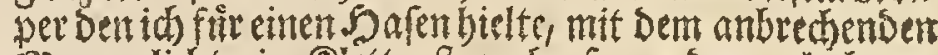

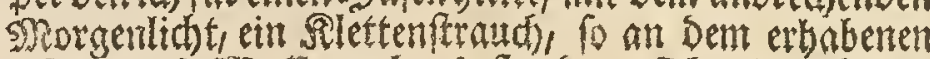
Ufer eines 2 baffergrabens funde. Db es mid mun gleid yeroros, Dafic ich mich to lebr betrogen batte, int id) nun, weil esi immen beller watbe, Eeinen Saren

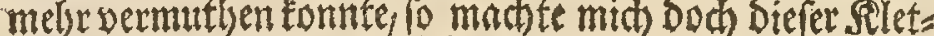
fenftratudy an weld)em fid eben wieder ein 23 lat po be= wegte, als ob man mit flets saran ftetefe, gans itentais:

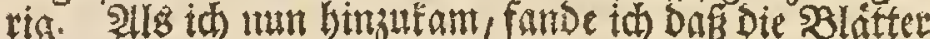
besielben bier uno da angefrefien waren, unb diejez brachte midh aur bie Bermuttang, id wuirde bier etto ant ente mir noch unbefante Shaupe entbeden; als ich aber nach folcher furthte, fanbe id) itnt Der Saupe einige weif

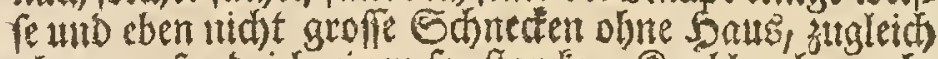

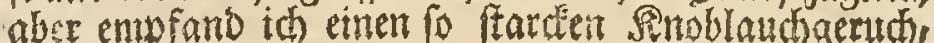

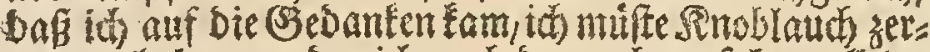
tretten Gaben, und mich auth Darnadi umfal): allente Da entsedte th, mit eintgem (E)

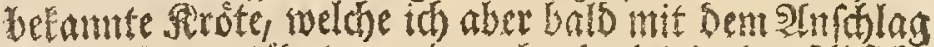
meinet Slinte toobete, uno nachgebentos in Der alb/ich

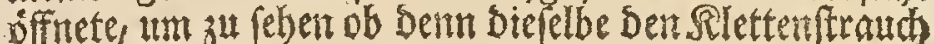
aitgefrefen batte: Dem Danals war mir Das Futter Dicfer (Ereaturen fo eigentlich nod nidbet betannt; alleint

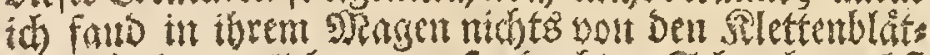
tern, fonbern etliche von erfigebanten Sdneden nebre einigen andern Jnfecten.

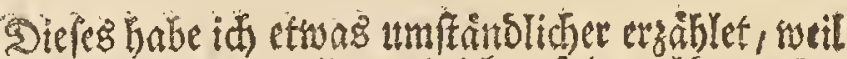

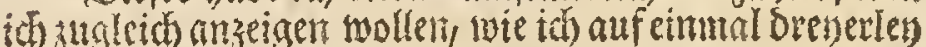
entbecket: mamlich eine mir nod unbefamte Rioter weldye id aber niemalen wieder auf Dem Rand, fondern allezeit im $53 a$ fier nadigebends geftnoun babe; inte Speife, bie nicht, wie ta) fálf(c)lich glanbete, als soflan: zen, fondern aus Intecten beftebet, und Dent Denbefon:

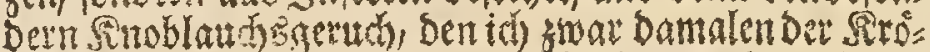

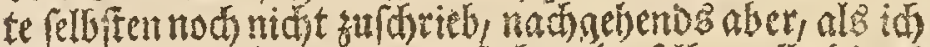

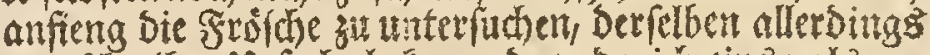

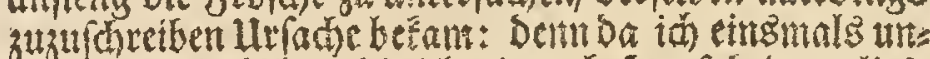

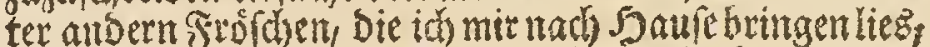

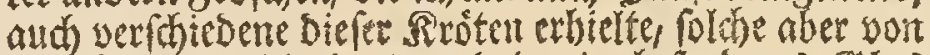
ben vibrigen abfonderte und in ein beronderes ejlas

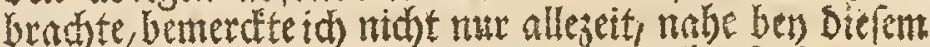
(Sla8, cinten wibrigen Sinoblauchgerndi, fonocrn t8 watroe felbiger, wern ith etwamn Die Rroten bemtuthigs

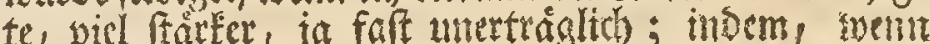

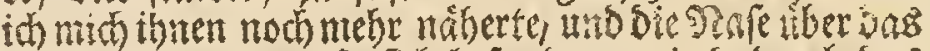
(3) las bielt worinn fie fio befonden, miv Daburdi bas

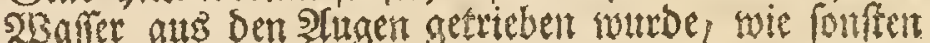

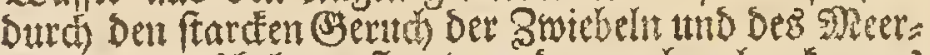
rettigs zu gefdeben pfieget; und mantlmalen fam ess.

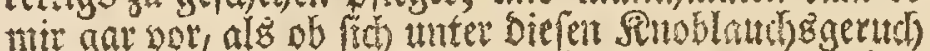

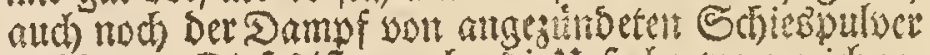

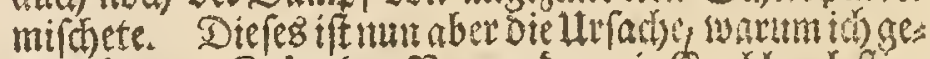
gemoartiger Rrote ben Pamender wie Sinoblaubl fin: fertben Sirote bengeleget unb eben bestorgen verbience

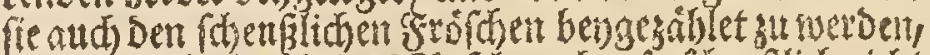

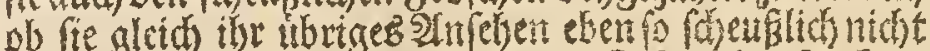
mad)et, folde audi melse als andere Siroten hup fen ton. Don ibrem garfigen (S3ertud aber babe ich nod Diefes

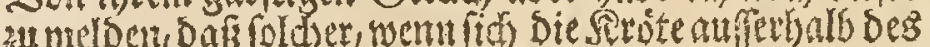

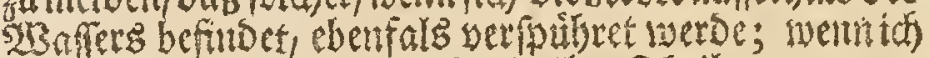
fie aber anfaefonitfent unt alle ibre Sheile gettat uns

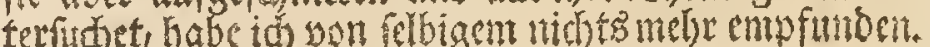
Daber weis ion midjt angugeben, woljer berfelbe feinent

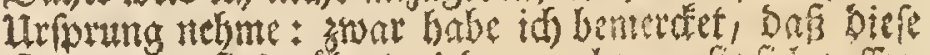

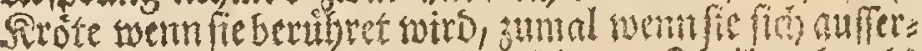

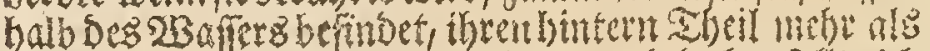

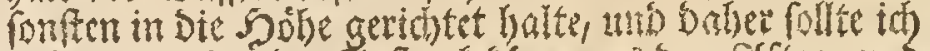

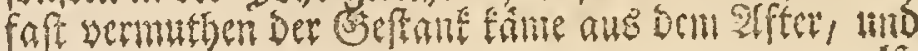




\section{4.}

alfo ats Dem Saftsarm; Da fich aber nidbt mur alletne bie SJarnblafe, fottoern audh, ben Den Nainnlem, bie Eaantenbléslein, uno be1) Den SBetblein Die Bermuts ter in Denjelben soffinen, fo laffet fith Desinegen nidhts serwifes beftimment. Warum it aber, in Der Benents thut Diefer Rrote, auth Der bramten šleden ged adt,

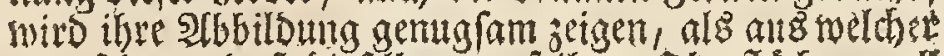
zu erelen, bas biejelbe, auf ibrer Sberfläche, woll

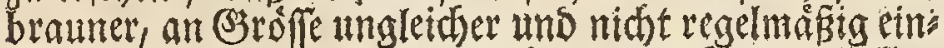
getbeilter Fleclen fene, weld)e alle auf etrem bellert 3ranto ftelsen, und worunter Die aroffen alleseit bie Duncfelften find, aud insgentein Den SRliden einnebnten

Sollte femand Diefe Rróte aufzuludyen \&uff befoms

Si quis bufonem hunc fuerit capturus, menfibus Martio atque Aprili id peragat oportet; iisdem enim et coire et oua emittere folet; fed cautius hac in re agendum eft: licet namque toto interdum corpore, majoribus pulnonibus fuis aere repletis, aquis innatet, vtplurimum tamen caput fuum non vitra oculos exiisdem exferit; fimut lac vero propius quençuam accedere percipit, fundum petit inque eo tam diu moratur, vt vbi turbida profundiorque fuerit aqua, eundem vix amplius confpicias. Eam ipfam ob cauffam labor certe ac fumtus mihi fuit impen. dendus, vt pro examine horum bufonium inftituendo fufficiens mihi eorundem fuppeteret numerus; id quod praefertim anno 1754 ex voto mihi fucceffit. Sed confideremus jam bufonem hunc diligentius.

Superat femper foemella mafculum, vbi vterque fo: litam adeptus eft màgnitudinem; nullam tamen vidi foemellam quae, ad alias ranas comparata, majoren fuperarit ranam aquaticam, fi tempus illud excipias quo coeunt: tum enim $o b$ abdomen ouis refertum turgidiores videntur ; funt tamen mafculi aeque ac foemellae hujus bufonum fpeciei magis craffuli contractiorisque corporis quam aquaticae ranae, cruraque illorum pofteriora, perinde ac omnium bufonum, breuiora funt quam reliquarum ranarum. Ceterum parum differt mafculus a foemella, ti mat gnitudinem excipias, quoad ftructuram externam, neque eft illi tam craflus nigerque pollex, qualem in pedibus anticis ranae aeque terreftris ac aquaticae vidinus; aft enimuero, quemadmodum rana arborea eodem minus indiget, fic et mafculum hujus bufonis illo carere poffe, patebit, vbi de coitu illius fumus loquuturi. Quod vero ad colorem attinet, differre mafculum a foemina facile cernimus: in illo namque flauefcit vnicolor albaque inferior fuperficies, in hac vero cinerea eft ejusdemque coloris maculis confperfa. In vtroque ceterum cranium magis eft fornicatum quam in reliquis ranarum fpeciebus。

Fufca eft fuperior fuperficies ob maculas, quibus fcatet, ejusdem coloris dilutiores faturatioresque, vter tamen horum colorum haphe fit dicendus vix diiudicaueris. Dilutiorem eam effe ponam, faturatiorem maculis relinquens. In foemellis itaque dilutior color valde interdum ex pallido cinereus eft, in mafculis contra ex flauo fulcus; fed obfcuratur hic plúrimis minoribus nec non quibusdan majoribus faturate fufcis maculis, inaequalis aeque ac irregularis formae. Maiores femper fere funt obfcuriores, mediumque inprimis occupant dorfum, vbi tamen dilutiore, nec non in longitudinem ducta linea ab.inuicem disjunguntur. Annumerandae majoribus quoque funt maculis illae capitis crurumque, latera vero occupantes, v.t magnitudine

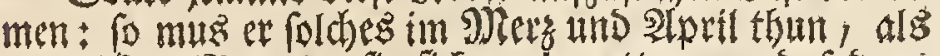
in welchen Sonaten fie fich su-begattent zu laichen pfleget: man bat aber baben sieler Borfich nothig; Dem ob fie fich wohl, went ibre groffe 2 ungte mit Suft angefillet if , mandimalen mit Dem gansent Reib alf Der Sberfhede Des 2 Gafers zeiget, folâfetfie Doch meiftentheils ibren Ropf nut bis an Die 9angen

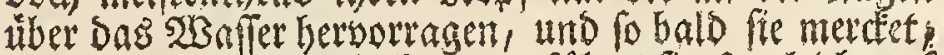
Das ibr etwas zat nabe fonme, fabref fie fo gleted anf

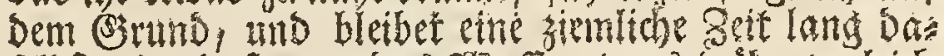

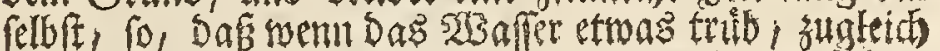

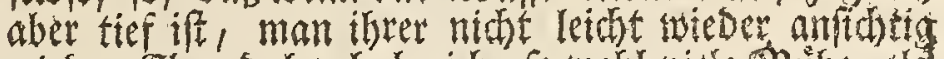
wird. Eben baher habe id), fo wohl viele putithe als

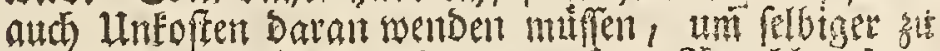

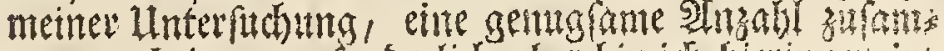

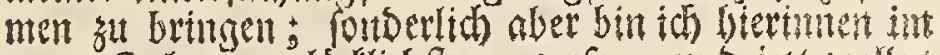

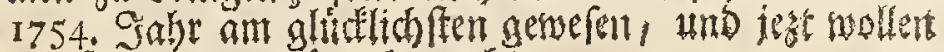
toir fie etwas genatuer beftadient.

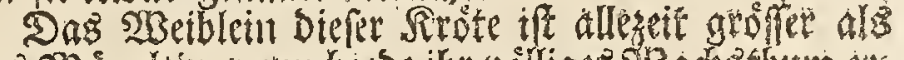

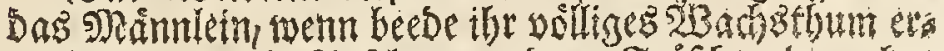

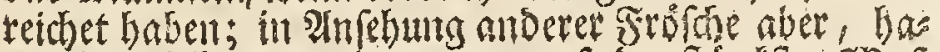

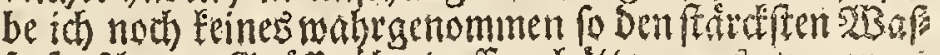

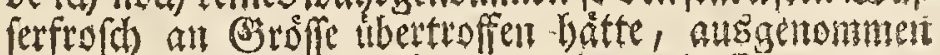
sur Sananngsoit, Da fe weaen bes mit Enern an fillten Reibs vel buter erfotmen; Ded fim fo wobl Die Matnnlein als W3eiblein, von Diefer serotenart, oon Reib megr unterfester anto zufammige foblener, als bie Safferfrofore, und die bintern Sdjender finb ben fé nen, wie ber allen Siroten, aud Eurzer als ber Diefer.

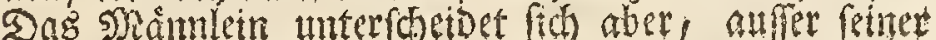

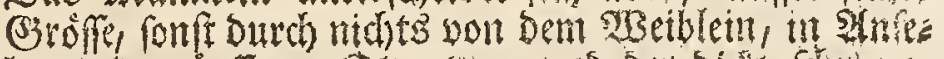

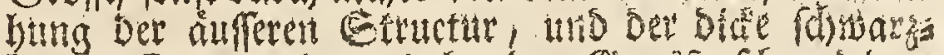
braune Daume, ben wit bey Dem Sresfrofoh uno best 23aferfrof

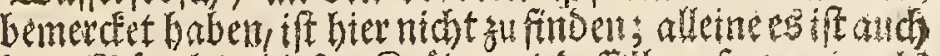
Das SRannlein Diefer Serotenart Deftelben fo postig als

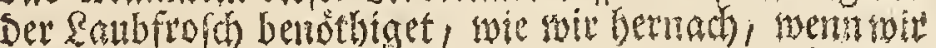

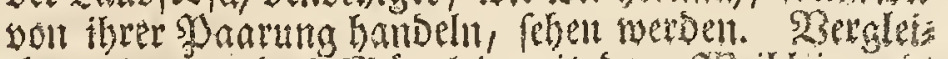
chen wir aber Dab SRannteit mit Dem SBbiblen, in

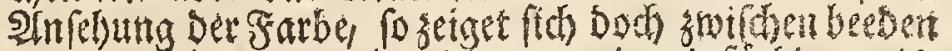

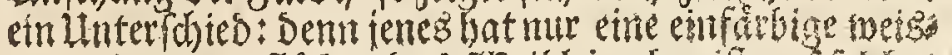

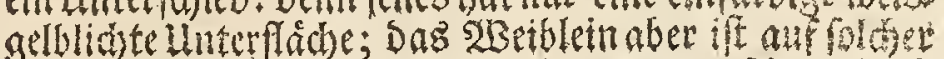

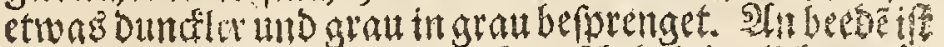

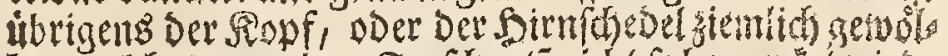

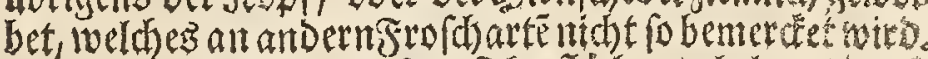

T3as die Farbe an Der Dberfláche andelantget fo if foldhe swar braun gefledt, aber fo, Daf es far

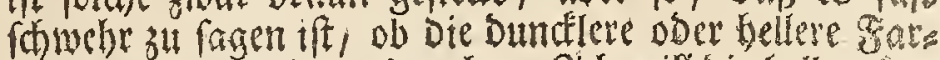
be die (Gnmo rarbe ausmadb. Sith mill bie bellere bas fir annehmen, und Die Dimdelere Die Bierrntén ober

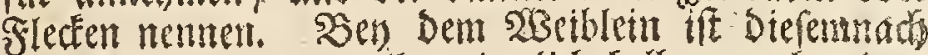
Die (Srumb farbe zandeilen giemligh Gellgrat, ben bem spennlcin ober geneiniglich gelbbram, uno in biefer befinden fich feth viele tleine; nebfe eintgengroffent but celbramen slecten, welche alle voit maleidser món un regelmåşiger Form fint. Die grôfen fallen sllemal an Dunderfen ans uno befinden fich fonberfich tam bie shits te Des Sultens, in Der s)dite folbft abet werben fiey

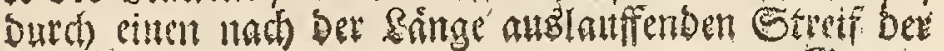




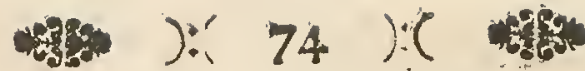

decrefcunt, fic pallidiores fenfim fenfimque redduntur. ?aucis vtrem dicam, fumilis mihi videtur fuperior haec uperficies tabulae cuidam geographicae, praeter maiores quasdam infulas, minores, innumeras vero minimarum reFerenti : fingulae namque maculae margine cinguntur faturatiore, ipfae uero aliis rurfus fcatent minoribus pallidss, forma magnitudineque inaequalibus.' Notantum infuper eft, omnes hafce maculas, poft tempus quo bufones hi coire folent, et diftinctiores, et magis effe confpicuas. In nonnullis horum bufonum comparent quoque, prope crurum articulos, inque corporis lateribus, puncta quaedani maculaeque floride aurancii miniaceique coloris, et numero et magnitudine variae. Quod vero reliquun eft, aeq̣ué laeuis exterior eft cutis ac terreftri in rana, neque, $v t$ in vulgari terreftrique bufone, verucis afpera.

Quemadmodum vero digiti pofteriorum pëdum, omnium hactenus a me defcriptatum ranarum, membrana quadam junguntur, natationem faciliorem reddente: fic et nofter, ea minime caret, bufo; ab aliis autem, praeter jam dicta, faltu etiam differt in terris majore; nec non vngue quodam fpurio, cornede duritiei, pofterioribus pedibus F:g. I. et $2 . g \mathrm{~g}$ fubter calcem adhaerente; infupervero prae reliquis, mihi cognitis, ranarum bufonumque fpeciebus, hoc fere folus habet, vt oculorum fuorum pupilla contracta, non transverfe, vt in reliquis, fed ad perpendiculum fiffa appareat, ceu in felibus bubonibusque, aeque, ac bufo nofter, lucis tadios auerfantibus. Atque hinc eft, quod pupilla bufonis hujus in tenebris orbem nigrum, vt in foemella a fig. I. Tab. XVII. clara vero in luce, tenuem nigramque ad perpendiculum ductam referat lineam, vt fig. I in mafculo, in vtroque vero $f i g .2 . b \mathrm{~b}$.

Edit mafculus hulus fpeciei bufonum clamoren quoque, tempore praefertim quo coitum anhelat, crebriorem. Parum tamen ipfi ineft gratiae: nunc enim ranae terreftris imitatur grunnitum; nunc autem ad modum ranae arboreae coàxat; fed dum clamat, neque ad latera capitis v1la cernitur vefica, $v t$ in rana aquatica, neque etiam, vt in rana arborea gulam inflát. Contra vero grunnit tantum foensella fuum inftar; quodfi tamen ejusdem ctus forcipe forte arripias, aeque ac mafculus, tenerae felis inftar, miferrime eiulabit, fimulque tetrum illum allii fparget odorem,

Coeunt bufones hi, verno tempore, pro tempertatis conditione, citius tardiusue, quumque fub veris anni 1754 initium, fingulis fere diebus, nonnulli eorum mihi afferebantur, fexto ejusdem menfis die, quosdam obtinui, quos generationis negotium copulauerat; quum vero mafculus toemellam in regione lumborum prope crura pofteriora amplexu fuo tenebat, infolita prorfus copulatio haec mihi videbatur. Seiunxi hinc eosdem iteratis vicibus, ratus, fingularem hunc coitum a mafculo minore ex nimia exerceri libidinem, quod, propter breuiora anteriora brachia, foemellae thoracem amplecti non poterat; licet autem illas crebrius feparaffem, eadem tamen femper ratione mafculus denuo arripuit foemellam, tandem vero et reliquos meos bufones fimilem in modum coire vidi. Quo

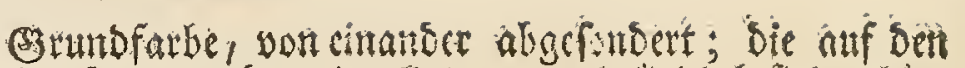

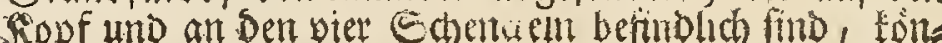
nen auch allerdings noch zul ben grofien gerechnet wers Den, und Die an ben Settent nebmen, wie all Der Brobife, fo auch in Intiebung Der Saibe nadi) und tach ab, its Dem fie immer blafter werden. Siul'ses tommet ntir dies fe Dberfádbe unterer Strote wie eime Landcharte für auf welcher ttebfteinigen grofien Infelm, aud siele tlets nere und noch mebr gallz lleine vorgeftellet werden Denn alle Flecten baben eine Dunctlere evinfafints yno in felbigen setgen fith wotederum einige belle GFlectlein

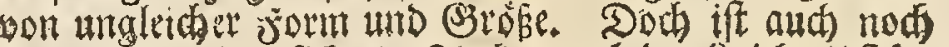

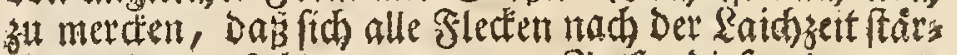
der, als oor relbiger, zetgen. 2Utifer biefen braunet Flecten, find aud noch, ant einigen Diefer Seroten, um Die Segent mo Die Sabendel ibre Einlendiunty baben, an Detr Esetten Dez Letbes, eththe boch oranten= oder mennigfarbe suncte und Stedtein zu bemerden, Deren

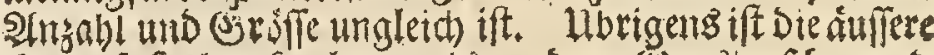
Sout fait eben fo glatr, als an Dem Estabtrof ch, unto gar nidht fo blattertabt wie an Der gemeinen LandErote.

WBte aber alle bisher von mir befdriebene Frofdats ten, an Den bintern Finfen eine Saut baben, vermit, telf welcher die Beben Derfelben mit einander verbuts Den find, und ihuten Das (Shwimmen erleichtert wird: (o mangelt (sid)e audy an unferet Sirote nicht; bon an bern Sroten unterfdeet et fie fich aber aufferdem was bes reits gemeldet worden, nidat nur alleine Durd) ibre gróf fere Spruinge, weld)e fie auf Dem Land zu machen pfles get, fortbern aud nod) Durd eine befondere bornbarte

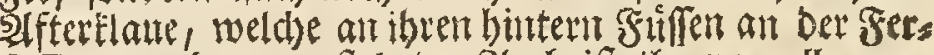

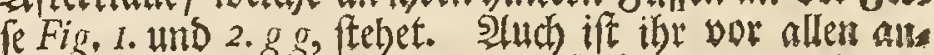

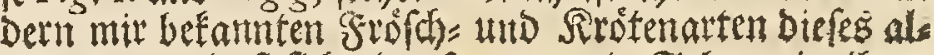
leme eigen, Dafs fich, Der fo genantite Seber, in thren 2litgen, wern fie felbigent jufanmenziebet, nid)t nad Der Duere wieber Den altorn, fondern fencted the ghe theilet zeiget, wie bey Den Sazen und enlen, welde

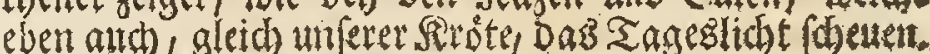
Diefennach zeiget fid) Der Seber doer Der Stern im 2luge ant unferer sitote, int sundeln, jirckelrund, wate an oem 2 Beilusin a Fig. I. Tab. XVIl. im bellen Qidet aber als ein rentetred)ter fonmaler Streif, soie Fig. I. om șainnlein unb Fig. 2. b b. ant beeden.

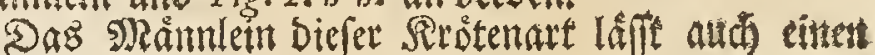
saut oon fid boten, Den mant zut Paarungsofit an bäuffigften vertimmt. Es ift felbiger eben nidst ange nehm, und bals aleichet er Dem Sechren Des Strastros

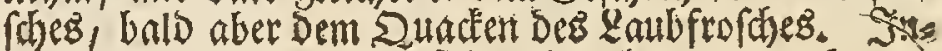
Sem $\mathrm{eB}$ aber felbigen won fich giebt, Eam man weder at Den Seiten Des Supfes, eme Bla ferforda), noch auch an Der Seble, wie an Dem laub. frofd wabrtebmen. Das 2 Beiblein bingegen grungef mur nah Det Sdrweine 2 int; went man es aber nit et net Sange an eintem Fus etgreiffet, fo fdyenet biefes fo

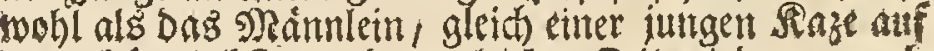
bas erbármlidfite, und zu gleidier Zeit wiro manaud ben wibrigen Sinoblaudgeftand felje ftare empfinden.

(es yaaren fid Diefe Sirtent im Fraibling, nad

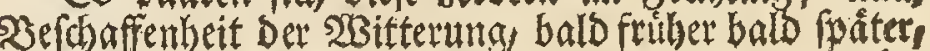
und Da mir su Infong Des SIDrils im 1754. Talyr tágs

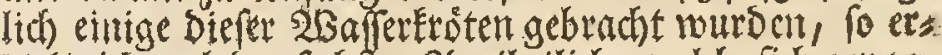
bielte id aud Den fedften P(pril etlid), weldhe fid gepans

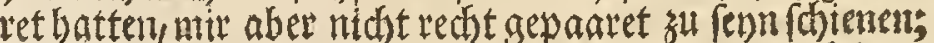

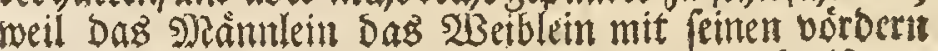
Sd)enkeln un Die Renden unfaffet hatte, imb alio an ben huttern Shendteln vefte hielt. Geb rieffe fie etliches ntal von einander, uno glaubte diefe beiondere $p_{\text {cias }}$

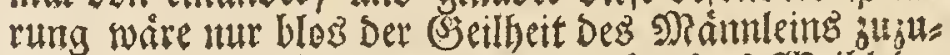
f(t)retben, weil felbigez su flein twáre baz 2 Beibleit, wegen fetter furzen sorderf(hendel bey Det Şruft zu umrafien; alleine id mogte fie gleid nod fo offt bon ems

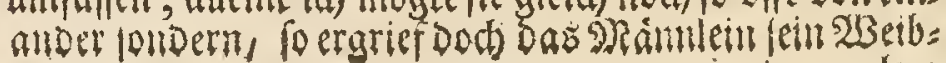



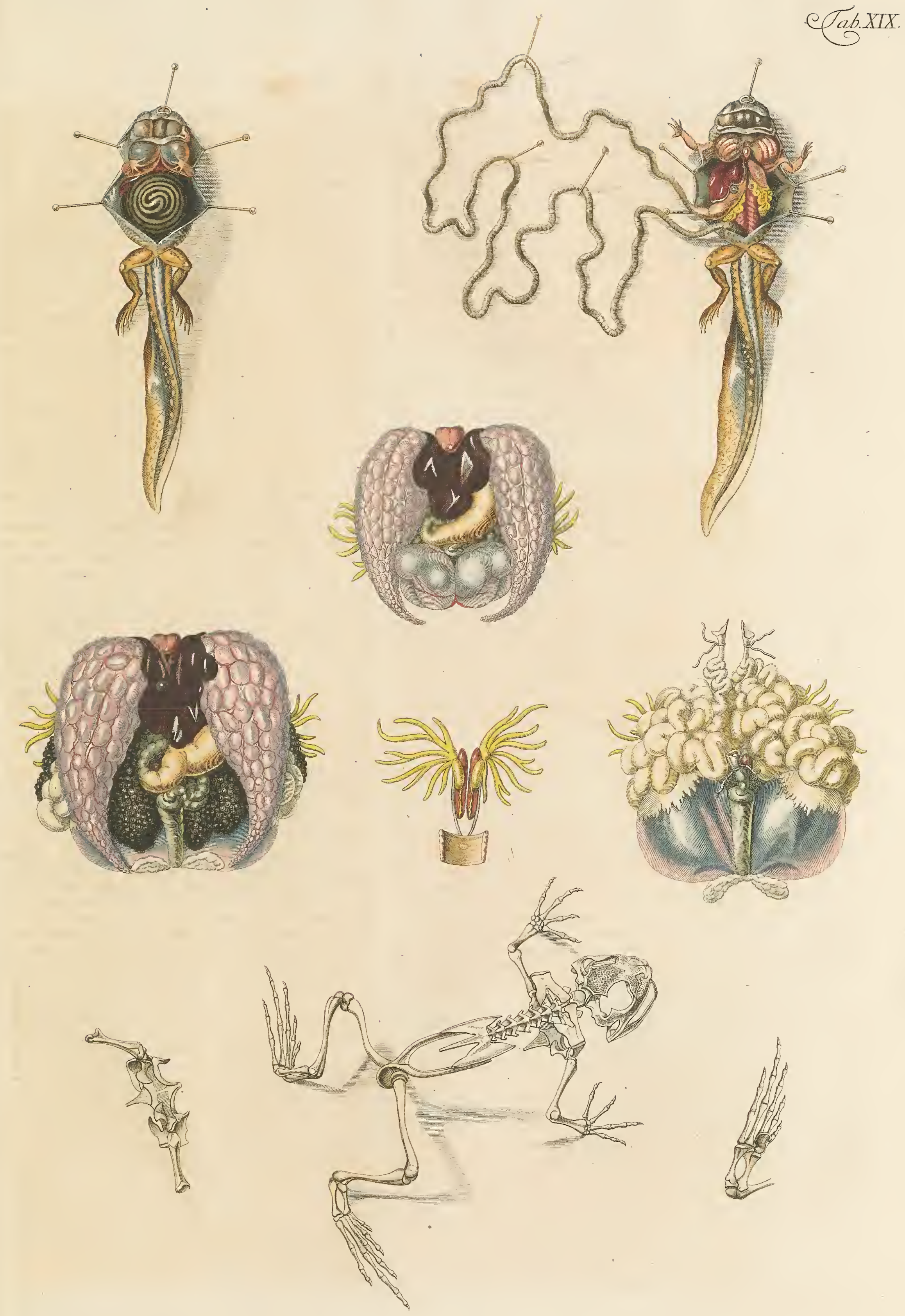


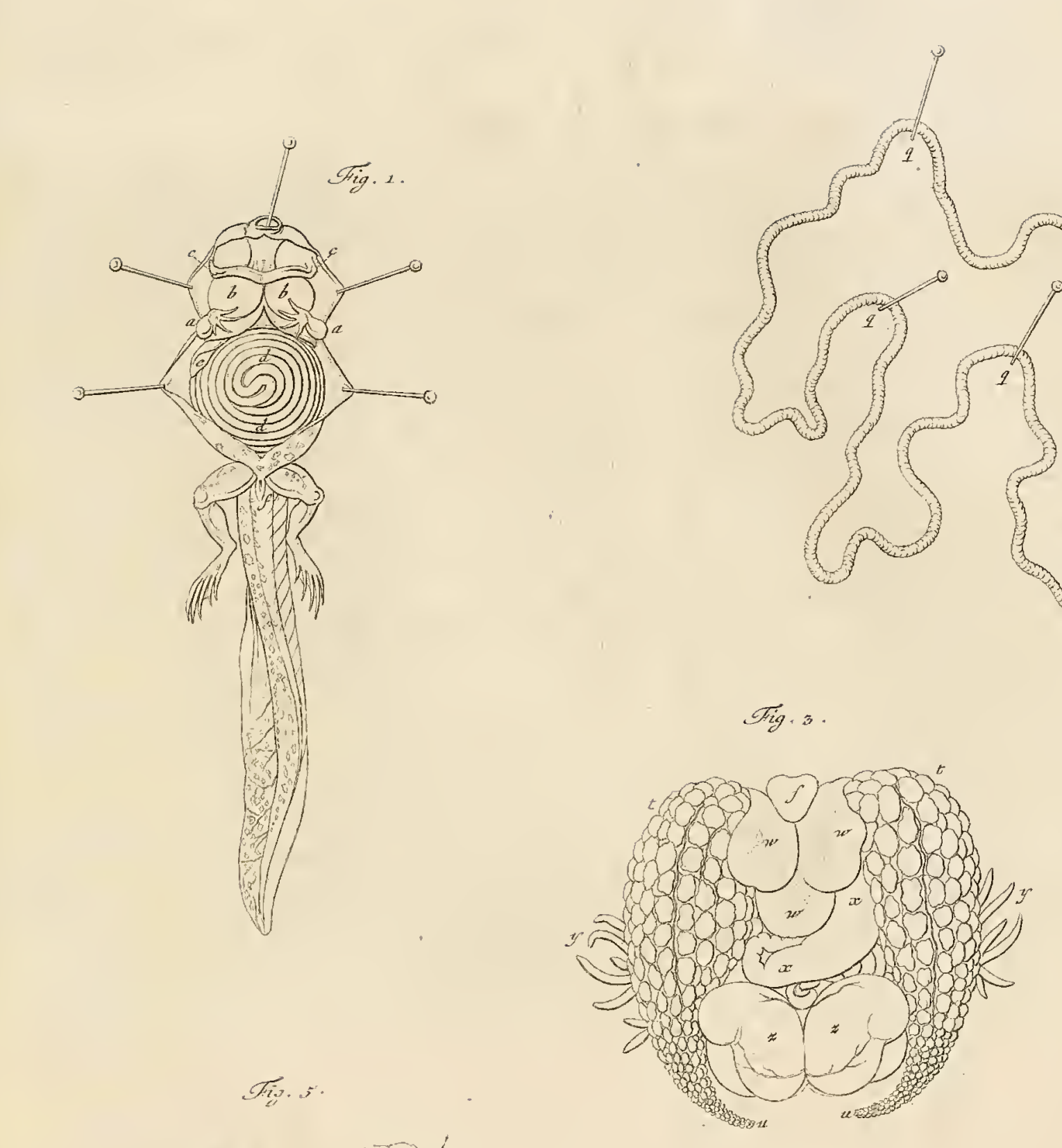

efab. XIX
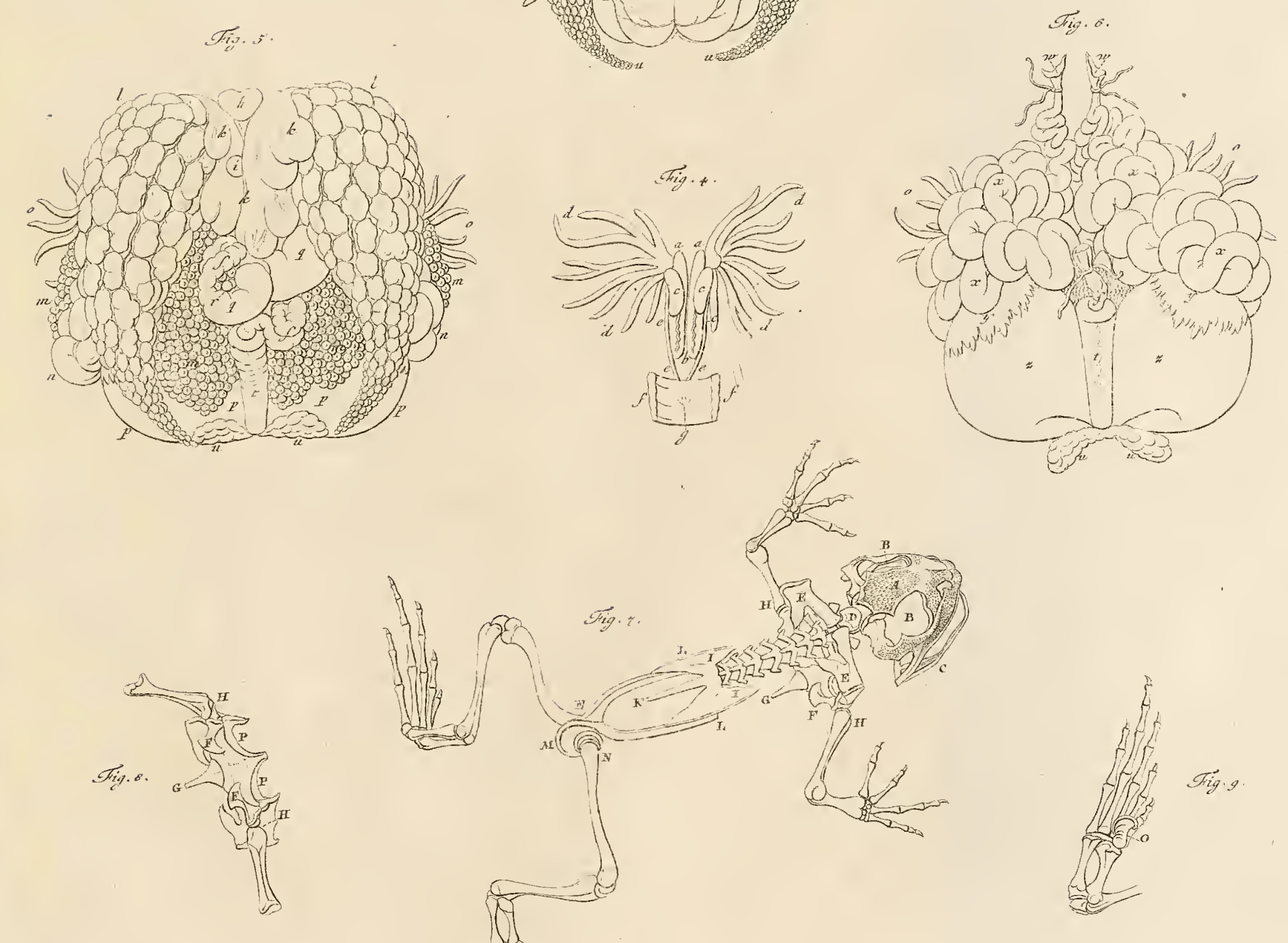



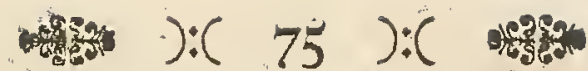

nath a cutem coitum hunc mirabar, eo maiore flagrabain cupiditate videndi, quisnam ipfius futurus effet finis, quum vix fieri poffe credebam, vt mafculus foemellae fit foe cundacurus oua, ob amplius inter vtriusque pofticam corporis partem intèrcedens fpatium, id quod ex prima $X V I I$ Tabulae confpicuum fit figura qua par horum bufonum cooulatum fiftitur foemellaque litteris a aaaan, mafculus vero, foemellam ad $d$ binis fuis brachiis complectens, $b b b$ defignatur. Prius tamen quam id, quod ardentius optabam, cernebam, plures praeterierant dies, Immiferam bufones co pulatos in vitra majora cylindracea, aqua ad medium vf que repleta, quod cum reliquis ranarum fpeciebus, praefertim vero cum rana arborea, fimiliter feceram, atque fic eosdem commode ex omni comtemplari poteram parte, id quod diu quoque noctuque fedulo agebam : tandem emittebat, duodecimo Aprilis, foemella quaedam oua fùa, reliquis idem etiam non ita multo poft facientibus, quum jam per fex octoue dies cum mafculis fuerunt copulatae. Sed antequam foemella oula pariebat, nunc in hoc nunc il lo in latere abdominis ejus fortem vidi motum; tum vero vitri fundum petehat, hocque facto partem edebat per matis, vbi dein pet quadrantem horae quieuerat, prrie bat denuo; atcue fic fedecies quin vicies alternis requiefcebat vicibus, ita, ve nonntllae poft fex tandem, ócto, pluresue horas omne fuum pepererint fperma. Haec dum fiebant fuo non deerat mafculus officio: quiefcente foenella, quiefcebat ipfe fimiliter, vbi vero illa fpermatis edi tura erat partem, atque hinc fundo vafis incumbens cru ra pofteriora explicabar, continuo mafculus fuum mutabat ftatum: contrahebat enim corpus fuum ea ratione, vtcru ra pofteriora anteriora prope contingerent, atque dorfum ipfius gibberum redderetur, ceu secunda finura ad $i$ monftrat; hinc vero propius admouebat ani fui orificium ad anum foemellae, quem fimul binis pofterioribus pedibus adeo conftrictum tenebat, vit iisdem fuerma e foemellae vtero protracturus videitetur: indicant illos in fizura $\int e-$ cunda, modo adducta, litterae $f f$, in qua infuper, vt in praecedenti, foemella litteris a a a a $a$, nfafculus vero $b b b$ eft fignatus: Quodft itaque pars quaedan fpermatis e foemellae ano prodibat, quate fere femper non vltra pollicis lonitudinem exteîditur: earidem mafculus bini Tuis propius coniunctis pofticis pedibus tamdiu cuafi remorabatur, donec ipfam femine fuo afperfffet, fimul vero eadem fe motabat ratione qua canes coeuntes motari fó lent; ceterum citius haec quidem peragebantur quam nar rantur, atque vibi dein bini bufones momenta aliquot in codem mánerunt ftatu, diducebat mafculus pofteriores pedes fuos tum vero in confpectum prodiliat fperma ab ipfo retentum foecundatumque; hocque facto cernebam, habere portionem hanc fpermatis longitudinem pollicis. Foecundata vero ejusinodi parte, quiefcebant bini bufones, ad modum figurae primae compofiti, donec foemel la denuo parerer; atque haec fiebant alternatim ad vsque omnem permatis exclufioneth; tum autem finem coeuti di faciebant, mafculo foemellan dimittente. Durante coitu, pendet fperma, ex ano foemellaes inteftini inftär pellucido muco plurimisque nigris granis repleti, atque id ipfum cernimus fiouris prima jecundaque ccccec, ex quibus fimul apparet, aeguare illud interdum binos longitudine pedes. Quodf bufo partus tempore libertate fua gaudeat, fperma illius vtplurimum in aquis ftagnantibus prope ripam, arundinetis, graminibus aliisue plantis aquaticis adhaerecens deprehendes: hic enim crebrius id ipfum, quam in fundo inuenis lein allegett wieser auf sorige 23 eife, unb endlid fabe ith, Dafi fich alle Dietentgen, fo ich benfammen batte, au gletche Qrt paarten. Je mebr mid diefez nun wunber. te, ie begieriger martete id barauf, was Dod aus bies fer soarung werben wurbe, troent idf mir nidbt bot:

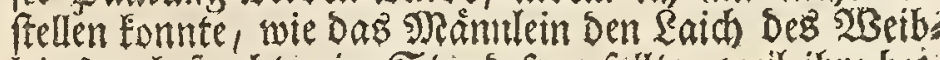
leins zu befudten im Stano fenn follte; weil itre bees De Sintertbeile, ben folder soamutg; fo weit on eint ander entfernet waren, wie aus ber 5. Sigur unferer XVII. Zabelle zu erfeben, melde ein begattetes Spaar Diefer Siroten vorftellet, uno wo Das SBeiblein mit a a a a $a$ a, Das s)ånnlein aber mit $b$ b b bezeidnetifín nel

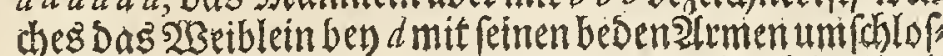
fen bailt. (Es giengen eflithe Sage vorben ebe ich Dastenis ge, was id fo febnlid zu feben wunf b te wabrnebmen fort te. Sch batte Die gevaarten Siroten in groffe und bis zuc Salffte mit 2 Bafier angefullte Butferglâfer gebrad)t wie th mit Den tibrigen Srofoharten; (onderlid abet mit bent \&aubfoofic ebenfals getlan i und alfo fonnte id fte um fo biel beguenter bot allen Setten betradtent

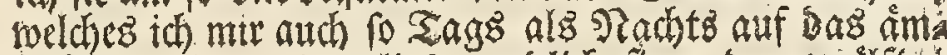
figfe angelegen fentt lies: enoltof fteng den zwolffet

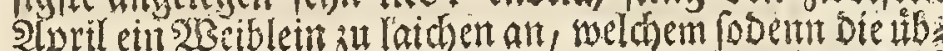
rigen bald folgten, nad) Dem fie feds, fieben bis adt

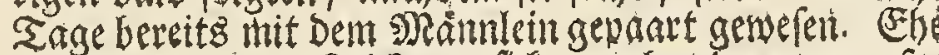
Sas syeiblein Den Raid opit fith zul geben beromen fas be idh nie fidt feir Reib bals auf biefer ballo auf tenet Seite aufferoloentlid fard bemegtej gleidf Sarauf be gab esfich auf Den 30 beit Des Slafes; uno alsoent trieb es emen Sheil Des a aidhes beraus, bierauf rutbes te es bev ciner Sisientelfunde lang / nacisgefentos aber fieng es wieder an zu laidhen, uns fo arbeitete

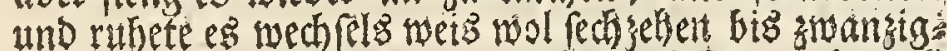
tunl, fo, sas ber) einigen Derfelben feds, adt und

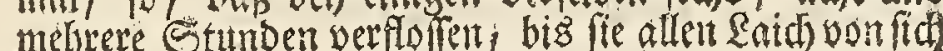

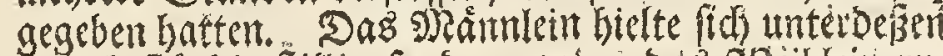

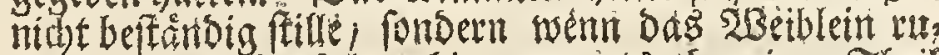
bete, wares ebenfals whig; went es aber emen shei bes Raidses uon fich geben wollte lind fidh Deswegent

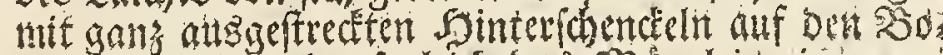
ben legte fo nabm fogletch Das spantlein eite gan anbere Etellung an:

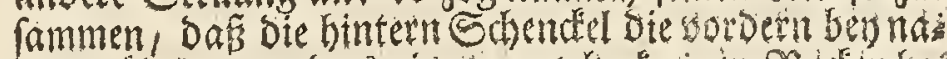

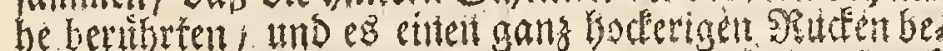
Ent pie in ber 2 Sigur ber $i$ su foen eben savurd aber buchte es die Definumg femes strters gans uabe

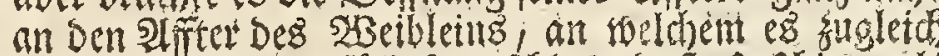

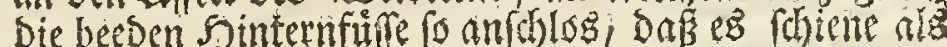

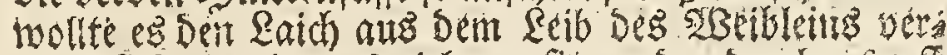
inttelf foldier beraus gieben: fie weroen Durh if erf angefithrter sweyten figur altgejeiget/ in weldser nites

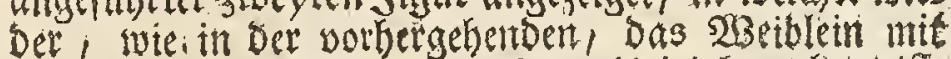
a $a$ a a $a$ a, $\quad$ as )

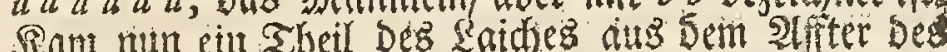
2Beiblems heraus, Der felten mebr als cinen 301 , bet

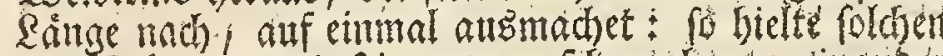

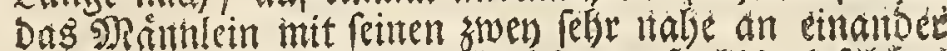

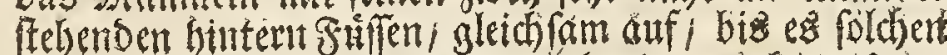
mit feinemt Saamen befprenget batte; toober es gui aleid faft eben eite foldhe Bewegung madite / Derglei

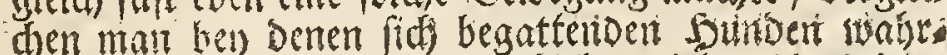

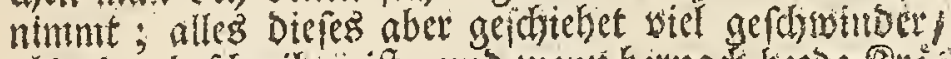

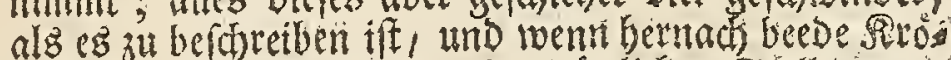
teit nod eititae sgetniten in Der inamlidfen Stellung ges blieben zon Sas sanuletin feine bittern fune etwas aus cintuber, tooratif Der vorber oon ibm sulani

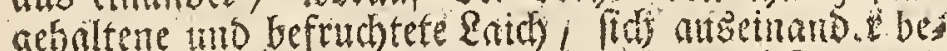

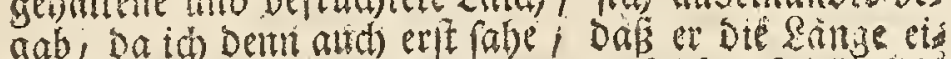
nes Bolles batte. 2Benn aber ein lolder sleil bes ?aidses befrudetef worder / rubeten bie beeden sitstem woben fie Dic Stelung Der erfen figut annabity bis

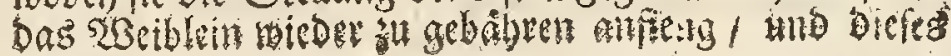




\section{(4)}

geidathe wech felsmeis fo lange, bis es aflent said oblh iich gegeben batte, womit bemt auth Die Saarung 3 H Ende gieng und Das פ) Ránnlein feine (3)attin mied er los

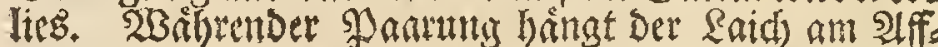
ter Des 2 Beibleins, als ein burd)fichtiger nut bellem Sd)leim unt vielen fleimen chnarzen Siormern angefith fer Darmy weldhen wiv, fo wobl in ber erfen als snoy ten Sigur mit, c c c c c bezeichinet felsell, uno bermando malen eine Sánge von zwet Sahthen hat. Sft Diefe Prote zur Raichseit in ibrer Frenheit, fo wirs man bie

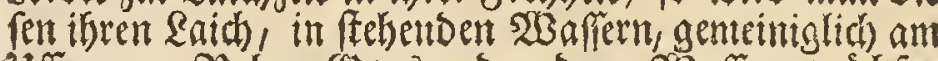

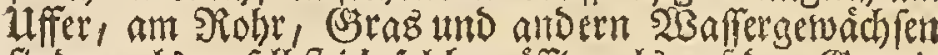

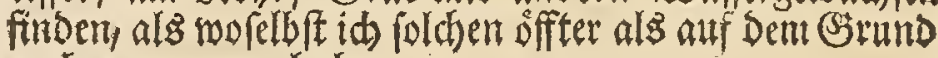
wabrgenommen babe.

Quemadmodum vero bufo hic a reliquis ranarum noftratium fpeciebus odore allii; pupilla ad perpendicuIum diuifa, vngueque illo fpurio, in figuris $g g g g$ fignato, differt: ita etiam ratione coitus partusque, fibi foli propriis, a ceteris difcrepat. Quum etiam fuperius dixerim, reperiffe me eundem femel tantum ipfa in terra; neutiquam hinc, continuo in aquis illam verfari, affirmare volui; fed petere ipfun interdum quoque terram, omnino fum perfuafus.

Non dubito plerosque lectorum meorum fidem mihi effe habituros, fi dixero, fieri ouorum bufonis noftri mutationem eadem fere ratione, ac illa ouorum trium a me jam defcriptarum ranarum; fed quum in ouis fingularum fpecierum diuerfi quid notauerimus: haud abs re erit, fi fenfim fenfimque factam horum mutationem fimiliter narrauero: nam et hic quaedam, quae in reliquarum fpecierum ouis minus obferuauinus, occurrent.

Poftquam itaque die duodecimo Aprilis primum ex bufonibus hifce obtinui fperma, augebantur in ipfo contenta nigra grana fenfim fenfimque magnitudine, elapfo vero fecundo tertioque die, forma ipforum rotunda prorfus erat mutata, ita, vt plurima eorundem die decimo quarto, nec non decimo quinto Aprilis pyro fimilia effent, quemadmodum ex Tab. XVII. ad k patet. Die decimo fexto in binas fecedere videbantur partes $l$, fic tamen, vt vix dijudicare potueris, vtra harum partium caput caudaue fit dicenda; fed inueni poftmodum, partem crafliorem eamque fimiliter bipartitam, in ventrem, alteram vero in caput abiiffe; ceterum nullus prorfus in gyrinis hifce percipiebatur motus. Die decimo feptimo Aprilis habebant plurimi eorundem formam figurae $m$ : atgue tunc dignofici non folum caput a ventre poterat; fed corfficiebantur quoque bini oculi papillas referentes, nec non caudae pars. Hanc adepti formam, ex gluthofa illa prodibant materia, in qua hactenus et nutriti et formati fuerant, jam etiam ex crebra corporis agitatione vivere ipfos patebat. Sociam nunc porro amare videbantur vitam, dum fefe congregabant; qua vero ratione, omni fine motu, de loco in locum alterum fefe conferrent, nulla ratione perficiciebam; fed poftquam vnamillorum in ejusmodi vitrum, aqua repletum, quo horologia minnualia conteguntur, indidi, illumque microfcopio adhibito contemplatus fum, vidi, ciere eosdem vorticem in aqua, prope caput confpicuum, vtrum vero eundem oris ope vel alia ad aures apertura excitent, indicare nequeo; adjuuante tamen vortice hoc non folum huc illuc ferebantur, fed vitri lateribus adhaerefcentes fefe etiàm promovebant. Die duodevigefimo vndeuigefimoque Aprilis ambiebat jam omnium horum gyrinorum caudas pinna, cujus ope natare tentabant, fed initio irrito quidem fucceliu: mox enim, vbi ad altitudinem duorum triumue pollicum a fundo vafis recefferant, in éundem rurfus languore correpti decidebant. Sociaminterim continuabant,

Sleit)mie fid nut aber biefe Srote son andern Frofharten biefiges \&andes , Durch ibren Sinoblauds: geftand ; Durch Den fendfredt gefpaltenen Seber ibrer alugen; und Durch Die in ben siguren mit $g$ g $g$ g be= seichnete siffer Elauen unterfocheid: To bat fie auch in

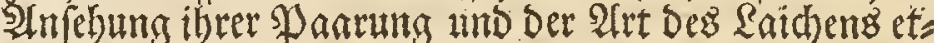
was befonderes unt ibr alleme eigenes. 2 benn id aber oben gefaget babe, baể ich felbige nur einmal auf Dem Rano angetroffen: fo behaupte ith Deginegen micht, Dari fie beftándig im 2 Bafler fid) aufbalte; fondern idh slaus be vielmehr, Dap fie aud) mandimalen auf das laatb fomme.

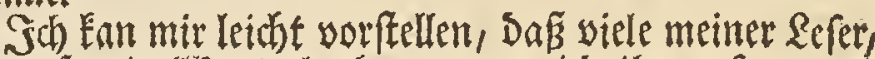
mir auf mein 53 ort glauben, weun id thren fage, es grhe mit Der Beránoerung Der Eyer unferer Siote cben fo $u$, alz wie mit ben Evern Der bereits von mir be

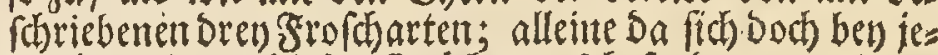
Der Derfelbenin Diefem Stite etwas beronderes gezetuet: fo wito es nid)t uiberfluifig reven, wenn ids foldhe aud hier be(t)reibe, zumalen ba bey biefem $\mathfrak{R}$ aid) fich eben: fals eir und anders zetgent wird, fo wir bey jenten nidht wabrgenomment babett.

Rachbem ich alro, mit Dem joblften alpril, Den er: ften Raid von Diefen sitròten erbalten batte, fo fiengen bie in felbigen befinblidbe (d)warge Seorner an nad) und nach, groffer zu werben, bis fid mit bem zwentent uno britten Tag ifre runde Form yóllig verindert batte, fo, bấ die mebreften Den vierjebenden und funftzelsenden 2pril birnformig, wie $k T a b$. XVII. ausjaben. Den fedsetbenden fehtemen fie fich in isen Theife abzufon.

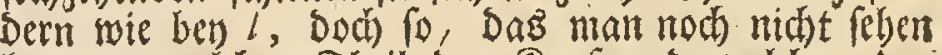
fonnte, weldher Theil Der Sopf und welder Der

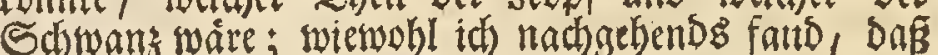
Der Didere Theil, weldher fich wieder ill zwev; absurons Dern fchien, Den Letb; und Der andere Den Rapf alls: madte; bisher aber war nod) gar leine 2 erwegung an biefert S3ưmern zu merden. Sen fítebenzelsenden 2lpril famen Die meiften, Der (S)eftalt nad), Der șigur $m$ gleid): ba Denu nidht mur alleine ber Ropf uno seib Dedtlid a unter (d)eiden waren; fombern man wurbe aud) foron Der becoeñ Theils bes Echwanges gewatr. Lutter Diefer Form verliefien fie insgemein Den Echleim in weldhem fie ihre bisberige Bildung uno Nabrung erbalten batten, aud fiengen fie an ibr 2 eben, Durd) (d) nelle Arummung bes Seibez zu erkenten zu geben. Sie fhienten nun ferner ein

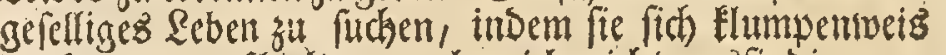
ber fammen aufbiclten, woben id) nid)t ausfindig mas d) en fonnte wie ez zugieng, Daf fie fith won ciltem Dort ju Den andern begaben, olhne Dabei Die geringite ?bes.

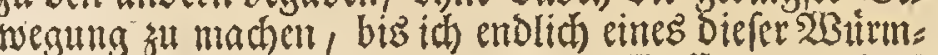
lein, in einem Uhralas mit etwas sBafier unter Das Nicrofcopium brad)te, Daid) Denn geroalse wutrde, Daf́ fie um Die Begend Des Sopfes im sz3affer cinen 23 ir: bel madten, oline ieboch anzcigent zutotnett, ob fie (id) Gierzu Des s) Dhren bedienten; Durch Sulffe eben Diefes 2 Bublez aber begaben fie fich midht nur von cimem Drt ju Den vitam, 


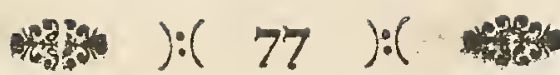

vitam, atque ore e variis pendebant plantis aquaticis, ipfis nunc etiam pabula praebentibus. Tertia hoc repraefentat figura $q q q$, prope illam vero cernitur ad $n$ gyrinus a fuperficie inferiore, ad o autem a latere. Die vigefimo nec non vigefimo primo Aprilis in his quoque bufonibus, $v t$ in ranis fupra depictis, oftendebant fefe pone caput, vtroque in latere, appendices fimbriatae, quae quidem hic ex fufco flauefcunt pedesque fere anteriores mentiuntur. Siftit figura p, Tabulae XVII. ejusmodi gyrinum in naturali magnitudine, fig. vero $I$ et 2 Tabulae $X V I I I$ in magnitudine aucta. Monftrat prima figura fuperiorem ejus fuperficiem, fecunda inferiorem, in qua etiam os ipfius comparet, multo hic majus quam quidem in aliis gyrinorum fpeciebus. Exhibet figura 2 appendices fimbriatas, quales effe folent vbi perfectifimae funt, figura vero $x b b$ easdem altero in latere jam defcrefcentes; adfunt enim per breue tantum temporis fpacium, tandemque penitus difparent. Quis ceterum eorundem fit vfus hic quoque, vt reliquis in fpeciebus, iudicare nequeo; quantum autem $a b$ aliorum gyrinorum appendicibus difcrepent, facile cuilibet has cum illis comporanti patebit,

Similes erant, trigefimo Aprilis, plurimi gyrinorum meorum, figurae tertiae, vnum eorundem a fuperficie inferiore repræentanti. Cernebantur jam in capite, quod nunca corpore diftabat, oculi nec non os,caputvero cum corpore albo pellucidoque cingebatur folliculo mutabatur niger hujus fuperficei color notabiliter, ipfi vero gyrini jam $a b$ aliquot diebus, eandem non amplins, vt initio, fociam agebant vitam. Circiter diem decimum Maji referebant, colore denuo nonnihil mutato, quartam fir uram; pinna caudam cingens exporrecta erat per dorfum ad caput vsque, inferius vero emicabat e corpore propendens rectum inteftinum $c$, faecibus femper repletum quoad gyrinis pabulum non deerat; quin et harum exferta cernebatur femper pars quædam, in reliquis etiam hujus tabulae figuris littera $c$ fignata. Licet vero gyrini hi adhuc lenticula paluftri, aliisque plantis aquaticis contenti effent, plus tamen earundem indies ipfis erat praebendum: in eam enim nunc excreuerant magnitudinem, $\mathrm{vt}$, non obftante tenera æatate, gyrinum ranæ viridis aquaticæ, in quo pedes funt prodituri,jam aequarent. Sed augebanturilli majore infuper incremento referebantque, die vigefimo quarto Maji, fisuram quintam; valde tum fimile erat caput ipforum pifcis capiti, pone quod in omnibus, ea in fede, qua pifcium branchie hiant, albam veliculam referens, led finiftro tantum in latere, confpiciebatur eminentia, quae ipfo cum gyrino fenfim fenfimque augefcebat. Jam vero mutabam eorumdem pabulum,dum lactucae brafficaeque ipfis praebebam folia, quae valde appetebant, ita, vt diem verlus nonum decimumqueformam fext ae haberent figuræ. Quemadmodum vero jam antea inferior eorundem fuperficies pellucebat, fic jam multo erat pellucidior, adeo vt ipfa inteftina, cochleae vel ancorarii funis inftar conuoluta, per illam confpicerentur.

paue. andern, fondern fiefoboben fid and an ber Setten Des

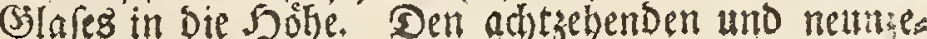
Gentent 2tpril hatten fie bereits alle mit einer Floffe unts gebene Schwainge, Da fie fich Denn ubten, Durd Sullf fe Derfelber, im sBaffer auf und absuchivinmen, toelo ches aber im sinfang nithe reche vor fich gieng, inden

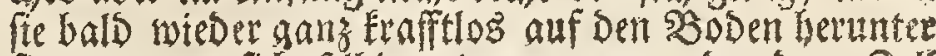
fielen, wenn fich relbige etwann swen oder Dren 301 hoch bavon bitmueg beaeben hatten. 2utch jest bieltent fie fich nod gefellig benfamen, und biengen fir mitifs

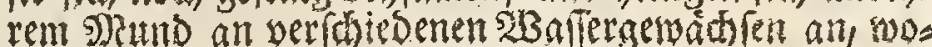
von fie fith numebr zu nábren fudten. Diefes zetget unfere britte Figur $q q q$, unto gleith Daben feben wit

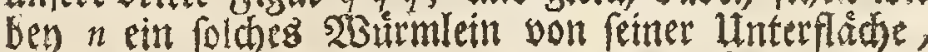
ben o aber son Der Seite. Den zroanjigften und eit

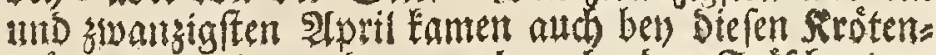
mirmern, wie an Den vorbergehenden Frofoharten,

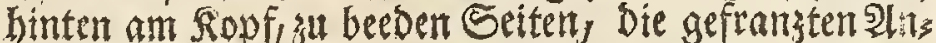

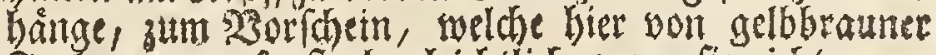
Sarbe warem, fonft aber leithetlith, wenn fte nichtgenau

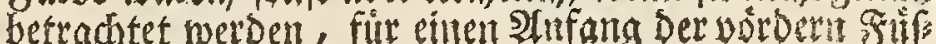
fe gehalten werben Eointen. Die mit $p$ bezeiduete 5 t gur Der XVII. Tabelle fellet einen folchen 23 urm in matirlicher Ssrofie bor, uno auf Der $X V I I I$ feren wir inn Fig. I. unt 2. vergroffert: Fig. I. zetget ithn bont Der pbern Sláche, und Fig. 2 von ber untern, in welcher aud hier Der SRund erfothet, Derbiel groffer als ben anbern 2 rrten folcher 2 Burmer ift. Die gefranzten

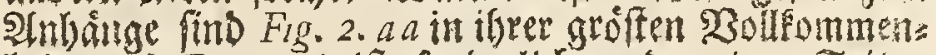
heit, unt Fig. I b $b$ ift, ronberlidi) all ber einen (Seite,

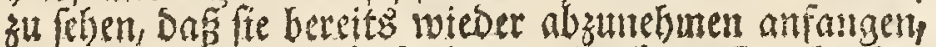
wie fie benn auth wirclid nur eine furse Beit bletbert

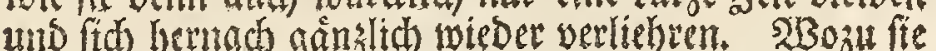
ibnen aber bienen, weis id bier eben fo wentg, als beb obigen Sorten, anzugeigen; in nie ferne fte bingegen voa biefen ibren unterfáteden fenen, wiro jeser leidsts lich) bet) (sigeneinemberbaltung Derfelben, wabeneb: mert.

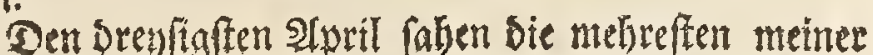
Thurmer ber britten firme gleid, welche einen Derfele ben won Der untern Flladie yorftellet. PRumehr was ren, in Dem vom Reibe abgefonderten Siopf, Die Sta gen nebf Dem Sumb zu erfemen, Ropf und Reib aber

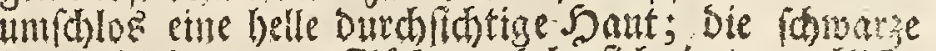

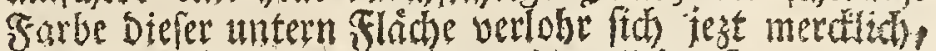
13no Die 5 Birmer blieben fis on fett etlichen Tanen micht mebr fo gefollig, wiesorber, bebfammen. 33 te tm Sen sebemben sian erbielten fie, bey etwas beránseter

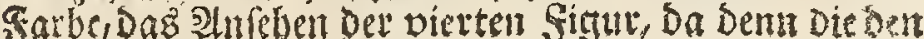

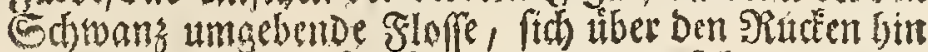
bis an oen Ropf erftredte, tmb unten fabe man wie burch eben Dieretbe, ber seaftorm c, aus Dem Reib hers sornteng, weldier alleseif, fo lange bie scirmer an Jutter teinen 2 dangel batten, mit unrath angefiflet war, twowen beftantig ein Skeil beraus bieng, wel the aud in ben folgenden finguren burch $c$ angedeutet wirs.

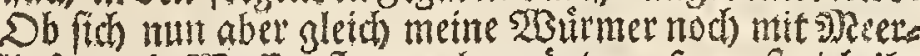
linfen und 2 Bafierpflansen begnigten: fo mufte id ibs nen Dod munmebr immer melse Davon geben, indert fie berete fo an Groffe zugenommen batten, Dafi fie,

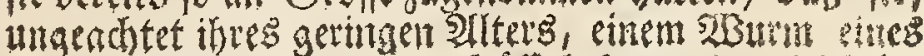

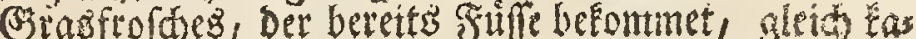
men. Interdefen wurben fie nodi groffer und batten

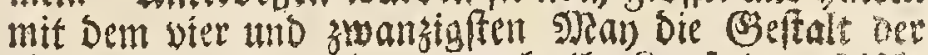

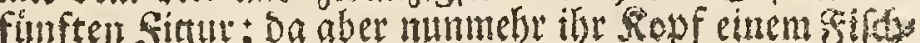
fopf zienlith sunlich fabe, fo zcigte fid) auth, ben als len, binter Demfelben, und da wo fonf beo Den sifuest Die fogenamten Sthobren ifre Defmung baben, ein

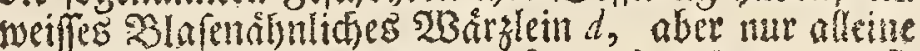
an ber lintén Srite, weldes, fo wie Der $2 B$ atrm fribr nod immer nach und Had groffer wurde. Slumebr fing 
Pauebant jam omnia gyrini mei, atque hinc, non fine magno aquae motu, protinus fundum petebant, fimulac quicquam prope vitrum cernebant; fed ea jam illorum erat magnicudo, vt mirarer, crura eorundem pofteriora adhuc latitare; quin expectandum erat per integros duodecim dies, donec comparerent: conficicabar namque vigefimo demum Junii die in craffioris corporis extremo, ad caudae nriginem, vtroque in latere, leuia horum crurum primordia, quae feptima figura ad $f$ monftrat, et in qua ad e eminentia illa, veficulam referens, comparet, cujus jam fupra aliquam feci mentionem. Jam vero inueni in eadem orificium quoddam pofteriora verfus, vnde poftea turbidam, ore naribusque hauftam a. quam, fæpius vidi rejectam, ita, vt prorfus habeam perfuafum, fimilem in gyrinis hifce, ac in pircibus, adeffe pariurn conformationem, quippe qui pari ratione aquam, quam ore trauriunt, per branchia reddunt. Erat autem orificium hoc adeo patulum, vt, vbi gyrinum eo in fitu contemplabar, in quo oftaua eundem fiftit figura, ipfam eminentiam, tubulum carnei coloris referentem, introfpicerem. Exhibet eadem etiam figura ad $f f$ crurum pofteriorum primordia.

Quum gyrini mei tantó augerentur incremento, quotidie etiam majore pabuli indigebant copia, quumque vafa, in quibus illos feruaueram, eosdem vix amplius caperent, femoui partem illorum, viginti tantum in pofterum nutriturus. Arrodebant illi tum lactucae brafficaeque folia adeo ftrenue, ut crepitus inde fubortus ad fex feptemue paffuum diftantiam perciperetur; fcatet quippe os eorum exiguorum quadam dentium fpecie, quae tamen, vbi in ranas transformantur, fub oris mutatione perit. Obtinuerant gyrini mei die decimo Julii fummam, quam adipifci folent, magnitudinem, qua figura nona fiftuntur, necque refpuebant tunc priftinum pabulum; fed faeces non propendebant amplius e recto inteftino, vi antea. Os, fupra quod nares cernuntur, apertum eft in figura, ita, $\mathrm{vt}$ interior illius aliquatenus pateat ftructura. Oculi iris aureola latior nunc eft lucidiorque, ea vero in fede, vbi antea ad $e$ fpiraculum aderat, cernitur tuberculum, quod mihi latentis fub cute brachii, vel anterioris cruris cubitus, quuns altero in latere frmile jam exftaret tuberculum, effe videbatur. Erant nunc etiam pofteriora crura $f$, quoad formam externam, perfecta: non folum enim quinque fuis inftructi erant digitis, fed etian membrana hos jungente; vtebatur hinc iisdem gyrirus vbi natabat, nec parum juuabat tum eundem cauda, multo major reddita perfectaque. Coloris horum gyrinorum nullam hic feci mentionem, quum, qualis ille fit, ex figuris pictis facile queat perfpici: addendum tamen eft, repraefentari eundem in hujus aeque tabulae, ac in reliquis fimiliuin gyrinorum figuris, talem, qualem, vbi gyrini aquis innatant, fefe fiftit.

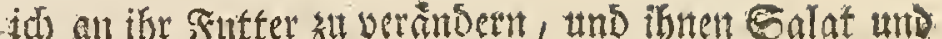
Sirantblátter zu geben, wolche fie firh fowohl fámmediea lieffen, Das fie bis Den neunten und zebenden sian Die Brftalt Der rediften Sittur erbielten. Und gleichnte ber Der borigen (3)roffe ibre Unterfláche fóson burchfich)= tig aeveren, fo wonde fie nun noch Durdsfichtiger, fo, Das man Durch relbige, die Bedarme gemahr mutue:

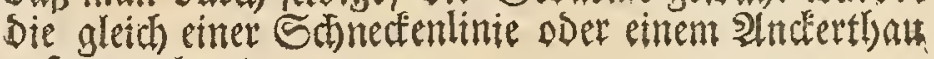
sufammaeleget waren.

Nunmefr murben meine 23 tirmer fo fittidtern,

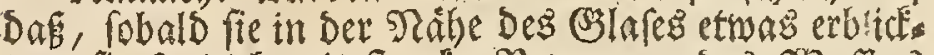
ten, fle fogled mit farder Bewegung Deg SBaffers auf Den Branto fuhrem, wegen ihrer Sirofle aber, wats berte id midh, Dafifich nod nichte von ben bintern Friffen an felbigen zeigen wollte, tmo Doch mufte id nod ganzer sudif Sage Daranf watten; Dent erfit Dent

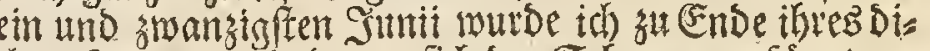

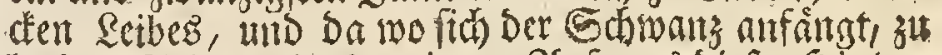
beeden Eeiten, eines geringen 2 Unfang Diefer Sinters fiffe getwahr, swie wir an ber fiebenden Sigur ben $f$ fes ben, an welcher fith aud bey e, Das obengemeldte wars zenforrmige SBlåsleint zeigct, worinten ich nun hinten

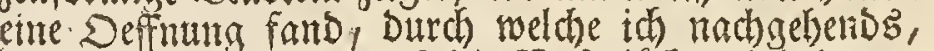

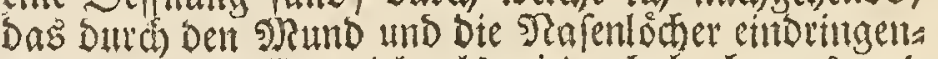
be unreine 2Bafier, vielmals mieder babe beraus treta ben ferten, fo, daf id allerdings bavor balte, es ferse

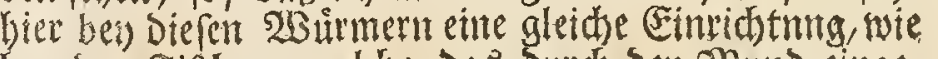

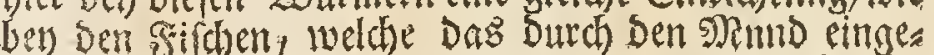

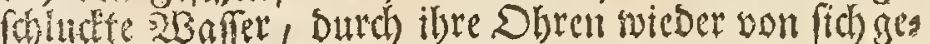
ben. Diefe Deffintmg aber war fo mereflich, Dafis went id eimen foldhen Sisurm in Derienigen \&age betrathtete,

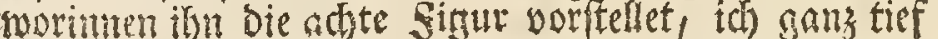
in folbige biencin feben Eomnte, ba fie Denn and) gans

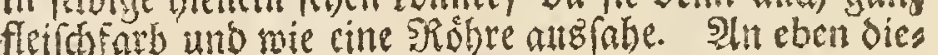

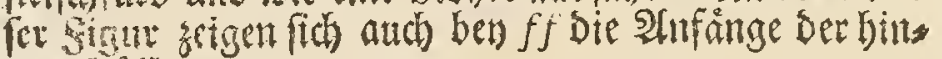
tern șin

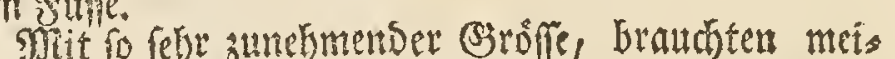
ne soumer trighth immer mebt futter, and murbe ibnen ber Solum in Den (Sefhitren worimen ich fiever:

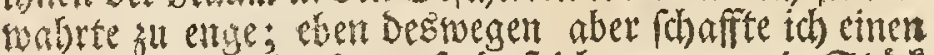

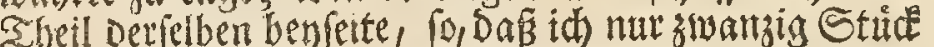
zu meiner Seforgung aufbebielte. Diefe nagten nut ntebr an Den Ealat = und Sirautbláttern to ftaré, sofis man fie an febigen auf fedis bis fieben Sdritt

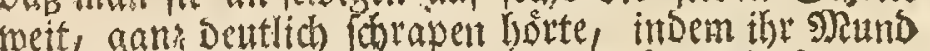
mit einer alrt tlemer Bálne verfehen ift, weldhe fie aber, wom fich Diefer bey iber Berwandtana verändert, vieber vertielyrent. Den zehenden Jullit zeigten fich

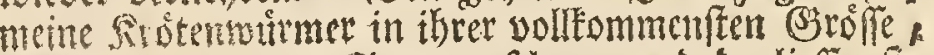
wic an ber nement sigut zal felsen, und Da lieflen fie

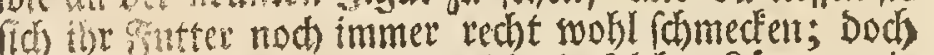
Gieng nummetr ber linratb nidbt in folder Ránge, wie yorber, aus oem sRaftoarm berans. Den flemen

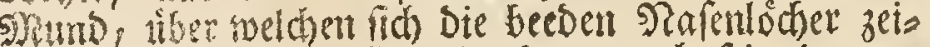
gen, folen win hice offen, Da bcm aud foin imtere

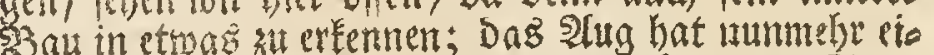
nen bretern golvfarbett, unb mebr glânzenden sling als vorber, Da aber, wo an Der linden Sette ber e Die

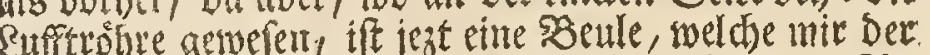
Ellenbogen bes unter Der Saut nod) verborgenen 2 r mes do er: Der andern Seite eben aud ente folche Benle munmebr zunegen war. Ferner baben jest aud) bie beeden Shins terfine $t$ ibre vollige Form, inbem an felbigen nidhe mur bie funf Beben, (ondern aud) bie Salt Dutd wels che fie miteinander verbunden find, gans Dentlich za

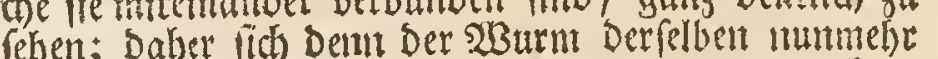
beyn Schimmen bebiente, weldhes aud Der mereflich grofere und volleonmene Shbwanz um vieles erleith: terte, 23on ber Farbe Diefer 23 inner meloe ich hier Deswegen nithts, weil fie aus Den gemablten Figuren 

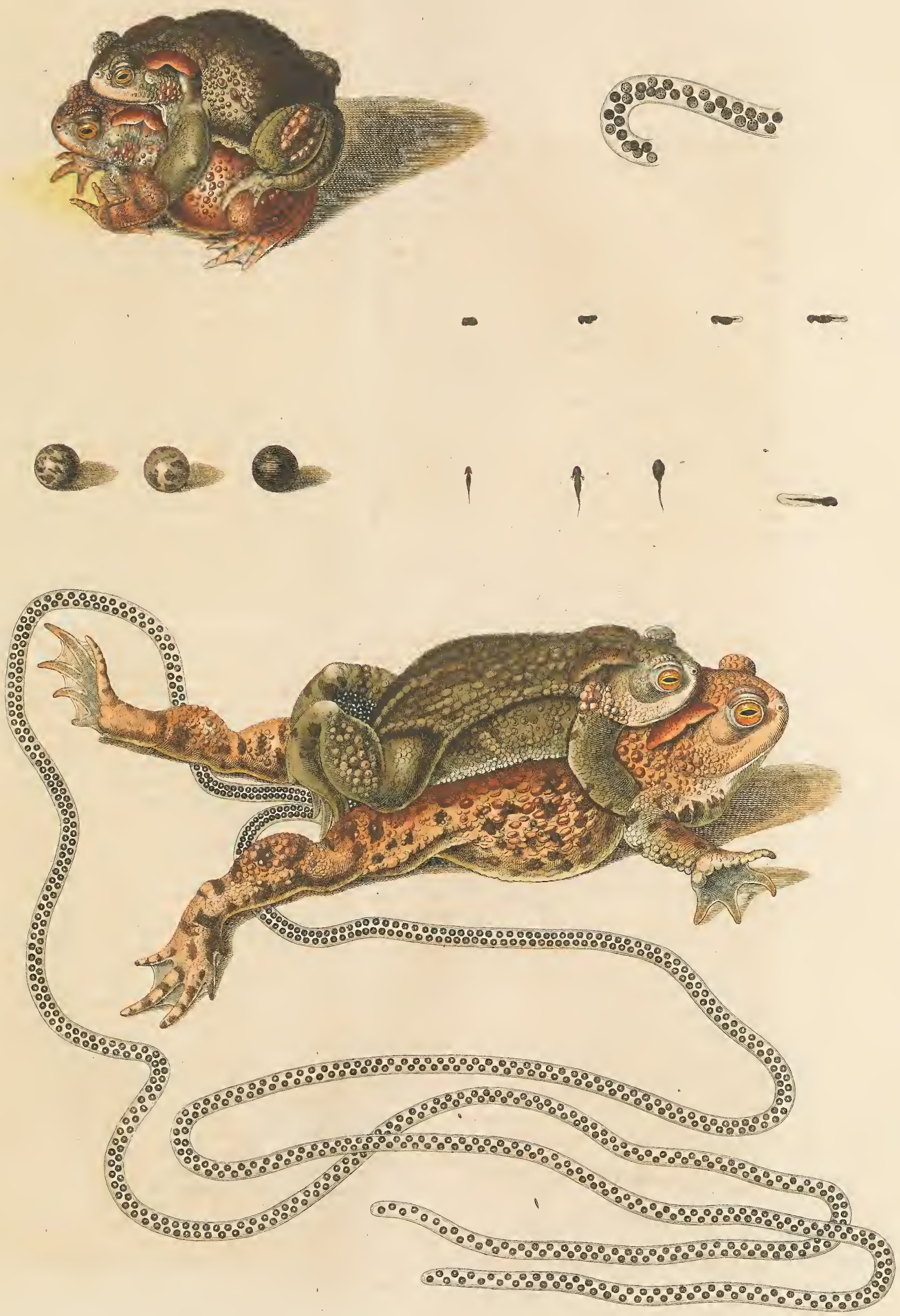



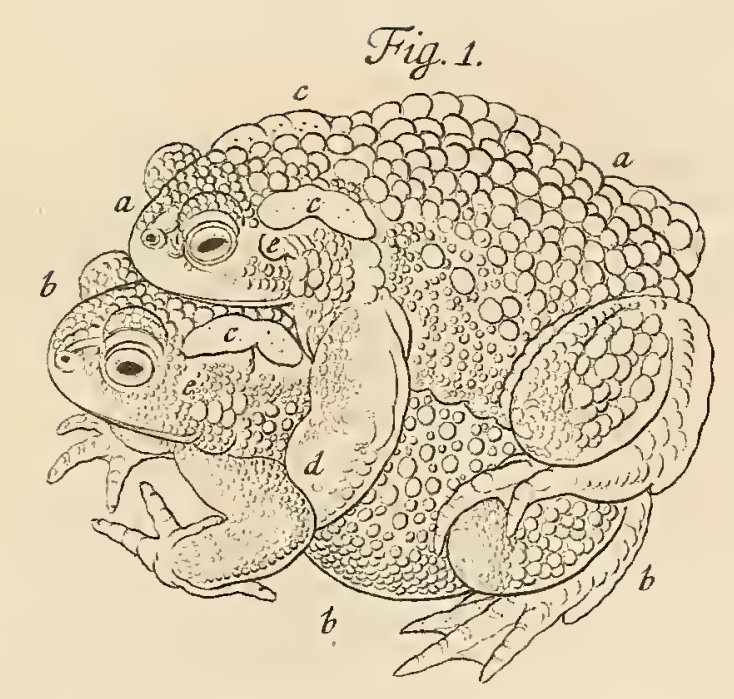

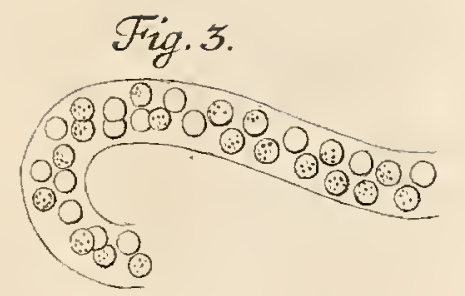

$$
\begin{aligned}
& \text { Fig.7. Fig.8. } \quad \text { Fig } 9 . \quad \text { Fig.10. }
\end{aligned}
$$
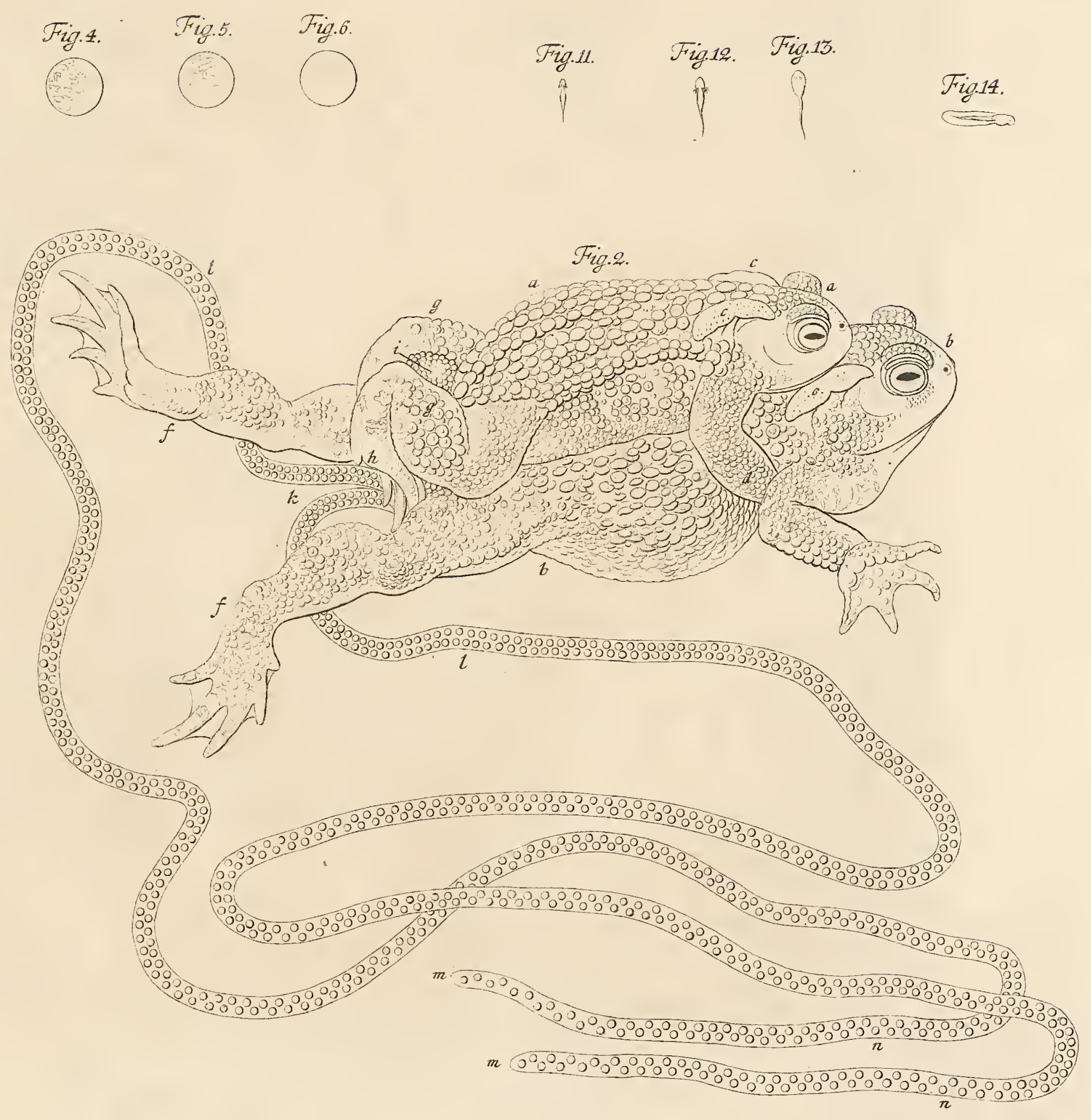



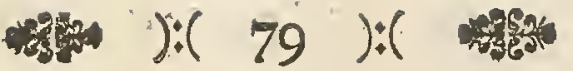

Quamuis vero polteriora gyrinorum meörum crura, quoad formam, effent perfecta, crefcebant illa tamen, donec tandem elapfis decem diebus, atque adeo die vigefimo Julii, anteriora fimiliter comparerent, ita, vt eodem in loco, quo nona in figura cubitum $e$ eorundem vidimus, finiftrum primo ex aperturaquadam, ipfa cruris craffitudine non ampliore, atque dein dextrum emergeret. Sequebatur femper finiftrum crus, polt fex demum horas dextrum, id quod tamen nonnunqua citius etiam tardiusue fiebat. Retrahebant aliquamdiu iteratisque vicibus crura hæc anteriora per eandem illam aperturam, per quam prodierant, ipfam fub cutem, vt prorfus laterent; fed non ita multo poft procendebant ea denuo, ac fi ipfo hoc moru, cutem qua abfcondebantur, quamque cum reliqua erant depofituri, effent faciliore opera remoturi.

Quae fit forma hujuscemodi gyrini quatuor fuis pedibus nec non longa lataque cauda inftructi, decima oftendit finura, atque fic fimilior eft fingulari cuidam lacertae aquatica fpeciei, vel pifci quadrupedi, quam bufoni: funt etiam gyrini hi ipfi illi quorum jam fupra p. I3. naturalis bujus I-Iiftoriae ranarum noftratium memini, ybi retuli, affirmare SEBAM mutari ranas in pifces: funt enim ex omnibus ranarum noltrarum gyrinis maximi, atpue vbi pedibus adhuc carent, tantam habent pifciun fimilicudinem ve paupercula gens rufticana eosdem inter pifces referat comedatque: mihi certe nonnulli ruftici id erant perfuafui o quumque ipfis indicarem, mutari pipirces hofce, quos fpeciem capitonis efle putabant, in veros bufones, vehementer funt mirati.

Erat quadrupedibus hifce gyrinis os aeque paruum et cauda aeque magna, ac illis quos nona fiftit fipura; fed obferuabam, haud ita multo poft, incipere jam eorundem mutationem. Reddebatur cauda breuior aeque ac gracilior; os contra dilatabatur, ita, vut die vigefimo fecundo Julii undecimae fimiles effent fizurae. Oris dilatationern ipfe perficiebat gyrinus continua ejusdem diductione, qua cutem, binas maxillas ftringentem, dilacerabat, quam dein ope crurrum fuorum anteriorum dextre fatis remouebat. Erat tum ea oris forma, quam duodecima monfrat foura, quae hujus fpeciei gyrinum repraefentat, il lo, Fig. II, hinc multo minorem, quod neceffario caruerat pabulo: quum enim, ve fupra jam dictum eft, viginti tantum gyrinis efcam praebuerim, reliquos vero femouerim, neglexi hos in angulum quendam repofitos, donec,aliud prorfus agens, eosdem rurfus conficarer, vidi vero tunc, miratusque fum, fuiffe illos, non obftante quatuor hebdomadum inedia, in perfectos ejusmodi bufones mutatos, cujusmodi vnum decima quinta refert figura.

Decre-

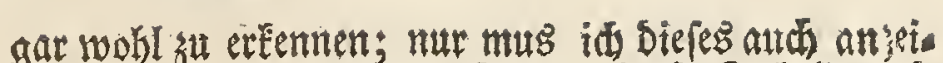
gen, bafi id folche in allen stignten biefer Tabelle, unt auch ber Den vorigen 2 (rten von Dergletdjen 2 Burmern, fo voraeftellet, wie fie altsfiebet, wem felbige im sisa fer befindiet find,

Ob mun aber gleidh bie bintern Ftiffe meiner 213 tir mer welche mun immer wentger शahrung zu fidh nahe men, ifre wollige form hatten, fo wublen fie Dod nod ftets fort, bis endith nach 2 erfits von zeben Tagen, und alro Den zwantigften Jullit, atth Die yorbern zun Zorffein Eamen, fo, Das ant eben Dem Drt, two wir in Der meanten Sigur den Ellenbogen $e$ berfelben gelea ben, erftlich Der lincle Durch eine nicht groffere Deffs mung, als reine Dide erforderte, uno bernad) auth

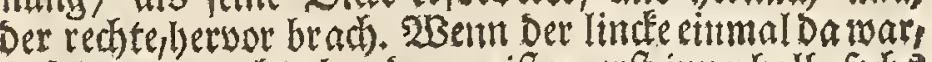
fo folste Der redse bey Den meiften enf immertalb fech Stumben, bey einigen aefhabe foldhes aber auth ebents Der und bey andern rpater. Eine Zeitlang zogenfie bies fe thre 20Derfiffe zu wiederbolten malen, Durd bie Deffunt Durd welche fie beratsigelommen waren, unter die Saut zutud., fo, das man you felbigen gar nidhts mebr iahe; balo aber fichoben fie foldse wieser beraus, eben als ob fie fich Dutch biefe semegung yon Der 5 ant woruntet fie felbige verbargen, unt welche fie, gleid Der tibrigen, nod absulegen batten, um fo siel efienber zu entlebigen traditeten.

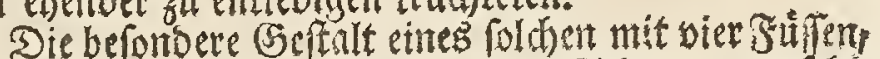
und fernem itod langen und bretten Saman verrefes

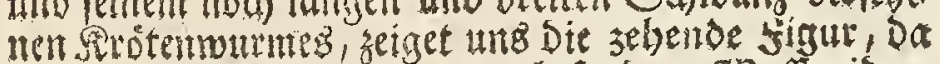

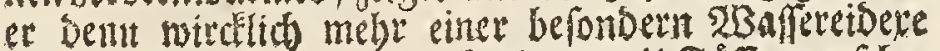
als eimer serote, ober aud) einem mit Fiffen berfebses nen šith gleithet + cben biefe Rrotentwirmer nber find

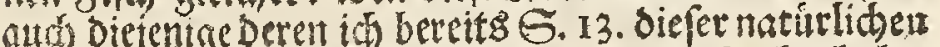

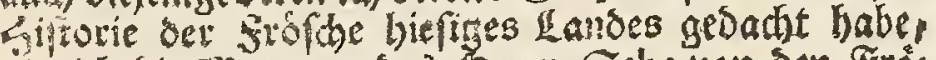
als id Die 5eennuth Des Jerrn Geba von Den Fre: forn fo su firchen merben, anfubete: Demt fie fint whter affen sibitutern Der biefigen Frofd artent bie gro:

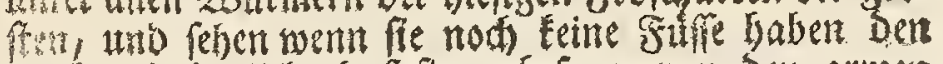

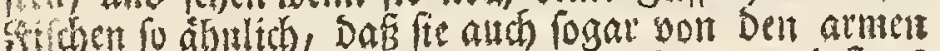
Renten auf Dem \&ant Dafur gesfen werden; wentgfens baben mid eintige Derfelben foldes verfithert, tabs fith

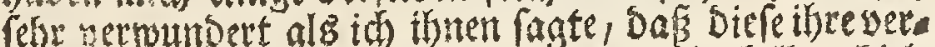

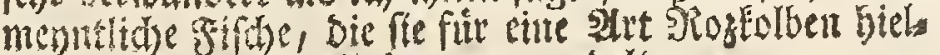
tein fith in wabre Seroten werwandelten.

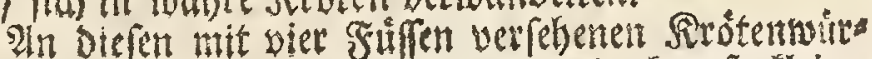
mern, war min zwar der Mund itod ebeit fo fleir, und Der Sd)wans von glether (S)roffe, wie an benen, Deruleithen Die newnte Sigur youftellet; alleite fie fiens

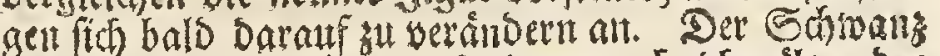
murbe nidst nut furger, forbern aud (a)máler, bee S)und aber erweiterte fich mefer uns mebr, fo, bas fie alo Den zwen tuto swantsinfen Julti Der eilfen Sis gur gleid) fahent. Die (Evwetterung Deb sRundes

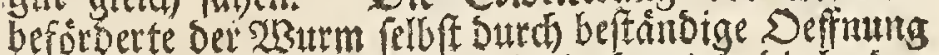
Desfelbigen, imbent er Dasurh Die Saut lo bie berben geiefer bisher verfahlofien gebalten zerrié; auts mas

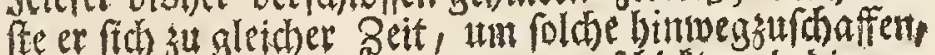
feiner becoen vorbern Finfe, gar gerhidet ju bedienten. Der sqund fabe hierauf fo aus, wie er fid in be swolften fitur zeinet, meldie einen Diefer firotenmirs mer vorfellet, Der vid fletmer ift, als ber in ber eilfo ten sisur, er if aber Desnegen so Elein gebliebent weil eş thm an notbiger Nabrung gemangelt: Demot icf, wie bereits oben bon mit gemeldet torber, nue

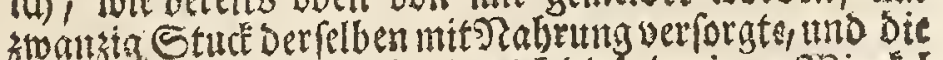
swatstg. Stuct derfelbenm its

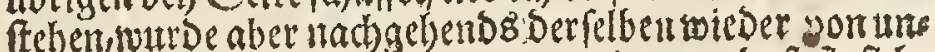

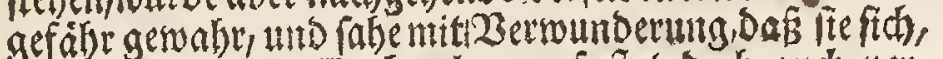

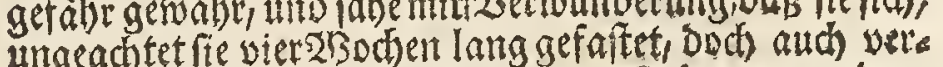
mandelt batten unt zu vollfommenen Groten g:worben, von welchen bie funtsebende Sigut eitte voifillet.

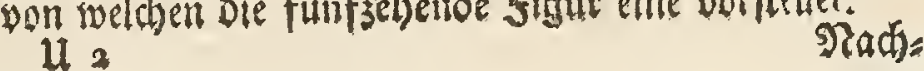




\section{4:}

Decrefcente femel gyrinorum horum cauda, omni ratione ommibusque viribus ex aqua emergere tentabant, id quod illi prae reliquis agébant qui decimae tertiae figurae formam habebant, quam plurimi eorundem, die vigefimo quarto Julii, induerunt; quin quum paullo tardius aliam ipfis pararem habitationem, mortui funt, ipfa in aqua, eorum nonnulli: vt ergo reliquos feruarem, in alia eosdem immifi majora vitra cylindracea, quorum fundus terra erat tectus, cui caefpes incumbebat. Grata effe videbatur noua haec habitatio gyrinis meis, quippe jam non folum quiefcebant, fed fequenti etiam die fefe fub caefoidem abdebant. Supererat jam parua tantum pars caudae, antea adeo procerae, poftquam vero haec quoque euanuit., finiles prorfus erant, aeque ac foura decima quarta, et forma et colore, fola magnitudineexcepta, adulto allium redolenti bufoni; et licet interdiu quiefcerent, noctu tamen multo fe monftrabant alacriores.

Poftquam itaque bufones hofce multo labore educaueram, vifurus eram, vtrum priftinam fuam adhuc appeterent efcam, fed ignota ipfis effe videbantur brafficae lactucaeque folia, quin auerfabantur illa. Neque arrodebant, quos ipfis porrigebam, maturos hoc anni tempore fructus; quum vero ipfis mufcas, lumbricos minores, aliaque praeberem infecta, in arripendis illis deuorandisque fumma vtebantur alacritate, ita, vt bufones hi, aeque ac ranae, lacertae, ferpentes teftudinesque nullis vefcantur plantis, nullis fructibus. Quemadmodum vero fumma inter bufones hofce juniores adultioresque erat finuilitudo, ita et al'ii odorem fpargendi non deftituebantur proprietate : protinus enim, vbi eosiniquietabam, feriebat odor ille nares meas.

\section{SECTIONIS IV.}

\section{Caput 11 .}

\section{Defcriptio internarum partium bu-} fonis aquatici, allium redolentis, maculis fufcis.

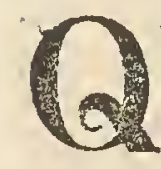

uum gyrini bufonis aquatici allium redolentis maculis fufcis, reliquos gyrinos ranarum noftratium, quemadmodum XVIII. Tabulam contemplantes vidimus, magnitudine fuperent; fufcepturus eram in vno eorundem, internarum partium examen, ad quod fingularis illa me impellebat ratio, qua, in his aeque ac aliis ejusmodi in gyrinis, crura anteriora fefe confpectui noftro primitus fiftunt: non enim, ceu vidimus, fenfim fenfimque ad modum pofteriorum crurum procrefcunt, fed prodeunt fimul ac femel, atque vbi comparent, jam quoad ftructuram perfecta funt. Vifurus itaque vtrum fub cute incrementum fuum caperent, talem pro examine inftituendo felegi hujus fpeciei gyrinum, qualem nona figura XVIII. Tabulae fiftic, enmque non folum fat magnum, fed cruribus etiam pofterioribus jam inftructum, anterioribus vero carenrem. Diffecui hunc die vndecimo Julii ea ratione, vt ip fum in inferiore corporis fui parte in longitudinem aperirem, atque hoc facto cutem muículofasque partes ad
Tacbsem nut eitmal bet Schrom an biefet SWirimern fleiner zu werden und abzunefimen anfieng ruchten biefelben immer befftiger, und endich gar mit

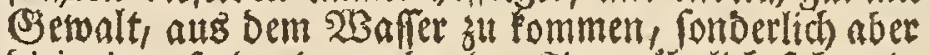
Dieienigen, so Der dreysebenden Fittur ăhnlid faben it welcher S3eftalt Die meiften Den vier und - zwanzigften

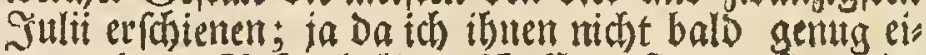
tten anbern $2(u$ fenthalt verifhafte, fiengen fie an int SBaffer zu fterben: an mun alfo Diefem vorsutommet IIIto Die nod) uibrigen beum Seben su erbalten, brachte ich fie in andere arofle Buterglárer Deren 2 oben mit etwas erde bedectet wat, worallf oben ein $23 a$ fe lag. Diefes neut Duartier fohtent ifnen siel amftándiger ju fern, indem fie fich nummetgr gan's rubig unb ftille biels ten, unb Den folgenden Tag bernady vollig unter Den sbaffer verbargen. Damalen jeigte fid mur tod eir fleiner Reft von ihrem vormaligen groffen 5 d) mants aut ibnen. temo als fie aud siefen ben adt und zwanzig: ften Julli gar verlobren batten, faben fie, wie Die viev: sebende Sigur, Die Ërófle ausgentommen, fo Der Form als Der Farbe nach, einer alten Sinoblauchterote voll Eommen gleid), uns bielten fich bel) Tage zwar fille, waren aber gegen 2 (betto und ber) Nadit um fo viel nututterer.

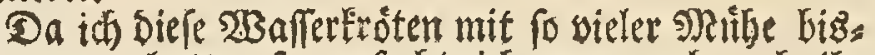
ber ergogen batte: fo werfudbte ith mun aud

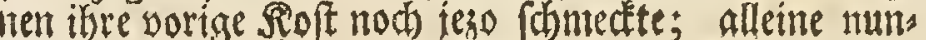
mebr folienen ifnen Die Rraut: und Salatblätter etwas frembdes, ta gar sumider zu renn, aud lieffer fie Die zn Diefer Sabresseit reiffe sruchte, fo ich ibnen vorlegte, unbertibret; als id ibnen aber Rudfen, Elei= SRegenwatrmer und andere Infecten Darbot, fáumten fie inicht lange foiche zu bafchen und zu verfolucten fo, Daf allo diefe firoten eben fo menig etwas von SPlanzen unt Fraibten zu fich nebmen, als wenigan

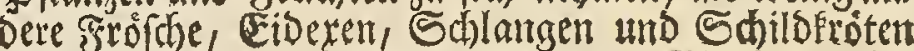
Derfelben fich zur Nabrung bedienen. BSteichie aber mun meine iunge Siroten Den alten in alber ábnlich toa ren, fo feblte ithen aud biefe Eigenchaft nicht, Dar fie gleidh Denfelben einen Sinoblauthgeftand bon fich gaben: Denn wenn ich felbige beunrubigte, liếen fie mich foldsen bald empfinden.

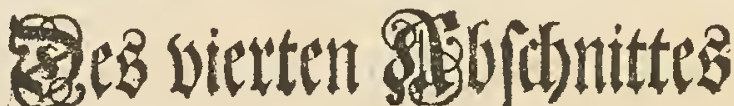

\author{
Jweyteg Capitel.
}

Befdreibutng der imetlidentsheileder

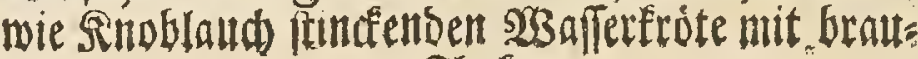
tent flecten.

G(Seil Die \$itmer unferer wie Snoblaud ftits

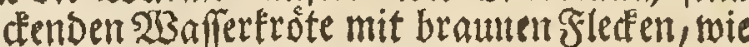
mir auf ber XVIII. Crabelle gereben baben,

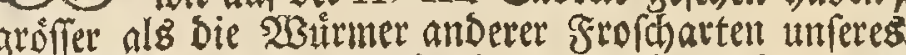
Sandes find: fo nafm id mir vor, aud) yon Disfer eis nen reitter innerlidoen Structur nach zu betradtert.

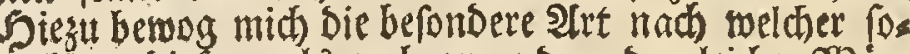
wohl an biejen, als auth an andern bergleidben 23 urs urern, sie worbern Fitfe zum :Borfhein Eonmen: Dent wie wir gefehen haben, fo wad) fen fie nid)t gleid) Dest. bintern nach und nach, fondern fie seigen fich auf eins mal, unt fint bereitz, wenn fie fich feben lafen, der Structur nach volfémnten. $\mathfrak{D}$ a ich nun allo febent wollte, ob fie Denit unter Der Şaut nach und nads. whidfen, fo fieng idy meimeldnterfuchung mit cinem fols d)en voll Diefen SBurmern an, Der bereits Die Broffe Der neunten Figur unferer $X V I I I$. Cabelle hatte, uno alfo mit feinen bintern Friffen fofon werfehen war, Dem aber bie vorbern nod mangelten. Diefen effnete id 


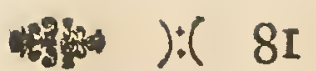

Iatera aciculis affigerem, poftquam gyrinum ipfum, acicula per os transmiffa, jam antea firmaueram. Monftrat diffectum hưnc gyrinum figura prima vndeuigefimae tabulae. Confpiciebam protinus, vbi gyrinum hunc aperueram, crura anteriora $a a$, jam quoad formam perfecta, quæ tamen minus perfecta me inuenturum credideram; poenitebat hinc me, quod examen hocce non cum ejusmodi hujus fpeciei gyrinis infituerim qui minores, farurisque fextae nec non feptimae, $X V I I I$ Tabulae fimiles fuiffent: jam enim hujus magnitudinis gyrini non poterant reperiri. Aft enim vero refarciebatur, quod hac vice ob tardius infticutum examen perdideram, aliis partibus, quas praeter omnem opinionem, in diffecto hoc gyrino reperi.

Sed agedum infpicianus propius gyrinum noftrum diffectum, quem prima fiftit figura. Cernimus fub anterioribus cruribus a a transuerfum feptum, quod a thorace abdomen diducit. Super crura anteriora bina majora funt tubera $b b$, quae, viuente gyrino, nunc paulum dilatabantur, nunc contrahebantur; de quibus tamen quid ftatuerem, tum quidem ambigebam. Prope haec confpicitur fuperne transuerfa, gracilis nec non duriufcula pars $c c$, quae mihi, non fterni crefcentis portio, fed inferior potius maxilla effe videbatur, qua bufo hicce mutato ore, omnino indiget; vetabat tamen accuratius hujus rei examen, deproperanda teneriorum harum interiorum gyrini partium delineatio, quum breui ficcefcant. Indicat littera $e$ in for $u r a$ hac paruam hepatis portionem, cujus reliqua eaque maxima portio, perinde ac ceterae partes, inteftinis $d d$, duplicem in gyrum conuolutis, cooperitur; recti vero inteftini orificium, fiue anus, ad $f$ hiat.

Poftea vero quam hanc hujus gyrini delineaui iconem, reliquas quoque illius partes contemplaturus, die decimo nono Julii, alium rurfus diffecui, binis anterioribus cruribus jam inftructum, quemque decima figura, XVIII Tabulae, hic vero fecunda icon repraefentat. Signata hic rurfus funt bina crura anteriora litteris $a a$, illa vero pars, quae inferior maxilla effe videtur $c c$; fed longa alia jam erat facies binorum tuberum in priori figura $b 6$ notatorum, quum cutem qua tegebantur detraxeram: hoc enim facto non folum cor, inter illa fi tum, veniebat in confpectum, fed bina illa tubera $b b$, nitentes antea cinereoque colore tinctas veficas referentia, coloris iam erant carnei, nec non obliquas quasdam monftrabant crenas, ita vt pifcium branchiis prorfus effent fimilia. Repraefentatur ad $k$ finiftra pulmonum vefica, dextra vero fub hepate $i i$ latet. A pulmone propius abeft lien $l$, rubrum referens globulum; $m$ felleam indicat veficulam, ejusdem quidem formae, fed majorem nec non faturate viridi tinctam colore. Fuiffe jam gyrinum hunc materno in vtero, vel et in ipfo feminali patris vermiculo foemellam, clare fatis indicant ad vtrumque fpinae latus politi ouiductus $n n$; minus tamen tum confpiciebatur ouarium cum vtero, fed tecta erat, ea ipfa in fede quam bina haec vifcera occupare folent, fpina majoribus quibusdam mufculis $o$. Ventriculus $m p$ in finiftro femper haerens latere, hic dextrorfum magis vergit, quippe ex naturali fua fede, ob inteftina $q q q$ euolata atque e corpore protracta, dimotus. Aequant inteftina haecce a ventriculo ad inteftinum rectum $r$, ejusque exterius orificium $f$ vsque dimenfa, lon-

\section{)$:($ :}

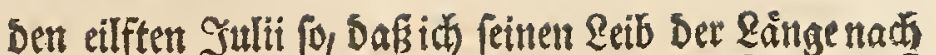
auffanitte, uns als foldiegs gef hehen, bie Saut nebit Den fleirhernen Theilen an ben Seiten mit Stednabeln

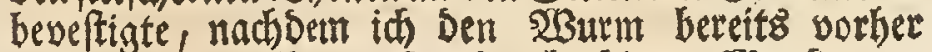
mit einer Derrelben , fo burd feinen Inumb ges ftectet worbert, veft gemadet hatte. EEs geiget uns Diefen geoffineten 2 Burm Die erfte Signt Der XIX C: belle, unb Das erfte, was it in Demfelben erblidte, waren bie swen vorbern Futre a a, Die bereitz ibre vóls lige (Seftalt hatten, weldie it aber minder yolleomment

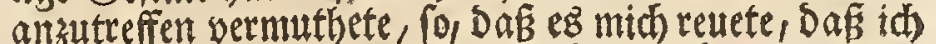
Diefe Innterfud)ung nid)t mit foldsen 2 suirmern biefer Sirt angeftellet hatte, weldhe nod) fintiger und yon ber Brofife Der fectifen und fiebenden fitgur Der XVIIL Tabelle geswefen wáren: Denn mun tonnte idh Derglei

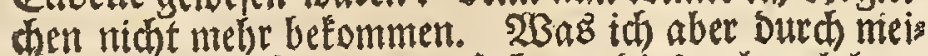
ne zu fyat angeffellte Unterfuchung Diesmal verlohrelt batte, Das murbe Dutrh Die Ëntbectung anderer Shetle erfezet, welche id in bierem aufgefdnittenen 23 urm wieder mein $\mathfrak{B e r m u t h e n ~ a n t r a f . ~}$

2Bir wollet iegt unfern geoffineten 2 Wurm, nad) Dee erftel Sigui, genáuer betrachten. Inter ben mit $a$ at

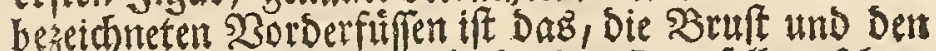
unterleib son einander fajeidende, Duerfell zu reben. Heber ben beeden Füfen zeigen fid ein spar groffer Beulen $b b$, bie fid, , fo lange Der 5 (3urm nod) lebte, int etwaz auf und mieder bewegten, und sondenen id mis nidit forleich vorftellent tonnte, was fie fenn follten; iber diefen lauft ein famaler, aber etwas harter'sheil

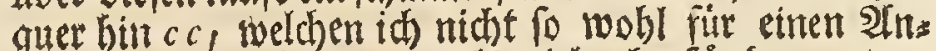

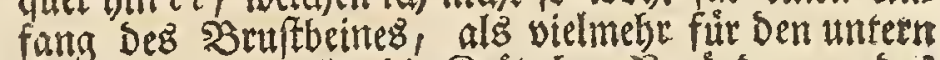
Riefer hitelte, Defien Die Rrote ben Beránderung Des s)unbez benothiget ift, wienobl ich folches fo genaut nidyt unterfuchen fonte, weil Die noch zarten inmeret Theile einez fold)en Arotentwurmz za gefthinde ver

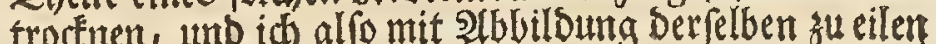
batte. Der Budfftabe e zeiget in Diefer Sigur einen Eleinen Sheil Der Leber an, Deren grófferer Siefít, gleich Den tibrigen Theilen hiet yon Den in einer Sdnedens linie gedoppelt zulammengelegten S3ebármen $d a$ bedes cket iff; unt Der શluzgang Des Maftoarms oder bee

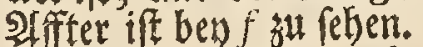

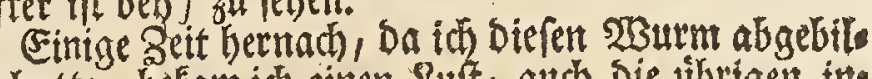
bet hatte, befam ich einen ?uft, audh Die tibrigen itt nern Theile Desfelben zu rehen, baher offitete id ber neumzethenden Sulti einen andern, Ser aber beritis die beeden vórdern Fuffe hatte, und Der sebenden Figut Der XVIII Tabelle ábnlich fabe, hier aber in Der zwey. ten voraeftellet iff. Die beeden 20 orderfiffe fino biet ebent wieder mit $a a_{1}$ Der Theilaber Der Der untere Siefer zu feisn (heinet mit $c c$ bezeidinet, unt Die ill voriger Fiaur mit $b \quad b$ bemerEte s (wel SBeulen baben munmebr in

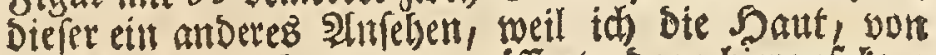
welcher fie bebectet waren geóffnet: Denn bierauf fant nicht mur Das znificen ithen liegende Ser's g zunt Sorfhein, fondert Die beeden Beulen $b b$, welde zusoe sweven glanzenden grauten $\mathfrak{B l a}$ len gleid) faben, zeigtet fich iest rothlid thet fleforb, und batten eimige fobrege vertiefte Einferbungen, fo, Dab fie Den fo genannten Fifhobren voltommen gleidh fahen. $\mathfrak{B e y} k$ ift Die lins fe Rungenblafe vorgeftellet, bie rechte aber liegt hiet 1unter Der Reber $i$ verborgen. Nitjt weit yon bes.

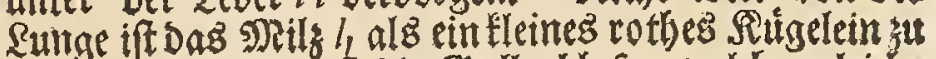
reben, ben $m$ aber if bie S3allenblare, meldhe gleithe Form alleine mehr Srófie und eitue sunfelgrtime sarbe haf. Das Diefer W̛urm vielleidt f(t)on im Enerftod reiner Nutter, ober int Saamenthierlein Des 2 atters zu einem $23 e$ blein beftimmet gewefen, geben die zubees Den Seiten Dez SRutigradez liegente Energänge $n$ : mehr als zu mobl zat er enten, von Dem Enerfad hite gegen uns Der Bârnutter war nod nid)ts za febert pondern Das SRuckgrad war in Der Sigend wo fontio 列

beede 


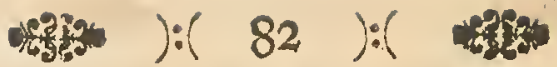

gitudine pede $m$ fere : aequalis infuper funt vsquequaque craffitudinis, nee non, ob faèces quibus fcatent, coloris ex fufco viridis.

Prae reliquis verô, quas in gyrino hoc diffecto vidi, partibus, notari merentur bina illa tubera $b b$, pifcium branchiis prorfus fimilia. Memini quidem, me jam, in Hiftoria ranae terreftris, de ranarum quaedam dixiffe branchiis; fed factùm id eft occafione branchiarum quàs ranis ineffeSW AMMERDAMMIVS dixerat, cui equidem hac in re tum minus adftipulabar; fed mutaui non ita multo poft, et ante quintae hujus operis plagulae editionein, meam de branchiis hifce fententiam, id quod jam pag. I9. indicaui; nunc vero minime dubito, effe non folum hifce, fed reliquis omnibus, bufonum aeque ac ranaruin, gyrinis, fuas omnino branchias: licet enim pulmonibus jam fint inftructi, non tamen his aeque, vbi gyrini formam habentes in aquis morantur, ac illis indigent, quwim, perinde ac pifces, branchiarum ope, eo ipfo tempore, plus, necelfarii adeo ad fuftentandam vitam, áeris, quam pulmonibus hauriant. Credens itaque cum SWAMMERDAMMIO, gerere ranarum bufonumque gyrinos branchias, minus etiam refragabor eidem dicenti, fuccrefcere appendices illas fimbriatas, quas in ranarum aeque, ac in his bufonum gyrinis Tab. XV II. fip.p. et Tab. XVIII. fi, I. et 2. vidimus, ipfas in branchias: licet enim fuperius dixerim, ignorare me earundem in gyrinis hifce vfum hoc tamen vtfcriberem hinc eft, quod minus cum SWAMMERDAMMIO viderim, particulan earundem, quae fubter et intra cutem jam conclufa erat. guoad jormam et habitum priftimum aliqua ratione fuifje mutatam. + Quum vero hic fententiae, cui antea concradixi, affentiar, facile hinc fieri poffet, ve naturalis haec mea ranarum hiftoria nonnullis manca erroribusque. referta videatur; hos vero ad eum praefationis meae remitto locum, vbi inter alia haec quoque leguntur: non refragari me, fiopus boc pro mifcellis potius de ranis obferiationibus, quam pro consinna carundem habeatur bijtoria.

Thefrui infuper has in gyrinis hifce repertas branchias, in ita multo poft, in aliis eorundem, fedincafum; aft enim vero erant hi aetate prouectiores illis, in quibus easdem vivero erant hi aetate prouectiores illis, in quibus intat trans.
derum. Q 10 propius itaque gyrini in bufonem infat figuratio, eo magis ip fae decrefcunt branchiae, donec tandem prorfus aboleantur. Oua vero hoc continget ratione, equidem exponere nequeo; af aboleri easdem, aeque ac fat grandis horum gyrinorum, fine praeuia feparatione, euanefcit cauda, horum gyrinorum, fine praeuia leparatione, euane citcauda, perfuafifimum tabeo. Mouet vero hoc ipfum maximam quadrupedibus aeque ac ipfo in homine, dum in vtero latent, quars fimilter pares, quibus, pnitguam in lucem prodierunt, non amplius indigent; aft xion abolentur illae, fed coeunt cuncrefcuntque, ita tamen, ve earundem nunquarm non fucuncrefcuntque, ita tamen, vt earundem nunquam non lu-
perfint reliquiae, id quod, in foetu, canalis finus venae por. perfint reliquiae, id quod, in foetu, canalis finus venae por. guinem ex arteria pulmonali in aortam effundens, fatis tiperque comprobant, ita, ve fuperuacaneum foret, fi alia. rum ejusmodi partium infuper hic fieret mentio. Eundem vero

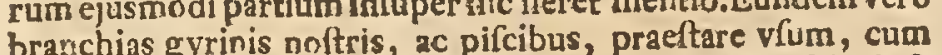
branchias gyrinis noftris, ac pifcibus, praeftare vfum, cum
SWAMMERDAMMIO certo certius credo, licet hic ipfe SWAMMERDAMMIO certo certius credo, licet hic ipfe id corporis latera vilis paseant aperturis, adeffe tamen aperturam, vti in icone fepsima $e$ atque octaua 2 Tab. XFIII t Coafer fis ciusdem Biblia Nafuras Tomo II. p. 8Ig.
Ierbe sul liegen pflegen, mit ftarEen Nufcern o bebes ce: Der shagen $m p$ liegt hier mebr auf Der reften als linfen Seite; weil er Durh Die aนt Dem Leib gesos

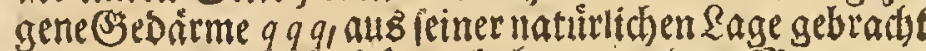
worben. Dicre Ëedárme haben, von Dem MRagen an, bis zu Dem Naftoarm $r$, und Der åuferen Deffnunt besfellben I, bennabe eine Qánge von einem Sduhb, find aud Durb)aus wort gleider Dide, und reben wegen des in ibnen befindlichen Intathes braungrin.

Das befonderfte was i i num in biefem geoffiteten 2Burm gefunden, find Die beeden \$Beulen b $b$, welde Den Fif hohren vollfommen gleidjaben. Sn ber bes

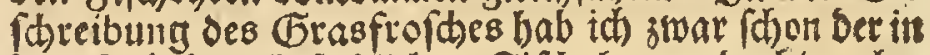
Den Srofden befindlidhen Sirchohren gedadt, aber

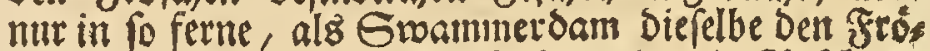

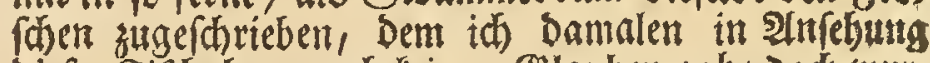
biefer Fischokren nod feinen (Slauben gab; Dod tour: De id bals Darauf, und ebe id) nod) Den funften 20

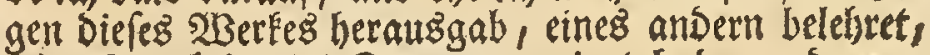
wie id auch bereits. .5 . 19. angezeiget babe, utto utus methr alaube ids, Das nidit nur alleine biefe, fondern

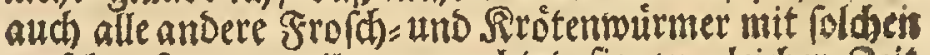
verfehen renen, weil, ungeachtet fie zu gleicher. Seit auch bereits Rungent baben, fie Diefer, fo lange fie nod sBurmer fino, uno blos im 23 affer lebes, nidat fo mohl beourfen als Der Sifhohren, vermittelít welder

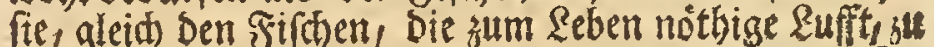
biefer Beit methr, als Durch ibre \&ungen, erbalten. Da th) nun alfo mit Dem Gwammerdam glaube, Dafis bie

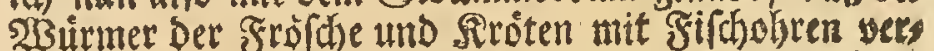
feben fenn, fo twill idf ifm eben aud mat wioeripes d)en went er fatreibet, Die gefrangten Inbånge, welde wir wie an andern Frofhiolirmern, alfo aud andies fen Sirotenmirmern, Tab. XVII. fis.p. uno Tab. XVIII, fig. I. und 2. gefeken, whirben zu thren Dhren: Deriu

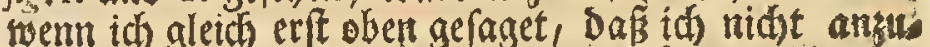
zeisen wüke, nogu felbige biefen sburmern dientert, fo if foldes Doch baber gefchelen; weil id nidit, wis Gwammerdan, einen Cheil derfelben unter uno ins nerlgalb der Saut eingefhlofen, und der form tuns Geftalt nad verinbert gefehen habe. Da id abes Gie etwas annebme, weldies id worber miderfiprodjety tonnte foldhes wohl Baelegenbeit geben, Dafs cintige Diefe meinte naturtide Sifterie ser frofbe für feblerb beft und unvollfommen bielten; alleime biefe vertweifs ith auf Dieienige Stelle meiner 330 rreby wo id gefaget babe: oaf id mir es gar wobl gefallen liefe, woem man mein Dert nidt fo wolj fur eine ordentlids Siftorie, als vielnebr fiur vermif te 2lumerênger voin ben frófhen halten wollte.

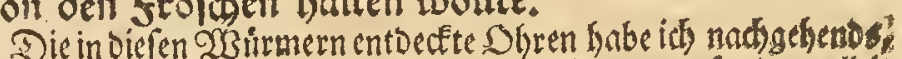

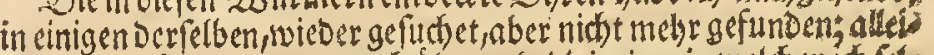

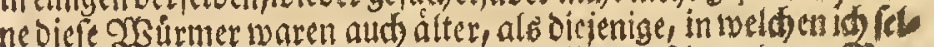

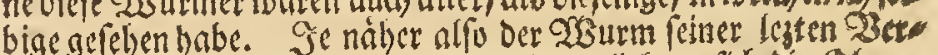

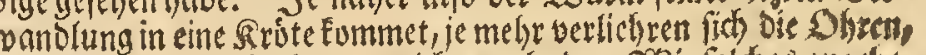

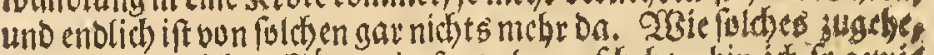

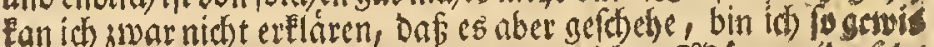

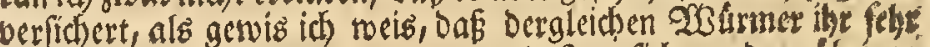

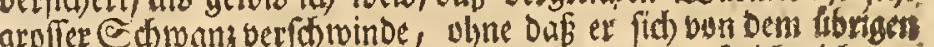

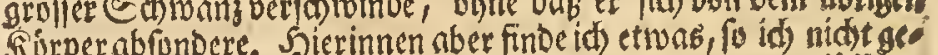
Rúrperabfundere. Shierinnen aber finte id) etwab, fo ids nider gee

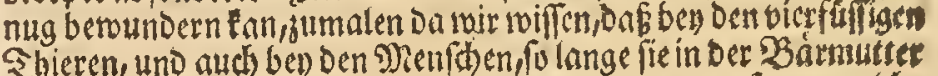

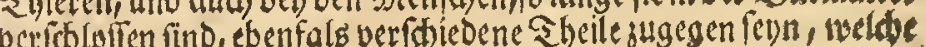

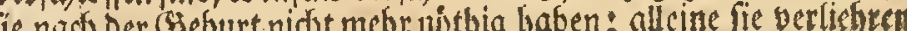

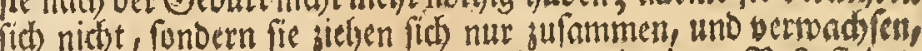

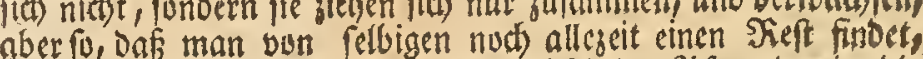
wie folches ber been Findern aus ber Shíle ber Jy fortaber in bie Solader gehende Eanal, uno der fo beeveben benfelbigen das 2 liut gus Der \&ungenpulsaber in bie grofle Đulsader fúhret, genugfan

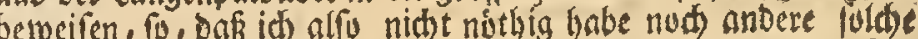

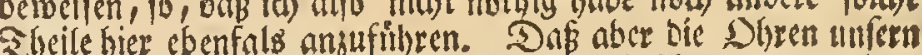
ogsürmern eben Daju dienen, woju fie Den Fifhen nuken, glau

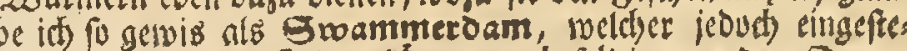

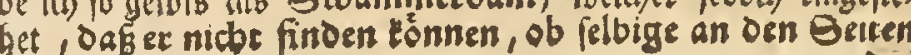

* Joc, p. 82\}, 
Tab: XXI

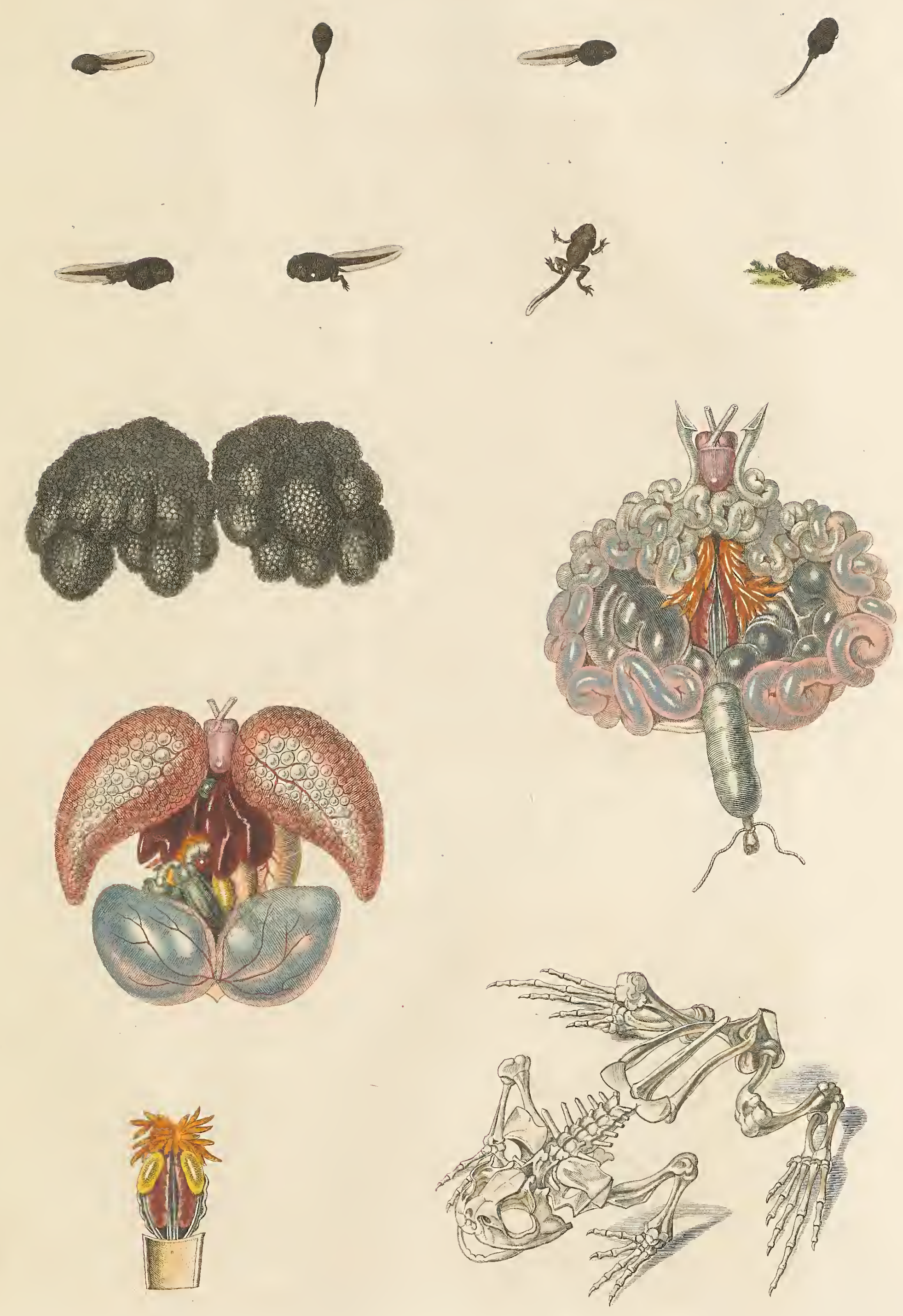




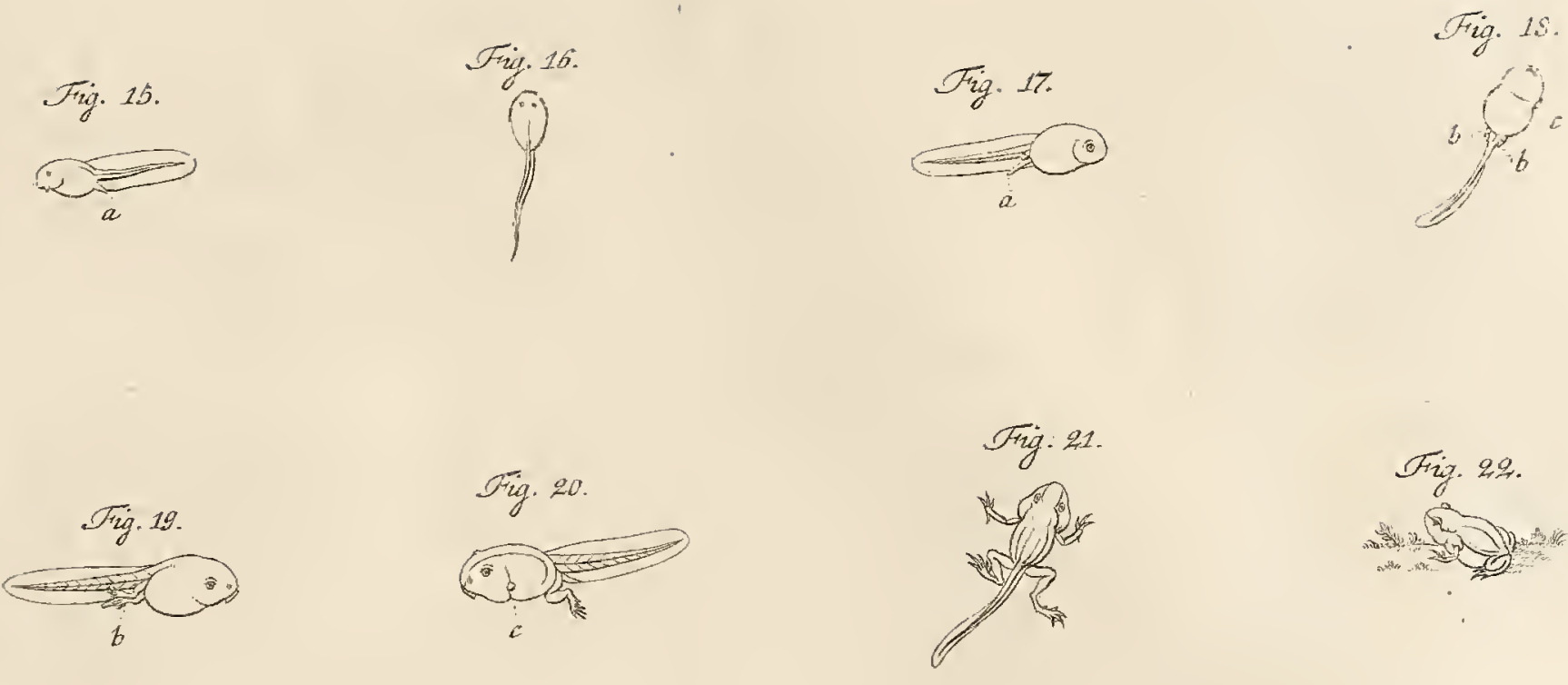

Fij. 25.
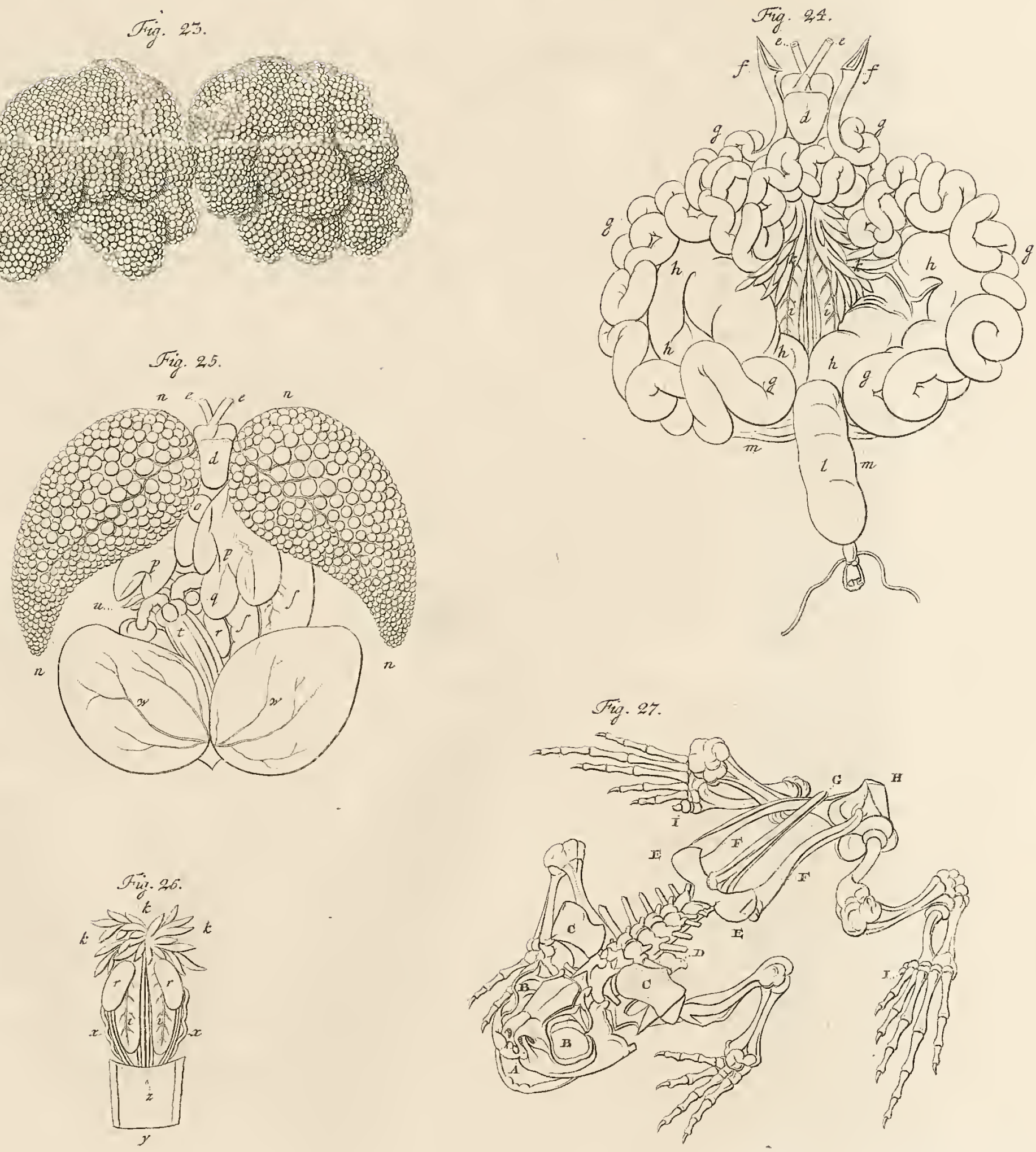



\section{6\%}

vidimus, ego quidem demonftrai, licet illam in finiftro tontum repererim latere. Notari etiam meretur, longiora effe in gyrinis hifce inteftina (Fig. $2 . \mathrm{g} 9 \mathrm{~g}$ ) qu\&m quidem in ranunculis vel bufonibus inde natis; quum vero gyrinus tenui tantum nutriatur cibo, ventriculus ipfius non aeque diftenditur, $2 c$ vbi majora corpora quin integra deuorat infecta, neque etiam, dum gyrini habet formam, veficae ejusdem pulmonales tam crebro tarnque furtiter inflantur; poftea vero quarn in ranam vel bufonem perfectam eft transformatus, vtrumque fit; tunc sutem verifimile eft, reddi \& partium reliquarum prelfion inteftina illius non folum breuiora, fed et cráffiors, firmiora que.

Sed contemplemur jam interiores etiam adulti, allium redolentis bufonis partes, quas reliqure XIX Tabulae icones repraefentant, quasque eo delineaui tempore, quo bufones hi coire fulent, atque partes ad generis propagationem $\mathrm{f}_{2}$. cientes eo diftinctius in confpectum veniunt.

Monftrat frura tertia, in bufone mafculo, partes illas, que, vbi diffecatar, protinus confpiciuntur; monendum tamen eft, aere 2 me fuiffe repletas veficas pulmonales nec non vrinariam, Cernitur fuperius ad $\int$ cor magis pallidum quam in ranis antee depictis. Differunt valde etiam binae veficae pulmonales $t u, t u$, non folum enin ea ipfarum eft magnitudo ve a corde ad rectum vsque pertingant inteltinam, atque bufo. nis ventrem ex vtroque fere repleant latere, fed conftare etiam videtur fuperficies earum ex meris femirotundis bullis, Ipu. mam Capone atque aqua factam, referentibus, illic vero vbi pulmones amplifimi funt, majores etiam funt bullae, fedquo propius ad extremum atque incuruum accedunt spicem $u, u$, co etiam euadunt minores. Interius caui funt pulmones, fubrotundae vero eorundem bullae tot vacuas referunt cellu. las. Pellucent infuper, atque ob majora minoraque per ipfos affim difperfa, Innguifera vafa, carnei funt coloris, Effi ciunt quoque rajores hujus bufonis pulmones, ve valde tuineat, fi haultum retineat f'piritum; quin fi reque notus effet ac vulgaris, terreftris bufo, ortam hinc crederem confuetam illam loquendi furmulam : tumet bufonis inftar. Haeret fub corde, in icone noltra, trib:ıs conftans lobis hepar ขvขv vv, admodum fufco tinctum colore, Infra illud cernitur ad $x \times$ ventriculus, inteltina cooperiens; quumque hoc in bufone lutea foliaceaeque non defint appendices, extremi earundem apices litteris y y indicantur; vefica vero $z z$ vrinae colligendae dicata, fat ampla eft profundiusque diuifa. Non equidem caret bufo hicce veficula fellea atque fpleae, minus tamen hic conlpiciuntur ob fitum in quo reliquae in icone hac fiftuntur partes, quæet organa generationis mafculis propria hic contegunt, ita, ve hinc eadem a reliquis feparata, quarta delineara exhibuerim icone.

Siftuntur in icone hac quarta, ad a $a b$, renes formam oblonam coloremque carneum habentes. Incumbunt hifce bini, in bufone hoc, valde exigui nec non pallide Haui tefticuli $c c$. Sigatae funt litteris $d d d d$ foliacere appendices, citrino po tius quam aurantio tindtae colore, neque renibus, fed ipfis tefticulis adhaerentes. Magnitudine, qua hicrepracfentantur, gaudent tantum generationis tempore, quum alias adeo fin paruae, vt vix reperiri queant, licet ceterum ipfis in gyrinis admodum magnae compareant. Confpiciendum fe praebet in vtriusque renis dorfo tenuis canalis $e c, e e$, ad inteftinum vsque rectum $f f$, decurrens, nec non ipfis fub tefticulis atque foliaceis appendicibus furfum vergens, Effe binos hofce canales veficulas femen continentes, prorfus mihi fit verifimile: quum enim inteltinum rectum, cujus hic tantum par tem sliquam $f f$ feruaui, eum in finem dilfecuerim, vt veficularum feminalium orifica, atque adeo veficulas ipfas inuenirem; aeremque per minora illa foramina ad $g$ immiferim, comparebant protinus bini illi canales $e e, e$ e : quin lice veficules hafce in aliis hujus fpeciei bufonibus iteratis vicibus quaefiuerim, femper tamen vidi, effe iisdem eandem, quam in icone noftra habent, formam: valde itaque differunt veficulis feminalibus ranarum priorum, parumque tume fedes illa, qua in inteltino recto hiant.

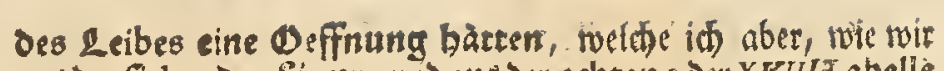
aus Der fieb noenfiaure und aus Der achteng Der XVIII a a helle gefehen, geseget, Dudt nut an Der linken Scite gefunden babe.

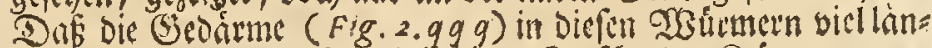
ger feyen, als wenn fie fich in einen Frufd vier frote berwan belt, ift aud etwas merfmétoiges; beil aber Der odsurm nut

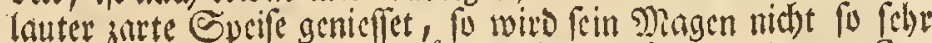

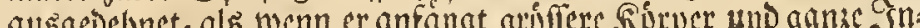
fecten zunerfblingen fecten zu verfolingen; aud werben, fo lange cr bie - wo urmgeitalt bebált, feine Sungenblafen nicht fo ufft uno fine aufg:blafen; beedes aber gefobielset, wenn er zu einem vollfummenen frufd

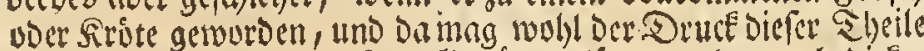

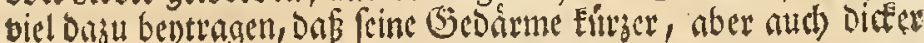
und ftriter werdocn.

Dod wir wollen nummeth auth Dic inneren Sheile einer ers

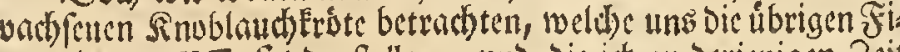
guren Der XIX Tafel Darfeclen, und Die ich ju Derjenigen Beit abgebildet babe, Da fich Diefe Siroten zu paneen pficgen, um Die

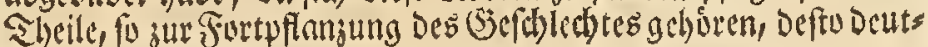
(id)er feben ju Eunmen.

Dif oritte \$1gur geiget uns aub cinem Mánnlcin biejenis en Sheile, wetdye fuglcidh, wenn man eine fuldhe Sirvte sffinct, in Die \&lugen fallen; Doch babe id Dabed ju eriunern, Daf Die Sun gen nebf ber formblafe, bon mir mit sufte coven angetullet wor:

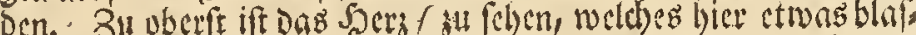

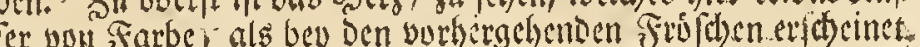
Die becden Sungenblafen $t u$, $t$, find bier bon jenen ifren sat Die becben sungenblafen $t u, t u$, find bier bon lenen thren gat

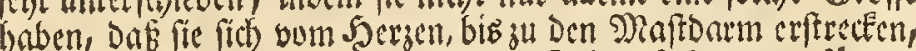
uni aljo Den scib Der Sirote zu becden Sciten faft gans anfullen: undern ihre vbere Fláche, beitehet nudb, wenn fie auforblalen îno, gleid) fam aus fauter balbrunden Blafen, wie ein aus 6 cifie uno

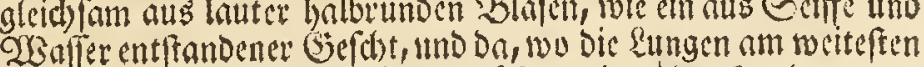

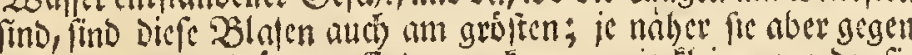

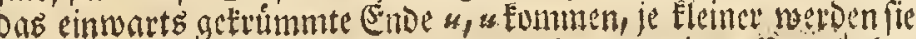

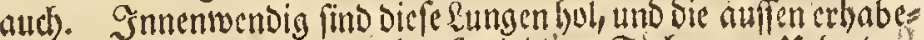
ne Slafen Derfelben, frellen eben fu viel leere Fother bur. Ileberdem

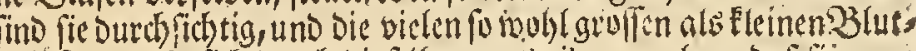

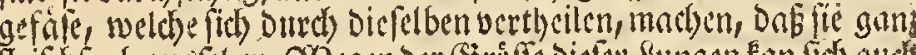

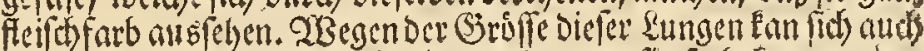
unfere Frote fels ftare aufblelyen, und wenn fic fo betannt ware als Die nemeine \&anofréte, io sloubte id), fie hatte zu Der gemeinen Tedenbart, et blabe ficb auf wore ene Kiröre, Gi:legenlieit g:= geben. Linter Dem Serzen ift in unferer sigur Die aus drey \&aypen

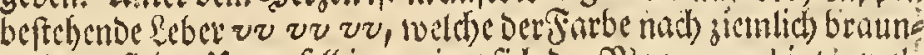
roth ausfechet. Llnter felbiger zeiget fid) Der Diagen $x x$, binter wel dem die Geosime licgen. Sa auth bey diefer frute bie gelben bitit terformisen atnbange nid)t mangeln, fo zcigen fids bie beb y y die

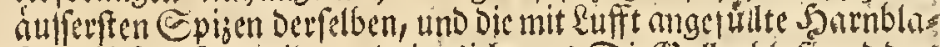

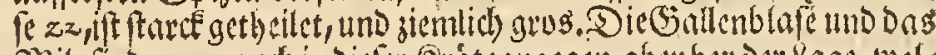

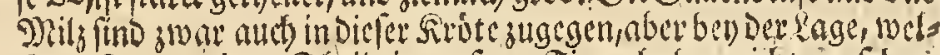
be erft angezcigte Sheile in unferer Jigur baben nicht is fober.

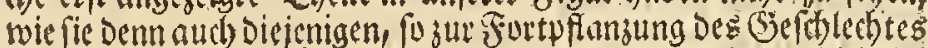
gehoren, und dem ?2 anulein eigen find, bedecten; wešivegen icl) fol

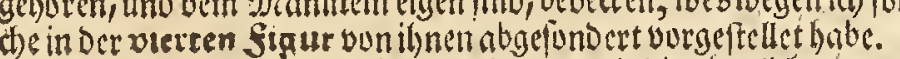

Es zeigen fith alfo in ferbiger bey a $b$ bie langlidsten uno

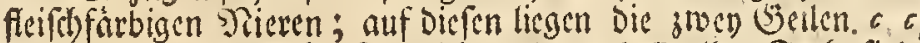
weld) bey biefer Fivte felyt Elein und oun bellgelber Farbe fino.

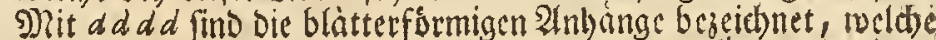
bier mebr eine cituonen= als uraniengelbe Jirbe lúlben, uno nidhe fo wolgl mit Den Jieren, als viclmels mit Den Gcilen jufams men ju bangen fobeinen; die Grofle aber, in weld)at fie bier et

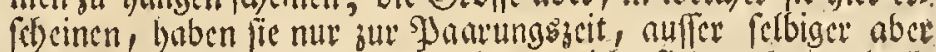
find fie fo Elein, Daf man fie falt gar nidbt finden Ean, ub fie

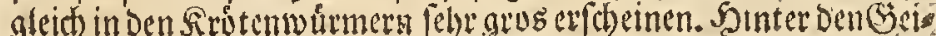
len Eummet an Der Siucfeite Der beeden ?ieren, ein búnite Canal jum Surficin ce, e e, Der fich bis in Den Minftarm ff enftrectet, aber aud unter Den Geilen und blatterformigen Pln

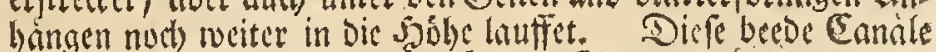
Ean ich fúr nichts anbers als thir die Gaamenbliblein balten: Denn als ic Den Srattonrm, von welticm bier nur Der Sbeil $f$ beybehalten wurben, in Der 2(bjitht gcoffnet, um Den Plusbang Der Gamenblaskin, uno Durd felbigen fie felbft zu finben, und in dic jtuen satten Oeffnungen bed $g$ sufft cinblies, tamen die

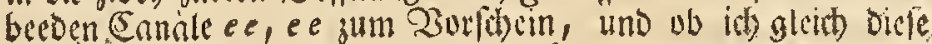
Bláslein ben mebreren von Diefen fruten, in twieberhultenmas len gefuct)et, habe idf fie such allizeit cben fo geformt gefrinoen, wie lie bier abgebildet find, fo, onf fie alfo in bicfer Sinublath

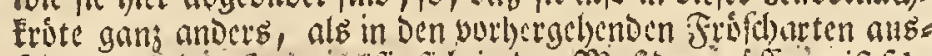

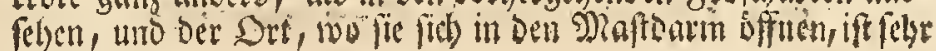
wenig erbaben. 


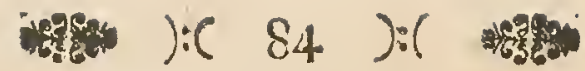

In foemella ipfo illo tempore diffecta, quo cu $n$ mafculo fuerat copulata, fimiles erant interiores partes, poltguam veficas pulmonales nec non vterum aere repleueram, quintae $i c o n i$. Signatum eft cor littera $b, i$ fellis eft vefica, $k k \dot{k}$ hepar, $l l$ veficae pulmonales, $m m m$ ouarium ouis refertum, $n n$ pars ouiductuum, oo foliaceae appendices, $P p P p$ vterus aere turgens, $q$ ventriculus, $r$ lien, $\int \delta$ tenuia iuteltma, t inteftinum rectum, u vacua collapfaque velica. Quodfi vero cor, pulmones, hepar, ventriculus atque inteftins e corpore auferantur, ea elt vteri nec non oudu. ctuam, in corpore reliatorum aereque repletorum, facies. quam fexta in icone habent." I dicantur orificis ouiductuum, eque ac in ranis, prope cor reperiunda, litteris vv vv; conftricti ibidem funt ouiductus filo, ne aer inmiffus elabatur. Eadem ouiductuum eft forma atque longitudo ac in ranis, differunt tamen colore pallide flauo, ea vero in fede qua vtero $z z$ cohaerent, expanduntur ipfumque quafi operiunt, binae evim illae partes $y y$, eiusdem ac ouiductus funt coloris, atque in huius tantum bufonis cernuncur vtero, qui hic pinguedine liguefacta perfufus effe videtar. Situm ert in anteriore vteri parte inteftinum rectum $t$, cui pars tenuium inteftinorum $\int$ filo praeftrict adhaeret. Pone inteitinum hoc comparet ex parte ouarium vtero incumbens, ouis immaturis repletum; ipfo vero in vtero cernuntur inferius veftigia impreffa vefi. cae, $u s$ hic quidem collapfae nec non vacuae, quae in ranis me vidiffe non memini.

Ound ad vfum internarum harum attinet partium, deeo quidem jam non fum expofiturus, quum id in hiftoria ranae terreftris fufius egerim. Quemadmodum vero ftructura ab hujus internis partibus admodum differune, fic et fceleta haud mediocrem monftrant difcrepantiam. Quodfi enim fceleton ex fremella majori defumtum b fonis noftri, fepti. maque icane XIX Tabulse repraefentatum, confideremus, facile patebit, habito ad commenfum re'pectu, muiro hic breuiorz effe quatuor crura, quam quidem in ranis fuete, licet ceterum offa, quibus conftant, quiad numerum et fortmam, vtrimque congruant. Seabra eft caluaria $A$, perinde ac maxilla fuperior, ob minimos aculeos, quibus fcatent, retrorfum fpectantes. $B B$ bina funt foramina in quibus ocuil fuam habuere fedem. $C$ eft gracilioris ftructurae maxilla inferior, quae aejue ac in ranis, nullis confita eft denticutis, quales in fuperiore cernuntur. $D$ prima eft verteora, qua ceruix conftat. Reliquae octo vertebrae vtroque in latere apophyfi funt inftructa, coftae vices fubeunte, nec non, in tribus prioribus, quam in reliquis, longiore. Magna atque angularis in binis fcapulis $E E$ elt incifura; committitur cum fcapulis hifce, ad angulum minus acutum, os, in quod humerus $H$ inferitur. Excipit hoc vtroque in latere aliud rurfus os $F$, inter vtrumque vero fternum $G$ confpicitur. Hæc vt clarius pateant, oct auam addidi figuram, monftrantem quae huius Iceleti in pectoris regione lit facies. $\quad P P$ binae fust clauiculae parum incuruae, $H H$ offium humeri comnif. furae, $F F$ bina funt offa palae formam habentie commifuram barc, ac fi binae aliae effent cla iculae, firmantia, $G$ vero os ipfum eft pectoris. Terminatur fpina ad os coxae fingularis prorfus forme: non folum enim ex binis quafi vomeribus $I I$ ccmpofitum effe videtur, fed habet ttiam caudam; quam os coccygis format, magnitudine vix dimidiam partem ollis coccygis ranarum aequantem. Agglutinate quafi inferius furst, huic offi coxae cum vltima vertebra juncto, bina illa cornue $L L$, quae ad $M$ creunt atque os furcae fimile efficiunt, quaeque in bufone carnibus cuteque tecto, ita cum reliquis nectuntur partibus, vt libere queant moueri; atgue hinc non folum in coitu gibberum mafculi redditur dorfum, fed poteft ille etiam ani fui orificium ad anum foemellae propius admo. were. Tandem etiam in fceleto hoc notari meretur fingularis quidam Rpuriusque vnguis, quem, quum in Septima figura cerni nequeat, nona ad 0 repraelentaui icone.

Finis Hiftoriae bufonis allium redolentis.

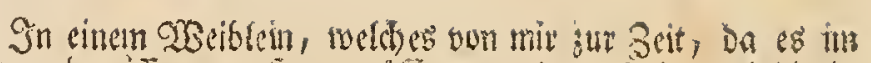

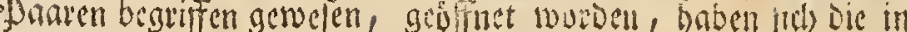

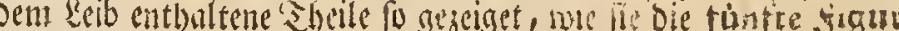

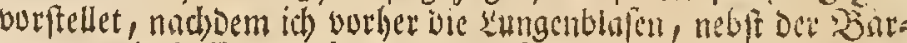
mutter nit \&uift angefinlet batte. Sas Serg ift bier mit bo be seithnet, $i$ ift Die Gallenblale, kkk Die suber, $l /$ bie sungen blafen, $m m m m$ Der mit Evern angefulle: Everfroce, $n *$ cin Sheil Der Euergange, o o bie blatterformigen sinbange, $p$ p p

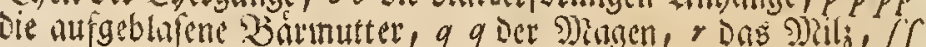
die Dimme Sebárme, $t$ ber SMaftearm, mo $u$ u bie lecre uni Jufammengefallene Jarnblaje. SRinmt man aber ias

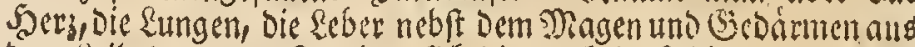
Deni seib beraus, fo jeiget fich die nuet in felbigen befinolidye Barmutter mit ben Eyeriangen, wenn fie autgeblafen murben fo, wie fie bie fechfte Sigut barfellet. Sie Definung Der Eyergange, melche fie, wie bel) Den Frufben, um Die Giacni

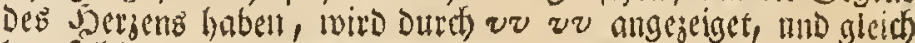
bey felbigar ift jeder Energang mit einem Forben jugcbunden oamit fieb Die eingeblafene suffe nid)t wieber berausziche. Die Eyergange $x x x x$ fino wobl eben fo lang als bey Den Strofils baben aud gleidse Form, aber eine blate hellgelbe Farbe, uni Da, tov fie in bie Barmutter $z z$ bineingeben, fobeinet es, als ob fie fich ausbreiteten, und felbize bedecten: Denn bie bceden ausgezacten Sleste $y$, baben thit Den Evergangen eitrenten Farbe, uno find Der Nutter Diefer Rrotenart allcinc cigen, wel t)e Daburth Das 2Infehen befommet, ahs ob fte mit Jerlaflentm Fett ware beguffen worden. Bornen liegt auf Diffe Scbars

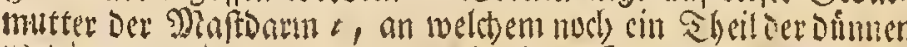

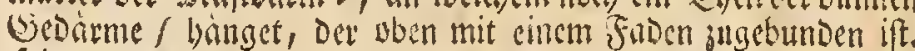
Sinter Dem gholitsum lirgt auf Der giutter em Sheil bes Everftucese Der mit unecifon Enern angefillet ift, bic Sarnblas

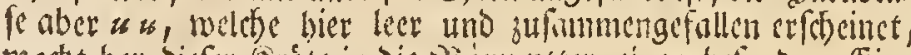
mad)t bev biefer sirste in Die 23 remutter eimen befondern Ein

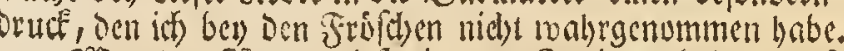

WMas Den Sinten diefer inneren Sheile anbelanget, fo ba

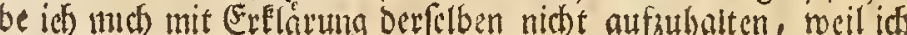
fulchen in Der Ssifturie Des (3̈ragfrufdes genugfam beforieben babe. Sleichwie lie aber ber Gtructur nad bon biefes feinen innern Sheilen unterfhieden fino: fo seiget fid audh in 2 (nfer bung Dis Serippes lein geringer linterfdict. Sern an Dem Seriple unferer Firote, welthes Die firbenoe figut Der $X I X$ Cabelle Darfellet, uno bon einem gruffen okeitelein genummen norden, ift o bemerken: Daf bie vier $E$ dhenfel nach Jropors tion un vieles furger als ben Den Srriftsen find, ubgleid funften die sindeden, woraus fie befieben, fo wobl Der Etruetur als

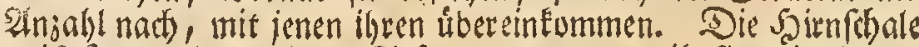
$A$ it fammt Dem obern Siefer gam rau, weil fie mit lautes ruefwarts geridsteten zarten Cpijen bejejet find. $B B$ find juen grolie Seffumgen, worinnen bie alugen gefelfen. $C$ ift ber ges

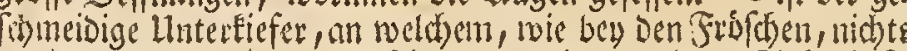
bon Denzarten Babmen zu feben, womit ber ubere Siefer befee set ift. D ift Dab exfte 2 Burbelbein, weld)es Den Sals ausina d)et. Die adt barauf folgende baben an beeden Eeiten einen Jurtfat, Der bie Etelle Der ?ibben bertritt, uno an ben trey erftern linger als an ben úbrigen ift. Die bceben Edulter blatter $E E$ baben eineit fraren effiditen Einidunit, mit Diefen batbinbet fid unter einem nid)t gar frigigen 2 sinfel ein anderes Bein, in roelches Das $E$ dulterbcin $H$ eingelentet ift, auf Diefes folget an jeder Seiti, nad) Der binft ju, wieber ein anderes $F$ und swifden beeden ftebet Das ibuftuein $G$, um foldses abes Deutlicher zu weifen, babe id Die acote Jigur nudh bartugen wollen, welche uns jeiget, wie diefer Gerippe un bie Giegent

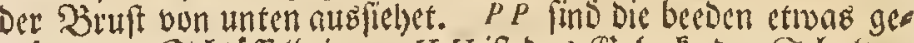

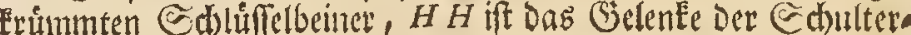
beine, F F lind ziven) fibaufelformige Beine, fo dicfes (stalente gleich nod stoenen Calúlelbeinem, beveftigen belffen, $G$ aber if bas eigentiche Dzuttbein. (Dab Siufgrad endiget fid) an bie fen Gerippe mit eineul gan befonderen Súfftbein, welches nicht

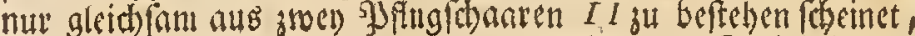
fondern aud nuch einen Edwan hat, ben Das Eteisbeinma

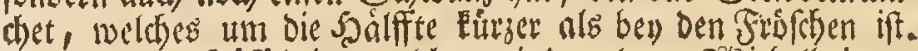

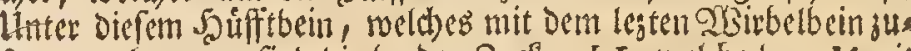
fammen banget, find bie becoen Bacten $L L$, welebe bel $M$ mit cinander berweach (en fino, uno ein ciniges gabelformiges ? 3 ein aubmadjen, gleich fam angclemet, in Der Sirote aber bie nuch mit Saut und Fleifd verfelen ift, fino fie beweglid), werwegen Denn awd Das Dánmlein bey Der Jaarung einen bo sferigen ?iu cfen maclsen, unb feinen affer gans nabe zu Dem 2ffiter Des 2 Beibleins bringen Ean. Endlit) ift and noth an siefem Gee rippe die befondere 2lffertaue ju bemerfen, weld)e, weil wie fie in Der fiebenoen figut nicht felen timnen, in Der neuncen bey $O$ bon mir burgeftellet woroen ift.

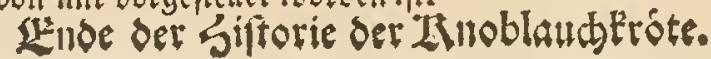




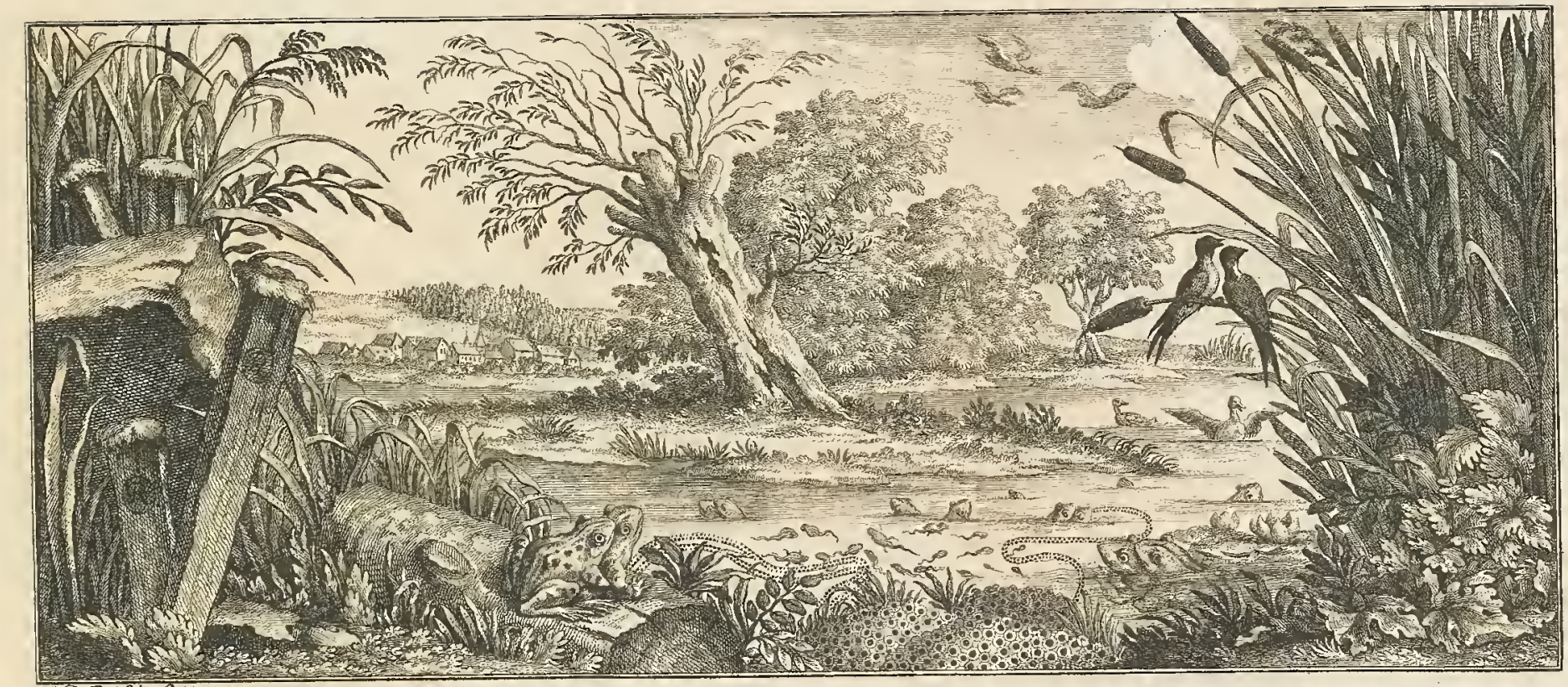

\section{HISTORIA NATVRALIS RANARVM NOSTRATIVM. SECTIO $V$.}

\section{BVFO TERRESTRIS, DORSO TVBERCVLIS EXASPERATO, OCVLIS RVBRIS.}

DDer

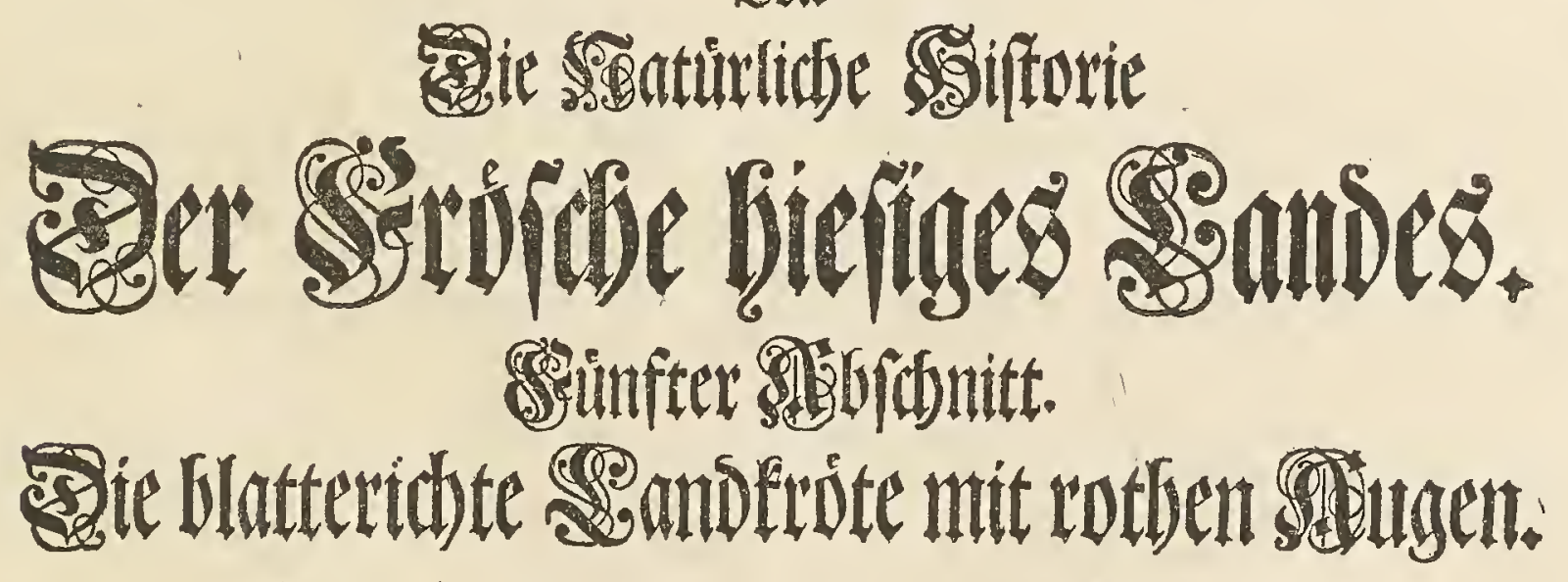

CAPVT 1 .

Lerftes Capitel.

Bufonis terreftris, dorfo tuberculis Det blattetidten Randerote mit $\mathfrak{n}$ exafperato, oculis rubris, generatio nec

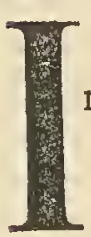

ndicaui in praefatione operi huic praemiffa, binos tantum notos mihi effe bufones noftrates: aquaticum alterum, alterum vero terreftrem; fed addidi tum, credere me, dari et rertiam quandam his in locis fpeciem, meque in ea inueftiganda effe occupatum. Neque fruftra rei huic operam impendi: non folum enim hanc; fed et quartam quandam reperi, atque proin hiftoriae bufonis allium redolentis addere nunc poffum, illam trium aliorum: binorum nempe bufonum terreftrium vniusque aquatici, ex quibus primus nunc proditurus eft bufo terreftris, dorfo tuberculis exafperato, oculis rubris.

tben2ugent sryenguth utb andere sigen

(क) affter.

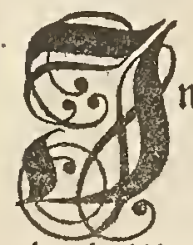

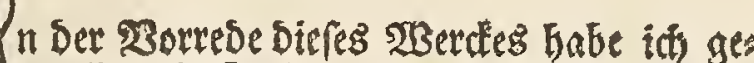
meldet, Dafis mir nur zwen Siroten unferes Sandes betannt wåren: eine 2 Baffererote und eine Landépte; Daf́ aber auth nod cine sritte meiner $\mathfrak{2}$ ermutbung nad bes uns befind

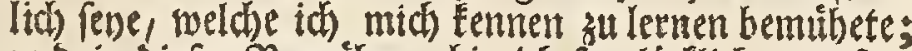

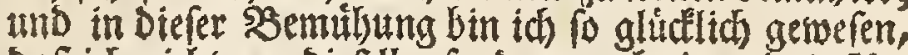
Dafich nid)t nur diefelbe, fondern aud eine vierte 2 ret entodectet babe, fo, Dafí ich allo, auffer Der bereits bes

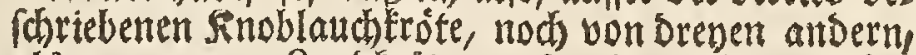
als vou zweven Eanderoten und ciner s3afferterote, umftánbliche $2 a d$ richt za geben im Stand bin: und von biefen foll bie blatteridite Ranotróte mit rotgen 2uigen Die erfife fentt. 
Eft hec bufonis fpecies, inter quatuor illas mihi cognitas noftrates, notifima. Terreftris bufo hine dici poteft, quod magis in terris quam in aquis verfatur, quumque in corporis fuperficie, prae reliquis bufonibus, plurima monftrat tubercula puftulasue majores, prae reliquis etiam bufo dorfo tuberculis exafperato eft appellandus, quumque porro ab altero bufone terreftri, cui oculi pallide flauent, oculis differt rubris, et horum in eo defignando meminiffe, me quidem judice, necef fum erat.

Corpus bufoni huic eft adeo ignalum, curtum arEtumque, vt primo ftatim intuitu, praefercim vbi quis tardiorem ipfius perfpicit motum, a tribus illis jam deicriptis ranarum fpeciebus diftinctus appareat, atque eadem illa difcrepantia, quae ranas inter reliquosque eft bufones, inter aquaticos quoque atque terreftrem buno obtinet,

Monftrat prima aeque ac fecunda vigefimae Tabulae figura, gerere ipfum truncum caput, fupraque majores oculorun globos bina pofita effe tubera, pone illos autem bina alia $c$ c $c$ eminere eaque crafliora, quorum longitudo latitudinem quinquies fuperat, quaeque varis featent poris puncto vix majosibus, nec non ad pleniorem hujus bufonis characterem confituerdum omnino pertinere videntur. Puftlae illae vel tubercula qua omnem fere bufonis hujus exafperant fuperficiem, majora funt in dorfo craflioribusque pofteriorum crurum partibus, quas furas dicere poffis, quam alibi, inferiora autem verfus lenfim fenfimque minora euadun numeroque decrefcunt。

Quaternos bufo hicce anterioribus in cruribus, quinos in pofterioribus habet digitos, atque hi membrana quadam nectuntul vitra mediam fingulorum digitorum partem vix quidem extenfa, bufonum tamen, aquas petentem natantemque, haud parum juuante.

Certum guendam bufoni huic colorem effe, vix afferi poteft. Id quidem generatim valet, effe illum turpem potius quam amoenum, fin fpeciatim eundem confideremus, varium, aeque ac in rana fufca terreftri, vixque binos, quibus vnus idemque fit, hujusmodi reperiri bufones, deprehendemus. Vbi e caueis progrediuntur, in quibus durante hyeme latuerunt, color ipfis eft fpurcus fufcusque; poftea vero quam cutem, quae lentoris inftar abfcedit, femel irerumque exuerunt,
(E) ift Diefelbe unter Den sier mir betannten glts ten, unceres Landes, Die gemeinfte. Eine Randerote fan fie Deswegen beiffen; wetl fie fich nebr auf Dem Land als im 2 Baffer aufiubalten pfleget; und da fie unter Den tibrigen am bouffigften mit bielen En'bó bungen, oder aroffen erhabenen SSlattern auf ifrer Oberflád)e berezet ifi, fo mag fie aud vorzliglich die

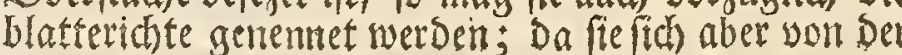
andern Ranofrote, welche blasigelbe Intaen bat, burch itgre rotbe 2lugen unterfcheidet: To babe ids and Diefer ben ifrer Benennumg zu gebenden fir nothig befumben.

Shre Reibegageftalt ift fo plump, Furs und zulants mengefdoben, Dab man fie aleid) bevm erften 2 dit

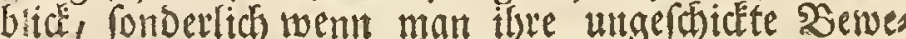
guntg fiebet, won ben bren befhriebenen Frofdortent letchtlid unterftheidet, und fo gros als Der Dafee entfitekende unterfchied swifhen Den Frofden und ben andern ferotenarten if:; fo.gros ift aud Der Ltr:

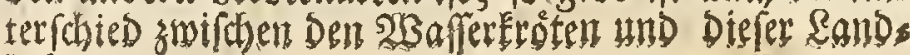
tróte.

Sie hat, wie fo wobl Die exfte als sweyte Sigut unferer zwanzigfter Tabelle zeiget, einen ftumpfen Sopf und úber Den groffen 2lugen ein Syaar pol

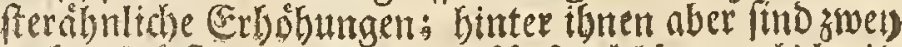
Dicfe 2 sulfte $c c c$, Die wobl fủnfmal lánger als breit, uno mit verfósiedenen wertieften Deffnungen mie mit souncten befezet find auth allerbing ein befonderes Semngethen Diefer srote abgeben fonmen. Die SDos fen oder Slattern momit fie faft iiber und über au ibrer Dberfláche befezet ift, fins auf Dem SRutere uno

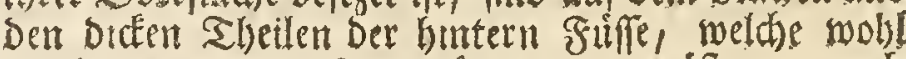
SBaber zu nemen fenn mógten, amt gróften; nad unten za aber berben fie immer teiner, und trebmen nadi uno mach ab.

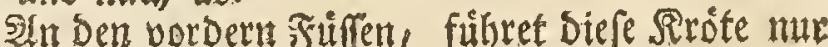
vier Beben, an ben bintern aber fünfe, uno diefe Iezern fitro mit eimander Durch eine Saut verbundeng

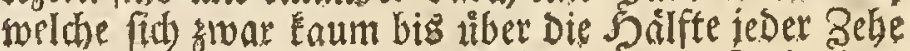
crftrectet, aber Dod Der Serote, wem fie it Dos sibafer gebet, Das Edjminnten erleichtern Ean.

Fin Shrehung Der Farbe, weldie Diefe Sirotenars.

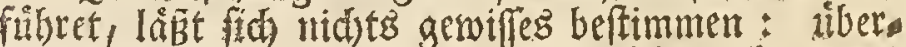

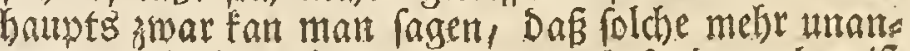
genclym als lieblich zu nemnen; insbefonbere aber if zu mercien, Dafi biefelbe, wie mil bereits ald ben Dem braunen (Sraefrofh beobad)tet baben, werichies Den fene, und man felten znen Diefer Rroten finder werbe, weldse in ber Farbe mit eitaniser íbercinfome

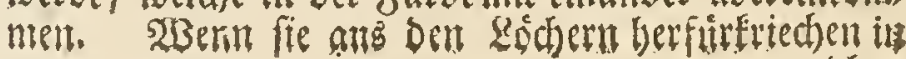



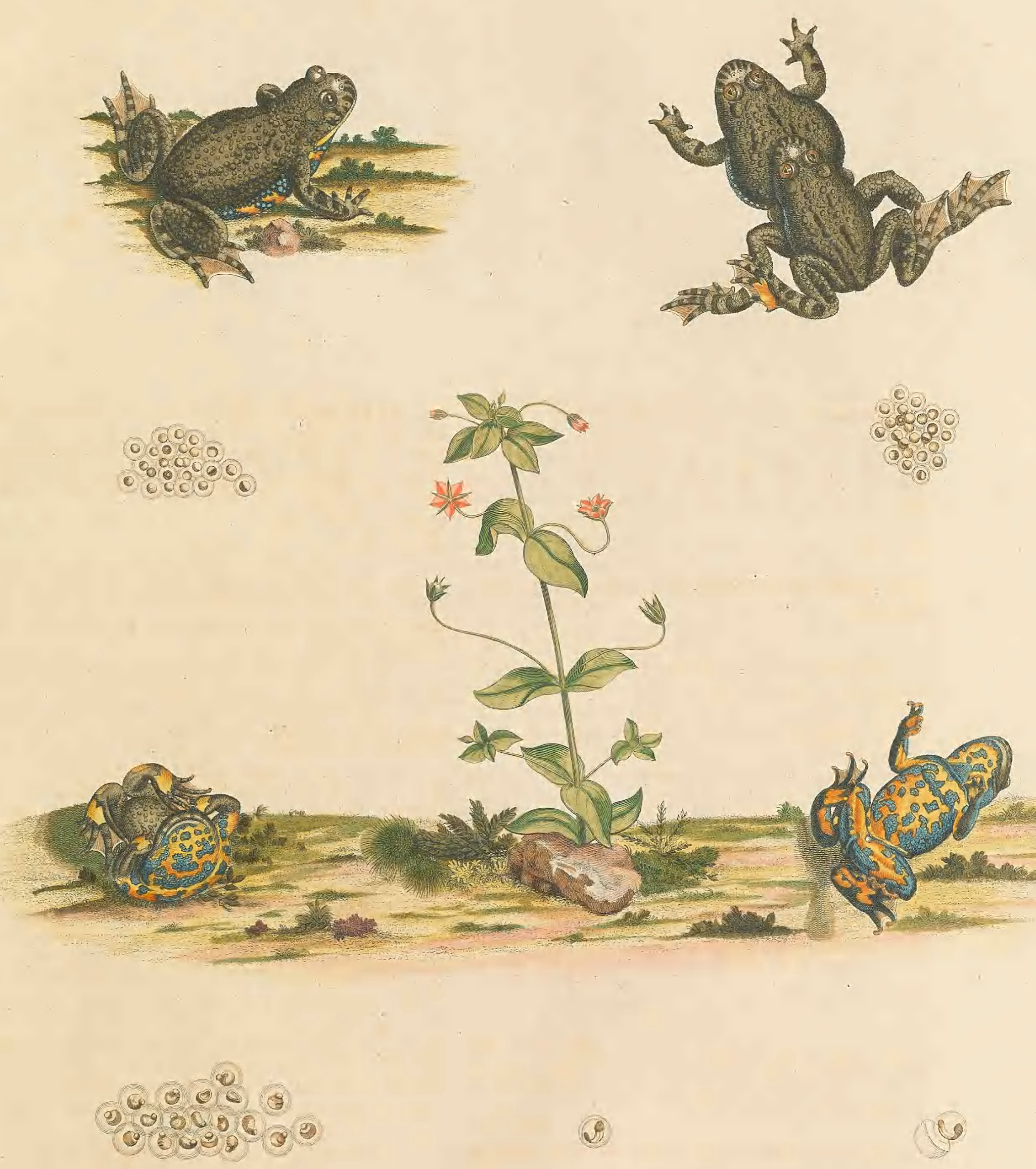

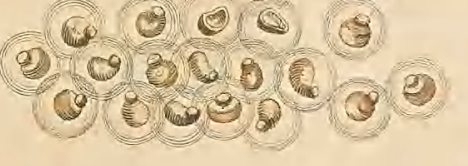

(9)

$+\infty \quad 5 \quad$ रेखिए 

Fig.i,
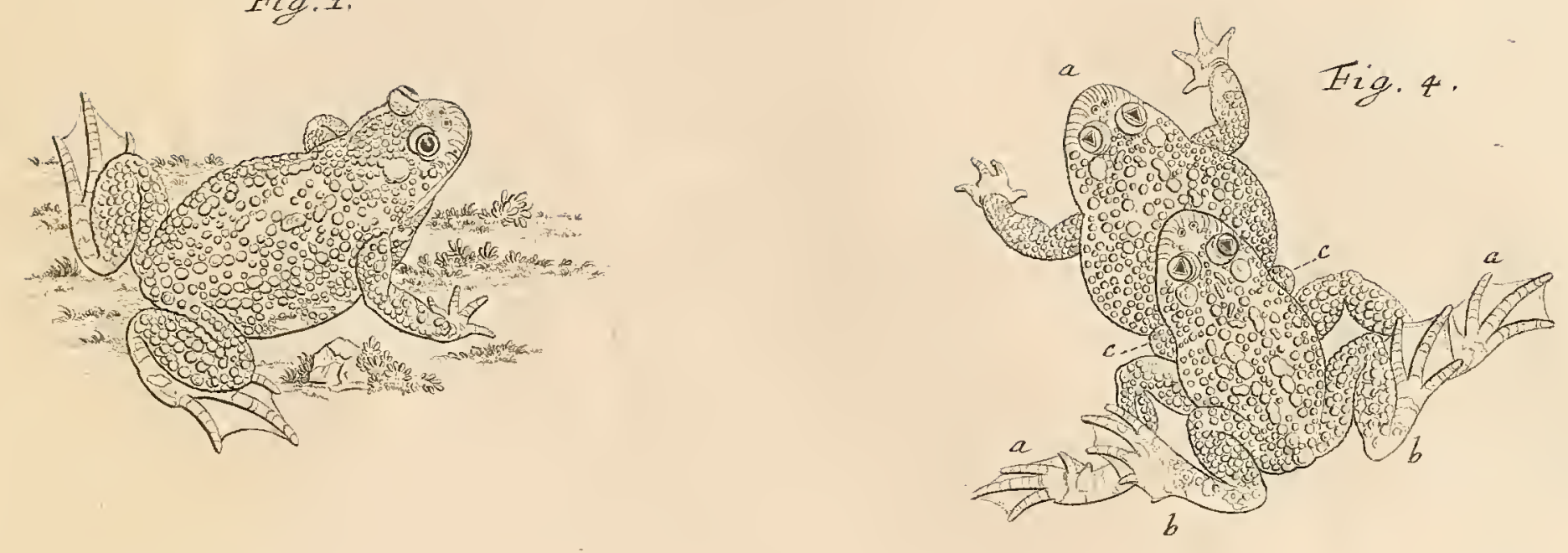

Fig.6.

0.900
0.000
00000
0.0000
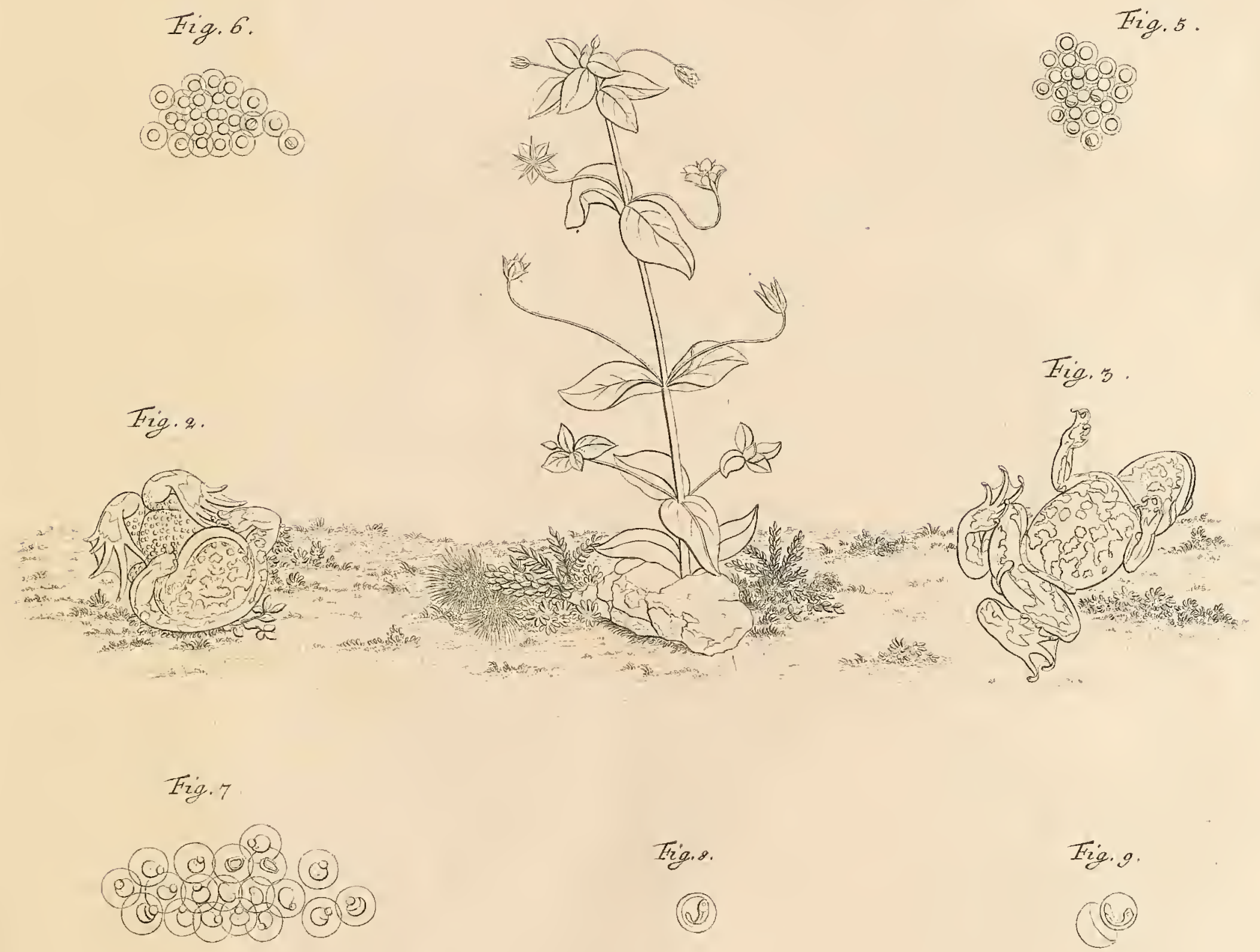

Fig.7

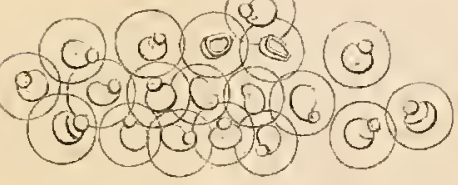

Fig.

Fig.g.

(aid)

(6)

Fig.io.

$\infty$
Fig.ii.

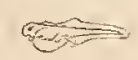

Fig. iz.

andon. 



\section{4.}

finguli fere quoad potiorem differunt colorem, quippe Gul func oliuae inftar viret, nunc nigrefcit, nunc cinefleeus eft, nunc vero ex rubro vel flauo fufeefcit; in quibustan autem rubent maximam partem tubercula, atque proin hi reliquis afpectu funt gratiores; fit vero hec ipfum in fremellis fere, id quod ex prima atque Seciinda apparet firura. Praeter rubra haec tubercula difitinguitur etiam, nunc hic nunc ille, hujus fpeciei, bufo a reliquis, pluribus paucioribusue, majoribus nec non minoribus, nigris aeque ac ex fufco rubentibus maculis, nutlo ordine pofitis; bina vero illa colli tubera $c c c$ vtplinimum ex rubro fufca funt.

Aft enim vero quemadmodum fuperior eorundem forperficies femper fére furua eft, fic contra inferior vel patlet, vel ex albo in cineraceum vergit; bini auten oculi, pone quos auris e fignata comparet, in hac buforium fpecie colore femper micant adeo rutilo, vtauri cưni cupro mixti imitentur fplendorem; ipfa vero iris nutnc circulum, nunc, vbi contrahitur, fcifluram refert hưrizonti parallelam.

Nofcitur ex inferiore cineracea fuperficie cujusnam bufo hicce fit fexus: in foemellis namque, multis faturatioribus variaeque magnitudinis diftincta eft maculis; in mafcu. lis contra vnicolor magis pallidiorque eft; tempore veso illo quo coire folent, differunt etiam mafculi a foethellis, cruribus primo anterioribus $d d$ Fig. I et 2, tum quidem craffioribus; dein vero particulis nonnullis eutis cujusdam nigrae in pollice aeque ac proximo ipfi in digito confpicuis, fed coitu peracto rurfus euanefcentibus; notandum tamen infuper eft, non tumere tunc temporis, quo nigrae hae adfunt particulae, binos holce, vt in aquatica terreftrique rana, digitos.

Quum bufo nofter in terris plurimum commoretur, temo mirabitur, reperiri illum prae reliquis, varia magnitudine, in agris hortisque; aft prodit fere tantum vefperam verfus, quum in caueis profundioribus atqus cum telluris fuperficie parallelis, quas fibi effodit, diurno tempore lateat, noctu vero infecta, quibus folis vefcitur, quaerat, donec, illucefcente die; in latebras redeat. Viuit ille vitra quindecim fere annos, atque hinc aequat, quin fuperat nonnunquam, magnitudine aquaticam ranam; quoniam vero, perinde ac alii bufones, humidiora prae reliquis amat loca, in cellis quo. que ftabulisque inuenitur, atque hinc eft quod dubitem, vtrum rubeta illa vel bufo cellularis, prout a nonnullis appellatur, fingularis bufonis fit fpecies: quum enim omnes bufones hibernum fugientes frigus in terras, interdumque profundius, intrent, aberrant faepius recta a via, vbi, vere ingruente, coitum celebraturi, aquam petunt, ob humitatem enim non tam altiora quam profundiora quaerunt loca, hinc autem fit vt verno tantum autumnalique tempore cum variis lacertis aquaticis in cellis reperiantur; quum et hae, aquas vel latebras quaeritantes, per vias a bufonibus paratas, nullo fere negotio in expetita deferantur loca.
Gulchen fie ibr Winterquartier gebalten, 震 fo fübren fie cine totbigbraune forrbe; wein fie aber nachge: bends ibre Saut, weldhe fie in Form cines Sdylemes ablegen, ein paarmal berándert haben, fo bat tmmer eine, eine bellere ober Dundere Grund farbe, als Die antere, indem felbige bald olivenfarb, bald fownirs lidt, bald grau, bald aber roth ober gelborciunlicht autsfebet, und bey einigen fins bie socien groften theils roth, Daber benn auth Diefe nod doas lieblidb) 2infehen baben; fonderlich aber pflegt fict biefes an Den șetblein zu ereignen, Dergleidyen unfere extre und sweyte Sigur zeiget. Wuffer Diefen rotben $\$ 0$ : deen aber if immer eine Diefer. Ardeten vor Der antoert, mit mefr ober wenigern, Eleinel und groffer, bald fdrwargen bald rothbraunen Fleden unordentlid be: fezet, und Die zwen 2 Bitlfte des 5 alfezccc, fino ges meiniglidf rothbratin.

(Sleichmie aber ifre Dberflathe alleztit Dundel ift: fo zeiget fich im (SFegenthetl Die untere bell Doer weisgran, und die beeden 2agen, finter weldien Das imit e bezeidunete Obr zu fehen, finto ant Diefer 包et beftandig fo fobon hochroth fenerfatb, Dafifie wie mite Aupfer vermengtes Sold glanzen; Der Stern abet im 2lug zeigt fith bald rund, bald aber fo sufamment gegogen, Dafi er nur cinen horizontalen Spalt vors fitellet.

Dite araulidite unterflache giebt ung bey Dterer Sirotenart Das Ssechlecht zu erfement: Dem ben bem

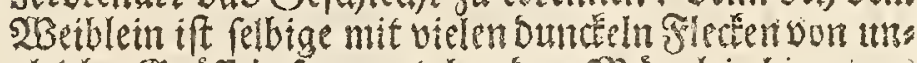

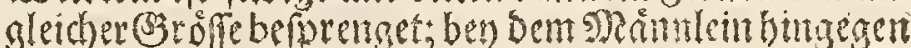

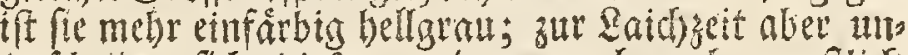

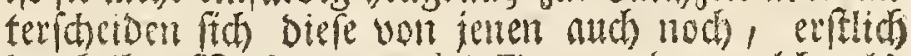
Durd ibre SBorberarme $d d$ Fig. 1 . Into 2. weldte als: Demi ficterer als ben Den SBetblein erfochen, uns Denn auch Durds einige zerftrente fledtein eine:

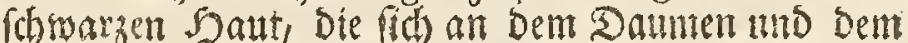

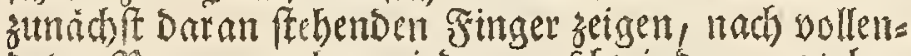
Deter sparung aber wieder verforwinden; wobers noch sa merefen, Daf sur Beit, wein fid) biefe Slece:

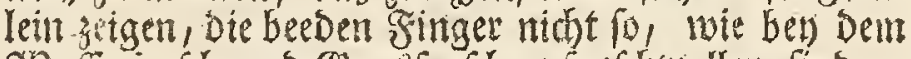

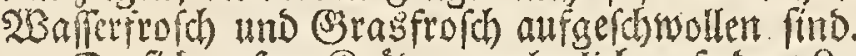

Da fich unfere Rrote bornebmlich auf Dem Qand aufbơlt, fo if es auch kein 23 under, Das man felbi: ge beiffiger als andere, in Den Feldern und Ģärten,

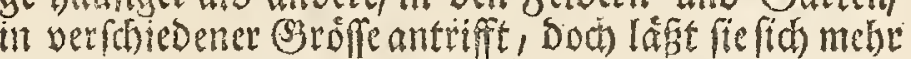

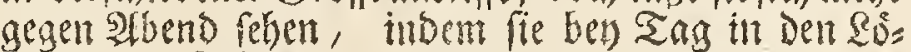
chern, Die fiefich tief tuts horizonterl in ber sroe aus: grabt, verborgen bleibet, nit bem etbens aber foldse verláfit und die Sadbt binourd iber Nabrung nadb: gebet, welche aus lauter Jinfecten beftehet, bis fie Der

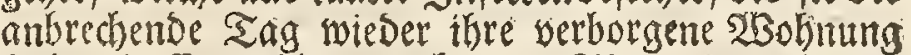
futhen beiffet. Sie erreid)et ein Plter son mebr als

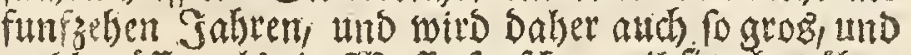
wobl grofier, als ein 23 afferfrofd; weil fie aber tibers Gaupts bie fentren Drte gut threm 2rufenthalt mie andere Sevoten wáblet, fo findet man fie aud in Dent siellern und Etâllen, Daher ich faft zatifele, bas Die von eintaen fo genamnte Rellerterote eine befondere Nirt fene: Demn Da fich alle Groten vor Der sbinter: Fâlte in die Erbe, unb zum Shetl/ fehr tief veraras ben, fo vetfeblen fie vielmahlo gegen den fruthling, wenn fie wegen itrer inftebenden Slaarung Das 53 afo fer futhen, bez rechten 23 ges, indem fie mitht fo

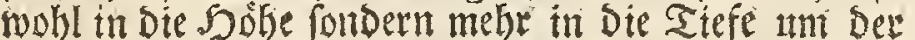
Fiaffe willen geben, und elen Daher wirb man fie stur im Frubling uns Serbft in Den Rellern antefefen, $\mathrm{Da}$

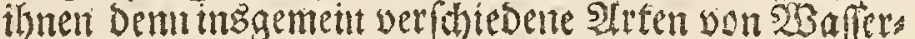
enderen Befellikgafteiften, weil Diefe, went fir bas şaffer futben, ober fid verbergen wollon, buth bie bon ben Siroten gemadite und ausgegrabene SBege,

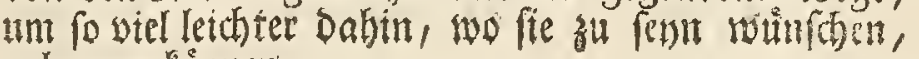
gelangen fónten. 


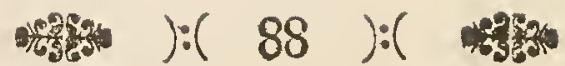

Quoniam bufones, et prae reliquis nofter, in ftabulis etiam offenduntur, faepius, fi vaccis vbera tument, ipfos eadem fuxiffe accufantur; quin perhibent ruricolae, fi quis aeftate, tempore nocturno, accenfalucerna, in ftabula fit intraturus pecoraque, non tam dormientia quam quiefcentia tantum, vifitaturus, reperturum illum effe bufones vaccarum vbera fugentes; licet vero hoc ipfum, nulla nixus experientia, affirmare haud aufim, negare id tamen nollem, quamuis et hoc verifimile mihi videatur, fieri interdum feruarum negligentia, vt vaccae vberuni tumore laborent; acculare vero tum illas, infontes bufones, haberique ipfis eo facilius fidem, quo vulgatior eft opinio, venenatos effe bufones, prae reliquis vero terreftrem, dorfo tuberculis exafperato, quippe qui halitu, faluia atque lotio laedere poffit.

Quod vero ad hoc attinet venenum, fateor, vidiffe me, bufonem hunc exagitatum, id quod et omnibus ranis folenne eft, ejaculalfe lotium; fateor etiam vidiffe me fuccum album ex binis illis colli tuberibus $c c c$ promanantem; vtrum vero hic nec non lotium ipforum venenatae fint indolis, afferere nequeo; nocere infuper illum halitu quoque, hinc quidem vix credo, quod, vbi eundem examinaui, vno plures incidi, atque, quo veficas pulmonales ipforunt probe cernerem, os eorum aperui, tubilique ope in laryngis pone linguam fiti rimam aerem immifi, nullo prorfus inde percepto incommodo; hinc autem perfuafum fere habeo, venenum terreftris noftri bufonis, fi quod habeat, vix illa pollere vi, quam omnes fere ipfi adfcribere folent auctores. Quando vero putant, exin fe probaturos, venenatos effe bufones, quod ciconia eosdem minus deuoret, confentientem me quidem habent, fi de illis loquantur, qui, quemadmodum bufo allinm redolens, tetrum fpargunt odorem; fed deuorare ipfam bufonem noftrum terreftrem, perinde ac ranas, certus noui: faepius namque eosdem cicuri objeci ciconiae, neque vnquam ipfam illos refpuere vidi.

Quemadmodum itaque reor, bufonis venenum in dubium poffe vocari; fic illis minus affentior, qui perhibent, fummum bufonis inimicum araneum efre, illumlive, fi hic propius ad ipfum accedat vel ipfi impendeat, qlico difrumpi: tentaui namque rem variis araneis variisque bufonibus, atque hinc, experientia edoctus, afferti hujus falfitatem, facile deprehendi.

De bufonite, cujus contra omnia fere venena vim maxime praedicant, inferius plura dicendi dâbitur occafio; jam vero dicam de coitu bufonis noftri cum rana terreftri. Legimus in eorum, qui de bufone hoc agunt, fcriptis, coire illum non tantum cum fui generis rubeta, fed et cum rana hortenfi *): atqui verum quidem eft, parere ranam terreftrem noftrumque bufonem vro eodemque tempore, deprehendique bina haecce prorfus diuerfa animalia nonnunquam copulata; fed parum durat haec ex coeca libidine orta copulatio: fimulac enim mafculus fui generis confpicatur foemellam, derelicta aliena illa, cum hac congreditur; atque hinc nulli dantur $\Phi$ e obárpoxos, id quod tamen, qui talia nugantur, nobis funt perfuafuri. Quin docent binorum

*) vid. Schvvenckfold Theriothropheum Silefiae p. 159 . horum

Da man Die Sirōten, fonberlich aber gegentuais tige, aud in ben Stállen antrifft: fo werben fe off ters befchudoiget, menn ben Sithen bie Euter ge: fdhellen, als batten fie biefelben ausgefauget, wie Denn attó Das Ranbvolde behauptet, Das went man im Sommer Des গachts mit einer bremenden Raters the, fat bem nicht fo wobl follafenden als mur rubenden SBieh in Die Stálle fomme, fo werde man Die an Den Suben faugende seroten antreffen; alleine, wenn id gleich Diefes aus Der Erfabrung uidft bebaupten fan,

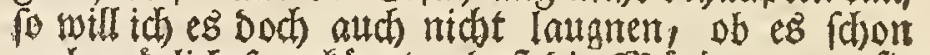
auch móglich fenn Eonnte, Dafí die Seágoc, wenn fie

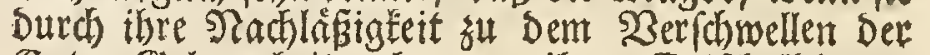
Euter Ëelegentjett geben, zut ifrer Entfhuldigung Die Sivoten anElagen, Da fie bent um fo viel ef enber Glauben finden, ie allgemeinet die Némung ifi, DaÉ Die Seroten, und fonterlid) bie blatterichte Lanofro: te, bergiffetet fenent, und Dielezere mit ihren Saud, Beiffer uno Sarn alles bergiffen forme.

YBas nun aber Den Gifft Diefer Rrote anbelar get, fo mus ich zwar geftehen, Dafi ich felbeft gefeben babe, wie fie, wenn man felbige verfolget, itsen 5 arn won fich fiprize, gleidhwie audh alle Frófharten fu thun nfegent auch habe ich gefehen, bas fie nus ben bee Den 23 silften $c$ c c ibres Salfes eine meifie Feudtigket bon fich gegeben; ob aber diefe, nebfit ifrem. Sarn, yers geffet fene, taa id nicht ragen. Das fie aber mit ibs rent Sauch bergiffte, glaube id Desmegen nidht, weil id) ben miner mit its angeftellen Itnterfut)ung mefs als eine lebendig aufgefdomitten, und un ibre Run

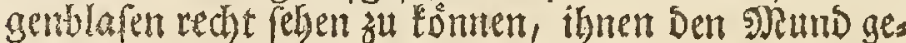

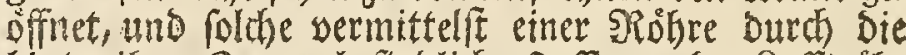
binter ibrer Bunge befindiche Oeffinutg ber \&ufftrōhs te Iuffe eingeblafen habe, ohne Dabich nur im gerings ften etwas wibriges bavon empfunben hátte, uns Daber follte ith meinen, Daf́, wenn unfere Ranberote ia etrags gifftiges bev fich fubres, ihe Esifft boch lange fo farde nidit lepe, als er insgemein bon Den Scris benten angegeben wird. Llth wern fie zum SBeweis Des Bifftes Den die Siroten ben fith fithren, Den Storch anjieben, als welcher Feme Serote, wie fiemels Den, frefen foll: fo gebe id ibnen foldbes in bung Derientgen, welche, gleith unferer Rnoblaudbero: te, einen Geftand von fich geben, zivar z̆ DaẼ er abee unfere Landerote wie Die Frófhe verf́blucte, Ear ich Daker behaupten, meil ich Dergleiden einem zahs men Storch offters vorgeworffen babe, Derfich foldbe

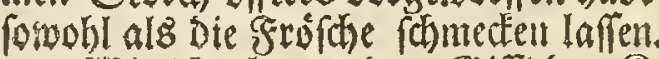

Sie to aber an Dem (Siffe Der Arote noch in ets (was zweifle, fo gebe ich audh Denientgen Eeinen (3) laus ben, weldhe uns beresen wollen, die Spinne fene Der Rerute ein fo gefábrlicher Freino, Daş fie foaleid, wenn fie fich etmann in ibrer शRachbarfhaffi befindet, oDer bie Spinne tiber ityr zu hangen fonme, zerplazent miffe: Dent Die Erfabrung, nach meldber ich mit

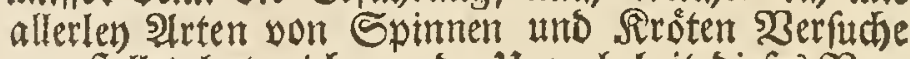
angeftellet, hat mid von Der lmwahrbeit Diefes $\mathfrak{B}$ or: gebens uberzenget.

Bon Dem Rrotenftein, meldier gegen alle 2 inten von BSifft, grofie Sirafft befizen foll, werben wir unten zu reben befere (jolegentheit finden; tezt aber will ids etwas yon Der \$aarung unferer Rrote mit Dem (Srabs. frofd melden. san findet mänlich in Den Schrifften

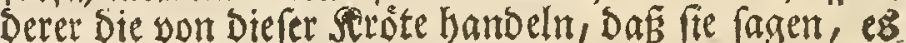
parre fich Diefelbe nicht nur mit ibres gleiden, fons Dern audh mit Dem Srasfrofd, nun iffes zwar wabr. Dafí Die S3rasfrófhe mit biefen Siroten zu eimer zeit laichen, und man alfo diefe beebe, fonft son einander ganj unterf fitedene Ereaturen mandbmalen gepaaret antreffe; alleme biefe Daarung, welche nur blos aus blinder Bseilleit gefhiehet, Dauert nicht lange, und

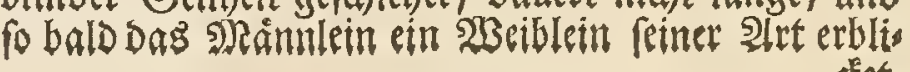




\section{8)}

corum animalium fetus contrarium quoque, quemadmodum enim terreftres ranæ bufonesque cum fui fimilibus vno eodemque tempore generationi operam navant: fic etiam ipforum vno eodemque tempore excluduntur foetus, atque hinc Iunio lulioque menfibus, magna illorum in terris reperitur copia; fed poffunt $a b$ inuicem facile difcerni, neque vllum vnquam inter illos nothum inuenies ranunculum.

Quemadniodum autem bufo nofter cum rànà terseftri generationis opus nullatenus exercet: fic \& cum aliis bufonum fpeciebus eundein ob finem minime copula tur, id quod, a me propte rea inftitutis cognoui experimentis. Non enim, quod primum eft, onnes vno eodemque tempore coeundi flagrant libidine, quum nonnullae fpecies duobus menfibus tardius quam aliae eadem capiantur, licet ceterum fimiles fere videantur; dein modus quoque diferepat coeundi: quemadmodum enim ex hactenus dictis apparet, non amplectuntur omnes horum animalium mafculi foemellas fuas eaderu ratione: accedit huc quod interiorum ad generationem pertinentium partium ftructura in fingulis fere fpeciebus differat; nec non quaeliber earum certo fibique proprio modo oua Ina pariat.

Quod vero ad ipfum Bufonis noftri attinet coitum, eundem quidem quotannis verno celebrattempore, fed fit ille, pro tempeftatis ratione, nunc citius nunc vero tardius, atque hinc eft, vt hoc anno jarn inenfe Martio, alio vero Aprili demum illos copulatos inuenias. Quum vero bufo nofter in terris magis quam in aquis verfetur, non femper mafculus foemellam in aquis it quaeritatum, fed vbi illam generationis tempore in terra offendit, $c n$ : feftim illi affilit, atcue hinc etiam extra aquas illos ea ratione conjunctos deprehendimus, qua eosdem Fig. I. Tabule $X X$. copulatos fiftit; fed licet foemellae gravius tum ferendum fit onus, femper tamen aquas petit; coire vero illos ipfis etiam in aquis, vt hic indicem $m_{j}$ vix eft necelfum.

Bufones, quios módo citäta iconê depi beo, non quidem ex majoribus funt vel annofioribus, licet forte jam quinque habuerint annos; quum vero prae aliis viuidioribus exornati effent coloribus, prae aliis etiam eosclem depingere malui. Mafculus heic quidem foemellam eadem ratione videtur amplecti anterionbus cruribus $d$, qua rana terreftris foemellam fuam iojo in coitu amplecti folet, aft non extendit brachia fua ad foemellae pectus vsque; fed adigit illá, ceu rảna arborea folet, in foemellae alas ita, $\nabla t$ ipforum digiti minime confpiciantur. Quamuis vero fic copulati bufones octo decemue dies in aquis commorentur, antequam foemella oua fita pariar mafculusque eadem foecundet, femper tamen hic illam firmo tenet amplexu; edunt etiam durante hoc tempore, diu noctuque, fereque indefinenter, ingratum fuum clamorem, grunnientes vlulantes. que ita, vt vbi plures horum bufonum fimul inuicem vno eodemque funt in loco, plures vlulantes te audire credas canes. Sub ipfo vero hoc viulatu, quem inafcuLus prae foemelia iterat, nulla, neque ad oris latera, neque etiam fub gula, confpicitur, vt in aliis ranarum fipeciebus; infolens cutis expanfio, nulla vefica.

Quan- cet to balí lafite es Das frembse fabrem uns begat. tet fichi mit Dem fo feitter 2 Int if ne fo genannten Frotenfroidhe giebt, wie Dieientge borgegeben, weldse die \$aaruns Des Jirasfrofites mit unferer Srote behaupten. esz berweifen folbes aud Die Sungen Diefer Creaturen: Dent wie fids Die alten Brasfrofore uno Sioten zu einerlen sart mit thres gleichen paaren, fo fommen alth ibre Sungen

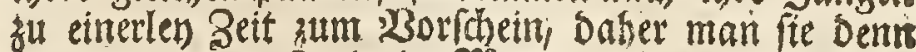
im Sunin ober Jutio in Mlense auf Dem Rand ane trift, aber Doch, ob fie gleid nod fo Elein find, gae wohl von einander untericheiben fan, obne einigen Faftart unter ihnen ansutreffen.

So wenig fich aber unfere sirote mit Dem (s) frofdi paaret: fo menig paaret fie fict auch mit alls Dern Grótenarten, wie mich bie deswegen angeftelfo te Berfuche gelebret baben. Dem ertsidid, fo ems pfinden fie nicht alle zu einerley Bett Die Begierdes (id) su begatten; indem fich folche bey einigen 2 reten um zmen Nionate pacter als bey andern eimfindet; ob fie gleich fonften stemlich viel शlebnlid feit mit eins ander zu haben formen; bernach aber fo if aud in

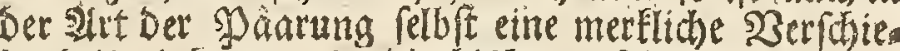
oenfeit, indem, wie wir bisher gefehen haben, Die Hmfafing biefer Thtere nibt ben allen auf etnerles æ3eife gefótebet: Dasu aber Eommt audj nod), Das Der Bau Der inneren Sheile, bie zur Sortoflansung Des (S)efblechtes geboren, faft ben jeder 2lut anders

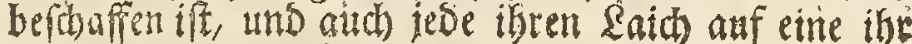
eigene soife vot fid giebt.

$53 a$ min aber bie elgentliche Saanm unifere Rrote anbelanget, fo gebet folche stoar alle Tabre im

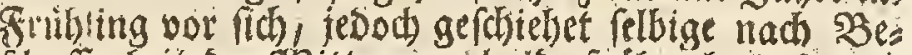

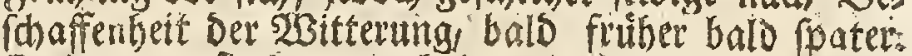
Daber matt fie Deitn auth in mandyem Sabr bereits in Nex; ret antriffit; und Da fie fich meht alf Dem \&and, als

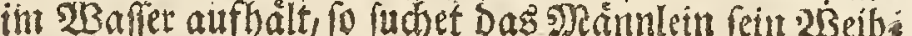
lein eben mot allezeit im 2 Baffer, condern wein $e E^{2}$,

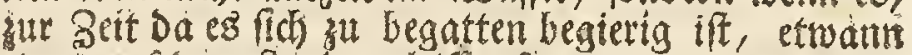
etries auf Dem Eano antrifft, fo sereintget es fich fo gleich mat felbigem, und Daber finbet man fie ofters aud aufer bem SBaffer, fo wie ith fie auf ber $X X$. Cabelle sig. I. vorgeftellet babe, mit sinander ges pares; Dod eillet fobem Das Sreiblein, ungeawtet Der fotwerenssirney fo felbiges zutragen bat allezete

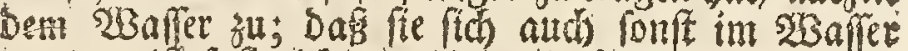

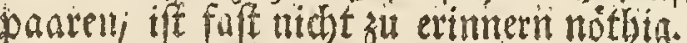

Die beeden in erfit angefúprter Sigur boraeftellte Aroten, find swar nidy oon Den alteften noer aro ften, ob fte gleich fonon fün Sabr alt genefen reyn mögen: weil fie aber fur andern mit frischen Farben

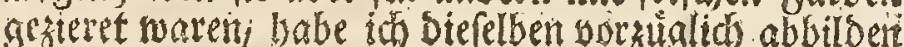
wallen. Dem Snfeten nach umfafet swar bier Das Meănlein fein 28 siblein auf gleithe 2 Beife mit Den

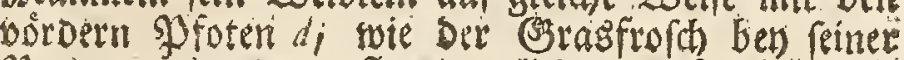
s)airumg su thun ofleget, alleine es frectet feine

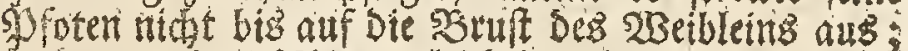
fondert es fesct felbige, gleid Dem Raubfrofch; unter

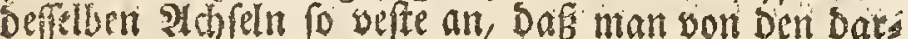
an befinolichen Beben gar nidgts zu feben betomnet: Sb tun abir gleidh biefe, fo mit cinamber gewarte

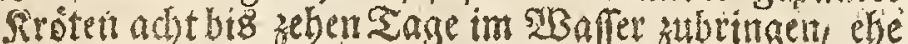

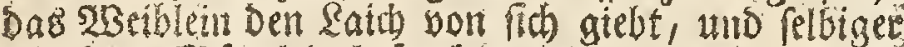

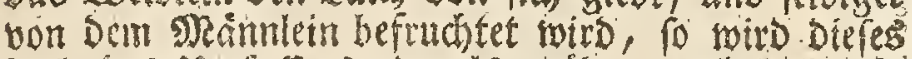
Doch bes limfaffens niemals mide; auch lafien fie

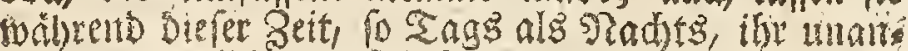

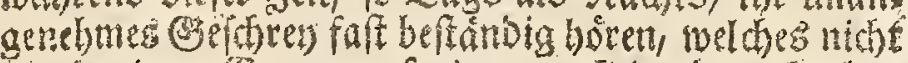
mur in sinem (Grunzen, fondern nudi in einem Fienleti

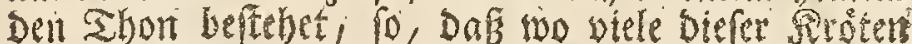
bevfanmen find, es eben fo lautet als ob etliche Sumts

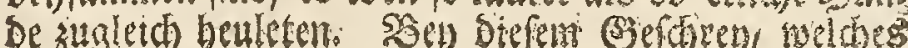
(3) 


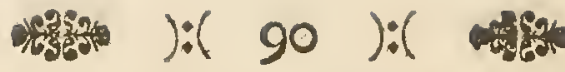

Quantum operae ea in re pofui, vt viderem, qua ratione foemellae ranarum, quarum hactenus dedi hiftoriam, oua fua parerent mafculique eadem foecundarent; tantum eandem ob rationem nauaui etiam, in obferuandis hifce bufonibus, atque hoc meo ftudio id perfeci, vt ope experimentorum, quae cum multis horum bufonum terreftrium paribus inftitui, non folum ouorum partum fed \& eorundem foecundationem iteratis vicibus, eademque femper ratione factam fuiffe, obferuauerim; nunc vero omnia ea examufim narrabo, quae, quum anno 1754, idem egi, a me funt notata, fimul tamen monendum effe duco beneuolum lectorem, vt Secundam, $X X$. Tabulae contempletur iconem, in qua litterae $a b$ mafculum, $b b$ vero foemellam indicant.

Selegeram, dicto anno, fub menfis Aprilis initium, ex horum bufonum majoribus, fex paria, eademque totidem commiferam cylindraceis aquaque repletis vitris, quae diu noctuque oculis contrectabam: quumque illa continuos octo dies accuratius contemplatus eram, animaduerti tandem, coepiffe foemellas binorum parium, uno eodemque die, oua fua edere, id quod dein reliquorum parium foemellae fimilicer egerunt. Agitabantur initio quidem inquietudine quadam crebriusque, quam alias folebant, nunc fundum vafis verfus defcendebant, nunc rurfus aquae fuperficiem petebant; paulo vero ante quam oua fua ejaculabantur, fortior quidam in foemellae ventre animaduerti poterat motus, ac fi viuum quoddam animal illum effet difrupturum, qua. lem jam \& in aliis notaueram fpeciebus, quemadmodum in hiftoria hac indicatum eft, quoque ouorum $a b$ ouario folutorum in vterum ingreflus haud parum promoueri videtur. Durante interno hoc ventris motu, afcendebat defcendebatque foemelia aliquoties, donec illico in fundum fefe praecipitabat fimulque non folum corpus fuum \& bina pofteriora crura $f f$, quantum quidem fieri pote erat, in longitudinem extendebat. Diftendebat eodem etiam tempore mafeulus corpus fuum eousque, vt ani fui apertura, directo ad anum foemellae fpectaret; pedes vero pofteriores $b$ binaque femora $g g$ tremülo quodam motu contrahebat, atque haud ita multo poft edebat foemella partem fpermatis vel ouorum fuorum. Hoc dum fiebat denuo non folum mafculi tremebant ciura, fed motitabat etiam pofteriorem corporis fui partem eadem fere ratione, qua lafciuiens alterique inequitans canis, illam ipfam agitare folet, fimul vero ita vtebatur pedibus fuis, ac fi foemellat oua ftatim violenterque iisdem effet protracturus, id quod tamen minime fiebat; fed congerebat fic pauca illa, quae foemella vila vice emittebat, oua, vt globun quafi formarent commodeque femine ipfius confperg foecundarique poffent; quin vidi faepius transuerfe il lius, eodem tempore, diductum anum exiguamque feminis, liquorem turbidum referentis, partem in oua fuifle effufam. Hoc facto ita intra mafculi femora $g g$ emergebant oua $i$, vt ipfius non folum cooperirent anum, fed ex endem propelli fere viderentur. Singula haec vix durabant diutius quain quidem galli cum gallina concubitus, atque vbi dein bini bufones paulifper conquieuerant, diducebat mafculus aliquatenus bina pofteriora crura, tum vero oua, hac vice a foemella emiffa \& a mafculo foecundata, fubforma binarum ex nigris paruisque coralliis compofitarum linearum in confpectum prodibant, quae, initio quidem, binos cum dimidio jollices longitudine aequabant, vel a $k$ ad $/ /$ vsque fefe extendebant. Cohaerent coralliahaecce ope mebr von Dem Nănnlein als 23 eiblein gemachet toito if aber, weber an Den Seiten Des S) Nundes, nod auch unten an Der Fehle, wie ber einisen andern Frofharten, eime befondere श्रusbebnung ber \$auts ober etwas blafenábulidies wabrzunebmen.

So viel es midh Muibe gefortet, ben Den bereits bes (4) riebenen Frofdhen, Das Qaidien Des 2 Beibleins und Die Befruchtung Des Raiches Durch Das $\mathfrak{\text { Rämmlein }}$ wabrzunehmen: fo forgfáltig habe ich aud, um eben Diefer Lrfacte willen, biefe Srotenart beobachtet, uno Dadurch fo viel gewonnen, Dafi ich ben Den, Dren Saba re lang, mit dielen

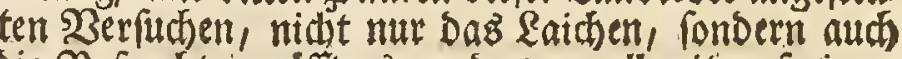
bie Befrudstung offters, und zwar allezeit auf einer (ev) WBeife wabrgenommen babe; und nun will ich" mas Daben vorgesangen, als ich folches im Jabs 1754. beobadtet, auf bas genauefte befochetben, wos bev) es aber aud notbig fenn wiro, Dafi Der geneigte Lefer bie 2. Figur oer $X X$. Cabelle betradhte, in wela đer Das Mianntein mit $a a$ und $D a s$ wetblein mit $b b$ bezetonnet ifit.

Sch batte mir zeigten Jahr, fechs Der anfebnlichifen $\$$ aare Diefec Rroten ausgefuchet, uno foldhe, zu meinem 2 orbas ben, in eben fo viel mit 2 baffer angefüllten Bucters nläfern verwafiret, welde ith weder Tags nod Siachts aus ben शttigen lies. Sachoem ith nun fel. bige, acht Tage lang, auf Das genauefte beobachtef,

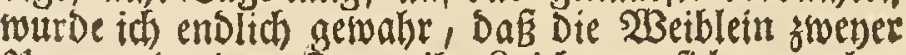
Saare, in einem Sag, ibr Raid) yon fid zu geben anfiengen, welchen rodenn Die 23 eiblein Der tibrigen Paare, in gleidser Berrichtung, auch bald folgten. श्ufaugs wurben fie febr unrubit, uno begaben fich

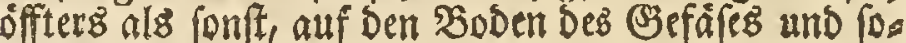
Denn wieder iu die Sơbe, bis an Die Sberfláche bez waffers; Eurz vor bem Eaichen felbft aber ánferte fich, in Dem Reib Des 2 Beibleins, eine ftarte gung, als ob eine lebendige Creatur burch felbigen burchbredsen wollte, welche id wud fhon an anbern IIrten bemerket, wie ich in Diefer Siftorie bereits an gezeiget babe, und 10odurd) vielleidft bas eintretten Der vom Everftod fich lófenden Ever in Die Nutter, nid)t roenig mag befórbert werben. Bey diefer itw nern 2 semegang bes Reibes aber, gieng Das $20 \mathrm{beib}$. lein nod immer etlitbemal auf und nieder, bis es endlich viel gefdymber als fonft auf ben 30 ben fubc und nicht nur alleine feillen Leib, fondern and) bie beeben Sointerfbentel $f f$, fo ftare als es itgm nur ims mer móglich, Der \&ánge nach ausftredite. Bu aleidhes Beit Debnete auch Das SRannlein feinen Reib in fo ferne aus, Dafí Die Seffinung feines श्Afters über Die támliche Deffinung Des Weibleinz in gerader Rich= tung zt ftefen fam; feime bintern Suffe b aber, uns Die beeden Sdjenfel Derfelben $g g l$ zog $\mathrm{CS}^{3}$ mit einer zitternben Beneaung ganz nabe an fich, und ballo Darauf gab Das SBeiblein einen Theil feines 2 aid)es ober feiner Ener von fich. Alls aber biefes gefthake, feng Das s)annlein nicht nur son neuem mit feinen Shenfeln zu zittern an, fonbern es berwegte aud Den bintern Leib gletch einem in Der SDaarung begriffenen geilen Sumb, uns arbeitete zugleich mit reinen bintern

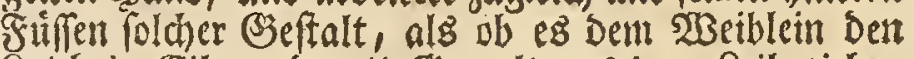
Raich in Eile uno mit (S) sivalt aus Dent Reib siebent wollte : unterdeffen aber gefd)abe foldhez Dod nidit; fondern es bradite vielmefr Dtrd Diefe Beivegung Denjentgen geringen Theil Des Qaidjes̉, welchen Das Beiblein auf einmal von fid $\mathrm{gab}$ gams nabe uno gletchfant auf einen Slumpen jufanmen, um fold)ent Eurd feinen Saamen um fo viel beffer befruchten 3 . Eonnen, wie ich Denn aud wirflich offters wahrges nommen babe, Dafíf fich fein Iffer, zu gleidher zeit,

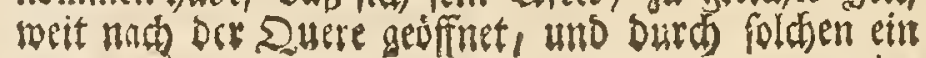




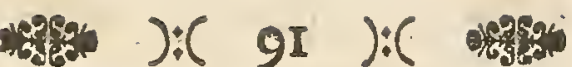

tenacis pellucidique glutinis, lineaque quam formant fuperat parum craficudine inferiorem partem culmi majoris. Poft partum primae hujus ouorum portionis, commode magis difponebant membra fua, fuperficiem. que aquae verfus enatabant, aerem non folum, vt videbatur, liberiorem ducturi, fed \& paulliper conquie. turi.

Vix per quadrantem quieuerunt horæe, quum rem veneream integrarent eademque omnia vt antea peragerent; reddebantur tum lineæ ouis glutineque compofitae duplo longiores, neque a foemellae ano feparabantur, fedipfi junctae haerebant, ita, vt bufo easdem poft fe traheret; poftquam vero bufones negotium hoc nouies iterarant, in eam lineae excreuerant longitudinem, quam figura fecunda ad $k, l l, m m$ \& $n n$ exhibet; fed quum foemella ab,ouorum excretione nondum ceffaret, quin decies adhuc partem illorum egereret, quarun quanlibet. mafculus femine fuo perfuderat: aequabant tandem binae illae ouorum lineae quaternos fe. re pedes. Poltea vero quam vltima egefta fuerat portio, derepente fecedebant bini bufones ab inuicem, quum foemella vix tres integras in partu abfumferat horas. Exemi tum bufones e vitro, oua pro vlceriore obSeruatione, feparatim feruaturus.

Quemadmodum vero nonnulla paria in ouörum partu foecundationeque plus temporis confumebant, fic alia rurfus idem opus citius perficiebant, ita, vt interdum fpatio binarum horarum jam effet finitum; vtplurinum tamen noctu tantum diemque verfus, rarius in terdiu negotio huic operam nauant. Plura porro majores foemellae pariunt oua quam minores junioresque atque hinc etiam majora funt ipfa fila fpermatica; ad dendum etiam, copulari cum majoribus foemellis non remper majores mafculi, fed minores quoque, Pars ouorum a foemella edita non femper binos cum dimidio aequat pollices; fed eft interdum longior interdum bre. vior quoque. Oua in tenaci filorum glutine contenta, non proprio fingula cinguntur glutine, fed haerent illo in glutine ita, vt in extrema aeque ac in prima filorum parte fingula fere compareant, reliqua binas conftituant feries ita difpofitas, vt rhombos quafi forment, hic illic tamen interruptos. geringer Theil Desి, eine truibe Geuditigeeit sorfter lenden Saamenz, liber Den \&aich ergofien norben. æ3enn foldhes gerdseben, fo Eam Der Raid i, zwot. (c) ett Den Sc) enteln bez Miånnleins g $g$, fo berwot, Das er nidht nur Den 2 ffter Deffelben bebedte, rondern

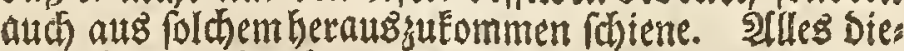
fes målyrte nicht länger als Der $\mathcal{h}$ ahn Die Shenne tritf und wenn beebe Rroten bierauf ein wenig aubigerubet J)atten, zog Das Männlein feine Sinterfochentel etwas ausemander, sorauf ftch Denn Der fur Diefesmal bor

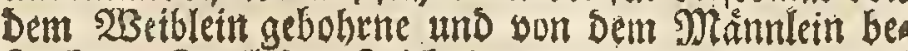
fundtete Theil Des Saiches auseinander begab und

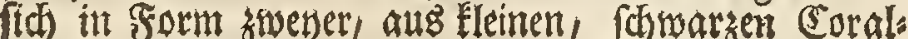
len beftebender Schmire zeigte, weld)e anfangs utt gefäbr Dritthalb zoll lang waren, ober fid woit $k$ bis Il erftrecten. Diefe Corallen hängen bemittelf eto nes zâtben und burhfihtigen Shleimes zufantmen, und Die Sd)nur weldbe fie antsmadhen, if etroas bi. cfer als ein ftarker Strobhalm untenber zu fentr bfte get. Tah Gebäbrung Diefes erften Theiles Des Lais ches, nabmen meine firoten wieder eime bequentere Stellung an und begaben fith nach Der Dberflache

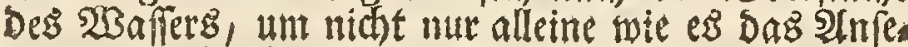
ben batte, frifhe $\mathfrak{L}$ aff $z^{\prime}$ fobogfen, ronbern aud in etroas auszuruben.

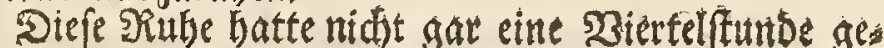
bauert, als lie thr Riebesiptel oon nettem anfiengen und in allem mieder wie borber verfubren; bierauf aber fourden Die alts Den Enern und einem sethen Sdbleim beftebende Sobutire nod einmal fo lang als vorker, forderten (id) aud nid) ton Dem 2(fter Dez $2 B$ eibleins $a b$, fondern blieben an relbiaem bangett, fo, Dafi fte bie Sirote allezett nach fich folleppte, uno als bie ge. Daarten Siroten Das nåmliche SBere stt nettnmalen nieberholten, Gatten bie Schmitre Dicienige Rainge er. balten, in weicher fie utrere zwergte Figur ber $k, 11$, mm uno un zeiget; weil aber Das suseibleint nod nithe auphorte feine (Ever von fich zu geben, unto fich nod it zehen beridjtebenten malen eincB Theils Der: felber entiroigte, Deren jeben Das Mánnlein mit fies nem Eannen befprentgte: to erftredten fith enolicts Die Echmire bennahe auf vier Schuh. श्als aber Der lezte Theil Derfelben zum Sorfitein getommen, io rateden Die beeden froten blofliti won eimander, nachocm Das 2Beiblein mit Ssebagrung feittet Enes nidjt gar brey Stmben zugebrad) hatte. Sierauf nabm ith Die beeden Sroten aus Dem SHIas beraus uno verwabrte ben $\mathfrak{E a i c h}$ befonderg, atm mit felbigent fernerbin meine $5 B$ eobachtungen anjuffellent.

SBie nut aber Diefes Rathen tnto 3 efruthten ber einigen loinger bauterte, fo gieng foldhes atth bey an bern gefdrwittoet von ftatten, fo, bas bey etlidien interbalb ziven Stunden allés gethan mar inzes mein aber gefhiebet foldhes ben sadit und gegen Tasi feltener aber am hellent sag felbit. Finerner to pflegen Die gróferen $23 e i b l e t m$ mebr Ener als die flét neren ober jungen sulegen, Daber Dentt aud bie Sd)mire worinnen felbige enthalten fitts länget aus:

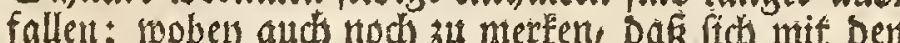
grofferen 2betblein nicht eben alleseit groffe s)eants lein, Condert vielmals auch Eleine paren. Wyent

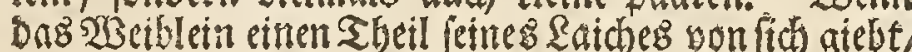
fo if felbiger nidjt jedesmal brittbalb Bofl langy fonts Dern belo länger, bals aber auch hurser. Die in ben aus einem zâben Échleim beftehenden Schnuren befinolis

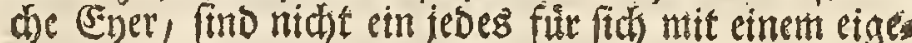
nen Sbeil Sdjleimes umgeben, fortbern fie fisen im Sobleim ro, Dafi fie am ende deffilbent $m m$, wite an 2Unfallg, metre eingeln erfheitten, Die tibrigen aber

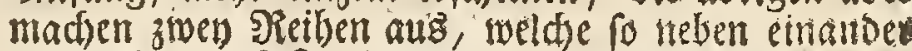

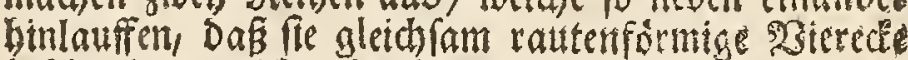
berderiber welche aber bie und da aud mieorer unter
lnue
broben erícietren. 


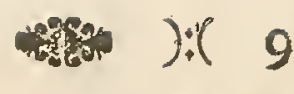

In ueniri quoque poffunt oua hæcce, verno femper tempore, ad ftagnorum foflarumque ripas: quin reperiuntur interdum quoque in lacunis propter vias, in quibus tamen, quum facile exarefcant, non poffunt non perire.

Addendum adhuc eft, extraordinarium prorfus vifum mihi effe, quod, vbi femel par horum bufonum valde magnum obferuabam, mafculus, licet foemella fua jam defierat edere oua, huic tamen per duodeviginti continuas horas adhuc inequitaret, femperque, elapfis quindecim temporis momentis, eosdem motus cieret, ac fi femen effet ejaculaturus, foemina tamen nulla denuo edente oua; meque etiam hoc inuita fieri videbatur foemella, quum mafculo motus fuos iterante, eadew ratione fefe extendebat ac fi ouula effet excretura. Cogitabam hinc, delitefcere forte in foemellae ventre plura adhuc oua, quac ob hanc illamue caufam edere nequiret, atque adeo eam ipfam diffecui; fed nulla in illa reperi oua, nec eam ipfam ob rationem, quae diuturnioris hujus concubitus fuerit cauffa, indicare poffum,

Haec fere omnia ea funt, que, dum bufones noftri generis propagationi incumbunt, obferuare potui; licet vero eam ipfum ob rem, ceu fupra jam a me dictum eft, plura attentius continuoque ftudio contemplatus fim paria, nunquam tamen vidi, quae in Hiitoria Academiae Scientiarum Parifinae, anni 1741, relata legi: adjuuare fcilicet mafculum in ouorum partu foemellam, protra. hereque eundem illa ipfa pofteriorum pedum fuorum digitis e foemellae ano. Communicauit obferuationem hancce medicus quidam, cui DEMOVRS nomen eft, \& fi verum fuerit, agere mulculum, dum oua eduntur, quemadmodum ipfe loqui amat, obftetricem: de alia bufonum fpecie, quam quidem noftra eft, id intelligi debere omnino reor, praefertim quum ipfe fcribat, loqui fe de minori fpecie terreftrium bufonum, effeque oua ipfius oblonga, binas lineas longitudine aequantia, opeque brevioris fed fortioris fili cohaerentia, quae fingula noftro de bufone afferi nequeunt; fed vellem, dediffet D. Demovrs ipfe nobis ampliorem minoris fuae bufonum terreftrium fpeciei notitiam: ex illis enim quas ego noui, fpecies haecce neutiquam effe poteft.

Aft infpiciamus jam fperma bufonum noftrorum fepararim a me feruatum, quodque ex iisdem die vndecimo Aprilis obtinueram. Augebatur illud indies mole: dilatabantur namque oua non folum, red \&, in quo haerebant, gluten, ita, vt die duodecimo nec non de cimo \& tertio tertiam fimilitudine referrent figuram; ipfa vero eam infuper fubierant mutationem, vt quum tnitio ex toto fere nigrae effent, nunc altera eorum pars ex fufco grifea punctisque \& maculis nigris confperfa compareret; altera vero priftinam monftraret nigritudinem, quumque illa ope lentis vitreae contemplarer parui videbantur terreftres globi: pars namque nigra fpeciem habebat aquatum, pars vero lucidior terrarum infularunque, id quod ex iconibus 4. 5. \& 6, patebit: quarta namque refert ouum ex parte nigrum nec non sx parte altera lucidum; quinta partem tantum exhibet Iucidiorem, fexta nigram; iple vero gyrinus nondum in isdem comparebat.
$2):($

Eben Diefen Raich Der Siroten fann man audi alle

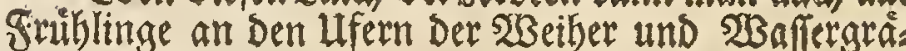
ben finden: tâ es iff folcher mandhmalen in ben shes genpfübet an ben Strafen ebenfalls anzutreffer. mofelbit er aber, weil felbige leidtlich austroezner, Derserben mus.

श्Is etwas auferorbentlidfes babe id aud nod

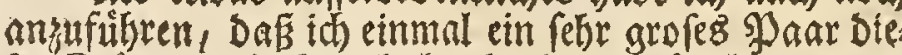
fer firóten beobachtet habe, da das soánnlein, Hnges achtet Das sBetbleit bereitz zu laichen aufgehóret bat te, Dod) nodh immer auf Dierem, bey adt treben Stum Den lang fiben blieb, und alle funfzeben Minutery bie sBewegungen machte, weldse felbiges allezeit, wern eš Den Saamen von fít) giebt, ju madsen pfleget, Dhme Dafi Das 2 Beiblein von neuem za laiden anges fangen båtte; aud zeigte biefes bieben gar feinen 2Biberwillen, fondern ftredte fich bey Den wiedert)ol ten 3 enegungen Des Nonmlemb eben fo aus, als ob

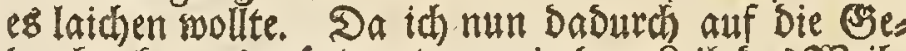
Danten fam, es mógten etwann in Dem Leib Deß 201 eib. leins nod mehrere Ener verborgen renen, Deren es fió um Diefer ober fener lurfache willen nidjt entledigen Fonnte: fo offinete id Daffelbe, traf aber in foldhem ene Ener mebr an und weis baber aud nicht, was fuit einer Lurfache Diefe ungemóbnlich lange sparung zuzurdyeriben fenn mógte.

Diefes ift mun alles was id ben ber Fortpllan zung Des (5e(d)led)tes an unferen froten beobaditet babe; und ob idj (4hon eben deswegen, wie bereits oben gemeldet worben, viele saare mit groffer 2 (d) fameit, faft unablásig betrachtet: fo if Dod niemal Dasienige von mir wahrgenommen worden, was in

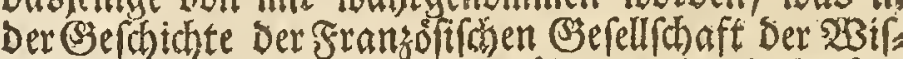
fenchaften von Sabr I 74I. erzáblet wird: Dafi naims lich Das Mainnlein Der Sróten, Dem 2 Beiblein in Der Geburt Der Ener zu Stilffe Eomme uns foldhe, mit ben Behen reiner Sinterfiffe, aus Dem श्ञfter Deffel

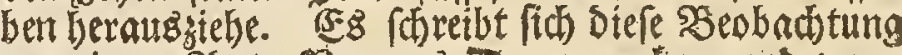
uon einem 2irst, STamens 3 Demours ber, und wenn es fich in Der Shat fo befindet, Daf Das Rrótenmainm lein ben Der Bseburt Des Raiches, wie er felbit fagts einen 2iccoucheut abgiebt: fo mus foldjes eite ande

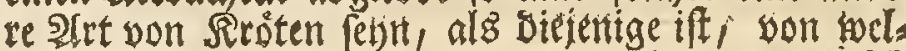
(d)er id bie fojreibe, zumalen ba er meloet/ es fene- fol d)e Die flemere Itrt ber RandEróte; ifre Ever wáren länglidt, erffrecten fich auf zwen Sinien und biens gen vermittelit eines turzen und febr ftarten Fradens zulanmery weldes lauter folche Dinge fino, fo fid yon unferer Sirotenart nibt fagen laflen; Dod wollo te ich winjoten, Das uns Serr Demours von feiner

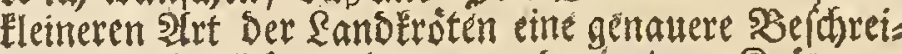
bung gegeben båtte: Dent bon benienigen Serótenars ten, Die mir befaunt find, falln es feine fenn.

Doch nut wollen wir bas befonders von mir ver: wahrte Raich unferer Siroten betrachten; soldjes ick Den eilften 2rpril crhalten batte. tảglid groffer, inbent fich nidst nur alleine bie Evyer, fondern aud ber Shleim, in weldhem fie enthalten waren immer mebr und mehr ausbreiteten und alfo Den I2 und I3. 2Tpril Das 2infehen Der oritten Sigur Gatten, uno uberdem, fo waren bie Ever audh nitn= mebr in fo ferne verándert, Dás ba fie anfangs fafe ganz fotwars ausfaben, jebund bie eine Sälfte bets felben braunlidft bellgrau und mit bunflen \$sunctert unto Slecten befprenget twar; bie andere aber ibre Sd)máre bebalten hatte, und alb id fie mit emem Beraróferungsglaz betrad)tete, fo fteliten fie Eleine SBelttugeln vor, wenn man nånlich Den fitwarzen

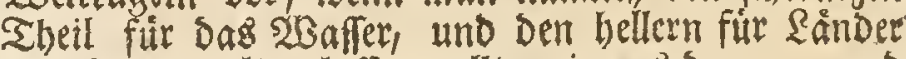
uno Inifeln gelten laffen wollte, wie aus Der 4. 5. uno 6. Sigur zu erfeben fern mirb, als voit welden bie

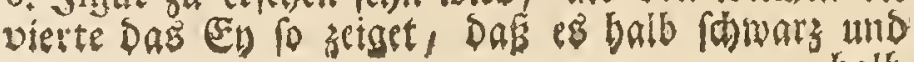




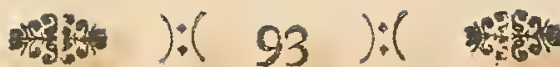

Quum faepius fieri foleat, vt oua illa quae vno partu a foemella eduntur, non omnia a maf́culo foecun dentur, vtraque vero, hoc non obftante, poftmodum intumefcant formamque globofam mutent, non foecun data autem diffluant, atque in aqua fermentatio nec non putredo quædam hinc oriatur ouis foecundatis, vel inde natis gyrinis, noxia: vt ab inuicem feparentur necelle eft; quod vero ipfum, ope tubuli vitrei, quo fiphonis inftar vtimur, facile perficitur: habent namque oua foecundata plus femper nigritudinis quan foecundata, atque hæc magis quam illa intumefcunt. Idem etiam omnium reliquarum ranarum patiuntur oua, quumque in præcedentium defcriptione hujus rei non memini, e se fore duxi fi eandem nunc indicarem.

Sed afpiciamus rurfus fperma noftrum. Die decimo fexto Aprilis, qui poft partum illius quartus erat quintusue, obferuabam, plurima contentorum in illo ouulorum foecundatorum, formam induife 7 . iconis, in qua tamen neque caput neque cauda poterat dignofći; die tamen decimo feptimo nec non duodevigefimo diftinctius jam comparebant, id quod 8 oftendit icon. Hac fub forma in ipfo illo, quo cingebantur gyrini hi, fe adhuc tenebant glutine albumineue; fed aninaduertebam iam cieri eosdem interdum pernici, vix tamen diuduran te motu. Die vndevigetino vigefimoque deferebant plurimi eorundem dictum gluten, finiles tunc erat icanibus 910 हf $I I$, magnitudine tamen differebant; caudam circumibat pinna, obferuabatur etiam ventris a capite diuifio, in hoc vero prater oculos ofculurn quoque cernebatur. Nunc fuperiorem aquae fuperficiern ver fus enatare tentabant; mox tamen, defatigati quafi, in fundum cadebant, In gyrino, quem II icon ab inferiore fittit fuperficie, jamjam proditurae funt appendices fimbriatae, quippe quarum apiculi in vtroque jasm adfunt latere; fed adinifcebantur illae tum demum f litam fuam magnitudinem, vbi gyrinus per nouem jam decemue vixerat dies, atque tum duodecimne figurae habebat fimilitudinem. Sed difcrepant fimbriatae hae arpendices neque magnitudine, neque forma, neque.colore ab illis gyrinorum bufonis allium redolentis. Confabant hinc, aeque ac in his, quinque fexue, digitorum formam haben tibus, ramis diuerfae longitudinis, pofteriori capitis part ope binorum breuium truncorun affixis.

Parum hactenus appetierant gyrini mei aquaticas plantas; fed nutriebantur lentore ex aqua nato, plantis acque ac vitso adhaerente. Die vigefimo tertio quartoque nihil fere amplius in gyrinis hife ex fimbriatis con fpiciebatur appendicibus, quum aeque ac alii gyrini vix vitra diem iisdem inftructi erant; contrahebatur contr corpus eorum craffefcebatque nec non vnacum capite in eam abibat formam, vt corpus nunc referrent oui forme, fi præfertim gyrinus a fuperiore inferioreue adfpiciebatur fuperficie, cet1 ex 13 apparet icone. Licet vero ipfum corpus breuius redditum fuiffe videretur, in majorem contra cauda exporrecta erat longitudinem. Monftrat If icon eundem hunc gyrinum a latere, vbi quidem corpus gracilius apparet, cauda vero, quam lata, ad extremum rotunda, fufcaque cingit pinna, in longitudinem extenfa eo cernitur diftinctius.
Galb bell erfbeinet, bie furfte wetret mat bie belle

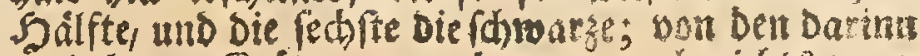

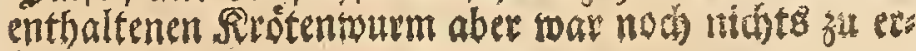
Eennen.

Da es vielfältig zu geícheban vfleget, basin nitht alle Dietenigen (ever, fo ein 2 Beiblein von fít) giebt, bon bem Másnlein befrudstet werben beeb aber bente unatasís

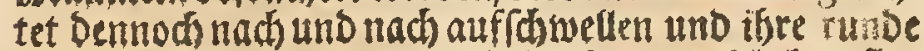
form verándern, und bie unbefud)teten endich) zerflic

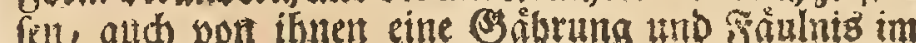
23 affer entftehet, woburch bie befrudteten Ener, ober Die Daraus getommenen Sirótenwürmlein Shadan leiben: fo if es nótbig folche von einanber zu fondern, welches vermittelft eines gláfernen Soróbrleins, Deffent man fid) als eines Sebers bedienet, gar leid̄t gerthes

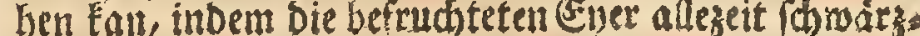
lichter als bie unbefrudteten auBreben, und diefe auds metr als Die anbern auffow wellen; eben oteres aber vile: get auth bey allen andern frofharten ju geíneben,

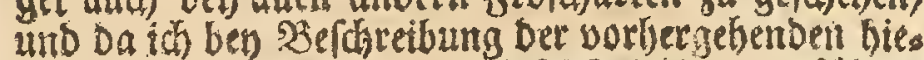

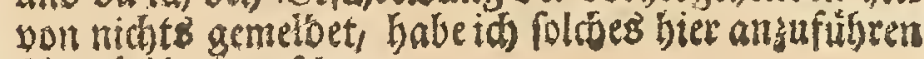
fur nothig angereben.

Dodh wir wenón unessieber zu unfern Eaich.

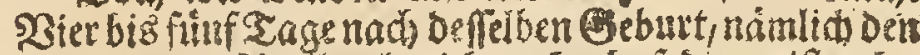

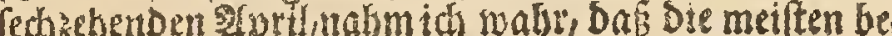

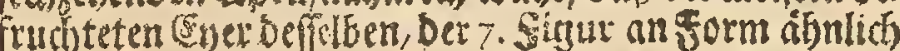
gemorden roeren, troran man aber weder Stopf nod Somans erfenten Fonnte; ben fiebenzebenosn und actrothenden aber lies fich fojon mebreres von beeden untericheiben, wie aus ber 8. Sigur zu erfehen. In bier fer (Beffalt blieben bie 2Burmer swar nod) in beme fie umgebenden Sojleim; Dod) benterclete id bereitb, Dank uno wann, eine idnelle aber furze Bervegais an ifnen.

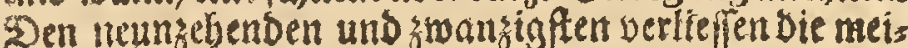
fren gebachten Sd)leim; fie faber bamals ber 9. 10. uno 1. Figut ẩnlich, waren von ungleidjer (Groffe; tim Den Ëd wans zeigtefich eine Flofie; Den \&eib tomite

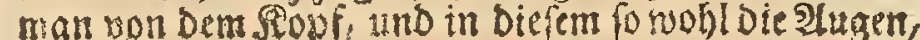
als aud ben fleinen Muno untericheibent. STunmilye fiemgen fie audh an gegen bie oberfindse bes 2 Bafler zu f chnimmen, fiten aber balo wieber, als ob fie oas yon nibe máren, fn 230 ben. Der in Der 1 . Figur voraiftilite s3urm, welder fich von Der linterfiche

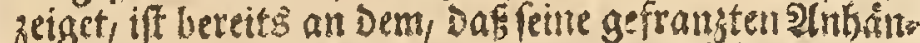

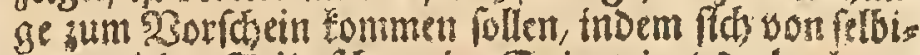
gen su jeder Seite fdion eime (Evizezeiaet, Doch erlang.

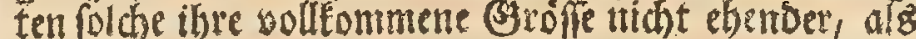
bis ber รBurm neun biช̄ gebeñage alt war, und alge benn fabe er wie bie 12. Sigur ans. ess baben abee Diefe Sinffranzen bier feme mebrere Brofle, Eeine att Dere Form uno Sarbe alz an Den $2 B$ úrmern ber Trnob. Iaukf frote, wie lie benn aud, wie an bieren, aus fuinf bis fech s tursen fingerfórmigen âteften von ungleicher Rånge beftunderl Die mit fwen fiurjen Stónmen bitt fen am Sovi deft rafien.

Bititer toollten biefe meine firötenwuirmex noch nichts yon ben grünen 2 bafferpflangen anbeifen, fons Dern fie nábrten fith nod) yon ben an biefen Mf fanzen fo wobl, als an bem B3las hanaenoen, uno aus Dem

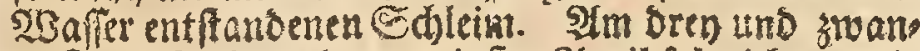
zigften unb vicr unb swanzigften Plpril fabe id en mets

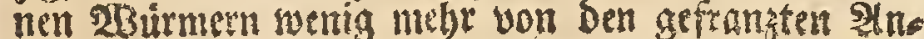
bängen, inbern fie felbige, gleid) anbern foldsen 583 tir, mern, niưt viel lânger als einen Tag bebiclten; hot, genen wurde ibr Reib viel Eirser uns Dider, uno betom,

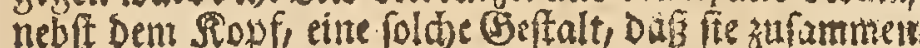
einen enformigen Rorper yorfellen; fonbelition went ich Den 3 burm von Der obern ober untern Flóche anfa he, weldes bie 13. Sigur zeiget; forien aber nunnelye ber Sórver nbgenommen zu haben, fo war bingegen Der Estram Deftolánger. Dite 14. Finut siget bent

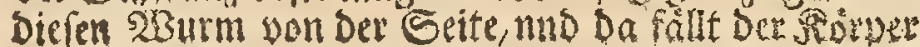
zwar etwas gefomeidiger aubs, Der Shmans aberzeigt 


\section{4.}

Similes erant plurimi gyrinorum meorum, die dundetrigefimo vndetrigefimoque $i$ conibus is atque $16, T_{a}$ bulae $X X I$. quarum illa gyrinum a latere, haec vero a dorfali fuperficie repraefentat. Licetvero gyrini hi jara notabiliter increuifent, conjectura jam tamen proipi. ciebam, vix illos adeo magnos euafuros, ac gyrini ill bufonis aquatici, quos $X V$ III. Tabula depictos exhibet, quamquam credebam in majorem eos excreturos molem, quam quidern poftea factum fuit. Eratipfis, fuperius aeque ac inferius, niger magis quam fufcus color; hoc ta. men non obftante fat diftincte bini confipiciebantur oculi, duo nigra nitefcentiaque referentes puncta. Magis etiam furua eft caudan cingens pinna, quam in aliis ra. narum bufonumque gyrinis, nec non in rotundam, vti jam dictum eft; terminatur extremitatem, hac vero, vt \& furuo colore gyrini hi a reliquis difcrepant peciebus.

Auidius nunc gyrini, hoc increnento aucti, plantas appetebant aquaticas, his tamen, quarum fapore maxime capiebantur, tamdiu vefcebantur, donec ad fatietaten illis effent expleti, tunc vero rectum ipforum inteftinum d Fig. I5 E 17. faecibus valde cernebatur repletum. Ex plantis, quas ipfis porrigebam, vix iplos paluftres alliciebant lenticulae; lactucam contra fatiuam magis ama. re videbantur, qua etinm fola eosdem, donec adoluiftent, nutriui. Iam vero nullam, per fexdecim dierum fpatium, illi, quantum quidem obferuabam, fubibant mutationem, nifi quod fingulis diebus nomnihil magnitudine augebantur, cieque decimo fexto Maji, crura pofteriora comparere incipiebant, atque ad diem vsque vigefimum quartum, tantum fumebant incrementum, guantum in icone 17. fupra inteftinum rectum $d$ pofita, atque in 18 ad $b b$ habere cernimus, Quum vltima hac icone gyrinus ab inferiore fiftatur fuperficie, in finiftro ctiam lacere, pone caput ad $c$, fpiraculum illud, veficam referens, confpicitur, quod in omnibus ranarum bufonumque gyrinis hanc occupat fedem, quodque in gyrinis ranae terreftris minus indicaui, quum illud, tum temporis, partem effe oragnicam minime credebanı.

Perfecta mihi videbatur, die nono duodecimoque Iulii, gyrinorum meorum forma, atque hinc maximos eorum depinxi. Habebant tum fpeciem 19 nec non 20 iconis. Corpus ipforum vix dimidium longitudine aequabat pollicem, cauda octo fere lineas, ita, vt tota gyrini longitudo pollicem vix fuperaret. Flaua jam oculis micabat iris, bina vero pofteriora crura, die nono Iunii, tribus folitis infructa erant partibus fuis, quemadmodum $19 \mathrm{Fig}$. ad b. monftrat, tenerae tamen adhuc erant gracilesque; die vero duoclecimo id fumferant incrementi, Fig. 20. vt gyrinus iisdem jam ad natandum vteretur, ille vero in quo id ipfum heic cernimus, finiftro in latere fat diftincte exhibet fpiraculum $c$ fignatum.

Seruarant hactenus gyrini noftri colorem nigrum, lam vero fufci quicquam admixtunt habebant, aeque ac pinna caudam cingens, fuperiore in parte, atris notata erat punitis.

Refpuebant, die decimo quinto Iunii, gyrini hi, quo hactenus vfi erant, pabulum, corpus vero ipforum jan gracilefcebat. Die decimo feptimo duodeuigefimoque, in nonnullis jam crura aderant anteriora omni ex parte perfecta, quorum quidem finiftrum, in pluribus, fiф) mit feiner breiten and binten rundgeftumpften. braunen floffe, feiner ganjen \&ange nad), um fo viel Deutlicher.

Dett ad)t unb stwangigften uno neun und smanzigs ftenPlpril gliecten bie mebreften meiner Srotenwuirme Der auf Der XXI Tabelle befind liduen 15 . unb 16. St tgur, Don weldhen iene Den 3 urm von Der Seite, Diefe aber von Der SRudeflade Darftellet. Ilnacaditet nun aber Diefe S3irmer um ein mertliches an 23 adhstbum zugenommen batten, fo Eonnte id bo d bereit vermus then, Daßffe zu Derienigen Stróffe, welche Die auf DCE $X V I I I$. Cabelle abgebildeten 3 affer frótenmurmer er reiden nid)t antwad) fen wüben, ob id (ch)on glaubte bierelben wutben grofifer torben, als fie nachgehendos mirflich nidtet genorden. Der farbe nach faben fie, fo swobl oben als unten, mebr fhwars als braun aus; beme ungeadtet aber Eonnte man bie beeden 2 ugen, it

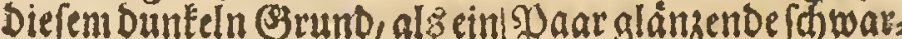
ze Suncte ganz Deutlid erfenten. Die ben S broan umgebende Glofle if hiter auch vid Dumtler alb an an Derit Frofd, oder firotenwuirmern, unb endiget fitch, mie bereits gemeldet worben, mit ciner ftumpfen sainde, biedurch aber, und Durd Die DunEle (S) rund farbe, unter. fheiben fíd Diefe 2 Burmer von allen andern 21 iten.

Die wuirmer Diefer (Siroffe fielen unmebr alle Waffergemád) fe fer begierig an, Doch blieben fie ben bemientigen, fo ibnen am beften fomedte, fo lange, bisfiefid) Darat fatt gefreffen batten, worauf ibr Mala Darnt $d$ Fig. Is unt 17 . von Unratb balo ftarde anges fillet er coten. Inter Denienigen soflanzem, womit ads fie verfahe, actetett fie Der Meerlinfen ant roentigftem, Der Sartenfalat aber foren innen beffer fu fohmeden, uno mit biefem bab id fie aud vóllig erzogen. $230 n$ nut an bemertete ich (ed) zeben Tage lang faft feine Merain=

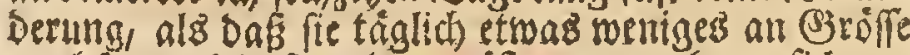
such (em, und Das an Den gróften unter ibnen, fich) am

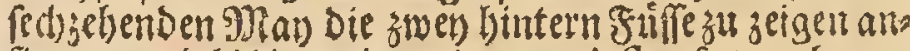
fiengen und bis ben vier uno zwansigften fo zumalnen, twie lie Die 17 Figur uber Den Maftoarra $d$ und Die 18 bes $b b$ seiget. Da Die lethtere figur ben 23 urm von feiner untern Siadie Darfellet, fo liebet man audi an ber lincien Seite, hinter bent govf, bey f, Distenige blafen: ábnlibe Eufftrobre ober Deffnutg, momit alle Frofict und Sirotentwirmer verieben find, Die ich aber an ben 2Butrmern Des S5rasfrofdies, Deswesten anzuzeigen ut terlafien batte, weil ich fie bamals noch fur teimen or Dentliden Theil Derfelben gegalten.

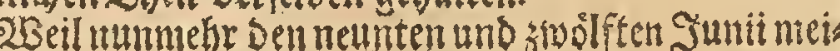

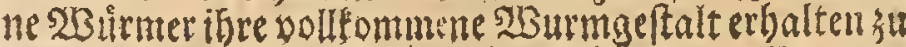
Gaben fohienen, mablte id bie groffen Derfelben ab. Sie Lattent Damals Das Pneben Der 19. und 20 Sigu. Shr fióper war faum cinen balben Boll lang, uno Der

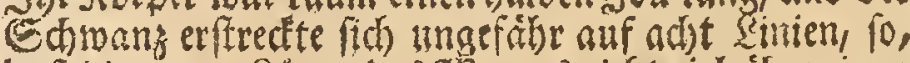
Daf die ganze Ranne Des 5 Surms nicht viel liber cinen Soll ausmachte. In Den Plugen war numebre cin gels ber Shing zu feben, unto bie beeben bintern Fiffe hatten Den neunten Junit ibre Dren Theile, wie ben 6 Fig. $1 \%$.

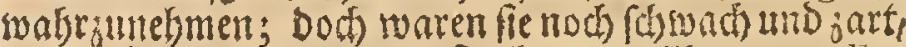
Den znolften aber fajon fo fark uno volffommen, Fig. 20, Daf́ fid) Der 2 Burm Derfelben im Echwimnten be: Dienen fonnte, unt Derienige an weldien wir foldbes bier retern, zeiget uns audh an feiner linten Scite bie Sufftofnung a gans Deutlió.

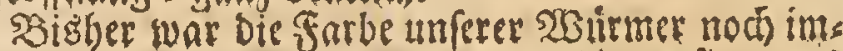
mer fow wars geblieben, nunmera aber fohiene fie etwas mit braunem untermifoht su. Fenn, roie benn and bie ben Sdywanz umgebende Flofle jezt mit.zarten fowarzen Sunctent obenber befprengt erfchen.

Den funfzebenden Ounit berlicfen diefe sBurmer ibr bisberiges Futter/ uno ibe \&eib fieng an gefolanger 34 tocroen. Sort fiebentebenten und adt tzebenden waren for on an einigen Die vordern friffe vollig ba von weld)ett ids Dert linEery an Den mebreftery zu erft 


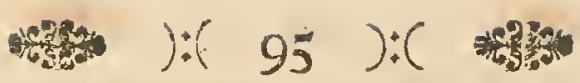

per aperturam minorem primum prodiffe vidi, quod fequerti lie dextrum eadem fequebatur ratione, atque tum feruabat cauda priftiram fuam formam per viginti \& quatuor tantum horas. Mutabitur nunc niger corporis color in fu. fcum, quatuorque crura, aeque ac lupérior luperficies, macuIas monftrabsut nigras; ipfe vero gyrinus vigefanam primam reftrebat iconcm. Decrefcebat tandem cauda longitudine la. titudineque, ite, vt die decimo nono vix dimidia, vigefimo vero, nulla prorfus fjuşdem confípiceretur pars. Iamitaque ornes gyrini in perfectos tenell. isque mutati erant bufones, red, id quod mirabur, tam paruos, ve abomn.bus aliis, ex gy. rins haud ita diu natis, differrent racarum bufonumque lpeciebus.

Poftquam tenelli mei bufones quatuor fua obtinuerant crura, ipfam vero caudam nondum amiferant: jam ex agug prorepere conabantur; hinc in aliud illos immirtebam vi. prorepere corabantur; hinc in aliud illos immittebam vi.
trum, crjus inferior tantum pars pauca tegebatur aqua, quad. que maioribus variarum herbarum repleueram folis, in quae, licet eadem non amplius appeterent, mox tamen fefe confe. rebant, minoresque, quas iplis, evulfis alis, porrigebam, mufcas, auidius deuorabant.

Qnum bufones hujus generis majores, vno eodemque tem. pore cum rana terreftri, oua pariant atque hinc nati ter elli bufones eodem etiam tempore, ac ranunculi teireftres, aquas derelinquant et poft tepidiores pluuias, prope lecus paludes. que, plura millia eorundem in terris verfentur: multi, qui horum animalculorum proprietates minus norunt, perfuafum hibert, e nubibus eadem vnacum ranunculis, pluibe inftar, delapfa effe, Ante quartum xtatis fuoe annum bufunes hi generi propagando minus funt apti; quam vero nonnulli eo. rundem admudum grandes euadant, nullsm certe eft dubium, quin vlera quirdecim, ceu fupra iam indicaui, .viuant annos.

\section{SECTIONIS QVINTAE}

\section{CAP. II.}

In quo bufonis dorfo tuberculis exafperato, oculis rubris, interiores defcribuntur partes.

Cupereft, vt nunc etiam bufonis terreftris, dorfo tubercu$\checkmark$ lis exafperate, vtriusque fexus, contemplemur interiores partes, reliquis Tabulae $X X I$. iconibus expreffas, quae eo ipfo quo coire folent tempore, quoque perfectiores compa. rent, depiatae fuerunt.

Quodfi hoc tempore foemella aperiatur, cuius oua nondum in tubas, perque eas in vterum fint delata: pra reli. quis partibus maxime confpicuum eft ouarium, maxinum abdominis occupans fpatium. Exhibet illud, e corpore ex emtum, icon 23. Duabus id conftat primariis partibus, qua rum qua liber aliquot centena continet oua, nigro colore gaudentia, quacque tunica quadam teners ea cinguntar ratione, vt pars quaelibet primaria pluribus compolita videntur 10 . bulis loculisque. Vbi vero ouarium hocce cum pulmonibus, hepate, venericulo atque inteftinis, caute e buforis corpore sufertur, reftantin illo cor, vefica nec non generationi inferuientes partes. Ex his confpiciuntur prae reliquis, binae lon gae, candidum referentes inteftiuum, tubae, quae fi mirus fuerint laefae, perque orificium, prope cor haerens, sere re. pleartur, fpeciem habent iconzis 24, In hac cor pericardio cinctum lirtera $d$ indicatur, binae vero exin oriundae arte. riae litteris $e$. Ad ff orificia binarum hiant tubarum, lit terae vero $g g \sigma, g g g$ vtroque in latere fcriptae, crebrinres earundem moiftrent flexus, vbi fimul notandum, reddi illas, in progreffu fuo, fenfim fenfimque ampliores, donec ad vltimam litteram $g$ vtero infersntur. Hic fignates eft litreris $h b h$, $b b h$, formaque inultum differt $a b$ vteris hactenus de fcripto. rum bufonum lanarumque, quum bins propemudum refe. rat cornua; quin crederes, effe illum nil nifi binas tubas continuatas, nifi pelluceret: gryfeum veficae haberet colorem, majorisque effet amplitudinis; quum contra alkerum tuba rum dimidium, vtero colizerens, turbide carrei fit coloris, alterum vero $\mathrm{ex}$ albo fauefcat. Ipfi autem fingulari huic vte ri conformationi, prucul dubio, adfcribendum eft, quod oua hujus bufonis, fub forma binorum fllorum radiarumue ex cernantur. Mediam inter jam defcriptas partes occupant redem, in iconze 24, appendices foliacere $k k$, aurantio colore hic timetae; ii bini indicantur renes, quoad colorem carnei $l$ inteftinum eft rectum, a reliquis inteftinis fectione feparatum; $m m$ vefica vacua atque hinc complicats.
Durth cine Eleite Deffnung oer 5 aut beroorbrecten fahe, on benn

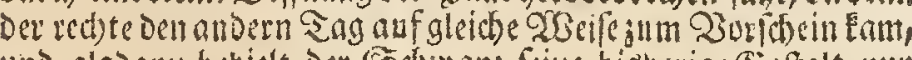
und alsoan behielt Der (Echivang feite bigberige Geftalt nut

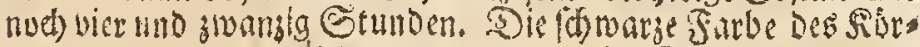
pers murbe nun etwä brauner, und de vier $S$ benel wurden,

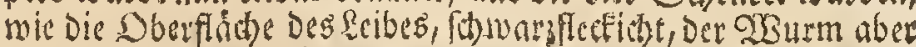

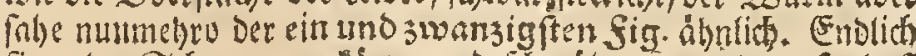

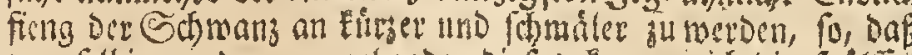

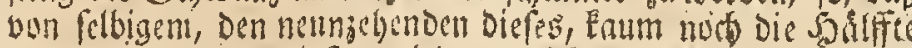

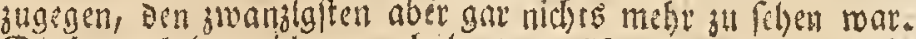

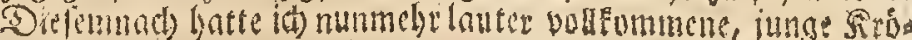
tón, Dic abst fu meinct Oerwunderung fo Elein waren, Daf fie

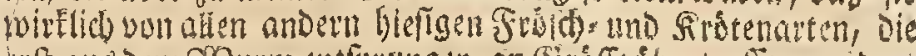

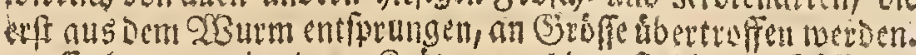

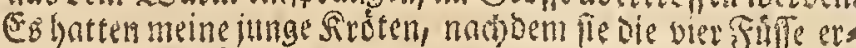

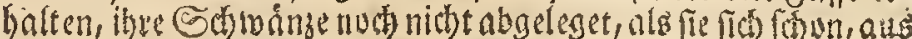

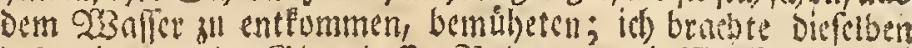

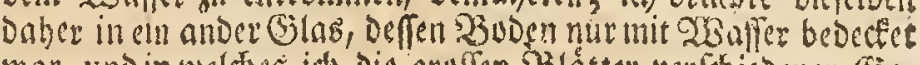
war, und in weld es ids die gruffen s3latter verfobiedener (Se. wadble geleget hatte, ba fie fido Dennfo gletith nuf Diefe begaben, fold) aber nidst mebe anjubeiffen berlangten; fondern de Elit then Pucen, weldbe idb ibnen nad) nbgerifienen Fligeln bins cinmanf, auf bas begicrigfte wegfomappten.

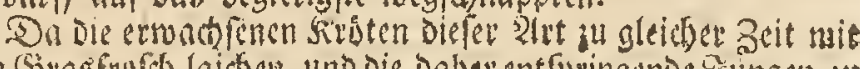

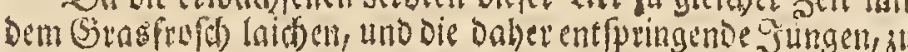

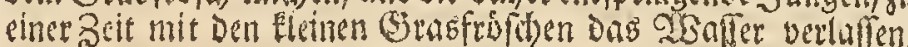
aud nad cinem warmen siegen fids, obnfern Der Ssiche uno Cumpfe, an vielen taufenden auf bas sano begeben: fo glatiben

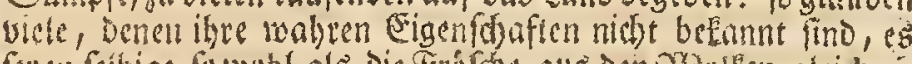

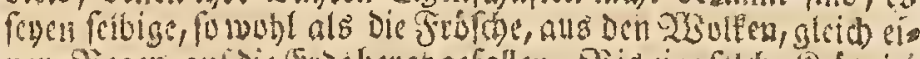

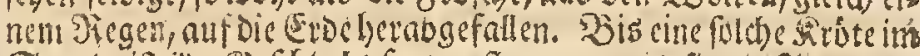

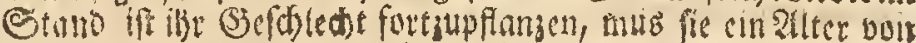

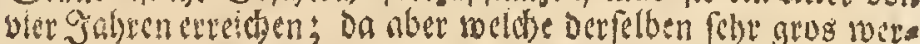

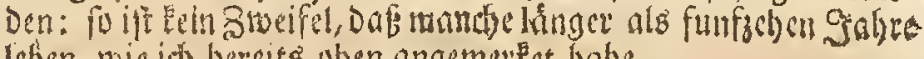
lsben, wie id bereits uben angemertet babe.

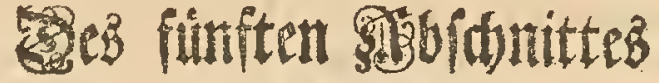

\section{3 meyters (Capitel.}

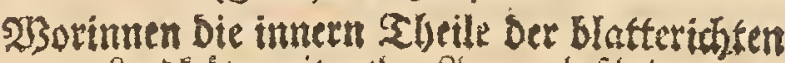

Ranberote, mit ratben Fugcin, bejorics

$$
\text { ben toeroen: }
$$

Bun wollen wir aud Die innern Sheile unferee blatteriditen

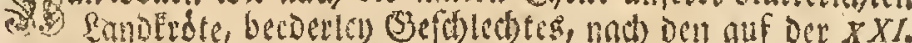

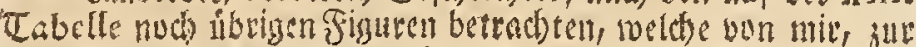

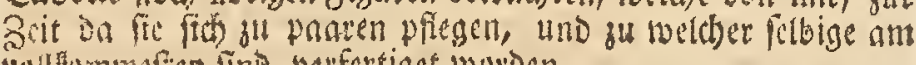
bullevanmenting, berfertiget worben.

Deffnet man zil Dicfer Seit ein Orbeiblein Deffen Eyer nud

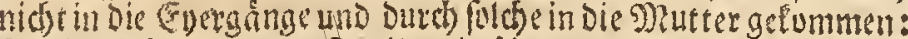

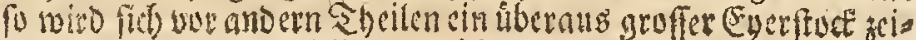
gen, oce in Dem linterleib oen grofiten 5 Raum cinnimmt. 23 ir

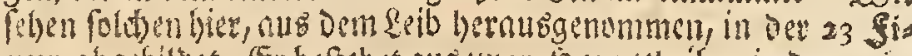

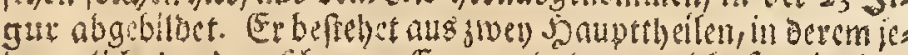
ben etlide hundert fowvarge (Eyer enthatten, welde fo mit cincr

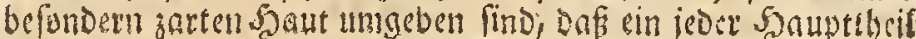

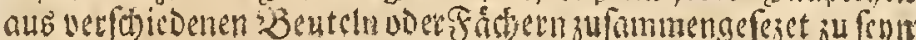

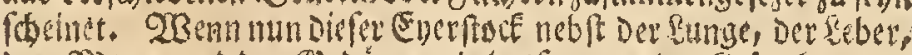

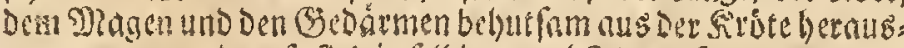
genummen worder, fofind in jeltigen, nebft Dem Seerzen und der

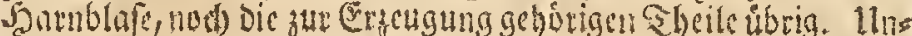
ter Diefen fallen bie becoen lanaen, einem tociffen Darm of bnliche Energange, wornelintio in bic \&ugen, wenu nun fétbige niç

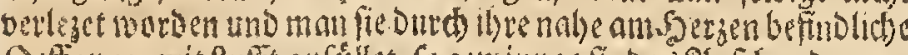

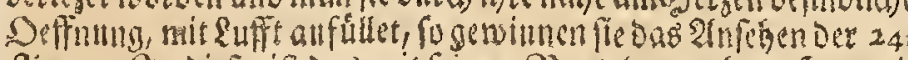

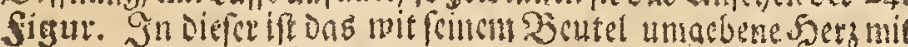
d begeidnet, Die aus fulbigem entpringende rwen Sulsadern aber mit ec. Dic Definnng Der bechen Eyergenge jeigen uns bie

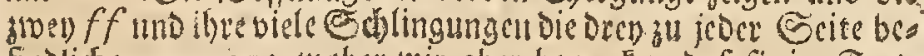
finolicbegg. $g g$; wobey twir aber bemerten, onf fir in Furts gang immer bicter werden, bis fie fich Do wo das leste g fechet, mis Der Dôrmutter bereiniget. Diefe if mit bhh bhb begciduret un

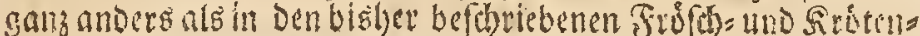

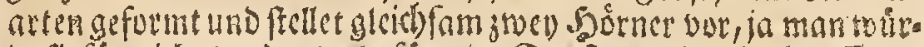

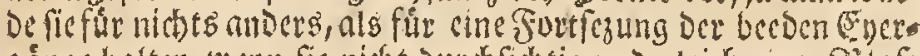
genge halten, wean fie nicht ourd fid) tig uno glcid) ciner 33 infe

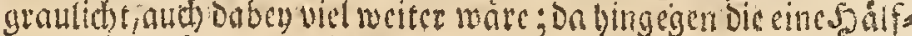

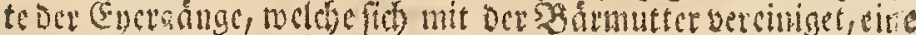

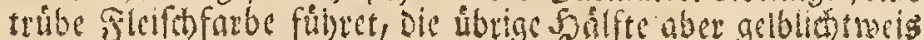

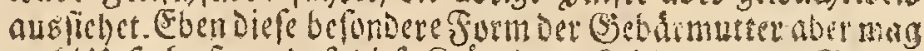

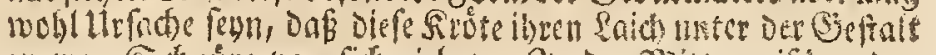

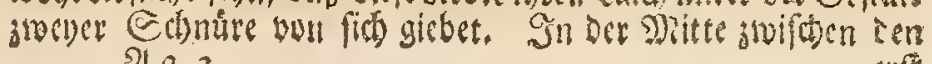




\section{\%}

Reliquae interiores hujus bufonis partes, pulmones puta, Aepar, fplen, ventriculus, inteftina etc, eadem fe habent ra tione in foemellis, ac in mafculis, jam vero easclem ex mafculo. figurae 25. ope, in riaturali fitu cohsefioneque fum repraefeuracurus; vbi tamen monendum fimul eft, pulmones veficamque aere a me fuiffe repletos, quum partes hafce eram depicturus. l'offunt pulmones aeris ope valde diftendi, atque hinc fat ampli apparent, licet longitudine a pulmonibus al. lium redolentis bufonis fuperentur. Qunad fuperficiem exceriorem, ex meris conuexis fereque rotundis, inaequalibus tamen, conftare videntur veficulis; permeat etiam eosdem vas majus fanguiferum, in plures minores ramos dif ertitum; color ipfis magis eft carneus, guam aliorum horum ani malium pulmonibus. Inter lobos pulmonum cor $d$. confpi citur, binaeque ex eodem prodeuntes arteriae $e c$. Sub corde fira oft rotunda atque ex atro virens cyitis fellea o, pp magni heparis funt lobi, $q$ paruus, ruber rotund sqque lien. Ad alter fe hic tantum confpiciendum praebet tefticulorum $\iint$ ventriculus eft tenuibus cohaerens inteftinis, quorum aijquam tantum hic videmus partem $u$, in rectum fefe inferen. tem inteftinum $t$. Vefice vथ $v \pi$ non folum ob magnitudi nem, fed eriam ob fui diuifionem, qua in duas aequales difpartita effe videtur portiones, notari meretur. $\mathrm{Ob}$ amplitudinem veficae majorem bufo hic colligere feruareque porelt vrinac copiam, qua, dum eandem, vti notum eft; propellit, in fur vritur defenfionem.

Reftant partes mafculi, generstioni inferuientes, fib ha ctenus defcriptis laterites, atqae ab hifce feparatae, 26. icone repraefentatae. $k k k$ folizceae, colore aurantio rinctae adipofaeque funt appendices, quae ipfo generationis tempure majores, quam quidem finito illo, comparent. Renes ijteris $i i$ funt fignati, quibus farui incumbunt tefticuli $r r$, nunc majores nunc minores, nonnullisque punctulis confperfi. Quod ad bina atrinet feminis receptacula, conftant illa rurfus, vri in bufone allium redolente, vnico tantum conali, fic tamen inflexo, vt triplex, atque exteriori in parte ferpentinos tractus imitari videatur. Notata funt bina haec receptacula $x x$, reorque, effe erdem, illo ipfo nomine, quod isdem in didi, appellande; quad illa per aperturam $z$, diffecti inteftini recti $y$, nere repleui, hujusque ope detexi. Admodum exigun eft dicta modo apertura, ita, vt vbi quis eandem fit detecturus, is illam in extremo inteftini recti diffecto, flatu tam diu quaerere debeat, donec cernat, bina haec receptacula acre effe repleta.

Monftrat fceleton Fig. 27. bufonis noftri terreftris, effe on folum caput ipfias $A$, in quo $B$ B binas indicant orbitas, breuius craffusque quam in aliis horum animalium fpecie bus; fed funt quoque crurum pedumque offa breuiora ficmioraque. Differt etiam forma fcapularum $C C$, offis fterni $D$, offum ilium $E E$, nec non fpinae. Offa contra coxae $F F$, ve et longius intra haec pofitum coccygis os $G$, magis fimilia funt iisdem offibus ranarum bufonumque aliorum, os autem pubis $H$, multum rurfus difcrepat. Digitis quaternis pedum anteriorum, aeque ac quinis polteriorum, non plura funt offa, quanı in aliis; potandus tamen in hifee eft digitus quidam fpurius, qui non, ve in bufone allium redo. leate, corneae eft fructurae; fed binis conftar ollibus, II. Quod ad fupra memoratum attinet bufoniten, quem hunc bufonem in capite gerere afferunt, fateor quidem, me in eodem nihil reperife lapidi fimile, nifi quis offa cranii bufoniten illum referife lapidi fimile, nifi quis ofla cranii bufoniten ilum anguftia, atque hinc id ipfum alii referuo occafioni.

\section{F. I N I S}

Hifroria bufonis terreftris dorfo suberculis exajperato É. erf beforicbenen Sgeilen fino in unferet 24- Sigut bie blatters formigen und bier vraniengelben anbange k ku fiben; Durd

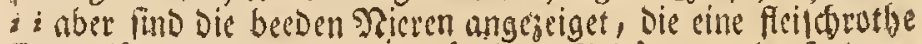
Farbe fíl)ren; / ift Der bon Den úbrigen (Şebármen abgefonderte

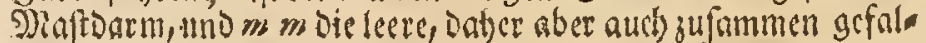
tetes Somblate.

Sie andern innerfidfen Sbeile Diefar Frote, als naimlid Die

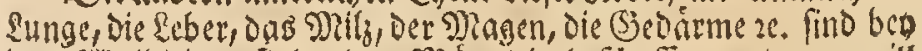

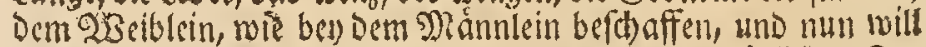

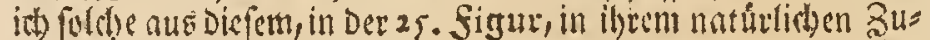
fanimenthang und Rane vorfeltia nadien mabey jevod ju erins nern, Daf Die Sunge uno S5arnblafe mit \&ufft angefüllet worden, alsich bie re Sheile abgebild et babe. Dic sunge $n n n n$ laffet fich

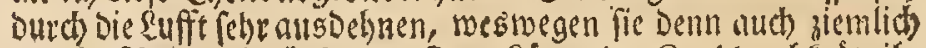
gros erfocillet, Dod fonmt fit an sange Der Sinoblaud trote it): rernicht gleith. Ser áfferen Flácbe nad focinet fir aus lauter erthobenen, aber fant sunden Bláslein ä befteben, Die aber uns gleicher (3roffe find, aud lauft ourch feibige eine fratte sloer, die (idt) in verfdiedene Eleinere Alefte bertheilet; Der Farbe nad) ift fie mebr fieifd fárbig als an andern. Brofljen ben sungenblåts tem, feben wir das Soev $d$, mit den aus felbigem entfuringenden.

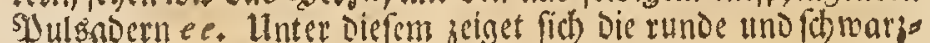
grume Gollenblafe o, und $p$ p fino die yruffen \&cbirlappen, $q$ aber if Das Eleine, ruthe und rundgeformte soil. Son den beren Geilen befommen wir hice num dic eine bey r zu felsen; // ift ber פRagen woran die binnen Sarmer hangen, von weld)en fid nue Der mit u bezeidnete Sheil zeigct, rocldoer in Den P)?aftoarm $t$ gebet. Die Sarnblafe vo vo ift nitbt uur alleine wegen il)rase

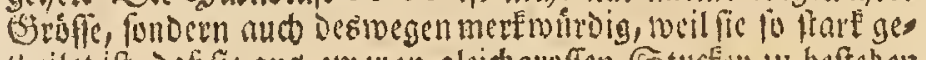

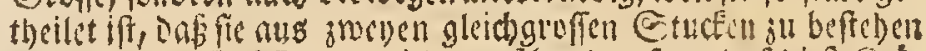

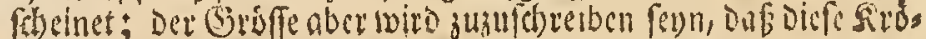
te melor Sorn als andere Stren fammeln, uno fid beffelben in ifrer Dertheidigung bebienth fan, wenn fic fulden befunntets maffen vonfich furugct.

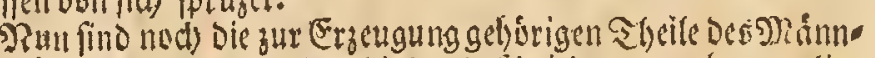
lcins úbrig, weldy unter Den bisher befortibenen verborgen lie: gen, uno von folden losgemactet in oer 26, fig. burgeftell et wer

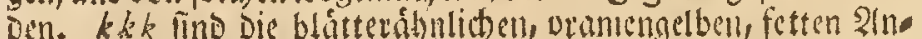

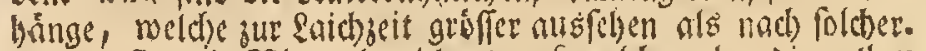
SRit i $i$ fino bie Siteren bezeidnet, auf weld sen vben Die gelben (S)ilen rr liegen, Die jumenlen auth groffer ober Eleiner uno mit einigen Juncten befurengt erfdeinen. 23 as bie beeden Ena= menblosilein anbelanget, fo beftehen foldhe mieder, wie in Der sinublaudbtróte nur blos aus cillemeanal, der aber bier fo gebus

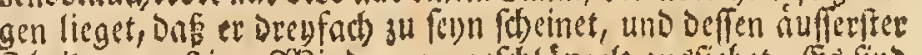

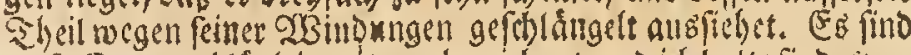

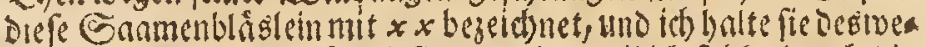

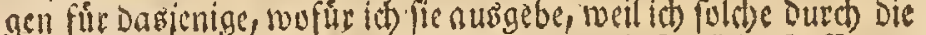

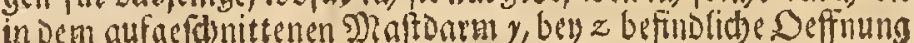
mis \&uft angefíllet und alfo zu felsen befummen babe. Erft ge Dachtc Definung iff fefre flein, wenn man fie alfo finder will, fo mus man bie und Da in Dem áuferfen uno aufgefonittenen Stuce Des 5)iaftoarmb Durd blafen diefelbe fo lange fuct)en, bis inan Whatnimme, Daf fid Die Gaamenblostein mit Sufft anfüllen.

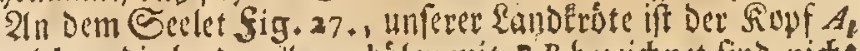

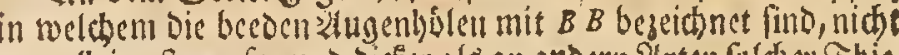
nur alleine ftumpfer und Dicetento an andern Iften foldoer Shie Ie: funtern es fino and Die Ginvden Der Gobened und Fúffe

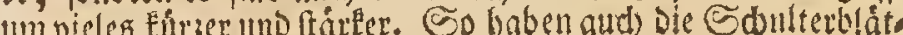

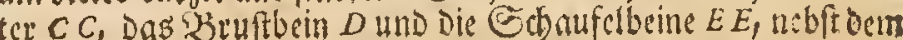
Siacforab in etwas eine andere Furm. Sie Sufftbeine aber $F F_{\text {, }}$ Gheinen lammt Dem langen bajwifden ftebenden Sowanzbcin

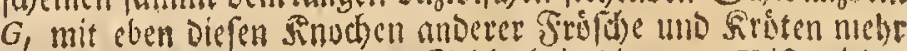

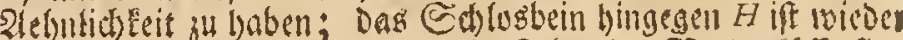
gar fehr unterfoleder. 2In Den vicr Zethen Der Z3orderfúfe, fino wie au ben fúnfen Der bintern nidst mebr finuden, als bey ans Dern acsiblet werben: Dud ift lier an Dim bintern Jus nuch sis

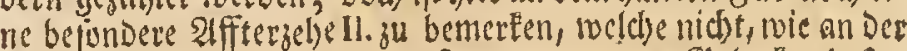
Fnoblautherite homartio if, fondert aus zrocy Gelenten beftes tot 23 as Den uben berubrten Gtein anbelanget Den unfere Srute im Supf fúlsen foll, fo babe id in fe(bigem nid)t einem

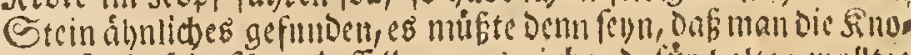

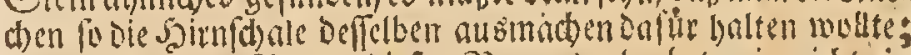
Dud ber wenige Siaum diefes Bugens erlanbet mir nikbt cil mehreces bievon zu fagen, westweren ids benn foldes auf eine andere Selegenbeit berfpare.

$$
\text { (ะ) } \mathfrak{R}
$$

oer Siftorie oer blateridben Lanotróte $2 c_{4}$ 


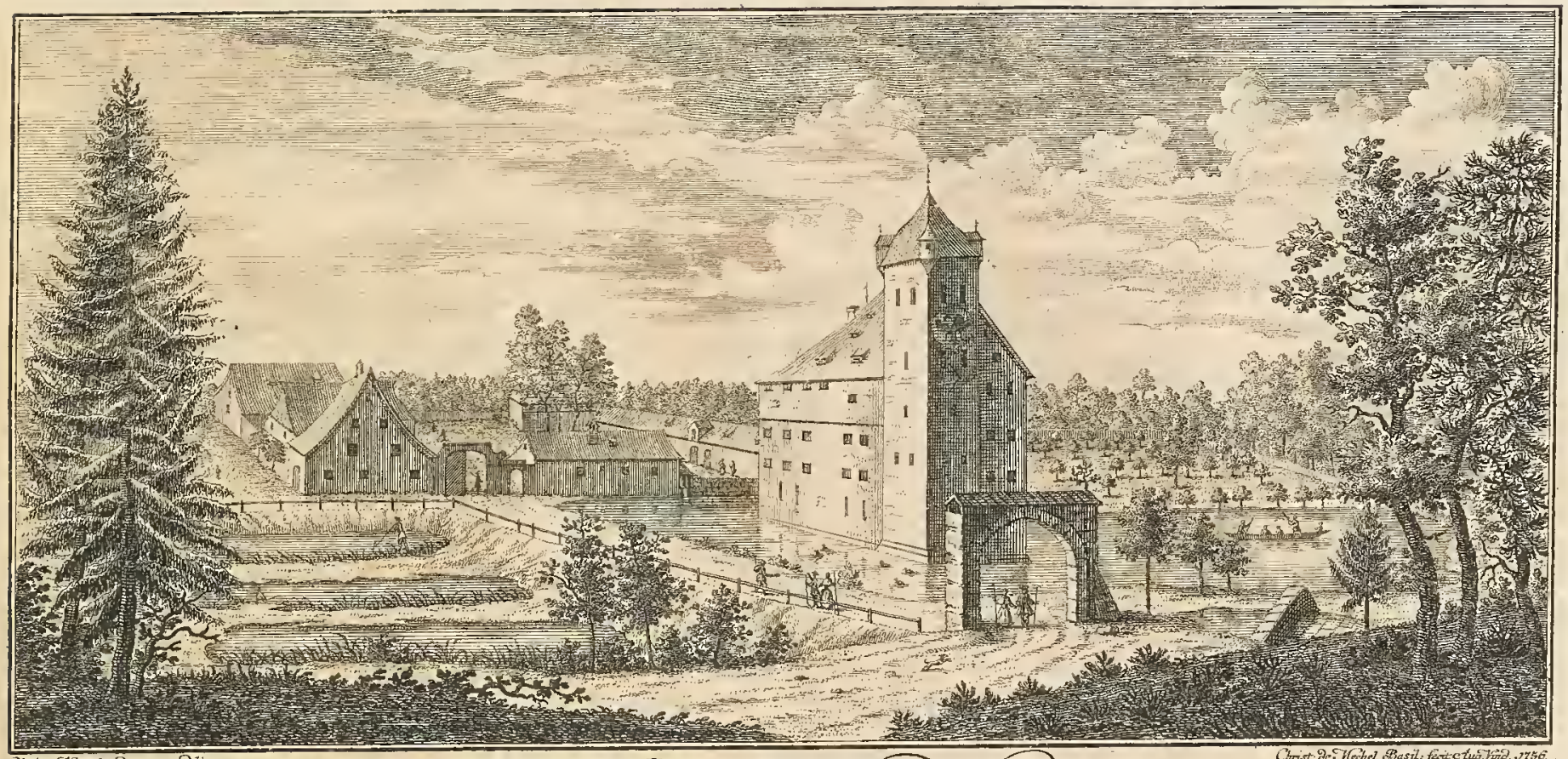

Die Unter=CBurg bey C Vurmberg.

HISTORIA NATVRALIS

RANARVM NOSTRATIVM. SECTIO VI.

BVFO VULGO IGNEVS DICTVS, SIVE BVFO AQVATICVS MINOR, RVTILIS MACVLIS IN IN. FERIORE CORPORIS SVPERFICIE INSIGNIS,

DDet

(ie

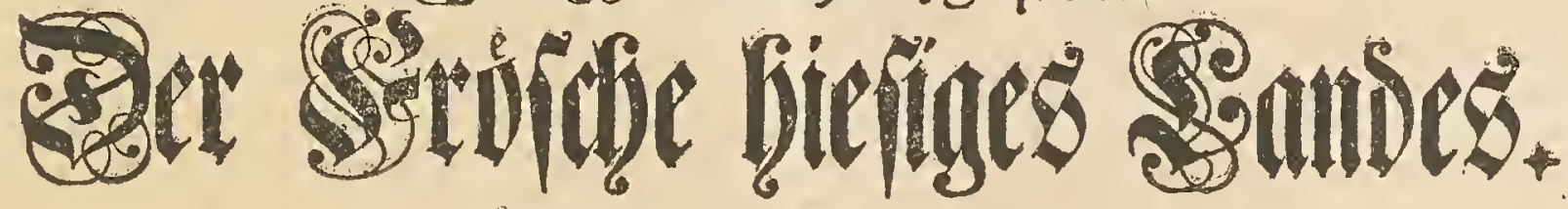

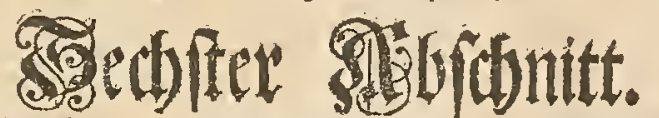

\& trote, fo an ber untert Geistinge mit fetterfarben

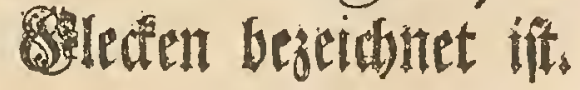

\section{$C A P V T I$.}

Generatio bufonis ignei.

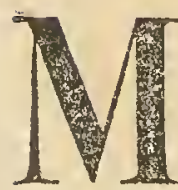

entionem feci in hittotia bufonis allium redo. lentis, p. 71 . bufonis etiam ignei, dixique me eundem heic loci femel tantum, \& licet iäm abeo tempore outo elapfi fuerint anni, nusquam anıplius vidifie, hitcque ine dubitare, vtrum illum hoc in opere effem defcripturus; fed accidit, preter omnem fpem opinionenciue meam, vt poftmodum; bis verno tempore, tot eiusmodi bufones

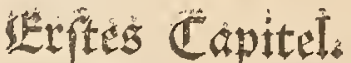

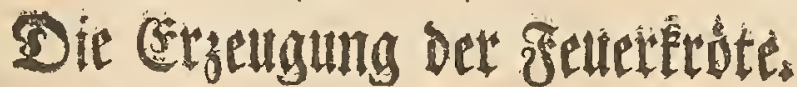

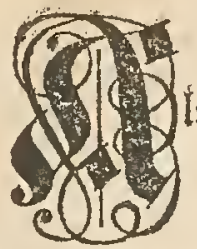

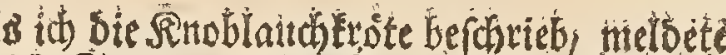

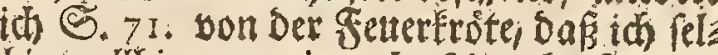
bige alltiter nur einmal, feit adht Jabreñ aber intht melfir, su BSefichte beFonnten

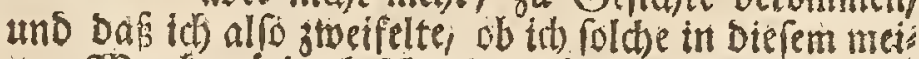

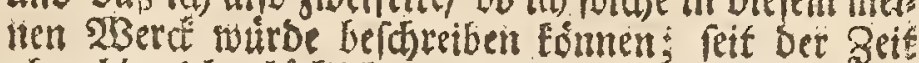
aber bin ith glhiditifer geweren als id vernuthet

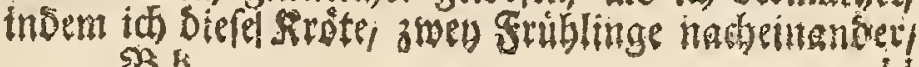


öbtinuerim, vt nunc plenam eiusdem tradere pofim hiftoriam.

Eft bufo hic, ex quatuor illis mihi notis fpeciebus, aeque ac rana arborea ex tribus a me defcriptis ranis, minimus, perfüafunique habeo, licet vitra decem viuat annos, eundem nunquam maiorem ralla viridi red. di, quin eandem vix magnitudine effe æequaturum. Repræfentaui vnum ex maioribus "Tab. XXIIT, icone I., foemellam, multaeque dantur ranae arboreae, hunc craffitudine magnitudineque fuperantes. ...

Originem germanicæ appellationis, qua igneus bufo dicitur, vix aliunde deriuandam effe puto, quam a rutilis illis vivideque aurantiis maculis, quibus in inferiore corporis fuperficie, Icater exornaturque, in quo confentientem habeo LIBAVIVM, *) fequeritem in modum de illo differentem: quia fub vintre plerumque flauities cum rubedine coniundt eft, fiamme a ex colore lycbni, flammam talem exbibentis, a rulgo eft diEa, (rubeta) vbi vero dein addit, nomen latinum $R u-$ beta, quad fpeciali prerogatiua vendicare fibi bec rama videtur, non a rubis tam, quam a rubore oriri, omino ipfi affentior; minus vero, quando dicit, appellari illam hoc nomine, quod rubus vepresque fervet phyfalo fanctius, tanquam'natales proprios. Licet vero de alia, non de men, fermo ipfi effe videatur, rubeta, dum dicit, vivere illam in ficco maxime, mi. nusque boc aenus in aquis deprebendi quam caetera omnia; nafci non in terra folum, fed है in folidis lapidibus: ego tamen ignoro, dari rubetam bufonibus terreftribus annumerandan; fi vero eiusmodi detur, perfuafum quidem habeo, parere eandem, perinde ac alios a me defcriptos bufones, oua fua in aquis, neque in terra folidisue nafci lapidibus. Sed concedam licet dari etiam rubetam terreftrem, mea certe aquatica eft, verifimileque mihi videtur, LIBAvivm veram illius minus habuiffe notitiam. in folder Minge enfalter, Daf id nunmebr im

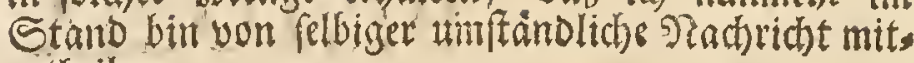
zutbeilen.

B:B if Diefe Rrote unter Den vier mir beEamnten Sevtenarteny, fo mie Der Raubfrofo, unter Den. yon nir befdriebenent orenerler) frófhen, Die Elempte, und ich glaube, bafi wern fie auch ein श्tler yon mehr als seben Sabren erreichet, felbige Dod nie mals groffer, ia faum to gros als ber Raubfrofí) twerbe. Sluf ber $X X I I$. Tabelle babe id) cine Det aroffen in Der I. Figur vorgeftellet, is ift felbige ein Beiblein, und es giebtwohl Renufróiche, welche von Eeib noch ftårfer und amiefinlicher als Diefez find

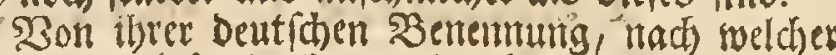
fie bie Feuertrote beiffer, meis ich fermen andern Ut: forung anzugeben, als weil fie auf ibrex ganzen Un, terfáche nit fóonen feuerrotben, ober bodjoranien gelben Flecken befprentget uno ausgesieret ift, uno bieriums ftimmet anth gibavius mit mir iberein, weld)er von ibr also (d)reibet: *) meil fie am $\$$ Batch gelb uns roth ift, wirb fie von Dem gemeinen 3 olde, indem fie mie bie Slamme cines Rid)tes gefálbet i|t Die Geturererote gementmet, und wenn er biefen nod benfiiget, baf man aud) Dafurt balte, Der lateinif(b) Rame Rubeta, meld)er ibs befonders bengeleget wiro, Eomme nidt fo wobl von rubis ben Bronbeers fránthen alš von rubore ber Risthe her: fo ftimmie

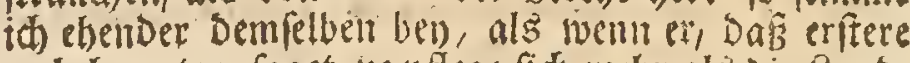
u behouptew, faget, lie pflege fid) mebr ale sie Rallos

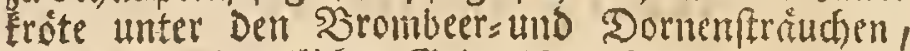

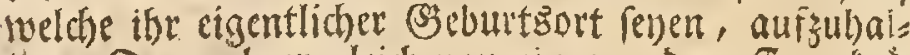
ten. Denn ob er gletch von eitter andern Fenterter te, als idh, zu reden focheinct, indem er melopt: fie Galte fich vornebmlich im Troctenell auf, werde auch meniger als alle andere Arten im 23 affer gefunden, und wuirde nicht alleiile in ber Erbe, fondern aud) in veften Strinen ergeuget: fo toeis ic Dod nicht $\mathrm{sb}$ es wohl wirtlid eine foldhe Feuertrote ssbe, welche un:

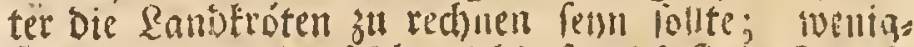
ftens wem es eine foldse gielt, fo wirs fie bod) and, gleich Delr andern yon mir befifriebenen Sirotenar tert, ifse Raid) im $2 B a f f e r$ von fich geben, uns vitd) in Der Erbe ober in weften Eteinen erzcuget merdent. Dod es mag mun aud cine Ranbfencrtiote geben 

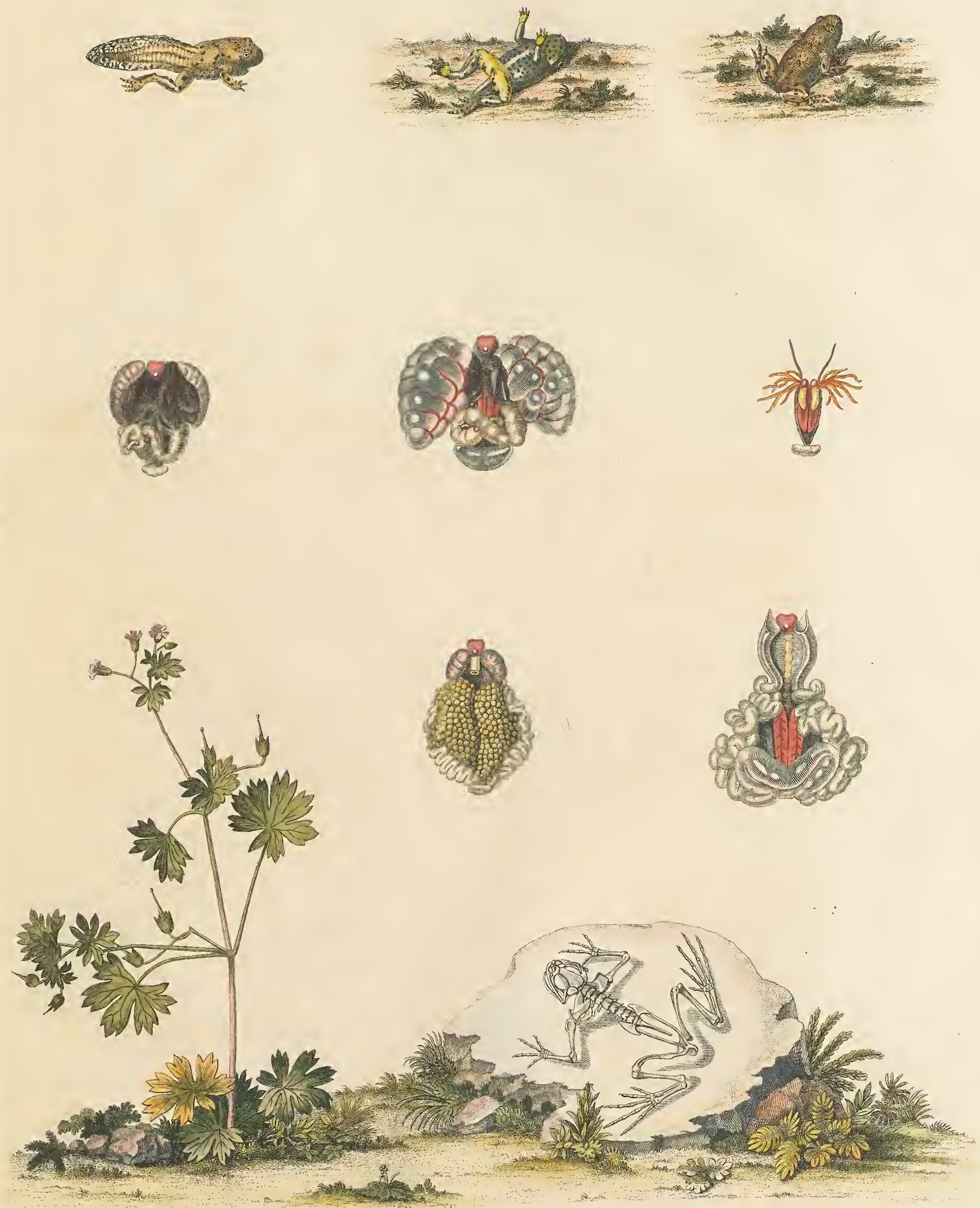

Fig.is.

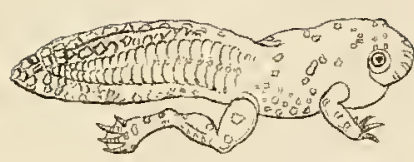

Figin

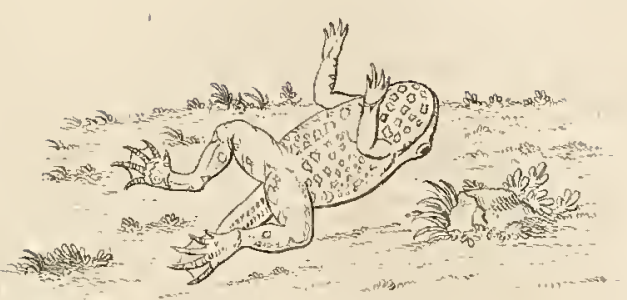

Fig. is
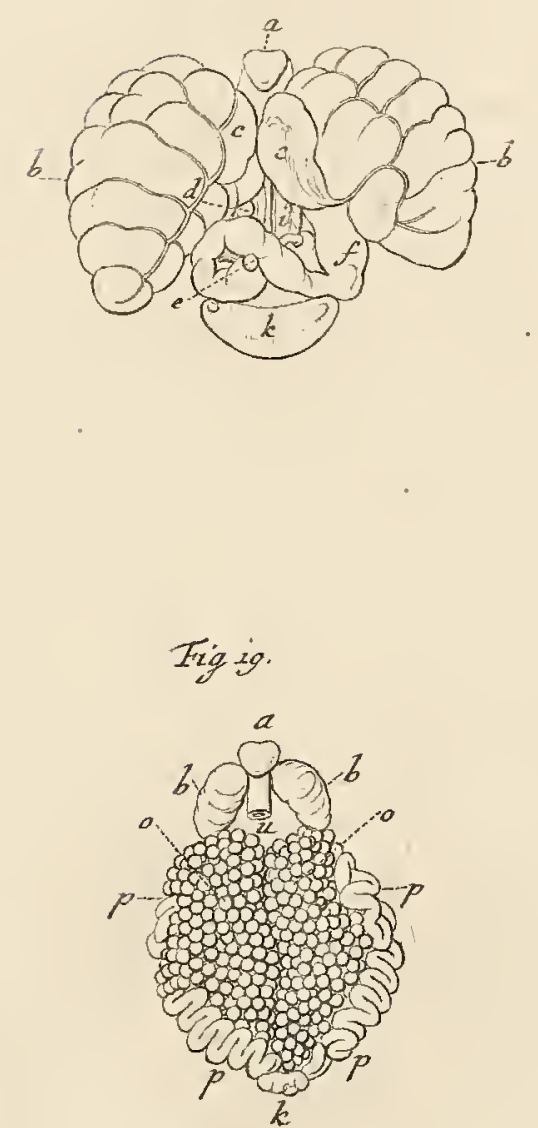

Fig.is.

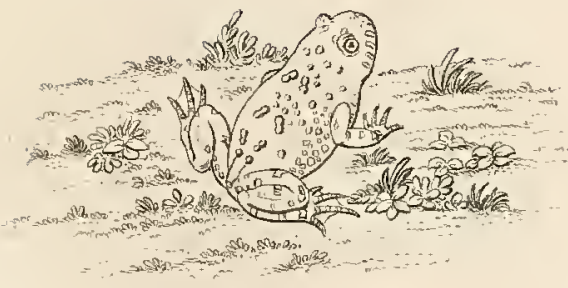

Frig, is

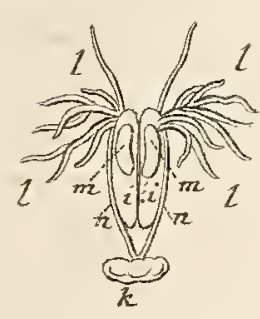

Fig 20.

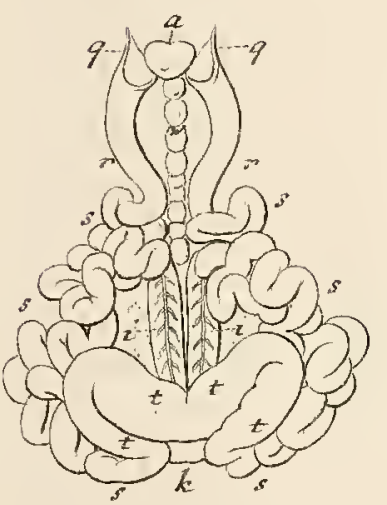

Fig. $2 x$.

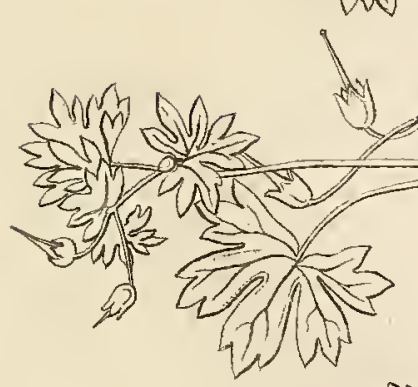

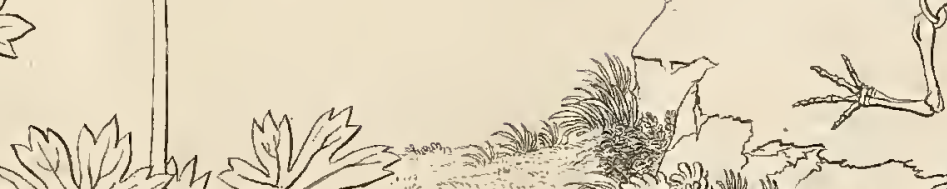

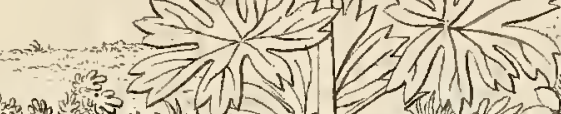





\section{-}

Crura pofteriora, quorum ope rubeta mea Galtat natatque, fatis fuperque indicant, effe illam aquaticum potius quam terreftrem bufonetn, quum quinque digiti pedum, aeque ac digiti pedun anatum anferuamque, ad extrema vsque, membrana quadam nectuntur, quæ ipfam natationem haud parum promouet; quoniain vero multo minor eft bufone allium redolente, minorem it lam appello bufonem aquaticum.

Quemadmodum vero bufo aquaticus maior, fiue bufo allium redolens, rarius apparet; fic \& minor hic difficulter reperitur; minori tamen capitur negotio menfibus Maio lunioque, quibus tempus, quo generationi nauat operam, appropinguat, rarius vero A prili. Verfatur maxime dicto tempore in turbidis for farum paludumque aquis; fed \& in hifce eundem vix fine adhibita deprehendes cautione; adeo enim timor illum reddit prouidum, vt vix integrum caput, fed protuberantes tantum oculos naresque, ex vndis exferat, ficque omnia e longuinguo eriam a propinguancia illico conf iciat fubitoque in inferiora ie praeci, et 10ca, nulla fere in aquae fuperficie facta agitatione.

Dicit L r в A vivs laborare rubetam fuam vocis defectu; mea vero gaudet voce; non quidem foemella, aft mafculus. Edit feilicet furdum fed citius iteratum grunnitum, \& interdum fimili ratione productum tonum, rifum fere referentem, minusque ingratum, quan reliqui fundunt bufones, nec non lenius acutiusque fonantem; fed sulla tum, neque in gula, neque prope os, vt aliis in ranis bufonibusque, conficicitur mutatio.

Minus diftant protuberantes oculi in capitis fuperficie pofiti, quam in reliquis; hinc vero eft quod bufo hic caput fuum, aera haufturus, parum ex vdnis ex. ferat. Notari vero meretur, ipfis in oculis, pupillam in obfcuro femper apparcre orbicularem, ceu ex $I$ paret icone, in aprico vero ita efle contractam, vt perfectum referat triangulum, id quod 4. indicatur isone, exin vero colligo, abhorrere bufonem hunc diurnam lucem, forteque noctu tantum terras petere. Ambit triangulum, ab iride formatum, tenuis aureusque limbus, reliquus vero oculi globus, fufcus magis quam flaus eft.

Tingitur vniuerfa rubetae noftrae fuperior fuperficies fpurco oliuae colore, in quibusdam faturatiore in aliis pallidiore; fatet infuper illa, in corpore aeque ac cruribus, pluribus diuerfae magnitudinis puftulis tuberculisque. Ornant eandem prope os, fuperiore in maxilla, obfcurae nigraeue maculae ordinatim pofitæ, fimilibus fere confperfi etiam funt pedes quatuor, eorundenque digiti. Gratior amœniorque afiectu eft fuperficies inferior, cuius vero exiguam tantum in $I$. icone cernimus portionem, prius tamen quam oculos noftros ab hac, in aliam conuertamus, notandum eft, monftrare illam, effe rubetam hanc agile vegetumque ober nidst, fo iff Dod Dic meinige mebre eime WBaffers frote, uno welleicht bat Sibavius von felbiger feine riditige STadriohten gehabt.

Die bintern Spring und Sthwimmfitfe geben

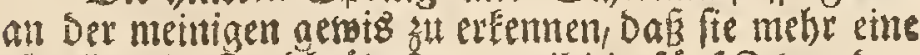

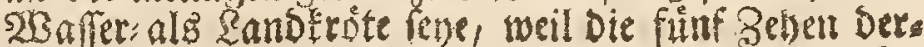
fellen, bis an thr cufferftes (Ende, gleid) Den (Ens

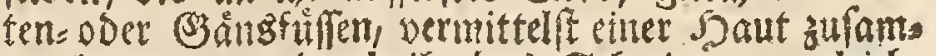

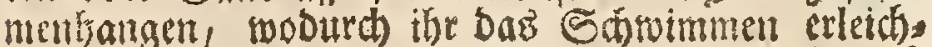
tert wito; weil fie aber Die Sinoblaubtrote, bie id cbenfalls fur eime $23 a$ ferteróte angegeben, an (3rós (e nid)t erreidhet; als nemme id bierelbe die teine 53 affertióte.

SIleichnte mut aber Die groffere SBaferterote, ober Die Sindoblauch Erote etwas felten sum 230 rethetn fummer, fo iff aud Diefe Eletnere eben nitht allezeit leicht su finden; bod fon man ibeer ant eloeften im

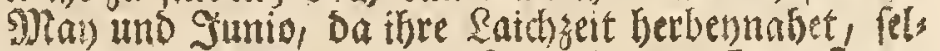
tencr aber im 2lpril habbaft werben. 34 erfít ges

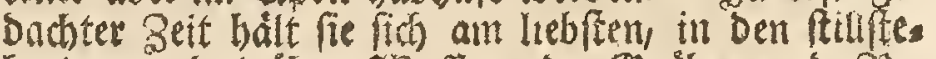
henden und trubet 23 afferit, Der Bråben uns Sie: genpfuizen auf. Dod) bat man fie aud ba mit ver. ficht but fuchent: Denm Die Furcht madit fie fo fiblau, baf lie nidht leicht then volligen fiopf, fondern mut ilste erhabene fungen und bie slafenlódier uber bie Sherfláde bes sBaffers hervorragen lást, wobeg fie alles was fidh ithr aud nur won fertie nabst, fogleish erblicket, und alfobald in die siefe fábret, obut ba: ber) in ber Dberfláde bes 23 afiers eine mertlide şenegung zu verurfachen.

Libovius faget, feine feuerforote aebe Eeinen Saut von fich; bie meinige bingegen lägt bergleidsen bóren: Dod nidht Das 23 eibletil. fondern Das Mánts leit. Es beftehet folcher in einem etwas fillen aber eflichemal hinter einander fohnell wieberbolten ङुur. ren, zumeilen aber auth in einem auf gleiche sibsire bervorgefraditen lunten, fo fait einem Bercibter gleid) fommet, uno nidht fo unangenebm als bey an: Dern Nroten lautet, indem es aus einem fanften uno bơbern Thon aehet; woben man aber all ber sethle Der Rrote, oder un Den SMund Derfelben, feine be, fonsele zerantoerung, wie an anhern frofd Sirotenarten toabrnimmt.

Die beeben erbabenen 2lugen fehert, auf Dex

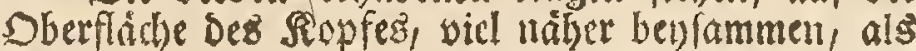
ben nubern; und cben besmegen bat Dicfe ferote nicht nothig, ibren Ropf, wemt fie Eufft bolen roill, aus bem 2 Bafir weit hervor zu freden. In Den 2luget felbft aber ift Diefez als was befonderez zu bemerfen,

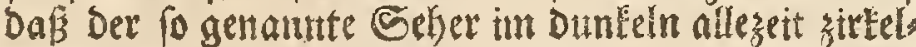
runb, wie an Dex I. Sigut erfdheinet, im bellen Richt aber fidc fo zufammenstehet, Das ex eit ordentliches Drenece vonftellet, wie ans der 4. Sigut zu erfeben,

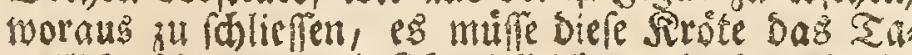

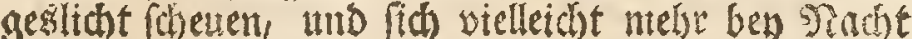
auf Das land begeben. Das von Der rogenamteil SRegenbogenbaut formirte Dreveck, if mit einet feís zarten golbaelben Sinie eingefaflet, Der ubrige Sheil bes allgapfels aber erideinet nubbr braun als getb.

2fuf Ser ganzen Oberfláshe fúfret unfere Rròte einen fotbicht olivenfarben (Brumo, Der in etmigen Dunteler, in einigen aber autch lycller iff; ferner setgen fich alf felbiger, fo wobl an Eeib als an Detr viev

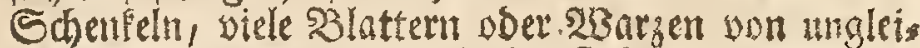

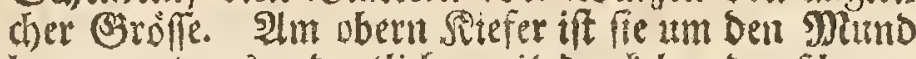
berum, etwas ordentlit), mit Dunfeln oder folwat zen Flecten ausgerteret, 1tito mit eben Dergleidhen find anch bie vier sulfe famme Den Beben befisenget. Shre linterfiche hat ein liellideres und friforeres $2 n^{3}$ feben, oon oveldser wir aber in unferer I. Signt wentg

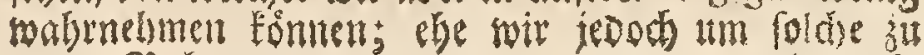

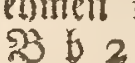




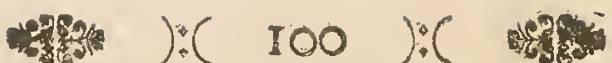

animal, quin aequat, ino vero fumerat, in natando aeque ac faltando, terreftem celeritate tanam.

Quum rubeca haec lucem diurnam minime amare videatur, hinc etiam matutino tantum vefpertinoque tempore, peracta generatione, in terris, prope aquagia offendicur, quibus, vbi propius quicquam accedit, confeftim fe occultat. Quodfi vero $a b$ is arceatur, ad terram fefe applicat, quo melius lateat minusque cerntur; vbi vero eandem turbaueris tetigerisque adeo mira formam fuam mutat ratione, ve credideris, beftiam, quam modo oculis vidift, in aliann prorfus fuiffe mutatam; atque tum fimilis eft 2. iconi. Ita fci licet caput, quatuorque cum pedibus crura, in dorfo, aluei inftar contracto, collocat, ve fuperficies potius inferior, aurantio, quam fuperior, oliuae colore tincta, conficiatur, atque ipfa colorem faltem mucaffe videa. tur. Hanc formam per decem fere momenta feruat donec fe tutam rurfus arbitretur; fi vero eandem denuo turbes, ex crafiore crurum pofteriorum parte fpoman emittie faponato fimilem, nullum tamen fundentem foetorem; fenfimus vero D. HvтH, ego atque alii, vbi eiusmodi rubetam viuam diffecabamus, in oculis aeque ac naribus, rodentem pruritum, qualem qui coryza laborant, percipere folent.

Vt vero etiam inferiorem huius rubetae contem plari poffinus fuperficiem, eanden icone tertia fupinam repraefentaui; haec vero monftrat, effe non folum omnem corporis inferiorem fuperficiem, fed \& quatuor crura, pedumque plantae, rutilis vel aurantiis infignia maculis, Quodfi vero quis putet, conftituere maculas hafce primarium colorem, intermiftus caeruleus atro cinctus, color, maculas efficere, dicendus effet fed quicquid fit, appellatur bufo hic ipfas propter maculas hafce, rubeta ignea flammeaue. Aft enim vero variant in rubetis hifce, oriundae ex binis illis coloribus maculae, colore \& magnitudine, inque teneilis pallidiores apparent. Nutriuntur hae rubetae infectis tantum.

Solent rubetae hæ folemniter menfe Iunio coire, ouaque parere. Copulantur equidem Aprili quoque \& Majo; fed parum durat copulatio hæc, quum frepius rurfus feparentur, atque adeo illa, verae potius dicenda fit praeludium. Vix dimitrit malculus foemellam fuam Iunio menfe, fed fortius eandem, ad modum maioris aquatici, vel allium redulentis bufonis, circa lumbos comprehenfam tenet, quemadmodum 4 . indicat $i c o n$, vbi foemella litteris $a \boldsymbol{a} a$, mafculus $b \boldsymbol{b}$ fignatus eft, huius vero bina brachia, quibus illam complectitur, oftendunt litterae $c c$.

Propagationis rationem vidi annis I754 \& I755. deque ea fequentia notaui. Primum, quod attentius, hoc ob negotium, obferuaui par, venereis calluctatio-

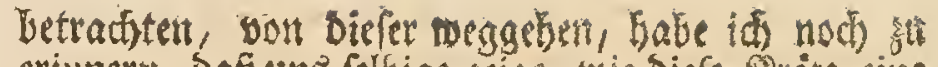

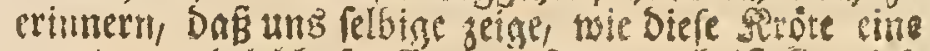
muntere und lebbafte Ereatur fene, much if fie mitss lich, fo wobl menn fie im sibafer founimmt, als auth

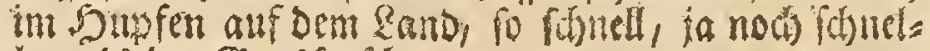
let als ber Brastrofi.

* Da biefe Futertrote feinisuegs bes Tages Freund zu ferm (heinet, fo trifft man fie and mut

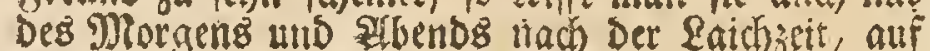
Dem \&and, obnfern der $23 a f e r g r a b e n$ an, in melche

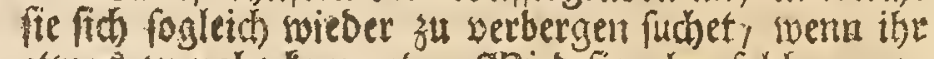
etwas zu nabe fommet. WBiro fie aber foldse zu ens reiden verbinbert, fo budef fie fich gan platt anf Die ErDe nieber, um fich atu verbergen und gleich fant entiditbar a machen: beunruhiget man fie aber und noird fie etwann berúbret, fo verandert fie ihte Form auf eine fo befondere siseife, DaB es DaB 2It. feben getwinnet, als batte fid bie Creatur, welche tman Den Sugenblic bor fith gehabt, in eine andere verwanbelt; und in eben Difer Stellung erfheinet fie in unferer 2. figut. Sic leget namlich ifren

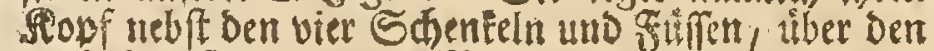
nach ber form einer Miulde ausgebolten und zuz

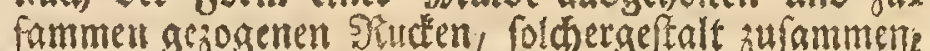
Daś man mebr Die oranienfarbe llnterfláche, als ber divenfarben (3ikuno Der obern zu feben belommet, und fie alfo wentigfens ibre Sarbe verrindert zu bas ben focinet. Sil biefer Stellung bleibt fie wobl bet.

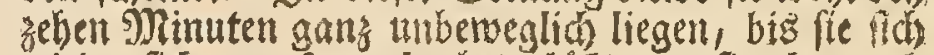
wieber ficher zu fenn alanbet; läbt man fie aber noch nidst in SRube, fo treibt fie auts Dem Didten Sbertbeil Der hintern Sdjenfel eimen Sdhaum heraus, Der Dem Seiffengefor gletcht, woben man zwar fetmen (3). ftant empftidet ; bod) aber hat fo mobl Serr $\mathfrak{D}_{2}$ Suth als idh und andere, went soir eine folche Sero:s

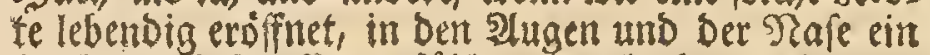
Sudten und 93 ciffen gefilblet, Dergleid)ent Diejenigen zu empfinden pflegen, meldye mit Dem Schnupen be* bafret into.

Damit wir aber auch bie intere Glát)e biefet Rroo verbt feben Eonnen: al babe ich felbige, in Der 3. Jirut auf Dem studen liegend vorsefillet, und Datwerden wir gerbabr, bafi nicbt nur alleine Die völlige linterfláche beź seơrpers, fondern aud Die vier Schentel nebfe ben fusfolen, mit fohomet feterrotben, oder oraniengelben flecfen gesieret feyen. 233ollat wir aber diefe Glecten fir Die SOrundfarbe annebmen: fo miste Das zwifhen benfelbigen befinds lithe fichar: cingefafite Blaue fite flecten angefeber werden; Doch genug, Diefe beede Garben madien chen Daf biefe surote bie Beutererote genennet wird. Es baben aber bie baber entfisebende Fleten, niche

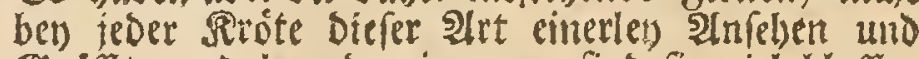
(Stroffer, und ben Den jungen, find fie viel blaffer. Sbre Salyrung befebet in lauter Strfecteth.

Der Monnt Sunius iff Die eigentliche Beit, stit welcher fich Diefe Siroten paaren, und fodenn laider

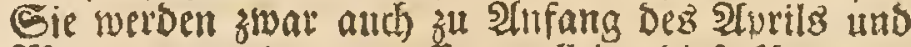
9)(ai) gepaarct angetroffen; alleme biefe syaaring if von feiner Dauer, weil fie cinander ófters biteder verlafien, und folche nur ein Borfpiel Der wahren z"I

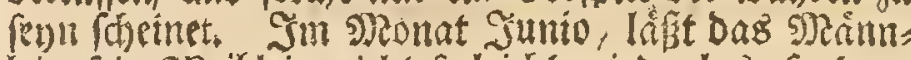
lein fein 23 siblein nicht fo leicht nieder los, fottoer: es brilt felbiges befándig, wie die grofe $23 a f i e r=$ doer Sinoblauch Erote, binten un bie lenden vefte, wie bie 4. Gigur weifety wo a a Das 28 eiblein uno b 6 Das Mlännlein anjetget, Deffen beede Alrme, mit

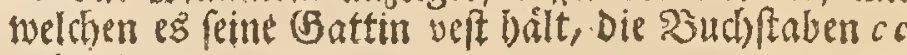
andecuten.

$28 a 3$ die 2ret anbelanget, nad werifer biefe

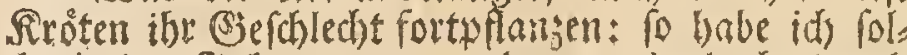
dhe in Den Jahren 1754 . und 1755 . beobadjet mind 


\section{* $):($ Ior $):($ sos}

nibus operari incipiebat die decimo feptimo Iunii, hora pomeridiana prima, vbi iam per octo dies fuerat copulatum. Quum vero haec bufonun! fpecies omnia velocius peragat, fic et oua illius citius foecundantur emittunturque, ita vt vtrumque opus ab hoc pari iam hora quarta, atque adeo fpatio trium horarum fuerit peractum. Durante hoc tempore duodecies iterabatur foecundatio, ratione iam enarranda. Vbi foemella amatorios fentiebat dolores, in fundum fefe demittebat, mafculus vero valde tum corpus fuum contrahebat, illud tamen non aeque ac mafculus maioris bufonis aquatici gibberum reddens. Propius tum ad foemellae anum ann adinoto, pofteriorem corporis fui partem velociffi. me ab vno alterum verfus motitabat latus, quod dum fiebat, paruam fpermatis foemella excernebat portionem, mafculus vero immota tenebat bina fua pofteriora crura atque vt antea $a b$ inuicem diftantia. Simul ac vero mafculus primam fpermatis portionem foecundaverat, exporrigebat foemella bina propius fibi admo. ta crura pofteriora fua, vt et ipfum corpus, in longitudinem. Defcendebat tum foecundata fpermatis portio in fundum, atque dein componebant fe rurfus bini bufones ad formam 4 iconis, poft quietem vero quindecim momentorum iterabant ludos fuos, ad duodecimam, ceu iam dixi, colluctationem vsque.

Separabantur illico poft excretam vitimam fpermatis portionem, atque tum duodecim in vitro numerabam eiusmodi portiones 5 iconi fimiles. Conftabant nonnullae earum viginti quatuor trigintaue ouis, quaedam vero paucioribus: in aliquibus enim viginti tantum numeraui. Quemadmodum vero ouorum, fic etiam por tionum fpermatis, quae poftmodum, dicta ratione, ex aliis obtinui foemellis, differebat numerus. Ipfum fperma fundo femper incumbit, neque vnquam, nifi fortuito id fiat, in fuperiorem aquae afcendit fuperficiem; hoc tamen habet fibi propriun, quod in ipfo contenta oua maiora fint illis aliarum ranarum bufonumque, licet nofter bufo omnium fit minimus. Erant oua haec rotundae formae colorisque pallidi vel flaui, in quo macula Irotabatur fubfufca tertiam fere fuperficiei occupans partem. Gluten pellucidum, quodlibet cingens ouum, initio quidem contractius eft, ceu 5. monftrat icon., elapfis vero binis horis magis iam erat dilatatum, ut 6 indicat, vtrumque vero eodem, quo foemella oua haec peperernt, obferuaui decimo feptimo Iunii die. Poftero mane, dieque adeo decimo octauo eiusdem menfis, ma. ior erat ouorum aeque ac glutinis moles, quin perierat prorfus fere rotunda illorum forma, quum, nonnulla eorum 7. id referente icone, eam paffa erant impreffionem vt dimidium referrent iuglandis putamen; nonnulla vero rotunda quidem erant, fed appendicem monftrabant verrucofani, ita, vt piri fere haberent formam; at. que haec foecundata, illa uero minus erant foecundata.

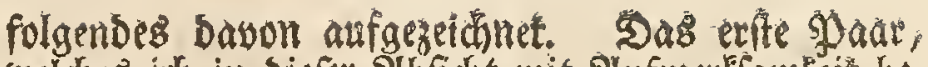
welches ith in biefer शrbficht mit NufmerEfamteit be: obahtet, fieng fein Rtehesfpiel Den fiebenzehenden Ju nii, Nachmittags um ein Lhr an, nadibem felbiges bereifs acht Tane vorber gepaaret gemeren. Bjeids: wie aber biele Sirotenart in allen ihren Bertichtuts gen fehr burtig ift: fo gebet auch bie sefruchtung unt Geburt Des Raidjes gefdimitio non itattem rop Da beedes ben Diefem Paar fabon um vier ubr and alfo in einer Beit von bren Stunden vollbracht wat: Während Diefer Zeit, sefhabe Die Befrudtuth sut stwolf verfchiebenen malen, sobet) es folgendermaffert

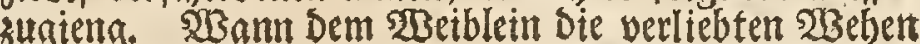
anfamen, fo legte es fich auf Den SBoden, Dấ Männ.

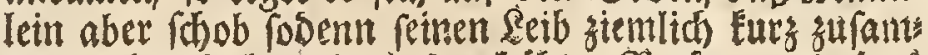
men, obne Dabey einert fo erboften Rufen, soie Das

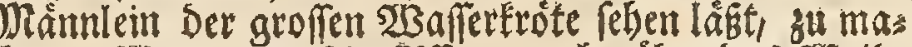
den. Wenn mun fein Sfffer, nabe uber Das $23 e$ eib. Iein feinem zu fteben kam, fo bewegte es feinten hitt: tern Theil gans fonell von einer Seife zur anderty wåbrent foldiem aber gab Das 2 Beiblein einen Eleinent Silumpen feines Eaiches yon fich, woben Die bintern Schenfel bes Männleins gant ruhis blieben, und vie fonft von eimanber ftunben. So balb aber Der erift: gebohrne Silumpen von Raich Durh Das s)eamtein befrudstet worben, fo bald fired te bas 2Beiblein feime bintern Schentel, weldhe gans nabe an einander las gen, fanmt bem Seib, ber Sarnge nach aus. Det fit

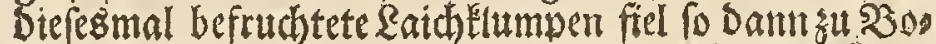
ben, beede aber mahmen hterauf wieder bie Stellung Der 4. Figur an; nachoem fie aber etwan funfzethen Minuten ausgerubet hatten, fiengen fie Das nåmlidy Epiel roteder an, bis fie foldhez, wie bereitz gemeldet, zmolfmal getrieben batten.

Eo balb Der Iente Rlumpen bes Raiches gebolit. ren war, to bald verlieffen Die beeden Rróten plóslid einander, worauf idj in Dent Slas smolf Situmpert Des Raiches áblte, welche fo, wie fie bie 5 Sigut Dars fellet, ausfaben. Einige berfelben beftunden atts siet und zwaltzig bis Drenftg Enern, einige aber anch aut

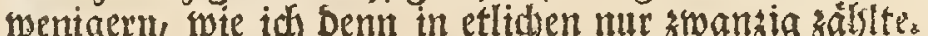

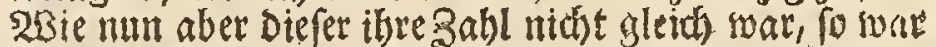

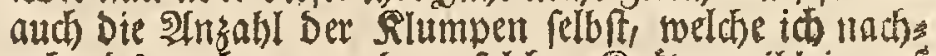
gekenos auch won anbern folchen Srotenweiblein auf oben befchriebene $23 e i f e$ erbielte, nidht allezeít gleid. Der Said) felbit bletbt immerzu im $23 a f f e r$ auf Dont BS rund liegen, tumb fommt, went es nicht sufálizer NBeife gefhiebet, niemalen auf Die Oberflädbe; biers innen aber bat er etwas befonderes, Dás bie in relbis gem enthaltene Sorner ober Ever, groffer find als als ler Der andern frófide uns Seróten ihre, obgleid) ges gentwátige Sirote unter ibnen bie fleinfte ifit. Sie filfren ber ifrer Fugelrumben Form groftentbeils eine blalle oder gelbe farbe sum (Grumb, in toeld)er eirt braunlithter SFlecten zu bemerdfen, Der nicht gat bert Dritten Sheil Der Dberfläbe einnimmt. Der Durd). fichtine Sdjleim, movon ein jedes biefer Ever umges ben wirs, iff anfange nidht stiel attzgebreitet, mie bie 5 figur zetget, Dod nad) 2 Berfus zwener Stundent batte er fith, wie aus ber 6 . Sigur zu erselen, rdort mebr ausgedebnet; beedes aber babe ids an felbigem ben fiebenzebenden Junii, an weldem fie Das 20 setb. Iein gelenet batte, sobhergenommen. Den Datauf fol. genden shorgen, und also Den adt tyehenben biefer solos nats, waren fo wohl Die ejuer als Der fie amgetsende

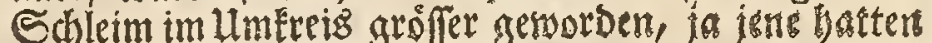
bereits ifje rumbe Form vóltig verlobert, mis.aus bet 7. Sighti: wabrgumebmen, unb faben theils lo einges

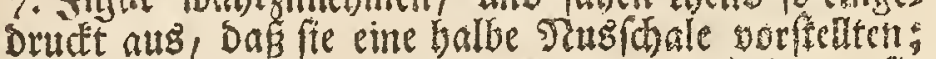
theils aber waren fie swar noch runb, boch gatsen fie

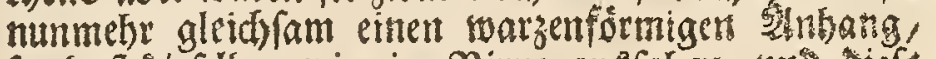

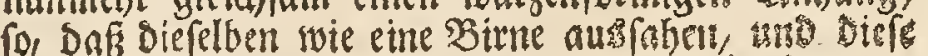
waren Die befubteten, jene aber Die unbefrughtsten. 


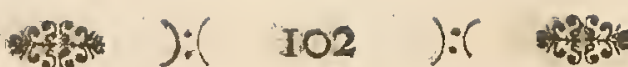

Die vigefimo Iuni;, confpiciebam iam, in ouis piriformit us foecundatisue, verniculum albidun, incurvatum, qui omnem iam abfumfiffe vitellum videbatur, quum membranula illum cingens pellucebat; quodlibet tamen ouum fum adluc circunfundebat gluten; ipfi vero vermiculi motu fuo iam gaudebant; non folum enim capiti caudam faepius admouebant; fed uertebant etiam, fat tamen lente, interdum corpus fuum: quac horum vermiculorum fuerit facies, ex \&. difci potent icone. Vbi vero poftea, fubuiride nunc redditum gluten continens, exterior rumpebatur pellicula, illa fupererat, quae vermiculum conclufum tenebat, ( $F i g_{\circ} 9_{0}$ ) fed hac etiam euanefeente, alia ille adhuc cinctus erat, quam tamen ipfe tandem difrupit, ita, vt die vigefimo quar to Junii, prorfus liber effet; id quod tamen his citius illis tartius obtigit.

Similes erant hi vermiculi Io. iconi, Corpus illorum gracilius aequabat caput craffitudine, acuminata vero cauda eandem cum corpore capiteque habebat longitudinem. Capiti fubfufcus erat color, corpori caudaeque, pallide flauefcens. Differebat caudam ambiens pinnil, ab illa aliorum gyrinorum, acuto quodam proceffu, prope corpus, fuperius aeque ac inferius, confpicuo, cui fimilis poftmodum etiam in dorfo eminebar; pinnae color in cinereuin vergebac.

Licet vero gyrini hi indies alacriores redderentur, hactenus tamen non aeque viuaces. illos effe animaduertebam, ac quidem alios fuiffe iam obferuaueram. Nu. triebantur lentore illo, qui tam in vitri fundo, quam aquaticis in plantis, in eodem contentis, haerebat; has enim ipfas, aeque vt lenticulas paluftres, minus appetebant, vafis fundo femper incumbentes.

Die trigefino Iunii referebant plurimi horum gyrinorum, forma fua, II. iconem, atque tum accedebant fimilitudine ad marinum illum pifcem, quem orbemtnon fininofum appellant; fed forma tantum, non magnitudine. Craflus ipfis quin tumidus erat venter, veficam fere referens pellucidam, in qua nulla omnino confpiciebantur inteftnia; reliquum vero corpus priftinam. feruarat faciem, priftinam longitudinem; neque etiam in capite yllam factam fuiffe mutationem apparebat. Nec aliam poftmodum induebant formam, fed crefcebant magnitudine, ita, vt nonnulli eorundem quinto fextoque Iulli 12 iconis fpeciem haberent, quo ipfo tempore caput oculique, cum craffo pellucidoque ventre comparata, fat erant exigua; ipfum tamen caput perinde ac cauda carnofa reliquumque corpus, quod a ventre feparatum quafi videbatur, obfcuriorem. nunc monftrabat colorem. Verfabantur tum gyrini mei in vi:ri adhuc fundo, vefcebanturque viridi lentore ibidem haerente, hanc ipfan vero ob cauffam rarius puram iisdem affun debam aquam: hunc enim illos comedere lentorem, hinc certior reddebar, quod videbam, loca illa quae arroferant alio induta colore; hinc autem in eam deducebar cogitationem, vefci potiffimum gyrinos hofce teneriore aquatico mufco, factumque hinc fuifle, vt eosdem nunquam, ceu alios gyrinos, in aquis viderim ftagnantibus.
Den zwanzigften Sunit wurbe ich in Den birnfö: migen ober befrubteten (5nern bereits eines weiflich. ten 2 Buirmleins aewabr, weldhes ganz gefrummt Dars innen lag, ben Dotter aber vollig anfgezebret zu habent

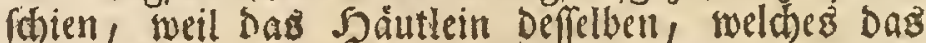
2Buirmlein nod) umgab, Dur(b)fichtig war; Dod lag jebez noth in feinem Echlcim, und Die 2 Burmlein fien: gen fich bereitz zn bewegen an, indem fie fo wohl sepf und Shwang sffters gallz gefhininde zurammen bradten, als and fith manthmalen ganzlang fam unts wanden: wie biefe 2 birmletn ausfehen, zeiget die 8: Sigur. Nachbem Gierauf Die Den Shbleim, Der unters Defifen gruinliche gerworben, umgebende zarte und aufs ferfte Saut geborften war setote fich noch Dieieniagy worinnen Das 2 Burmlein verfabloffen lag (Sigur g) i als aber aud biefe fich verlols, war foldhes Dod) noed in einer andern enthalten, welche aber enolich von ben

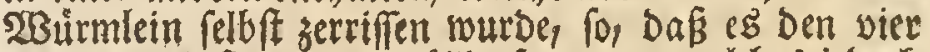
unb swansigiten Junit vollig fren war, meld)es jedoch ben einigen ehender und ben anoern fpáter gerchahe.

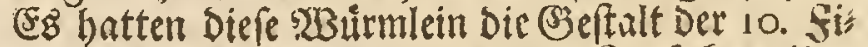
tur. Shr Reib war rabnis, uno Der Sopf Eam ibm an Didfe aleid); Der zugeppizte Schwans aber war fo lang als beede zufammen. Der Farbe nads war ber Sopf bráunlitht, ber Reib uno Sd)manz aber blas: gelblidst. Die ben Sduwanz umaebente Floffe, uns terfaciebe fid in fo ferne von eben biefer floffe ande ter Frofdwurmer, oasê fie nabe am \&eib, oben und unten, einen foizigen Fortfats batte, Dergleichen fich and nachgehends auf Dem siucten zeigte, ibre Jarbe aber fiel in Das gratte.

ob mun aber gleich Diefe ferotenmirmer tunmeki tåglid munterer wurden, fo Eonnte id) Doch zu biefer Beit an felbigen troch nidit jo viel Rebhaftigfeit beobs adten, als an andern. beraleidhen $2 B$ urmern, fonft von mir bemerfet worben. Sjgre siabrung fuditen fie in orm Selleim, Der fo wohl auf Dem Boven Dez Bjla fers, als an bentn felbigem befinolident Wafferyflanzen hienge; Denn Diefe wollten fie, fo wentg/ als bie 23 afs ferlinfen anbeifien, wie fie benn aud immer auf sem Boden liegen blieben.

Den Drenfigften Sitmii batten Die meiften Derfels ben bie Bseftalt ber I . Sigur angenommen, uno Da zeigte fich an ibnen mit Demienigen Seefifd, welden man Die glatte Meertaube nemet, einige 2lebnlichteit: wiewohl nur ber Form nach, Denn Der (Siroffe nach wurbe hier Eein Sergleidh ftatt finben. Shbr 93 aud war refr bick uns gleich fam aufgerbinollen, glich auth faft, weil nidjts von Den eingeweiden Darinneit zu fehen war, einer burdfichtigen Slafe; aufer diefent aber batte ibr ganzer Sorber noch Die worige. Beftalt und Rănge, wie Denn audi an Dem Ropf Eeme ßerảns Darung wahizunebmen genuefen. Und fo blieben fie noch sine oute beit tmveránbert, auffer Daf fie an Sroffe wathfen, uno alro zum Theil Den funften utto fechiten Tulit Der 12. Figur gleid) fahen, zu wel= wer Beit Der. Ropf mit fetmen 2lugen, in 2lnfefung

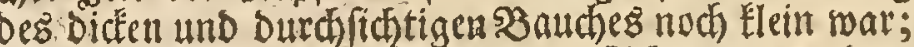
Doch hatte er nebft Dem fleirdernen Sdwan' und Dem ubirigen Siórper, Der-fich vom Baud febr merlid un. terichieden seigte, nunmehr eine Duntlere Farbe. Lit: terbeffen blteben fie nod immer auf Dem $B$ oben Des (3) lales, und nåbrten fich von Dein Dafelbit befindit d)en glinten Sd)leim, fo, Das id ibnen nicht oifters

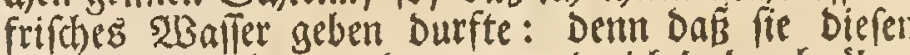
Sdileim versehrten, Davon wurbe id) Dasurd) tibers zeuget; weil Der Drt wo fie Diefen Sd/rim abgena: get batten, eine andere Farbe befam; eben biefes aber brad)te midh auf Die (Siedanfen, Dafi fie vornebmlid Das zarte $2 B$ affermous zu ibrer Epeife gebraudhten, und Dafi Diefes mobl bie Lrfache fenll mosgte, warum idf fie niemals, wie andere Deraleichen $2 B$ irmer, in Den fte benden wafiern zu Esefidhte befommen britte. 

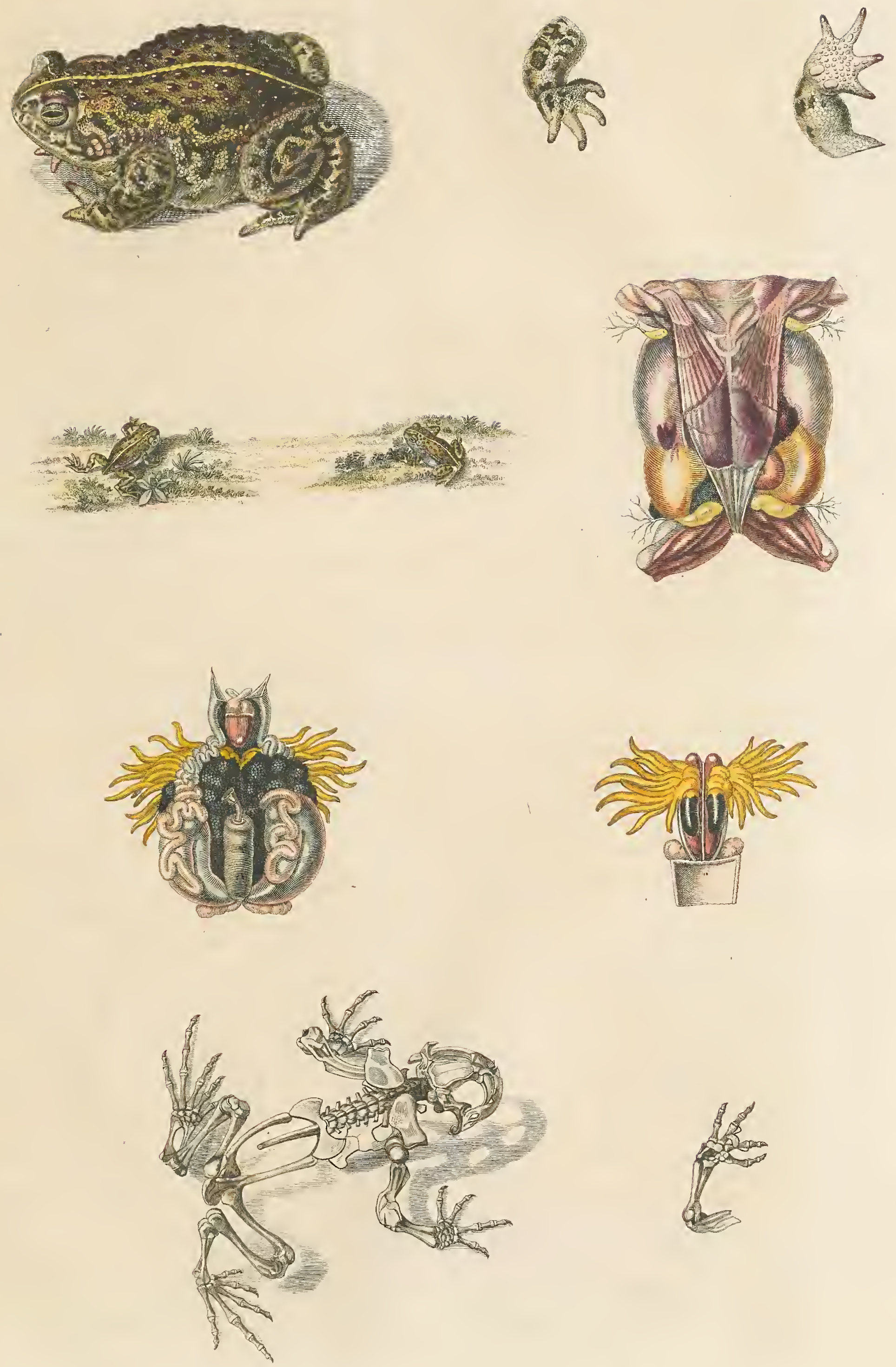


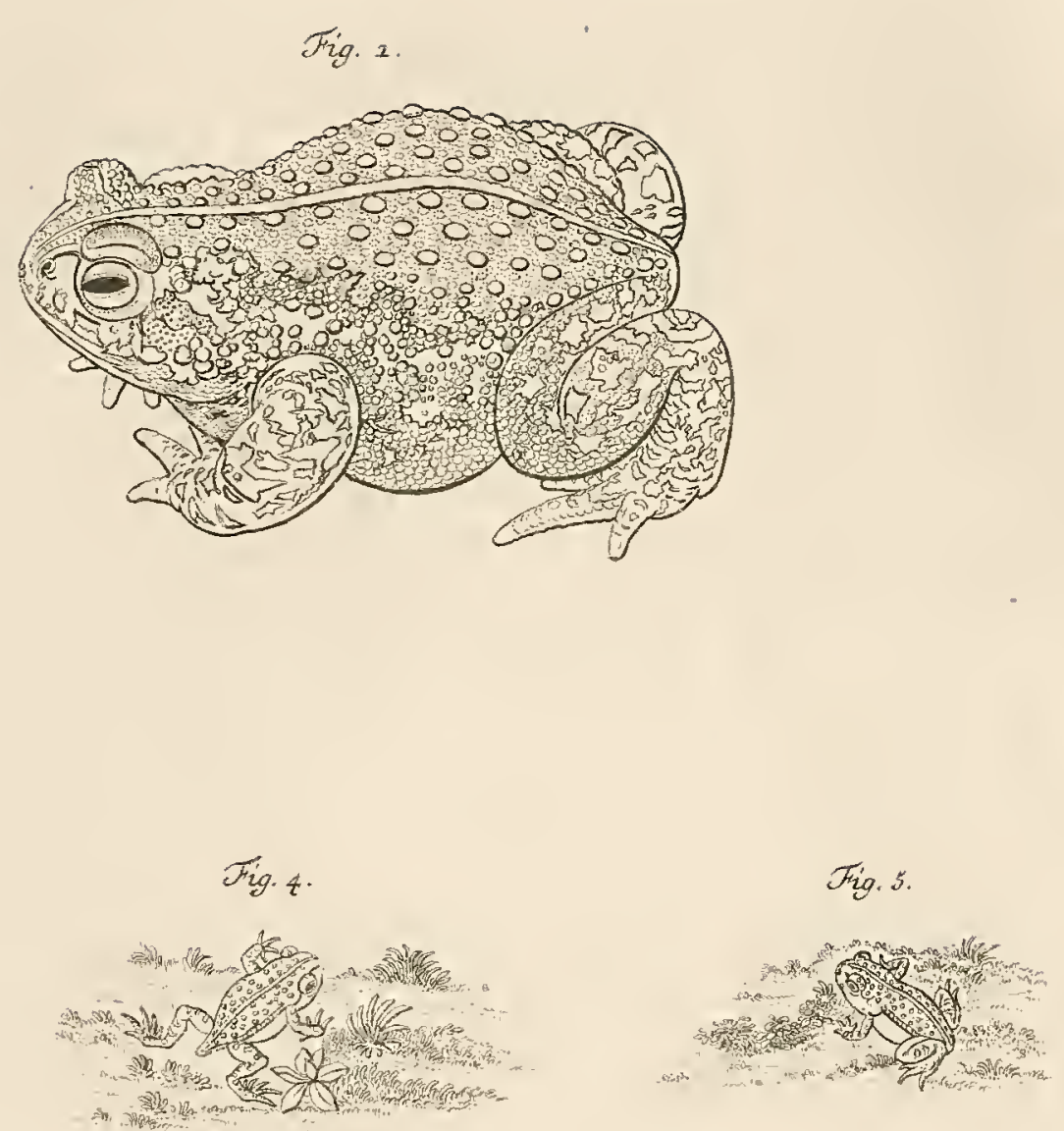
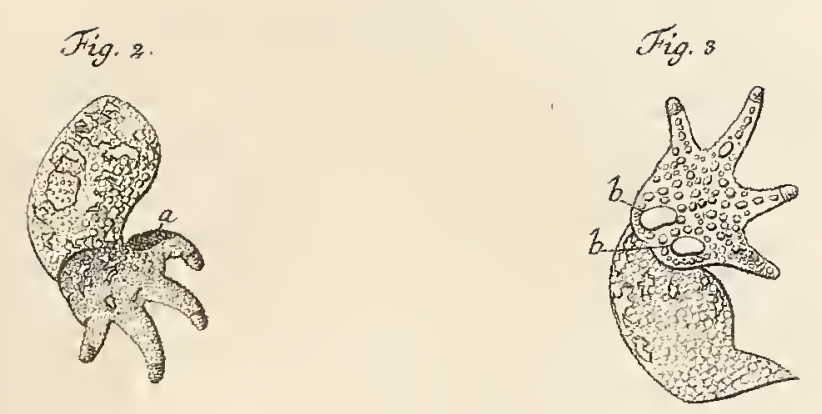

Fig. 6 .

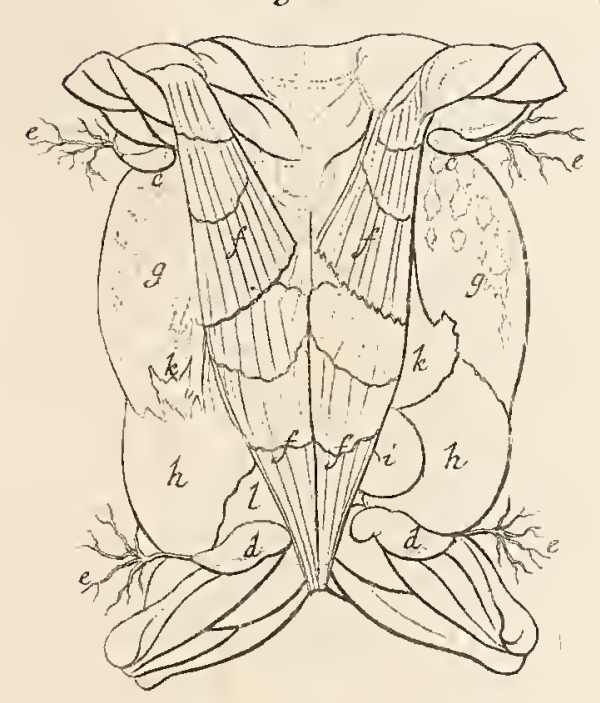

Fig. 8

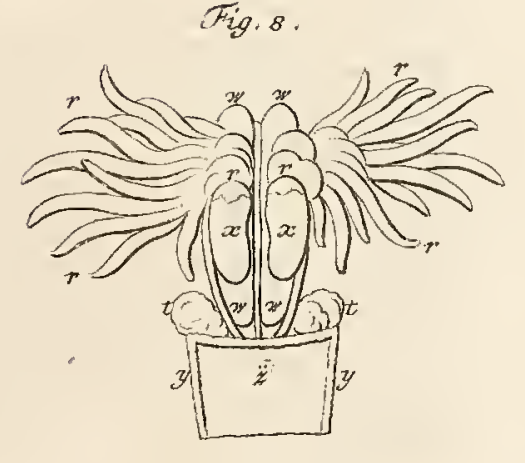

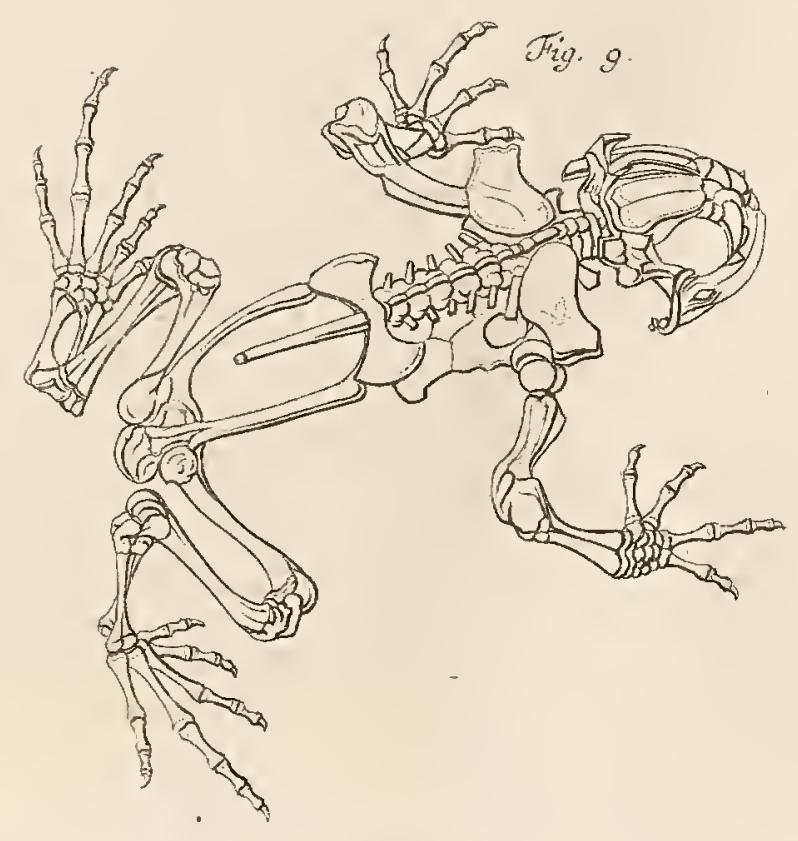

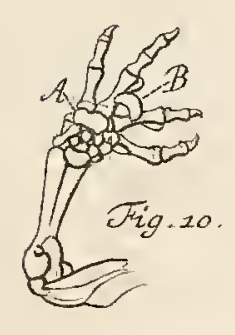





\section{*}

Inftructum eft hỏc tempore os eorum papilla quadam, cuius ope laeui nonnunquam adhaerent vitro; vidi etiam, quum teneriores decimaeque iconi fimiles effent, duxiffe illos ex eadem illa papilla tenacius filum, ex quo non folum pendebant, fed cuius etiam ope ea ratione locum mutabant, ve repere viderentur. Id iplum alios qunque peragere obferuaui quidem ranarum bufonumque gyrinos, quum vero quomodo illud fieret, tum ignoraui, minus adhuc hac de re mentionem alicquation feci,

Reliquas îllas mutationes, quas gyrini hi paff funt ad prouentum vsque quatuor fuorum crurum, quae in hac bufonum fpecie, perinde ac in rana viridi aquatica; fub finem demum Septembris, vel inchoante Octobri comparere folent, furfus iam non fum enarraturus; quip. pe qui perfuafum hábeo; Lectores obferuationum a me in praecedentibus traditaram, fidem milhi habituros, dixero, non differe illas a mutationibus reliquarum fpecierum, atque hinc ea tantum de lisdem referam, quae mihi notatu vifa funt digniora.

Primarius horum gyrinorum color lucidior femper obferuabatur, quam in gyrinis fuperius defcriptis, lice augefentibus illis, in fuperficie praefertim tuperiore cor. poris, faturatior fenfin fenfimque redderetur. Venter fupra modum craffus pellucidusque, nec non bini illi acuti pinnae caudam cingentis proceflus, quos gyrini hi yroprios quafi habent, diutius in isdem confpiciebantur, dum vero bina pofteriora, faltum natatumque iuvantia crura procrefcebant perfectaque euadebant, euanefcebant fenfim fenfinqque, ipfa vero caudae pinna maioribus nigrioribusque diftinguebatur venis maculisque, ita vt conuolutum fcre referret rete, Haerebant tum gyrini hi femper adhuc in vafis fundo, atque ex putrefcentium plantarum nutriebantur lentore. V $\mathrm{b}$ bi vero eam nacti erant formam, quam $X X X I$. Tabulae, 13. repraefentat $i c o n$, iteratis vicibus fuperiorem pecebant Juperficiem, quod forte puriore iam magis, quam antea, indigebant aere: Crura pofteriora lente fatis, vt reliquis in gyrinis, procrefcebantit; fed perfectis illis, non ita wulto port in confpectum etiam, fimul ac femel, prodibant anteriora eaque integra.

In gyrino iconi $\mathrm{i}$. fimili, compofita tum erat, fat adhuc craffa, longa carneaque caudae pars, meris robuftis eminentibusque mufculis transuerfilibus, ex fiauo ochrae colore in fufcum vergentihus, apicem caudne ta men verfus magis nigre fcentibus, Lata tenuisque eandem ambiens pinna, obfcurior equidem reddita, pellucebat tamen; fuperior autem illius pars pluribus fcatebat venis nigris máculisque, quain inferior. Color primarius totius fuperioris fuperficiei corporis iam multo erat faturatior; quam antea, quum gyrinus pedibus adhuc carebat, atque ex pallide flauo in fulcum cinereumque vergebat, Confperfa infuper exant dorfum, caput quatuorque fuperiorum crurum pedumque fuperior pars variis nigris maculis atque punctis, magnitudine diuerfis; in fuperiore vero maxilla pofitae erant, anterius prope os, nonnullae harum mäcularunı ex ordine. Maior nigtorum horun punctorum erat numerus in fuperficie inferiore, quae ex coeruleo cineracei erat coloris, in hac vero icone a latere et pro parte tantum cernitur. Anterius circa thoracem pars quafi fupererat venţris antea tam cruffi, atque vbi gyrinus in lumine effet collocatus, iam cernebatur, contrahi eiusdem pupillani ita, vt triangulum de. Icriberet.

Shr Mund if fit biefer Beit untentier nod mit einer theitten $2 B$ arse berfeben, mit swelcher fie fich sus weilen ait bas glatte B̧las anbaingen; aud habe ith wabrgenommen', Das ba fe nod in ibrer zarteften Sugend waren, worinnen fie Die 10. Sigut seiget, fie aus felbiger einen foleimigen. Faben fonen, woran fie fids nidbt nut alleine biengen, fonbern aud fo von einer Stelle zur andern leiteten, Dafi fie fortzukrieden (f)ienen; eben biefes babe ich zwar anth an anbern frofh) und Sirotentionmern wahraenommen, aber vor: ber nid)t angejetget, weil ich nidet redht gewuet wie folches zugienge.

Die ubrigen Zerảnberungen biefer Whinmet, ô mit ithen 1orgegangen bis. The thre Fiffe erbalten, wel's

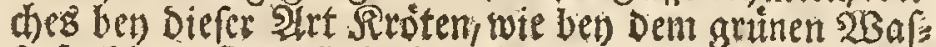
rerfrofh, erfi st Ende Des Septembers oder mit In: fang Dess Sctobers zu gefdsehen pfleget, will id nut nitht weitliuftiger berobreiben; weil ich glaube bie \&e: fer biefer SBlatter, wetben aus metnent vorfit angé

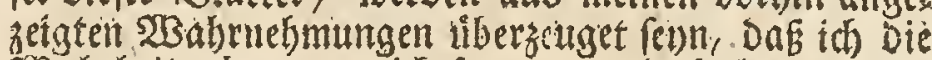
23 abrheit rebe, wenn ith fage, es gebe Dabei eben fo wie mit Der librigeu 2(rten gu; Doch ivill id) bas merfwirsigfte Davon, nur mit wenigem anfutheren.

Die Şrundfarbe Diefer 23 ürmer blieb iberhaunts beftindig beller; als bey allen Den vorkergetendents

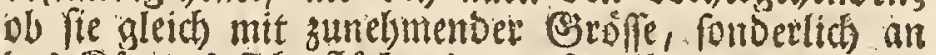
Des Rorpers Dberflache, iminer Dunfler wurbe. Det aufferordentlid groffe, Diffe unto helle Sand Derfel: ben, und bie beeben at ber Sdjwanjfloffe befindit:

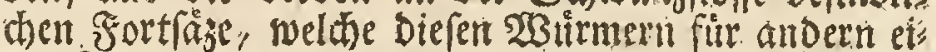
gent fint, waren altch lange an Denfelbent zu bemerfen; bis aber bie beeben hintern Spring= uno Shiwimm. fuife zum $230 \mathrm{rfh}$ cin famch and thre vollige Sieftalt erbalten batten, serlofisen fie fidi nach und anchi und bie un ben Sd)wanz gebende. Floffe befam immer nief):

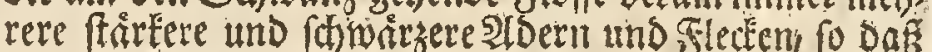

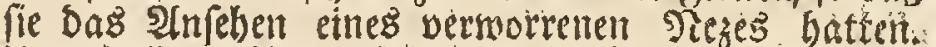
Unterbeffen nổiten fich Diefe 23 irmer nod immek von Dem Sdhleim Der verfaulten Mflanjen, unb biels

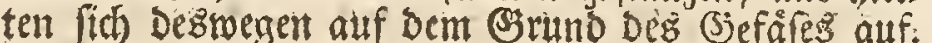

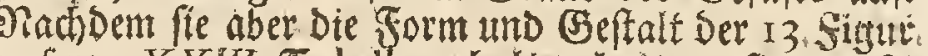
unferer $X X I I I$. Tabelle erbalten hatten, fiengen fie an fich zu vicberboltenmalen in Die 50 be zu.begeben

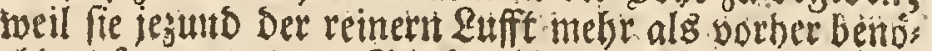
thiset fevn mogtet. SBis bie bintern Friffe vollio bei" an gewahten waren, gients es; wie ber andern foldient 2Burmern; febt langfam ber; als fie aber ba waren To kamen bald Darauf Die gwen vorbern Fitîe auf eitit mal uno gans bolleomment zum Sortchein.

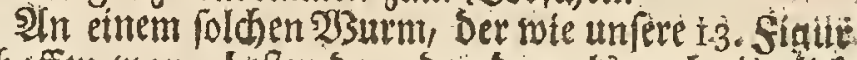
befhaffen wae, beftunde, Der bamals nod) siemlid Dicte und lange fleifherne Thefl Des Schwanzes aus lauter ftarken, crbabenen Duermufceln von odergelb: braunliditer Farbe, weldie gegen die Spize zu inmer fhwärer allsfiel. Die um Denfelben herumactienbe binne uno breite floffer saar swar nod burchfintigh aber etwas truib uno oben mit mehrerent forisarsen

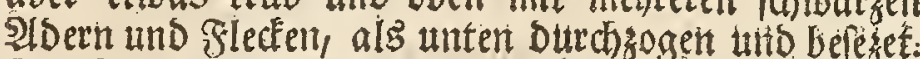
Die Srunbforbe war att Der ganzent Oberfiche Des

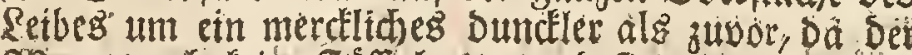

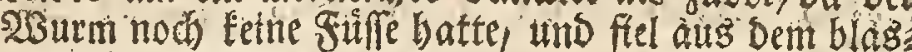
gelblichten in Das braungraute. In Diefem Esitus geigten fich ro wobl auf Dem SRiden unb bem Sopfi als aub) auf Der Sberfáche Der vier Edsendel uniro Fuffe bin tno roteder einige fobrorze Stecten uns spun cte von verfbieberter Brofle am Sberfiefer abeé ftutroen vornen am Mand etlitbe Derfelben in etreer or Dentlichent Iethe benfammen. Die blaulichtarauelins terflache, weldie man aber in biefer Figur nur sum Ibeil mo voll ber Seite za feheit betominet, war mite inebreren bergleiden fobroarzen Puncten befprenget.

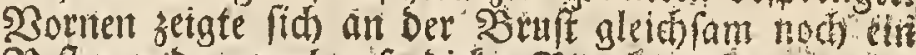

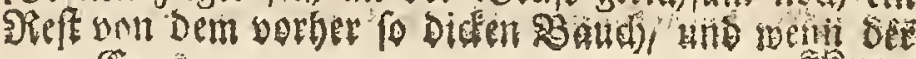




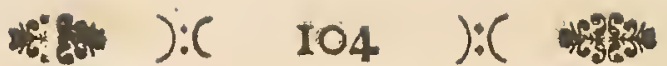

Iam vero accedit bufo talis aquaticus propius ad ripas; iam etiam, cruda ipfius fenfim decrefcente, tandem ipfam petit terram, fic tamen, vt haud longius ab aquis recedat, atque periculo imminente in iisdem latibula quaerere quear.

Depictam dedi icone 14. Tabulae XXIII. minorein eiusmodi rubetam, cuius cauda vltra dinidiam fere partem iam decreuerat, tergo incumbentem, quo fuperficies illius inferior in contpectum prodeat. Eft haec in eiusmodi tenellis rubetis ex pallide caeruleo cineracei coloris, plurimisque nigris punctis nec non maculis confperfa. Femora tamen pofteriorum crurum, quatuorque pedum plantae, citrini quid habent, inferiorque capitis fuperficies, vel gula potius, nec non reliquae quatuor crurum partes in cinereo flauent; fed mutatur poftmo. dum fuperficies haec renfim, ita, vt aurantium prorfus, quem iam in adultioribus hifce vidimus rubetis, induat colorem.

Vbi cauda eousque decreuerat, vt portio tantum illa fupereffet, quam I4. icon exhibet, euanuit tandem duodecim horarum fpatio $\mathrm{ex}$ integro. Siniles tunc erant tenellae hae, fed iam omnibus fuis partibus inftructae rubetae, quoad magnitudinem formamque, 15 . iconi; cum vero non amplius lentore vefcebantur, fed vermibus aliisque infectis, quibus etiam nonnullas earundem, domi meae, in hyemem vsque nutriui; hac vero ingruente fuheunt tenellae hae rubetae, aeque ac adultae, anuas, fubque illis, ad moduin aliorum bufonum ranarumque in limo atque terra latitant, donec primo rurfus vere excitentur.

Tertio exacto vere apta eft huiusmodi rubeta generationi; quamdiu autem viuat, minus quidem indicari poteft: vbi enim tres habet annos, vix amplius magnitudine augetur; licet vero aeque velociter, ac ranae blandae, faliat, his tamen annumerari nequit, turpein potius ob afpectum bufo eft dicendus, a reliquis hinc diuerfus, quod inferior eius fuperficies flammei vel au. rantii fit coloris coeruleisque infignita maculis; quod pupillam fic contrahat vt triangulum formet, quodque membrana illa quo pofteriorum pedum nectuntur digiti, ad horum extrema vsque pertingat.

\section{Sectionis Sextae}

\section{Caput II.}

\section{Quo interiores Bufonis ignei re- cenfentur partes.}

Tnteriorum partium bufonis ignei habitudinem in mare 16. Tabulae XXIII, exhibet icon, Monftrat haec easdem naturali in fitu, fic tamen, vt partes nutrition ipfique vitae inferuientes, prae illis quae generis propagationi dicatae funt, confpiciantur. Signatum eft cor in icone hac, perinde ac in reliquis, littera $a$, binae veficae aereae, fiue pulmones $b b$; hi quum non ex integro contracti, fed aere parum fint repleti, carneum habent colocem ; $c c$ hepar eft, lobis aliquot conftans, at que hife in bufonibus colore fufco femper tinctum.

Wurm fith gegen Dab Riđt Eebrete, Fonnte man nums melyr bereits bemerden, Daś fí Der Stern in feinem Tug Drenecticht Darftellte.

In Diefer Beftalt begiebt fich nuneine foldhejunge

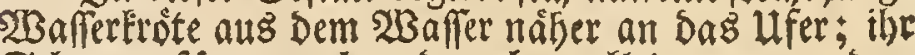
Schwans fängt mad tmo nach an Eleiner su werben, und endlich gebet fie gar an Das Rand, obne fich je= Doch yon Dem 2 Bafer weit zu entfernen, um ber be vorftetender SSefabr, fich twieder in foldem verbergen 子 to tormen.

Sn Der I4. Sigut unferer XXIII. Tabelle babe id eine folche jumae Nrote, an welcher ber Shtwans foron tiber bie Sálfite abgenommen, auf Dem shuten liegend

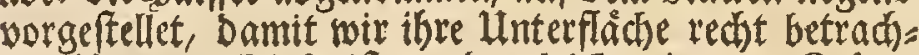
ten foonner. Diefe ift an Dergleichen jungen Srótent nur noch blasblauliditgrau nnd mit vielen fotrarzen Suncten und fleinen F̧lecken befinrenget; an Den bees Den Dberfhendeln Der bintern fruffe aber, und an Den Solen aller vier Ftuffe, zeiget fid etwab citronengels

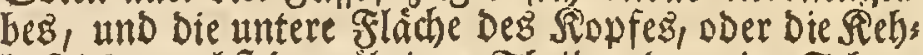
le spielet, nebft Den übrigen Theilen Der vier Schen ckel, auch mefrin Das Belbe, als in Das B3raue; nad und nach aber verfärbt fich Diefe Unterflåd)e immer mebr, bis fie endith yollig oranienfarb wird, wie twit folche an Den áltern. Siróten gefehen baben.

sBenn Der Schwanz einmal to weit, wie in Der 14. Sigut abgenommen batte, fo verlobr er fich ens, lid) innerbalb zmólf Stunden ganz uno gar, unb fos benn hatten diefe junge unt munmebr vollfommene Feurertroten die Bróffe und Šeftalt Der 15. Fitur, ba: ben fie aber Diefe erbalten, fo nábren fie fich nicht mebr yom Sd) leint; fonbern von 2 Burmern und andern Infecten, und mit Diefen babe idh aud einige Derfelben in meiner $\mathfrak{B}$ ctoohnung, bis in Den sointer erbaltem, zu weld)er Jabrezsett, Diefe junge aroten, wenn fie in ibrer frenheit find, eben fo wie die alten, ibren 2 uff enthalt unter Dem 2 Baffer, im Shlamm und in Der Eroe fuchen, uno Dafelbit, nach 2lrt anderer frofoche und froten, bis in Den Fruhling verborgen bletben.

\$Y Bem Diefe Srotenart Den Dritten Fruibling erle bet hat, ift fie bereits zur Sortpflangung ithres (S)efhled). tes tuidtig. WBe bod fie aber ibr alter bringe iff nidht wobl anzuzeizen, weil fie, wenn fie einmal bren Jahre crlebet bat, nid)t viel mebr an Siroffe zunimmt. Im Springen ift diefe Rrote faft fo (d)nell und burtig als Die lieblichen Frófhe, Dem ungeadhtet aber fan fie Doch nicht za Denfelben gezáblet werben, fontoern fie bleibt um itser fabeuslichen 2lnfehenswillen eine Sirote, wels che vor andern barmmen etwas befonders hat, Das ith. re untere Flåche feuerroth, oder bod) orantengelb uns blaugeflectet ift; Dẩ fie Den Seher ober Stern im 2Ug orenecticht zurammen ziebet, und Daś fich Die all Deit Springfuffen sivifhen Den funf Beben befindliche Saut, bis an Die áuferfiten Spizen Derfelben erftredet.

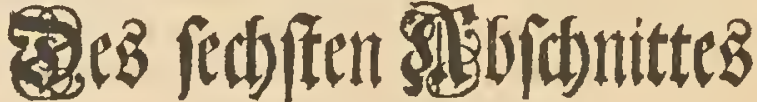

\section{3weytes Capitel.}

\section{शBorinten von Den inmern sbeilen det Feuerferite gebandelt mirs.}

69ie bie imneren Theile unferer reuertrote ben eis

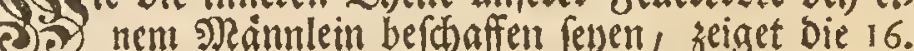
Sigur unferer $X X I I I$. Tribelle, welche foldhe in ither mattirtichen Iage Darftellet, Da Denn Die zur Nahrung und zum Reben achortigen Shetle mebr, a!s Die zur Fort pflanzung Des (S3e/d)led)tez erforbert werben, in bie 2lugen fallen. Das Sers ift in Diefer Figur, mie it Den anbern ulit a bezeidjuet, Die bceocn Rungenblaren mit $b b$, weldse bier nid)t vollig zufammen gefallen, condern nod) in etwas mit Suffe angefillet lino, atmo 


\section{4.}

Sub hoc confpiciendam fe præbet, ex atro virens, cy- Daber fleifhfânbig ausfellen. cc Sif Die aus eflichen ftis feliea $d$; fplen fphærula illa eft lucide rubense. Ventriculus $f$, maximam partem hepate tectus, ex pallido vel flauo carnei eft coloris, quo \& tenuia tincta funt inteflina $g$, quæ inteftinum excipit rectunn $b$, ex cinereo in oliuae vergens colorem. Ad $i$ fiti funt renes aliis hic tecti partibus; $k$ vefica eft lotio vacua.

Siftit icon 17 . easdem partes, fic tamen, vt illae in quas aer immitti poteft, codem turgeant; quadruplo hinc majores hic comparent pulmones $b b$ quain antea, fimul vero apparet, conftare illos amplioribus veficulis, atque has inter varia confpiciuntur vala fanguifera rubentia cum ramis fuis, ea ratione per fuperiorem fuperficiem difcurrentibus, ut filis rubris ligatæe effe videantur, ceterum veficam referunt pellucenten. Signata funt, hac quoque in icone, hepar $u$, cyftis fellea $d$, liens, ventriculus aere diftentus, ipfique cohærentia inteftina $f$. Renum alter eft ad $i$, vefica $k$, quæ licet aere valde turgeat, exiguae tamen eft molis, tamque fingula ris formae vt par referat cornuum detruncatorum, neque, vt aliis in bufonibus ranisque bipartica fffe videtur; nullum certe confpicitur extrinfecus in illa feptum; paruitati autem ipfius adfcribendum forte eft, quod, vbi bufonem hunc exagitaueris, nullum ille, vt alii bufones ranaegue fimili in cafu, ejaculet lotiun.

Latent fub partibus jam indicatis, prorfus fere, partes in mafculo ad generationem facientes, illas tamen fi auferas, has iconem noftram 18 . referre videbis. Tot harum funt partiun, quot in aliarum fpecierum mafculis; differunt tamen quaedam forma. Pingues illae coloreque aurantio tinctae appendices folinceae $1 / 1 / \mathrm{cum}$ fuperiore renum tefticulorumque parte coliaerentes, graminisque folia forma imitantes, decrefrunt in hac quoque bufonum fpecie, aeque ac tefticuli, fi generationis tempus fuerit finitum. Tefticuli $m \mathrm{~m}$ pallide flauent', formamque, $\mathrm{vt}_{\mathrm{a}}$ in majore bufone, tererem habent ad renum formam accedentem. Incumbunt illi binis renibus $i i$, planis oblongisque. In exteriore horum renum latere filiformis cineraceusque eft canalis $n n$, vltra ipfos renes furfum verfus excurrens; infra illos vero coeunt fikb vefica bini hi canales, in inteftinum rectum vno eodemque orificio hiantes, hinc eosdem veficulas effe fernini colligendo dicatas, reor : praeter hos enim, omni adhibita opera nihil reperire potui, quod veficularum harum fimilitudinem haberet, in bufone vero ante hunc defcripto, eadem earum erat ftructura.

Si ex foemella hujus bufonum fpeciei hepar, ventriculum atque cum hoc cohaerentia demferis inteftina: in confpectum prodeunt, ad generis propagationem $\mathrm{fa}$ cientes partes, quas 19 . fiftit icon, Confpicitur in illa

Rappen beftebende Reber, weldie ben Diefer Rroten art allezeit ganz suntel braunroth ausfiebet. lin:

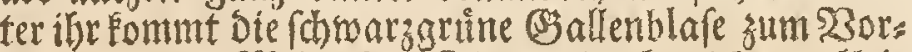
6hein $d$; Das פMils aber ift Das mit e bezeidhete, Eleis ne, hochrotbe Rugelein. Der Magen f, weldet groften Theils non ber Reber bebecket wirb, fuibret eime belle, ober gelblithte Fleifdfarbe, Dergleithen auth Die Dumenl Sebirme g haben, auf welche Der oidfe uno hier araudivenfarbe Safto arm $h$, folitet. Sen $i$ baben bie bier bedecte Slieren ibre Rage, und $k$ ift Die bon Sarn leere Sarnblafe.

Die 17. Fitur ftellet Die namlichen Shetle, tes Doch mit biefem Interfichico Dar, Dafi Dieienige, wot: eim Die Ruft zu bringen if , mit foldher fid hier ange: fillet zeigen. Dicfemmach erficheinen Die beeben?uns genblafen $b b$ biter, Dem Durbmeffer nach, mobl viet: mal grófer, als yor, autd) fiehet man, als etwas ifs: nen eigenes, DaÉ fie aus fehr groffen fä́chern beftes

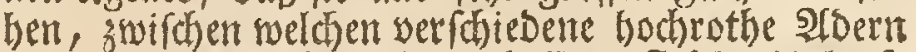
und Derfelben शlefte auf Der áufferen flähbe hinlauf: fer, fo, das fie Daz anfelien baben als ob fie mit ro: then fáden unterbumben wären; im íbrigen aber

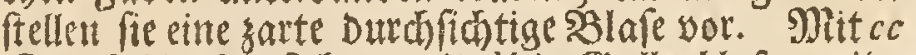
iff anch hier bie Reber; mit $d$ bie Ballenblare; mit $e$ Das Mils, uno mit $f$ Der von Rufft ausgebefinte ga: gen, nebit Dent Daran bângenden (S) airmen bezeich:

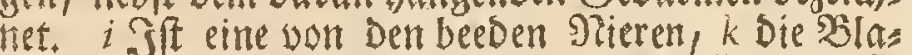

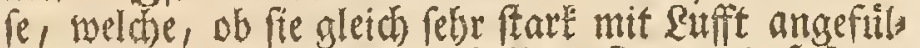
let worben, Dennoch stemlich Elein if, und in fo ferne eitse befonocre Form hat, Daf fie ein Paar abges ftumvfter Sormer vorfellet, auch föeinet fie nidh soie bey andern Siroten und Frof fhen abgetheillet zu feyn, mentigftens ift an felbiger yon auffen Feme Scheidewano zu bemerfen, ibre fletnigfeit aber mag

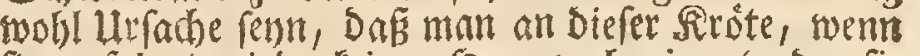
fie verfolget wird, Eeinen Sarn wahrnimme, Den fie son ftch fprtbet, wie in Dergleichen Frillen andere

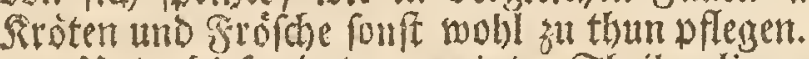

Unter biefen jezt angezeigten Ihbetlen, liegen mun Dipienigen, fo sur Fortpflanzung Des (S)efdiechtes geboren, ben ben Mánmlein faft vollig verborgen; nimme man aber tene weg, fo zetgen fich biefe fo, wie fie yon intr in Der 18. Finut vorgeftellet worben. Es fino aber bier Diefer Theile eben fo siel, wie ben Den Mearnlein anderer शirten; alleine Der Form und (S) ftalt nach find eintae berfelben unterfichen. Die fetten uno pomeranzengelben 2 intänge $l l$, ll fo oben an Den beeden Pieren und Seilen veft fiken, und ib:

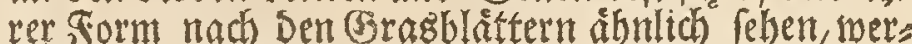
Den auch ben biefer sert nebft Den Beilen, wenn bie Raichget vorben ift, fleiner, als wir fie bier fehen, angetroffen. Die (s)ilen $m m$ fithen eine bellaelbe Farbe, und find wie bey ber groffen 23 afferfrote, Der form nad) lánglicótrund uno nierenformig. Ete liegen auf Den beeden fleifchfarben Nieren $i$, wels che eine slatte und lánglichte Form baben. 2(n Der änferen Seite biefer Nieren lauffit ein faoenåknlicker,

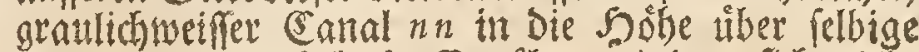
binauf, uno diefe bede Canale bereinigen fich, niche weit yon Dem untern Sheil Der Nierell, unter Der Slafe, wo fie in Den Maftoarm bitneingeben, in wels bem fte eine gemeine Deffintug haben, Daber id ffe Denn fur Die Sanmenbläslein balte: Denn aufer its: nen, habe ith, alles Nadjfudens ungead)tet, nidhte finben formen, fo Den Saamenbläblein zu verglei: chen ware, und itr vorbergebender Nrote fino felbige son aleither sefchafienbeit getweren.

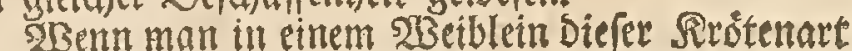
Die Reber, Den Magen und Die an Diefem hangende (B)o arme hintueg ninmt: fo fommen Die Sarunter

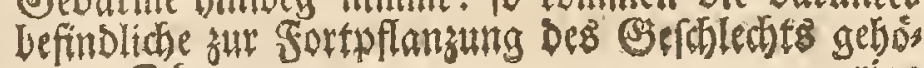
(2) 


\section{4.}

ad $a$ cor, ad $b b$ aere vacux, atque adeo admodum exiguae veficae pulmonales; $u$ pars reliqua eft oefophagi. Notari tamen prae ceteris hic merentur ovarium tubaeque vterinae. Illud oo, aeque ac aliis in fpeciebus harum animaliun, duabus conftat, praecipuis partibus, ipfa vero in illo contenta oua, magis flauent, quam vbi eadem foemella edidit. Quantus vero eorundem fit numerus, nunquain quidem, grauioribus femper netotiis diftrictus, dinumerare potui, licet minori id hic praeftari potueric negotio, quam aliis in fpeciebus, quum ipfa majora fint oua. Sitae funt fub ouario hoc, vtrimque a corde $a$, ad veficam vsque $k$ excurrentes, praelongae crebriusqueinflexae tubae $p p, p p$, jamjam alia fefe nobis oblaturae forma. Quodfi enim ouarium eo in loco, vb fupra renes adhaeret, caute feparaueris abftulerisque, atque dein ope tenuioris tubuli in orificia tubarum $q q$, prope cor $a$ hiantia, aerem immiferis, magis vna cum vtero redduntur confpicuae, ita vt iconi 20 . fimiles fint. Initio quidem magis funt patulae quam in progreflu, licet fenfim fenfimque anguftiores euadant, pars vero illarum litteris $q$ atque $r$ diftincta pellucet, pars autem reliqua $5 s$, , eam vsque ad fedem, vbi in veerum hiant, minus pellucida, ceram fere refert albam flaui quid habentem. Vterus $t t, t t$, hic, vt reliquis fere in beftiis bina quafi format cornua, atque hinc fimilis fere eft vtero praecedentis bufonis, nihilque nifi binarum ipfum crederes tubarum continuacionem, nifi ab iisdem et amplitudine et pelluciditate difcreparet. Ob longitudinem vtroque in latere duplicatus eft, \& quanuis, exterius quidem, pars dextra a finiftra non videatur feparata, interius tamen feptum adeft intermedium, eo tantum in loco apertum, quo oun ex vtero in rectum propelluntur inteftinum $k$. Cernimus infuper hac in icone, inter tubas, binos renes $i i$, fpinaeque partem $v$. Foliaceae aurantioque colore tinctae appendices, eadem hic fe habent ratione, ac in mafculo, talesque funt, quales in icone 18 . repraefentatas vidimus; quum vero exacto generationis tempore in vtriusque fexus bufone decref cant contrahanturque ita, vt curiofius fint querendae, hic eas monftrare non potui.

Exhibet icon 21. Tabuls $X X I I I$. perfectum bufonis ignei fceleton, quod tamen nihil mihi notatu dignum exhibuit, nifi, quod bina coxae offa, quae, vt in bufone allium redolente, binos referunt vomeres, cum offe furcae formam habente, cui foemoris committuntur offa, ea. dem jungantur ratione $v t$ in dicto modo bufone, ita, $v t$ hinc bufo nofter igneus corpus fuum commode elongare contrahereque poffit, id quod hic quoque eam forte ab cauffam neceffum erat, quod bufo hic fimiliratione, ac bufo allium redolens, coire folet. Differt quidem os fterni, quod \& hic cum fcapulis junctum eft, ab eodem reliquarum fpecierum offe, non tamen tanta eft differentia illa, ví icone illam exprimendam effe, e re duxerim, nec aliud quidquam anilladuerfione dignun. fupereft, nifi, effe fceleti hujus offa, quam reliquis in bufonibus atque ranis, proportionaliter minora tenuioraque.

FINIS Hiftoriae bufonis ignei. rige Sheile, fo, wie fie Die I9. Sigur Darftellet, sum

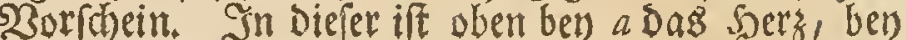
bb aber Die von Ruft leere umb Daber ziemlid Eleine sungenblafen zu feten; $u$ ift Der Reft DeE Schlundes. Das vortlebmite aber was wir bier zu betrachten has ben, ift Der Enerftocé neblit Den Energången. Jener o o, befteliet aud bier, wie ber Den anbern 2irten aus swenen Saltottheilen, und Die (Ev)er felbfit, fithren in felbigem mebr eine gelbe farbe, als nachgebends, went fie Das sBeiblein von fid gegeben bat. SBie hoch fich aber Die \$inzabl Derfelben belaufe, babe id

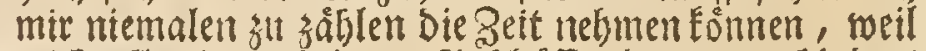
mich) allezeit widhtigere (S3efd)affte Daran verbindert haben, ob es fonon hier nidst fo mib ram als bet andern Srten, geweren fent swirbe; weil felbige greffer fimb. Inter Diefent Enerftor liegen nun Die, zu beeden Sei. tem, fíb vom $\mathcal{5}$ erzen $a$, an bis zur S arnblafe $k$ erftre: céende, rebr lange uno vielmals gebogene Esyergánge $p p, p p$, Die wir fogleich in anderer (S)eftalt fehen wer: Dent. Dent wenn man Diefen Enerftod, liber Den Spies ren, wo er wefte fiset, bebutfam ablófet und bevfeit (c)affet, bernad) aber mit einem zarten SRobrlein, it Die am Serzen $a$, befindolidte Mindung Der Energän. ge $q q$, Euft sinblåfet, fo zeigen fich Diefelben. nebft ber Siebarmuttter, wiel Deutlid)er und fo, wie fie Die 20. Fígur vorftellet. शnfangs find biefe Energänge et: was weiter als nadber, ob fie gleich immer enger wer: Den; und von $q$ bis $r$ find fie Durdffichtig; ibr úbriges

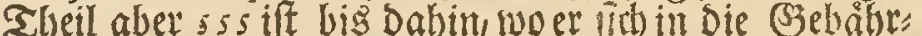
mutter offnet, nicht mehr Durdhfichtig, folldern es fiehet folcher fait wie weiffes und etwas in Das gelblichte fallente $23 a c h z$ aus. Die Biebaibrmutter $t, t t t$ befte: bet wie bey andern Shieren gleith fam aus ziven Sơr nern, fommet auch bierinnen mit Der S3ebärmutter Der vorigen Sirote in etwas ziberein, und würbe ebenfals nur eime Foriezung Der Energainge zu fenn foheinen, swenn fie fid nidit Durd) ibre mebreresBeite und Durchs fichtigleit von foldhen unterfhiede. Fitre Sånge ma: d)et, Dafifie zu jeser Seite zwiefach bevfammen lieget, und ob man gleid son aullen Eeinen unterfesied swi fhen Dent rechten und linten Sheil wabrnimmt, ro ift fie boch imnenter Durd eine Dimne Scheiderwand $a b=$ getbeilet, weldhe nur Daunterbrodken iff, no die Enser, aus felbiger, ithren 2uBzgang in Den'Naftbarm k baben.

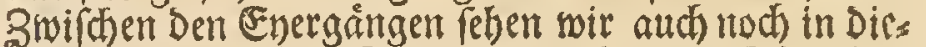
Ter Figur bie beeden Nieren $i, i$, und émen Theil Des SRucigrads $w$. Die blåtterformigen unto orantengel

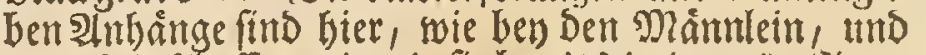
zwar fo befidaffen, wie wir fie bereits in Der 18 . Sight gefehen haben; Da fie aber nach der Saidzeit in bee; Den (ङ̈efoled)ten, Eleiner werben und fich zulanmen zie: ben, fo, das man fie fudjen mus: nls baben fie auth bier nicht vorftelliog gemachet werben tonnen.

Die 21. Sigur unferer XXIII. Tabelle ftellet daş volf Fonmene (33erippe Der Feutertrote vor, an weldgem id) aber

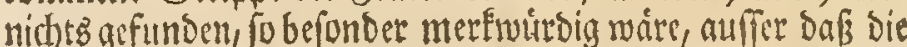
beeden Shiftbeine, sweld)e auth hier wie an der Sinoblatchtróte

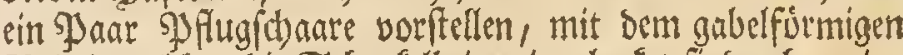
Bein in welthes bie Sduenelelbeine eingelentet find, wben sine foldye Zerbinoung baben, wie bey erft benannter Frote, $f_{0}$

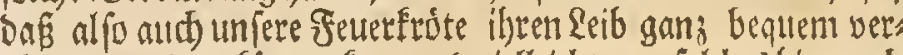

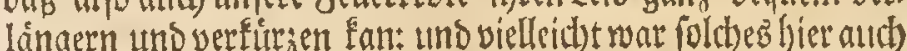
beşwegen nothig, weil fid) biefe Srotenart eben fo mie bie Sinubs land) frote paaret. Dả Bruftbein weldes auth bier nit ben Shulberblattern verbunden ift, iff zwar etwas anderft alb bel Den ibrigen Atrten geformet, alleine ber Linterfidies ift bods

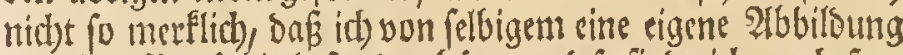
au geben fur nothig befunden batte, unt fo finde id) and for

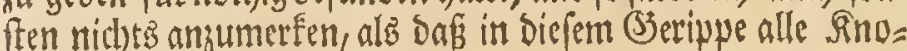
d)en nad) \$roportion Eleiner und zarter alb an anderm firo: ten und Frofititen find.

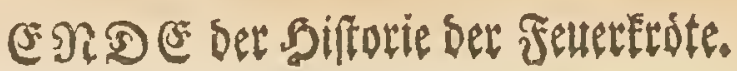




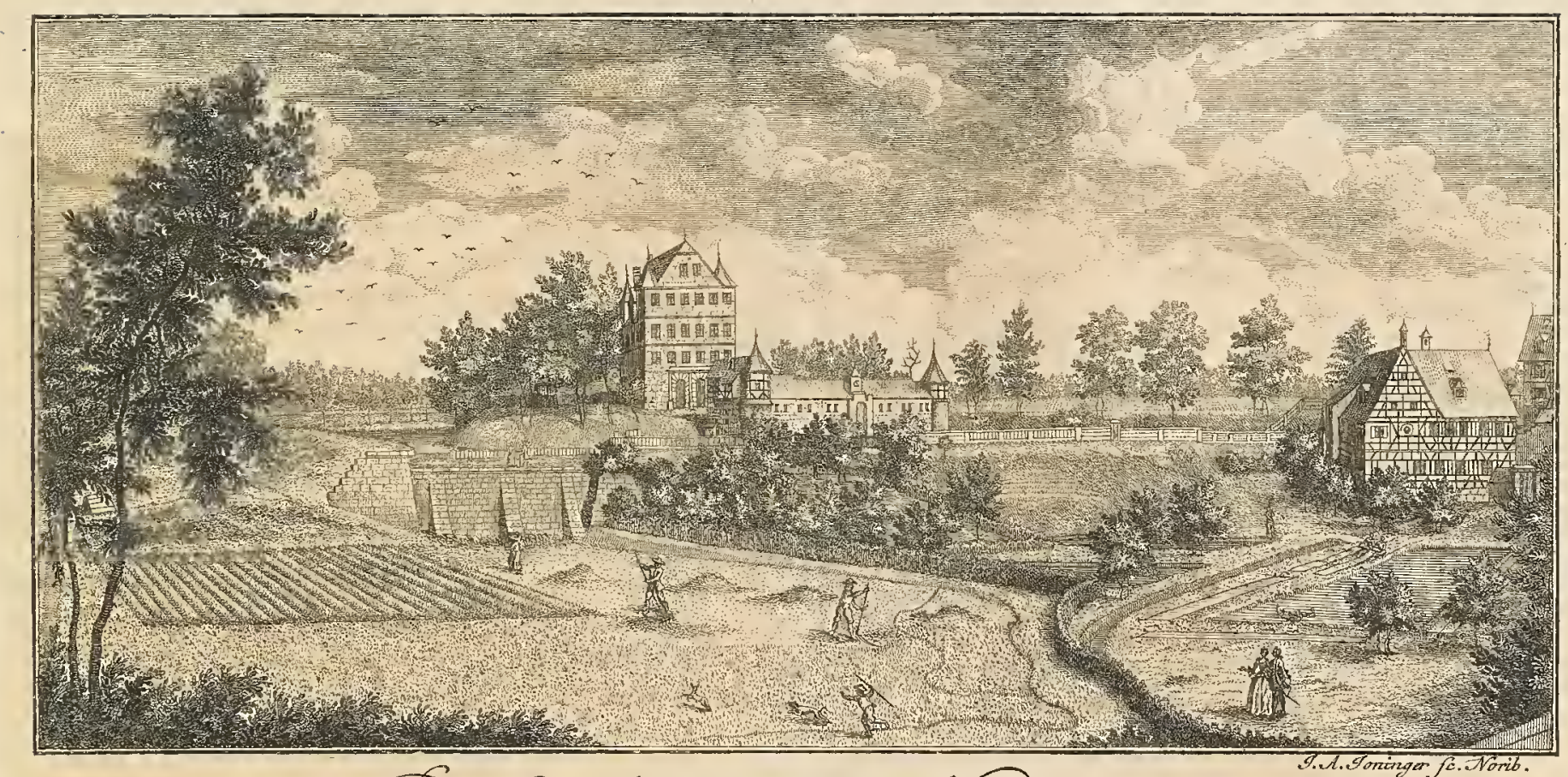

Der Gleishammer beï Jürnberg 9.

\section{HISTORIA NATVRALIS RANARVM NOSTRATIVM. SECTIO VII. BVFO TERRESTRIS FOETIDVS.}

Doer

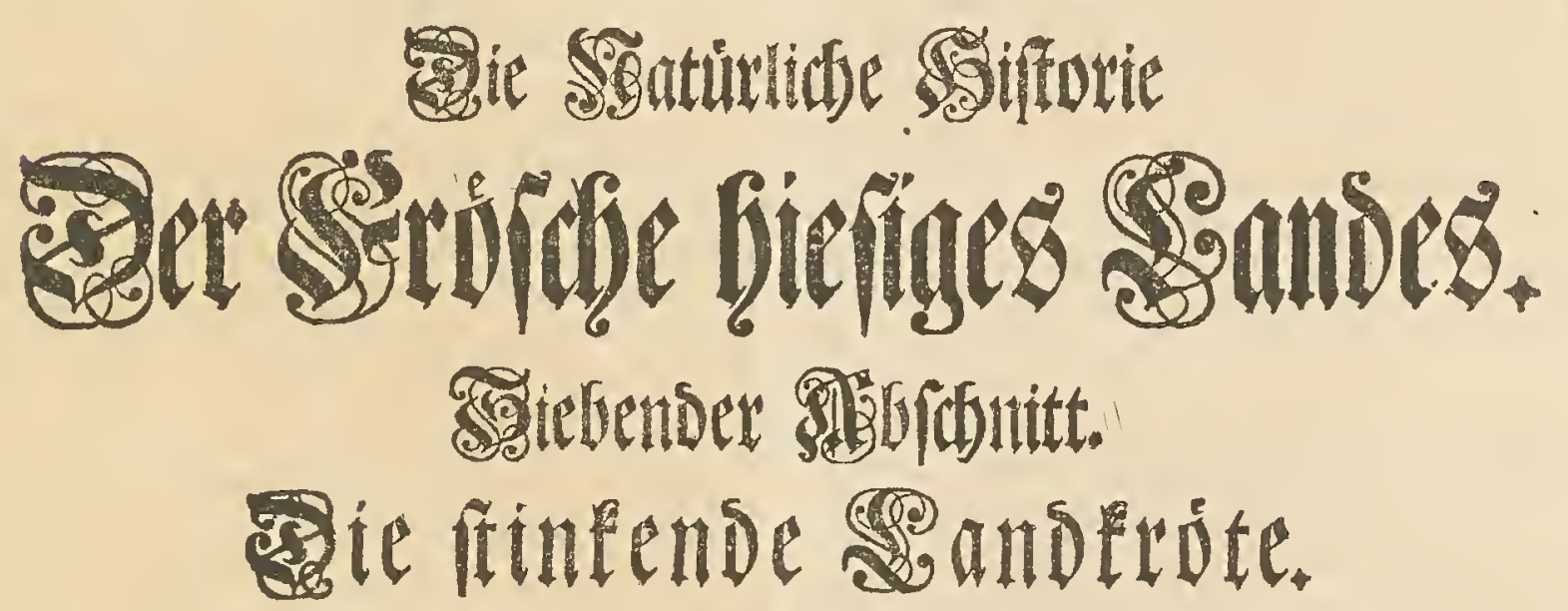

CAPVT I.

Bufonis terreltris, foetidi pro. prietates, coitus \& generatio.

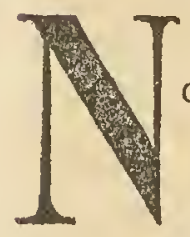

ta eft fingularis hæc bufonem fpecies, $T a b$ $X X I V$. Fig. I.nonnullis in locis, fub nomine, bufonis arundineta habitantis (der Robrling) quodadulto jam vere, generationis tempore, in arundinetis ftagnorum pifcinarumque, fortem nec non fingularem edit clamorem; in Thuringia cruciatum eandem appellant bufonem, quæappellatio a fácia illa flaua, per medium hujus bufonis dorfum excurrente, forte originem fuam traxit; circa feftum vero diui Iohannis quærunt eundem multi curiofius: parant namque ex eodem oleum quod, vti.quidem prædicant, articulorum doloribus nec non neruorum refolutioni, illitum, optime medetur. Ego quidem eundem bufonem appello faridum, quod, vbi exagitetur, intolerabilem
Gerites Capitel.

Die esigentidaften ber ftimlettben Ranberote, iare Waarang und Gr: zengung.

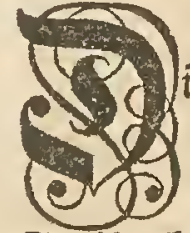
iefe befondere sicotenart Tab. XXIV. Fig. I. if an einigen Drten unter Dem Namen shóbrling betannt, weil fie firt fpat in Frukling, zat Raichzeit an Den Itfert im

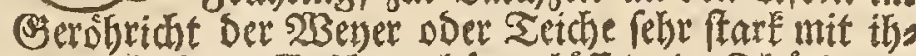
rem bofondern (अefdren boren läfet; in Shuirtngent aber wits fie Die Rreubetrote genannt, weithes bers mutblich Daber fommet; weil fie einen nad) ber Lätta ge bes Stuckens aublauffenden gelben Strid fubret. und um Sobannis wirs fie bon vielen mit fleis aufs gefuchet, weil fie aus felbiger ein Debl bereiten, wels

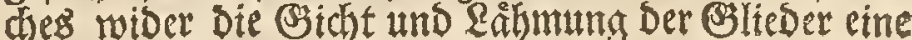
berwaitrte Sirzenen fenn foll, wenn relbige Damit ges

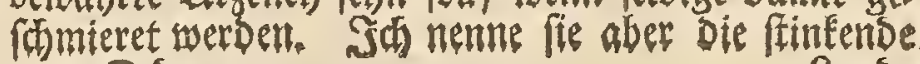
D 2

Sand 
fpargit fæetorem, odori pyrii pulueris accenfi, fimilem quidem, fed grauiorem; nec non hinc, quod aquaticus etiam datur foeditus bufo, cujus jam fupra tradidi hiftoriam.

Defcriptione hujus bufonum fpeciei Hiftoria $n a-$ turali ranarum noftratium finem fum impofiturus; quum præter feptem illas ranaruni fpecies, tres nempe ranas proprie fic dictas, quatuorque bufones, nullam aliam nouerim. Vtrum enim ille etiam bufo noltris in terris degat, cujus nuper modo in litteris Hala Saxonum ad me datis Dominus I. C.D. Schreber mentionem fecit, eft quod dubitem. Scribit ille, examinaffe fe lapides, qui e lapicidina prope coenobiuin Rosleben, quinque milliaria ab Hala Saxonum diftans, eruuntur, inueniffeque fub faxo qudam bufonem maffam inertem referenteir, qui in fundo carneo, fuperioris fuperficiei, viridibus, inæqualibus, transuerfim directis \& in medio abruptis exornatus erat frriis. Quenadmodum vero litteræ hæ fumma me perfudere voluptate: fic etiam maximo illis ipfis incendebar defiderio, hunc minus mihi notum bufonem oculis contrectandi; fed prorfus ignota eft, his in terris, fpecies hæc, effe vero eandem fpeciem hanc, quam nunc fum defcripturus, vividiore forfan, ob exuvias modo pofitas, tinctam colore, mera eft conjectura; plura hinc non additurus, ipfam nunc præfentis bufonis ordiar hiftoriam, addita fponfione, me vbi bufonem illum viuum forte fuerim vifurus, ipfius defcriptionem, Hiftoria Lacertarum quam proxime fum editurus, effe additurum.

Quod ergo ad bufonem noftrum terreftrem fostidum attinet, fimilis ille fere eft bufoni terseftri, dorfo tuberculis exafperato, oculis rubris, fupra Tab. $X X$. defcripto, ita, vt eundem, initio quidem, vix aliam effe fpeciem crediderim ; fed vbi illum curatius contemplatus fum, facile vidi, difcrepare hunc ab illo, hujusque difcrepantiae indicium effe fafciann fulfuream, a capite, medium per dorfum ad illis extremum vsque excurrentem. Minus etiam bufonis hujus terreftris fæditique rubent oculi, quum potius circa pu. pillam palleant, atque ex lucido viridi in cineraceun vergant. Breuius ipfi etiam eft contractiusque corpus, quain reliquis fpeciebus omnibus, id quod de ipfius etiam dicendum eft cruribus ac pedibus, atque vt ante-
Sand Erote; weil menn man fie beunnubiget, Diefelle einen unertriglidien Beftant von fich giebt, Der eini ger maffen wie angezundetes Sdjiespulver riechet, Daber aber etwas viel wibrigershat; uno Denn auch weil wir eime ftimEende 23 afferterote baben, weldbe be: reits oben von mir befchrieben worben.

Mit Diefer firofenart werbe idb meine natiulide

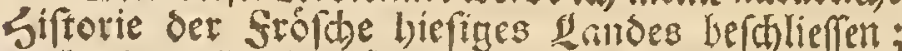
weil mir auffer Den fiebnerlen efrten won Frôtchen, worutter Drey eigentlich to genannte frobiche, und viererley aroten find, Eeine andere 2(rt befannt iff. DenII ob atch) Diejenige Siroote in unferer Segend be: finblich fene, wovon mir erit juingftrin Serr S. E.D. Ghreber ans Salle in eitnem an mich abgelafienen Sdreiben, Nachridht geacben, follte io faft twei feln. (Es meldet mir nåmlid) Derfelbe, Dafis al\& er die Steine in Dem bey Dem Selofter Nosleben, funf Miei. len von $\mathfrak{5}$ alle befindichen Steinbuth felbit unterfus d)et, er unter einem Stein, eine Arote gefunben fo wie ein filumpen obne alle S̈erwerung Dagelegen eine blafie fleifhfarbe Brundfarbe gebabt, uno auf ber obern flách)e mit grasigrunen, ungleiden uno in Der Mitte abgebrocbenen suerfitreifen augigesteret ges wefen. So angenelim mir biefe Nadbricht war fo begierig bin ich audh gemad)et worben, diefe mir zur seit nod) ganz unbetamute Sirotenart zu feljen; ooch hier zu Rande will man tidsts von ifr wiffen, und Daß ez etwann gegenwártige Sirt fenn fönnte, wel be vielleicht wegen erfit verănderter Saut, ein frifcheres Infehen gebabt, ift auth une eine Snutbmafiung; weswegen ich mich Dem auch biebey nicht länger aufs balte, fondern nielmebr zu nâkerer 28 échreibung ges

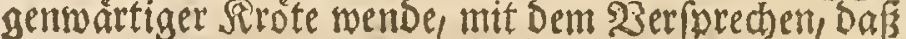
wenn id) obige nod lebendig zu reben befommen folls te, ich felbige, in Der folgenden Sef(d) reibung Der (E): bexen nachbringen merde.

$23 a 8$ num alfo unfere ftinfende Eandervite antbe: trifft, fo fuhbret felbige mit Der oben Tab. XX. befá)ries benen blatteriditen Sanberote mit rother Puaen viel

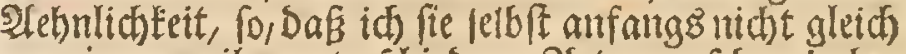

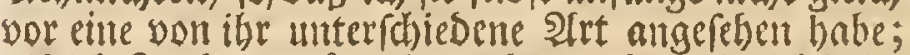
als ich fie aber genånet betrachtete, fo fande ich balo,

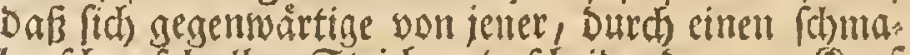
len forvefelgelben Stria) unteridbeide, Der bom Sepp an mitten burch Den Fudien bis an Das EnDe Deşel: ben fid erftredet. Sernad) hat Diefe ftinfende 2 and. frote Eeine feuerrothe श्lugen, wie jene; fonbern fie find um Das Eduroarse berum, blas uno bell aruinlidit: grau. Ferner ift gegenwártige Sirt vom Leibe viel fumpfer uns zufammengefdobener, als die tibrigen 


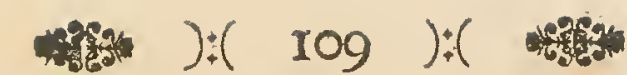

riorum pedum digiti nulla natatum juuante nectuntur membrana, fic et in pofteriorum digitis eadem illa prorfus abeft, fic, vt ob hoc ipfum bufo hic fuo quodam jure terreftris dici poffit. Proprium denique huic eft bufoni, quod non ad modun reliquarum ranarunn falter, fed pedilus inixus eleuatoque corpore muris inftar currat. Aft minus hunc ipfum continuat curfum, vbi enim iter quatuor quinqueue pedum emenfus eft, quiefcit aliquamdiu. Quemadmodum vero terreftrem illum bufonem, annofior etiam, magnitudine nunquam aequat, fic valde ab illo differt maculis primarioque corpus fuum tingente colore, qui tamen $v t$ in reliquis fpecicbus, fic etiam hic, in quibusdam faturatior magisque fpurcus, in aliis vero lucidior eft amoeniorque. Eo quo oua edunt tempore, gratior eft color hic quam omni alio, atque talis, qualem $I$. noltra exhiber, foemellam fiftens, icon.

Scatet fuperficies ejus fuperior, illa crurum pedumque excepta, in fundo faturato olinarum colore tineto, variis eninentibus fufcisque puftulis, aequalis fere inagnitudinis, minoribus tan1en paucioribusque, quam illae funt, quibus dorfum bufonis terreftris, oculis rubris, exafperatum eft, aft concinniorem feruantibus ordinem. Superficies inferior ex lucide cinereo, in oliuae nonnihil vergit colorem. Ad latera inferioris hujus fuperficiei variae cernuntur maculae, oliuae adinftar, virentes, quarum nonnullas quidem inferior quo. que exhibet pars; quibus tamen illae ad latera majores funt faturatiorisque coloris. Separat hinas hafce fuperficies, ab inuicen, lucide ex rubroflauefcens, lateralis fafcia inaequalis latitudinis, varie inflexa atque denticulata, vtrinque ab oculo ad crus pofterius ex. currens, et inferiora verfus, in fundo faturatiore, aliquot majoribus rubentibusque puftulis, nullum ordinem feruantibus, obfita. Similes aft pallidiores ju. ftulae occupant illum, pone oculos, locum, quo in bufone dorfo tuberculis exafperato, bina illa fita funt tubera; angulum vero oris verfus, aliae rurfus majores confpiciuntur puftulæ, lucide carnei coloris, ea racione coaceruatae vt cohaerere videantur. Primarius quatuor crurum ad pedes vsque color, idem fere eft, ac ille inferioris fuperficiei, fed variant eundem plurimae furuo oliuarum colore tinctae maculae, transuerfim pofitae, diuerfae formae atque magnitudinis, quales circa os quoque comparent. In nonnullis horum bufonum fufci funt extremi digitorum pedum apices, in aliis nigri fere.

Viuit bufo hic variis infectis, quibus, vti jam dictum eft, reliquae etiam nutriuntur fpecies. Haec noctu tantum fectatur: diu enim, vt omnem per hiemem, latebris fe occultat, quas dirutis in muris petrarumque foraminibus, vel elatiora ad loca et ad tumulos in terra quaerit, vbi interdum, praefertim vero in muris, deni quin bis deni deprehenduntur. Habitant nonnun. quam ad altitudinem, tres fere fuperantem pedes, in muri ad perpendiculum erecti foramine hiatuue, faepiusque miratus fum, poffe bufonem hunc in editum ejusmodi afcendere locun, quuın non, reliquorum more, faliat; fed didici tandem qua ratione eo perueniat, quum forte, oriente luce, alia prorfus eram inueftiga.turus. Vidi enim tum, nonnullos horum bufonum fat fecure, lentius tamen, veterem murum rependo afcendere, donec ad rinam perueniffent habitationis fuae portam, ex qua noctu, venatunn ituri, eadem rurlus delcen-
Srten alle; aud find ibre Sdentel und Fuiffe firrser unb Dider ; ta zwifben Den Beben Der Gintern Futfe finbet man fo wentg eine Floffenthaut, als zmishen Den 3 eben Der vorbern; meswegen fie Denn aud um fo vielmehr eime Ranbfrote genennet werben fan. (Endlid) bat aud gegenmartige Srote Desnegen ets was ifr alleine eigenes, Dafi fie nid)t wie anbere Frofd)arten hupfet, fondern auf ihren vier Filfen, mit erkabenem Sórper, faft fo finell als eine Maus Iauffet. Dod) unterbridt fie biefent ibren \&auf: Denn wenn fie etwann vier bif fanf Sd) weit getommen iff, fo ruhet fie wieber in etwas aus. 2lmferden

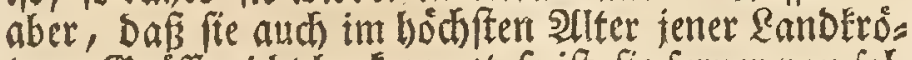
te an Sroffe nidit benfommet, fo if fie ferner von fols der Durd ibre Fledten und (Srund farbe mertlid) uns

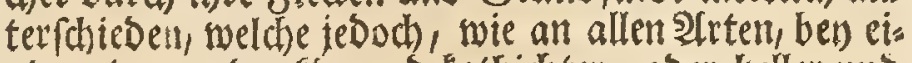
nigen immer Dunf(er.und fotbidster, ober heller und fricher, als ben andern ausfiebet. Bur \&aid) zeit if Diefe (srund farbe am fäbonften und fo befalfen, wie fie fid) an unferer i. Sígur ssiget, weld)e ein 2 beibs lein vorftellet.

Shre ganze Dberflide fuibret, Die vier Sthen: Fel nebit Den filfen nidjt mit Dazu geredyitet, einent Dunteln olivenfarben (Brund, auf welchem fich vers fobiésenc erbabene braunrotbe Şlattern zeigen, die faft alle cinerlen ESrófe baben, aber bod nidit fo gros noch aud fo zabletch als an Der blatterictitert Sanderote find, hingegen in befferer Dronung ftes ben. Die untere Flache ift ganz hell weislichtgrau unb fotelat Daben ein wenia in Das Dlivenfarbe. Iin Den Geiten biefer untern fláche zeigen fich in fets brger verfitiedene oliwengrine flecten, Dergleidsen zmar auch untenker zu faben; an den Seiten aber find fie groffier und Dunfler. Diefe beede fláchen find burch einen ungleith breiten, bellen uno róthlid)tgels ben, auch vielmals gefohmungenen und ausgeferbte Ecitenftreif bon einander unterf(b)eben, Der fith vom 2Ug an bis zu bem bintern Shbenkel, an jeber Seis te erfitedet, uno untenber, in Dumfeln (S) rund, mit cintgen grofien, rótblid)ten $23 a r z e n$ unorbentlid) be= rebet ift. Eben bergleiden, aber etwas hellere 23ars sen, freisen auf einem Slumpen binter Den 2rugen bens fammen , wo bey Der blatterichten Ranberote bie beeben 23 ullfte befindlid find, uno gegen Den 2 Bin kel Des s) Bunbes find ebentalls cintige groffe, bells fleifof arbe 2 Bargen fo nake beyfantmen gut reben, als ob fie aneinamber hiengen. Die vier Shenfel fübren bis ant Den Fus eitte faft eben fo helle Brund farbe wie Die Unterfládbe Desseibes, in relbiger aber zeigent fich viele buntle, olivenfarbe Suerflecten volt vers fhiebener (Srófie uns Form Deraleidhen and umbert Muno berum ftehen. Die aufferften Spizen Der $\mathrm{B} e=$ ben an allen vier Fuiften, find bey einigen foldten Siroten rótblicftbraun, bey einigen aber aud mebe fdimars.

Die Nahrung Diefer Rroite beftebet aus verfbie. benen Infecten, wovon fidh, wie bereifs mekrmalen gemelbet worben, auds bie ủbrigen 2irten náhren. Diefen pfleget fie nur Des ?achtz nadjugehen: Demt Den Tag uber bleibet fie; wie Den ganzen \$inter bins Durch, in ilyen Sdhlup fwinteln verborgen, weldhe fie (id) in alten Mauern und Steinriłen, ober aud in

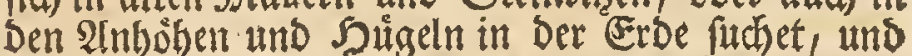
toorimten man, fonberlich aber im B̧emáter, mandh. malen zehen bis zwanjig berfelben bejfammen ans trift. Diefer ibr \$lufenthalt if zuweilen, wobl ubee Dren Sdub bod, in einer fentredten Mauter, eine Sitze ober Siluft zwirden Den Steinen, und Da bas be id) mich offers gewunbert, wie bod Diefe firote (o hoch binauf fommen Eorme, zumalen Da fie nicht, gleid andern, foringen Ean; endidi aber wurbe ids (ดld)e (E) 


\section{* *}

defcendendum ipfis erat ratione. Neque deeft pedibus ipforum neceffaria eum in finem ftructura, quatenus enim digitorum pedum apices nigri fufciue funt, corneam habent duritiem, atque adeo ipforum non pof funt non juuare reptatum; in anteriorum vero pedum vola, bina eminent offea tubercula, quae, ceu 3.monftrat icon, pallide carnei funt coloris, veraque funt offa, cum reliquis offibus propriorum ligamentorum ope nexa, id quod fceleton bufonis noftri clarius oftendet. Adhaerefcit bufo hic inferiore fuperficie fua, quam n11nores puftulae continue humectant, rectum ad murum, dum aerem hunc inter corpusque fuun, propiore acceffu, arcet, atque hinc ab aere ambiente ita ad murum apprimitur, vt aliquamdiu ex eo pendeat, aeque ac rana arborea laeui ex vitro pendet, id quod fimiliter aeris preflioni, nec foli cutis glutini, quemadmodum quidem in hiftoria ejusdem diximus, adfcribendum eft.

Extra generationis tempus, nullae quidem adfunt notae externae, genus indicantes: tum enim prorfus fimilis eft mafculus foemellae; ipfo vero illo tempore nofcitur mafculus, non folum ex graciliore corpore crurumque anteriorum craffitudine, fed etiam ex eorunden crurum pollicibus pedum; hi quippe tum nigram fcabramque habent maculam, vt rana fufca terreftris, led minorem, ceu 2. icon ad aidocet, quae tamen, hoc non obftance, ipfo in coitu, mafculum juuat, vt foemellam firmiore ftringere poffit complexu.

Celebrant Iunio menfe coitum, quo rana quoque aquatica viridis coire folet; quum contra bufo, dorfo tuberculis exafperato, binis tribusue menfibus prius opus hoc aggrediatur. Congregant fe hoc tempore, poft folis occafum, bufones noftri terreftres foetidique, iis in aquis ftagnantibus, quae ad ripas vadofae, nec non herbis et arundinetis circumdatae funt. Morantur ibidem omni illo tempore quo generationi operam dant, multoque clamore amoribus luis indulgent. Imitantur autem ranae arboreae fere clamorem, atque hunc mafculi tantum edunt, fimulque, ceu rana modo dicta, gulam ita inflant, vt faccuni aere plenum referat, quidilute cnerulei eft coloris neque, $v t$ in rana arborea, ad os vsque pertingit, atque adeo ipfis in faucibus prope oefophagum hiat. Clamant equidem jam Majo menfe, fi calidiores fuerint noctes, aft coitum eo ipfo tempore nondum exercent.

Info in coitu amplectitur mafculus foemellam ea. dem fere ratione, ac bufo terreftris, quem, hoc in opese, primum defcripfi, non tamen adjgit pollices fuos in einmal gerwathr, als ich eben anbere entdectungen zu madhen bef fáfftiget geweren: Denn Da fahe id et lid)e Diefer Rroten in aller Siderheit, aber gleid)fam ganj bedáchtlich, an einer alten 5auter hinatt Erie: chen, biz fie an einen Spalt DDer Deffinung famen worinnen fie ibren 2ufenthalt batten, anż melciben

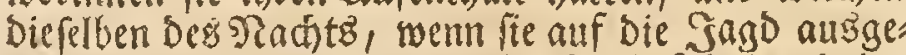
ben wollen, wieder auf gletche $23 e i f e$ fid) herab be= geben miffer. Sare Fulfe baben auch Die hisut er. forberliche (Einrichtung: Denn fo weit bie Zehen Der= felben, yormen an ben Epizen braun oder fhwars find, to meit fino fie aud) fo bart als 5 orn uno foon= nen alro gar wohl zum Selettern Dienen; tiber Dem aber ro (ind autch die vordern Fuffe mit zroed beintbar. ten Erbobangen an ibrer untern Fläche berfeben, weldse wie die 3. Sigut ber) bb zetget, eine blalfe

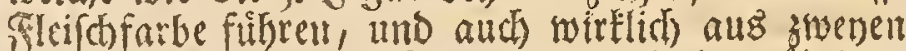
befondern Rnoken befteben, Die mit ben itbrigen

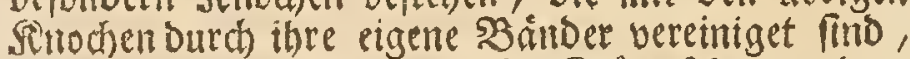
wie wir an Dem (33erinpe Diefer Rroote fefien werben. Sit ber. untern Flähe ihres \&eibes, weldhe Durch Die in felbiger befinblidse fleme Blattern beftandig an gefeutiotet mird, weis fid) Diefelbe aud all einer fent" = red)ten Minuer, wenn fie Die zmifhen ito umb Der

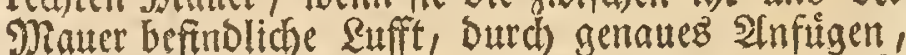
weggetrieben bat, ganz befte anzubaingen; wetl fie

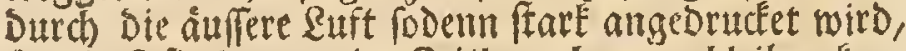
fo, Dafi fie Daran eine Beitlang hangen bleiben Eam twie Der Raubfroish an einem glatten (Jlab befangen bletbet, welches eben auch Dem Drute ber $\&$ uft, ntdit aber reiner doleimichten 5 aut alleine, wie in Der $\mathfrak{B} e$ : fhreibung Desfelben gemeldet worden, zuzufarets. ben ift.

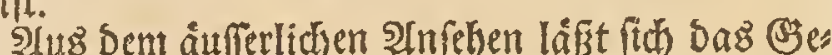

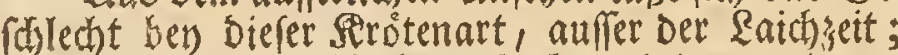
nicht fo leicht unterideiben als ben einigen andern: Denn beede Berdislecte reben eimander yolleommen ånnlich; zur Qatd)zeit aber find Die sgannlein nid)t alleine an ibrem geffimeidigen $2 e i b$ uno fegr Didfent Sorderichenteln, fondern audh an Den Daumen Der vovbern Fitffe bald zu erenten; indem diefe alsoent eiten fohmargen rauen Flecten fübren, wie Der Daus me bes Srazfrofdes, Der aber bier, wie aus Der 2. Sigur bey a zu erfetien, etwaz Eleiner ift, aber eben

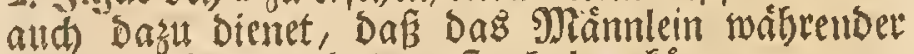
Maarung fein 2 Beiblein wefter balten fonne.

Shre orbentliche Segattungszeit fált in Den Jus

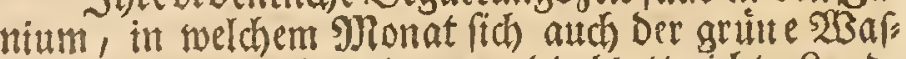

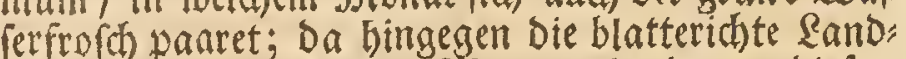
Eröte um zwey bis Dren Monate ebender zu Diefem SBerE forreitet. IIm Diefe Beit mut finden fich unfes re ftintertbe Qanberoten, nad) Der Somen Inter= gang, in siemlicher SRenge, in loldhen ftebendent 2 Baffern zulammen ein, weldhe am ufer febr feichte und Daben mit (3) ras und (Seróbricht berwadjenfind.

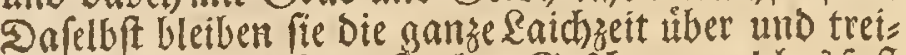
ben ily Riebezwert mit ftartem Sefchren, weldhes faft

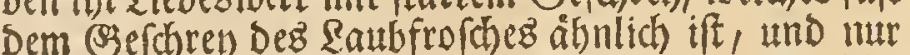
alleine von Den siámlein aenachet wirb. Ben bies fem Sefdrey ift an ibrer aeble eben auds, wie ber erifbenanutem Frord), ein siemlich groffer, bon Ruft aufgetriebener Sentel wabrzunebinen, weld)er blaus Iith tweis ausfielset, fich aber nidht, wie bev Dem $\mathcal{L} a u b=$ frofd bis an Den Mund erftrectet; und eben Daber hat biefer Bentel reine Deffinung binten im Muno nahe benm Sulunb. Sie laffen zwar diefes ibr (Be: (d)rey, bey warmen Siachten, auch fation im s)onat Man Goret, Deswegen aber begatten fie fít) um bies fe Beit Dodh nod nidht.

Ben ber SDarung felbft bålt Das șännlein fei: ne SSattin faft auf eben Die 2lrt umarmet, wie Die ers

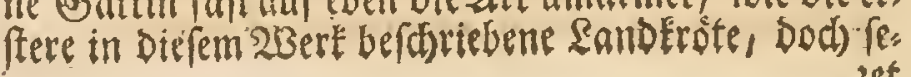




\section{)}

foemellae alas, fed admouet illos pectori potius. zet ez Die beeden Daunten mebr auf Der $\mathfrak{B}$ ruft, als

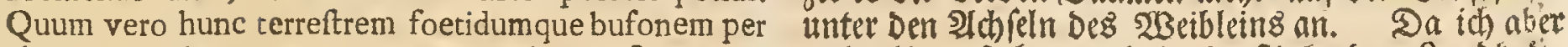
aliquot continuos annos examinauerim, octo, anno meine Interfutdung mit biefer ftimfenden Eanberóte 1756. quarto quintoque menfis Iunii die, collegi pa. etlid)e Jahre nach einander angeftellet habe, tnto fols ria, jam copulata. Singula in vitrum immifi cylindra. de im Jahr 1756. wieberfolte, brachte ich Den vier.

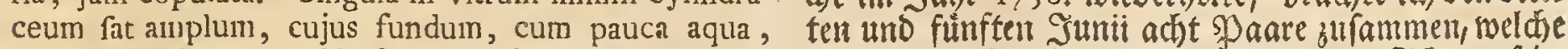
caefpes tegebat; quod bufo hic profundiores nunquam beretts mit einander veretniget waren. Jich warf jes

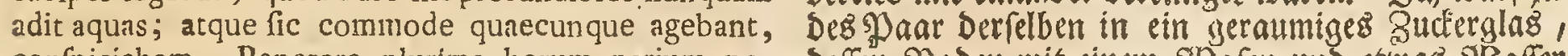

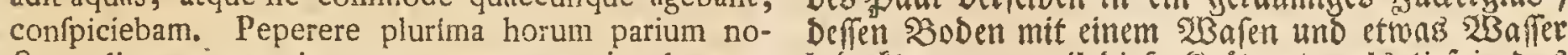
Etu, reliqua et matutino tempore, et quum jam luceret; bebeckt war ; weil Diefe Sróte niemald tief in Das notaui tamen, licet omnia fere eadem fierent, quae 23 affer gebet: und fo fonnte ith alles was fie thatem, de bufone terreftri, dorfo tubereulis exafperato, nar. ganz bequem wabunebmen. Die meiften von Diefen raui, citius hic ouorum foecundationem ac partum, adt Paaren laichten bes Nacht8, bie librigen aber vniusque tantum horae fpatio, fuife peractum. Pro- theils Des' Morgens, und theils am hellen Tag, wo:

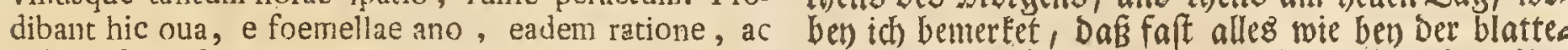
dicti bufonis foemella eadem edere folet, fic, vt bina ridften \&anderote zugieng, nur folgte hier Dag $\mathfrak{B}$ es

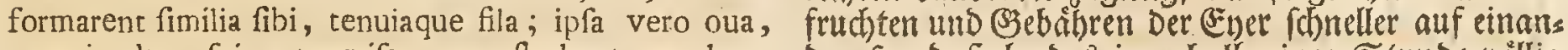
quae in altera fui parte grifeam monftrabant maculam, Der, fo, Daßi beedes innerbalb einer Stumbe vólitg cingebantur quidem pellucido glutine, fed nullos for- gethan war. Der Saich aber fam aud fier, wie ben

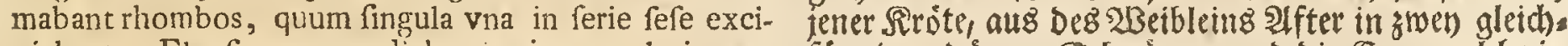
piebant. Elapfis quatuor diebus ita jan euoluti erant fórmigen Dimnen Edburen, und Die Ener, welhe in gyrini, vt facile difcerverentur. Die quinto ex itera- ibrer eimen Sälfte ebenfals einen weisgrauten Flecten to pernicique eorundem n1otu, viuere eosdem, jam zetgten, lagen zwar bier aud in eitrer bellen uno apparebat, neque ita multo poft, relicto fenfim len- Durchftel t gen (Sallerte. aber mebr einzeln, als Da fimque glutine, natatum exercere occipiebant, athae- fie rautenformige 2 ierecke formirten. Nach bren bis refcebant etiam herbis, quae ipfis pabula praebebant, vier Tagen hatten fit Die in felbigem entbaltene Rro: atque fic indies crefcebant. Erat ipfis color ex fufco tenwoirmer foblr fo entwickelt, bafis man foldbe Deuts niger, quem etiam feruabant, donec crura pofteriora lidh ertemen tomnte. Den fuinften Tag aabenfie bes comparerent; quae in nonnullis fib finem Auguft, reits ibr Rebon Durd mandimaliges fohnelles $\mathfrak{B}$ emes in aliis, menfe Septembri, confpiciebantur; fuperfi- gen zu ertemnen, worauf fie fid nad und nad aus cies autem illorun inferior multo jam prius cineracea ihtem Shleim beraus begaben, und imnter mebr und fuerat reddita. De reliquo fimiles prorfus erant gyri- mebr, von einem Drt zum anderit zu fotwimmen wag: nis bufonis terreftris fuperius defcripti, fi excipias, in- ten; aud biengen fie fid an Das (Srab an, woran duiffe illos tandem habitum magis verficoloren, eua- fie ibre ?aburung fanden, und wurben alfo von Tag fiffeque tantuin non majores. Referebant nonnulli eorundem, fub finem Septembris ingruenteque Octobri, omni ex parte, 4. iconem; alii tardius fub eadem comparebant fpecie, reliqua etiam tun erat pars exigua caudae, qua remi inftar vfi erant. Albebat jam ex cineraceo inferior eorundem fuperficies, fuperior vero olitae obducta erat colore, atque in hac flaua, cum puftulis rubris, nunc fefe monftrabat fafcia, laterales autem illae ex flauo rubentes fafciae, quae in hac fimiliter cernuntur icone, antea jam et confpicuae, et magis fuerant rubrae. Qunerebant jam, aquas derelicturi tenelli hi bufones, ficcum folum, hinc vitri, in quo illos feruabam, afcendentes parietes, iisdem, ad modum ranae arboreae, integros interdum adhaerefcebant dies. Euanefcebat reliqua caudae pars dimidii diei fpatio, atque tum fimilis erat bufo 5. iconi; ceterum eundem, ante tertium quartumue aetatis fuae annum, aeque ac reliquas fpecies, generi propagando non fore aptum, perfuafum habeo.

Dixi in bufonis, dorfo tuberculis exafperato, hiftoria, accufari eundem quod vaccarum vbera fugat, addidique me id ipfum nec affirmare nec negare; quodfi tamen fiat, vt et hic bufo eadem fugat, verfimile eft: prodit nanque fimiliter, paftum quaerens, noctu e latibulis fuis; quemadmodum autem rem certam effe haud 2jo: fic certo fcio, ejaculare illum, vexetur, nun-

z! Sag groffer. Eie batten anbey eime braunlidits fow warze Farbe, und biefe behielten fie fo lange, bis faft ibre hintern fiutfe zum 230 richem Eamen, weld bey eittigen zu (Ende Des 2 ugufte, und bey andern im September gefhabe, ifre untere Släbe aber wurbe vidl ehender weizgrau. Llebrigens famen fie faft in allem mit Den 23 trmern Der vorigen \&and fróte liber: ciil, ausgenommen Dafí fie endlid) von Farbe etwas bunter wurben und ein faum mertlich grofferes 2 ns fehen befamen. Bu Ende Des Septembers und mit Infang Des Dctobers, waren einige unferer 4. Figut volleommen åthnlid ; eintge aber gelangten auch et. was fpater zu Diefm 2(nfeben, und Da hatten fie noch

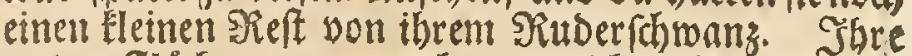
untere fFlåche war nummehr graulidstweis, Die obere aber fithon olivenfarb und in Diefer zeigte fich auch test Der gelbe sadkenftreif nebit Den rotben Slat. tern, Die gelblichtrotben Gettenftreife aber, welche int Diefer Figur ebenfals zu feben find, waren bertits ehen: Der Da geweeren und hatten rother ausgefehen. Nun: mehr fuchten biefe junge §róten aus Dem $2 B$ affer auf Das Trodene su fommen, wešmegen fie Denn aud an ben Seiten Des GHlafez, worimnen if fie batte, in Die Solbe Frochen, und offters ganze Tage, wie Det Laubfrofh, Daran bangen blieben. Der Reft inres Schwanges verlobe fich imerhalb eimes halben $:$ a ges gånlich, und alsbenn war bie junge seróte Des 5. Figur áfnlich; bis fie aber in Den Stand tommet thr (Bef(d)lecht fortzupflanzen, wird fie meiner Ders muthung uad), fo wie bie andern 2leten, wobl bren bis vier Tahte brauchen.

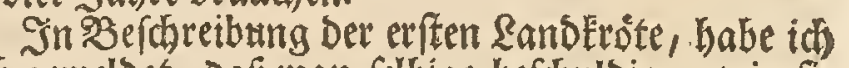
aud gemelbet, Das man felbige befohuldige, wie fie Die (Euter Der Ruibe auşauge, zugleid) aber if von mir gemeloct worben, Dafi ich foldhes weber bebaups ten woch verneinen wollte; gefhiebet felbiges abee wirtlich), (o Eonnte es auch wohl gegenwairtige 2urt thun, weil fie fich ebenfals bes SRacts aus itrem 


\section{)}

quam lötium fuum, vt primus ille bufo; humorem vero quem vexatus per cutem reddit, et quo non profluente nunquam foetet, omnino vi quadam emittere poteft, quemadmodum fequenti capite fum narraturus.

\section{SECTIONIS VII.}

Caput II.

\section{Bufonis terreftris, foetidi interio-} ra, generationique inferuientes

partes.

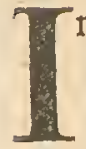

teriora ejusmodi animalium rimaturus atque adeo eadem diffecturus, forcipe vtor, qua pedem animalis arripio, dein fingula crura filis conftringo, illudque ad afferculum alligo, vt magis conmode diffecare queam. Bufonum itaque fcrutaturus interiora eademque agens, tam e tuberibus bufonis terreftris, dorfo tuberculis exafperato, pone oculos fitis, quam e cruribus pofticis bufonis ignei, profluentem vidi humorem quendam, nullo fimul percepto foetore; quum autem hanc bufonis peciem diffecui, manauit non folun ex ipfius corporis fuperficie albens fpumofusque humor; fed objectus eft finul naribus meis, intolerabilis ille foetor, ob quem ipfan, bufonem terreftrem, foetidum appellaui. Differt tamen ratione graueolantiae foetor hic, prout nempe bufo, vel ob captiuitatem, vel alias ob cauffas, plus minusue humorum perdidit; fimilis etiam eft odor ipfius, odori quidem pyrii pulueris accenfi, fed accedit magis ad odorem auripigmenti ex tritu calentis; olent fic etiam tubuli nomnulli fictiles, recentes adhuc, quibus tabaci fumum haurimus; aft enimuero odor ifte femper eft deterior. Oriri autem eundem ex humore quem vexatus bufo ennittit, hinc certus fum, quod, vbi nullus cernitur humor, nullus etiam percipiatur foetor, quumque nuper in conclaui meo ejusmodi bufo e vitro exemtus fuifet, foetidum hunc humorem ea ejaculauit vi, vt licet ad quatuor remotus effem pedes, guttulae quae. dam in qum meam defluerent; fuiffe vero eundem latius etiam difperfum hinc concludebam, quod foetorem in ejus loci vicinia, in quo bufo diffectus fuerat, binos fere olfeci menies. Cupidus hinc reddebar, ipfam virulenti hujus humoris fcaturiginem viasque, per quas ad cutem deferatur, nofcendi: has tamen detegere non potui; quum autem, vbi pellis huic bufoni detrahitur, in alis aeque ac circa inguina, ex pallido flauefcens adipofumque corpus, vel glandula quaedam, in confpectum prodeat, quam in nulla alia ranarum bufonumque fpecie confpexi, tenuem, vt videtur emittens canalen, in alios tenuiores difpertitum, eandem foetid hujus humoris fcaturiginem effe, perfuafun habeo. Ad exhibendas glandulas hafce, depictam dedi icone 6 Tabulae IV. inferiorem bufonis hujus fuperficiem cu cutem detraxi ; indicant in eadem litterae $c c$ fuperio. res, $d d$ inferiores glandulas, e e e e autem ex iisdem prodeuntes canales. Hi, quantuin quidem conjectura affequor, alios tenuioresque in cutem dirnittunt ca. nales: licet enim cutis, quibusdam in locis, ipfi corpori vix adhaerere videatur, cum abdomine tamen cruribusque, ope tenuium fibrarum, ea cohaeret ratione, vt licet hae ipfae vix cernantur, cultri acie fit diffecanda.
2)

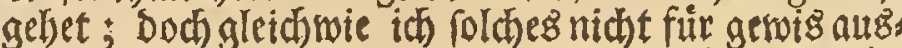
gebe: fo fan id hingegen behaupten, Dafis gesenwär. tige 2rt, ibren Sarn ber) einer $\mathfrak{B}$ erfolgung niemas Ien fo, wie die erftere Randfròte von fich foribe, bie Fenú) tigfeit aber weldbe fie Durch Die Shaut von fid giebt, wenn man fie beummthiget, unio oljne weldse man feinen Sefeftant ben ihr merfet, fan fie gar wohl

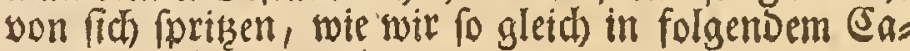
pitel bernehmen werden.

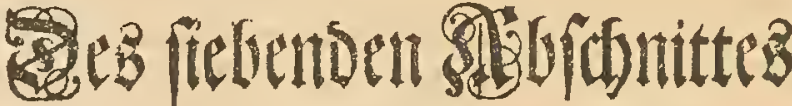

\section{כwweytes Capitel.}

\section{Der fitinfenden Randeróte immerlide} Beichaffenbeit nebit Den zur Fortwfantjung

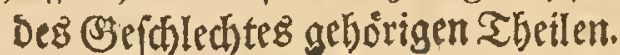

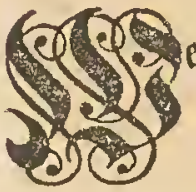

enn id Sergleichen (Ereaturen aud) nad) ibrer inneren Structur unterfuchen und beswegen offinen will, fo bebiene id mich Dazu einer Sange, um fie mit felbiger an einem fus zu ergreiffer, uno bernach lege ich um ib)= re vier friffe Fidoen womit ich diefelben focenn all eis nem Sretlein beuctige, um fie fo viel bequemer auf= (d) bat fo wohl bie blatteridte Landtrote, aus ibren bin: ter Den 2(tigen befindlit)en 2 (Bilften, alz aud) Die Geuererote, aus ibren bintern Shenléln, eille Feud). tigfeit von fid) gegeben, oblue Dafi idh zugleidh einen mertichen Seftank empfunden bátte; als ich aber mit (Sroffinumg von gegenwårtiger Sirotenart befd)åf: tiget war, seigte fich an felbiser uber uno liber ntdist nur eine fhanmende weiffe Feuchtigfeit, fonbern id empfant audi zugleich Denienigen unertrågliojen Sie frant, um welches willen ich fie die ftintende $\mathfrak{L} a n b=$ frote genennet habe. (F8 if fold)er ben einer folden Rrote immer ftrinker als ben Der anoern, nach bem felbige námliç megr oder weniger Sisffe, wáhrender ifser (Sefangenfd aft, ober aud) um snberer Lrfachen willen serlobren baben mag, und riechet zwar wie angertindetes Schiespulver, aber Dod melne wie Raulchaelb wenn es Durch steiben erwårmet wit'

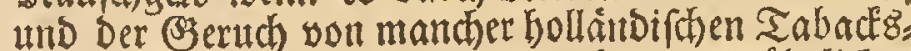
pfeife, bie noch nent ift, hat aud) etwas afhnliches mit ibm, Dod if er allezeit ftáter uno viel wieber mårtiger. Das aber Derfelbe von Der Feuditig Eeit berEumme Den Diefe SRote auz ben $23 a r$ zen ibrer D: berfläd) werm fie geangftiget wirb von fid) giebt, bin idf Daher ủberzenget; weil wenn man nichts von Diefer Feudhtigfeit fiebet, auch Eein Geftank empfun: Den wirs, und als jungfthin in meinem Bimner eine folde Sirste aus Dem (S)laẺ genommen wurde, fprizte fie Diefe ibre ftinfende Feudtigkeit to weit von fich, Dasi, Da idh vier 5 d)uls weit Davon entfernet war nir etlicke Sropfen auf Die 5 and fielen, und Daś fel bige auch an andere Orte bingefallen feyn mufte, fonnte id Daraus foblieffen, weil ich) Den (J)eftant faft swen Monate lang in Der Siegend wo fie geofinet worden entyfand. Eben Desmegen aber wurbe it begierig Die Duelle Diefes einiger maffen giffitigen

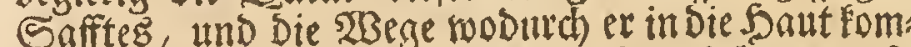
met zu entoedferi; alleime was biefe anbelanget, to war nichts za finden; $D a$ aber, wenn Diefer firote Die Saut abgezosen wird, fo wohl unter Den $2\left(c^{2}\right)=$ reln alb in Den 2Beichen ein befonderer bellgelber Fett. Forper, ober eime Drife zum Borfdein Eommet, wels dhe ich in Eeiner andern Froff = DDer Sirotenart an getroffen, tho bie fid) wie in einen zarten Sanal en 
Diget, woraus wieber andere fleittere und zártere entfpringen: fo follte id foldhe fait fuir Die suelle dies fer ftinfenden Feuditifett balter. Um Diefe Drus rem Deutlicher za zeigen, babe ich in ber 6 . Sigur uns ferer XXIV. Sabelle den von feiner Saut entblófen Siorper einer foldhen Sirote von feiner atntern Fläche vorftellen wollen, uno Da find Die obern Dritfen mit $c c$, Die untern aber mit $d d$ bezethnet, bie aus fels bigen entipringende weiffe bemerfet. Diefe nut erfirecken fich meiter 2 ermus thung nad) Dur(h) veridhiedene andere zartere 2lefte bis in Die Saut, Denn ob Diefe gleids an mand Drtell faft gar ntcht mif Dem fiorver zufanmen bangen fdeintet, fo iff fie bod am unterleib und an Den Sdhenteln vermittelif fo sarter Fafern mit Dem: felben verbunden, Daśfie allezet mit Dem Mieffer ab= gefondert werben muf , Die fafern relbft aber faft nidht gefeben merden.

Fateor quidem nullum, fi flauas has glandulas Siun nusich 3war gefteben, Daf in Diefen gyelbent Drifen, ment fie abgel ofet ooer entztoet) geftuniten

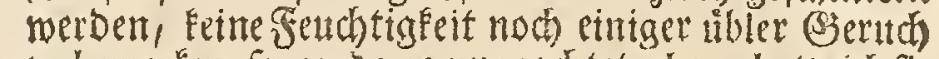
za bemerken ferte; Deme ungenctet aber, balteich fie Dod) fo lange tur fold e Jeorper, Die zur 20 fonderung befer fintenden endigtigket etwas bentragen, bis ich Durd weitere unterfubung, ob? aud burd ans Dere, bie fich Darum bemihen wollen, befier belebs= ret werbe: Denn wenn aud gleidi in felbiaen fetne tibelriechende feudtigleit entbaltent if ; To Ean Dods wobl burch lie etwas abgefonbert werben, weldies went $e^{5}$ in jer 5 aut Det Sirote mit einer aubern Mias terie bermifhet woird, erft Den Steftane machen hilft. So bat weder ber Salmtar no d) Das Weinfteinfals

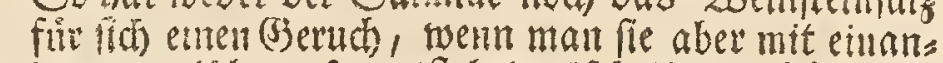
Der vernifdhet, fo entifibet alfobald eit flicditiger Esiritus der bie Nafe siemlia angreift. Ob aber

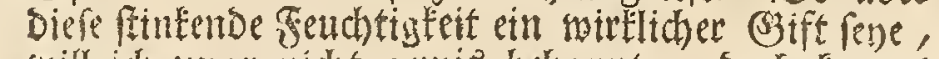
will th swar utcht gerwis bebanten; Dod fomme mir folches bezwegen wabrefoeinlid) fir ; weil fid ote Serote derielben, wite Dif vorige 23 alfererote und

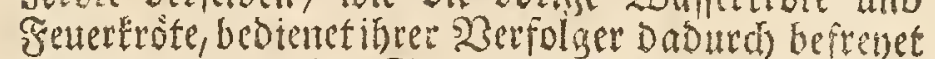
zu werden, uno Der Stord) Diep Drewerley Arten Der Siroten niemalen verfchludfet.

Dis erft angefunrte fedy) fite Sigur seiget nod) fers

Monftrat porro fexta fuperius citata icon, effe huic bufoni prae reliquis, carnem admodum furcam ; fiftunt fefe etiam, in illa, confpectui noftro, mufculi pectorales, rectique abdominis cum tendinofis fuis in. terfectionibus; illos binne indicant litterae $f f$ fuperius, hos illae $f f$ inferius pofitae. Ad $g g$ latent binae vericae pulmonales, quae, in hac bufonis fpecie, firniliter admodum magnae, inferius tamen, non aeque ac in aliis acuminatae, fed magis planae funt atque obtufae, cellulasque habent fat grandes, inter quas majus quidem difcurrit fanguiferum vas, ex quo tamen haud multi oriuntur rami. Confpiciuntur ad $b b$, fub tenuioribus mufculis, luteae adipofaeque renum appendices, quae tempore generationis, vt reliquis in ranis, valde funt magnae, poft illud autem rurfus decrefcunt. Ad $i$ fita eft inteftinorum pars, ad $k k$ hepar, ad $l$, denique exigua ovarii portio.

Partes generis propagationi inferuientes, quae tum demun in confpectum prodeunt, fi ex diffecto ejusmodi bufone pulmo, hepar, ventriculus atque inteftina auferantur, in foemellis fimiles funt parribus quas 7 . fiftit icon. Orificia binorum ouiduetuum, quae prope cor 0 hiant, licteris $m m$ funt fignata, ipfum vero cor pericardio fuo adhuc veftitum, ex quo fuperius bina ad $n$ prodeunt vafa fanguiflua, heic eum in finem huic addidi iconi, ve ipforum horum orificiorum propria cerneretur fedes: partibus namque generationi dicatis minime eft accenfendum. Sar huic bufoni eft magnum, sunquam ner, Dafi diefe Sitrote, fuir andern ein befonderez (d) warboraumes Fleifh babe, auth find an filbiges

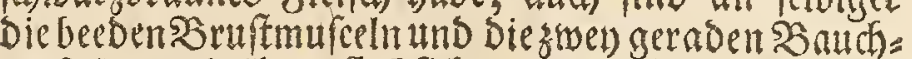
mufceln, mit itgren flechfichten Durdhichnitten, zu fes ben, da Demn iene Durh Die beedent obern f't, und Diefe Surch die untern ff angezeiget merben. 'sien gg liegen Die zwers Rungenblafen verborgen, weldhe in biefer 2(rt zwar aud stemlith gros, abet untens ber nidhe fo zuaepizizet, wie beis andern, fondern platter unto ftumpfer find, and febr groffe Fradhet haben, zwifden weldhen zwar auch eine Sauptaber Durdilanfer, fich aber nitut in vide शlefte bertbeilet. SBen bl (d)einen Durch Die Dunne Fleitchlaut Die gels ben und fetten 2 (nhange Der Nieren Durch, weldie, wie bet) andern, zur $\mathfrak{E}$ atd zeit febr gros find, nablyer aber wieber ziemlith abnehmen. Ben $i$ liegtein Sheil

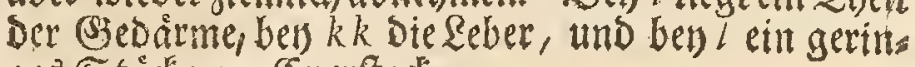
grs Stud vom (Fverftok.

Die zur Fortpflanzung Des Sefoledetes gehơris ge Theile, welche alsbenn erft recht zu feben find, wenn Runge, Reber, Nagen und Sseoarme aus einer folchen eroffneten Srote berauggenommen werben, baben in Dem $2 B$ eiblein, nach unferer 7. Figut, folgen, De SBefdaffenthet. Die Deffnungen Der beeden Ever. gainge, welche allezeit am Serzen ofich befinden fimb bier mit $m m$ bezeirhnet, Das. Sers felbft aber, fo now in feinem Bentel liegt, worans oben Die zwen SBlutaefáre ben $n$ fommen, if in biefer Fiaur von mir beibebalten worden un oie \&age Diefer Deffimn 


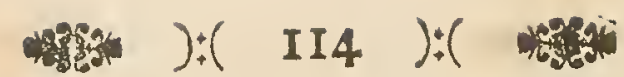

nunquam tamen tam grate rubet, ac cetcris in bufonibus ranisque. $\mathrm{Ab} m \mathrm{~m}$ admodum amplifunt bini ouidu. ctus, an te tamen quam fedem illam pertingant litteris $p p$ fignatam, fenfim lenfimque contrahuntur magisque pellucent quam reliqua eaque longior ipforum pars, quae multo eft anguftior varieque inflectitur, in progreffu tamen fuo, praefertim vbi ab vtero propius abeft, denuo dilatatur; vergit etiam partis hujus color in carneum, ipfius vero cum vtero conjunctionem litterae indicant $p$ p fecunda vice occurentes. Lacer femper magna horum ouiductuum pars fub ouario $u u u$, vt ad laeuum iconis noftrae latus videre eft, fed dextro in latere de induftria protrastum ouiductum ouarioin1pofui, vt varias ejusdem oftenderem flexuras. Vterus bifarian diuilus, qui aeque ac ouiductus aere eftrepletus, fic autein aere dilatari poteft vi prorfus pelluceat, bina refert cornua introrfum flexa, litceris $p p, q q$, notata. Appendices luteas adipofisque littcrae indicant $r r r r$, inteftinum rectuin $\int$, veficam duplicem, quae, aere repleta, valde eft magna $t t$. Adipofne ap. pendices ipfumque ouarium nunc majores funt, munc minores, prout nempe easdem vel ante, vel poit ge. eerationis tempus contemplamur.

Partes generationis mafculorum, a reliquis abdominis partibus liberatas, 8 . monftrat icon. Titterae 2070, 1070 oblongis adfcriptae funt renibus carneo tinctis colore, $x x$ tefticulis, qui hoc in bufone liuent atque in fuperiore fui parte adipe tecti funt. In exteriore eorunden margine defcendit in vtrogue fimplex, cinereus haud ita tenuis canalis, rectum inteftinum verfus, cujus pars diffecta $y y$ hic cernitur, in qua bini hi canales duplici orificio ad $z$ hiare videntur. Confpicuae porro funt in eadem icone luteae adipofaeque ap. pendices $r r, r$ nec non exinanita vefica $t$ t.

Quod de fceleto hujus bufonis 9. icone repraefentato dicam, vix habeo, fi excipias bina illa offa in inferiore fuperficie anteriorum pedum haerentia, quae, vt fuperius indicaui, muros fcandentem juuant; haec vt recte monftrarem, addidi 10. icone inferiorem anterioris pedis fuperficiem, in qua ofla haec $\mathrm{A}$ et $\mathrm{B}$ fignata funt, efficiunt eadem, ipfa illa plana carneoque colore tincta oflea tubercula, quae 3. in icone litterae $b b$ indicant, quaeque ceteris cum offibus ea ratione cohaerent, vt in ipfius fceleti praeparatione facile auferantur, vel, vt hic factum eft, dimoueantur. Ip fa ceterum crurum offa breuiora funt quam reliquis in fpeciebus, offa cetera quae eundem, ac in illis feruant ordinem atque numerum, praeter mutatam nonnullorum conformationem, nihil notatu dignum exhibent.

Ante vero quam finem huic imponam hiftoriae, indicandum mihi eft, appellari bufonem hunc in Saxonia die Hausuncke, quod crebrius ruri in domibus habitat nec non in illis terram fodit egeritque. Sed memini etiam, dixiffe me in hac ranarum hiftoria p. 88, quum de terreftri bufone, dorfo tuberculis exafperato agerem, me gen Der Energänge genauter anjuzeigen: Dent zan Den zur Eraengung Dienenden Theilen geboret es nicht. Es ift hier ziemlich gros, niemalenaber fo fobin rotb, wie bey andern Siroten und Froffien. Bon $m$ m an find bie (syergánge fehr weit, Doch werben fie bis an Den Ort, wo Die zwen $p$ p Dag erftemal ftelen, immer enger, und bis Dabin fins fie auch Durdhfid)s tiger als Der úbrige léngfte Tlact Derfelben, welcher viel enger if uns mandherler 2 seugungen madet, fid

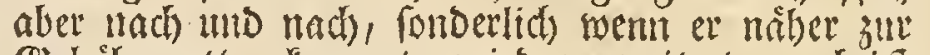
Bjebályrmutter fonmet, wieder erweitert; aud ift Diefer Theil etwas fleichfarbig, und feituen Eingnitg in Die Szebáthrnutter, zeigen Die zum ztuentermal vorEommendent pp an. Droentlidber 2Geife lieget ein groffer Theil Diefer Eaergänge unter Dem Evyer. frott $u$ u u verborgent, wate all Der linter Seite anles rer Figut; an Der rechten Seite aber habe id Den (E)ergang init fflets darunter bervorgezogen und uber polchen geleget, um Die verfhiebenen sBengungen Desfelben Dentlicher ju zeigen. Die geboppelte siut. ter, welche, wie bie beeden Evergainge felbften, mit Ruft angefillet ift, fich aber noch ftoriter uno fo alts, blafen lảst, Das fie gans Durchfichtig wirb, formitet cin Saar einwärtz gebogene Sörner, meld)e burd) $p p, q q$, angedeutet werben. Die gelben Fettanl)ảs ge fint mit rerr bezeichnet, Der Siafto arm nit $f$, uno die gedoppelte Sarnblafe, weldbe, wenn fiemit Suft angefullet wird, fich jiemlich gros seiget, mit $t$ t. Die fetten 2(nt)inge und Der Everfto malen groffer, mands) malen aber auth fleiner, nach bent man felbige namilich vor oder nach ber Raitbzeit zu fes ben befommet.

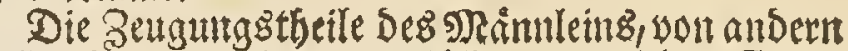
FGeilen sez unterleibs entbloffet, zeiget Die 8. Figur. jom, wro find Die langen fleifis farben Nieren, uno $x x$ Die (S)ilen, welche ben Diefer Strotenart braun= fowwarz ausfeben unt obenber mit gelben fett bedes fFet find. İn Dern áufiert SRand Derfelben lauffet an jedem eim einfacher, weiggrauer etwag farfer $\mathfrak{C} a=$ nal berab nad) Dem Maftoarm zu, yon welchem bier ein Sheil $y y$, Der aufgefdintten worder, za fel)en ift, wo fie ben $z$ cine Doppelte Deffinng fu baben fobei nelt. Ferner fehen wir alth) nodh in biefer figur Die gelben und fetten 2 anbange $r$, $r r$; neblt bee leeren Sarnblare tt.

Ben Dent (Berippe Diefer Srote, weld)es id it ber 9. figur mit babe beufingen wollen, habe ićs

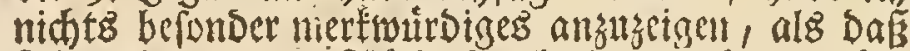
fich an Der untern Fläde Der beeden vorbern Sulfe stwet befondere platte finochen befinden, welche wie tch oben gemeldet habed Diefer Seróte zum Silettern bels fen, uno um fold)e redst zeigen zu Eónten, ift in Der IO. Sigut, ber vordere Fus mit feincr untern Flá. d)e von mir vorgeftellet worden, da fid) Denn bei) $\mathrm{A}$ und B Diefe beede Sinochen befinden, welche Die it Der 3. Figur Duta) $b b$ angezeigte swer) platte fleif(t) farbe $23 a r z e n$ ausmat)en, und mit Den librigen Rnodjen fo yerbunden fino, dấ fie gar leichts Iidh in SEereitung eines folchen Sceletes verlobren geben ober audh, wie bier gefibeben, fith verfoteben. ubrigens find atth Die Sinodien Der vier Sd)entel wiel furzer als an allen andern 2(rten, und von bet

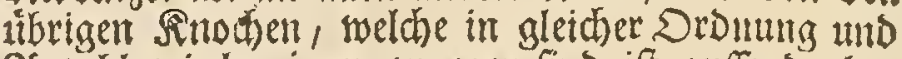
श्(ngahl, wie bey jenen zugesen find, iff, auffer ber ben einigen in etwas veránberten S3eftalt, nidhts befon: Deres zu merten.

Ebe ith aber biefe Siftorie endige, mus ich anth nod) anseigen, Dafi Die jest befhrtebene Rrote in Sadfen bie Sautinde genemmet werbe, indem fie

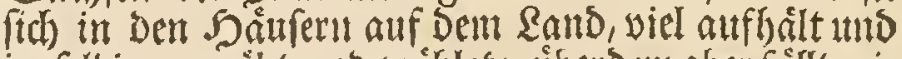
in felbigen grábt uno weiblet; uberdem aber fallt mit

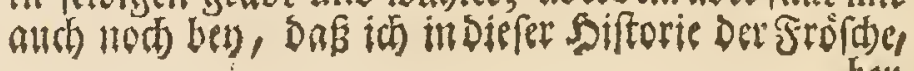




\section{)}

inferius plura de bufonite effeprolaturum, atque hinc the illo quoque pauca adhuc funt addenda. Libavivs fufius de eodem differens *, tres ejusmodi defcribit lapides: primum gemmam appellat e capite bufonis detractam; fecundus mineralibus eft accenfendus; tertius arte paratur. De binis hifce heic quiden nihil fum dicturus, quod vero ad primum attinet, ajo, quod in plurimis illis, quos diffecui examinauique, quatuor fpecierum bufonibus nullum, inuenerim lapidem, neque etiam credain, poffe fic dictum bufoniten ex offe quodam capitis horum bufonum parari, quum, quem. admodum fceleta, quatuor harum fpecicrum quas defiripfi, monftrant, nullum ex capitis offibus ejus fit magnitudinis, vt inde ejusmodi formari" poffit lapis, qui magnitudinem vnguis habeat, quam bufonitae habere folent, hinc potius eorun! accedo fententiae, qui lapides hofce cochlearum opercula, vel conchas minores petrefactas efle, autumant; plura vero hac de re addere fuperuacaneum mihi videtur: Arque fic finio hiftoriam ranarum noftratium, cui breui illam Lacertarum noftratium additurus fum, fi compererim, rerum naturalium cultores eandem effe defideraturos.

- Batrachiorun Lib. II. p. 4i2. feqq.

\section{F I N I S}

hiftoriae terreftris foetidique bufonis, ranarumque noftratium. bey Şerdreibung Der blatteridten Landerote S. 88.

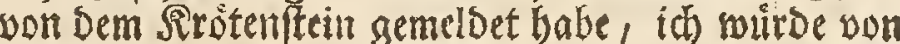
felbigem, unten befiere (Selegenticit zu reden befons men, uns alfo mus id auch noch bon fordem etwas melben. Sibavius ber Gievon meitliuftig bandelt* befdreibet unB Dreverlen Diefer Steine. Der erfte foll ein Stein ferm, Der aus Dem Sopf Det Slote Eom: met, ber andere getooret zum Steinetich und ber Dritte wirb Dutro sunft gemacher. $2230 n$ Den bee. Dent lekeren babe ith hier nicht zu banbeln, won ben erfterir aber, fage id) nur fo viel, Dafi ich in Den vies leat Siroten, von allen sier Ilrten, bie ich unterfits chet und zerfhnitten babe, keinen Stein geftmben, und and nicht glaube, Dafi Der angebliche Sirotens fein aus einem sinodrelt ibres Ropfes gemadjet wer. Den forme; weil, wie Die ESerippe unferer vier Seros tenartent nusweifen, in ibrem sopf feit Sindhe fo gros ift, Daf man Daraus einen Stein follte formis ret Eomten, Der Die Bstoffe eines Nagels am finger batte, wie Diefe firotenfteite zu haben pflegen; und alfo fimme iob vidmebr Deverjenigen Neinung bets welche Dergleichen Stzine, für Dectel von Sceidnes den ober fiir fleme verfteinerte Jiufdheln balten, ein melyereb aber allhter Davon zll melben, foheinet mir unnothig za fetyn. Diefemnad) fehlieffe ich biemit meine matinlidhe Siftorie Der Fróthe biefigen Eans

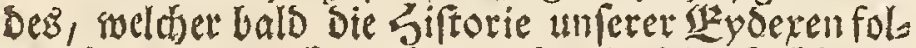
gen foll, wann ids merken werbe, Das Die Licbhaber Der uatirlichen Siftorie foldbe zu feren sBer

langett tragen.

\section{E $\Re$ C}

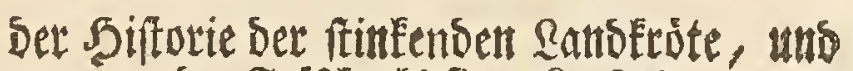
Der Fropiche biefigen \&aubes.

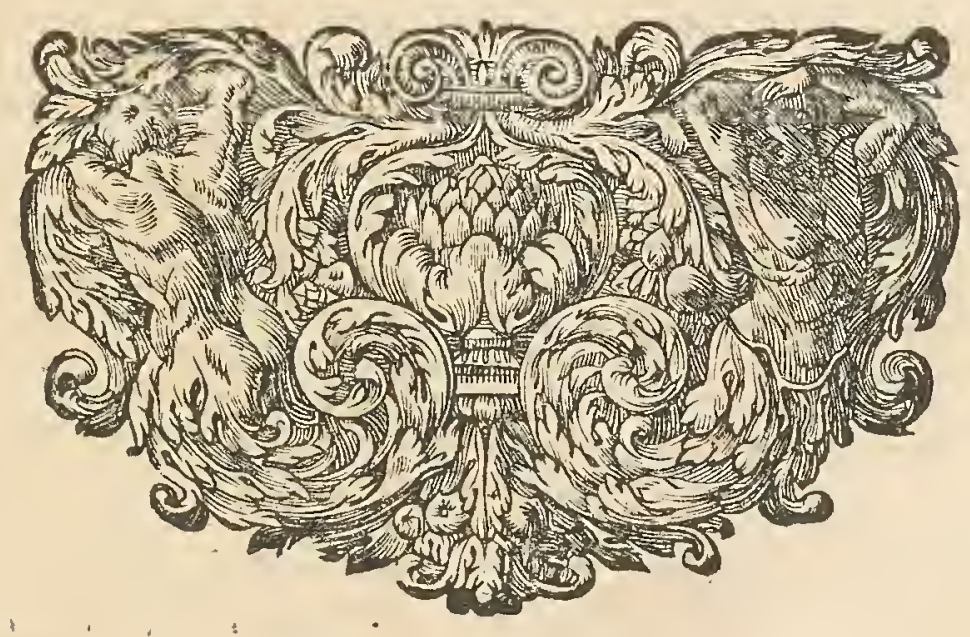




\section{E R R A T A.}

Rag. I Lin. 7, ante finem, bracchiis, lege, brachiis. - 2 - 17 , ititemque, lege, itidemque

- 5 - I, poft partent, adde aquis

- $6-3^{2}$, vndeuigefinoque, lege, ct vigefomo primo.

$-7-8$, idem occurrit error

- - - 27, duodecimo, lege, vigcfimo quarto.

- $9-18,-24$, fcribe 22 .

- 10 - 7,6, frribe $p$.

- - I, $\int$ f fribe

_ _ - I4, ante finem, dereliquentes, lege, derelinquentes.

- 12 - I, partinm, lege partium.

- - - 2, fuerit, lege, furint.

- 13 - 7, europaeas, lege, europaeas.

- - - 4, in fubjecta nota, Cent. lege, Cent.

- 16 - 25, moubatur, lege, fefe mouebat.

- 17 - 32, won mulla, lege, nonnilla.

- I $^{2}$ - 9, credecbam, lege, credeban.

- ID - 15, ante finem, poft defcriptione, ponatur,

— $20-16$ - - - vcntriculus - - ,.

- $23-26--$ - vidi - -

- 28 - $37-5$, poft arborea, ponatur:

- 38 - I, anterrioresque, feribatur, anterioresque.

- -4 , ante finem, pont affirmat adde, $(t)$

- 39 - 3, poft Gesnervis adde, $\left(^{*}\right)$

- 43 - I, poft fruftra deleatur.

- 43 - 10 , ante finem obfuram lege obfaram.

- $47-8$, cintero, lege cincrco.

- 50 - I, arboreae, lege, arborea.

- - ponantur ante linean 5 , a fine: CapvT II. Intemmae razlae arboreae partes.

$-54-6$, dadurus, lege, daturus.

- 57 - 12, ante finem, wanernm, lege mumerum.
Pag, 60 Lin. If, arboreaque, lege, arboreacque.

- - 27 , ante finem, nouanque, lege, noum mute.

- 60 - 4, ante finem, baec, lege, bae.

- 6I - 7, ante finem, primis, lege, primus.

- 64 - 26, ante finem, necefarii, lege, necefjaria

- 72 - 5, ante finem, cerminns, lege, comimus.

- $74-5$, ante finem, libidinem, lege, libidine.

- 76 - I4, ante finem, $27 n a m$, lege, vmum.

- 77 - 18, cortundem, lege, earundem.

- - 19, indicarc, lege, indicare.

- - 2I, comporanti, lege, comparanti.

- 79 - 12, ante finem, crurium, lege, crurum.

- $84-12,1$ dicantur, lege, Indicantur.

- - 37, ante finem, $b$ fonis, lege, bufonis.

- - I7, ante finem, offi $m$, lege ofium.

- 86 - II, ante finem, bufonum, lege, bufonem.

- 87 - 6, fere, lege, fere.

- - - ante finein; humitatcm, lege, humiditatcm.

- 88 - 24, polt plures, pone, vinos.

- - - 18, ante finem, line, lege, quc.

- $92-19,-$ - qlico, lege illico.

- 92 - 1, In ueniri, lege, imenivi.

- - 24, ipfim, lege, ipfan.

- - - 32, mufculum, lege, mafculum.

- - II, ante finem, nigri, lege, nigra.

- 93 - 9, oui forme, lege, ouiformi.

- 95 - 14, ante finem, de foriptorum, lege, defcripto. um.

- 99-4, anferuamque, lege, anferumque.

- - 22, ante finem, vdris, lege, vndis.

- IO, ante finem, vi ri, lege, witr.

- 104 - 16, ante finem, quo, lege, qua.

- $108-7$, ante finem, illis, lege, illius.

\section{febler.}

Geite 2 Sin. 28, Rinnanus, liēê, Limnáus.

- 3 - 16, cincm, lies, euren.

- 4 - 12, von unten, made nadi Weiblein, ein,

- 7 - 38, zmólffen, ließ viet und jwansigfter.

- $10-11$, fir $b$, lege $p$.

- II - I4, int, lieł in.

- 12 - 10, gleid)ten, ließ, tlid)en.

- I4 - 32, von unten, Eommen, lié, Eonne.

- -6 , von unten, angeher, lié, nact)geben.

- $16-2$, brounen, ließ, biatnen.

- 20 ill ber legten Śnie, ausobbnen, lies, ausoebrem.

- $21-30,6$, ezze $t$.

$-24-14$, von unten, 2 , fege 1 .

- 26 - 22, werden, liés, worben.

- 40 - 17 , feinen, lieg, feimem.

- -23 , fold sen, lies, foldiem.

- - - 27, felbigen, ließ, felbigen.

- 45 - 7, von unten, berrite, liek, beleits.

- 46 - 29, insgefammt, ließ, insgefamt.
Eeite 46 sin, 3r, betfurragenden, ließ, berooragenden.

- - 24, werder, ließ, werden.

- 50, Seze bor Der 6 linie von unten : Smentes Cavitel: Die innern theile des Lanbfiofhes.

- 54 - 21, von unten, ciue, lies, cine.

- 58 - 3, befdrieben, ließ, befdreibetr.

- $59-12$, von unten, oetr, liefi, dert.

- $64-26$, jenem, ließ, jenen.

- $75-25$, von unten, bintern Siile, ließ̧, b̌unterfúffe.

- $76 \rightarrow 34$, bon unten, felbigen, lieis, felbigem.

$-\cdots-9$, von unten, Den, liȩ̄, Dcm.

- - I, am Enbe, oen, ließ

- 80 - IG, Maffer, liés, Woafen.

- 89- 7, 2tre, lié, Jeit

- $91-21$, 3wey, lies, 3tveyer.

- 93 - in ber lesten linie an einer, nno, lles, uno.

- 103 - r, fie, liek, fie.

- ros - Is, finfleten, ließ, wnfferen.

- IIa -35 , feje itatt; sin. 





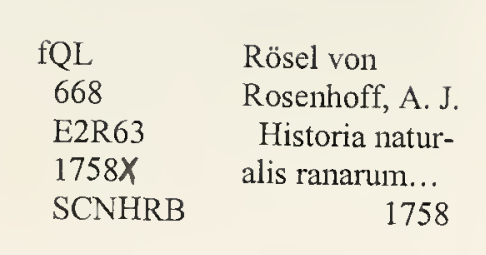




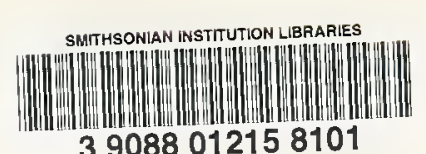


SeW $89+210$

-

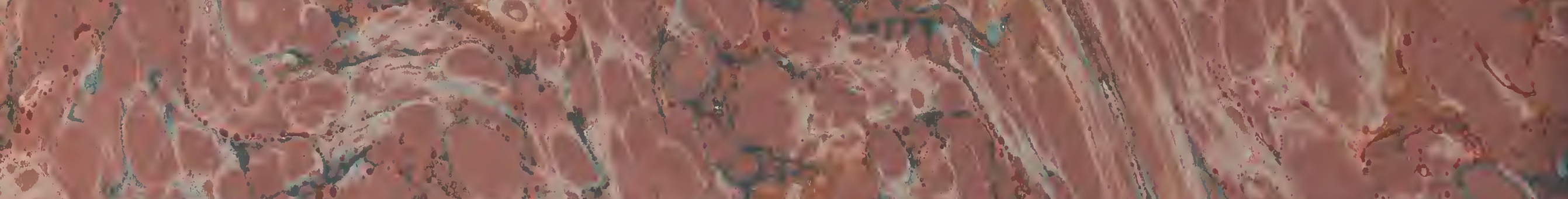

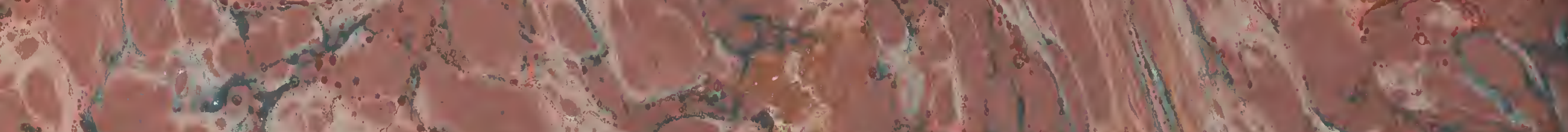

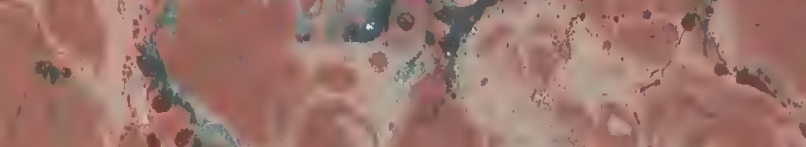

ary posin $=2$

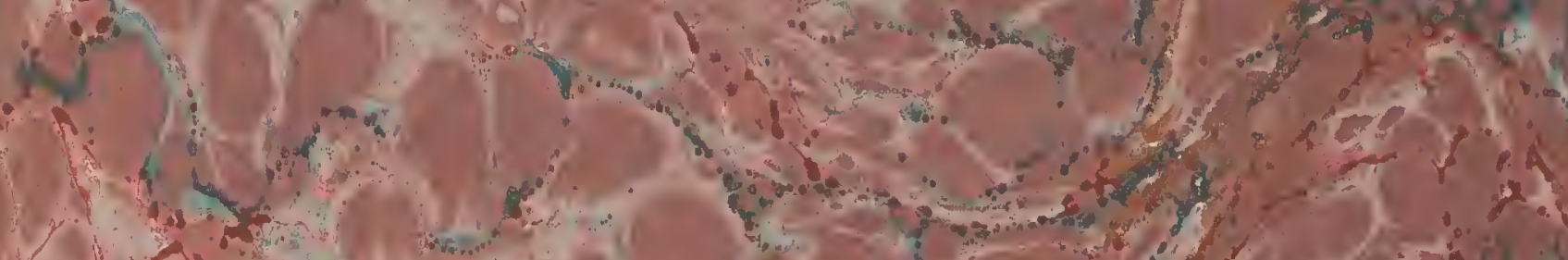
$20+2 x+2,2$ $2+1 / 1 / 4=$ Fen

\section{(x).}

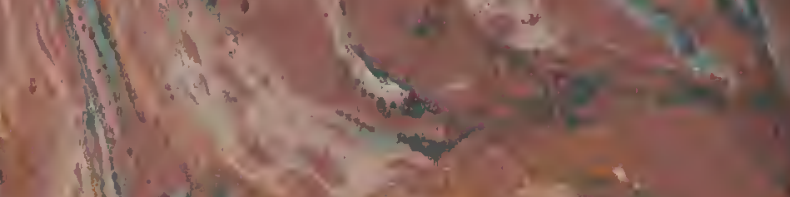

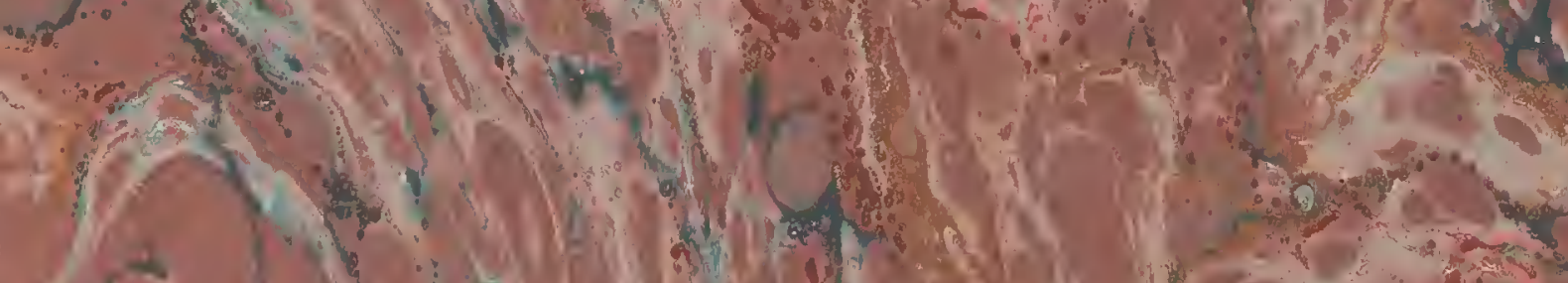
tis?

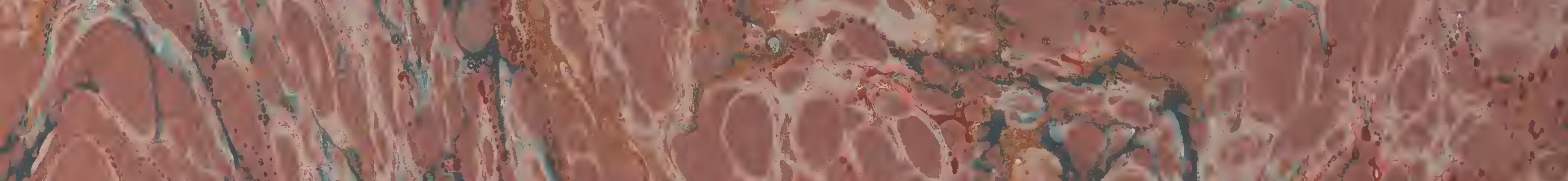

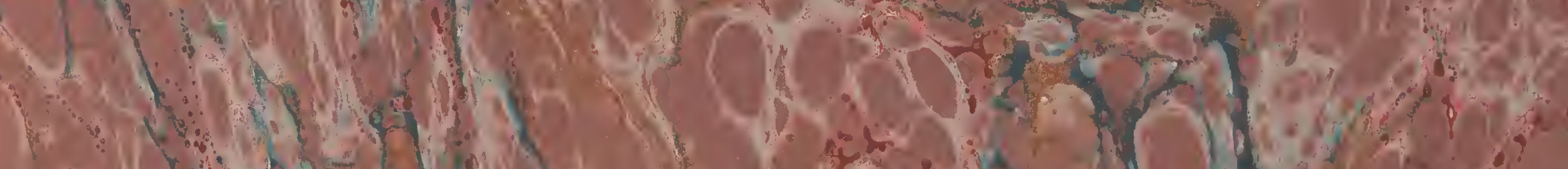
findwat $x_{4 \rightarrow-2}$

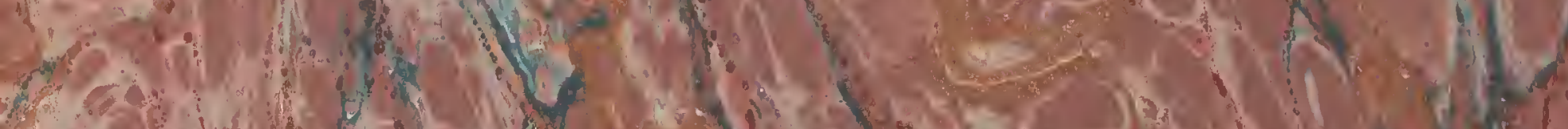

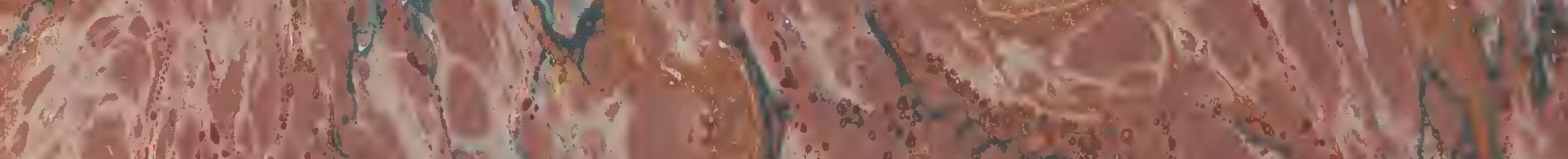

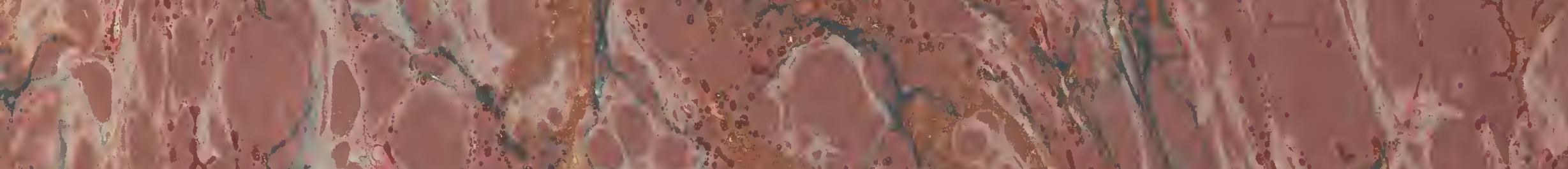

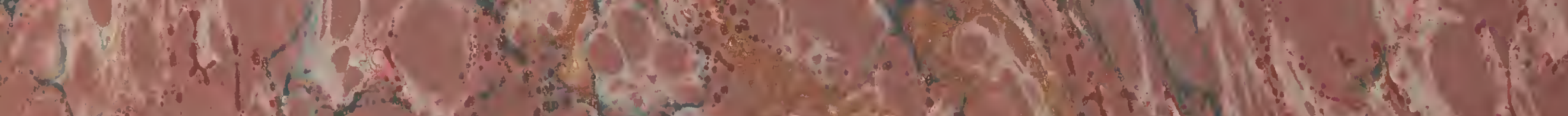

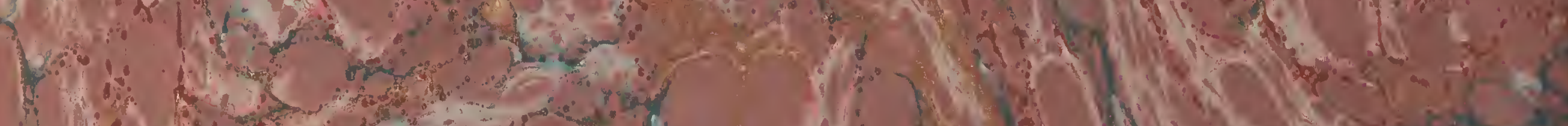

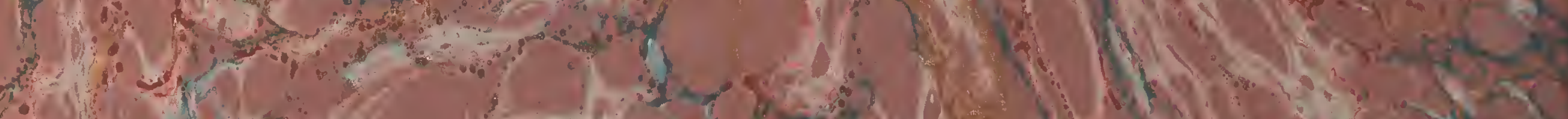

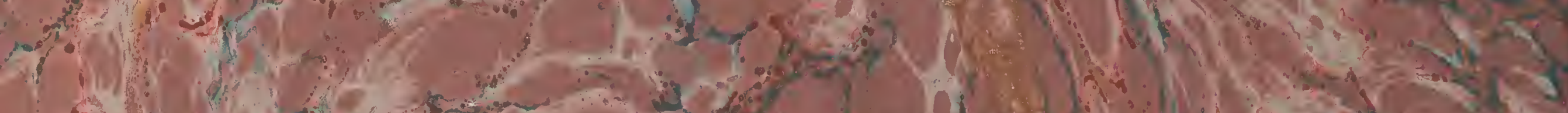

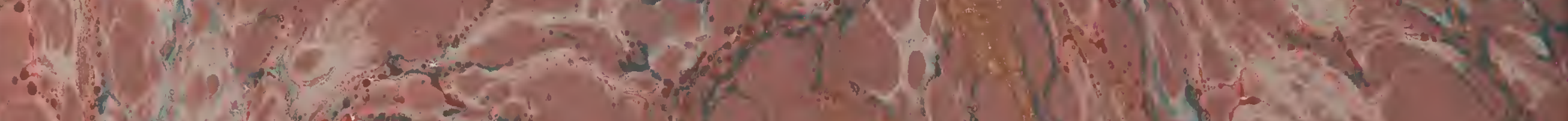

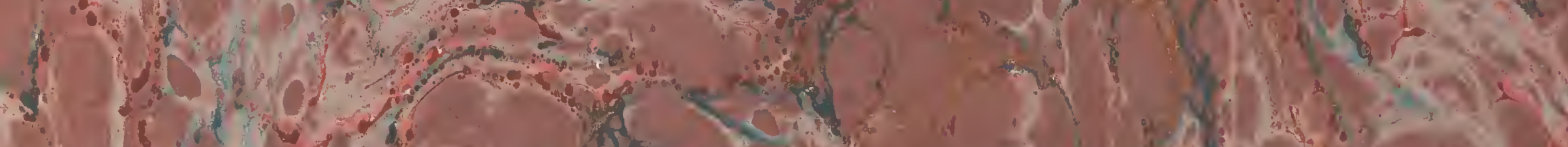
iverion 2

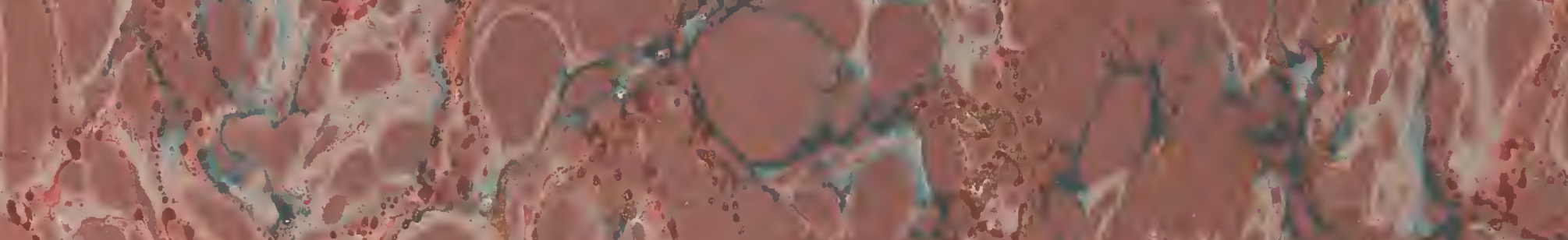
$+2$ m.

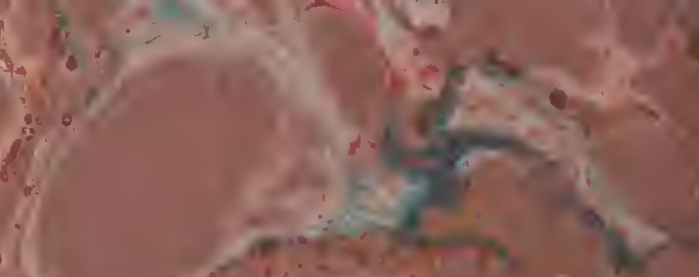

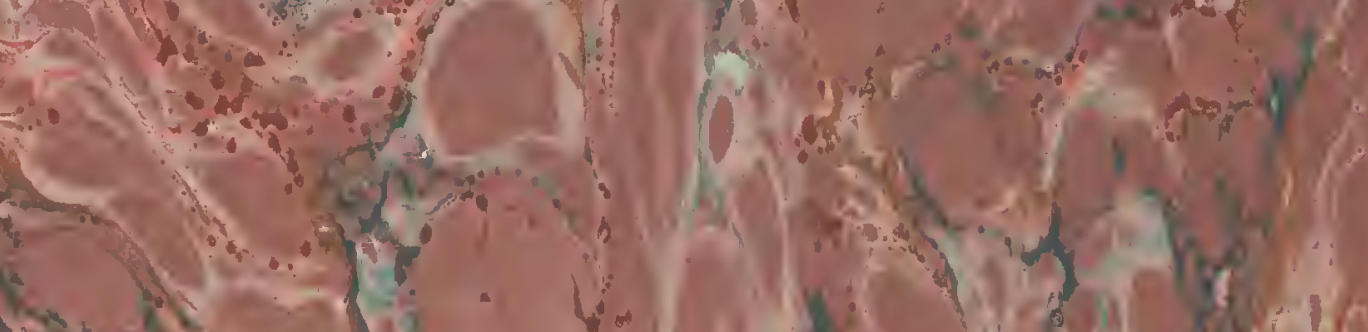
log tay d 11

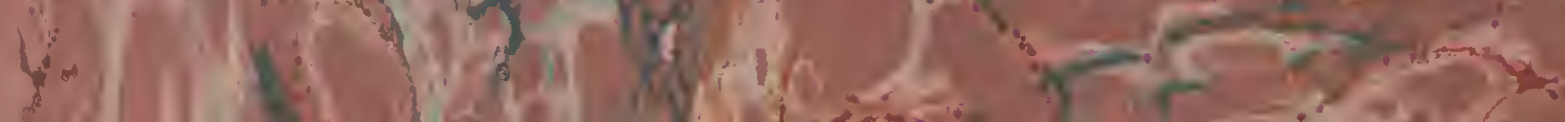




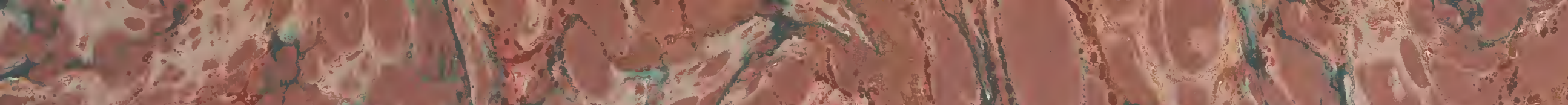
$x^{2}+20391+2$

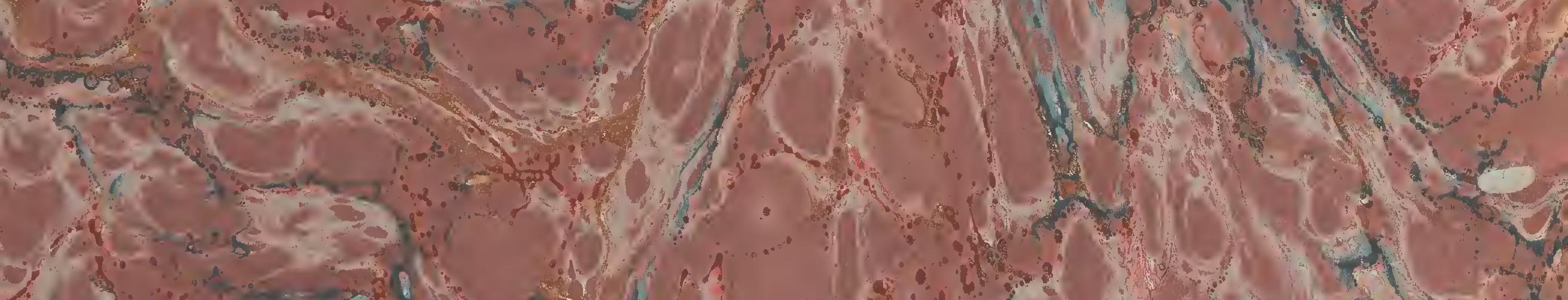
a

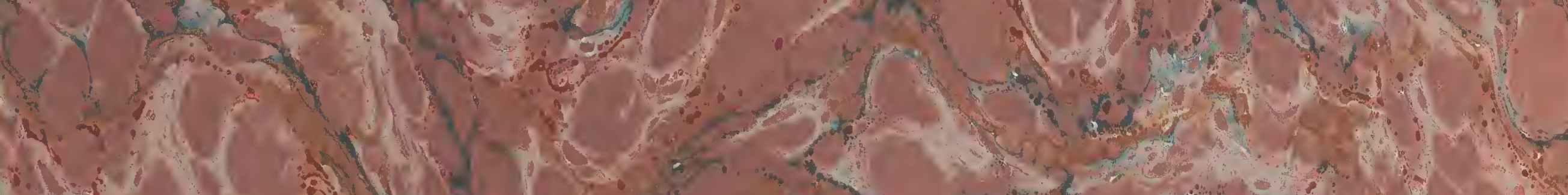

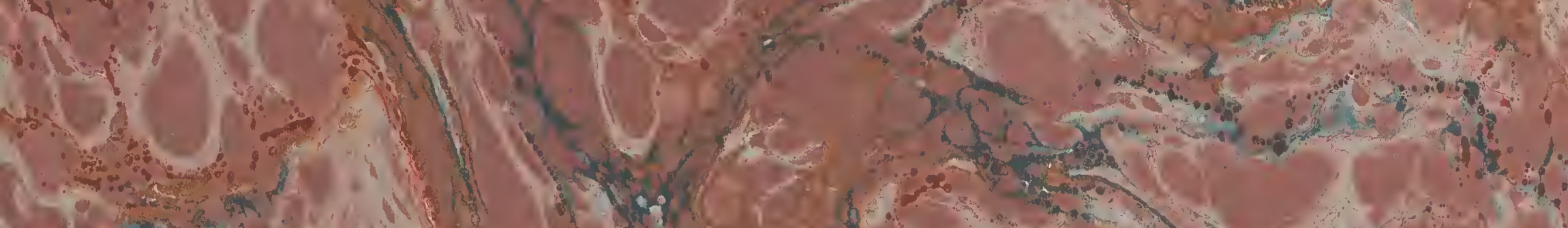

96 is $x^{6}$
Yits
axi $72+2-19$

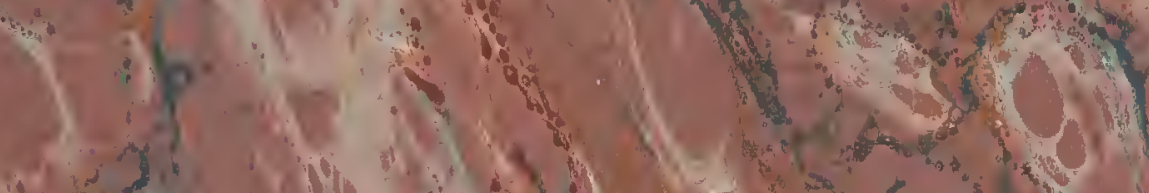

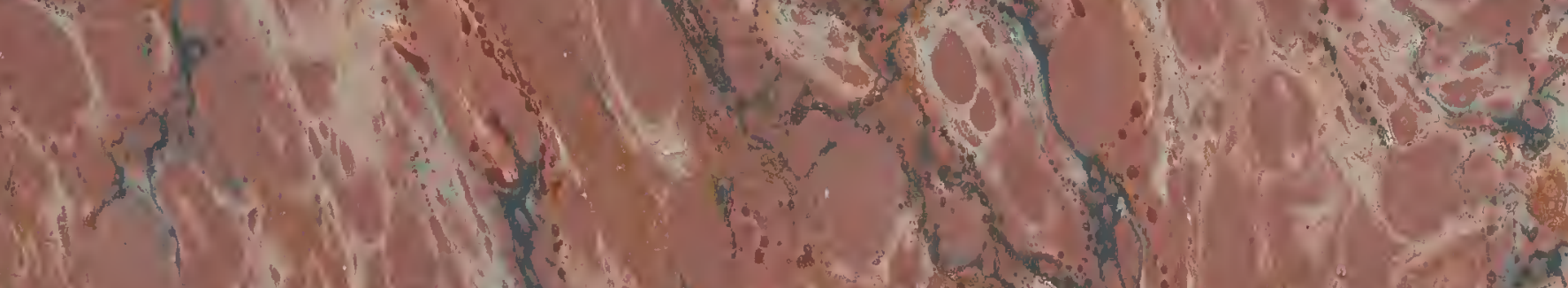

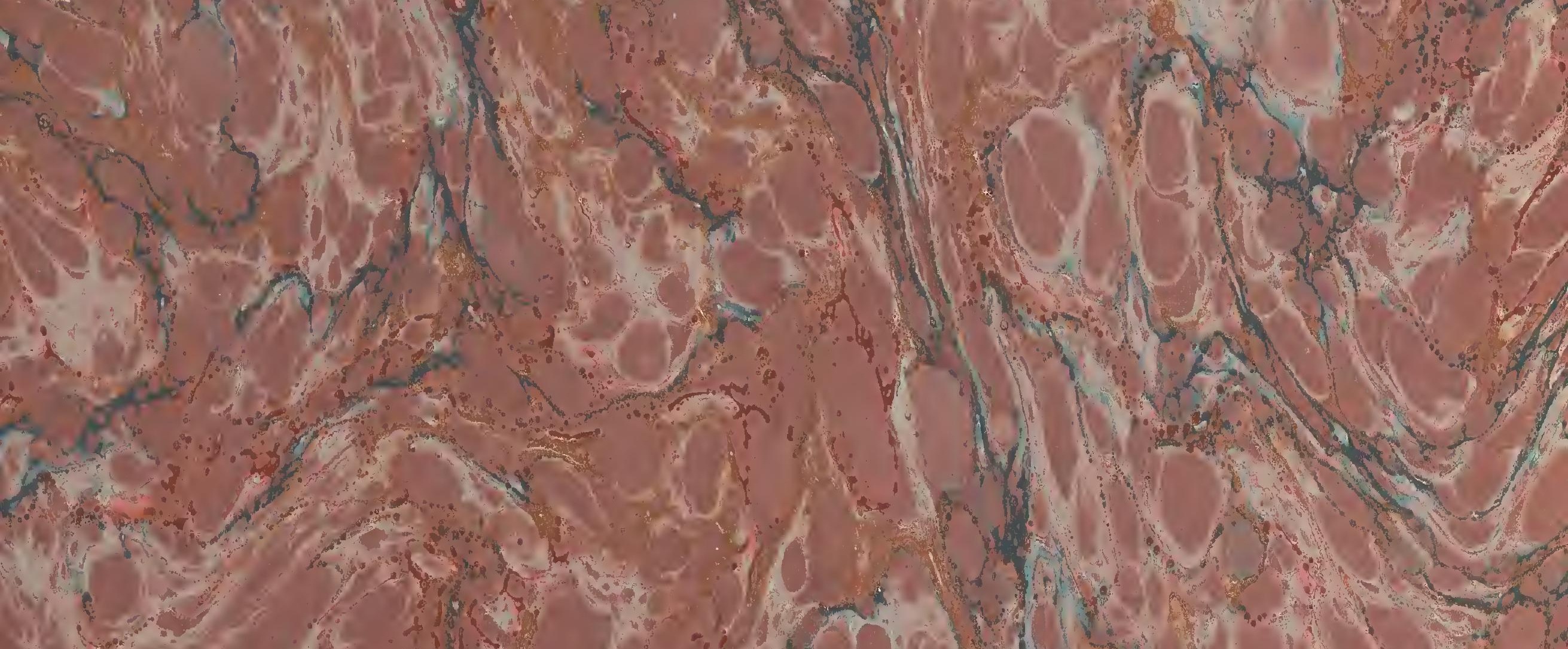

(5)

(5)

(5)

(5)

(5)

(5)

(5)

(5)

(5)

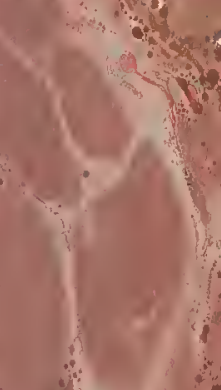
(iv) $x^{2}=3 y^{2}$

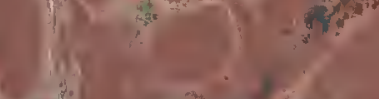

A. $10 \%$

vit:

rex

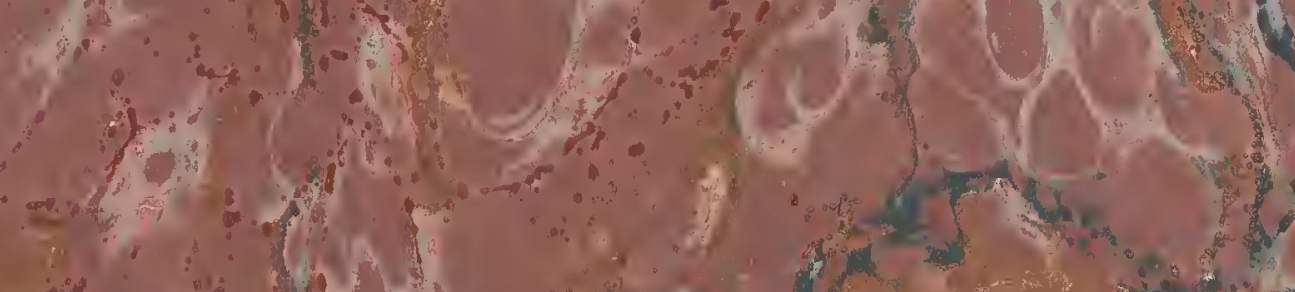

W Linting a . ili.

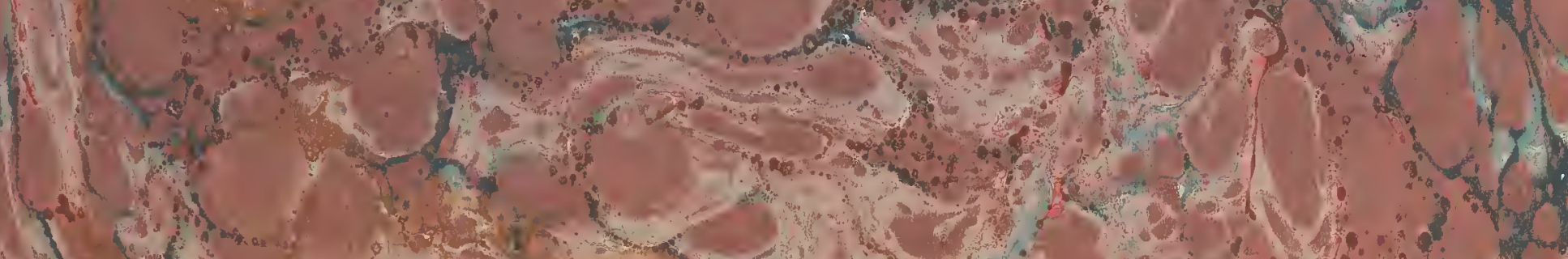

a

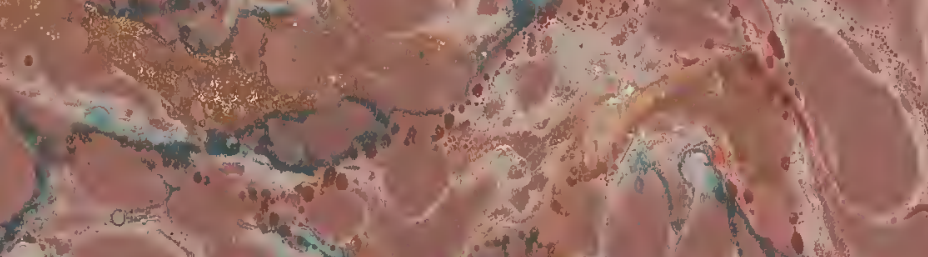
$1+y^{2}+\operatorname{sen}^{2} d$

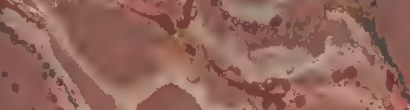
N) H.

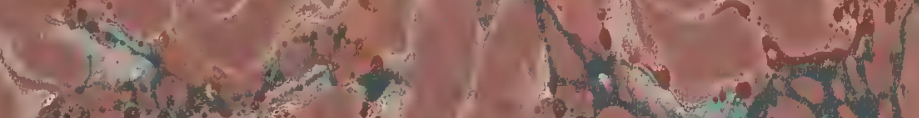
a $>1$ $0+20$ $+3$ 
